UNIVERSIDADE DE SÃO PAULO

ESCOLA DE ENGENHARIA DE SÃO CARLOS

PROGRAMA DE PÓS-GRADUAÇÃO EM GEOTECNIA

DÉBORAH MAYARA DE ASSIS AMOROSO PEROTTI

\title{
CRAVAÇÃO DINÂMICA DO AMOSTRADOR SPT COM ENERGIA CRESCENTE
}

São Carlos 



$$
\begin{gathered}
\text { UNIVERSIDADE DE SÃO PAULO } \\
\text { ESCOLA DE ENGENHARIA DE SÃO CARLOS } \\
\text { PROGRAMA DE PÓS-GRADUAÇÃO EM GEOTECNIA }
\end{gathered}
$$

DÉBORAH MAYARA DE ASSIS AMOROSO PEROTTI

\section{CRAVAÇÃO DINÂMICA DO AMOSTRADOR SPT COM ENERGIA CRESCENTE}

Dissertação de mestrado apresentada à Escola de Engenharia de São Carlos da Universidade de São Paulo, como requisito para a obtenção do título de Mestre em Geotecnia

Orientador: Prof. Dr. Edmundo Rogério Esquivel

\section{Versão Corrigida}

Original se encontra disponível na unidade que aloja o programa 
AUTORIZO A REPRODUÇÃO TOTAL OU PARCIAL DESTE TRABALHO POR QUALQUER MEIO CONVENCIONAL OU ELETRÔNICO, PARA FINS DE ESTUDO E PESQUISA, DESDE QUE CITADA A FONTE.

Ficha catalográfica elaborada pela Biblioteca Prof. Dr. Sérgio Rodrigues Fontes da EESC/USP com os dados inseridos pelo(a) autor(a).

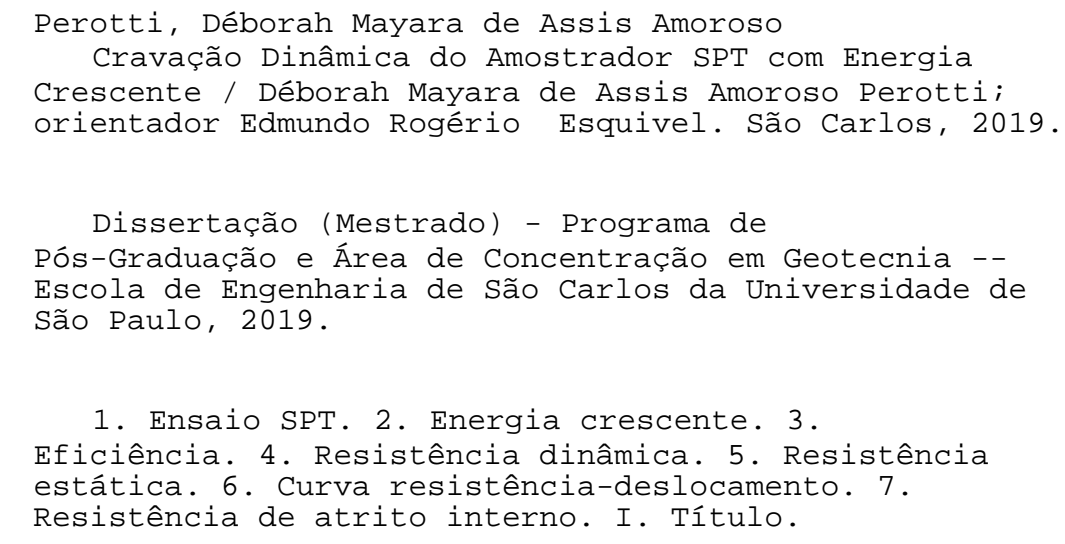

Eduardo Graziosi Silva - CRB - 8/8907 


\section{FOLHA DE JULGAMENTO}

Candidata: Bacharela DEBORAH MAYARA DE ASSIS AMOROSO PEROTTI.

Título da dissertação: "Cravação dinâmica do amostrador SPT com energia crescente".

Data da defesa: 29/10/2019.

\section{Comissão Julgadora:}

Prof. Dr. Edmundo Rogério Esquivel

(Orientador)

(Escola de Engenharia de São Carlos/EESC)

Profa. Dra. Bernadete Ragoni Danziger

(Universidade do Estado do Rio de Janeiro/UERJ)

Prof. Dr. Edgar Odebrecht

(Universidade do Estado de Santa Catarina/UDESC)
Resultado:

ABROUABA

Sprovada

arrovara

Coordenadora do Programa de Pós-Graduação em Geotecnia:

Profa. Associada Valéria Guimarães Silvestre Rodrigues

Presidente da Comissão de Pós-Graduação:

Prof. Titular Murilo Araujo Romero 



\section{DEDICATÓRIA}





\section{AGRADECIMENTOS}

Primeiramente à Deus, por ser minha força e segurança, meu apoio e esperança, minha vida e confiança. Aos meus amados pais, Sérgio e Euza, pelo amor e por todo esforço que fizeram e que me permitiram chegar até aqui. Ao meu irmão, Sérgio Júnior, pela amizade, companheirismo e amor. Ao meu amor, Gustavo, por ter me ajudado em todos esses anos, me motivando e encorajando.

Ao meu orientador, professor Edmundo Rogério Esquivel, pela oportunidade e pelos conhecimentos transmitidos ao longo desses anos. Aos professores, George de Paula Bernardes e Nelson Aoki, por toda ajuda no desenvolvimento dessa pesquisa. A todos os professores que tiveram envolvimento com minha formação geotécnica, pelos ensinamentos e experiências compartilhadas.

Aos técnicos do departamento de Geotecnia EESC-USP, pela disposição em ajudar e sanar quaisquer dúvidas, em especial ao meu amigo Oscar dos Santos Neto, por toda ajuda e apoio prestado ao longo do mestrado.

Às minhas amigas da pós-graduação, Nathália Marques, Fabiane Ferrer, Ivinny Barros, Camila Amorim, Liana Rocha, Fernanda Medeiros, pelas trocas de conhecimento e cultura, pelo suporte, pela amizade, pela força, pelo companheirismo, pelas risadas e pela amizade. Aos meus amigos de pós-graduação e companheiros de sala, Cauê Somenzi e Nélio Bastos pelas conversas e por toda ajuda prestada.

Às minhas amigas que acompanharam todos os meus passos, e, que mesmo de longe, sei que torceram e ainda torcem pelo meu sucesso. E às que participaram mais de perto desse período me ajudando, me ouvindo e me aconselhando: Ludmilla, Gracielle e Maria.

A todos aqueles que direta ou indiretamente me ajudaram ao longo desses anos. 



\section{RESUMO}

PEROTTI, D.A. Cravação dinâmica do amostrador SPT com energia crescente. 2019. 258p. Dissertação (Mestrado) - Departamento de Geotecnia, Escola de Engenharia de São Carlos, Universidade de São Paulo, São Carlos, 2021.

O Standard Penetration Test (SPT), devido à sua simplicidade é amplamente utilizado no meio geotécnico. Por esse motivo, é conveniente obter o máximo de informações possíveis deste ensaio. Os resultados do teste ainda são utilizados em correlações muito empíricas e uma interpretação racional desses dados pode resultar em melhoria de projetos geotécnicos. Nesse sentido, o objetivo desta pesquisa é propor e avaliar um novo procedimento para a realização do ensaio SPT, utilizando os conceitos de energia crescente propostos por Aoki (2000). Assim, os testes de SPT foram realizados com o aumento das alturas de queda do martelo. Para realizar esses testes, acelerômetros e células de carga foram instalados logo abaixo da cabeça de bater e logo acima do amostrador para obter dados de aceleração e força durante o evento do golpe. Os resultados mostraram que é possível estimar a eficiência do ensaio usando este método. Para as profundidades ensaiadas e se calculada em relação à energia do sistema proposta por Odebrecht (2003) a eficiência é constante em relação à altura de queda e em relação ao comprimento das hastes. Se a eficiência é calculada em relação à energia potencial teórica, a eficiência pode atingir valores superiores a 100\%. Também foi possível compreender o comportamento das forças de resistência mobilizadas pelo amostrador a partir de curvas de resistência-deslocamento. Testes de medição de atrito interno também foram realizados para estimar a resistência de atrito atuante nas paredes internas do amostrador, utilizando o procedimento proposto por Zapata-Galvis (2015). Os resultados obtidos neste teste não parecem ser úteis para o ensaio com energia crescente. Isso ocorreu porque a força de atrito foi medida apenas no final da sequência de golpes em uma determinada profundidade, e o valor da força de atrito correspondente à cada golpe era desconhecido. Também foram realizados ensaios de penetração estática sobre o amostrador SPT para determinação da resistência estática. Os resultados mostram que existe uma concordância no formato da curva de resistência-deslocamento dos ensaios dinâmicos com energia crescente e do ensaio estático

Palavras-chave: ensaio SPT, energia crescente, eficiência, resistência dinâmica, resistência estática, curva resistência-deslocamento, atrito interno. 



\begin{abstract}
PEROTTI, D.A. Dynamic increasing energy test with SPT sampler. 2019. 258p. Master Thesis - Master Thesis - São Carlos School of Engineering, University of Sao Paulo, São Carlos, 2021.

The Standard Penetration Test (SPT), due to its simplicity, is widely used in geotechnical projects. For this reason, it is convenient to obtain as much information as possible from this test. The test results are still used in very empirical correlations and a rational interpretation of these data could result in the improvement of geotechnical projects. In this in mind, the aim of this research is to propose and evaluate a new procedure for the accomplishment of SPT tests, using the increasing energy concepts proposed by Aoki (2000). Thus, SPT tests were performed with increasing hammer drop heights. In order to perform these tests, accelerometers and load cells were installed just below the anvil and just above the sampler to obtain acceleration and force data during the blow event. The results showed that it is possible to estimate the test. For the drilled depths and if energy ratio is calculated in relation to the system energy proposed by Odebrecht (2003), the energy ratio is constant in respect to the drop height, as well as in respect to the length of rods. If the energy ratio is calculated in relation to the theoretical potential energy, the efficiency may reach values greater than $100 \%$. It was also possible to understand the behavior of resistance forces mobilized by the sampler from resistance-displacement curves. Internal friction measurement tests were also performed to estimate the frictional resistance acting on the sampler internal walls using the procedure proposed by Zapata-Galvis (2015). The results obtained in this test did not seem to be useful for the increasing energy test. This occurred because the friction force was measured only at the end of the blow sequence at a given depth, and the friction force value corresponding to each blow was unknown. Also static penetration tests were performed on the SPT sampler to estimate the static resistance The results show that there is an agreement of the resistance-displacement curve shape corresponding to increasing energy dynamic tests with the curve shape corresponding to static tests.
\end{abstract}

Keywords: SPT test, increasing energy, efficiency, dynamic resistance, static resistance, resistance-displacement curve, internal friction. 



\section{SUMÁRIO}

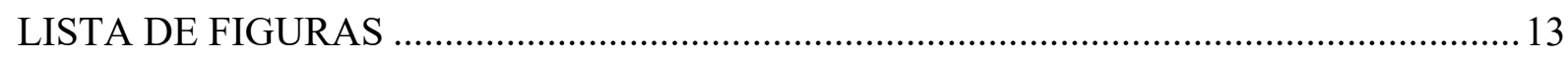

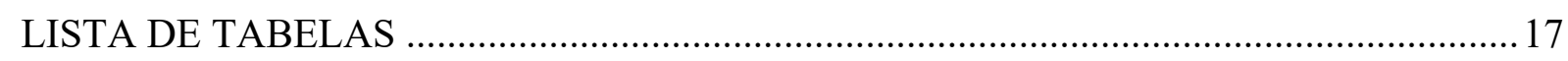

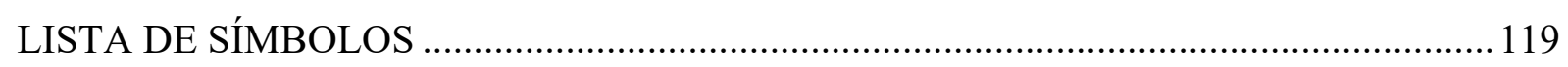

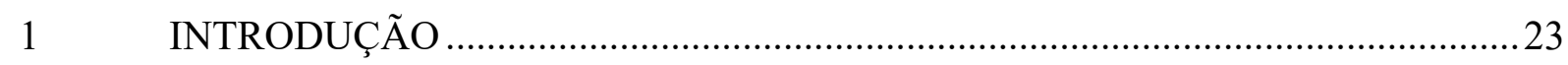

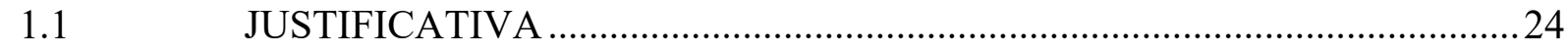

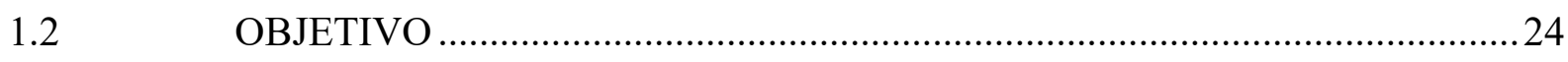

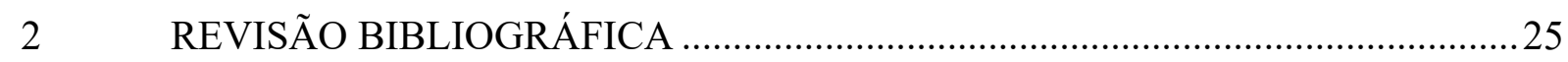

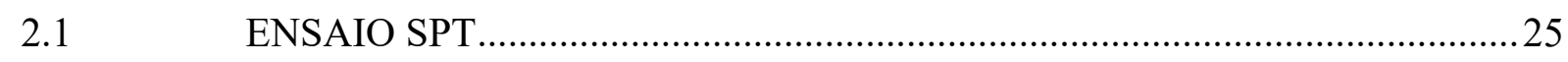

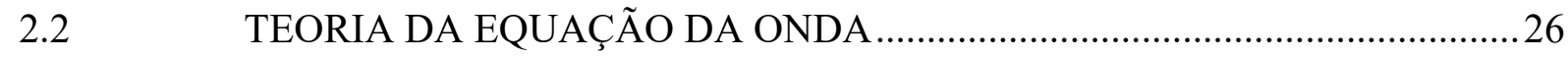

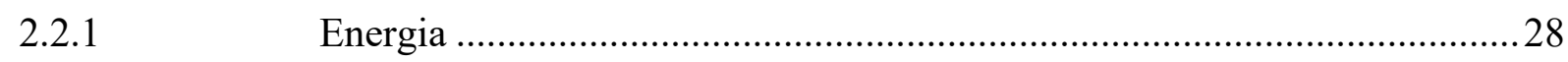

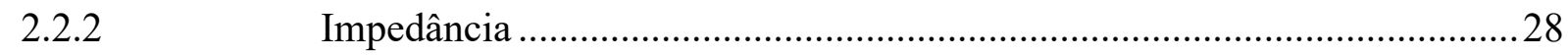

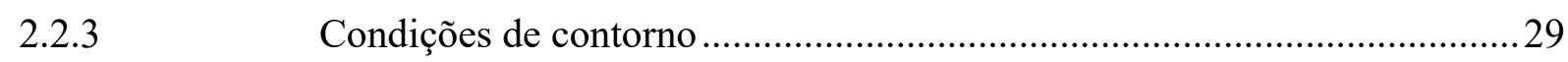

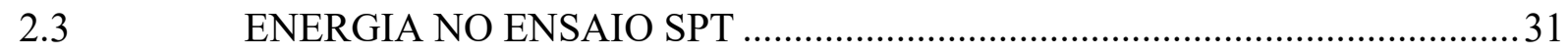

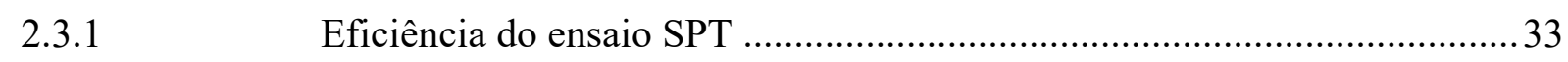

2.3.2 Aplicação do princípio de conservação de energia no ensaio SPT .............. 36

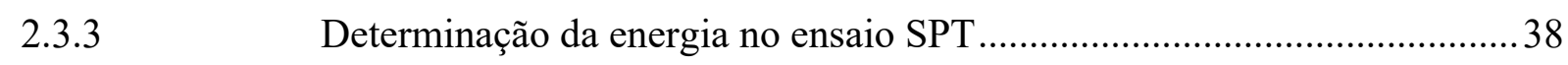

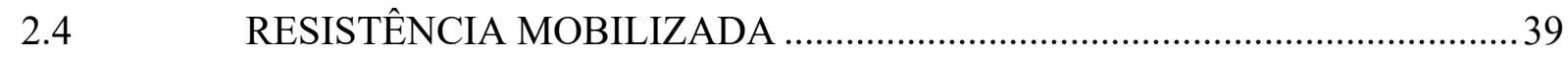

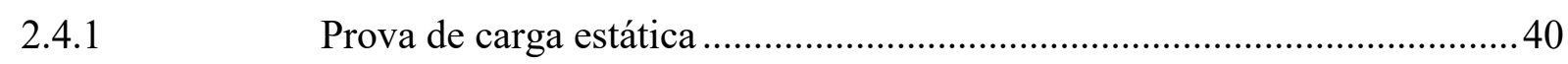

2.4.2 Prova de carga dinâmica com energia constante........................................ 43

2.4.3 Prova de carga dinâmica com energia crescente ....................................... 48

2.4.4 Resistências de atrito e de ponta no amostrador ........................................50

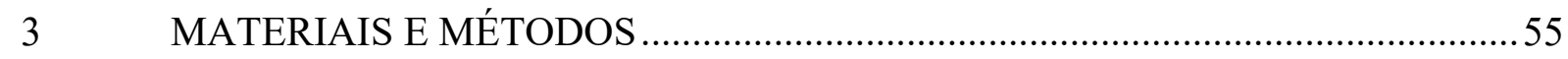

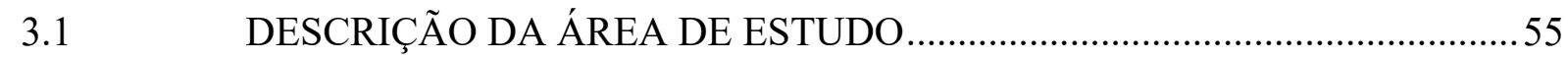

ORGANIZAÇÃO DOS ENSAIOS DE CAMPO …........................................... 57

ENSAIO DINÂMICO COM ENERGIA CRESCENTE....................................58

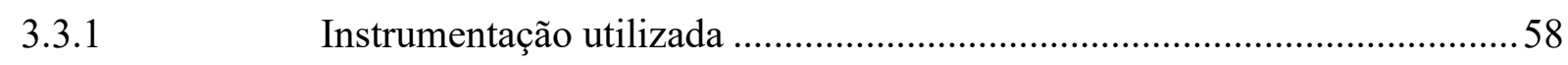

Sistema de aquisição e tratamento de dados .............................................. 61 
ENSAIO DE PENETRAÇÃO ESTÁTICA ...................................................... 106

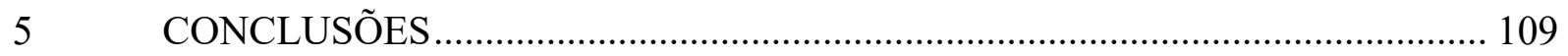

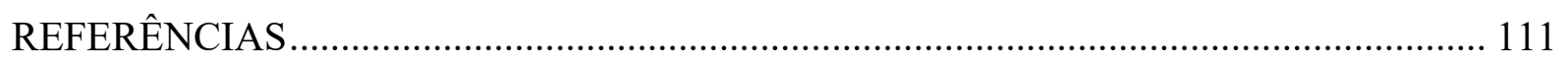




\section{LISTA DE FIGURAS}

Figura 1 - Esquema de uma onda longitudinal de compressão em hastes (Lukiantchuki, 2012 adaptado de Bernardes, 1989).

Figura 2 - Propagação da onda de tensão em um elemento com alteração de impedância (Lukiantchuki, 2012 adaptado de Bernardes, 1989).

Figura 3 - Condições de contorno da extremidade do amostrador (Lukianthucki, 2012 adaptado de Belincanta, 1985).

Figura 4 - Resultado típico de um ensaio dinâmico realizado sobre o amostrador SPT (Neves, 2004).

Figura 5 - Resultado típico de um ensaio de prova de carga estática sobre o amostrador SPT (Neves, 2004).

Figura 6 - Curva carga-recalque da prova de carga estática em um único ciclo de carga e descarga (Aoki, 1997).

Figura 7 - Curva carga-recalque em prova de carga estática com vários ciclos de carregamento - origem variável (Aoki, 1997).

Figura 8 - Relação carga-deformação na cravação idealizado por Smith (1960) (Noreña, 2011 modificado de Smith, 1960)

Figura 9 - Curva carga-recalque referente para ensaios dinâmico e estático (adaptado de Aoki et al., 2004).

Figura 10 - Curvas de força e deslocamento em função do tempo para determinação de $R_{D}$ (Lukiantchuki; Bernardes; Esquivel, 2012).

Figura 11 - Comparação entre com os valores de $R_{d}$, obtidos por Lukiantchuki (2012), Morais (2014) e Zapata-Galvis (2015) com os valores de $F_{d}$ e $R_{s}$, respectivamente.

Figura 12 - Curva de resistência estática mobilizada x deslocamento para prova de carga dinâmica com: a) energia constante; b) energia crescente (Tsuha; Aoki; Cintra, 2013).....

Figura 13 - Curva de resistência mobilizada versus deslocamento para prova de carga com energia crescente no amostrador padrão do SPT (Quintero Baños, 2016).

Figura 14 - Equilíbrio de forças atuantes: a) amostrador; b) ponta aberta do amostrador (adaptado de Aoki, 2013)

Figura 15 - Unidades geotécnicas no entorno do local dos ensaios. Produzidos a partir de mapeamento de superfície, sondagens, mapa topográfico e fotografia aérea (De Mio, 2005) 55

Figura 16 - Seção geológica AB (Figura 15) baseado em mapeamento e sondagens (De Mio, 2005).

Figura 17 - Resultados de ensaios de penetração e índices físicos (Machado, 1998; De Mio, 2005; Giachetti et al., 2004; Rocha, 2018).

Figura 18 - Locação dos ensaios realizados (Adaptado de Giachetti et al., 2004 e Rocha, 2018).

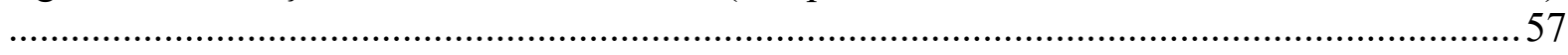

Figura 19 - Posicionamento da haste superior no sistema.

Figura 20 - Configuração dos acelerômetros nas hastes por meio de suportes de fixação (Morais, 2014). 
Figura 21 - Calibração das células de carga das hastes: a) superior; b) inferior... 61

Figura 22 - Sistema de aquisição HBM MX-410 (Morais, 2014).

Figura 23 - Etapas do tratamento dos dados obtidos no ensaio dinâmico. ............................... 63

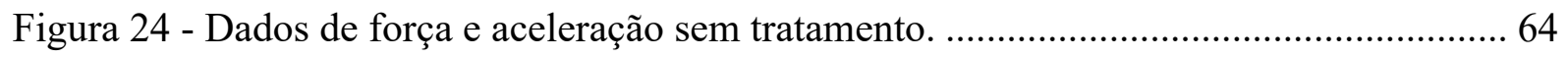

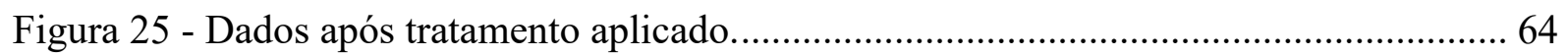

Figura 26 - Fluxograma da análise de dados para os ensaios dinâmicos................................. 65

Figura 27 - Velocidades em função do tempo. a) sem rotação, b) com rotação....................... 65

Figura 28 - Curva de deslocamento em função do tempo calculada pela integração da

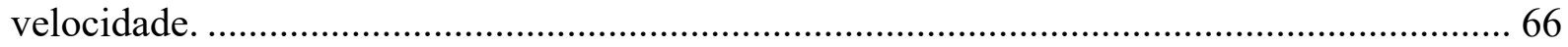

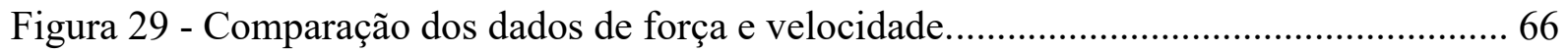

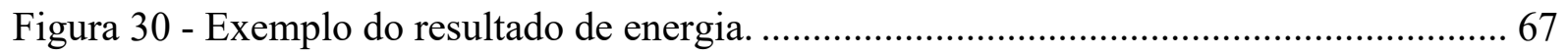

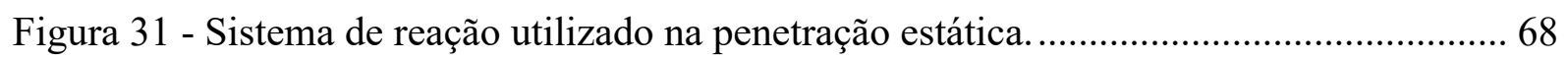

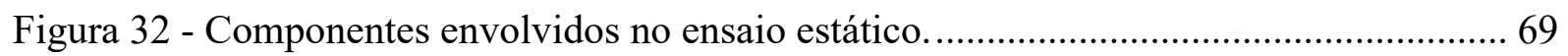

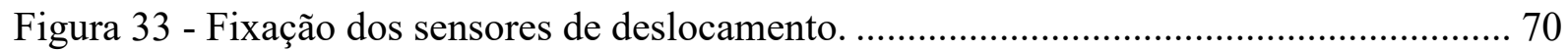

Figura 34 - Equipamento para medição de atrito interno (Zapata Galvis, 2015).................... 71

Figura 35 - Estimativa do comprimento da amostra recuperada. .......................................... 72

Figura 36 - Medição do comprimento da amostra após medição do atrito interno. ................ 72

Figura 37 - Exemplo da aplicação do tratamento nos dados de medição de atrito interno: a) sem

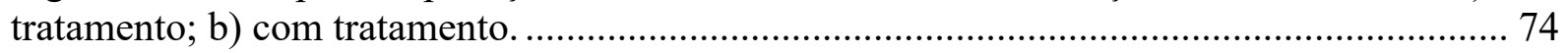

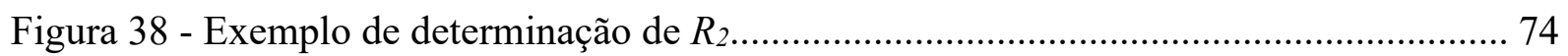

Figura 39 - Sinais típicos de SPT instrumentado para o furo SP01, profundidade de $2 \mathrm{~m}$ e $H_{q}$ de

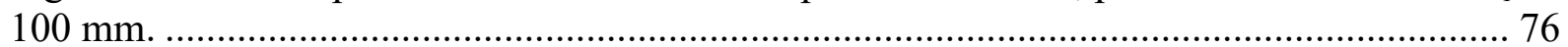

Figura 40 - Sinais típicos de SPT instrumentado para o furo SP01, profundidade de $2 \mathrm{~m}$ e $H_{q}$ de

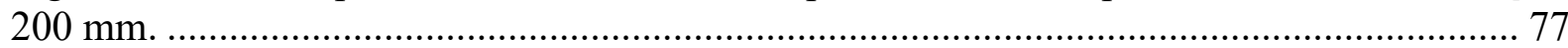

Figura 41 - Sinais típicos de SPT instrumentado para o furo SP01, profundidade de $2 \mathrm{~m}$ e $H_{q}$ de

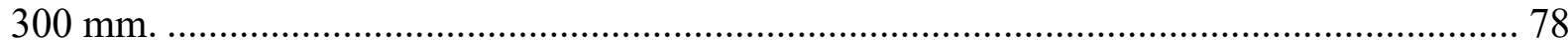

Figura 42 - Sinais típicos de SPT instrumentado para o furo SP01, profundidade de $2 \mathrm{~m}$ e $H_{q}$ de

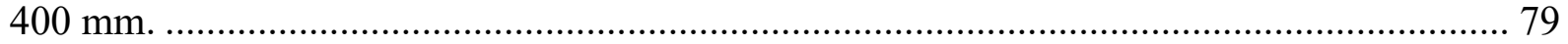

Figura 43 - Sinais típicos de SPT instrumentado para o furo SP01, profundidade de $2 \mathrm{~m}$ e $H_{q}$ de

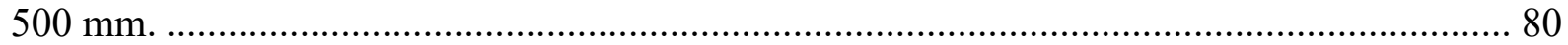

Figura 44 - Sinais típicos de SPT instrumentado para o furo SP01, profundidade de $2 \mathrm{~m}$ e $H_{q}$ de

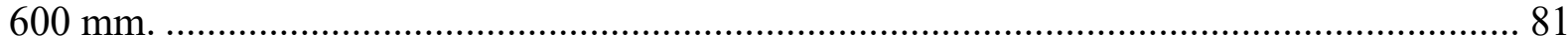

Figura 45 - Sinais típicos de SPT instrumentado para o furo SP01, profundidade de $2 \mathrm{~m}$ e $H_{q}$ de

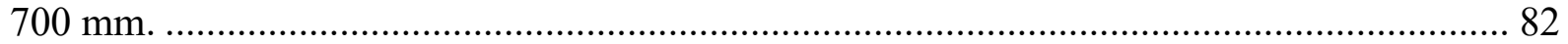

Figura 46 - Comparação entre os deslocamentos calculados............................................... 83

Figura 47 - Comparação entre deslocamentos medidos e deslocamentos calculados: a) deslocamentos calculados médios $\left(\delta_{A C M}\right)$; b) deslocamentos utilizando critério $\left(\delta_{A C}\right) \ldots \ldots \ldots \ldots . .84$

Figura 48 - Frequência dos erros relativos: a) haste inferior; b) haste superior....................... 85

Figura 49 - Comparação entre deslocamentos medidos e deslocamentos calculados com aplicação de critérios 
Figura 50 - Análise da consideração do peso do sistema no cálculo da energia para o ensaio realizado na profundidade de $6 \mathrm{~m}$ do furo SP01

Figura 51 - Avaliação da influência do peso do sistema nos valores de eficiência no topo e na base para os ensaios do SP01 e profundidades: a) 2 metros; b) 3 metros; c) 4 metros; d) 5 metros; e) 6 metros.

Figura 52 - Erro relativo entre as eficiências considerando o peso do sistema e sem considerar: a) topo; b) base. SP01, todas as profundidades.

Figura 53 - Eficiência calculada em relação à $E P_{T}$ versus altura de queda para SP01 e profundidades: a) 2 metros; b) 4 metros.

Figura 54 - Relação entre as energias envolvidas no ensaio e as alturas de queda do martelo aplicadas para o furo SP01 e profundidades: a) 2 metros; b) 3 metros; c) 4 metros; d) 5 metros; e) 6 metros.

Figura 55 - Eficiência no topo e na base versus comprimento de hastes (Furo SP01).... 95

Figura 56 - Relação entre o trabalho $(W)$ calculado a partir de $R_{D}$ com a energia na base $\left(E_{b a s e}\right)$ (Furo SP01)

Figura 57 - Curva de resistência mobilizada versus deslocamento acumulado para SP01 e profundidades: a) 2 metros; b) 3 metros; c) 4 metros; d) 5 metros; e) 6 metros.

Figura 58 - Comparação entre valores de $R_{u}$, para $R_{D}, R_{S}$ e $F_{D}$ para as profundidades e ensaios analisados. 100

Figura 59 - Comparação entre valores de $R_{u}, N_{S P T}$ e $q_{c}$ para as profundidades e furos analisados. 101

Figura 60 - Relação entre o comprimento da amostra recuperada $\left(L_{a}\right)$ e a penetração acumulada do amostrador ( $\left.\delta_{\text {acumulado }}\right)$ para o furo SP03 102

Figura 61 - Resistências desenvolvidas no amostrador no furo SP03, para as profundidades: a) $2 \mathrm{~m}$; b) $3 \mathrm{~m}$; c) $4 \mathrm{~m}$; d) $5 \mathrm{~m}$; e) $6 \mathrm{~m}$ 104

Figura 62 - Tensões desenvolvidas no amostrador - SP03, profundidades: a) 2 metros; b) 3 metros; c) 4 metros; d) 5 metros; .

Figura 63 - Curva resistência estática versus deslocamento para ensaio estático $-5 \mathrm{~m}$ de profundidade.

Figura 64 - Curva resistência versus deslocamento - 5m de profundidade. 107

Figura 65 - Perfis de teores de umidade para os ensaios realizados 108 



\section{LISTA DE TABELAS}

Tabela 1 - Convenção de sinais para força e velocidade (Belincanta, 1985). 29

Tabela 2 - Resultados dos ensaios de caracterização do Campo Experimental (Peixoto, 2001).

Tabela 3 - Configuração dos canais do sistema de aquisição de dados para o ensaio dinâmico. 63

Tabela 4 - Configuração dos canais no sistema de aquisição de dados para o ensaio estático.70

Tabela 5 - Configuração dos canais no sistema de aquisição de dados para medição do atrito interno.

Tabela 6 - Eficiência calculada de forma convencional e pelos coeficientes angulares das retas, correspondentes ao furo SP01

Tabela 7 - Eficiências calculadas de forma convencional e pelos coeficientes angulares das retas para casos específicos

Tabela 8 - Previsão de alturas de queda efetivamente aplicadas para as profundidades de $2 \mathrm{~m}$ e $3 \mathrm{~m}$ do furo SP01 94

Tabela 9 - Valores médios de eficiência obtidos em outras pesquisas. 95

Tabela 10 - Valores de resistências correspondentes ao furo SP01. .96

Tabela 11 - Parâmetros de ajuste de curva pela Equação de Van der Veen. .98

Tabela 12 - Valores de resistência de atrito interno - SP03. 103

Tabela 13 - Coeficiente $a$ de Aoki e razão de atrito $R_{f}-$ SP03. 106 



\section{LISTA DE SÍMBOLOS}

A: $\quad$ Área da seçãotransversal

c: Velocidade teórica de propagação da onda ao longo da composição de hastes

$D_{\text {ext: }} \quad$ Diâmetro externo do amostrador

$D_{\text {int: }} \quad$ Diâmetro interno do amostrador

$D_{p}$ : Diâmetro da ponta do amostrador

E: $\quad$ Módulo de elasticidade do aço

$E_{\text {amostrador: }}$ :Energia que efetivamente atinge o amostrador

$E_{\text {base: }} \quad$ Energia transferida à base da composição de hastes

$E P_{\text {sistema: }}$ Energia potencial imposta durante o evento

$E P_{T}: \quad$ Energia potencial teórica do sistema ou energia nominal do SPT

$E_{t}$ : Energia total (soma das energias de deformação e cinética das partículas)

$E_{\text {topo }}$ : Energia transferida ao topo da composição de hastes

$F(t)$ : Força normal daspartículas

$F_{d}$ : Resistência dinâmica (Schnaid et al., 2009)

g: $\quad$ Aceleração da gravidade

$H_{q}: \quad$ Altura de queda do martelo

$H_{q e}: \quad$ Altura de queda estimada

$H_{q p}: \quad$ Altura de queda prevista

Jc: $\quad$ Fator de amortecimento de Smith

$l$ : Distância da seção instrumentada até a extremidade do amostrador

$L_{a i}$ : Comprimento da amostra de solo a cada golpe

$L_{a}$ : $\quad$ Comprimento da amostra de solo recuperada

Lext: $\quad$ Penetração total do amostrador

$l_{h}$ : Comprimento da composição de hastes

$L_{p}$ : Comprimento da seção biselada do amostrador

$M_{h}$ : Massa da haste

$M_{m}: \quad$ Massa do martelo

$N_{s p t}$ : Índice de resistência à penetração

Q: $\quad$ Quake do solo

$q_{c}$ : $\quad$ Resistência de ponta do ensaio CPTu 
$R: \quad$ Carga aplicada ao ensaio

$R_{l}: \quad$ Força de atrito na parede externa do amostrador, resultante do atrito na parede externa $\left(r_{L e}\right)$

$R_{2}$ : $\quad$ Força de atrito na parede interna do amostrador, resultante do atrito na parede interna $\left(r_{L i}\right)$

$R_{2 i}: \quad$ Força de atrito na parede interna do amostrador para cada golpe

$R_{3}: \quad$ Força de reação na seção anelar da ponta do amostrador

R: $\quad$ Componente vertical da força de atrito vertical do atrito na seção biselada do amostrador

$R_{D}: \quad$ Parcela de resistência dinâmica devido ao amortecimento do solo

$R_{D}: \quad$ Resistência dinâmica (Lukiantchuki, 2012)

$R_{f} . \quad$ Razão de atrito

$r_{L e}: \quad$ Atrito lateral externo

$r_{L i}: \quad$ Atrito lateral interno

$r_{p}: \quad$ Resistência de ponta

$R_{s}: \quad$ Resistência estática (Aoki et al., 2007)

$R_{t}$ : $\quad$ Resistência total: dinâmica mais estática

$R_{u}: \quad$ Resistência última

T: $\quad$ Energia cinética total do sistema

$T_{A}$ : Energia transferida ao sistema amostrador-solo

$u$ : $\quad$ Deslocamento

$v(t)$ Velocidade das partículas

$V: \quad$ Energia potencial dedeformação

$V_{e s}: \quad$ Energia potencial de deformação no amostrador

$V_{e s}: \quad$ Energia potencial elástica devido a deformação do solo

$W_{A}$ : Trabalho realizado pelas forças não conservativas no amostrador

$W_{h}$ : Peso da composição de hastes e da cabeça de bater

$W_{n c}$ : Trabalho realizado por forças não conservativas

$W_{p}$ : Trabalho das forças resistentes

Z: $\quad$ Impedância da haste

$\Delta R: \quad$ Incrementos de carga

$\delta$ : Deslocamento 
$\delta_{m}$ : Deslocamento médio do amostrador

$\delta_{\text {total }}$ : Deslocamento total registrado ao final do evento

$\alpha: \quad$ Coeficiente de forma da equação de Van der Veen.

$\delta_{A C}$ : Deslocamento calculado pela dupla integração da aceleração

$\delta_{\text {acumulado: Deslocamento acumulado }}$

$\delta_{\text {medido: }}$ Deslocamento medido em campo

$\varepsilon: \quad$ Deformação

$\gamma: \quad$ Peso específico do solo

$\eta$ : $\quad$ Eficiência do ensaioSPT

$\eta_{1}$ : $\quad$ Eficiência do martelo (Odebrecht, 2003)

$\eta_{2}$ : $\quad$ Eficiência da composição de hastes (Odebrecht, 2003)

$\eta_{3}$ : $\quad$ Eficiência do sistema (Odebrecht, 2003)

$\eta_{\text {base: }} \quad$ Eficiência na base da composição de hastes

$\eta_{\text {topo: }} \quad$ Eficiência na base da composição de hastes

$\rho: \quad$ Massa específica domaterial 



\section{INTRODUÇÃO}

Em projetos de obras geotécnicas para quantificar as tensões possíveis de serem aplicadas ao maciço é fundamental avaliar de forma correta a resistência disponibilizada pelo solo. Nessa área de conhecimento a definição da carga de ruptura é o problema fundamental a ser resolvido. A capacidade de carga de uma estaca embutida em um maciço geralmente pode ser estimada por métodos racionais, baseados em soluções teóricas de capacidade de carga e parâmetros de solo. Também pode ser estimada por métodos chamados de semi-empíricos, que utilizam resultados de ensaios de penetração in situ, como SPT (Standard Penetration Test) e CPT (Cone Penetration Test) (Velloso; Lopes, 2010).

Outras formas para a determinação da capacidade de carga são através de provas de carga estáticas ou dinâmicas. Entre as evoluções desta área de conhecimento está a prova de carga dinâmica com energia crescente, proposta por Aoki (1997). O autor define que uma estaca atinge a ruptura quando a reação por atrito e ponta se tornam invariantes. Nesta ocasião a energia potencial de deformação não cresce mais, pois o diagrama de força normal torna-se constante. Com base nesta definição, Aoki (1997) verificou que o ensaio dinâmico com energia crescente avalia o nível de energia quando ocorre a condição de ruptura da estaca.

No Brasil, os métodos mais utilizados para determinação da capacidade de carga de fundações utilizam correlações com o índice de resistência à penetração $\left(N_{s p t}\right)$, obtido por meio do ensaio SPT. A ampla utilização do ensaio SPT deve-se ao fato de sua simplicidade de execução e de ter se mostrado suficiente para obtenção dos parâmetros necessários para o desenvolvimento de projetos de fundações (Belincanta, 1998).

Diversas críticas têm sido feitas à utilização de correlações empíricas com resultados do ensaio SPT. A maioria dessas correlações são baseadas em observações práticas, sem fundamento científico (Lobo, 2009). Essas críticas também estão relacionadas às dispersões obtidas nos resultados dos ensaios. Incorreto manuseio das ferramentas do ensaio pelo operador, variações dos equipamentos, atrito excessivo entre as peças do equipamento, diferentes metodologias aplicadas pelas empresas, são exemplos que podem afetar os resultados dos ensaios. As dispersões apresentadas na realização do ensaio, promovem diferenças na eficiência do ensaio, e consequentemente, nos valores obtidos para o índice $N_{s p t}$.

Com o intuito de padronizar o ensaio, a partir da década de 70, diversos autores começaram a realizar estudos voltados para quantificação da parcela de energia potencial que 
é efetivamente transferida à composição das hastes e ao amostrador. Assim, teve início a avaliação dos fatores que influenciam na perda e ganho de energia do ensaio, e consequentemente, os fatores que influenciam na eficiência deste.

As pesquisas que têm sido realizadas com objetivo de interpretar de forma mais racional os resultados do ensaio SPT, considerando as energias atuantes no processo de cravação do amostrador, tem ajudado a aumentar a credibilidade do ensaio. Isto se faz necessário já que este ensaio ainda é muito difundido no Brasil e no mundo.

\section{$1.1 \quad$ JUSTIFICATIVA}

Por ser um ensaio de simples execução e de baixo custo, Rausche et al., (1995) enfatizam que o ensaio SPT deve ser mais bem explorado e avaliado. $\mathrm{O}$ autor afirma que mais dados quantitativos além de um número de golpes devem ser extraídos do ensaio. Baseados nesta motivação, alguns autores têm tentado estimar as resistências do solo mobilizadas pelo golpe do martelo. Os conceitos de energia envolvidos durante o processo de cravação do amostrador padrão do SPT podem permitir estimar as resistências atuantes no amostrador e a carga de ruptura do sistema. Essas estimativas podem ser feitas embasadas em comportamentos já observado em provas de carga dinâmica de energia crescente em estacas. Esses fatores têm o potencial de alavancar a credibilidade do ensaio, possibilitando uma análise mais racional dos dados obtidos e redução de erros de projeto devido à má interpretação e/ou obtenção de parâmetros.

\subsection{OBJETIVO}

O objetivo deste trabalho é analisar o comportamento do ensaio SPT realizado com energia crescente. Assim, para atingir este objetivo será necessário:

- Realizar ensaios SPT com altura de queda do martelo crescentes a cada golpe;

- Avaliar o efeito das diferentes alturas de queda na eficiência do ensaio;

- Avaliar as resistências mobilizadas na cravação do amostrador;

- Realizar cravação estática no amostrador padrão do SPT;

- Investigar mecanismo de embuchamento do solo no amostrador pela cravação, através do controle da recuperação da amostra;

- Determinar a resistência de atrito interna atuante no amostrador durante sua cravação através do método desenvolvido por Zapata-Galvis (2015). 


\section{REVISÃO BIBLIOGRÁFICA}

Esta seção apresenta uma breve abordagem sobre os assuntos envolvidos neste trabalho. Inicialmente será realizada uma contextualização do ensaio SPT, suas inovações e as teorias que envolvem o ensaio. Em seguida, serão abordados tópicos sobre as resistências atuantes no amostrador durante sua cravação.

\subsection{ENSAIO SPT}

O ensaio de simples reconhecimento, mais conhecido como ensaio SPT (Standard Penetration Test), é um dos ensaios de investigação do subsolo mais utilizados no Brasil e em grande parte do mundo. Isto devido à sua fácil aplicação, sua robustez e seu fácil manejo, não necessitando de mão de obra especializada, e consequentemente custos reduzidos. Além de possibilitar a amostragem do solo para caracterização, o ensaio fornece ainda o índice de resistência à penetração $\left(N_{s p t}\right)$. Este índice é muito utilizado na previsão do comportamento do solo sob ação de carregamentos (Belincanta; Ferraz, 2000).

A obtenção de amostras através de processos dinâmicos teve início em 1902 com o engenheiro Charles R. Gow. Até então a análise do solo era feita a partir dos detritos provenientes da perfuração com circulação de água, de abertura de poços, ou até mesmo de escavações de grande porte. A partir de 1902 tornou-se possível obter amostras com melhor qualidade e na profundidade desejada (Cavalcante, 2002). O procedimento do ensaio evoluiu ao longo dos anos. Em 1948, com a publicação do livro de Terzaghi e Peck (Soil Mechanics in Engineering Practice) o ensaio se tornou mais conhecido. A publicação abordou aspectos relevantes sobre a execução e os equipamentos do ensaio. As recomendações feitas na publicação foram posteriormente absorvidas pelas normas elaboradas para o ensaio no mundo todo. Além disso, a publicação de Terzaghi e Peck apresentou as primeiras correlações entre a resistência à penetração do ensaio e propriedades do solo, tais como compacidade, resistência e consistência. A partir de meados dos anos 50, deu-se início à tentativa de padronização do ensaio. Em 1967 surgiu a primeira norma da ASTM regulamentando o ensaio (Belincanta, 1998; Cavalcante, 2002).

No Brasil, o ensaio SPT começou a ser introduzido a partir de 1939. Em 1977, a ABMS (Associação Brasileira de Mecânica dos Solos) envia para a ABNT a primeira proposta de normatização do ensaio, dando origem à norma MB 1211/79. Esta foi posteriormente 
renomeada como NBR 6484 (Belincanta, 1998; Cavalcante, 2002). O ensaio SPT com medidas de resistência à penetração se tornou extremamente difundido no país. Isto pode ser confirmado pelo uso constante das correlações propostas por Aoki-Velloso e Décourt Quaresma para previsão de capacidade de carga de estacas.

Apesar das normas vigentes, observou-se que ocorriam variações nos resultados dos ensaios, mesmo que os ensaios fossem realizados no mesmo local. Com isso, muitas críticas passaram a ser feitas, principalmente em relação a utilização das correlações empíricas para projetos de fundações e o ensaio começou a entrar em descrédito. A partir de então, alguns pesquisadores (Schmertmann; Palacios, 1979; Kovacs; Salomone, 1982; Belincanta, 1998; Cavalcante, 2002; Lobo, 2009; entre outros) começaram a analisar os fatores que interferiam nos resultados do ensaio SPT. As pesquisas concluíram que os resultados dos ensaios eram afetados pelas diferenças entre os equipamentos utilizados, a forma de execução do ensaio, o estado de conservação dos equipamentos, o tipo e a forma de liberação do martelo utilizado, entre outros motivos. Todos esses fatores influenciam na energia que é entregue ao sistema e que será responsável pela cravação do amostrador (Odebrecht, 2003). Dessa forma, estudos sobre a transferência de energia começaram a ser realizados com objetivo de definir a eficiência dos ensaios. Através da instrumentação das hastes, com acelerômetros e células de carga, e da aplicação da teoria da propagação da onda longitudinal de tensão, o ensaio SPT passou a ser melhor analisado e interpretado. Até os dias de hoje ainda são encontradas variações na execução dos ensaios. Dessa forma, a medição da energia tornou-se fundamental para a correta interpretação dos resultados dos ensaios (Lukiantchuki, 2012).

\subsection{TEORIA DA EQUAÇÃO DA ONDA}

O processo de cravação de um elemento no solo se assemelha aos conceitos da propagação de onda longitudinal em barras (Lobo, 2009). O impacto gerado pela queda do martelo sobre a cabeça de bater do SPT resulta em compressão de um pequeno trecho do material subjacente. Essa deformação gera uma tensão que será transferida ao trecho posterior, comprimindo-o e dando início a um novo ciclo. Dessa forma a tensão se propaga na forma de uma onda longitudinal ao longo do comprimento do elemento (Bernardes, 1989). A propagação da onda longitudinal de tensão, gerada pelo impacto do martelo sobre a cabeça de bater, está representada esquematicamente na Figura 1. 

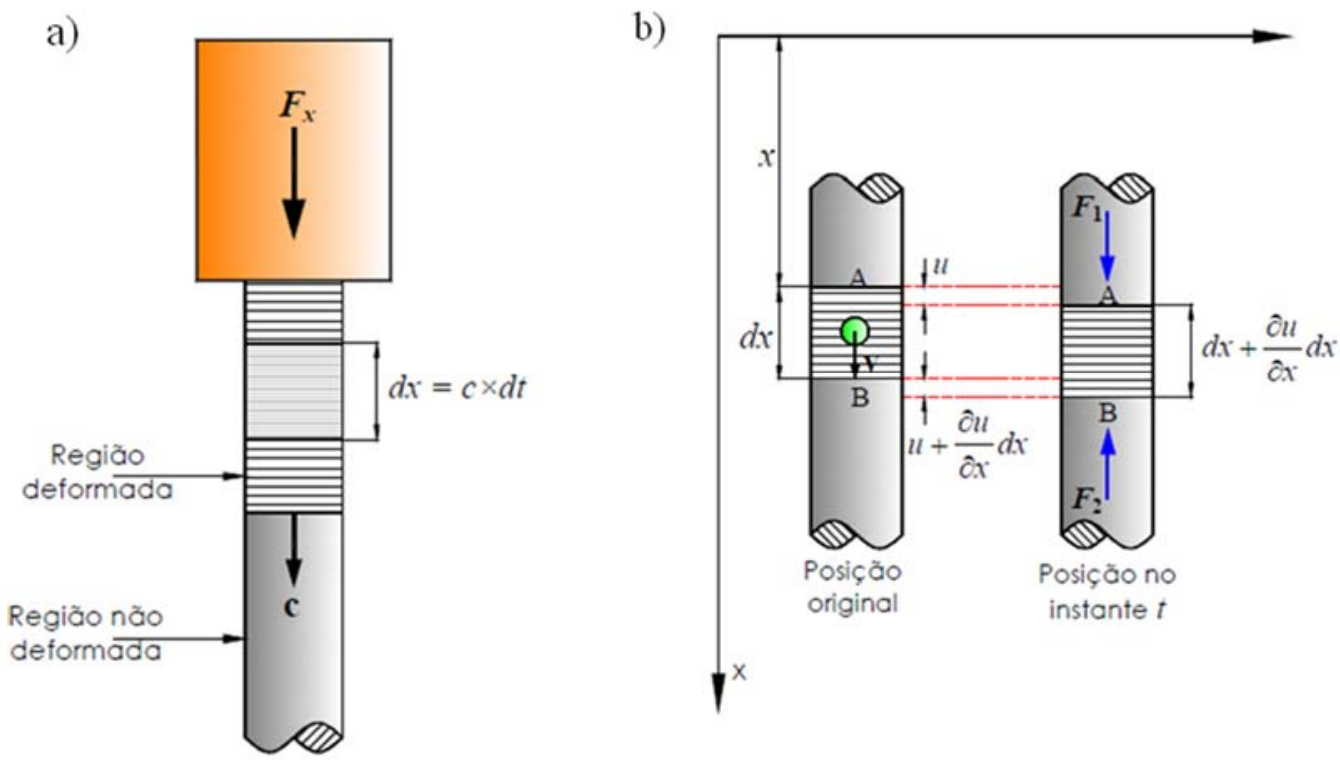

Figura 1 - Esquema de uma onda longitudinal de compressão em hastes (Lukiantchuki, 2012 adaptado de Bernardes, 1989).

A propagação da onda é governada pela conhecida equação da onda (Equação 1), que é uma equação diferencial parcial de segunda ordem. Através dessa equação é possível determinar o deslocamento $(u)$ de uma partícula localizada à uma distância $(x)$ do topo do elemento, em um instante $(t)$ após a aplicação do golpe (Odebrecht, 2003). Esta equação pode ser deduzida a partir de conceitos físicos (deformação elástica, forças, impulso, quantidade de movimento, velocidade de partícula, velocidade da onda de compressão (c), propriedades físicas e geométricas do material, entre outros). A sua dedução pode ser encontrada em Bernardes (1989), Odebrecht (2003), Lobo (2009), Lukiantchuki (2012), Morais (2014) e outros.

$$
\frac{\partial^{2} u}{\partial x^{2}}=\frac{1}{c^{2}} \frac{\partial^{2} u}{\partial t^{2}}
$$

Para a dedução dessa equação, algumas hipóteses devem ser assumidas: a seção transversal da haste permanece constante durante a propagação da onda; o material é isotrópico; a tensão axial é distribuída uniformemente sobre a seção transversal; o comprimento da onda é considerado muito maior que o diâmetro da haste; qualquer movimento transversal da partícula devido a passagem da onda pode ser considerado desprezível; a perda de energia devido à propagação da onda é considerada desprezível; a onda se propaga com velocidade constante (Belicanta, 1985; Bernardes, 1989). Diferentemente da propagação de uma onda transversal em uma corda tensionada, na propagação da onda longitudinal em barras, variáveis como tensão, 
velocidade da partícula e energia passam a ser fundamentais para análise do processo (Graff, 1991).

Issacs (1931) apud Hussein e Goble (2004) foi o primeiro a aplicar os conceitos de onda longitudinal de tensão à cravação de estacas. Posteriormente, com os avanços da computação, Smith (1960) desenvolveu uma rotina de cálculo para solução da equação da onda. Este fato tornou a aplicação destes conceitos corrente na engenharia de fundações (Hussein e Goble, 2004). Atualmente, estes conceitos têm sido aplicados não apenas à estacas, mas também à outros ensaios de penetração dinâmica como o ensaio SPT (Schmertmann e Palácios (1979), Belincanta (1985 e 1998), Cavalcante (2002), Odebrecht (2003), Odebrecht et al. (2005), Aoki e Cintra (2000), Aoki et al. (2007), Lobo (2009), Lukiantchuki et al. (2011 e 2013), Lukiantchuki (2012), Morais (2014), Zapata Galvis (2015), Santana (2015), Eberle (2018), entre outros).

\subsubsection{Energia}

A onda de compressão, quando se propaga pelo elemento, conduz uma certa quantidade de energia. Esta energia pode ser dividida em duas parcelas: energia de deformação, que fica armazenada no elemento submetido ao esforço; e a energia cinética das partículas (Odebrecht, 2003). Isto resulta nos métodos EF2 (Equação 2) e EFV (Equação 3).

$$
\begin{aligned}
& E_{t}=\frac{c}{E \times A} \int_{0}^{t} F^{2}(t) d t \\
& E_{t}=\int_{0}^{t} F(t) \times v(t) d t
\end{aligned}
$$

As deduções dessas equações foram apresentadas por diversos autores, incluindo Bernardes (1989), Odebrecht (2003), Lobo (2009), Lukiantchuki (2012), Morais (2014) e outros.

\subsubsection{Impedância}

Pode-se demonstrar que quando ocorre uma onda de compressão, em uma determinada seção da haste existe uma proporcionalidade entre a força axial $(F)$ e a velocidade da partícula (v) nesta seção (Equação 4). Essa constante de proporcionalidade (Z), que é denominada impedância depende do módulo de elasticidade do material $(E)$, da área da seção transversal da haste $(A)$ e da velocidade de propagação da onda (c) (Zapata Galvis, 2015): 


$$
F=\left(\frac{E \times A}{c}\right) \times v=Z \times v
$$

Por sua vez, a velocidade de propagação da onda depende somente do módulo de elasticidade $(E)$ e da massa específica $(\rho)$ do material:

$$
c=\sqrt{\frac{E}{\rho}}
$$

\subsubsection{Condições de contorno}

A forma como a onda se propaga pelo elemento depende das condições de contorno do sistema. Problemas como alterações da seção do elemento, resistência do solo e extremidade da haste podem alterar o comportamento da onda. Portanto, essas condições de contorno devem ser devidamente avaliadas. Essa análise consiste em verificar as condições de equilíbrio de força e a compatibilidade das velocidades das ondas ascendentes e descendentes. Para essas verificações se faz necessário estabelecer uma convenção de sinais tanto para a força quanto para a velocidade (Odebrecht, 2003). A convenção adotada está apresentada na Tabela 1.

Tabela 1 - Convenção de sinais para força e velocidade (Belincanta, 1985).

\begin{tabular}{cl}
\hline Onda & Força \\
\hline Descendente & $F \downarrow=v \times Z>0 \Rightarrow$ Compressão \\
Ascendente & $F \uparrow=-v \times Z>0 \Rightarrow$ Tração \\
\hline
\end{tabular}

As condições de contorno que afetam a propagação da onda serão apresentadas nos próximos itens.

\subsubsection{Alteração da Impedância}

Qualquer descontinuidade na seção transversal e nas propriedades do material do elemento de propagação da onda longitudinal de tensão, resulta em mudança da impedância (Graff, 1991). No caso do SPT, a alteração da impedância ocorre, por exemplo, nas ligações cabeça de bater-haste, haste-haste e haste-amostrador. A ocorrência dessas alterações resulta em reflexão de parte da onda de tensão que se propaga pelo elemento. Assim, ao se deparar com a seção alterada (alteração de $Z_{l}$ para $\left.Z_{2}\right)$, parte da onda $\left(F_{I} \downarrow, v_{I} \downarrow\right)$ é transmitida $\left(F_{2} \downarrow, v_{2} \downarrow\right)$ e parte é refletida $\left(F_{1} \uparrow, v_{1} \uparrow\right)$, como apresentado na Figura 2 (Belincanta, 1985; Bernardes, 1989; Odebrecht, 2003; Lukiantchuki, 2012). 


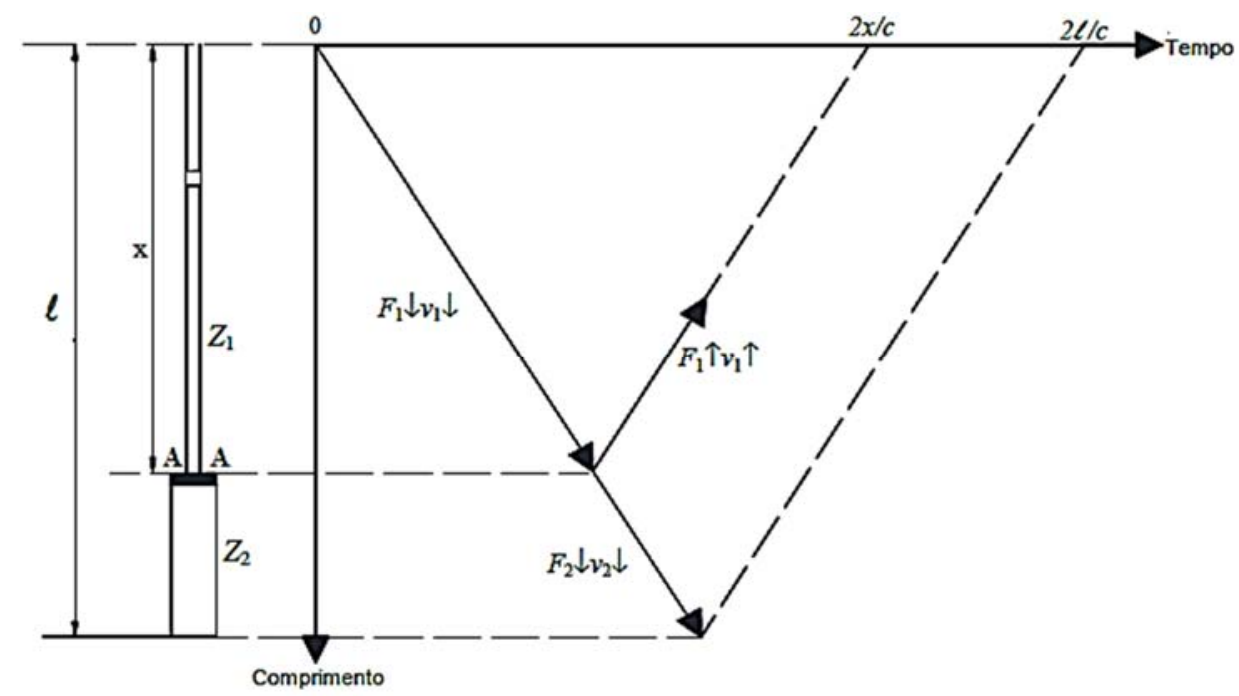

Figura 2 - Propagação da onda de tensão em um elemento com alteração de impedância (Lukiantchuki, 2012 adaptado de Bernardes, 1989).

Realizando medições de força e velocidade no topo do elemento, pode-se observar que:

a) se não houver alteração de impedância ao longo do elemento, a onda será refletida apenas quando atingir a extremidade do elemento e só chegará ao topo após o instante $(2 l / c)$

b) se a impedância da segunda seção $\left(Z_{2}\right)$ for maior que a da primeira $\left(Z_{1}\right)$, a onda refletida será de compressão, com velocidade inferior à velocidade inicial, chegando ao topo com intensidade maior que a inicial;

c) se a impedância da segunda seção for menor que a da primeira, a onda refletida será de tração e irá sobrepor a onda inicial, diminuindo a intensidade da onda e aumentando sua velocidade (Bernardes, 1989).

\subsubsection{Extremidade da haste}

A onda de tensão resultante do impacto do martelo se propaga pela composição de hastes até atingir a ponta do amostrador. Isso ocorre no instante $l / c$, sendo $l$ o comprimento da composição haste-amostrador. Neste instante ocorre a penetração do amostrador. Esse deslocamento mobiliza uma reação dinâmica no solo $\left(R_{D}\right)$. Após a penetração, uma parte da onda será refletida e a outra parte será transmitida ao solo e isso dependerá das características do solo abaixo da ponta do amostrador. Existem duas condições limites: resistência dinâmica $\left(R_{D}\right)$ nula, permitindo que o amostrador penetre livremente e resistência suficientemente alta, não permitindo nenhum deslocamento. Essas duas condições representam, respectivamente, a propagação de uma onda em uma haste com extremidade livre e extremidade engastada 
(Belicanta, 1985; Bernardes, 1989; Odebrecht, 2003). A Figura 3 apresenta as condições de contorno na extremidade da haste.

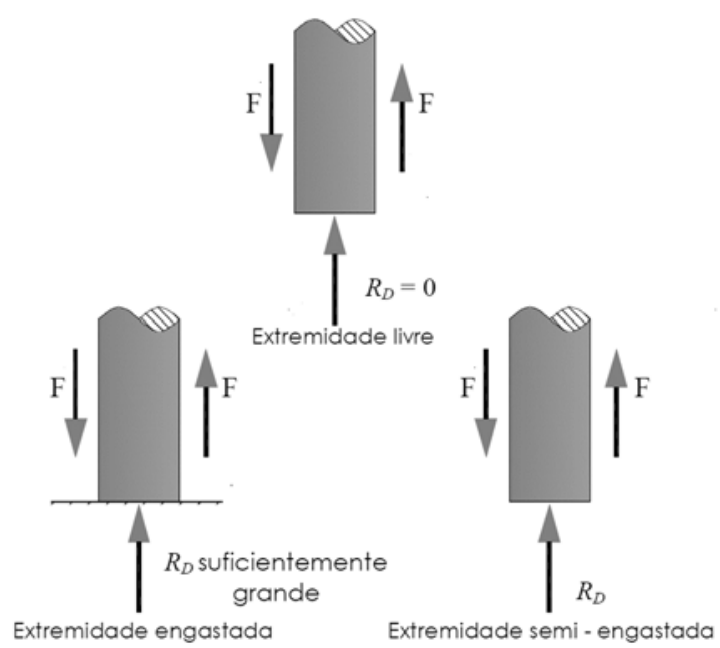

Figura 3 - Condições de contorno da extremidade do amostrador (Lukianthucki, 2012 adaptado de Belincanta, 1985).

Na condição de extremidade livre, a onda refletida terá a mesma intensidade da onda que chega ao amostrador, porém em sentido contrário. Assim, se a onda que chega ao amostrador for de compressão, a refletida será de tração. Na condição engastada, a onda refletida tem o mesmo sentido e mesma intensidade da onda incidente. Assim, se a onda que chega ao amostrador for uma onda de compressão, a onda refletida também será de compressão. Além disso, a onda refletida terá velocidade de partícula negativa. Portanto, quando ocorrer superposição da onda ascendente com a descendente, acarretará aumento de força e diminuição da velocidade. Por fim, para a extremidade semi-engastada observa-se que: se $R_{D}$ for igual a $F \downarrow$, não haverá reflexão de onda na extremidade; se $R_{D}$ for maior que $F \downarrow$, a onda refletida será de compressão; e se $R_{D}$ for menor que $F_{I} \downarrow$, a onda refletida será de tração (Belicanta, 1985; Bernardes, 1989; Odebrecht, 2003; Lukiantchuki, 2012).

\subsection{ENERGIA NO ENSAIO SPT}

O índice de resistência à penetração $\left(N_{s p t}\right)$ está diretamente relacionado com a energia entregue ao sistema em cada golpe do martelo. Esta energia será transferida pelas hastes do martelo e parte dela ficará disponível para a cravação do amostrador. Quanto menor a energia disponível para a cravação do amostrador, menor será o deslocamento do amostrador a cada golpe. Consequentemente, maior será o número de golpes necessários para a cravação de 
$300 \mathrm{~mm}$. Assim, conclui-se que o valor de $N_{s p t}$ é inversamente proporcional à energia que efetivamente chega ao amostrador (Belincanta e Ferraz, 2000).

A energia desenvolvida durante o ensaio SPT e a forma como as diferenças de equipamentos, execução, tipo de solo, entre outros fatores, influenciam nesta energia, foi alvo de estudo de diversas pesquisas. Entre os trabalhos desenvolvidos nesta área pode-se citar: Schmertmann e Palácios (1979), Yokel (1989), Abou-matar e Goble (1997), Belincanta (1985 e 1998), Aoki e Cintra (2000), Cavalcante (2002), Odebrecht (2003), Youd et al. (2008), Lobo (2009); Schnaid et al. (2009a), Cavalcante et al. (2011), Lukiantchuki (2012), Santana (2015); Lukiantchuki et al. (2017), Eberle (2018), entre outros.

Quando o martelo é elevado para dar início ao ensaio, a energia disponibilizada ao sistema encontra-se em forma de energia potencial gravitacional. Tendo o martelo $65 \mathrm{~kg}\left(M_{m}\right)$ e sendo este elevado a uma altura de $0.75 \mathrm{~m}\left(H_{q}\right)$ acima da cabeça de bater, conforme descrito na NBR 6484 (ABNT, 2001), a energia potencial teórica ou energia nominal $\left(E P_{T}\right)$ disponível no início do evento é de aproximadamente 478,2 J (Equação 6).

$$
E P_{T}=M_{m} \times g \times H_{q}=65 \times 9.81 \times 0.75 \cong 478.2 J
$$

Quando o martelo é liberado a energia potencial se transforma em energia cinética, que será máxima e teoricamente igual à energia nominal, no instante imediatamente antes do impacto. Porém, nem toda a energia potencial é transformada em energia cinética. Parte da energia pode se perder devido ao atrito entre a corda e a polia, ou por possível erro do executor em não soltar completamente a corda, diminuindo assim a energia disponível (Belincanta, 1998). Além disso, possíveis variações na altura de queda do martelo ou no peso deste, podem ser responsáveis por alterar o valor da energia disponível (Teixeira, 1977; Cavalcante et al., 2011; Santana et al., 2013).

Porém, a real energia disponível ao sistema não é igual a energia nominal. $O$ deslocamento do conjunto martelo-haste-amostrador provocado pela cravação do amostrador no solo proporciona aumento da energia potencial do sistema. Esse acréscimo faz com que a energia disponível do sistema seja maior que a energia potencial nominal (Odebrecht, 2003). Dessa forma, Odebrecht (2003) propõe uma correção para o cálculo da energia potencial disponível ao sistema que leva em consideração esse acréscimo de energia (Equação 7).

$$
E P_{\text {sistema }}=E P_{T}+\left(M_{m} \times g \times \delta\right)+\left(M_{h} \times g \times \delta\right)
$$


onde $E P_{T}$ é a energia nominal (478,2 J), $M_{m}$ e $M_{h}$ são, respectivamente, a massa do martelo e a massa do conjunto de hastes, $g$ é a aceleração da gravidade e $\rho$ é a penetração do amostrador.

No momento em que ocorre o impacto, parte da energia cinética do martelo é transformada em energia de deformação elástica e essas energias irão se propagar pelas hastes na forma de onda longitudinal de tensão. A primeira onda de tensão atinge o amostrador no instante $l / c$. Neste instante, parte da energia contida na onda é transformada em trabalho necessário para cravação do amostrador. Outra parte da energia é refletida em ondas de tensão ascendentes em direção ao topo da composição de hastes, atingindo este no tempo $2 l / c$. Neste momento, novos impulsos são refletidos na forma descendente, podendo atingir novamente o amostrador e continuar a cravação deste. Tendo a onda energia e magnitude suficiente, no instante que a onda ascendente atinge a cabeça de bater pode ocorrer a separação entre a cabeça de bater e o martelo, possibilitando ou não a ocorrência de um novo golpe secundário (Schmertmann e Palácios, 1979).

Estes ciclos de propagação de ondas ascendentes e descendentes continuam até que toda energia contida na onda seja transformada em trabalho para a cravação do amostrador ou seja dissipada, de forma que a onda já não tenha intensidade para vencer a resistência à penetração do amostrador imposta pelo solo (Belincanta e Ferraz, 2000).

\subsubsection{Eficiência do ensaio SPT}

A eficiência no ensaio SPT $(\eta)$ foi inicialmente definida como a razão entre a energia que atinge o topo da composição de hastes $\left(E_{t o p o}\right)$ no momento do primeiro impacto do martelo e a energia nominal $\left(E P_{T}\right)$. Posteriormente, Aoki e Cintra (2000) definiram a eficiência como sendo a relação entre a energia que efetivamente chega ao amostrador (Eamostrador), energia que será responsável pela cravação do amostrador, e a energia nominal $\left(E P_{T}\right)$. Após a inclusão da energia potencial do sistema corrigida $\left(E P_{\text {sistema}}\right)$, proposta por Odebrecht (Equação 07), a eficiência do ensaio SPT passou a ser definida como sendo a razão entre a energia que chega ao amostrador ( $\left.E_{\text {amostrador }}\right)$ e a energia potencial do sistema $\left(E P_{\text {sistema }}\right)$.

Para quantificar a energia que chega ao amostrador, pode-se realizar ensaios SPT devidamente instrumentados, como será visto adiante neste trabalho, ou de forma analítica conforme proposto de Odebrecht et al. (2004), separando a eficiência em parcelas, de acordo com os processos envolvidos no ensaio e suas respectivas perdas de energia (Equação 8). 


$$
E_{\text {amostrador }}=\eta_{3} \times\left[\eta_{1} \times\left(H_{q}+\delta\right) \times M_{m} \times g+\eta_{2} \times\left(M_{h} \times g \times \delta\right)\right]
$$

onde: $\eta_{1}$ é a parcela de eficiência do martelo, $\eta_{2}$ da composição de hastes e $\eta_{3}$ do sistema como um todo.

A energia que chega ao amostrador pode ser preliminarmente estimada, para as configurações do equipamento brasileiro, utilizando os valores de eficiências recomendados por Odebrecht et al. (2004): $\eta_{1}=0.76 ; \eta_{2}=1 ; \eta_{3}=1-0.0042 \times l_{h}$, sendo $l_{h}$ o comprimento do conjunto de hastes.

As perdas de energia durante o processo de cravação e consequente variação da eficiência do ensaio, ocorrem por diversos fatores tais como tipo de martelo, comprimento de hastes, geometria dos equipamentos, sistema de elevação e liberação do martelo, utilização de coxim de madeira dura, altura de queda do martelo, métodos de execução, reflexões das ondas nas luvas das hastes, etc. (Odebrecht et al., 2004).

Alguns autores demonstraram que através da aplicação dos princípios de conservação de energia de Hamilton também era possível determinar a eficiência do ensaio SPT através da realização de prova de carga estática no amostrador (Neves, 2004; Aoki et al., 2007; Noreña, 2011).

\subsubsection{Influência do comprimento de hastes}

A influência do comprimento de hastes na eficiência do ensaio SPT tem sido alvo de controvérsia entre pesquisadores. Alguns concluíram em seus trabalhos que a energia que chega ao amostrador é maior para maiores comprimentos de hastes, ou seja, quanto maior o comprimento de haste, maior seria a eficiência do ensaio (Shmertmann e Palácios, 1979; Skempton, 1986; Youd et al., 2008). Shmertmann e Palácios (1979), para estimativa da energia, consideraram que a energia da primeira onda de compressão nas hastes é responsável pela cravação total do amostrador, desprezando qualquer influência dos impactos subsequentes.

Cavalcante, 2002 verificou que até $14 \mathrm{~m}$, o comprimento de hastes não influencia na eficiência do ensaio. Daniel et al. (2005), através de análises em laboratório com hastes curtas, discutiram a influência dos impactos secundários na transferência de energia. Os autores concluíram que o acréscimo de energia devido ao segundo impacto é suficiente para tornar a transferência de energia independente do comprimento da haste.

Odebrecht et al. (2005) concluíram que, se a eficiência é calculada em relação à $E P_{\text {sistema }}$ o comprimento da haste influencia tanto no sentido de aumentar a eficiência do sistema, quanto 
de reduzir. Quanto maior o comprimento da composição de hastes, menor a eficiência, devido às perdas de energia pela propagação da onda de tensão pelas hastes. Ao mesmo tempo, quanto maior o comprimento, maior o peso das hastes, proporcionando ganho de energia e aumentando a eficiência. Para hastes de menor comprimento, os dois efeitos podem ser anulados e assim, a energia que chega ao amostrador pode ser igual à energia que chega no topo da composição de hastes. Essas relações dependem da penetração permanente do amostrador.

O acréscimo de energia devido ao peso das hastes, proposto por Odebrecht et al. (2005), geralmente não é levado em consideração nos métodos de interpretação. Youd et al. (2008) realizaram ensaios SPT com martelo automático e medição de energia e chegaram a resultados que parecem concordar com o proposto por Schmertmann e Palacios (1979). Em seus resultados, a eficiência aumenta com o comprimento de hastes tendendo à uma constante para hastes maiores que 6.0 metros. Porém Schnaid et al. (2009b), refizeram os cálculos com os resultados obtidos pelos autores, aplicando à interpretação os conceitos propostos por Odebrecht et al. (2005). Os novos resultados mostraram que, se lavada em consideração a penetração permanente do amostrador e o peso próprio das hastes, o comprimento das hastes não interfere na eficiência do sistema.

Os resultados apontados mostram ser necessário levar em consideração, no cálculo da eficiência do sistema, o acréscimo de energia potencial resultante do peso das hastes e do deslocamento permanente do amostrador.

\subsubsection{Influência do tipo de solo}

Cavalcante (2002) verificou que para hastes curtas e solos de baixa resistência ocorrem vários impactos subsequentes e vários ciclos de penetração em um mesmo golpe. $\mathrm{O}$ autor verificou que nesses casos, a energia é transmitida em sua maioria no tempo $2 l / c$. Porém, os deslocamentos que ocorrem após esse tempo são bastantes significativos. Esse fato também foi verificado por Daniel et al. (2005). Os autores mostraram que os impactos secundários podem provocar acréscimos na quantidade de energia que chega ao amostrador, aumentando assim a eficiência do sistema. Tal questão também foi discutida por Lee et al. (2010). Os autores realizaram ensaios SPT com hastes instrumentadas e fizeram o monitoramento do movimento do conjunto martelo-haste durante o impacto através de uma câmera do tipo line-scan. Os resultados mostraram que para solos de menor resistência os impactos secundários contribuíram com o aumento de energia e, consequentemente, aumento da penetração do amostrador. Já para 
solos com maiores resistências, ocorrem impactos secundários, mas estes não são suficientes para gerar acréscimos de penetração.

Odebrecht et al. (2005) mostraram que a eficiência do sistema além de ser dependente da energia potencial nominal é também dependente do peso da composição de hastes e da penetração permanente do amostrador. Logo, quanto menos resistente o solo, maior será a penetração sofrida pelo amostrador e maior será o acréscimo de energia.

Lukiantchuki (2012) verificou que para solos de menor compacidade, a energia que chega na seção instrumentada acima do amostrador é menor. Segundo a autora, para este tipo de solo mais impactos subsequentes são necessários para finalizar a transferência de energia. Assim, maior a dissipação de energia durante o evento, reduzindo a eficiência do ensaio.

\subsubsection{Influência da altura de queda}

A altura de queda do martelo influência de maneira significativa no resultado do ensaio SPT. Quando maior a altura de queda do martelo, maior a energia disponível ao sistema. Para tanto é de extrema importância que esta altura seja mantida constante e que a queda ocorra de maneira livre (Teixeira, 1977). Santana et al. (2012) verificaram as alterações sofridas pela altura de queda entre os golpes para uma mesma profundidade. Os autores utilizaram uma câmera de vídeo de alta velocidade para verificar as alturas de queda. Segundo os autores o operador do ensaio tem uma tendência em aplicar alturas de queda maiores que as nominais. $\mathrm{O}$ mesmo fato já havia sido observado por Cavalcante et al. (2011). Dessa forma, como a energia potencial nominal não considera o acréscimo de energia gerado pelo acréscimo de altura de queda, a eficiência do ensaio tende a ser maior (Santana et al. 2012).

Youd et al. (2008), realizou ensaios com martelo de liberação automática, alterando as alturas de queda do martelo. Os resultados mostraram que quanto maior a altura de queda do martelo, maior a eficiência do sistema. Vale ressaltar que, mesmo alterando e conhecendo as alturas de queda aplicadas, os autores calcularam a eficiência sempre relação à energia potencial teórica padrão dos ensaios realizados na região (475 J).

\subsubsection{Aplicação do princípio de conservação de energia no ensaio SPT}

Conforme mencionado anteriormente, Aoki e Cintra (2000), baseados em conceitos de conservação de energia, propuseram que a eficiência do sistema fosse calculada como a razão entre a energia transferida ao amostrador e a energia nominal do ensaio SPT. Neste estudo, Aoki e Cintra (2000) aplicaram o Princípio da Conservação de Energia de Hamilton. O 
princípio estabelece que a variação da energia cinética e potencial, mais a variação do trabalho realizado por forças não conservativas, atuando sobre qualquer sistema, dentro de um intervalo de tempo, é igual a zero (Equação 9).

$$
\int_{t_{1}}^{t_{2}} \Delta(T-V) d t+\int_{t_{1}}^{t_{2}} \Delta\left(W_{n c}\right) d t=0
$$

onde: $\Delta$ é a variação no intervalo de tempo $\left(t_{2}-t_{1}\right) ; T$ é a energia cinética total no sistema; $V$ é a energia potencial no sistema; $W_{n c}$ é a trabalho realizado pelas forças não conservativas (incluindo os efeitos de amortecimento).

Aplicando este conceito aos ensaios SPT, no intervalo de tempo da penetração do amostrador, a energia cinética transferida ao topo da composição de hastes é transformada em energia de deformação elástica do sistema haste-amostrador-solo e em trabalho realizado pelas forças não conservativas atuantes sobre o amostrador (Aoki; Cintra, 2000).

As etapas de transformações das energias envolvidas no ensaio podem ser representadas como uma curva carga-recalque (Figura 4).
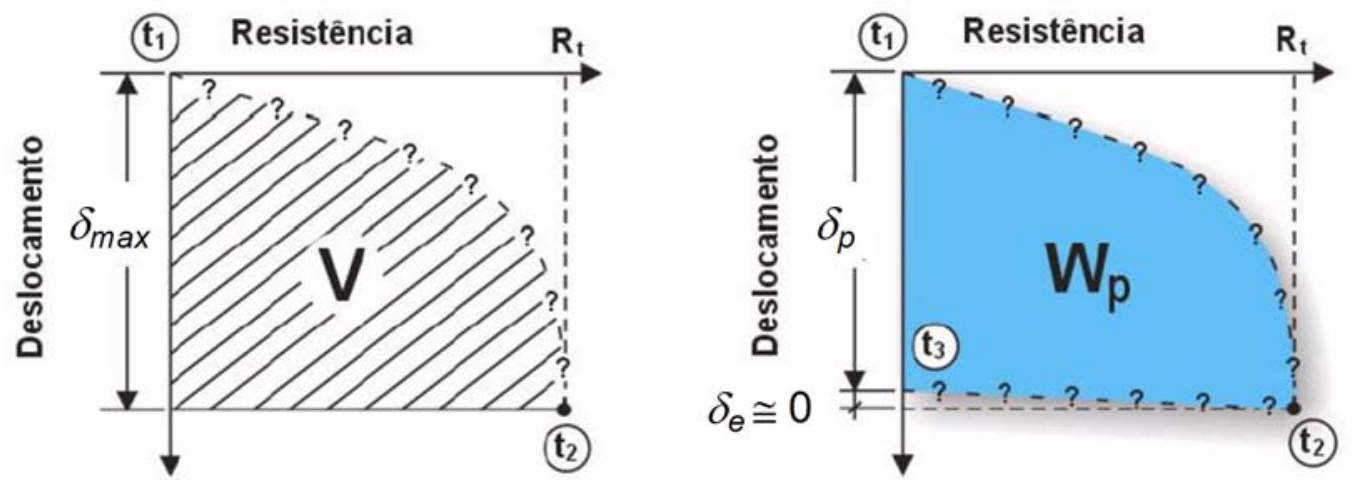

Figura 4 - Resultado típico de um ensaio dinâmico realizado sobre o amostrador SPT (Neves, 2004).

No momento em que a resistência total é mobilizada, ou seja, quando a penetração máxima do amostrador é atingida ( $\left.t_{2}\right)$ em um golpe, a energia cinética $(T)$ é armazenada no sistema como energia potencial de deformação $(V)$. $O$ descarregamento dinâmico ocorre entre os instantes $t_{2}$ e $t_{3}$. Neste intervalo, parte da energia potencial de deformação $(V)$ se transforma em energia de deformação elástica $\left(V_{e s}\right)$, responsável pelo deslocamento elástico $\left(\delta_{e}\right)$ e o restante em trabalho das forças resistentes $\left(W_{p}\right)$, responsável pelo deslocamento permanente ( $\left.\delta_{p}\right)$ (Aoki et al., 2007).

O princípio de conservação de energia também pode ser aplicado aos ensaios estáticos. Neves (2004) realizou provas de carga estáticas no SPT com objetivo de determinar a eficiência 
do ensaio SPT (Figura 5). O índice " $s$ " presente na representação das energias refere-se ao carregamento estático.
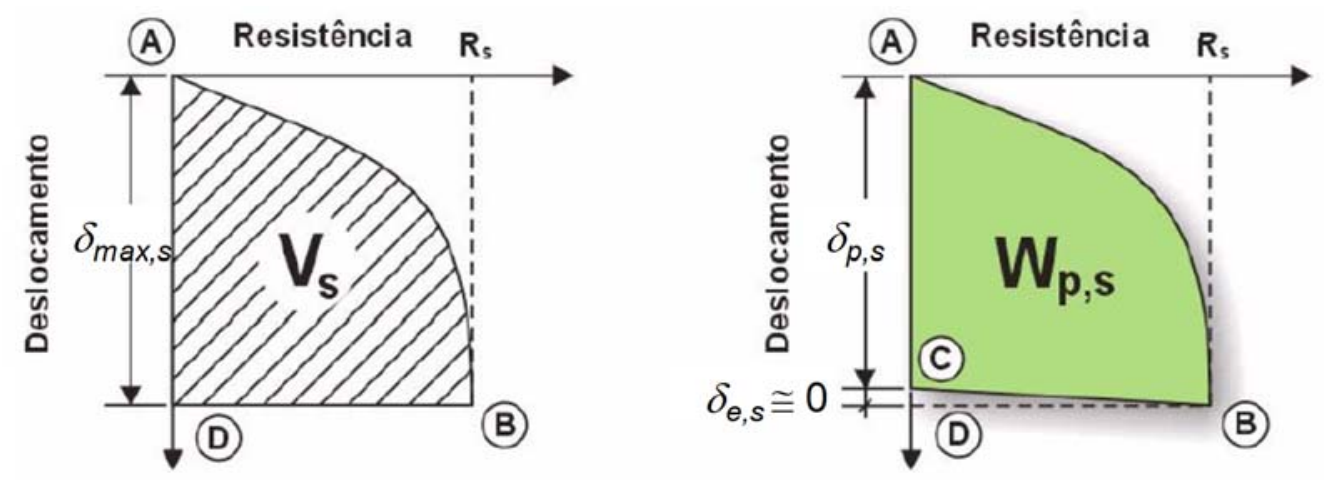

Figura 5 - Resultado típico de um ensaio de prova de carga estática sobre o amostrador SPT (Neves, 2004).

Em uma prova de carga estática, estágios crescentes de energias são aplicados até que a resistência estática mobilizada $R_{S}$ seja atingida, representado na Figura 5 pelo ponto $\mathrm{B}$. Cada incremento de aplicação de carga resulta em um incremento de deslocamento e, consequentemente, em um incremento de energia de deformação (Aoki, 2000). A energia potencial de deformação ao final do carregamento estático $\left(V_{s}\right)$ é representada pela área ABDA.

Após o descarregamento do sistema, a energia potencial de deformação armazenada se transforma em energia de deformação elástica ( $V_{e s, s}$, representada pela área $\mathrm{CBDC}$ ) mais trabalho realizado ( $W_{p, s}$, representado pela área ABCA). Em seu trabalho, Neves (2004) demonstrou que para solos arenosos ou siltosos a parcela de energia de deformação elástica $\left(V_{e s}\right)$ é muito baixa, podendo ser desprezada. Para os casos onde a parcela de energia de deformação elástica pode ser desprezada, pode-se utilizar o ensaio estático para determinação da eficiência do ensaio SPT. A eficiência será então calculada através do trabalho realizado para a penetração do amostrador.

\subsubsection{Determinação da energia no ensaio SPT}

A quantidade de energia envolvida no ensaio SPT pode ser calculada através do método conhecido como EFV, introduzido por Sy e Campanella (1991). Este método foi adotado pela norma D4633-10 (ASTM, 2010) como procedimento padrão para determinação da energia atuante em um golpe de martelo no ensaio SPT. A energia $(E)$ é calculada pela Equação 10. 


$$
E=\int_{t_{1}}^{t_{2}} F(t) \times v(t) d t
$$

onde, $F$ é a força axial, $v$ a velocidade das partículas e $t$ o tempo.

Para ser possível aplicar o método EFV é necessária utilizar hastes instrumentadas com células de carga e acelerômetros. As instrumentações fornecerão os valores de força e aceleração na seção instrumentada no intervalo de tempo estabelecido. A partir dos valores de aceleração é possível determinar, por integração no intervalo de tempo desejado, os valores de velocidade.

O intervalo de tempo utilizado neste método deve ser suficientemente longo para que aborde toda a transferência de energia envolvida. Dessa forma, todos os impactos contidos em um golpe do martelo são considerados (Odebrecht et al., 2004).

\subsection{RESISTENNCIA MOBILIZADA}

Ao se aplicar uma carga vertical em um elemento cravado no solo, seja estaticamente ou dinamicamente, uma parcela da resistência do solo será mobilizada. Sob ação de uma carga estática, se essa carga atingir valores suficientes para mobilizar toda a resistência do solo, esta carga é denominada carga última ou de ruptura. O conhecimento da capacidade de carga da fundação é fundamental para avaliação da segurança da fundação em relação à carga que será aplicada sobre esta (Aoki, 1997).

Esse nível de carregamento pode ser estimado ao submeter esses elementos a provas de carga estática. Outro método muito aplicado é a prova de carga dinâmica. Porém, este método necessita de modelos de interpretação para que, a partir do carregamento dinâmico, se possa conhecer o comportamento ao carregamento estático (Aoki, 1997). A princípio esse ensaio era realizado com aplicação de impactos de energia constante. Aoki (1997) propôs a realização do ensaio dinâmico aplicando energia crescente.

Nos projetos de fundações, a capacidade de carga é preliminarmente obtida a partir de correlações com resultados de ensaios de campo, tais como SPT e CPT (Cone Penetration Test). As correlações com SPT geralmente são empíricas, dependentes dos valores de $N_{\text {spt. Já pelo }}$

CPT, as correlações são feitas de forma mais direta a partir da capacidade de carga do CPT, separando em resistência de ponta e de atrito (Ferreira et al., 2016).

Com objetivo de utilizar o ensaio SPT para determinação da capacidade de carga de estacas, alguns autores têm estudado formas de se obter mais parâmetros deste ensaio. Ferreira 
et al., (2016) realizaram ensaios de tração para determinação das resistências de ponta e atrito lateral no SPT. Os autores determinaram a resistência de atrito externo do amostrador, assim como a resistência de ponta. Os autores obtiveram valores de resistência comparáveis qualitativamente com as obtidas no ensaio CPT. Outros métodos têm sido utilizados para determinação das resistências mobilizadas no ensaio SPT. Esses métodos serão apresentados dentro desta seção.

\subsubsection{Prova de carga estática}

Para determinação e confirmação da capacidade de carga em fundações são realizados ensaios de prova de carga estática. Este ensaio reproduz os carregamentos, geralmente crescentes ao longo do tempo, que as fundações serão submetidas em uma construção real. $\mathrm{O}$ objetivo é conhecer o comportamento da fundação quando carregada e avaliar o nível de segurança em relação à ruptura da mesma (Aoki, 1997). A prova de carga é considerada estática quando a carga de interesse é atingida em um tempo infinito com incrementos de carga infinitesimais. Porém, na prática não existem carregamentos estáticos. $\mathrm{O}$ incremento de força e o tempo de aplicação de carga possuem valores finitos (Aoki, 2000). Segundo Aoki (1997), a prova de carga pode ser em um único ciclo de carga e descarga ou em vários ciclos de carga e descarga. Detalhes desses tipos de carregamento serão apresentados a seguir.

A forma como a fundação se comporta ao ser submetida à um carregamento é representada pela curva carga-recalque. A partir desta curva se determina então a capacidade de carga da fundação. Em alguns casos a curva carga-recalque apresenta uma ruptura nítida, ficando claro qual a capacidade de carga da fundação. Mas, geralmente, a capacidade de carga é definida de acordo com as necessidades de projeto. Assim, esta pode ser definida limitandose o recalque ou para outro critério de ruptura como, por exemplo, o critério de Van Der Veen (Equação 11) (Cintra; Aoki, 2013).

$$
R=R_{u}\left(1-\exp ^{-\alpha \times \delta}\right)
$$

onde: $R_{u}$ é a carga última e corresponde à assíntota vertical da curva carga-recalque; $\delta$ é o deslocamento resultante da carga aplicada $R$; e $\alpha$ é um coeficiente de forma da curva.

\subsubsection{Métodos de ensaio}

O ensaio estático pode ser realizado em um único ciclo ou em vários ciclos de carregamento. Em um único ciclo de carga são aplicados incrementos de carga crescentes, 
mantendo essa carga até o próximo estágio de carregamento. O sistema não é descarregado no final de cada estágio. Desta forma, a carga final $(R)$, o recalque final $(\delta)$ e a energia total de deformação acumulada $(V)$ serão a iguais soma das parcelas de carga $(\Delta R)$, recalque $(\Delta \delta)$ e energia $(\Delta V)$ resultantes em cada estágio de carregamento (Figura 6).

$\mathrm{Na}$ prova de carga estática realizada em vários ciclos de carga e descarga, o carregamento é realizado em incrementos de carga crescentes e o descarregamento é feito ao final de cada estágio de carregamento. Para o descarregamento pode-se aguardar a estabilidade do recalque, ou não. Cada etapa de carga e descarga formam um ciclo de carregamento (Aoki, 1997). Na Figura 7, os pontos E, F, G e 1, 2, 3 representam, respectivamente o final do carregamento e do descarregamento para 3 diferentes ciclos.

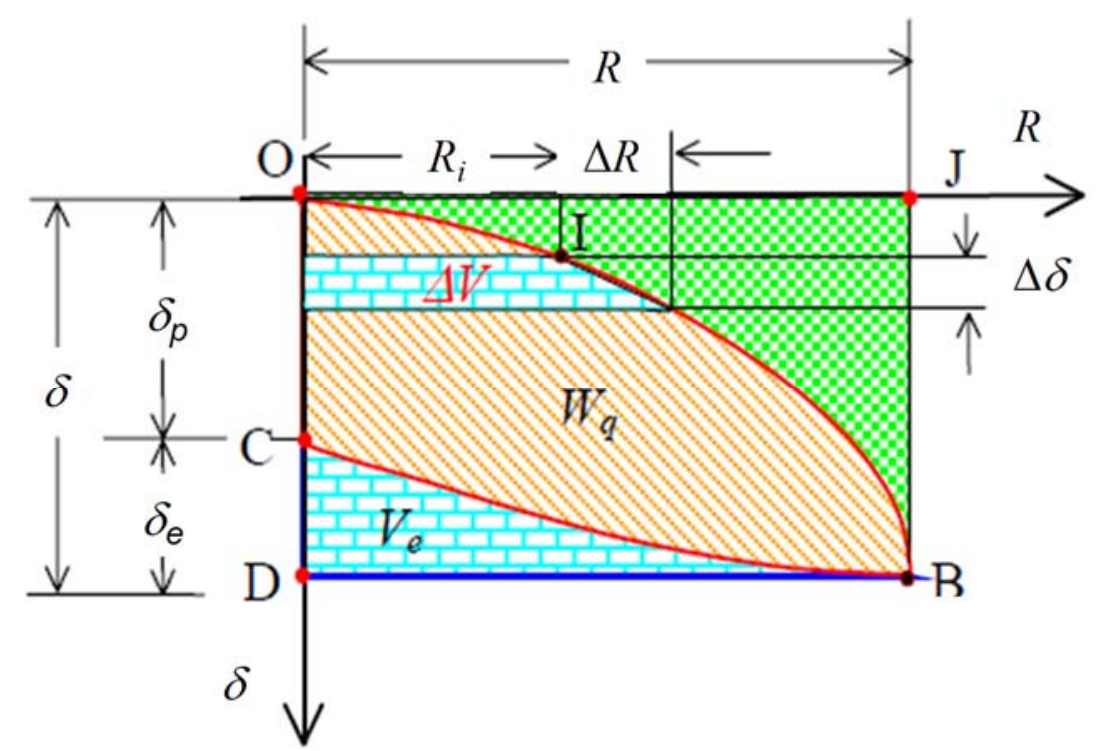

Figura 6 - Curva carga-recalque da prova de carga estática em um único ciclo de carga e descarga (Aoki, 1997).

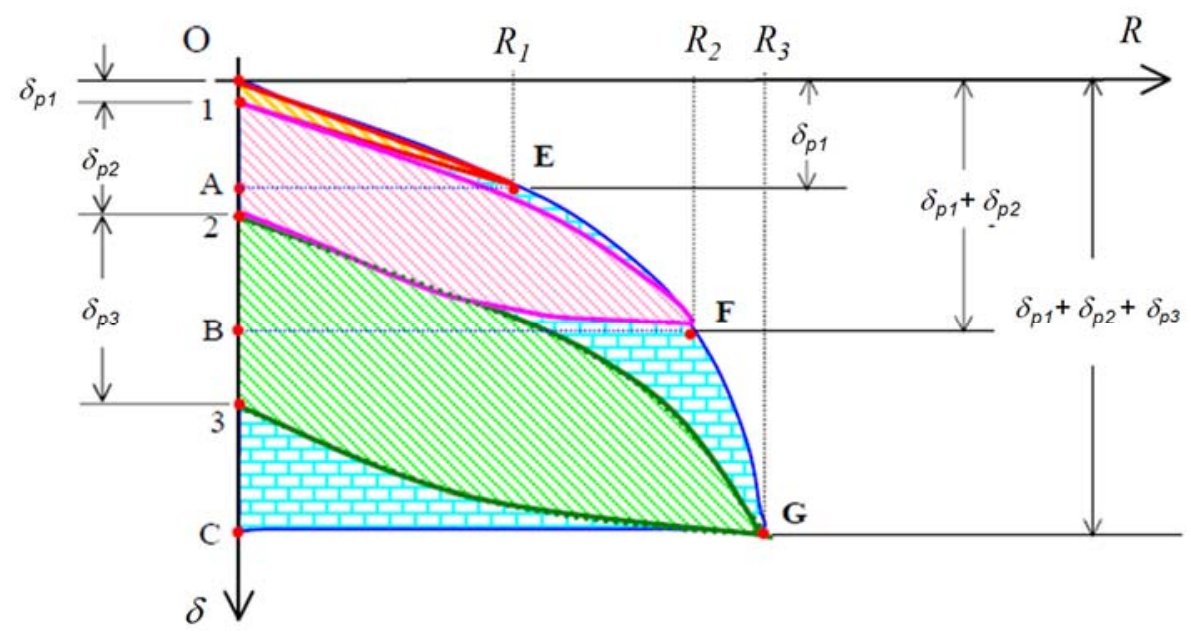

Figura 7 - Curva carga-recalque em prova de carga estática com vários ciclos de carregamento - origem variável (Aoki, 1997). 
Pode-se observar que no primeiro ciclo, a carga $R_{l}$ aplicada resulta em um deslocamento total $\delta_{l}$ e um deslocamento permanente $\delta_{p 1}$. A curva representada pelos pontos OEFG apresenta o histórico de carregamento. Deve-se notar que a área abaixo da curva (OEFGCO) não representa a energia total de deformação. Neste caso, a energia de deformação é representada pela área de cada ciclo (Aoki, 1997).

\subsubsection{Prova de carga estática no SPT}

Alguns autores realizaram prova de carga estática sobre o amostrador SPT (Neves, 2004; Aoki et al, 2007; Noreña, 2011; Eberle, 2018). O objetivo principal da realização deste tipo de ensaio por estes autores era determinar a eficiência do ensaio SPT. A partir da curva carga-recalque foi possível determinar a resistência estática mobilizada pela penetração do amostrador. $\mathrm{O}$ método de ensaio utilizado pelos autores foi semelhante à uma prova de carga em um único ciclo de carga e descarga. Primeiro os autores realizaram um ensaio SPT típico. Em seguida, sem a retirada do amostrador do furo, os autores montaram o sistema de reação e aplicaram cargas de forma estática sobre o conjunto de composição de hastes e o amostrador. Após atingida a carga planejada, os autores realizaram o descarregamento do sistema, obtendo a curva completa de carga e descarga.

\subsubsection{Resistência estática no amostrador por Aoki et al. (2007)}

Aoki et al. (2007) propuseram estimar a resistência estática do sistema solo-amostrador a partir de conceitos do princípio da conservação de energia de Hamilton. Neves (2004) verificou que, com exceção do que ocorre em solos resilientes, a energia potencial elástica $\left(V_{e}\right)$ é muito pequena, podendo ser desprezada. Assim, a energia potencial de deformação $(V)$ é aproximadamente igual ao trabalho realizado pelas forças não conservativas responsáveis pela penetração do amostrador $\left(W_{A}\right)$ (Equação 12) (Aoki et al., 2007).

$$
V_{A} \simeq W_{A}
$$

Como o trabalho das forças não conservativas é igual ao produto da força pelo deslocamento, tem-se que:

$$
W_{A}=R_{t} \times \Delta \delta
$$

Após a realização de ensaios estáticos sobre o amostrador padrão, Aoki et al. (2007) observaram que a resistência dinâmica obtida no ensaio SPT concorda com a curvas carga- 
recalque obtida a partir do ensaio estático. Isto significa que a resistência total $\left(R_{t}\right)$, ou seja, a soma entre a resistência estática e a parcela de resistência dinâmica, é aproximadamente igual à resistência estática $\left(R_{S}\right)$ (Equação 14$)$.

$$
R_{s}=\frac{W_{A}}{\Delta \delta}=\frac{V_{A}}{\Delta \delta}=\frac{T_{A}}{\Delta \delta}
$$

Considerando que o índice de resistência à penetração $\left(N_{s p t}\right)$ é dado para uma penetração de $0.3 \mathrm{~m}$, a penetração média do amostrador pode ser escrita como:

$$
\delta_{m}=\frac{0.3}{N_{s p t}}(m)
$$

Considerando que a eficiência do ensaio ( $\eta_{b a s e}$ ), é igual à razão entre a energia que efetivamente chega ao amostrador $\left(T_{A}\right)$ e a energia potencial teórica do ensaio SPT, a resistência estática $R_{S}$ pode ser reescrita conforme a Equação 16 (Aoki e Cintra, 2000; Aoki et al., 2007).

$$
R_{s}=\frac{T_{A}}{\Delta \delta}=\frac{\eta_{\text {base }} \times E P_{T} \times N_{s p t}}{0.3}(\mathrm{kN})
$$

Aplicando a correção da energia potencial, considerando o acréscimo de energia potencial do martelo devido à penetração permanente do amostrador, Aoki (2013) redefiniu a Equação 16, resultando:

$$
R_{s}=\eta_{\text {base }} \times \frac{M_{m} \times g \times H_{q} \times\left(\frac{0.3 / N_{s p t}+H_{q}}{H_{q}}\right)}{1000} \times \frac{N_{s p t}}{0.3}(\mathrm{kN})
$$

\subsubsection{Prova de carga dinâmica com energia constante}

Na prova de carga dinâmica com energia constante em estacas, ou simplesmente prova de carga dinâmica como é mais conhecida, supõe-se que a resistência mobilizada pelo solo ao impacto do martelo de peso $W_{m}$, caindo de uma altura de queda constante $H_{q}$ seja a resistência última do solo (Aoki, 1997). No evento, considera-se que a resistência total $\left(R_{t}\right)$ mobilizada durante a penetração é composta por uma parcela estática $\left(R_{S}\right)$ e uma parcela dinâmica $\left(R_{D}\right)$. Assim, a partir da resistência total mobilizada pode-se chegar ao valor de resistência estática última $\left(R_{u}\right)$. Para determinação de $R_{u}$ são aplicados modelos de interpretação ao ensaio dinâmico, geralmente baseados na teoria de propagação da onda. 
O modelo de solução da equação da onda proposto por Smith (1960) considera que a parcela de resistência estática apresenta comportamento elastoplástico (Figura 8). Assim, do ponto $\mathrm{O}$ até o ponto $\mathrm{A}^{\prime}$, ocorre uma compressão elástica do solo até a resistência atingir o seu valor máximo $\left(R_{u}\right)$. Nesse momento, o deslocamento é conhecido como quake do solo $(Q)$. A partir deste ponto, a resistência permanece constante com o aumento das deformações, que a partir de então se denominam deformações plásticas.

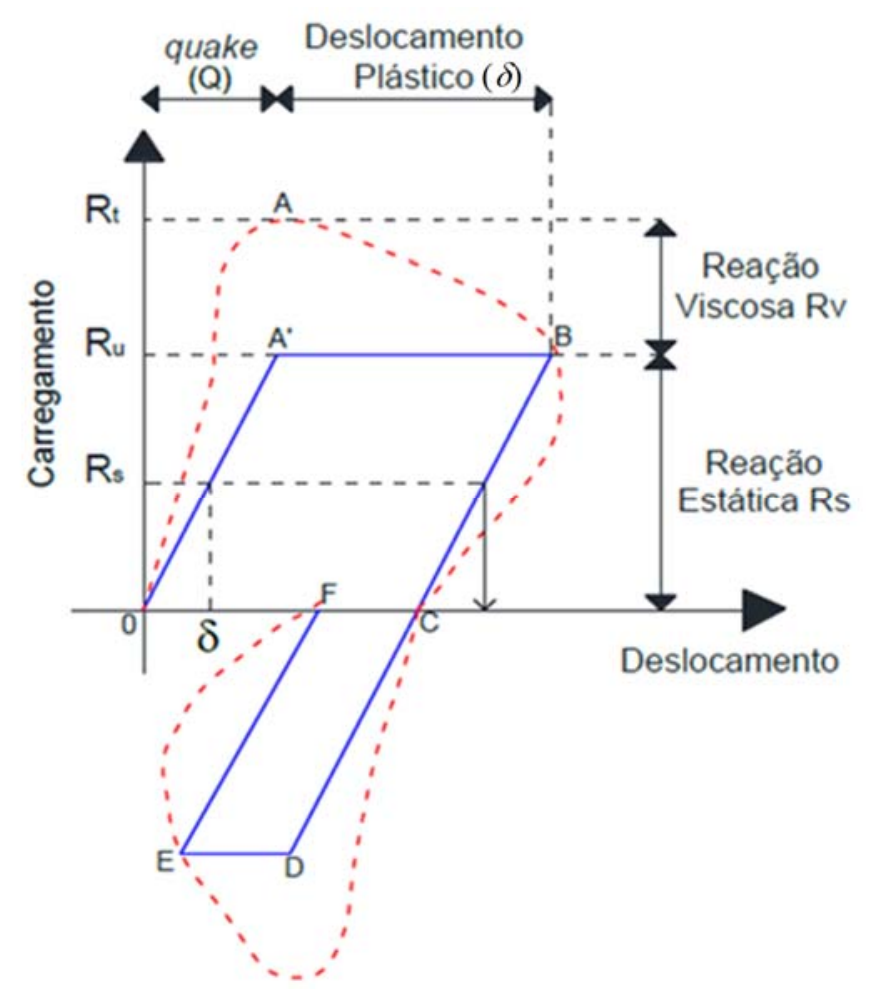

Figura 8 - Relação carga-deformação na cravação idealizado por Smith (1960) (Noreña, 2011 modificado de Smith, 1960)

A parcela dinâmica da resistência $\left(R_{D}\right)$, apresenta um acréscimo de resistência $\left(R_{a}\right)$ devido ao amortecimento do solo (Equação 18) (Smith, 1960). A partir do valor de $R_{D}$ a resistência estática $R_{s}$ pode ser então determinada (Equação 19).

$$
\begin{gathered}
R_{a}=J_{c} \times Z \times v_{p} \\
R_{s}=R_{D}-J_{c} \times Z \times v_{p}
\end{gathered}
$$

onde, $J_{c}$ é o fator de amortecimento do solo, $Z$ é a impedância e $v_{p}$ é a velocidade de penetração no solo. 
A Figura 9 mostra a transformação da curva de resistência total (OA), em curva de resistência estática $(\mathrm{OB})$, a partir do desconto da parcela de resistência dinâmica.

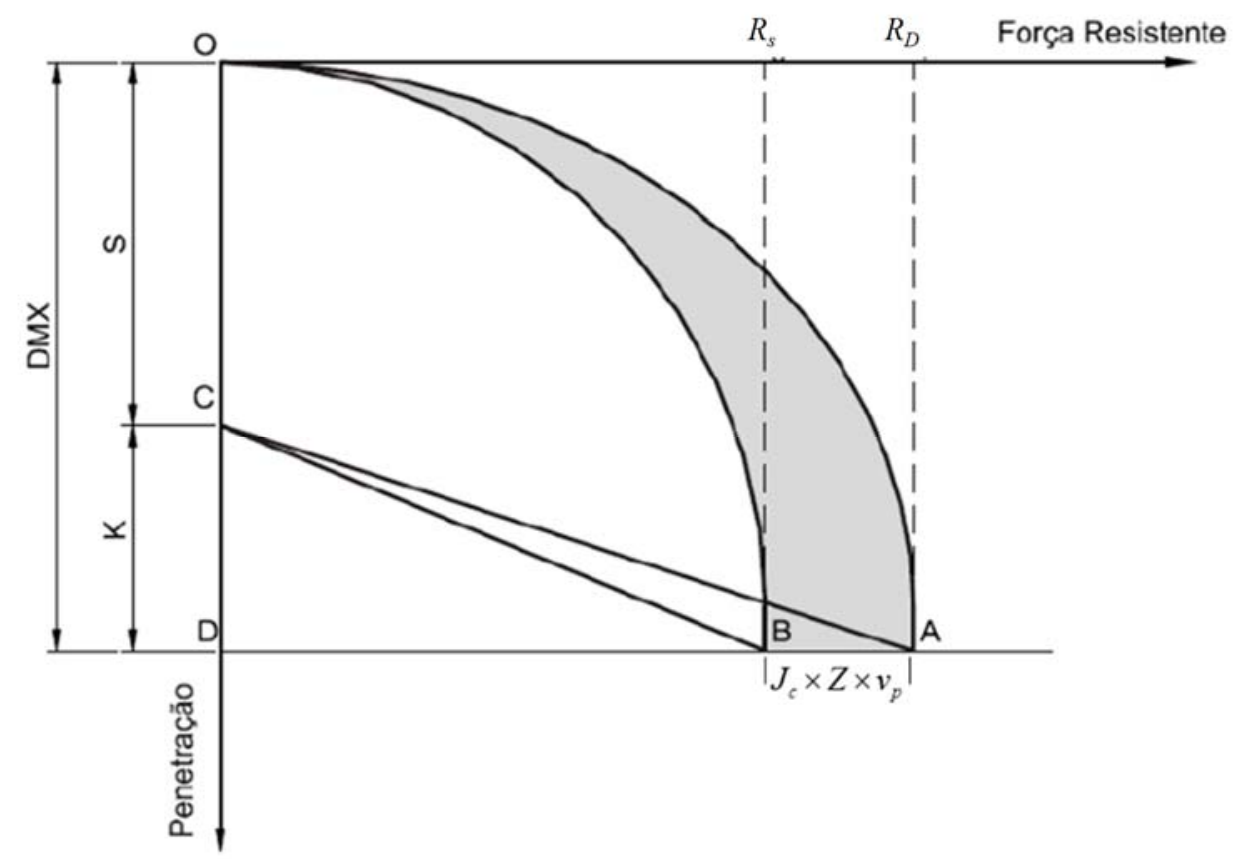

Figura 9 - Curva carga-recalque referente aos ensaios dinâmico e estático (adaptado de Aoki et al., 2004)

Considerando que o ensaio SPT é similar a uma prova de carga dinâmica com energia constante, autores começaram a estudar a interação solo-amostrador, com intuito de determinar a resistência mobilizada pelo amostrador durante sua cravação. Alguns autores determinaram a resistência dinâmica mobilizada no ensaio (Lobo, 2009; Schnaid et al., 2009a; Lukiantchuki, 2012). Outros determinaram a resistência estática atuante no amostrador a partir do ensaio dinâmico (Schmertmamnn e Palácios, 1979; Aoki et al., 2007; Noreña, 2011; Eberle, 2018).

\subsubsection{Resistência dinâmica no amostrador por Schnaid et al. (2009a)}

Também baseados no princípio de conservação de Hamilton aplicado ao ensaio SPT, apresentado por Aoki e Cintra (2000), Schnaid et al. (2009a) propuseram um método teórico para estimar a resistência dinâmica mobilizada pela penetração do amostrador. O método proposto considera que ao final da penetração do amostrador toda a energia cinética é dissipada e qualquer perda de energia ocorre durante a penetração do amostrador. Assim, a variação de energia potencial do sistema martelo-hastes é igual a variação do trabalho realizado pelas forças não conservativas (Equação 20) (Schnaid et al., 2009a). 


$$
\int_{t_{1}}^{t_{2}} \delta V(t) d t=\int_{t_{1}}^{t_{2}} \delta\left[W_{s}(t)+W_{n c}(t)\right]=0
$$

onde, $W_{s}$ é igual ao trabalho realizado por forças não conservativas atuantes no amostrador e $W_{n c}$ é igual ao trabalho realizado por outras forças não conservativas relacionadas com as perdas de energia.

Sendo a energia que efetivamente chega ao amostrador igual ao trabalho realizado pelas forças não conservativas e sendo essa a energia que provoca a penetração do amostrador, Schnaid et al., (2009a) propuseram estimar a resistência dinâmica pelas equações 21 e 22.

$$
\begin{gathered}
E_{\text {amostrador }}=W_{s}=F_{d} \times \Delta \delta \\
F_{d}=\frac{E_{\text {amostrador }}}{\Delta \delta}
\end{gathered}
$$

Devido à dificuldade em se realizar ensaios instrumentados para obtenção da energia que chega ao amostrador, Schnaid et al., (2009a) sugeriram que essa energia fosse obtida de forma analítica como proposto por Odebrecht (2003) (Equação 23). Assim, a expressão da força dinâmica mobilizada, pode ser reescrita como:

$$
F_{d}=\frac{\eta_{3} \times\left[\eta_{1} \times\left(H_{q}+\delta\right) \times M_{m} \times g+\eta_{2} \times\left(M_{h} \times g \times \delta\right)\right]}{\Delta \delta}
$$

Schnaid et al. (2017), compararam valores de $F_{d}$, obtidos pela Equação 23 com valores de resistência de ponta $q_{t}$ obtidos a partir de ensaios CPT. Os autores observaram que em solos granulares, os valores de $Q_{d}$ (tensão obtida pela razão entre $F_{d}$ e a área da seção transversal) e $q_{t}$ podem ser comparados diretamente. Assim, não há necessidade de aplicação de fatores de ajustes empíricos.

\subsubsection{Resistência dinâmica no amostrador por Lukiantchuki (2012)}

Lukiantchuki (2012), propôs um método para determinação da resistência dinâmica mobilizada $\left(R_{D}\right)$ de forma direta. A resistência é determinada pela média das forças normais atuantes na seção logo acima do amostrador, medidas por células de carga. O método proposto pela autora está apresentado na Figura 10. 

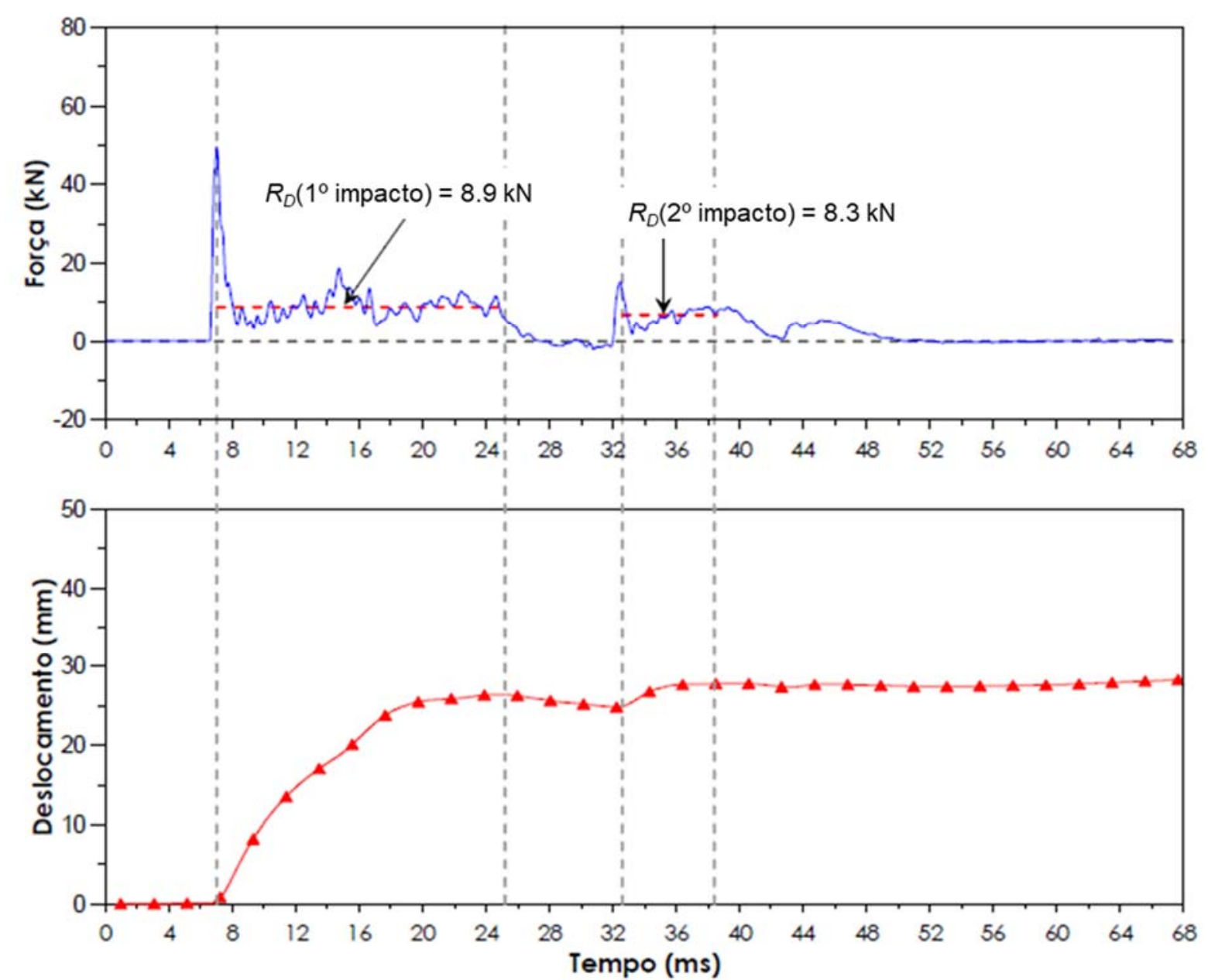

Figura 10 - Curvas de força e deslocamento em função do tempo para determinação de $R_{D}$ (Lukiantchuki; Bernardes; Esquivel, 2012).

Analisando os sinais de força em conjunto com os deslocamentos calculados a partir dos sinais de aceleração na mesma seção, observou-se que a penetração não se inicia até que a força atinja o pico inicial, conforme mostrado na Figura 10. Assim, a média é calculada com os valores de força que causam o deslocamento do amostrador (Lukiantchuki; Bernardes; Esquivel, 2012).

A Figura 11 apresenta os valores de $R_{D}$ obtidos por diferentes autores a partir do método proposto por Lukiantchuki (2012) e comparados com os valores de $F_{d}$ e $R_{s}$, calculados através das Equações 22 e 14: 

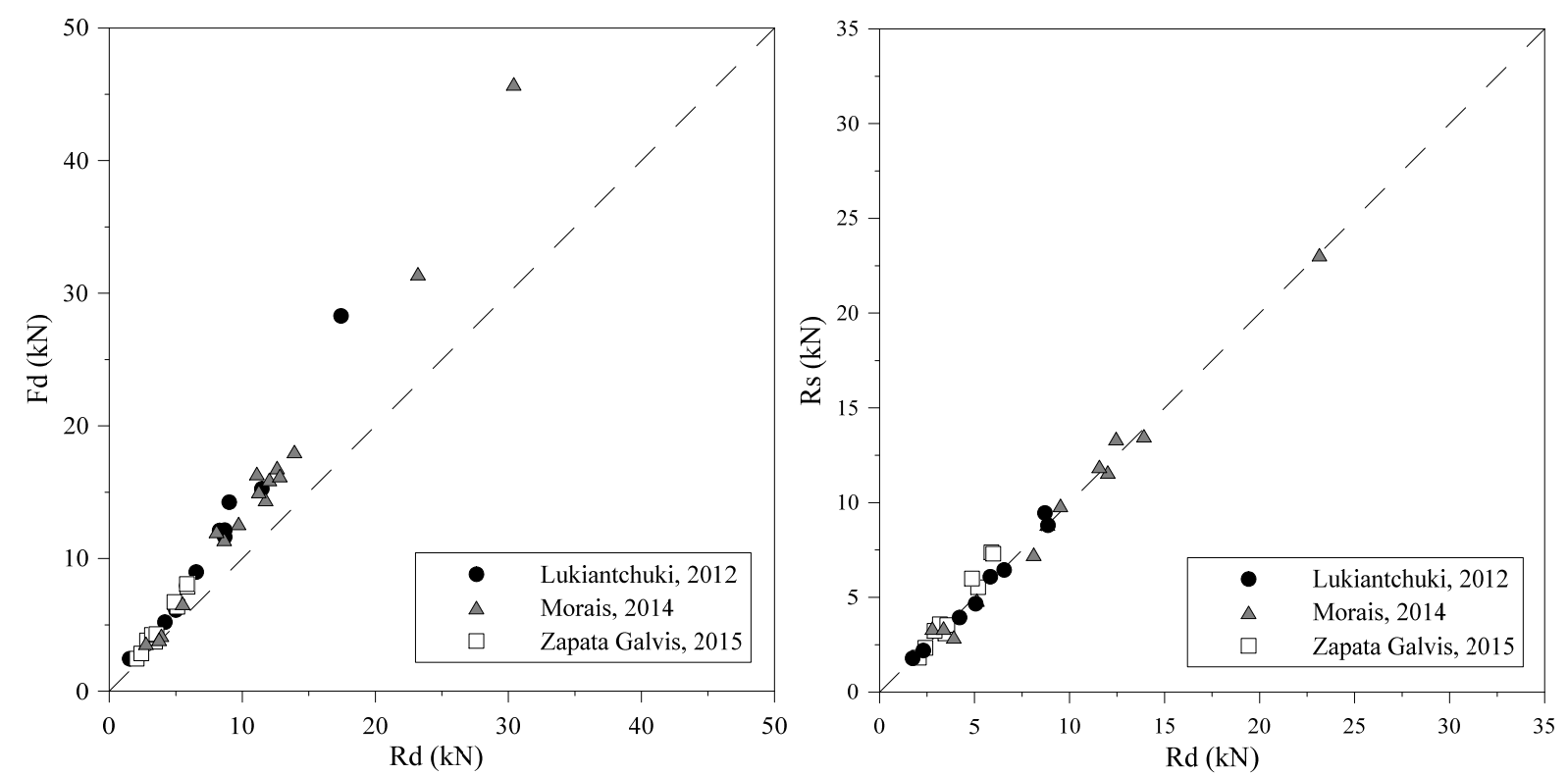

Figura 11 - Comparação entre com os valores de $R_{d}$, obtidos por Lukiantchuki (2012), Morais (2014) e ZapataGalvis (2015) com os valores de $F_{d}$ e $R_{s}$, respectivamente

A partir dos resultados obtidos pelos autores, conclui-se que os valores determinados pelo método de Lukiantchuki (2012) são muito próximos dos valores de $R_{s}$ propostos por Aoki et al. (2007). Isso mostra que a parcela de resistência devido ao amortecimento do solo, para os solos ensaiados, é praticamente nula. Além disso, $R_{D}$ ajusta-se melhor a $R_{S}$ do que aos valores obtidos pelo método de Schnaid et al. (2009a).

\subsubsection{Prova de carga dinâmica com energia crescente}

Quando são realizadas provas de carga dinâmica, a cada impacto de mesma energia, a estaca penetra um determinado valor, apresentando apresenta sempre a mesma resistência como resposta. Essa resistência indica, aparentemente, a resistência última do solo. Não importa quantos impactos de mesma energia sejam aplicados à estaca, estes impactos equivalem a um só impacto. Comparando com a prova de carga estática cíclica, seria o mesmo que aplicar a cada ciclo a mesma carga, obtendo sempre o mesmo deslocamento (Aoki, 1997). Isso implica que apenas um ponto da curva resistência total mobilizada - deslocamento pode ser conhecido, não sendo possível determinar o formato da curva, ou seja, conhecer o comportamento para diferentes níveis de carregamento.

Aoki (1997) observou que a resistência estática obtida a partir da prova de carga dinâmica pertencia à uma curva carga-recalque, mas para se obter essa curva completa seria necessário variar a energia fornecida ao ensaio. Assim, esse autor apresentou um novo conceito para a prova de carga dinâmica: o ensaio dinâmico de energia crescente (Dynamic Increasing 
Energy Test - DIET). Esse ensaio é análogo à prova de carga estática cíclica, porém, cada ciclo de carregamento corresponde um impacto de energia crescente. Os incrementos de energias são dados pelo acréscimo da altura de queda do martelo, aumentando assim, a energia potencial do sistema.

No ensaio dinâmico com energia crescente são aplicados diferentes impactos de energia cinética $(T)$ crescente, que mobilizam resistências $(R)$ e resultam em deslocamentos $(D)$ crescentes. A cada altura de queda, ou seja, a cada incremento de energia, são utilizados os mesmos modelos de análises utilizados na prova de carga dinâmica com energia constante para obtenção da resistência dinâmica e estática (Aoki, 2000). A Figura 12 apresenta um esquema da curva de resistência estática - deslocamento para os dois tipos de prova de carga dinâmica.

a)

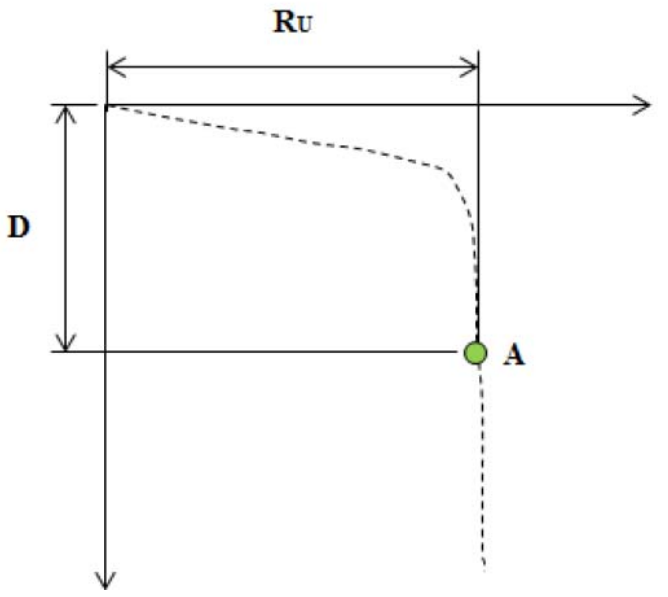

b)

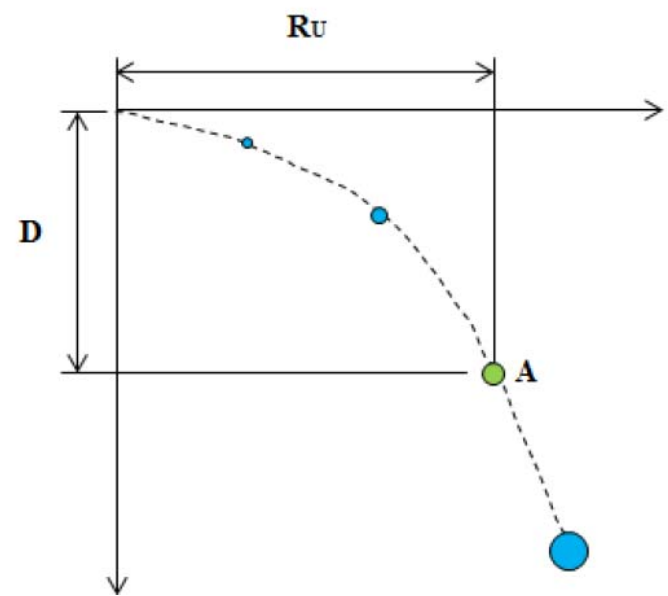

Figura 12 - Curva de resistência estática mobilizada x deslocamento para prova de carga dinâmica com: a) energia constante; b) energia crescente (Tsuha; Aoki; Cintra, 2013).

Realizar um ensaio com energia crescente não significa que a resistência estática máxima será mobilizada. O objetivo real é que se possa obter curvas de resistências estáticas mobilizada - deslocamento, nas quais possam ser aplicadas interpretações e extrapolações, como é realizado nas provas de carga estáticas (Tsuha; Aoki; Cintra, 2013).

Fellenius (2014) também realizou provas de carga DIET e provas de carga estática em estacas e conclui que o método DIET fornece resultados que mais se assemelham aos de uma prova de carga estática do que uma prova de carga dinâmica comum.

Sendo o ensaio SPT uma prova de carga dinâmica com energia constante, pode-se aplicar ao ensaio os mesmos conceitos mencionados acima. Assim sendo, a resistência mobilizada no ensaio SPT, não necessariamente será a resistência última do sistema soloamostrador. A realização de ensaios com energia crescente pode possibilitar a detecção do nível de energia que provoca a ruptura do sistema. 
Quintero-Baños (2016) simulou numericamente a aplicação de energia crescentes no ensaio SPT. A curva de resistência mobilizada versus deslocamento obtida através da simulação está mostrada na Figura 13. Através da análise realizada, a autora confirmou que a curva com a aplicação de energia crescente é similar à curva da prova de carga estática, possibilitando a extrapolação da curva para determinação da ruptura.

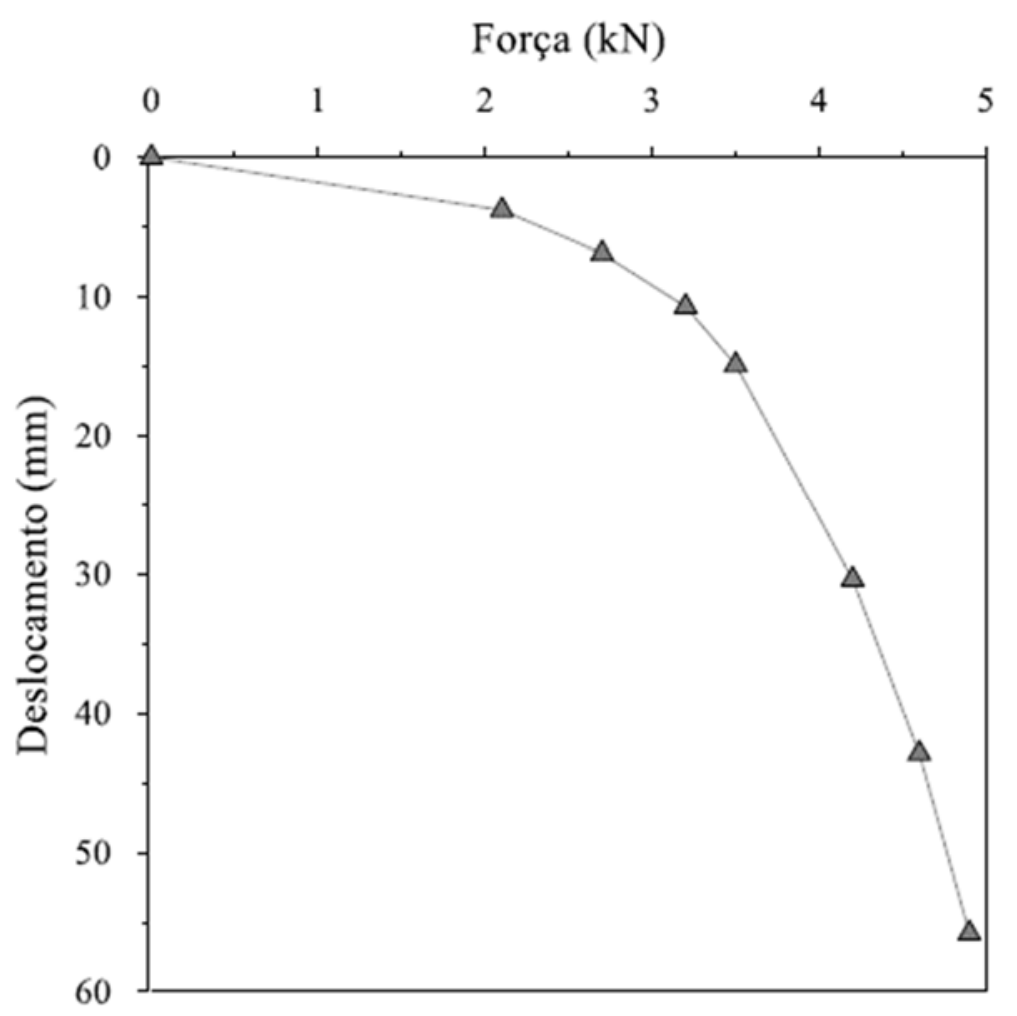

Figura 13 - Curva de resistência mobilizada versus deslocamento para prova de carga com energia crescente no amostrador padrão do SPT (Quintero Baños, 2016).

\subsubsection{Resistências de atrito e de ponta no amostrador}

Baseado no Princípio da Conservação de Energia de Hamilton, Aoki (2013) apresentou o equilíbrio das forças não conservativas que atuam no amostrador durante sua penetração no solo (Figura 14a). Esse autor também sugeriu um método para cálculo das forças resistentes no sistema solo-amostrador. Este cálculo é feito com base nos valores de $N_{s p t}$, do comprimento da amostra recuperada $\left(L_{a}\right)$ e da eficiência correspondente à seção logo acima do amostrador ( $\left.\eta_{\text {base }}\right)$ (Aoki et al., 2007). A partir do equilíbrio estático as parcelas de ponta $\left(r_{p}\right)$, atrito lateral interno $\left(r_{L i}\right)$ e atrito lateral externo $\left(r_{L e}\right)$ podem ser determinadas (Aoki, 2013). 


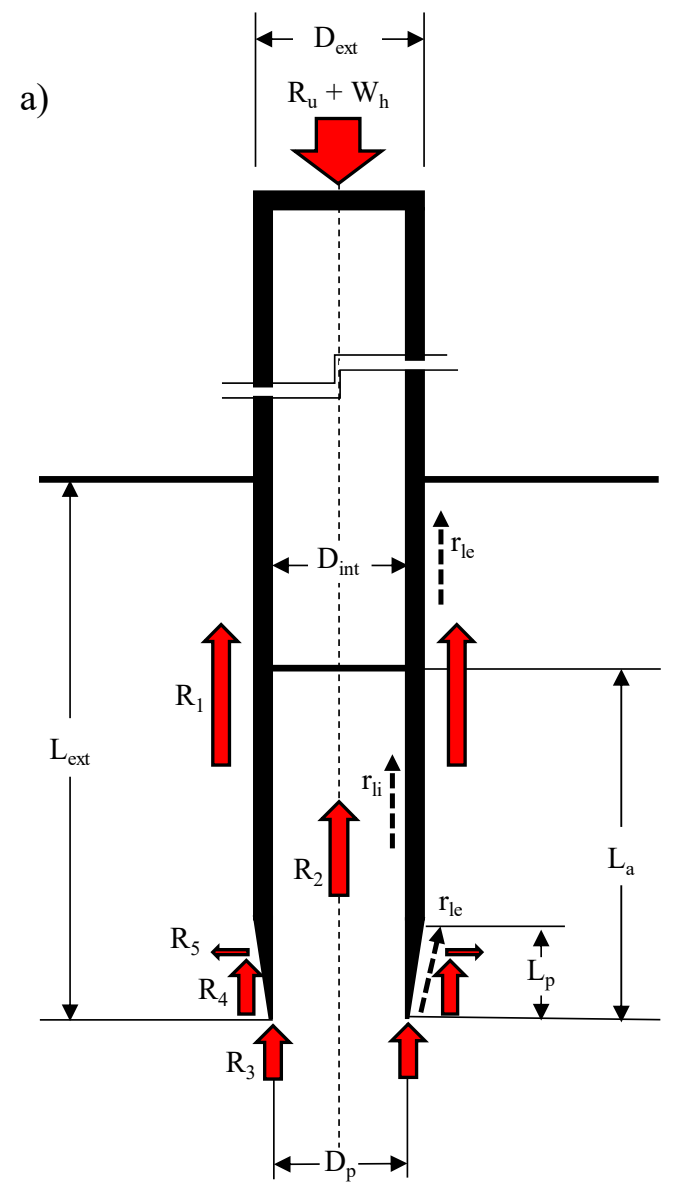

b)

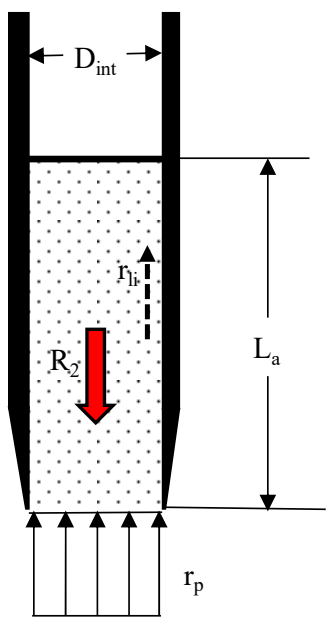

Figura 14 - Equilíbrio de forças atuantes: a) amostrador; b) ponta aberta do amostrador (adaptado de Aoki, 2013)

De acordo com a Figura 14a tem-se:

$$
R_{D}+W_{h}=R_{1}+R_{2}+R_{3}+R_{4}
$$

onde, as forças atuantes são:

$R_{u}$ : Resistência à penetração estática do amostrador;

$W_{h}$ : Peso da composição de hastes e da cabeça de bater;

$R_{1}$ : Força de atrito na parede externa do amostrador, resultante do atrito na parede externa $\left(r_{L e}\right)$; $R_{2}$ : Força de atrito na parede interna do amostrador, resultante do atrito na parede interna $\left(r_{L i}\right)$; $R_{3}:$ Força de reação na seção anelar da ponta do amostrador;

R4: Componente vertical da força de atrito vertical do atrito na seção biselada do amostrador.

As forças resistentes são dadas pelas seguintes equações:

$$
\begin{aligned}
& R_{1}=\pi \times D_{e x t} \times\left(L_{e x t}-L_{p}\right) \times r_{L e} \\
& R_{2}=\pi \times D_{i n t} \times r_{L i} \times L_{a}
\end{aligned}
$$




$$
\begin{aligned}
& R_{3}=\frac{\pi}{4} \times\left(D_{p}^{2}-D_{i n t}^{2}\right) \times\left(\frac{r_{L e}}{R_{f}}\right) \\
& R_{4}=\left(\frac{S_{L} \times L_{p}}{L}\right) \times r_{L e}
\end{aligned}
$$

onde:

$D_{\text {ext }}$ diâmetro externo do amostrador $(50.8 \mathrm{~mm})$;

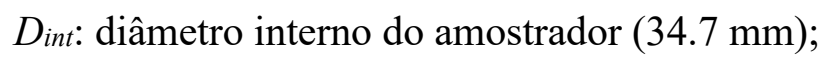

$D_{p}$ : diâmetro da ponta do amostrador $(38.1 \mathrm{~mm})$;

$L_{\text {ext: }}$ penetração total do amostrador;

$L_{p}$ : comprimento da seção biselada do amostrador $(21.5 \mathrm{~mm})$;

$L$ e $S_{L}$ são fornecidos pelas equações 28 e 29 , respectivamente.

$$
\begin{aligned}
& L=\sqrt{L_{p}^{2}+\left(\frac{D_{e x t}-D_{p}}{2}\right)^{2}} \\
& S_{L}=\frac{\pi \times L\left(D_{e x t}+D_{p}\right)}{2}
\end{aligned}
$$

A razão entre o atrito interno $\left(r_{L i}\right)$ e o atrito externo $\left(r_{L e}\right)$, atuantes no amostrador padrão, é denominada parâmetro $a$ (Aoki, 2013). A partir desse parâmetro, o valor de $R_{2}$ é fornecido pela seguinte equação:

$$
R_{2}=\pi \times D_{\text {int }} \times a \times r_{L e} \times L_{a}
$$

De acordo com a Figura 14b, por equilíbrio, a força de atrito interno $\left(R_{2}\right)$ é igual à resultante das tensões atuantes na ponta aberta do amostrador padrão $\left(r_{p}\right)$ :

$$
R_{2}=\frac{\pi \times D_{\text {int }}^{2}}{4} \times r_{p}
$$

Assim, com os valores das tensões atuantes na ponta do amostrador $\left(r_{p}\right)$ e atrito lateral externo $\left(r_{L e}\right)$, pode-se, analogamente ao ensaio CPT, calcular a razão de atrito $\left(R_{f}\right)$ :

$$
R_{f}=\frac{r_{L e}}{r_{p}}=\frac{r_{L i}}{a \times r_{p}}
$$


Com objetivo de determinar de forma direta a parcela de resistência $R_{2}$, Zapata-Galvis (2015) desenvolveu um sistema de extração da amostra de dentro do amostrador. Neste método, após a retirada do amostrador do furo, um pistão é colocado em contato direto com a amostra e é aplicada uma força axial com auxílio de um cilindro hidráulico. A força necessária para mobilizar a amostra é a resistência $R_{2}$.

Com o valor de $R_{2}$, a autora calculou os atritos atuantes ( $r_{L e}$ e $\left.r_{L i}\right)$, as demais parcelas de resistência $\left(R_{l}, R_{3}, R_{4}\right.$ e $\left.r_{p}\right)$ e o coeficiente $a$. A autora concluiu que o sistema criado para obtenção de $R_{2}$ é eficiente, pois os valores de coeficiente $a$ determinados à cada metro foram aproximadamente iguais a um, ou seja, o atrito interno e externo são praticamente iguais, o que era esperado já que os ensaios não apresentaram ocorrência de embuchamento (Zapata Galvis; Esquivel, 2016). 


\section{MATERIAIS E MÉTODOS}

Esta seção descreve os materiais utilizados e os métodos aplicados na realização deste trabalho. Primeiro é feita a descrição do local onde foram realizados os ensaios. Em seguida, é descrita a organização dos ensaios. Por fim, são descritos os materiais e os métodos utilizados nas etapas de execução e análise em cada ensaio.

\subsection{DESCRIÇÃO DA ÁREA DE ESTUDO}

Os ensaios foram realizados no Campo Experimental de Geotecnia da Escola de Engenharia de São Carlos - Universidade de São Paulo. O perfil geológico da região de estudo é formado por: arenitos das Formações Botucatu e Pirambóia; derrames de rochas basálticas da Formação Serra Geral; camadas de arenitos e conglomerados do Grupo Bauru sobre as formações rochosas e uma camada superficial de sedimentos colapsíveis da era Cenozóica (Bortolucci, 1983). As Figuras 15 e 16 mostram as características geológicas da região de realização dos ensaios.

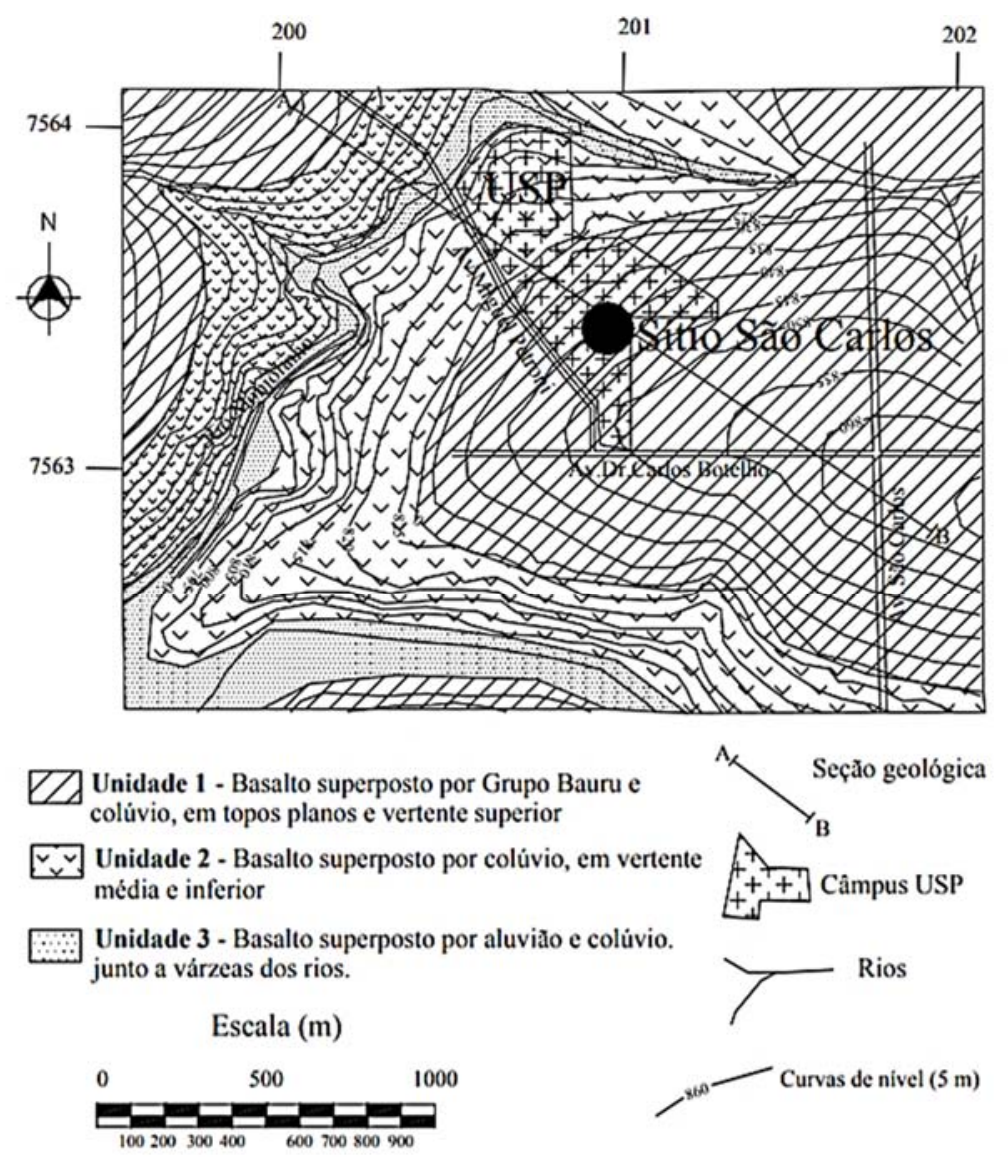

Figura 15 - Unidades geotécnicas no entorno do local dos ensaios. Produzidos a partir de mapeamento de superfície, sondagens, mapa topográfico e fotografia aérea (De Mio, 2005) 


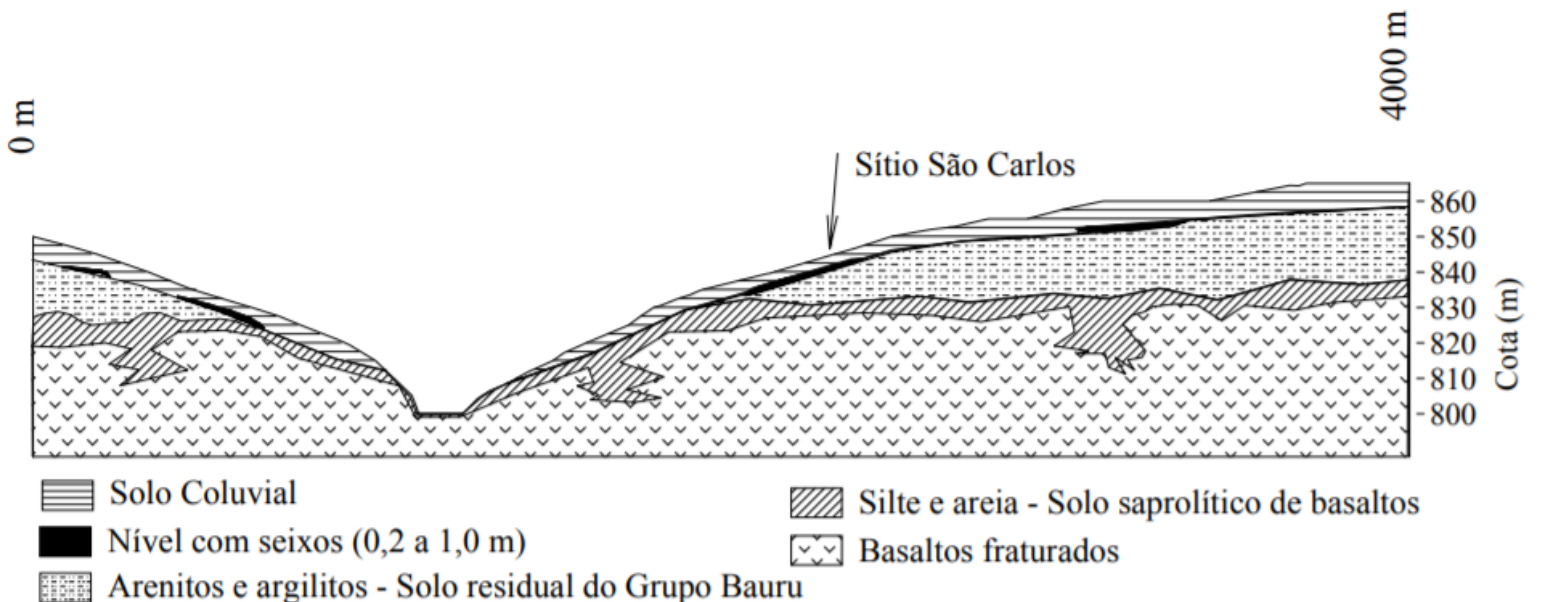

Figura 16 - Seção geológica AB (Figura 15) baseado em mapeamento e sondagens (De Mio, 2005).

O nível d'água varia entre 7 e $10 \mathrm{~m}$ de profundidade entre os períodos mais úmidos e mais secos do ano (Peixoto, 2001). A Figura 17 apresenta o perfil geotécnico local, assim como resultados de ensaios SPT e CPT e alguns índices físicos.

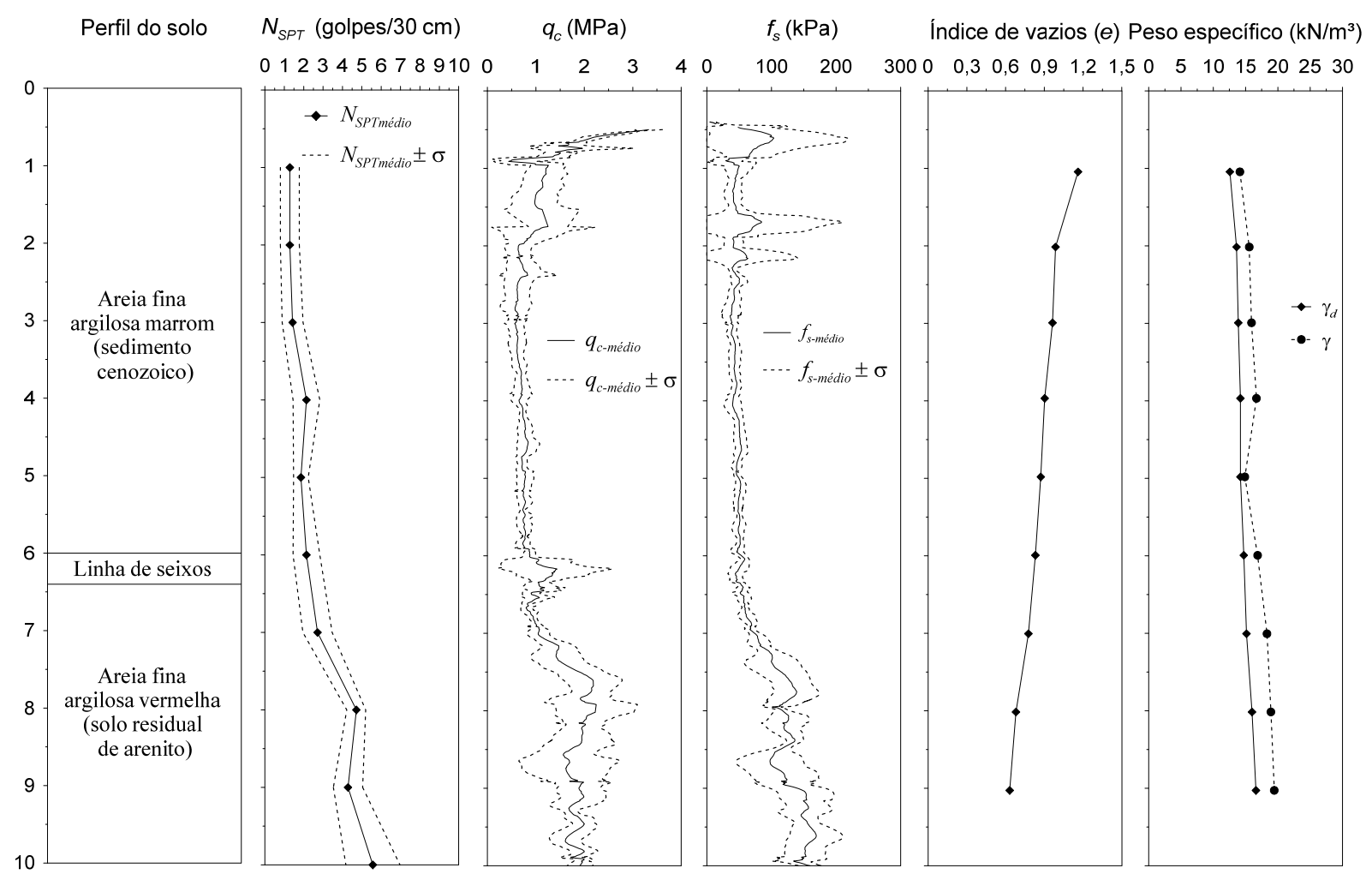

Figura 17 - Resultados de ensaios de penetração e índices físicos (Machado, 1998; De Mio, 2005; Giachetti et al., 2004; Rocha, 2018).

A Tabela 2 apresenta resultados de ensaios de caracterização do solo do Campo Experimental para diferentes profundidades, realizados por Peixoto (2001). 
Tabela 2 - Resultados dos ensaios de caracterização do Campo Experimental (Peixoto, 2001).

\begin{tabular}{|c|c|c|c|c|c|c|}
\hline \multirow{2}{*}{$\begin{array}{l}\text { Prof. } \\
\text { (m) }\end{array}$} & \multicolumn{2}{|c|}{$\begin{array}{c}\text { Limites de } \\
\text { Consistência }\end{array}$} & \multicolumn{4}{|c|}{ Granulometria } \\
\hline & $L L(\%)$ & $L P(\%)$ & $\begin{array}{c}\text { Argila } \\
(\%)\end{array}$ & $\begin{array}{l}\text { Silte } \\
\text { (\%) }\end{array}$ & $\begin{array}{c}\text { Areia Fina } \\
(\%)\end{array}$ & $\begin{array}{c}\text { Areia Média } \\
(\%)\end{array}$ \\
\hline 1.3 & 24 & 17 & 26 & 11 & 51 & 12 \\
\hline 2.3 & 26 & 18 & 21 & 14 & 55 & 10 \\
\hline 3.3 & 27 & 20 & 31 & 8 & 51 & 10 \\
\hline 4.3 & 28 & 18 & 28 & 11 & 56 & 5 \\
\hline 5.3 & 30 & 10 & 20 & 17 & 54 & 9 \\
\hline 6.3 & 31 & 22 & 22 & 16 & 54 & 8 \\
\hline 7.3 & 31 & 22 & 19 & 14 & 57 & 10 \\
\hline 8.3 & 34 & 20 & 21 & 9 & 54 & 16 \\
\hline 9.3 & 30 & 10 & 17 & 10 & 56 & 17 \\
\hline 10.3 & 32 & 10 & 20 & 8 & 56 & 16 \\
\hline
\end{tabular}

\subsection{ORGANIZAÇÃO DOS ENSAIOS DE CAMPO}

Os ensaios foram executados em uma única campanha nos dias 22, 23 e 26 de março de 2018 no Campo Experimental de Geotecnia da EESC/USP. No dia 22 foram realizados os ensaios SPT com altura de queda do martelo crescente a cada golpe e a avaliação do atrito interno no amostrador. Estes ensaios foram realizados para 5 profundidades em 3 furos. Nos dias 23 e 26 foram realizados os ensaios de penetração estática do amostrador padrão do SPT e a avaliação do atrito interno no amostrador. Estes ensaios foram realizados em um quarto furo para 3 profundidades (Figura 18).

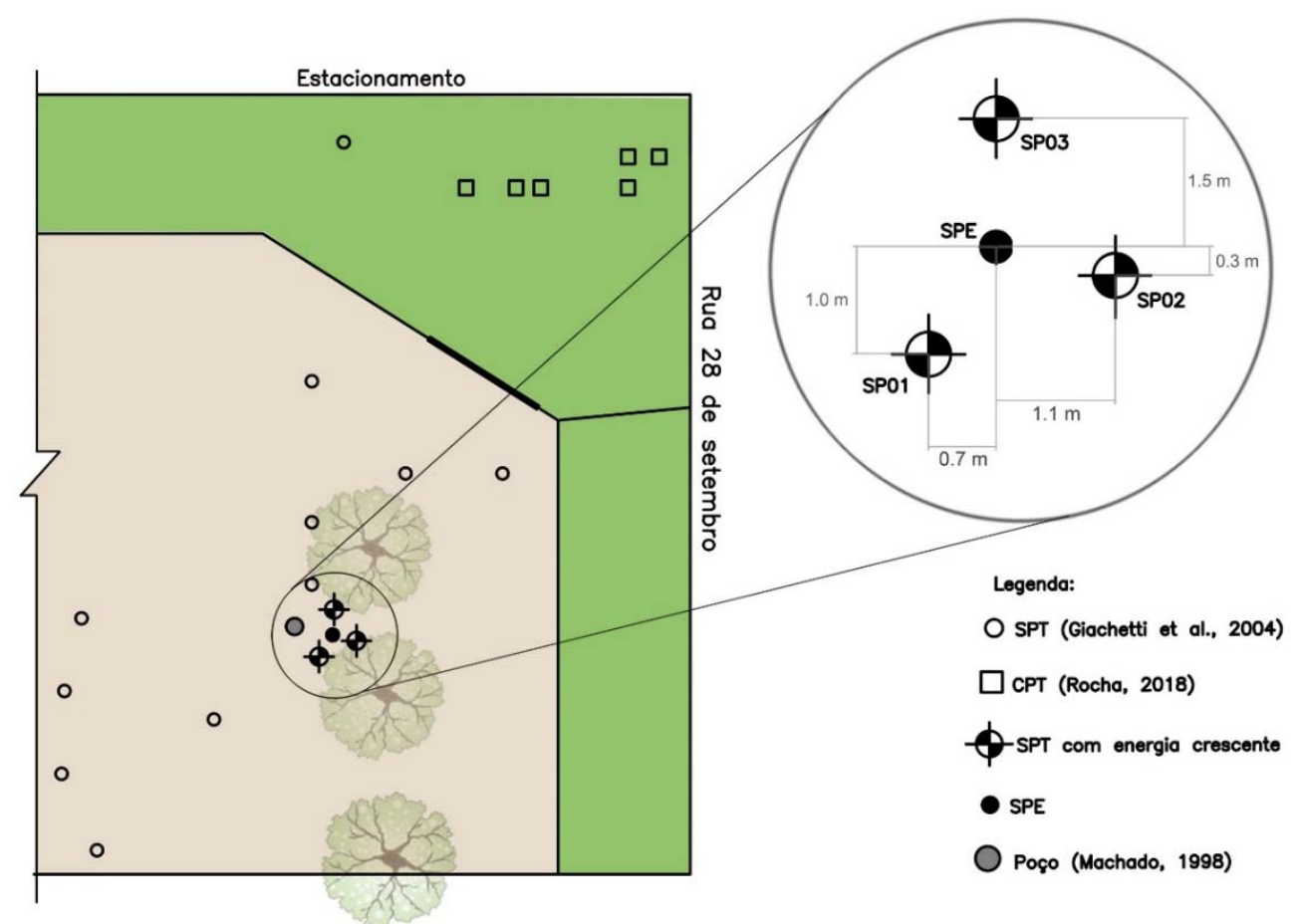

Figura 18 - Locação dos ensaios realizados (Adaptado de Giachetti et al., 2004 e Rocha, 2018). 


\subsection{ENSAIO DINÂMICO COM ENERGIA CRESCENTE}

Para a execução do ensaio de penetração dinâmica com energia crescente, foi utilizado o equipamento de ensaio SPT padrão, conforme NBR 6484: torre de sondagem; composição de hastes com $24.3 \mathrm{~mm}$ de diâmetro interno e $33.4 \mathrm{~mm}$ de diâmetro externo e peso teórico de $32.3 \mathrm{~N} / \mathrm{m}$; martelo padronizado, composto por uma massa de ferro, um coxim de madeira dura e uma haste guia de $1.20 \mathrm{~m}$ de comprimento, totalizando uma massa de $65 \mathrm{~kg}$; cabeça de bater com massa de $3.3 \mathrm{~kg}$; amostrador-padrão com $665 \mathrm{~mm}$ de comprimento, $50.8 \mathrm{~mm}$ de diâmetro externo, $34.7 \mathrm{~mm}$ de diâmetro interno e $32.8 \mathrm{~mm}$ de diâmetro interno do bico. Como complemento, foram utilizadas hastes instrumentadas com acelerômetros e células de carga tanto abaixo da cabeça de bater, quanto acima do amostrador.

O procedimento para execução do ensaio foi similar ao recomendado pela NBR 6468. Entretanto, as alturas de queda do martelo foram alteradas a cada golpe de forma crescente até atingir a padrão de $750 \mathrm{~mm}$. As alturas de queda utilizadas foram: 100, 200, 300, 400, 500, 600 e $750 \mathrm{~mm}$. A cada golpe mediu-se a penetração. Quando os $450 \mathrm{~mm}$ de penetração eram atingidos antes de todas alturas de queda serem aplicadas, o próximo golpe não era dado e o ensaio neste metro era finalizado. $\mathrm{O}$ controle das alturas de queda foi feito por meio de marcações na haste guia do martelo.

Os ensaios foram realizados em 3 furos diferentes: SP01, SP02 e SP03 (Figura 18). As profundidades ensaiadas foram 2, 3, 4, 5 e $6 \mathrm{~m}$ para SP01 e SP03, totalizando 5 metros por furo. Para o SP02, as profundidas ensaiadas foram 2, 3, 5 e 6, pois a tradagem ultrapassou os $4 \mathrm{~m}$ de profundidades. Sendo assim, o número de metros ensaios totalizaram 14.

A cada golpe, sinais da célula de carga e dos acelerômetros, foram salvos por meio do sistema de aquisição de dados. Após a penetração final em cada metro, o amostrador foi retirado e levado para a verificação de ocorrência de embuchamento e para medição do atrito interno. Por fim, o solo amostrado foi retirado e armazenado para determinação do teor de umidade.

\subsubsection{Instrumentação utilizada}

Para estimar as quantidades de energia atuantes no sistema durante o evento de um golpe do martelo, forças normais e acelerações foram medidas utilizando-se hastes instrumentadas com células de carga e acelerômetros. As hastes utilizadas neste trabalho foram desenvolvidas por Lukiantchuki (2012). O modelo das hastes desenvolvido por Lukiantchuki (2012) também foi utilizado por pesquisas anteriores (Morais, 2014; Zapata-Galvis, 2015). Cada haste foi instrumentada com uma célula de carga composta por extensômetros elétricos (strain gages), 
formando uma ponte completa, e um par de acelerômetros. Uma das hastes foi disposta logo abaixo da cabeça de bater e a outra logo acima do amostrador.

Primeiramente a haste inferior foi rosqueada ao amostrador e em seguida as demais hastes foram colocadas até atingir a profundidade pretendida. O conjunto foi colocado dentro do furo e em seguida a haste superior foi rosqueada à composição de hastes. A Figura 19 mostra a haste instrumentada disposta abaixo da cabeça de bater.

Figura 19 - Posicionamento da haste superior no sistema.

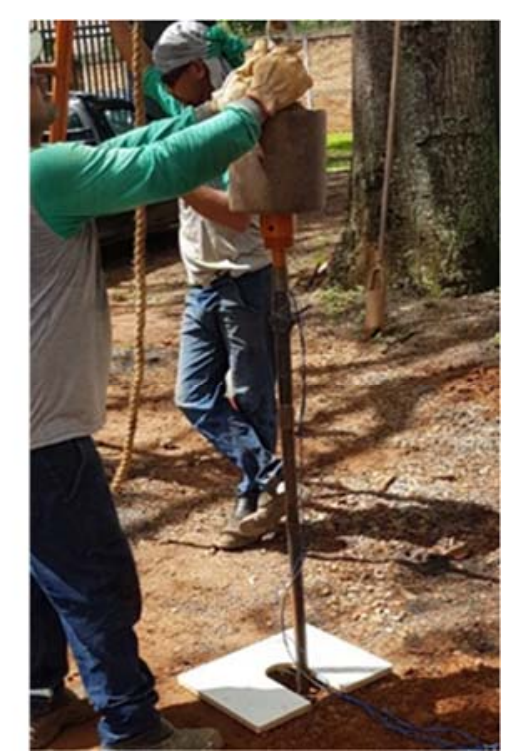

\subsubsection{Hastes instrumentadas}

As hastes utilizadas foram fabricadas em aço inoxidável martensítico (VC-150). O aço é composto por $0.35 \%$ de carbono e $13 \%$ de cromo. Após a confecção, as hastes passaram por tratamento térmico para melhoramento de suas características relacionadas com resistência. Por fim o limite de escoamento das hastes utilizadas e a resistência à tração são, respectivamente, $950 \mathrm{MPa}$ e $1084 \mathrm{MPa}$. As hastes apresentam a mesma impedância das demais utilizadas no ensaio SPT, $16.81 \mathrm{kN}^{\prime} \cdot \mathrm{s} / \mathrm{m}$, para evitar reflexões de ondas (Lukiantchuki, 2012). Morais (2014) alterou a geometria da haste inferior, acrescentando a ela uma rosca para que a mesma pudesse ser rosqueada diretamente no amostrador.

\subsubsection{Acelerômetros}

A utilização de acelerômetros se faz necessária pois estes possibilitam medir a aceleração das partículas devido ao golpe do martelo no ensaio SPT com energia crescente. A partir dos dados de aceleração é possível obter a velocidade das partículas mediante a integração 
da aceleração em função do tempo. Da mesma forma, a partir da integração da velocidade em função do tempo é possível determinar o deslocamento das partículas.

Os acelerômetros utilizados são do tipo piezolétricos da marca PCB Piezotronics. Na haste superior, localizada abaixo da cabeça de bater, o modelo utilizado foi o 350B04 que é capaz de medir acelerações de até $5000 \mathrm{~g}\left(\approx 4900 \mathrm{~m} / \mathrm{s}^{2}\right)$. Este modelo pode trabalhar em uma frequência situada entre 0.4 e $10000 \mathrm{~Hz}$. Na haste inferior, localizada acima do amostrador, o modelo utilizado foi o 350M77 que tem capacidade de até $20000 \mathrm{~g}\left(\approx 196200 \mathrm{~m} / \mathrm{s}^{2}\right)$ e trabalha numa frequência entre 1 e $15000 \mathrm{~Hz}$ (Lukiantchuki, 2012). Os acelerômetros são fixados nas hastes por meio de suportes, conforme pode ser visto na Figura 20.

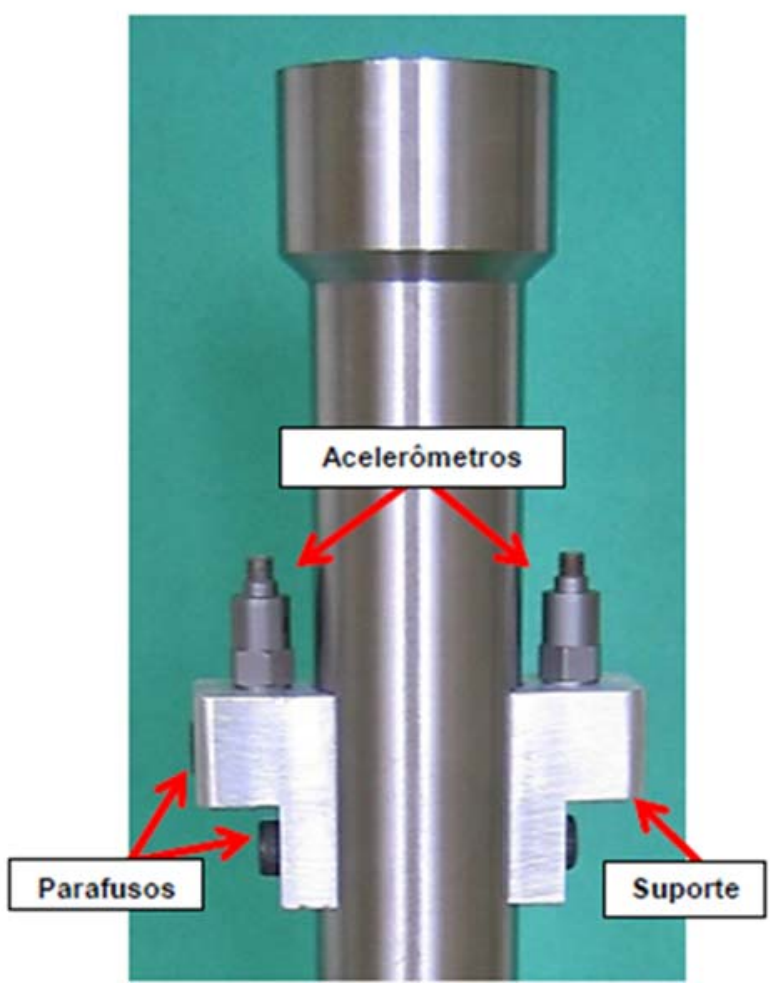

Figura 20 - Configuração dos acelerômetros nas hastes por meio de suportes de fixação (Morais, 2014).

\subsubsection{Células de carga}

As células de carga utilizadas na instrumentação das hastes foram conforme proposta de Odebrecht (2003). São formadas por extensômetros duplos (longitudinal e transversal) do tipo PA-06-125TG-350-LEN, fabricados pela Excel Engenharia de Sensores Ltda. As células de carga são constituídas por um circuito elétrico formando uma ponte completa de Wheastone (Eberle, 2018).

Para sua utilização, a célula de carga precisa ser calibrada. Dessa forma, as respostas da célula de carga, dadas como sinais elétricos $(\mathrm{mV} / \mathrm{V})$ podem ser relacionadas com unidades de 
carga $(\mathrm{kN})$. Para a calibração, as hastes foram submetidas à compressão axial em uma prensa servo controlada, modelo MTS 815 Rock Mechanics System, disponível no Laboratório de Mecânica das Rochas do Departamento de Geotecnia da Escola de Engenharia de São Carlos. A Figura 21 apresenta as curvas de calibração para a célula de carga da haste superior e da haste inferior.
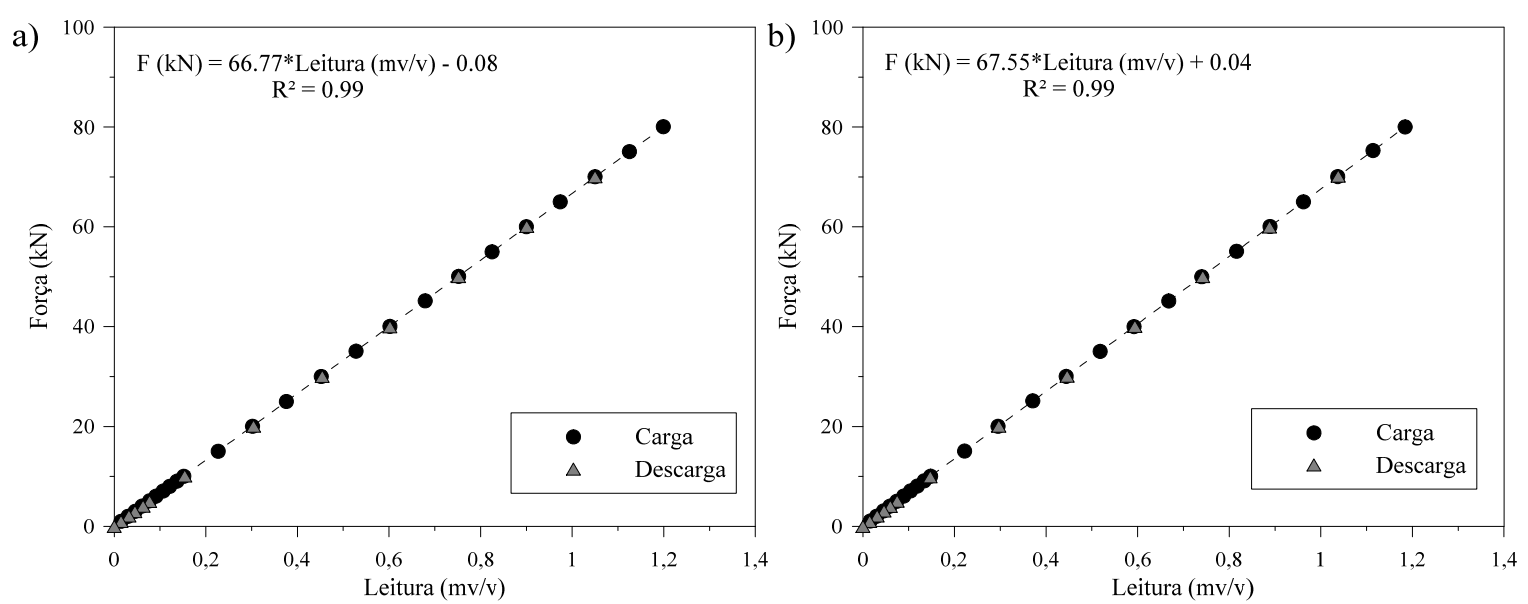

Figura 21 - Calibração das células de carga das hastes: a) superior; b) inferior.

\subsubsection{Proteção das hastes instrumentadas}

Para evitar danos às instrumentações utilizadas nas hastes é necessário envolver as hastes com camadas de proteção. A haste superior, por ficar na superfície, necessita de menor proteção. A haste inferior pode atingir o nível d'água, além de poder ter contato com as paredes do furo e por isso necessita de maior proteção (Eberle, 2018).

\subsubsection{Sistema de aquisição e tratamento de dados}

A aquisição de dados foi realizada utilizando-se o sistema da marca HBM, modelo MX-410 (Figura 22). Este sistema permite a aquisição de dados a uma taxa de até $96000 \mathrm{~Hz}$ por canal com uma resolução de 24 bits. Essa taxa de aquisição se faz necessária pois, no caso dos ensaios SPT, a dissipação de energia envolvida em um golpe do martelo ocorre em um intervalo de tempo entre 40 a 100 milissegundos, dependendo do comprimento de hastes e das propriedades do perfil investigado (Lukiantchuki, 2012). Para amplificar os sinais de aceleração, foram utilizados condicionadores de sinal do tipo IEPE (Integral Eletronic Piezoeletric). O modelo do IEPE pode ser visto na Figura 22. 


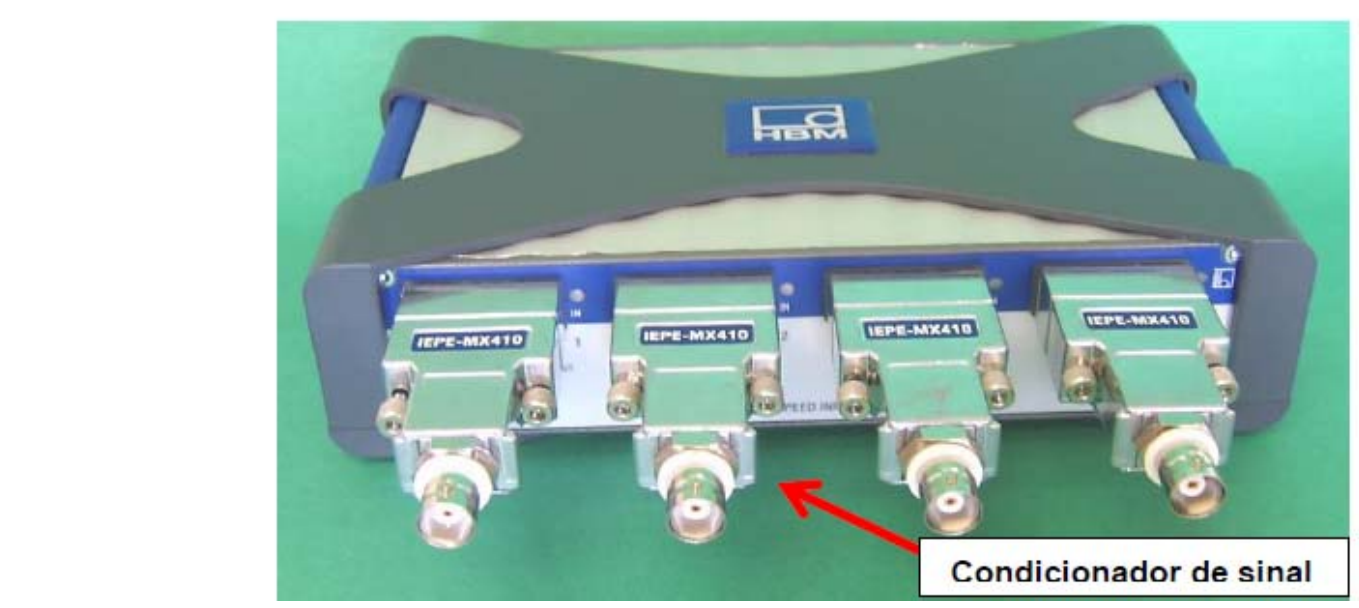

Figura 22 - Sistema de aquisição HBM MX-410 (Morais, 2014).

Cada módulo HBM MX-410 possui quatro canais para aquisição. Como eram necessários seis canais, foram utilizados dois módulos acoplados e sincronizados. Dessa forma, os dois módulos funcionam como se fosse um único, com oito canais. Os seis canais foram então conectados a quatro acelerômetros e duas células de carga.

O sistema de aquisição de dados foi controlado pelo programa CatmanEasy, desenvolvido pela HBM. Este programa permite configurar os sensores a serem utilizados em cada um dos canais, além de fazer o registro dos dados adquiridos. Este programa também possui uma ferramenta matemática que possibilita o tratamento e processamento dos dados após a sua aquisição.

\subsubsection{Aquisição dos dados}

Após a sincronização dos módulos, foram informados ao programa CatmanEasy as calibrações e propriedades dos sensores. A calibração dos acelerômetros é fornecida pela fábrica, enquanto que a calibração das células de cargas, foram previamente realizadas (Figura 21).

Após a configuração dos sensores e dos canais, foi necessário alterar a taxa de aquisição de dados para $96000 \mathrm{~Hz}$, pois o default do programa é de $2400 \mathrm{~Hz}$, taxa muito baixa para este tipo de ensaio. Também foi feita a configuração do sistema de trigger do programa. Com o trigger configurado, o programa finaliza automaticamente a aquisição de dados a partir de critérios impostos pelo usuário. Além disso, a configuração do pré-trigger permite armazenar uma quantidade menor de dados desnecessários, que ocorrem antes do valor do trigger, otimizando o sistema de aquisição. A sequência de configuração dos canais está apresentada na Tabela 3. 
Tabela 3 - Configuração dos canais do sistema de aquisição de dados para o ensaio dinâmico.

\begin{tabular}{ccccc}
\hline Canal & Tipo de sensor & $\begin{array}{c}\text { Taxa de } \\
\text { Aquisição }\end{array}$ & $\begin{array}{c}\text { Identificação HBM 0 - } \\
\text { Haste Superior }\end{array}$ & $\begin{array}{c}\text { Identificação HBM 1 - } \\
\text { Haste Inferior }\end{array}$ \\
\hline$\# 1$ & Célula de carga & $96 \mathrm{kHz}$ & CCS & CCI \\
$\# 2$ & Acelerômetro & $96 \mathrm{kHz}$ & AC1_320 & AC1_742 \\
$\# 3$ & Acelerômetro & $96 \mathrm{kHz}$ & AC2_321 & AC2_963 \\
$\# 4$ & Nenhum & - & - & - \\
\hline
\end{tabular}

Após todas as configurações realizadas, imediatamente antes do golpe todos os sensores foram zerados e deu-se início à aquisição dos dados

\subsubsection{Tratamento dos dados}

O tratamento dos dados foi feito através do modo de análise de dados do programa CatmanEasy. Antes de se iniciar o tratamento dos dados, é necessário selecionar o trecho de interesse contido no conjunto de dados brutos e fazer os devidos ajustes de forma que os dados estejam aptos para os cálculos a serem realizados. As etapas de tratamento estão apresentadas na Figura 23.

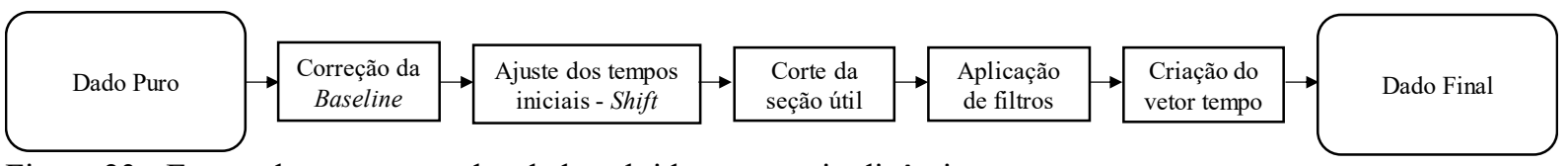

Figura 23 - Etapas do tratamento dos dados obtidos no ensaio dinâmico.

A correção da baseline trata-se de ajustar o "zero" dos dados. Para isso, determina-se a média dos dados que antecedem o início do impacto, que é subtraída de todos os dados do sinal. Os sinais obtidos dos acelerômetros e da célula de carga devem iniciar no mesmo instante. Os dados obtidos podem apresentar um pequeno deslocamento entre o início destes sinais. Portanto é feito uma mudança (shift) do tempo de início dos dados, para que estes sejam coincidentes. Devido ao posicionamento dos acelerômetros na haste, os sinais de aceleração obtidos têm o seu sinal invertido, sendo necessário corrigi-los. O corte da seção útil trata-se de eliminar os dados desnecessários, antes e depois do evento do impacto e que não serão necessários nos cálculos das etapas de análise dos dados. A aplicação de filtros se faz necessária para retirar sinais provenientes de ruídos, que não fazem parte dos sinais relativos ao impacto propriamente dito. Por fim, é criado um vetor tempo correspondente aos sinais de força e aceleração obtidos. A criação desse vetor é fundamental para a integração dos sinais nas etapas de análises, como será visto a seguir.

Para as etapas de tratamentos e análises os dados foram separados em função da posição das hastes instrumentadas. Portanto, para cada golpe existem dois conjuntos de dados a serem 
tratados. Os dados sem tratamento algum para esse golpe estão apresentados na Figura 24. A Figura 25 mostra os mesmos dados após os tratamentos aplicados.
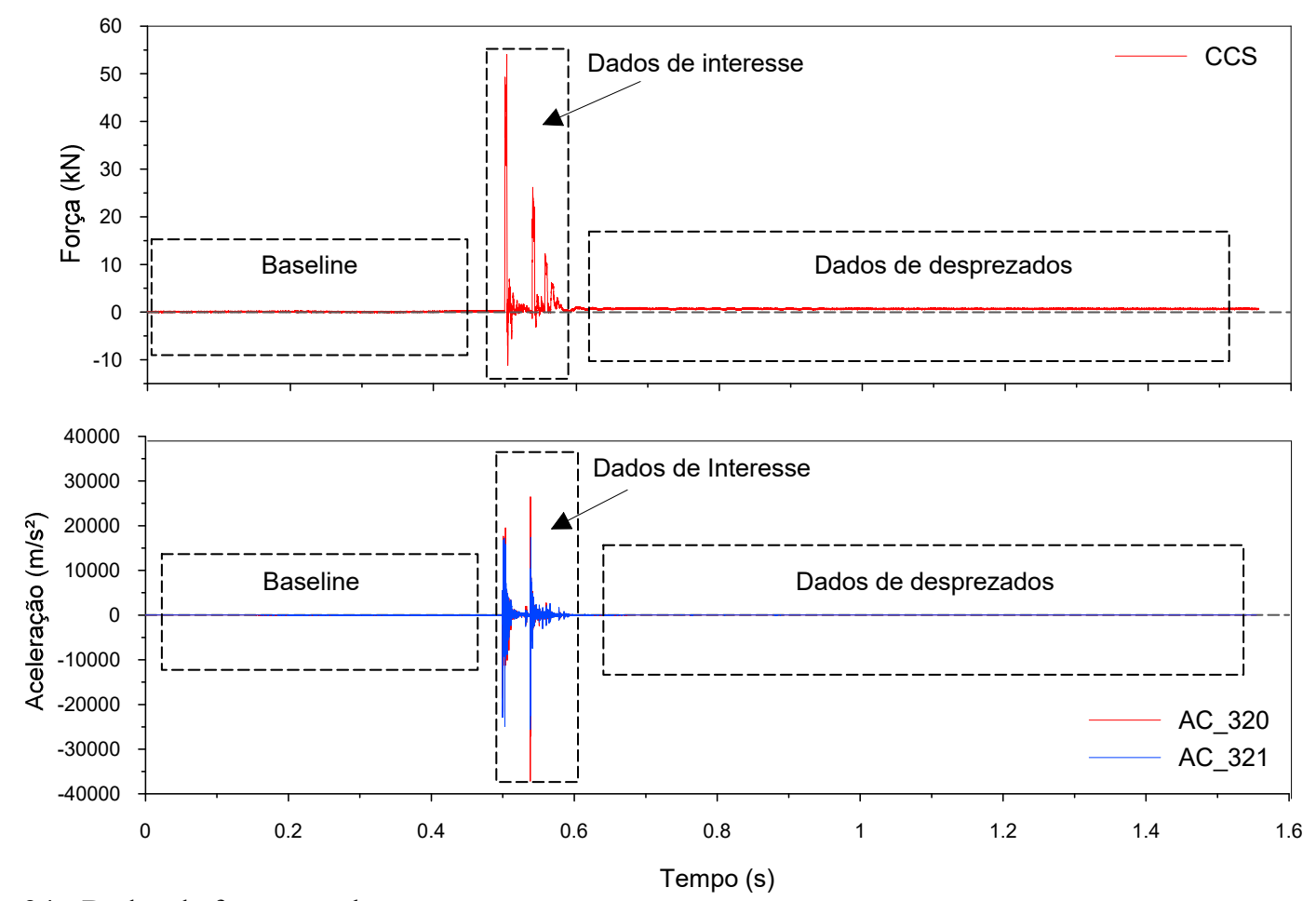

Figura 24 - Dados de força e aceleração sem tratamento.
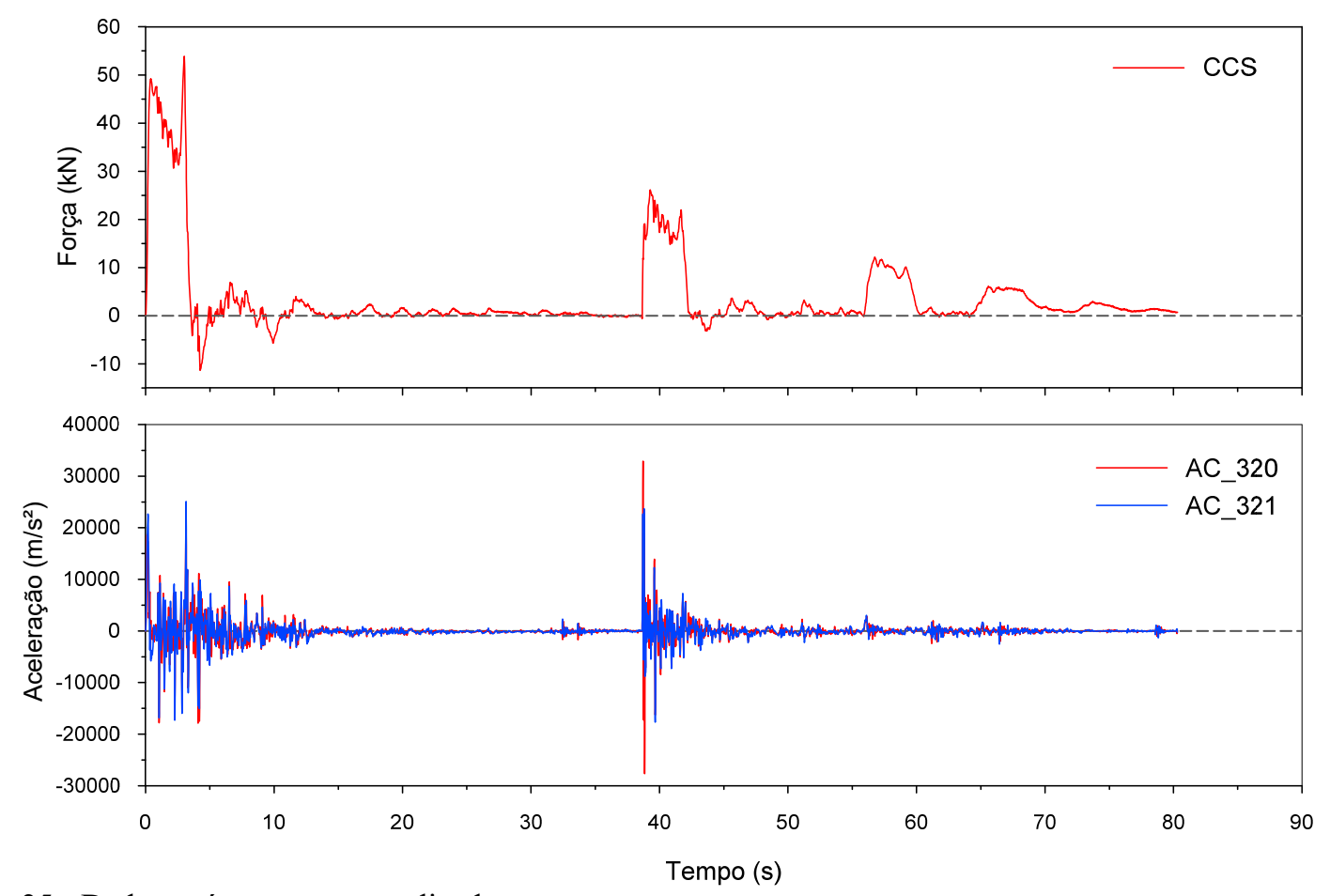

Figura 25 - Dados após tratamento aplicado.

\subsubsection{Análise dos dados}

Os dados obtidos no ensaio foram analisados separadamente para a haste superior e para haste inferior. As etapas da análise dos dados estão apresentadas na Figura 26. 


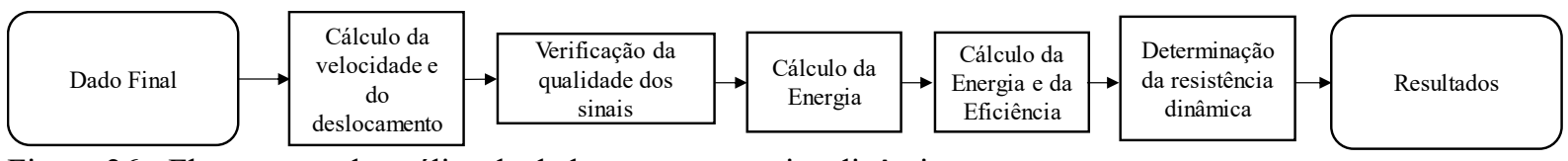

Figura 26 - Fluxograma da análise de dados para os ensaios dinâmicos.

\subsubsection{Cálculo da velocidade e do deslocamento}

Os sinais de velocidade são calculados integrando-se os sinais de aceleração em função do tempo. Da mesma forma, os sinais de deslocamento são calculados integrando-se os sinais de velocidade em função do tempo. As integrações foram realizadas através das ferramentas de cálculo do modo de análise do programa CatmanEasy. Como foram utilizados dois acelerômetros em cada uma das hastes instrumentadas, as velocidades e os deslocamentos foram calculados para cada sinal de aceleração $\left(v_{A C l}, v_{A C 2}\right.$ e $\delta_{A C l}$ e $\left.\delta_{A C 2}\right)$ e para o valor médio.

Como no início do evento o sistema encontra-se em repouso, o valor de velocidade é igual a zero. Assim, ao final do evento a velocidade também deve ser nula, já que o sistema volta a ficar em repouso. Porém isso não ocorre, conforme pode ser observado na Figura 27a.
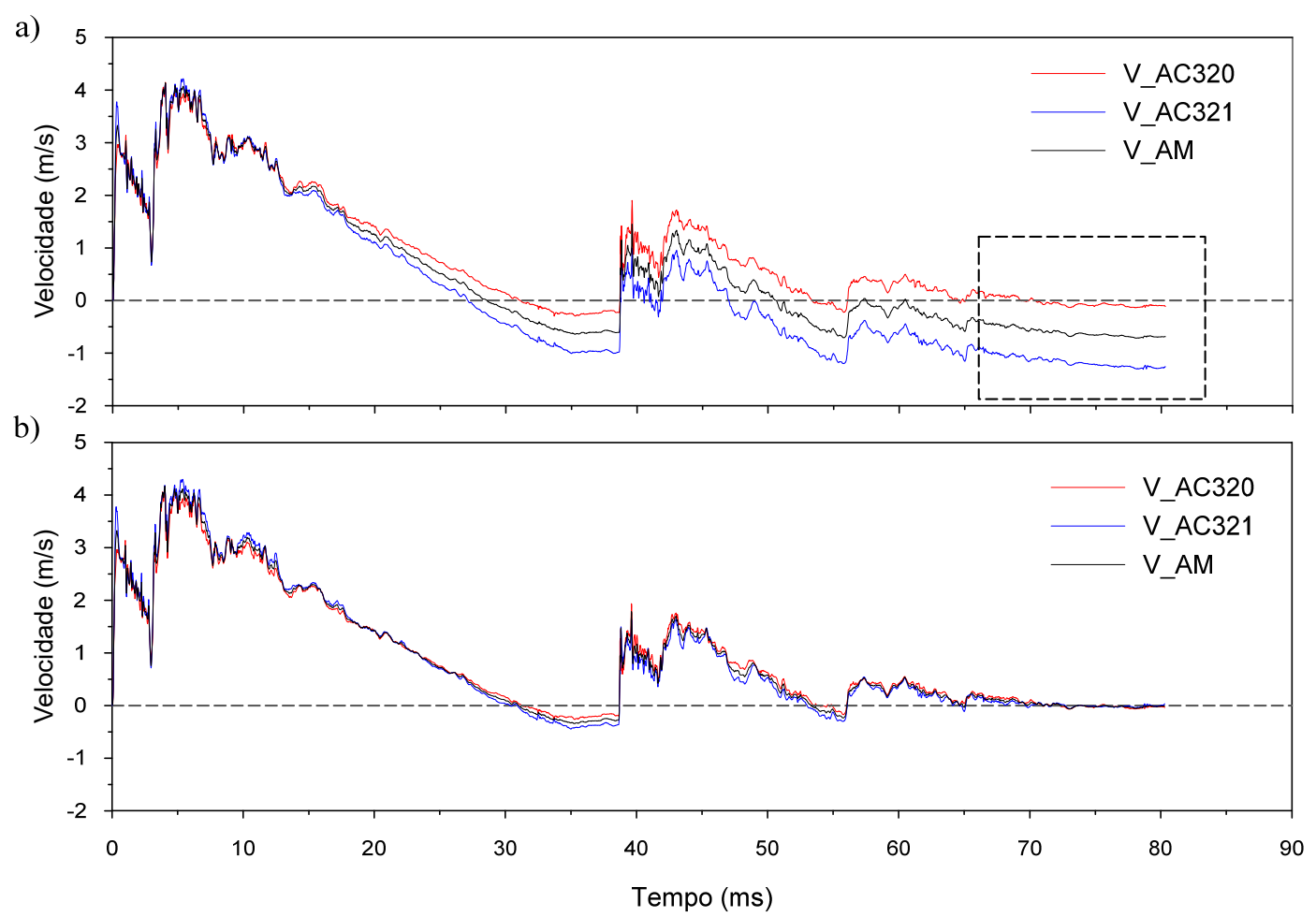

Figura 27 - Velocidades em função do tempo. a) sem rotação, b) com rotação.

Ao final do evento a curva de velocidade possui certa inclinação, enquanto deveria ser uma reta horizontal. Esse fato deve-se ao acúmulo de erros ocorridos na etapa de integração. Dessa forma faz-se necessário a aplicação de uma correção dos dados. Essa correção é feita 
através da determinação do coeficiente angular da reta formada no final dos dados. Exemplos dos dados de velocidade corrigidos estão apresentados na Figura 27b.

Os sinais de velocidade corrigidos são integrados em função do tempo, obtendo-se os sinais de deslocamento (Figura 28).

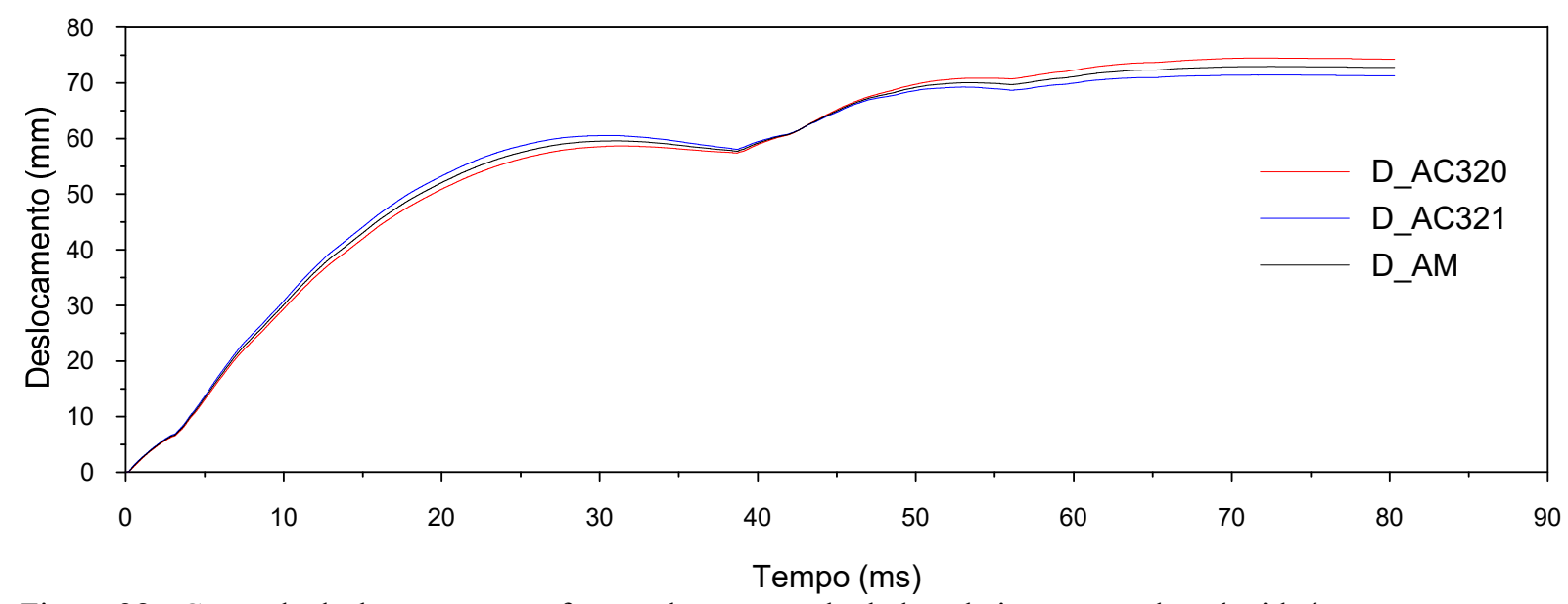

Figura 28 - Curva de deslocamento em função do tempo calculada pela integração da velocidade.

\subsubsection{Qualidade dos sinais}

A qualidade dos sinais pode ser avaliada comparando-se ao longo do tempo os sinais de força com os sinais do produto da velocidade ( $v$ ) pela impedância da haste instrumentada $(Z)$. Quanto mais próximos forem esses sinais durante o período inicial igual a $(2 l / c)$, referente ao tempo de propagação da primeira onda de compressão, maior a confiabilidade dos sinais obtidos. A Figura 29 apresenta as duas curvas plotadas juntas para possibilitar a comparação. A força foi calculada com os valores médios de velocidade. A impedância da haste é $16,81 \mathrm{kN} \cdot \mathrm{s} / \mathrm{m}^{2}$ (Morais, 2014).

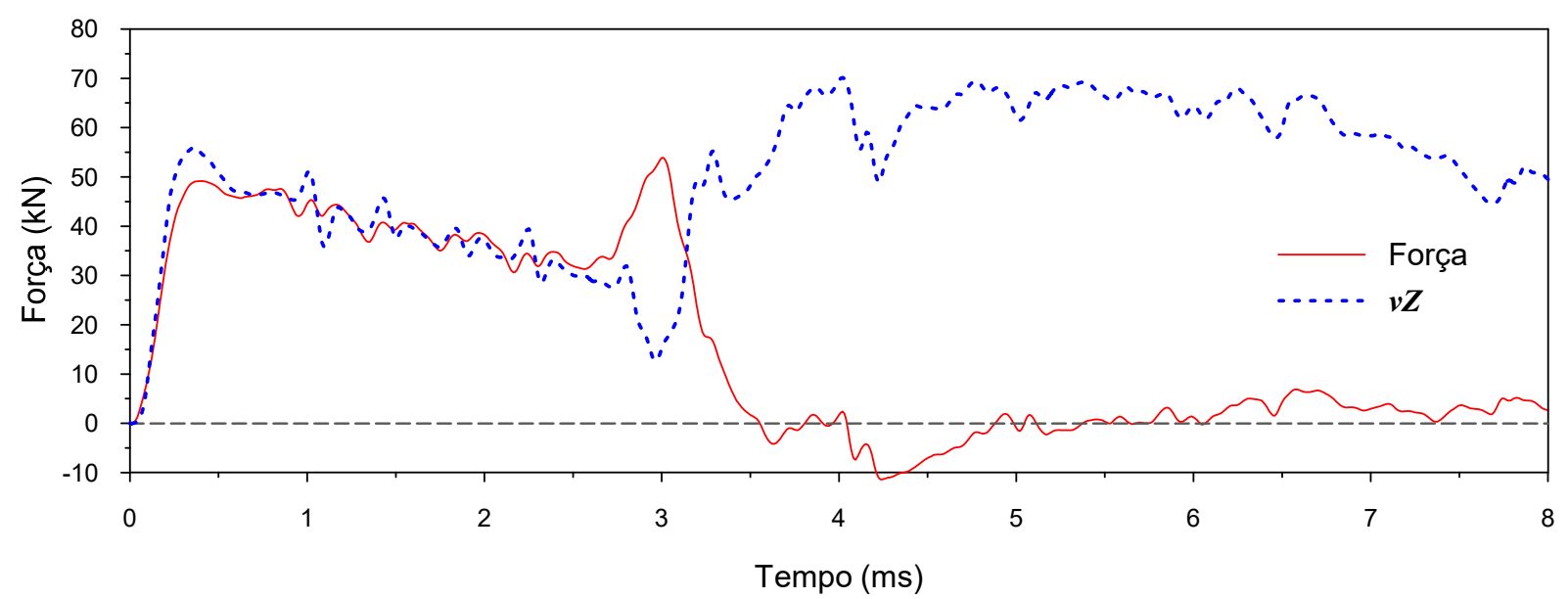

Figura 29 - Comparação dos dados de força e velocidade. 


\subsubsection{Cálculo da quantidade de energia}

A quantidade de energia total transmitida através de uma seção, pode ser calculada pelo método EFV, conforme a Equação 34.

$$
E=\int_{t_{1}}^{t_{2}} F(t) \times v(t) d t
$$

O instante $t_{1}$ refere-se ao início do evento, quando o valor de força deixa de ser nulo e o instante $t_{2}$ ao final do evento, quando nenhum impacto subsequente é observado. A Figura 30 apresenta um exemplo dos resultados da energia calculada.

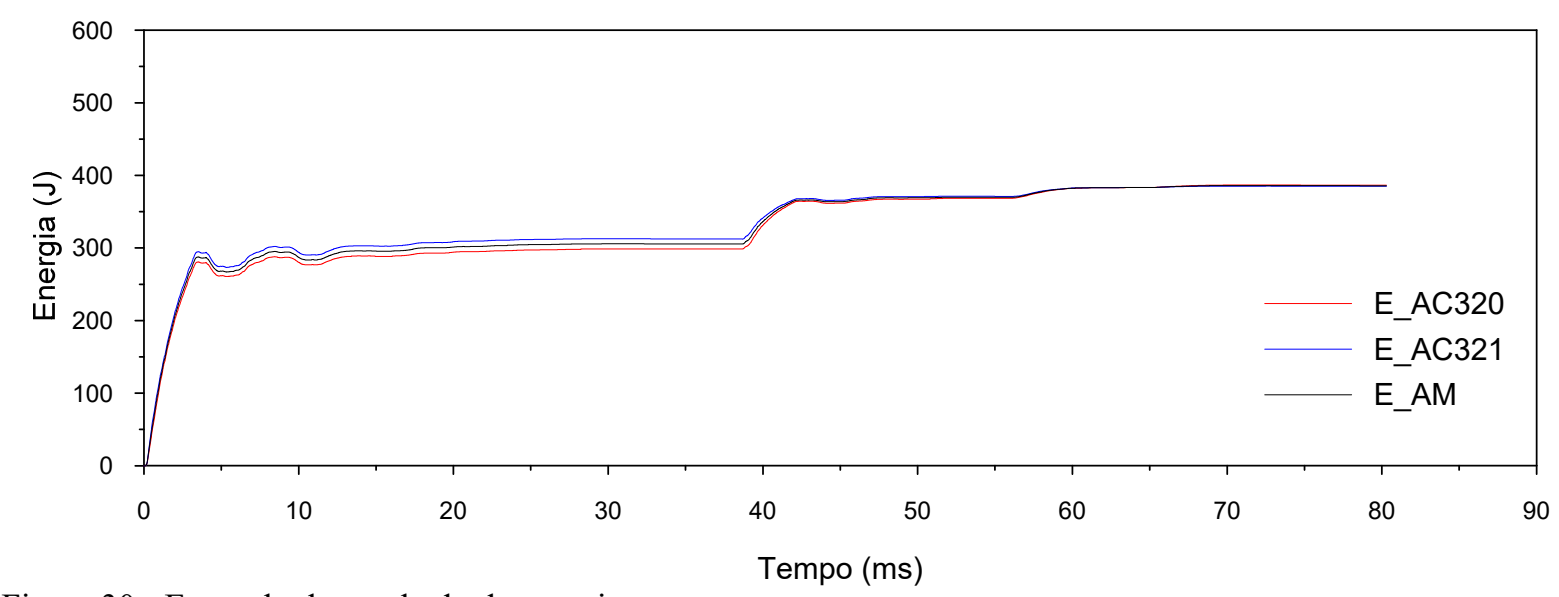

Figura 30 - Exemplo do resultado de energia.

\subsection{ENSAIO ESTÁTICO}

Ensaios estáticos no amostrador padrão do SPT foram realizadas anteriormente por Neves (2004), Aoki et al. (2007), Norenã (2011) e Eberle (2018) com intuito de determinar a eficiência do SPT. No trabalho desses autores, após a execução do ensaio SPT convencional, antes da retirada o amostrador, o conjunto de composição de hastes e o amostrador foram submetidos à um carregamento estático até que a carga atingisse a resistência estática estimada.

Neste trabalho, após a execução dos ensaios dinâmicos houve a necessidade de retirar o amostrador para verificação de embuchamento da amostra e do atrito interno. Por essa razão, o ensaio estático não foi executado em seguida ao ensaio dinâmico. Optou-se então, por realizar uma penetração estática do amostrador no solo em um quarto furo (SPE na Figura 18) nas mesmas profundidades em que os ensaios dinâmicos haviam sido realizados.

Para a execução do ensaio utilizaram-se as mesmas hastes e o amostrador utilizados no ensaio dinâmico, assim como as hastes instrumentadas. O sistema de reação adotado foi similar à um sistema de cargueira, com os pesos colocados sobre o ponto de fixação dos cavaletes 
utilizados para dar altura e mobilidade ao ensaio. A viga de reação foi fixada aos cavaletes por meio de travas roscadas, confeccionadas para esta finalidade. A carga para a reação foi estimada em relação ao maior índice $N_{s p t}$ encontrado na região de ensaio, adotando-se uma média de $1 \mathrm{kN}$ por $N_{s p t}$, totalizando $7 \mathrm{kN}$. Uma quantidade a mais de pesos foram colocados como medida de segurança, atingindo cerca de $10 \mathrm{kN}$. A Figura 31 apresenta o sistema de reação utilizado.

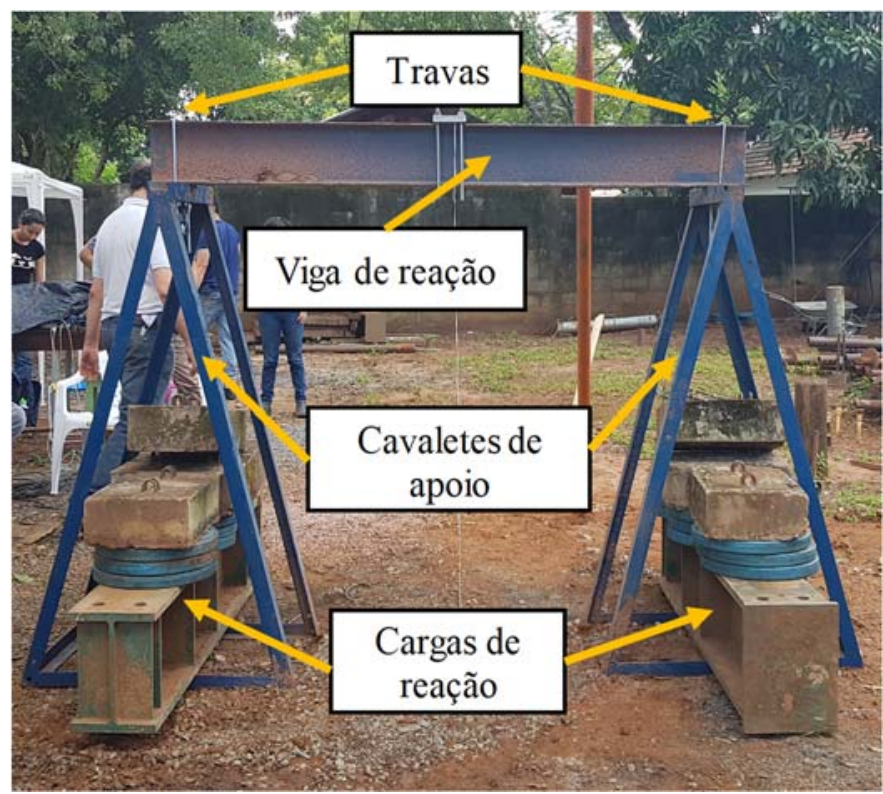

Figura 31 - Sistema de reação utilizado na penetração estática.

O ensaio consistiu em aplicar incrementos de carga ao sistema, por meio de um cilindro hidráulico manual e controlar os deslocamentos obtidos para cada incremento. O controle da carga aplicada foi feito pelas células de carga das hastes instrumentadas e o deslocamento por transdutores de deslocamento. Os sinais de força e de deslocamento foram registrados pelo sistema HBM MX-410.

O critério de parada adotado foi a penetração de $450 \mathrm{~mm}$, a mesma penetração total nos ensaios SPT convencionais. Como os cursos, tanto do cilindro hidráulico, como dos transdutores de deslocamento eram inferiores a $450 \mathrm{~mm}$ (158 e $100 \mathrm{~mm}$, respectivamente), foi necessário realizar os ensaios em etapas. Quando o curso do cilindro hidráulico não era suficiente, foram utilizados prolongadores metálicos. Quando o curso do transdutor não era suficiente, este era elevado para liberar o seu curso.

Por dificuldades de ajuste do ensaio, a penetração estática foram realizados em apenas uma profundidade: $5 \mathrm{~m}$. $\mathrm{O}$ ensaio à $2 \mathrm{~m}$ de profundidade foi realizado em 3 etapas, à $3 \mathrm{~m}$ em 4 etapas e à $5 \mathrm{~m}$ em 5 etapas. 


\subsubsection{Instrumentação utilizada}

A instrumentação utilizada para controle deste ensaio foi composta pelas hastes instrumentadas e pelos transdutores de deslocamento. As duas hastes foram instaladas, tanto abaixo da cabeça de bater, quanto acima do amostrador, possibilitando a obtenção das forças normais nas duas posições. Os incrementos de carga foram feitos por meio de um cilindro hidráulico com $250 \mathrm{kN}$ de capacidade. Os componentes envolvidos neste ensaio estão apresentados na Figura 32.

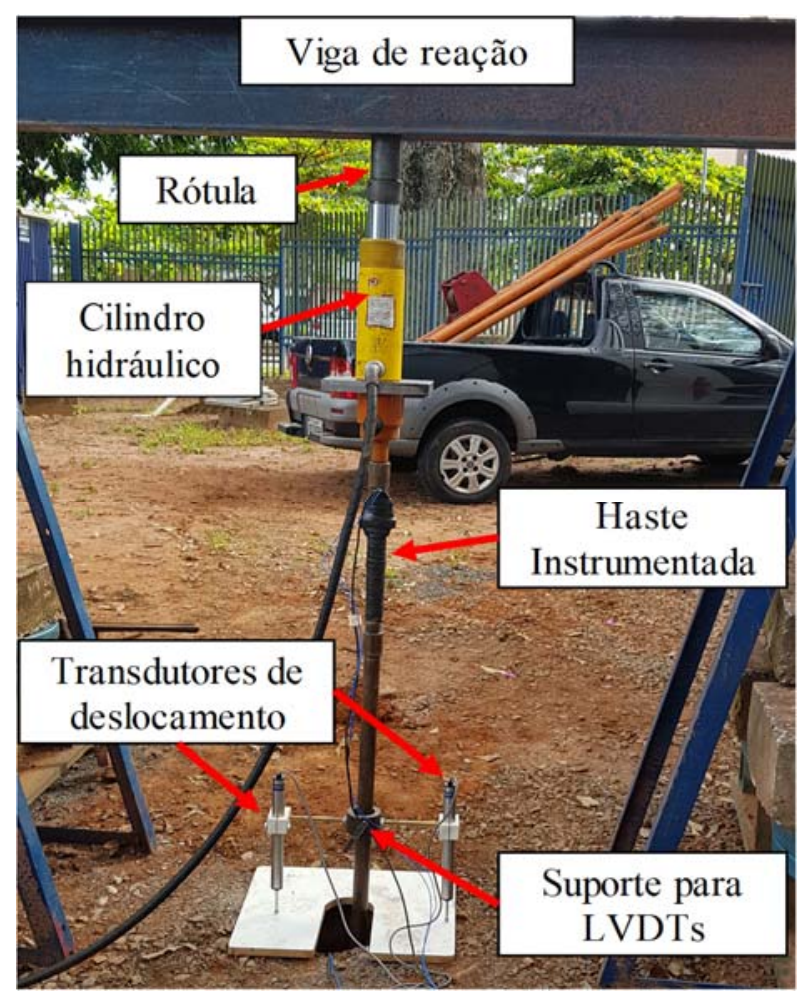

Figura 32 - Componentes envolvidos no ensaio estático.

Os transdutores de deslocamento, utilizados para determinação dos recalques com os incrementos de carga, são da marca Vishay Precicion Group, da linha Micro-Measurements (MM), modelo HS100. Esses transdutores consistem em pontes tensiométricas ativas com resistência $350 \Omega$ e excitação de $2 \mathrm{~V}$ a $10 \mathrm{~V}$ (AC ou DC) e sensibilidade média de $5.2 \mathrm{mV} / \mathrm{V}$.

Os transdutores de deslocamento foram fixados à composição de hastes por meio de um suporte fixado às hastes do SPT e tendo como referencial uma placa de MDF apoiada no solo. A Figura 33 apresenta uma imagem do sistema de fixação desses transdutores. 
Figura 33 - Fixação dos sensores de deslocamento.

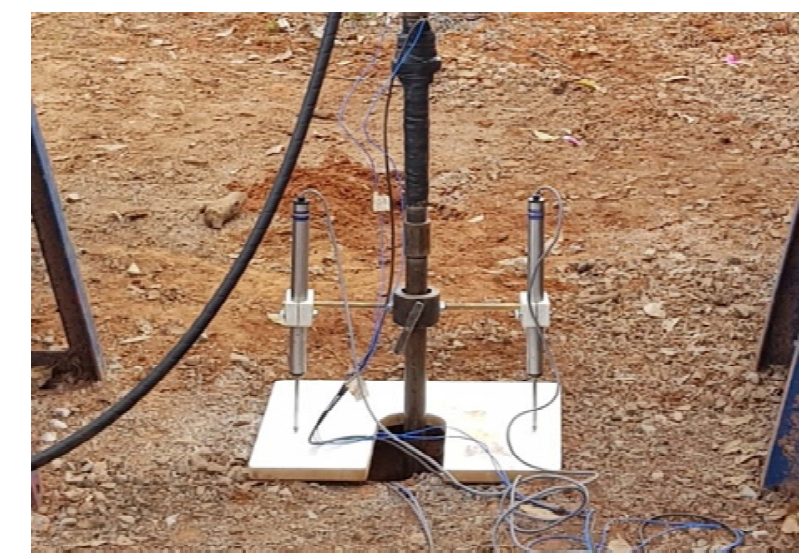

\subsubsection{Aquisição dos dados}

Para aquisição dos dados foi utilizado um único módulo do sistema HBM MX-410, pois foram necessários apenas quatro canais, dois para células de carga (CCS e CCI) e dois para transdutores de deslocamento (TD1 e TD2).

A frequência de aquisição dos dados utilizada nestes ensaios foi de $2400 \mathrm{~Hz}$, padrão do sistema, pois como o ensaio era mais lento, não havia necessidade de utilizar uma frequência igual ao do ensaio dinâmico. Para cada canal foi indicado o sensor que seria utilizado nele. A configuração dos canais está apresentada na Tabela 4.

Tabela 4 - Configuração dos canais no sistema de aquisição de dados para o ensaio estático.

\begin{tabular}{cccc} 
Canal & Tipo de sensor & $\begin{array}{c}\text { Taxa de } \\
\text { Aquisição }\end{array}$ & Identificação HBM 0 \\
\hline$\# 1$ & Célula de carga & $2.4 \mathrm{kHz}$ & CCS \\
$\# 2$ & Célula de carga & $2.4 \mathrm{kHz}$ & CCI \\
$\# 3$ & Deslocamento & $2.4 \mathrm{kHz}$ & TD1 \\
$\# 4$ & Deslocamento & $2.4 \mathrm{kHz}$ & TD2 \\
\hline
\end{tabular}

\subsubsection{Tratamento dos dados}

O tratamento dos dados consistiu em três etapas: selecionar os dados válidos, filtrar os sinais e adicionar o peso próprio. Na primeira, os sinais que foram armazenados antes e depois do intervalo de aplicação dos carregamentos são excluídos. Como a frequência de aquisição de dados de $2400 \mathrm{~Hz}$ ainda era elevada em relação ao tempo de aplicação do carregamento, o número de dados adquiridos foi muito alto. Assim, foi realizada uma redução do número de dados. A última etapa consiste em adicionar aos dados obtidos o peso próprio dos prolongadores utilizados, das hastes e do cilindro hidráulico. Antes de se iniciar a aquisição dos dados a célula 
de carga é zerada. Portanto, os dados de força obtidos são relativos aos incrementos de carga aplicados.

\subsubsection{Análise dos dados}

A etapa de processamento dos dados consiste em plotar a curva carga-recalque a partir dos dados adquiridos. Vale lembrar que para cada metro de profundidade ensaiado, obteve-se mais de uma etapa de carregamento e descarregamento, assemelhando-se à um ensaio de carregamento cíclico.

\subsection{ENSAIO PARA DETERMINAÇÃO DO ATRITO INTERNO}

A medição de atrito interno consiste em deslocar a amostra de dentro do amostrador, de maneira semi-estática, e verificar qual a força $\left(R_{2}\right)$ necessária para promover esse deslocamento, conforme proposto por Zapata-Galvis (2015).

O deslocamento da amostra é causado pela aplicação de uma força por meio de um cilindro hidráulico. O conjunto formado pelo amostrador, cilindro hidráulico e célula de carga é montado em suporte de alumínio, conforme mostrado na Figura 34. A finalidade da célula de carga é medir a força aplicada.

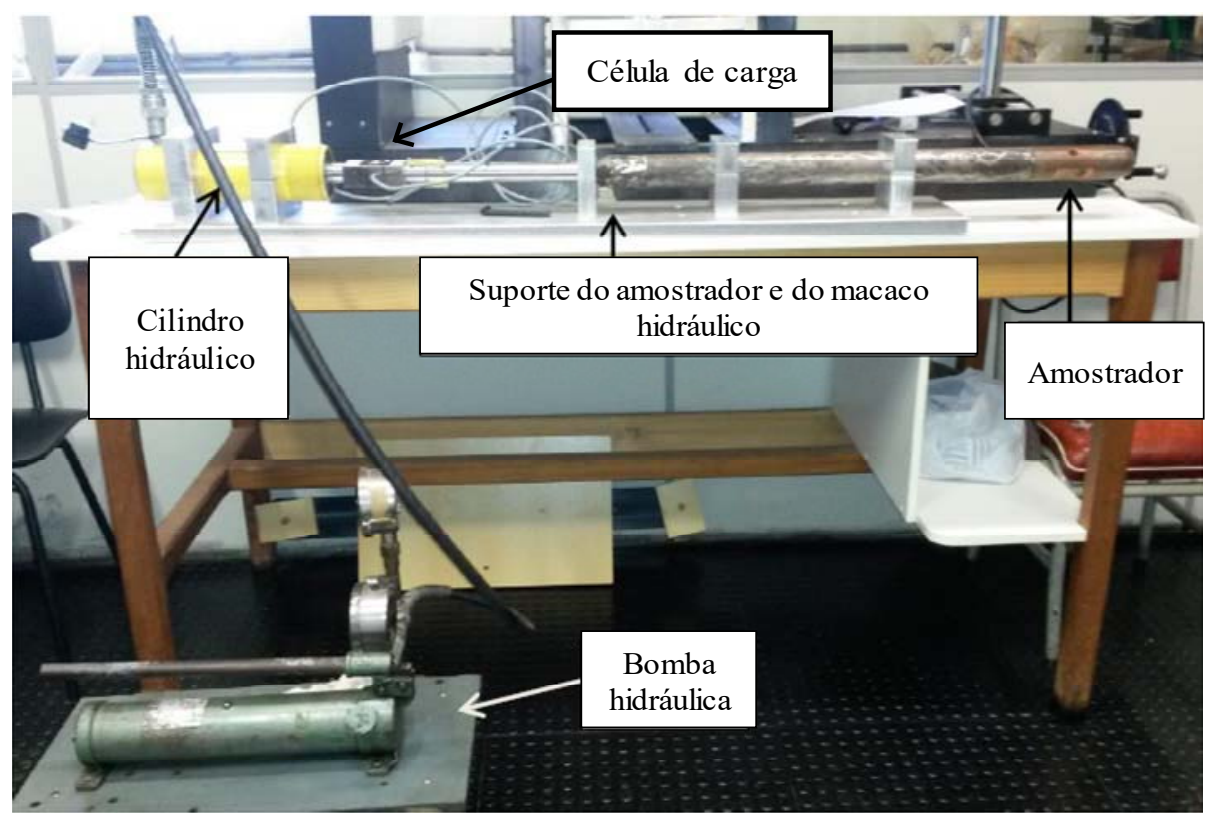

Figura 34 - Equipamento para medição de atrito interno (Zapata Galvis, 2015).

Antes de se iniciar o ensaio de atrito interno, após a finalização da penetração do amostrador em cada profundidade, o amostrador foi retirado e fez-se uma estimativa do 
comprimento da amostra, com o amostrador ainda fechado, inserindo-se uma trena na extremidade superior do amostrador (Figura 35).

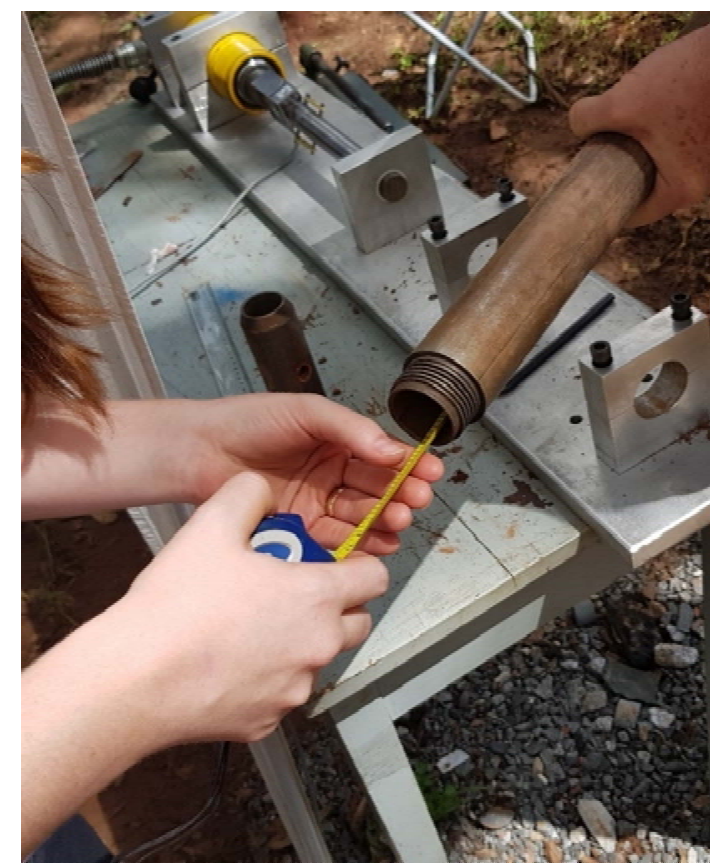

Figura 35 - Estimativa do comprimento da amostra recuperada.

Para a determinação do atrito interno, o amostrador foi acoplado ao suporte de alumínio e iniciou-se a aplicação de cargas à amostra com auxílio do cilindro hidráulico. As forças aplicadas foram medidas pela célula de carga e o registro das mesmas foi feito pelo sistema de aquisição HBM MX-410, em função do tempo. O incremento de forças era finalizado quando se notava uma tendência horizontal na curva força-tempo.

O ensaio foi realizado para todos os furos e profundidades de realização dos ensaios dinâmicos. Após a medição do atrito interno, o amostrador foi aberto e mediu-se o comprimento da amostra, conforme Figura 36. Por fim, a amostra foi armazenada para determinação do seu teor de umidade.

\footnotetext{
Figura 36 - Medição do comprimento da amostra após medição do atrito interno.
}

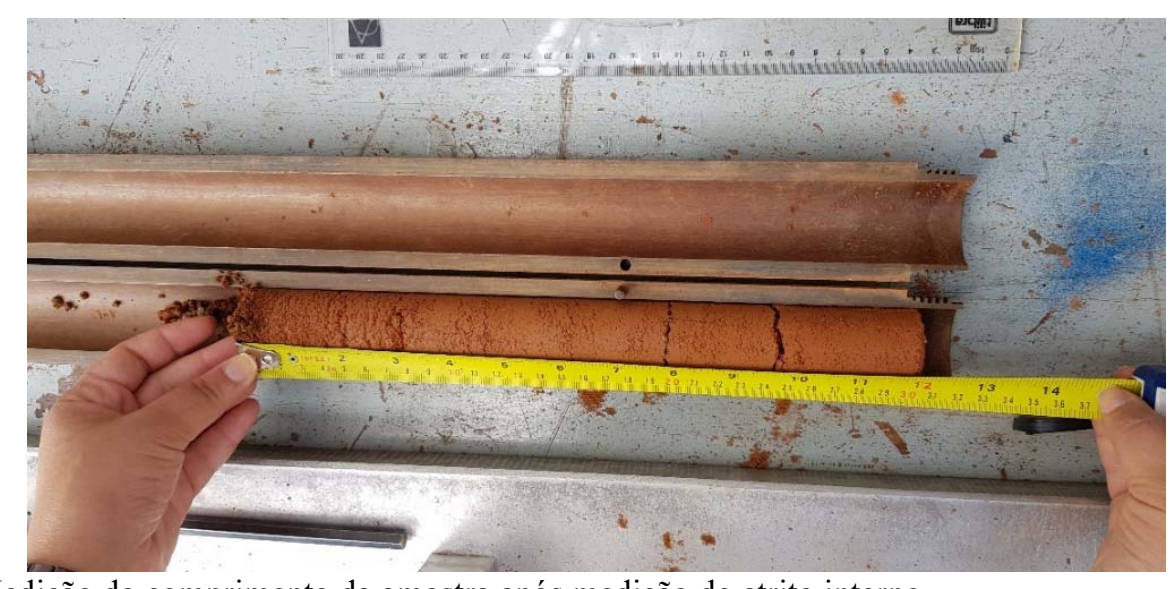




\subsubsection{Instrumentação utilizada}

Como instrumentação do ensaio foi utilizada uma célula de carga do tipo $S$ da marca HBM, modelo RSCBC3, com capacidade máxima de $5 \mathrm{kN}$, para medição das forças aplicadas. A calibração desta célula de carga é fornecida pelo fabricante, mas foram feitos testes para conferência da calibração.

\subsubsection{Aquisição dos dados}

Para aquisição dos dados foi utilizado um único módulo do sistema HBM MX-410. Para este ensaio apenas um canal de aquisição foi utilizado, pois apenas os dados da célula de carga precisavam ser registrados (Tabela 5).

Tabela 5 - Configuração dos canais no sistema de aquisição de dados para medição do atrito interno.

\begin{tabular}{cccc} 
Canal & Tipo de sensor & $\begin{array}{c}\text { Taxa de } \\
\text { Aquisição }\end{array}$ & Identificação HBM 0 \\
\hline$\# 1$ & Nenhum & - & - \\
$\# 2$ & Nenhum & - & - \\
$\# 3$ & Nenhum & - & - \\
$\# 4$ & Célula de Carga & $2.4 \mathrm{kHz}$ & RSCBC3 \\
\hline
\end{tabular}

Por se tratar de uma célula de carga de mesma marca do sistema de aquisição (HBM), ao ser conectada no sistema de aquisição, as configurações da célula de carga são automaticamente reconhecidas. Portanto, não houve necessidade de fazer identificação ou configuração do sensor. Semelhantemente ao ensaio estático, a frequência de aquisição neste caso foi menor que a do ensaio dinâmico por se tratar de um ensaio mais lento.

\subsubsection{Tratamento dos dados}

O tratamento dos dados foi feito através do modo de análise de dados do programa CatmanEasy. O tratamento aplicado aos resultados obtidos para este ensaio, consiste em ajustar a baseline e selecionar os dados válidos.

Da mesma forma como no ensaio dinâmico, a correção da baseline visa corrigir o "zero" dos sinais. Assim, determina-se a média dos dados iniciais, que é em seguida subtraída de todos os dados do sinal. Por fim, os sinais foram cortados, selecionando apenas os dados válidos que consiste no início da ascensão dos valores de força até o momento em que tomam tendência horizontal. A Figura 37 apresenta o sinal do ensaio sem tratamento (Figura 37a) e com tratamento (Figura 37b). 

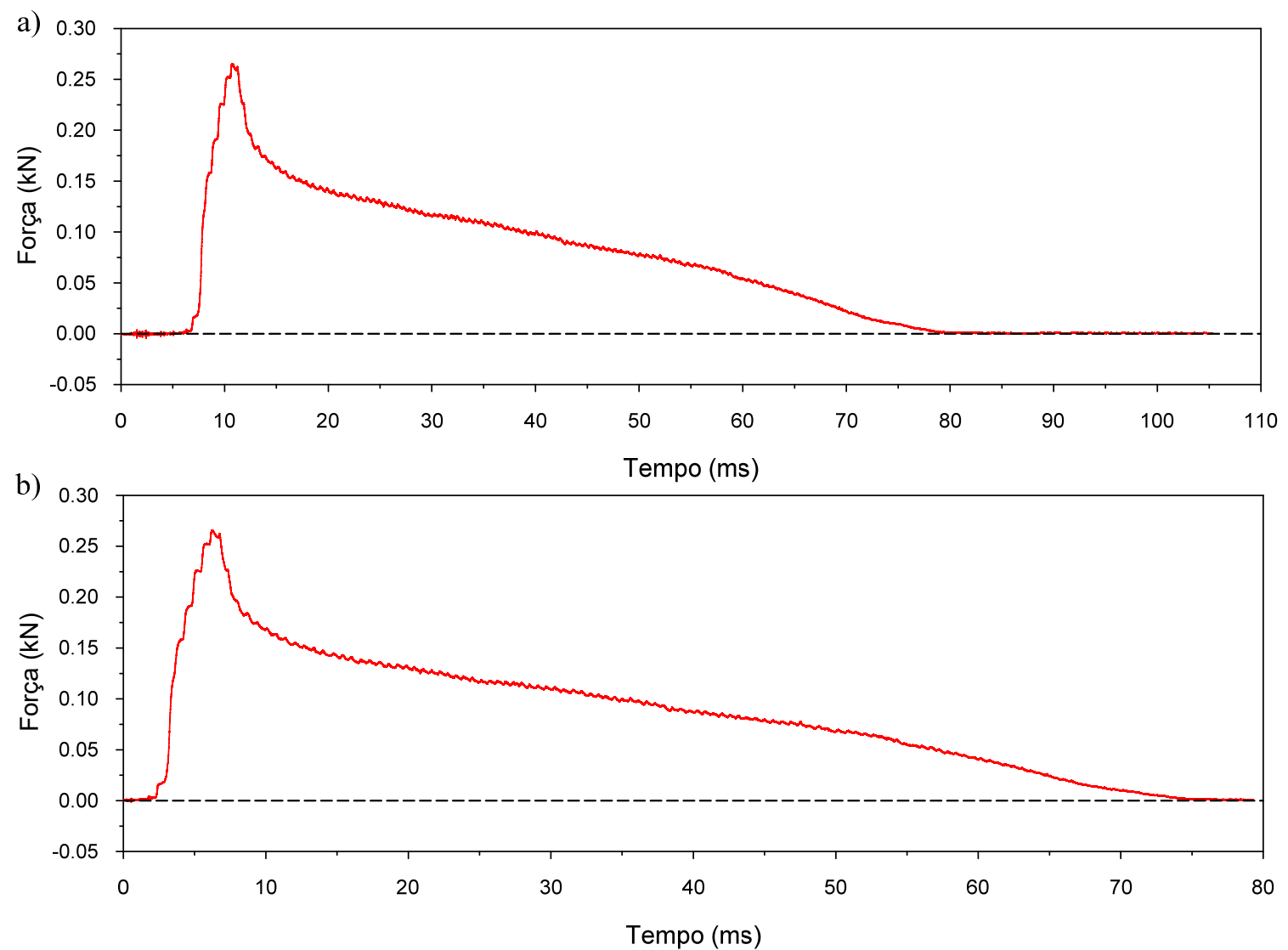

Figura 37 - Exemplo da aplicação do tratamento nos dados de medição de atrito interno: a) sem tratamento; b) com tratamento.

\subsubsection{Análise dos dados}

A determinação da resistência de atrito interno $\left(R_{2}\right)$ é feita tomando-se o pico da curva Força-Tempo. Um exemplo da forma de determinar essa resistência é apresentada a seguir na Figura 38.

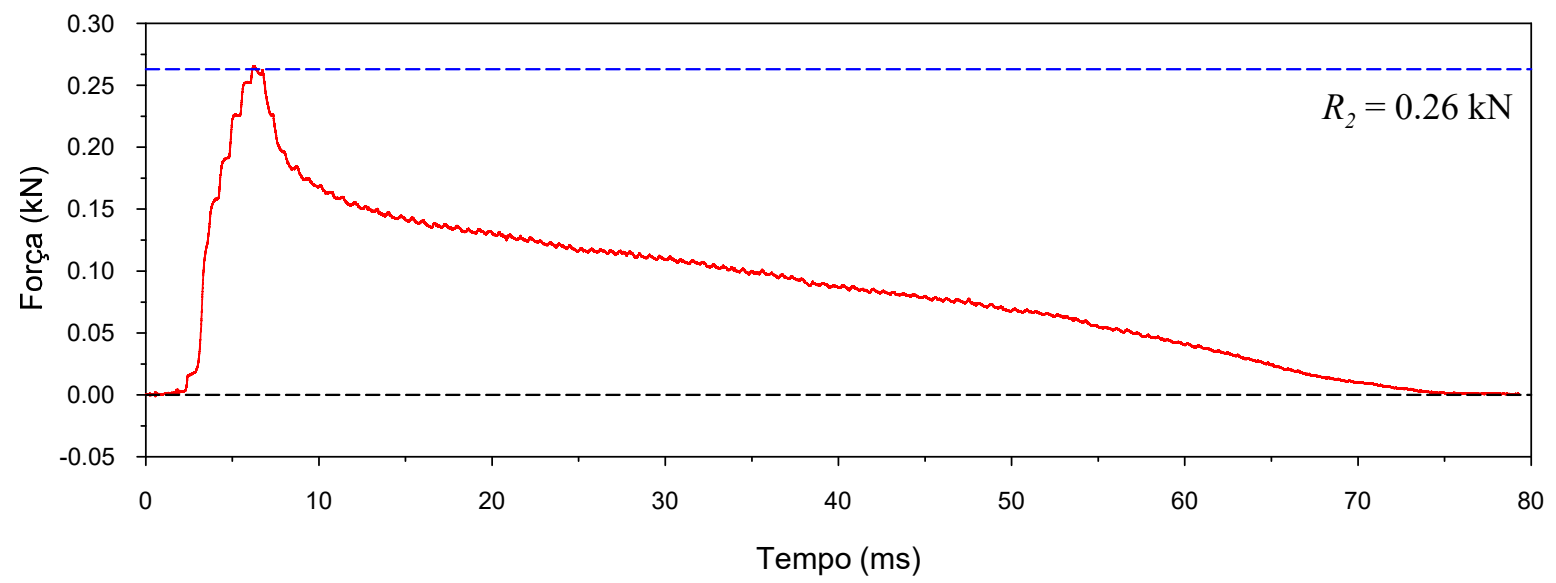

Figura 38 - Exemplo de determinação de $R_{2}$. 


\section{RESULTADOS E DISCUSSÕES}

Esta seção apresenta os resultados obtidos para cada ensaio, assim como a discussão a respeito de cada resultado. Primeiramente serão apresentados os resultados do ensaio de penetração dinâmica com energia crescente. Em seguida, serão apresentados os resultados do ensaio de atrito interno. Por último será apresentado o resultado do ensaio de penetração estática.

\subsection{ENSAIO DE PENETRAÇÃO DINÂMICA COM ENERGIA CRESCENTE}

\subsubsection{Resultados típicos do ensaio SPT instrumentado}

Exemplos típicos dos resultados do ensaio de penetração dinâmica com energia crescente estão apresentados da Figura 39 até 45. Os resultados dos demais ensaios se encontram no Anexo nas Figura A1 até A90. As figuras apresentam os resultados em ordem crescente de altura de queda $\left(H_{q}\right)$.

Observa-se que independentemente da altura de queda aplicada, os formatos dos sinais são muito semelhantes. São alteradas apenas as magnitudes dos valores entre uma altura de queda e outra. A diferença na magnitude dos valores correspondente ao primeiro golpe $\left(H_{q}=100 \mathrm{~mm}\right)$ e o último $\left(H_{q}=750 \mathrm{~mm}\right)$ é significativa. Como nos gráficos foram mantidas as escalas verticais para todas as alturas de queda, as acelerações correspondentes ao primeiro golpe são quase invisíveis.

Observa-se que existe uma tendência ao aumento do tempo do evento conforme aumenta-se a altura de queda aplicada. Além disso, o número de impactos subsequentes para cada evento também parece ter uma tendência a aumentar com a altura de queda, quando é analisada uma mesma profundidade. O número de impactos subsequentes também está relacionado à resistência do solo. Solos mais resistentes tendem a consumir a energia disponibilizada à cravação de forma mais rápida que solos menos resistentes, ocorrendo então, menor número de impactos (Lobo, 2009, Lukiantchuki, 2012). Se pela mesma lógica forem analisados solos de mesma resistência, ao diminuir a altura de queda será diminuída a energia fornecida ao sistema e consequentemente menor será o número de impactos.

A título de exemplo, seja considerado o caso correspondente ao furo SP01, na profundidade de $2 \mathrm{~m}$. Figura 39 à Figura 45 mostram os sinais de aceleração, força axial, deslocamento e energia. Observa-se que após o último impacto o sinal de força mantém um 
valor de força constante, o sinal de aceleração é nulo e a curva de $v Z$ segue uma tendência linear decrescente até o final do evento, onde a força se torna nula. Essa condição não foi observada em todos os metros analisados.
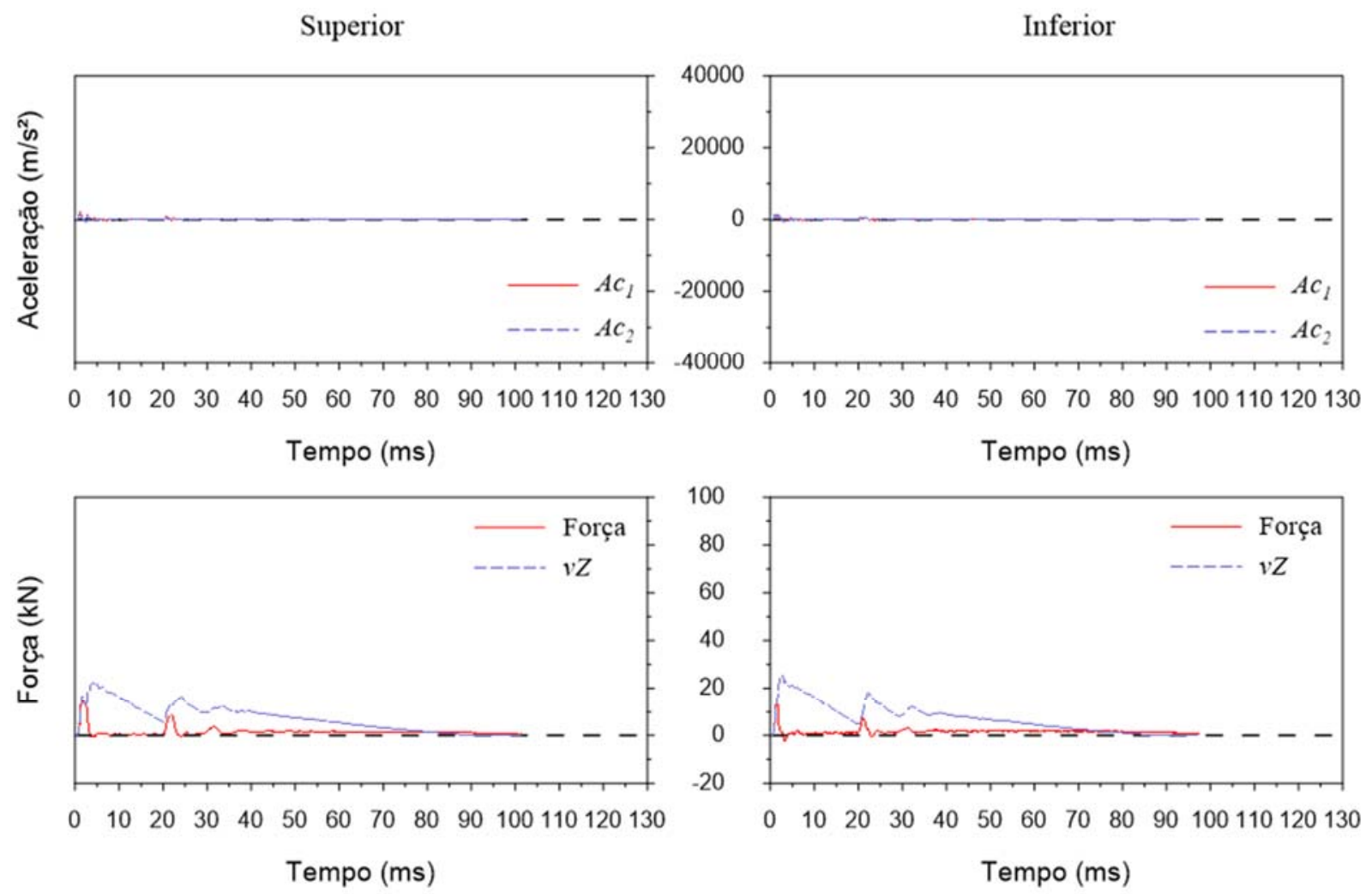

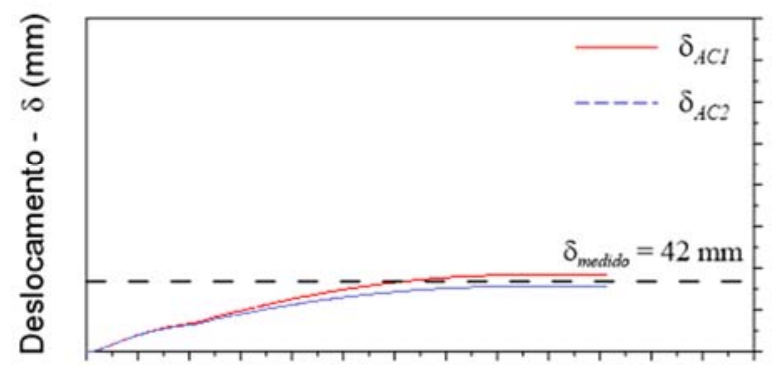

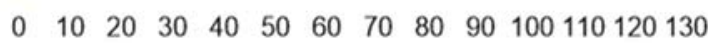

Tempo (ms)

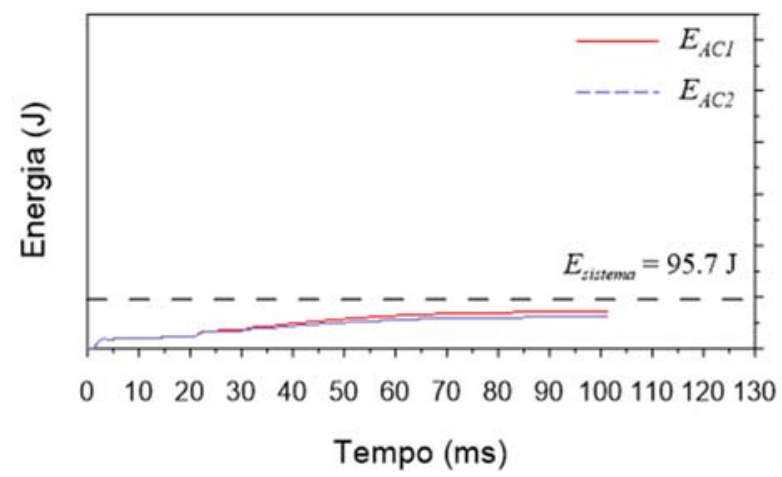

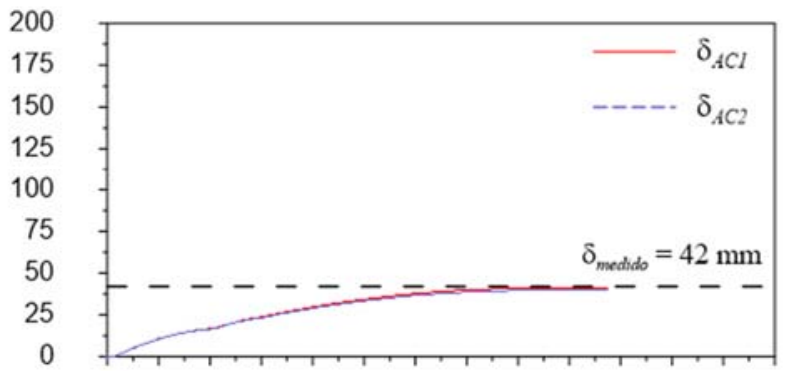

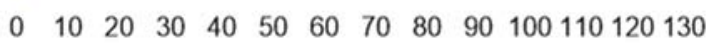
Tempo (ms)

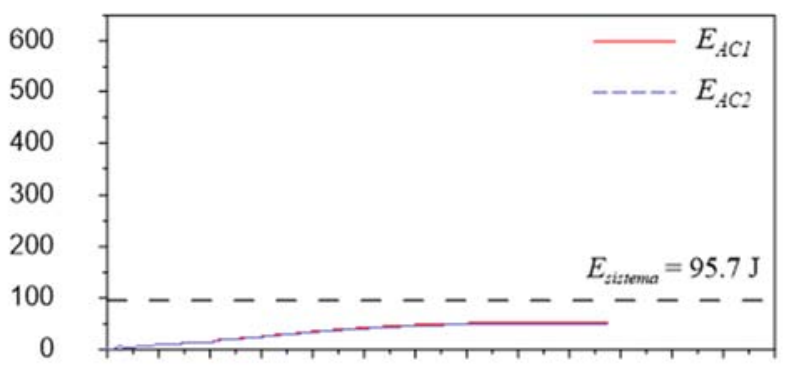

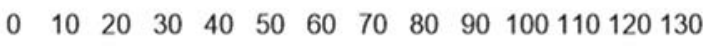
Tempo (ms)

Figura 39 - Sinais típicos de SPT instrumentado para o furo SP01, profundidade de $2 \mathrm{~m}$ e $H_{q}$ de $100 \mathrm{~mm}$. 
Superior
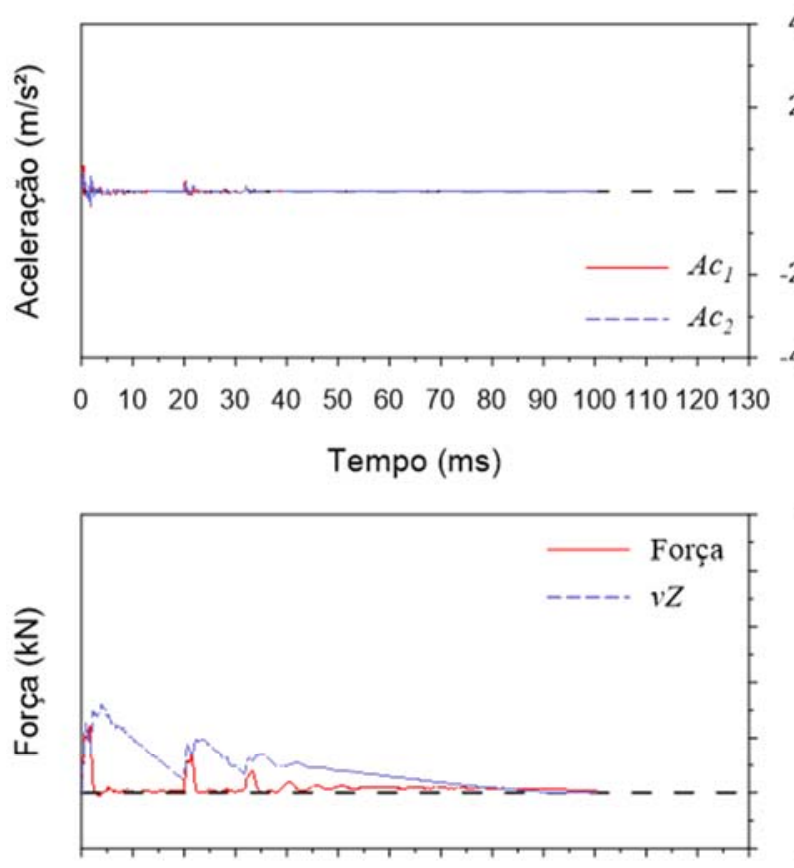

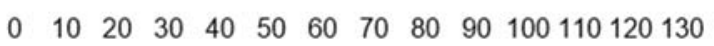

Tempo (ms)

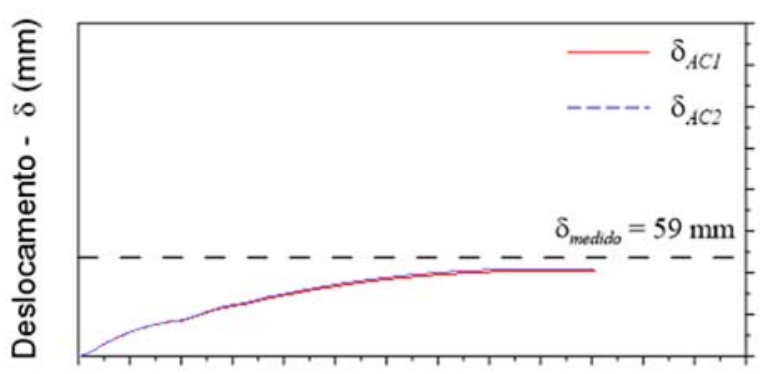

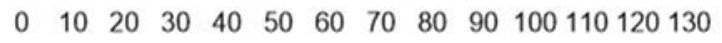

Tempo (ms)

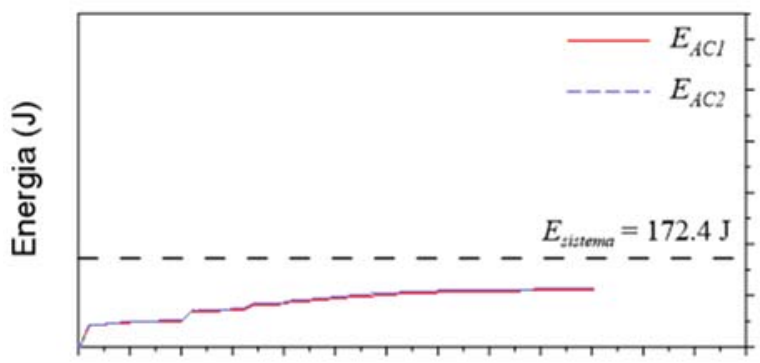

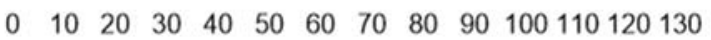

Tempo (ms)
Inferior
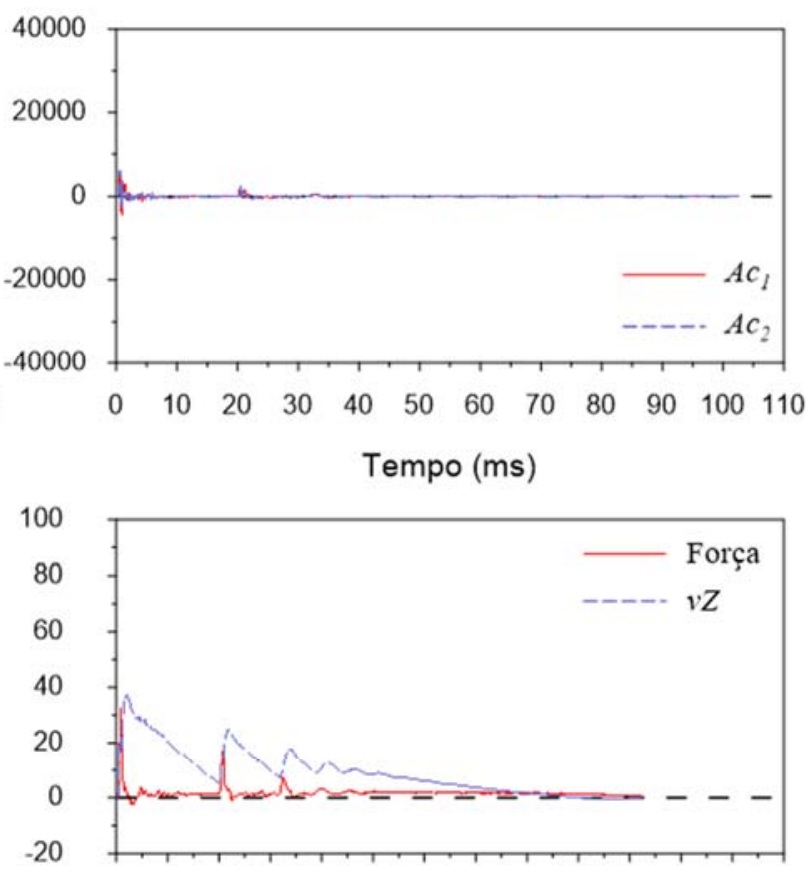

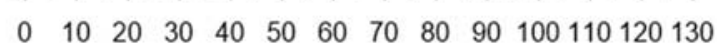

Tempo (ms)
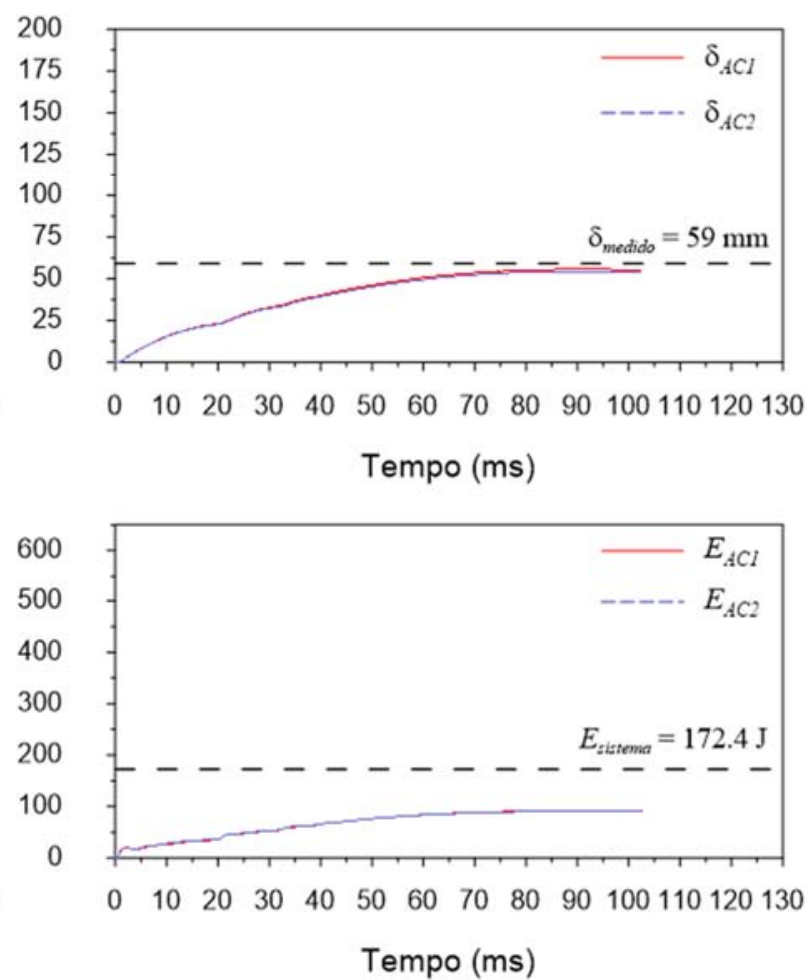

Figura 40 - Sinais típicos de SPT instrumentado para o furo SP01, profundidade de $2 \mathrm{~m}$ e $H_{q}$ de $200 \mathrm{~mm}$. 


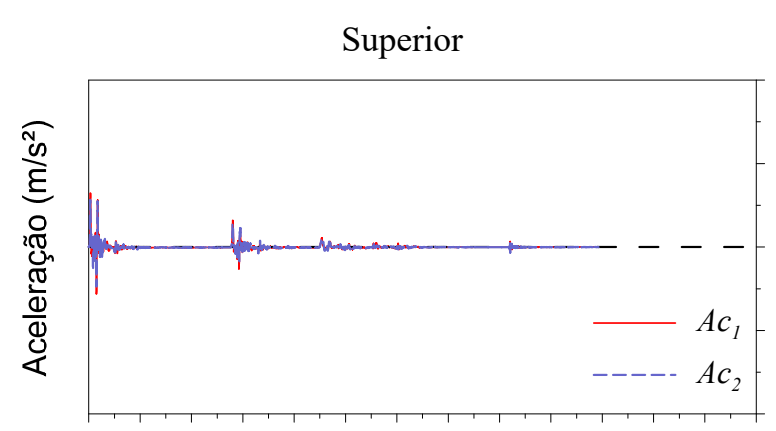

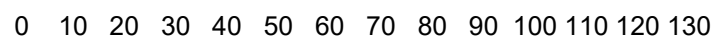

Tempo (ms)

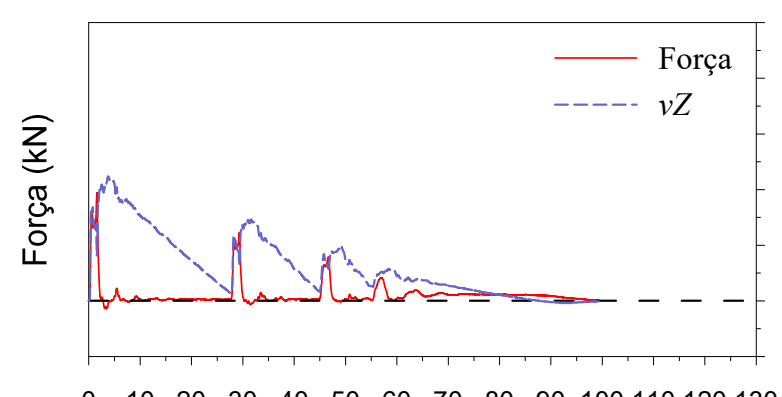

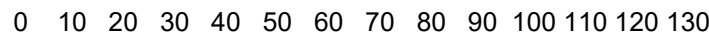

Tempo (ms)

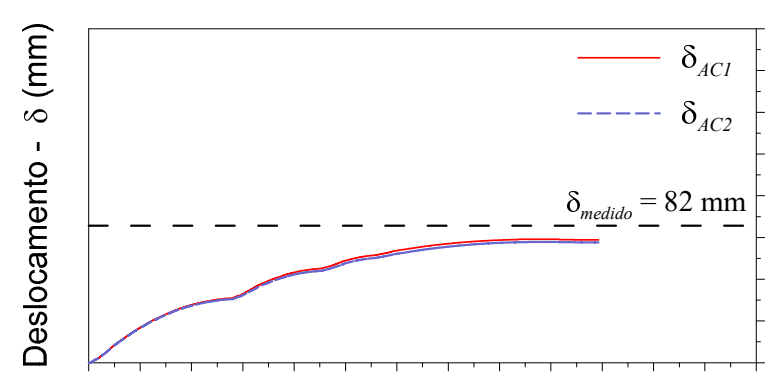

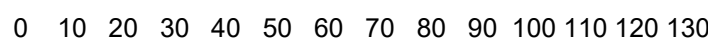

Tempo (ms)

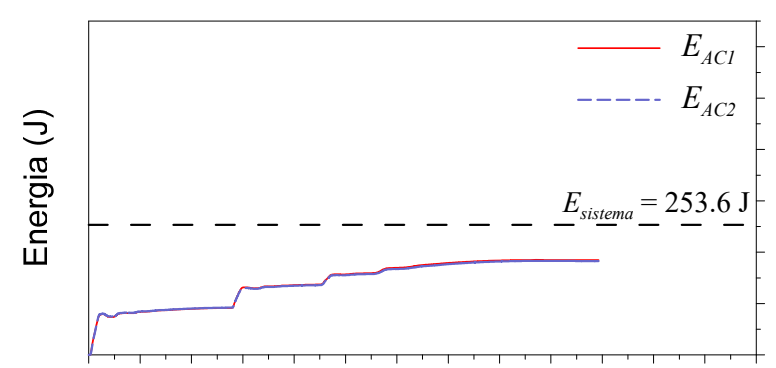

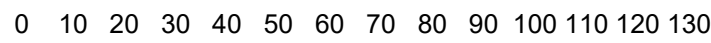

Tempo (ms)
Inferior
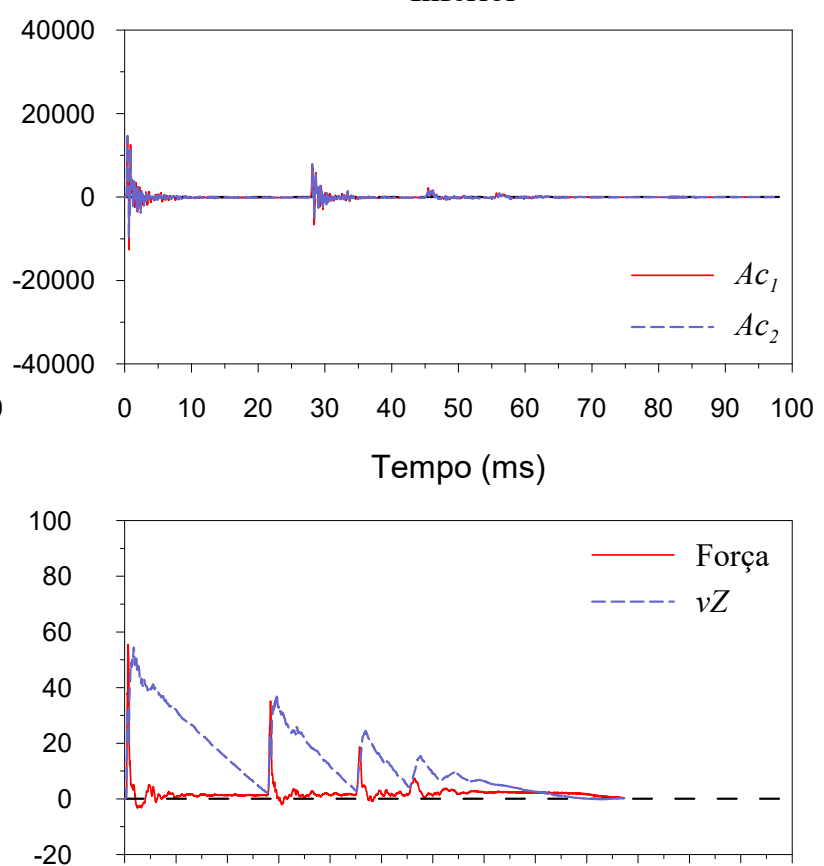

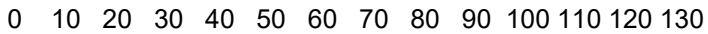

Tempo (ms)

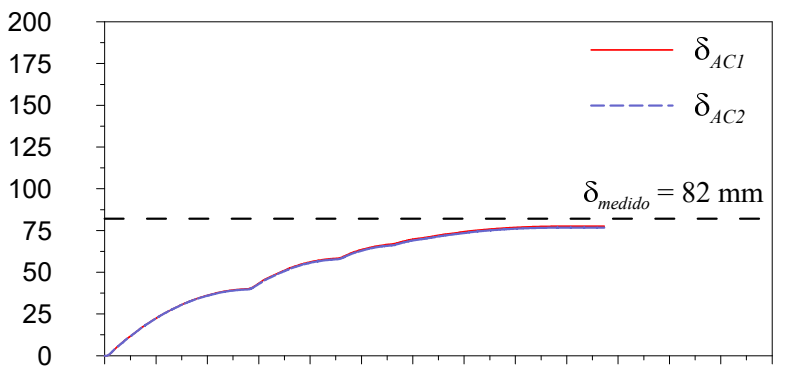

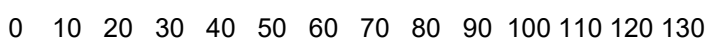
Tempo (ms)

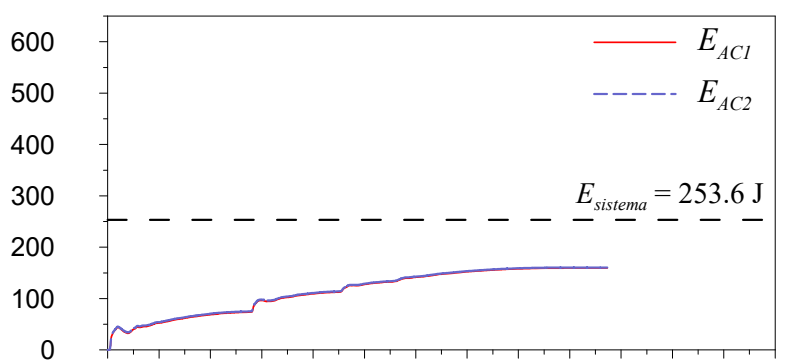

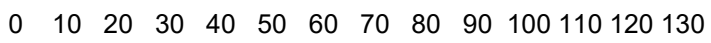
Tempo (ms)

Figura 41 - Sinais típicos de SPT instrumentado para o furo SP01, profundidade de $2 \mathrm{~m}$ e $H_{q}$ de $300 \mathrm{~mm}$. 

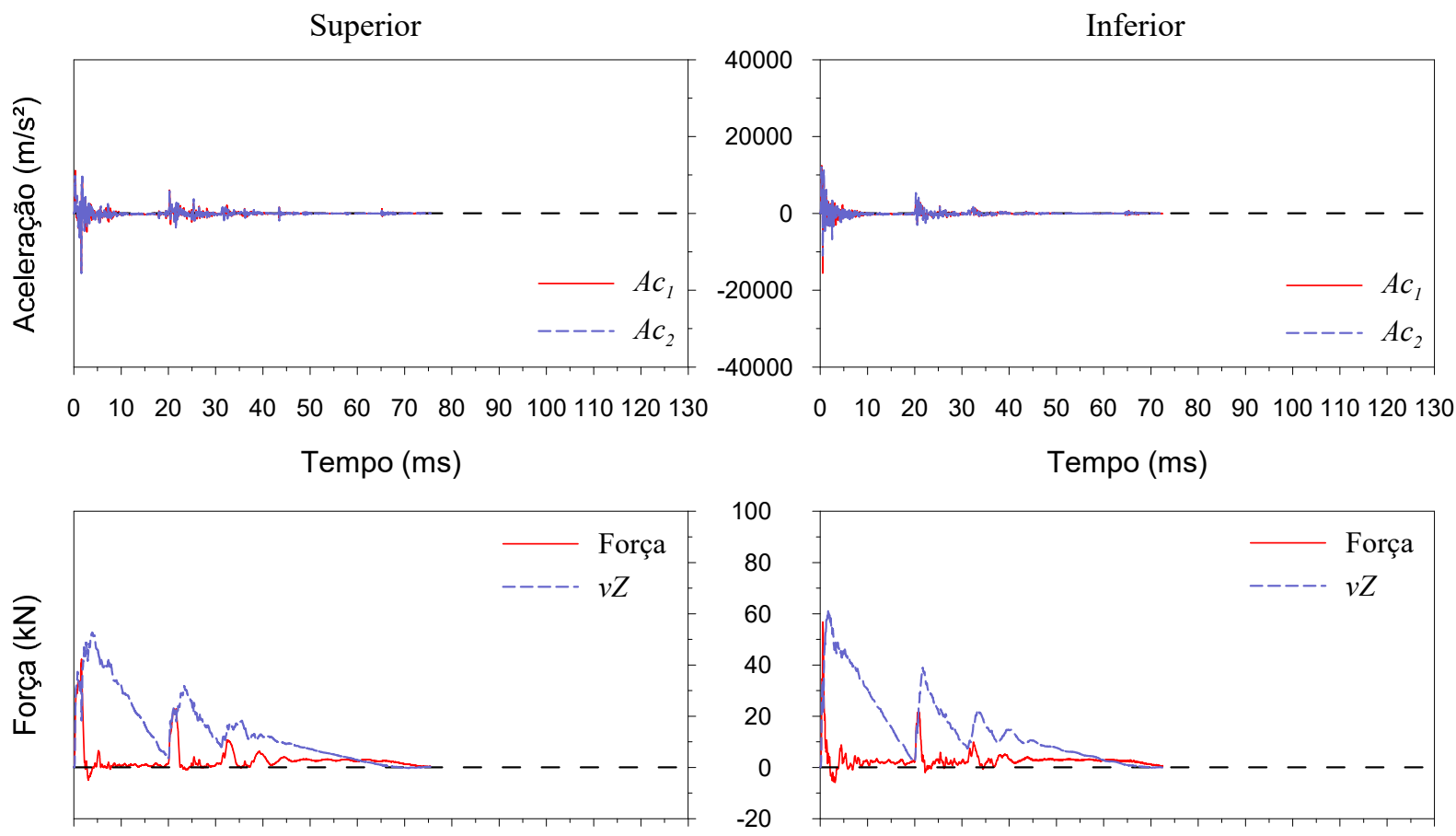

$0 \quad 10 \quad 20 \quad 30 \quad 40 \quad 50 \quad 60 \quad 70 \quad 80 \quad 90 \quad 100110120130$

Tempo (ms)

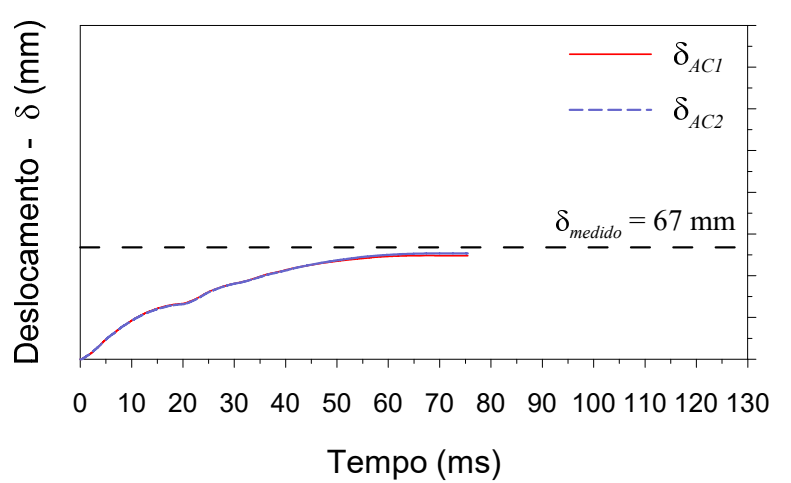

$0 \quad 10 \quad 20 \quad 30 \quad 40 \quad 50 \quad 60 \quad 70 \quad 80 \quad 90 \quad 100110120130$ Tempo (ms)
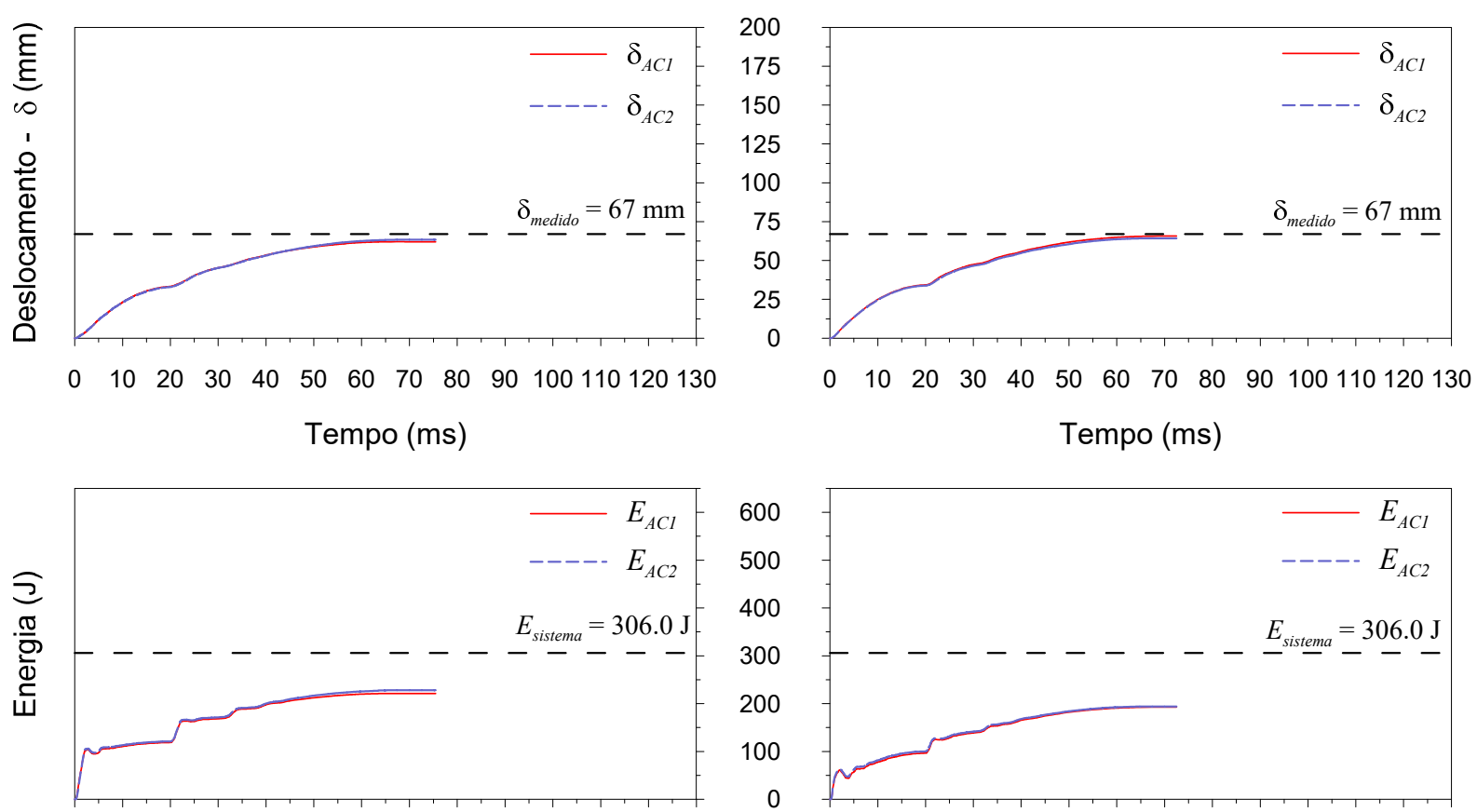

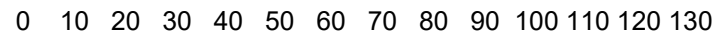

Tempo (ms)

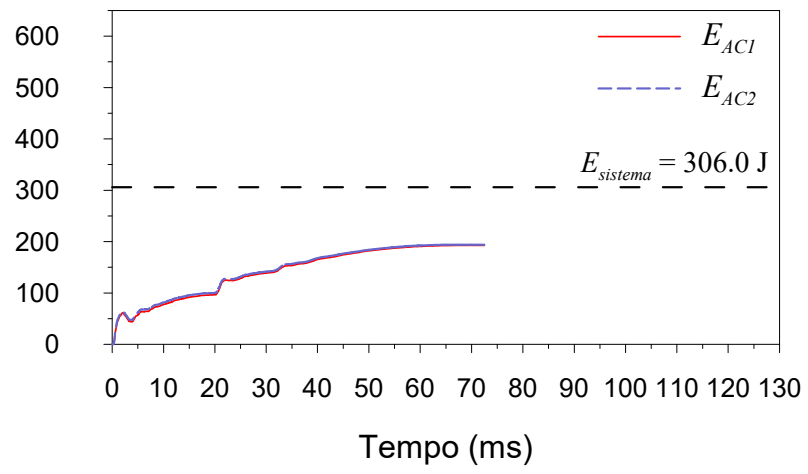

Figura 42 - Sinais típicos de SPT instrumentado para o furo SP01, profundidade de $2 \mathrm{~m}$ e $H_{q}$ de $400 \mathrm{~mm}$. 


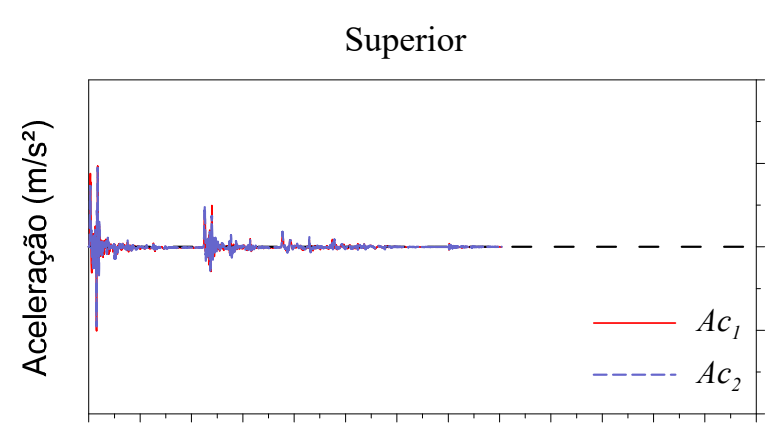

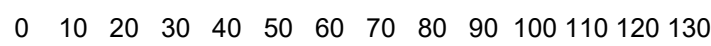

Tempo (ms)

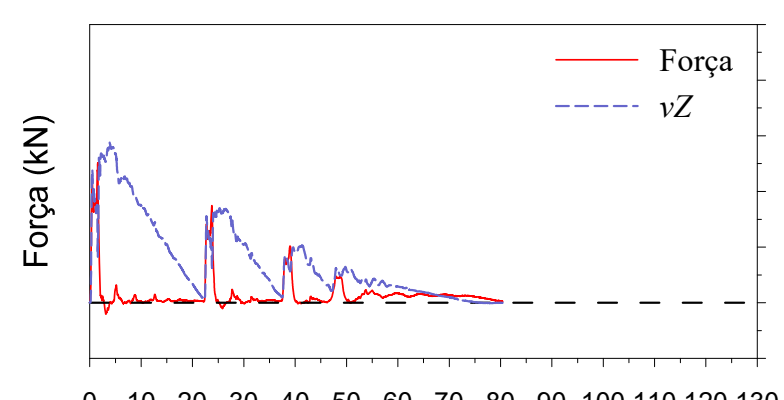

Tempo (ms)

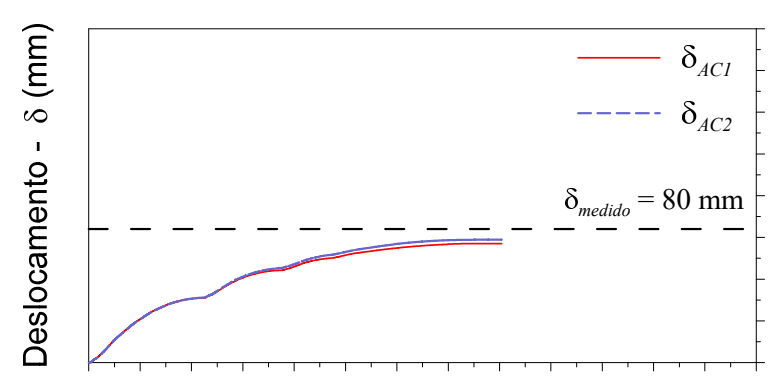

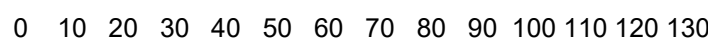

Tempo (ms)

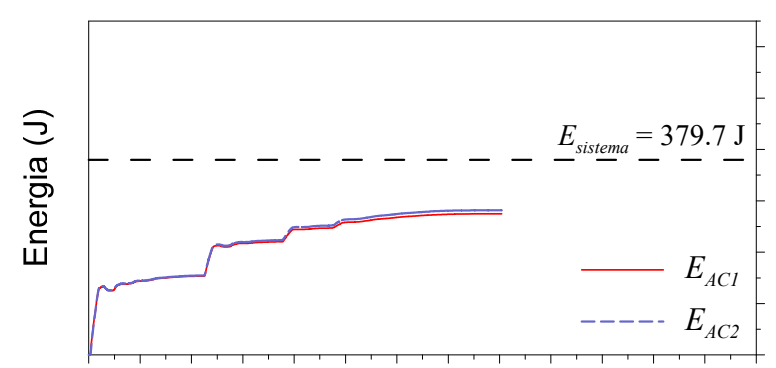

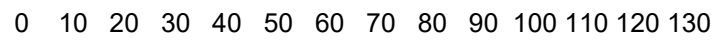

Tempo (ms)

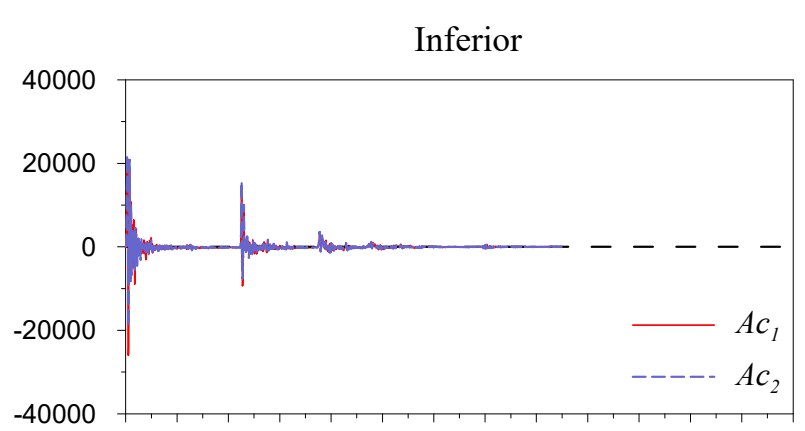

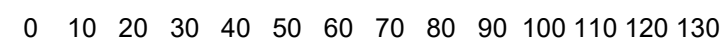

Tempo (ms)

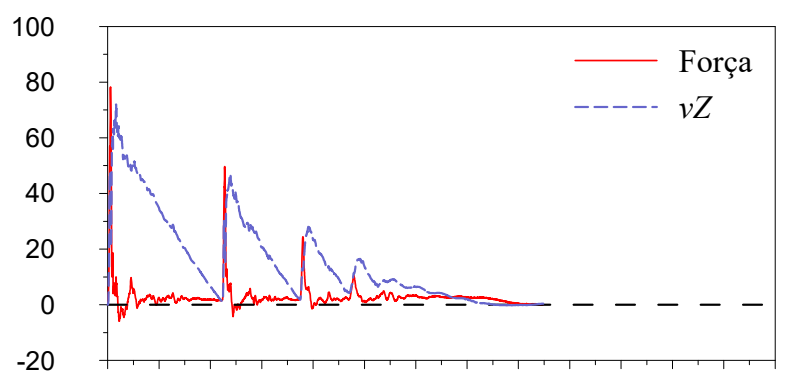

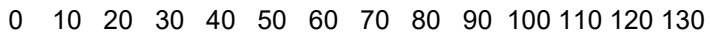
Tempo (ms)

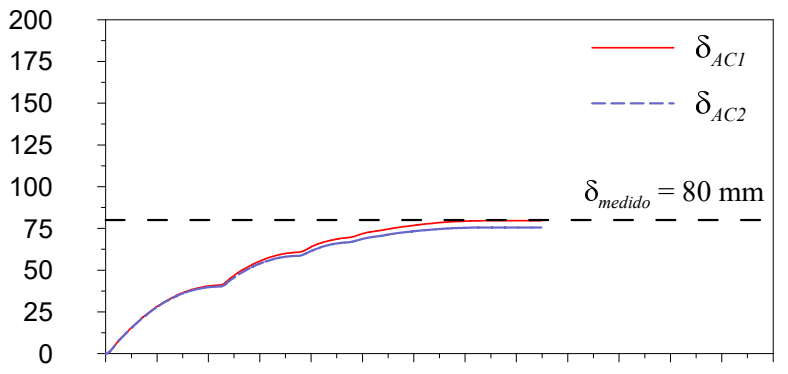

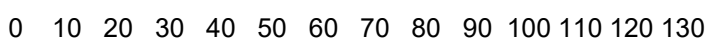
Tempo (ms)

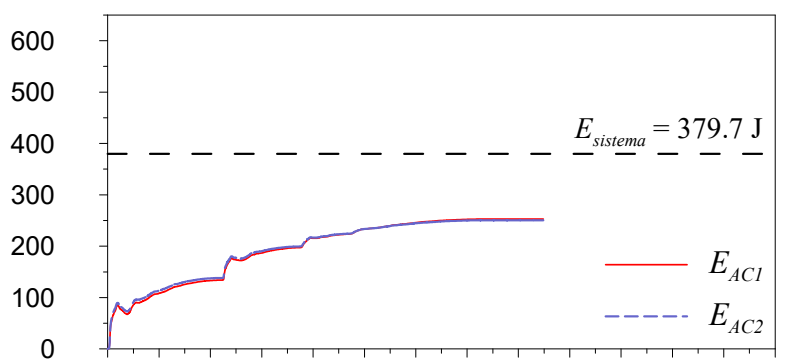

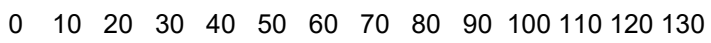
Tempo (ms)

Figura 43 - Sinais típicos de SPT instrumentado para o furo SP01, profundidade de $2 \mathrm{~m}$ e $H_{q}$ de $500 \mathrm{~mm}$. 


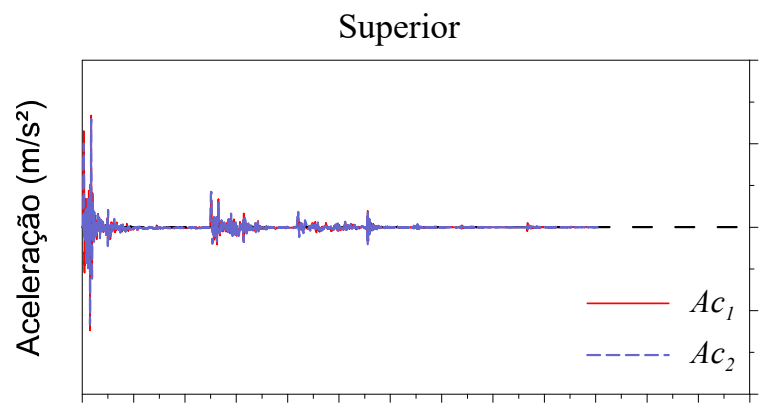

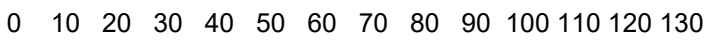

Tempo (ms)

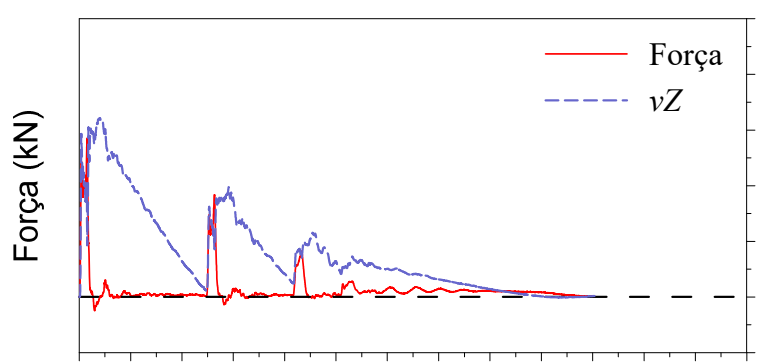

$0 \quad 10 \quad 20 \quad 30 \quad 40 \quad 50 \quad 60 \quad 70 \quad 80 \quad 90 \quad 100110120130$ Tempo (ms)

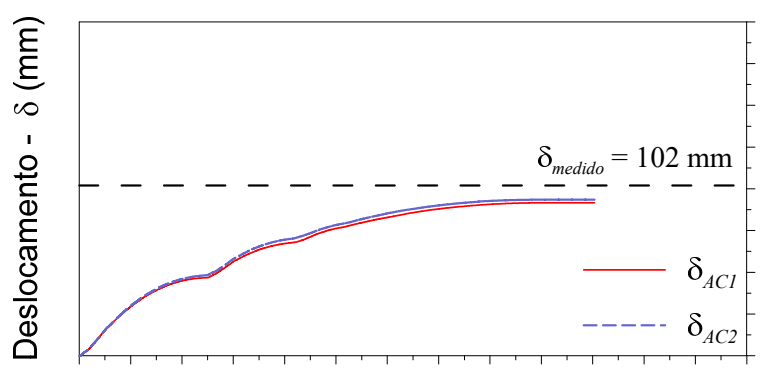

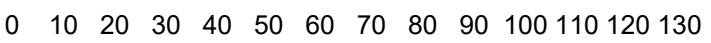
Tempo (ms)

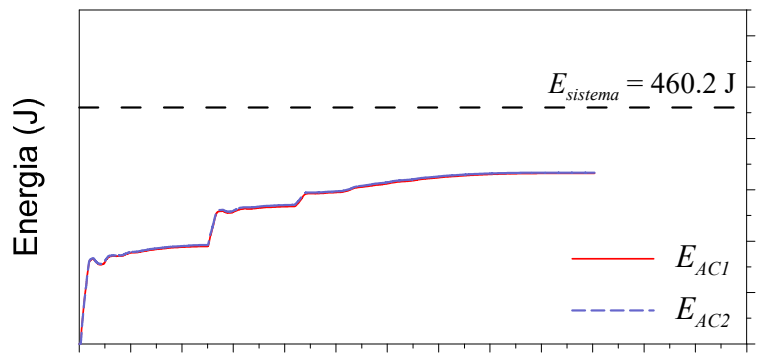

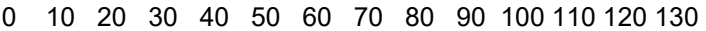
Tempo (ms)
Inferior

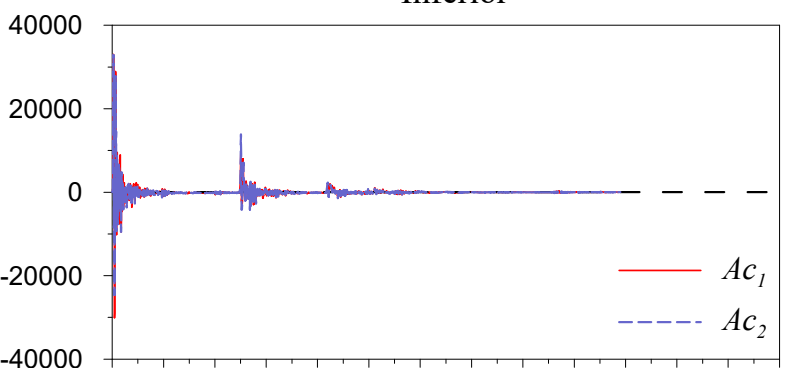

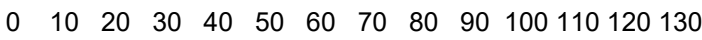

Tempo (ms)

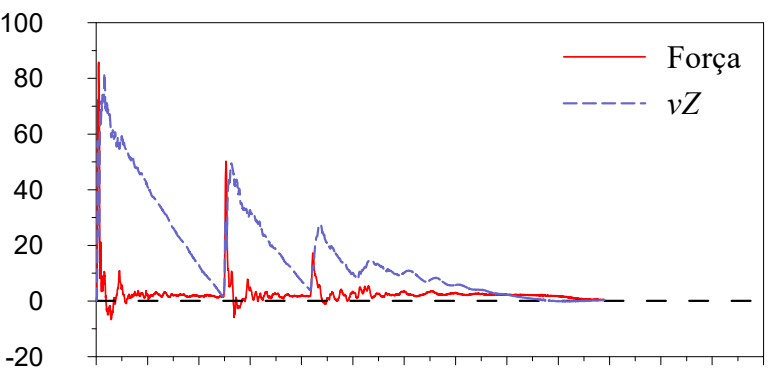

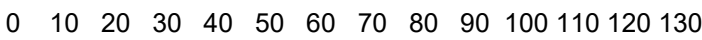
Tempo (ms)

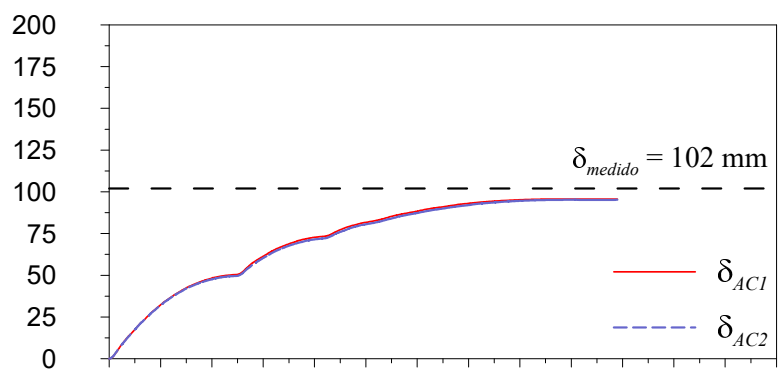

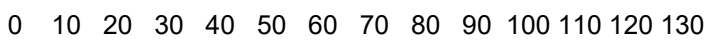
Tempo (ms)

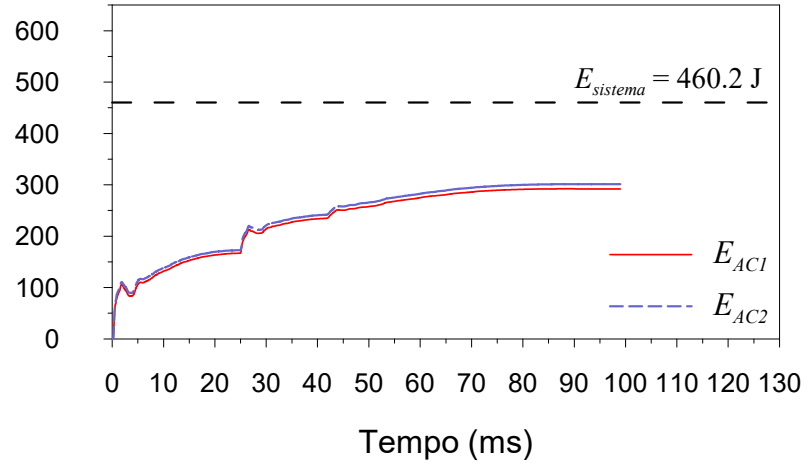

Figura 44 - Sinais típicos de SPT instrumentado para o furo SP01, profundidade de $2 \mathrm{~m}$ e $H_{q}$ de $600 \mathrm{~mm}$. 


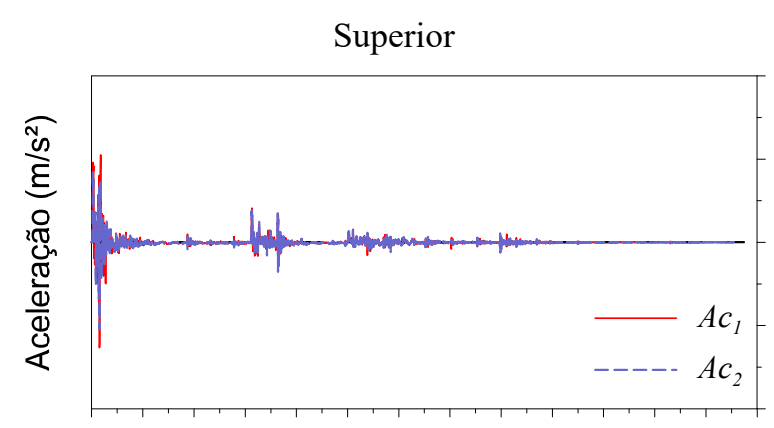

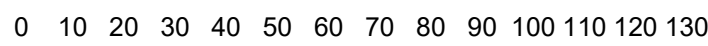

Tempo (ms)

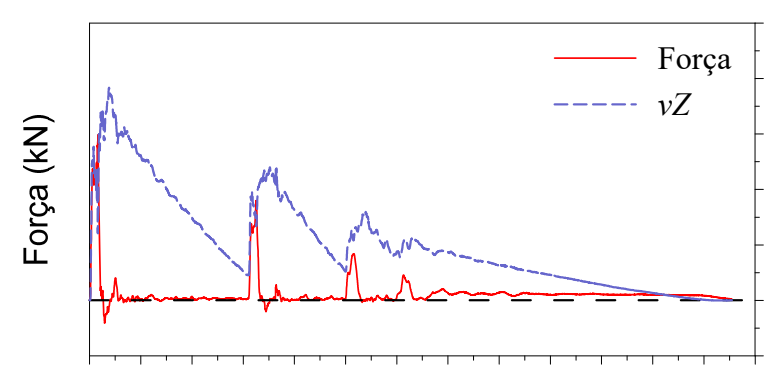

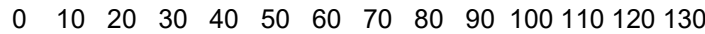

Tempo (ms)

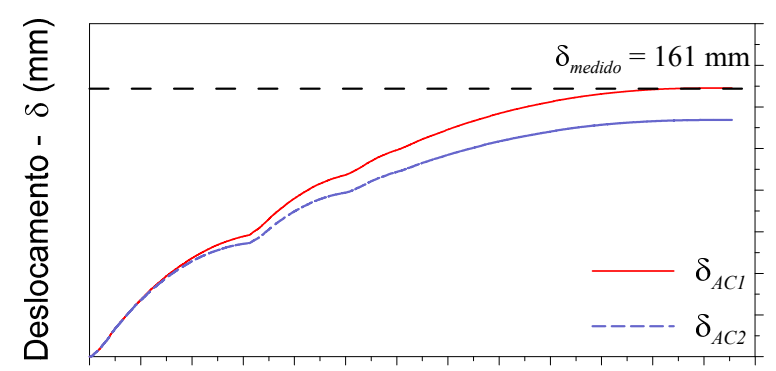

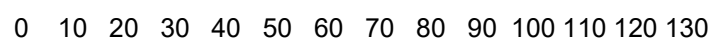

Tempo (ms)

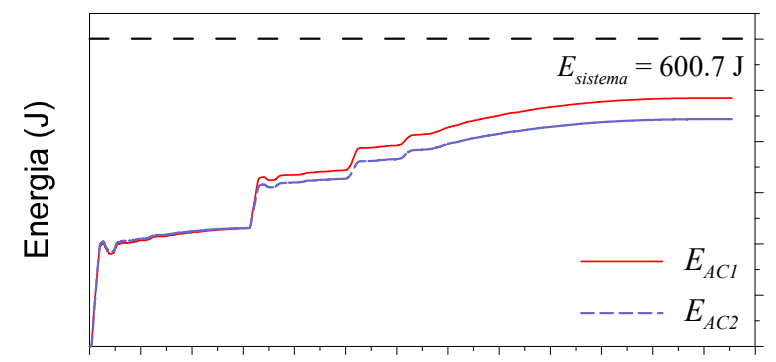

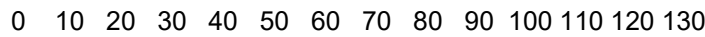

Tempo (ms)
Inferior

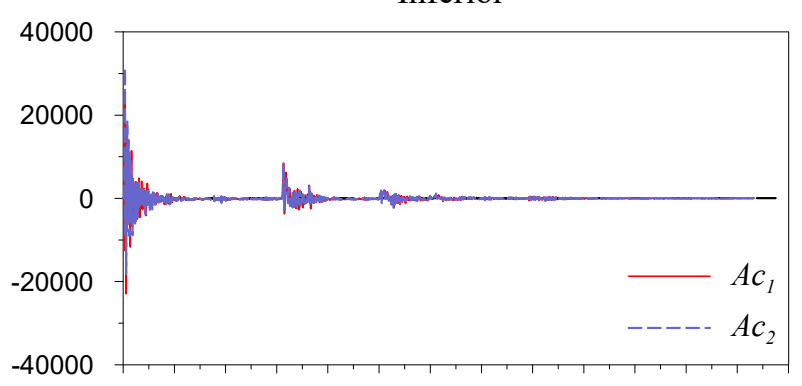

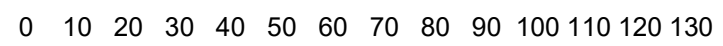

Tempo (ms)

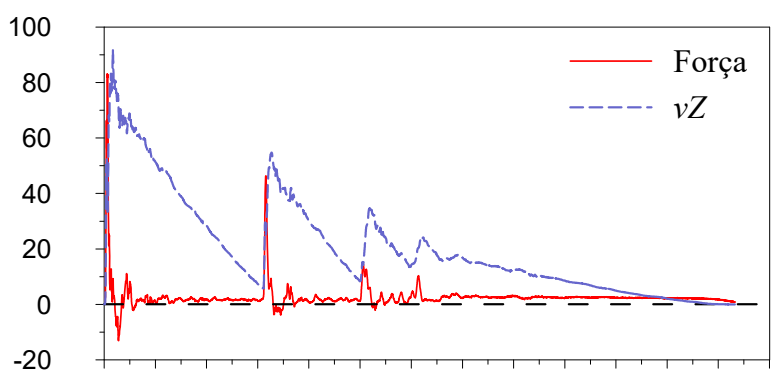

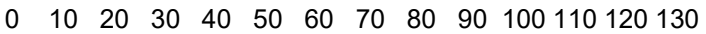
Tempo (ms)

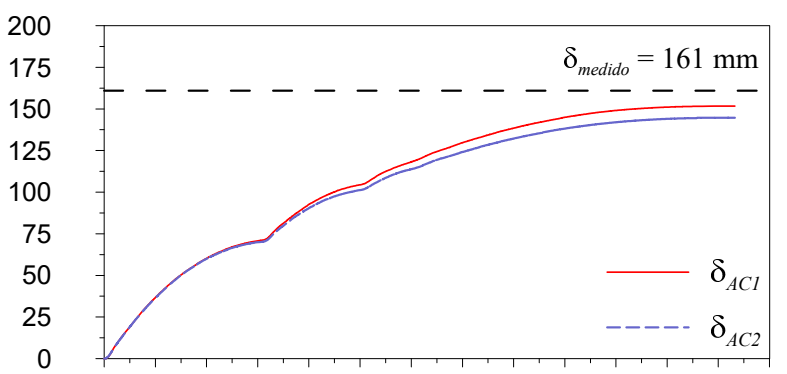

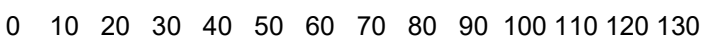
Tempo (ms)

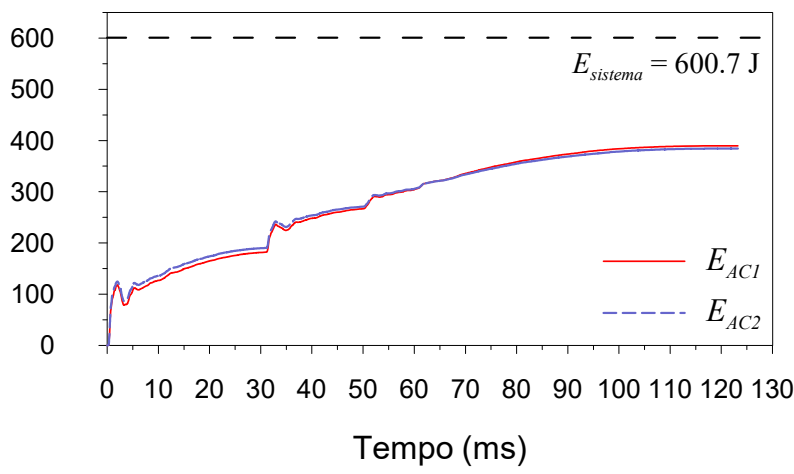

Figura 45 - Sinais típicos de SPT instrumentado para o furo SP01, profundidade de $2 \mathrm{~m}$ e $H_{q}$ de $700 \mathrm{~mm}$. 


\subsubsection{Critérios de seleção dos sinais}

Cada haste instrumentada é provida de dois acelerômetros e uma célula de carga. As análises dos sinais desses sensores resultam em velocidades, deslocamentos e quantidades de energia. Os sinais dos acelerômetros, designados por $A C_{1}$ e $A C_{2}$, resultam nas velocidades $v_{A C l}$ e $v_{A C 2}$, nos deslocamentos $\delta_{A C l}$ e $\delta_{A C 2}$ e nas quantidades de energia $E_{A C l}$ e $E_{A C 2}$.

Uma outra forma de se utilizar os sinais $A C_{1}$ e $A C_{2}$ é através da consideração da média entre eles $\left(A C_{M}\right)$. A partir dessa média são calculados os valores de velocidade $v_{A C M}$, deslocamento $\delta_{A C M}$ e energia $E_{A C M}$. Entretanto, caso tenha ocorrido falha em algum dos acelerômetros, utilizar um valor médio pode resultar em resultados errôneos. Portanto, em vez se de usar os valores médios, foram considerados os sinais correspondentes a apenas um dos acelerômetros, de acordo com os critérios descritos a seguir.

A primeira avaliação feita para determinação de um critério de seleção de sinais foi a comparação entre os deslocamentos $\delta_{A C l}$ e $\delta_{A C 2}$, conforme mostrado na Figura 46.

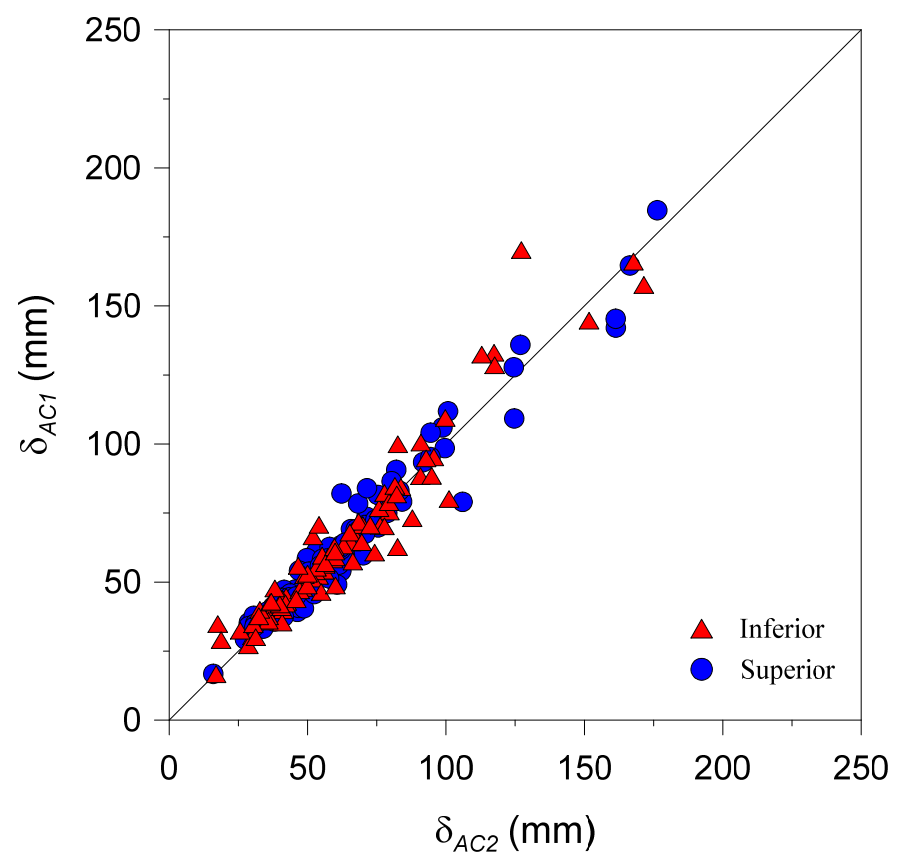

Figura 46 - Comparação entre os deslocamentos calculados.

De uma maneira geral, observa-se que os deslocamentos $\delta_{A C l}$ e $\delta_{A C 2}$ se mostraram muito próximos. Porém, em alguns casos, esses deslocamentos diferem um do outro de forma acentuada, indicando que nesses casos pode ter ocorrido alguma falha em um dos acelerômetros.

Para avaliar os sinais de aceleração $A C_{1}$ e $A C_{2}$, utilizando os deslocamentos medidos em campo como referência, foram calculados os erros relativos entre os deslocamentos finais 
calculados ( $\delta_{A C l}$ e $\left.\delta_{A C 2}\right)$ e os deslocamentos medidos ( $\delta_{\text {medido }}$ ) (Equação 35 ). A partir destes erros, definiu-se que os sinais de acelerações a serem considerados nas análises seriam aqueles que apresentassem menores erros relativos.

$$
\operatorname{Erro}(\%)=\left|\frac{\delta_{\text {medido }}-\delta_{A C}}{\delta_{\text {medido }}}\right| \cdot 100
$$

A Figura 47a apresenta os deslocamentos calculados a partir dos valores médios de aceleração e a Figura 47b apresenta os deslocamentos calculados de acordo com o critério anteriormente mencionado $\left(\delta_{A C}\right)$.
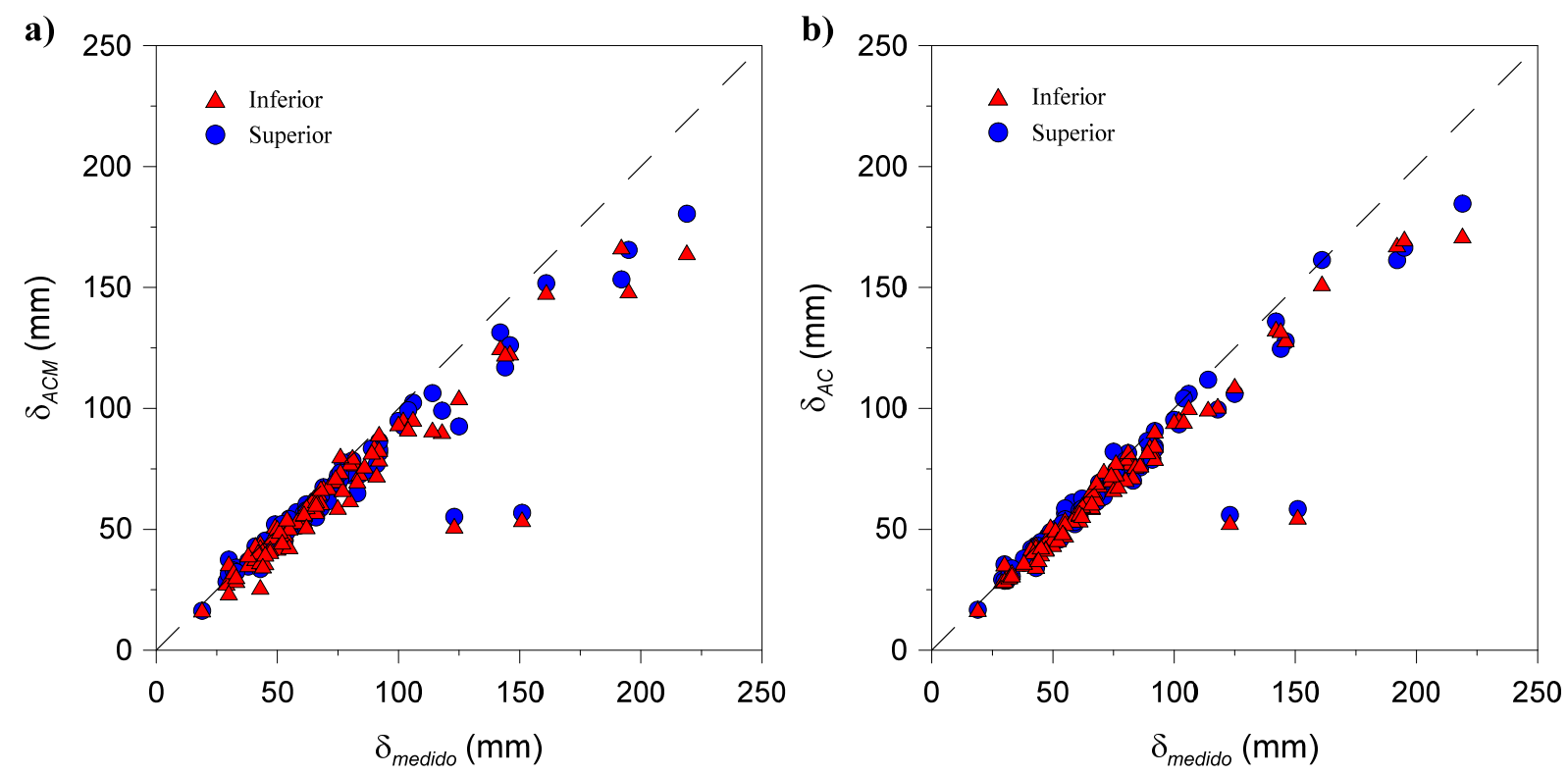

Figura 47 - Comparação entre deslocamentos medidos e deslocamentos calculados: a) deslocamentos calculados médios $\left(\delta_{A C M}\right)$; b) deslocamentos utilizando critério $\left(\delta_{A C}\right)$.

Observa-se que com a aplicação do critério, os deslocamentos medidos e calculados ficaram mais próximos. Porém, mesmo com a aplicação do critério, ainda ocorrem casos nos quais os deslocamentos medidos e os calculados são muito diferentes. Essas diferenças podem ser resultantes, por exemplo, de erros intrínsecos ao processo de integração dos sinais de aceleração, ruídos no sinal mesmo após a aplicação do filtro ou de eventual de erro na inicialização do sistema de aquisição dos dados.

Com os erros relativos entre $\delta_{A C}$ e $\delta_{\text {medido }}$ foi realizada uma análise da magnitude desses erros e de suas frequências (Figura 48). Observa-se que tanto para a haste inferior, quanto para a haste superior, mais de $95 \%$ dos deslocamentos resultaram em erros inferiores a $20 \%$. Dessa forma, como um segundo critério, optou-se por considerar apenas os sinais de aceleração que resultaram em erro relativo de deslocamento inferiores a 20\%. Com a aplicação deste critério, 
dos 178 sinais adquiridos (somando os dados referentes à haste inferior e superior), 172 foram considerados nas análises.
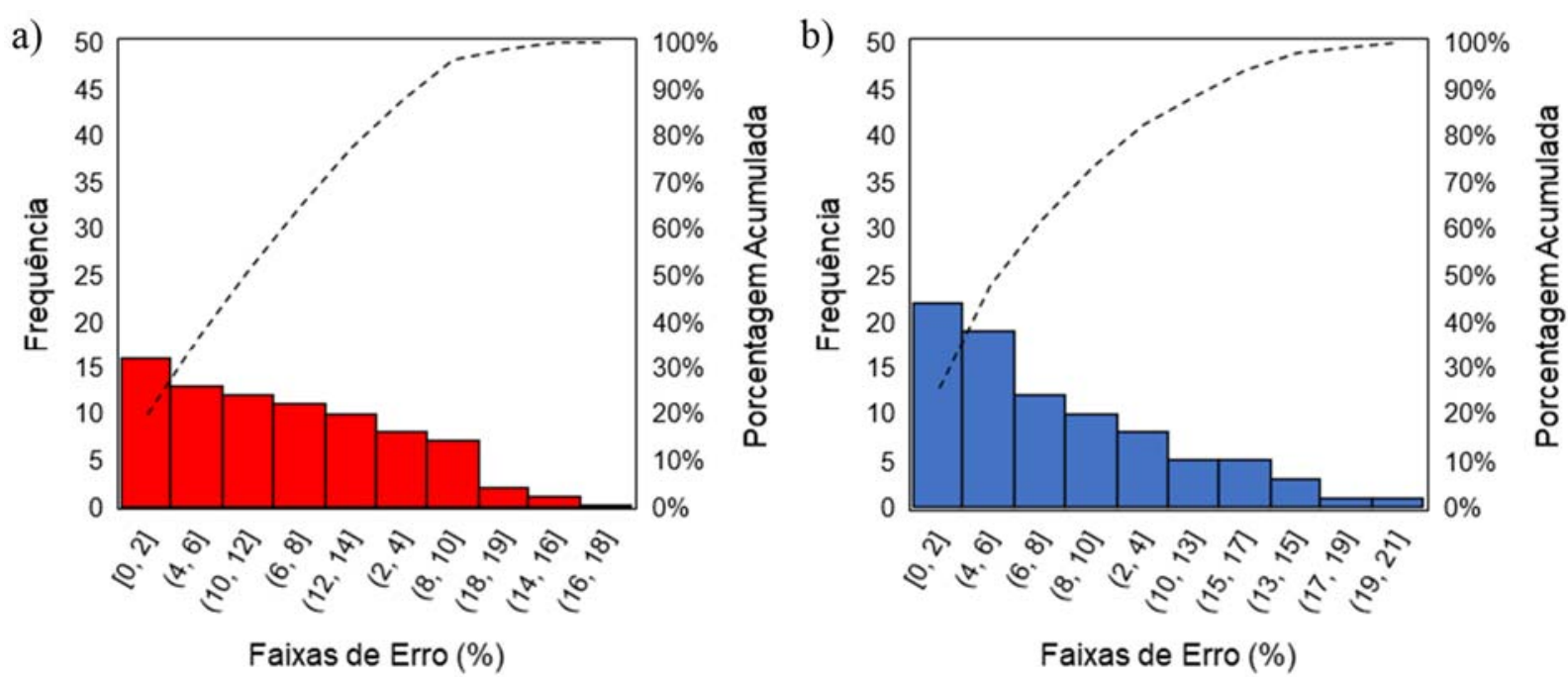

Figura 48 - Frequência dos erros relativos: a) haste inferior; b) haste superior.

A Figura 49 apresenta a relação entre os valores medidos e calculados de deslocamentos, aplicando-se o critério anteriormente mencionado. Observa-se que os pontos mais destoantes foram eliminados da análise. Os valores de deslocamentos e os erros calculados para todos os dados estão em Anexo (Tabelas A1, A2 e A3).

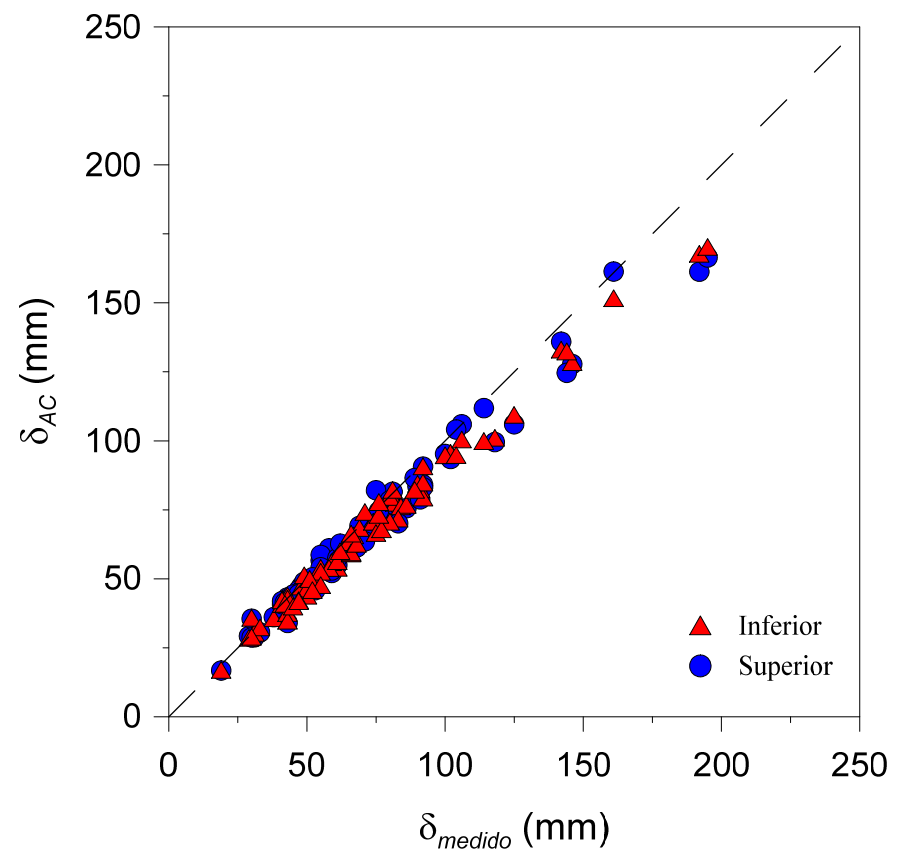

Figura 49 - Comparação entre deslocamentos medidos e deslocamentos calculados com aplicação de critérios. 


\subsubsection{Avaliação da energia}

Para cada golpe do martelo foram calculados os valores da energia no topo $\left(E_{\text {topo }}\right)$ e na base ( $\left.E_{b a s e}\right)$ da composição de hastes, pelo método $E F V$. Também foram calculadas a energia potencial teórica $(E P T)$ e a energia do sistema $\left(E P_{\text {sistema }}\right)$. Um dos principais objetivos de se obter os valores de energia é o cálculo da eficiência do ensaio. A eficiência nos permite determinar o quanto da energia disponível no golpe do martelo atinge as duas seções instrumentadas.

Quando se estuda a eficiência do ensaio SPT é necessário verificar os possíveis fatores que podem interferir nos valores de eficiência. Um dos fatores mais estudados é o comprimento de hastes. Como neste trabalho a penetração do amostrador foi realizada através de golpes do martelo com energias crescentes faz-se necessário verificar, além do comprimento de hastes, se as diferentes alturas de queda do martelo afetam os valores de eficiência.

Neste trabalho as eficiências foram calculadas aplicando-se a correção sugerida por Odebrecht (2003) para cálculo da energia do sistema (EP sistema). Assim, para a eficiência no topo, foi calculada a razão entre energia no topo $\left(E_{\text {topo }}\right)$ e a energia do sistema $\left(E P_{\text {sistema }}\right)$. Para a eficiência na base, foi calculada a razão entre energia na base $\left(E_{\text {base }}\right)$ e a energia do sistema $\left(E P_{\text {sistema}}\right)$. Para comparação, as eficiências também foram calculadas em relação à energia potencial teórica $(E P T)$. Os valores de energia e eficiência para todos os casos se encontram no Anexo (Tabelas A4, A5 e A6).

\subsubsection{Influência do peso do sistema}

As energias no topo e na base foram calculadas de duas maneiras. Pela primeira maneira, as energias $E_{\text {basel }}$ e $E_{\text {topol }}$ foram calculadas utilizando os dados de força como adquirido pela instrumentação, ou seja, sem acrescentar o peso da composição do sistema. Pela segunda maneira, as energias $E_{b a s e 2}$ e $E_{\text {topo } 2}$ foram calculadas acrescentando-se ao sinal de força o peso da composição do sistema. No caso do topo o peso é referente apenas à cabeça de bater. A Figura 50 apresenta a relação dessas energias com as alturas de queda para o ensaio realizado na profundidade de $6 \mathrm{~m}$ do furo SP01. 


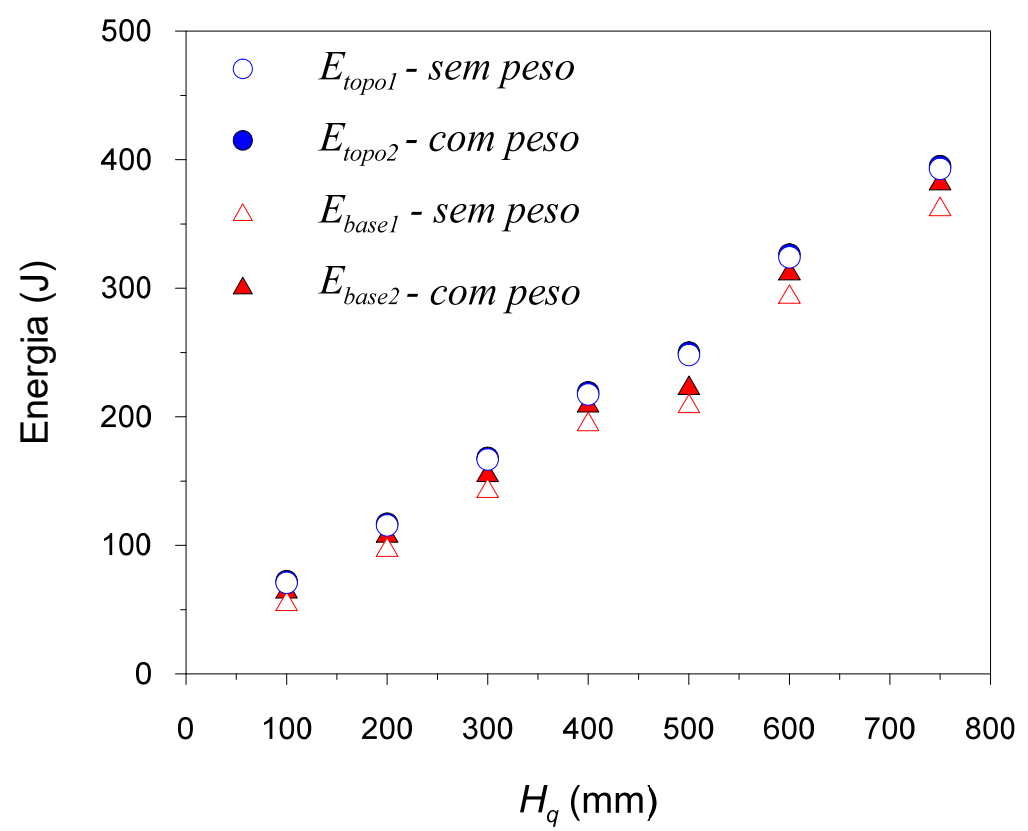

Figura 50 - Análise da consideração do peso do sistema no cálculo da energia para o ensaio realizado na profundidade de $6 \mathrm{~m}$ do furo SP01

Também se verifica que para baixas energias, considerando o peso do sistema, a energia da base pode se igualar à energia do topo ou até superá-la. Isto significa que em alguns casos, o acréscimo de energia devido ao peso do sistema pode superar a perda de energia envolvida no ensaio.

Avaliando a energia em si, o acréscimo de energia devido ao peso do sistema não parece ser muito relevante. Porém, como o principal objetivo da avaliação da energia é o cálculo da eficiência, é importante verificar se a consideração ou não do peso do sistema no cálculo de energia afeta os valores de eficiência. A Figura 51 apresenta os valores de eficiência no topo e na base sem considerar ( $\eta_{\text {topol }}$ e $\left.\eta_{\text {base }}\right)$ e considerando $\left(\eta_{\text {topo } 2}\right.$ e $\left.\eta_{\text {base } 2}\right)$ o peso do sistema na energia em relação com a altura de queda. Os gráficos para os demais dados encontram-se em Anexo (Figuras A91, A92 e A93).

O acréscimo de energia devido ao peso do sistema para a eficiência no topo não é significativo. Porém, para a base, observa-se um acréscimo considerável nos valores de eficiência quando considerados os pesos do sistema. Além disso, como já observado na Figura 51, o acréscimo de energia na base devido ao peso do sistema pode resultar em valores de energias próximos aos verificados no topo. Assim, em alguns pontos a eficiência de topo e base são bastante próximas (Figura 51b,c, d). 

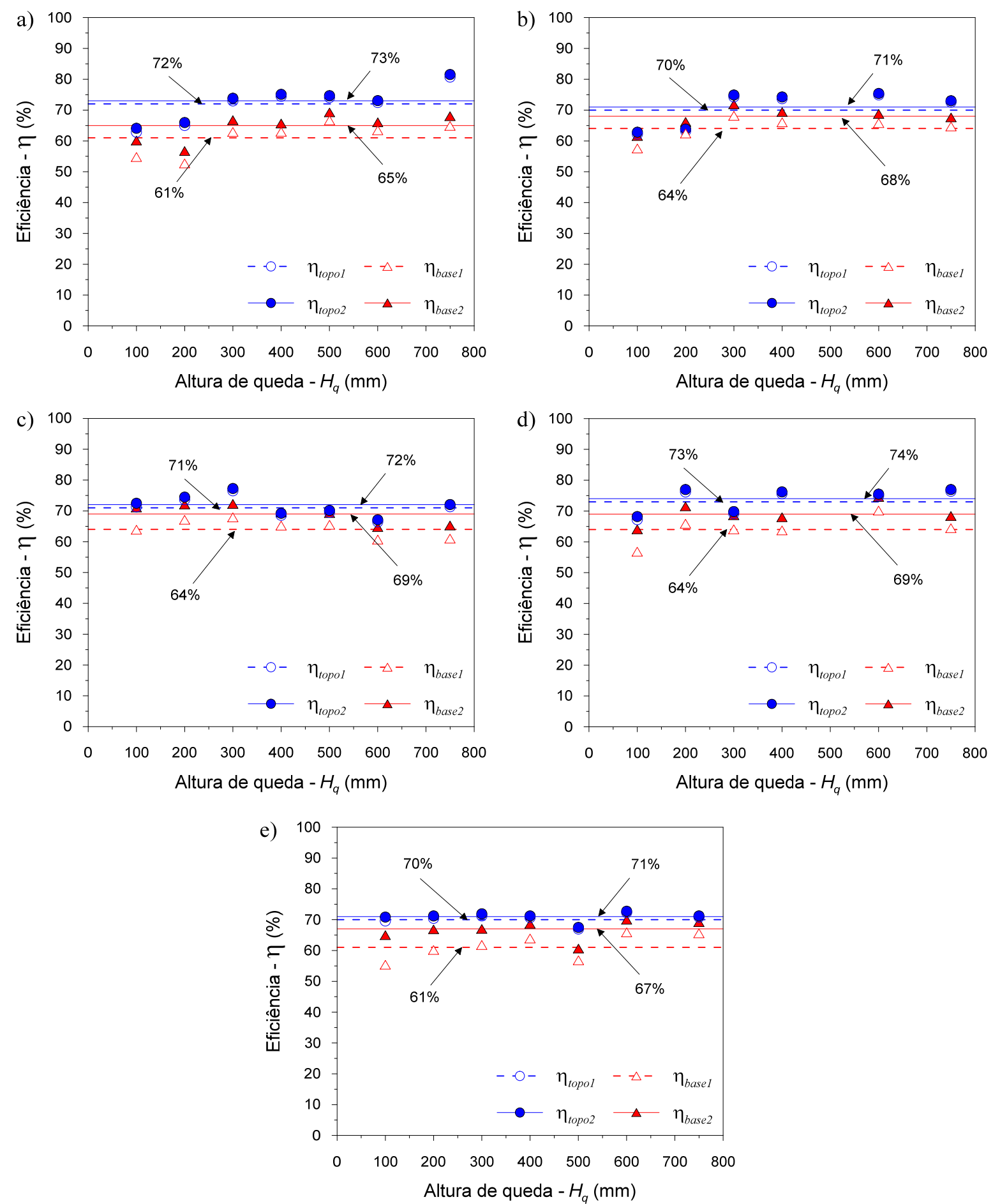

Figura 51 - Avaliação da influência do peso do sistema nos valores de eficiência no topo e na base para os ensaios do SP01 e profundidades: a) 2 metros; b) 3 metros; c) 4 metros; d) 5 metros; e) 6 metros.

A Figura 52 apresenta o erro relativo calculado para eficiência no topo e na base considerando ou não o peso do sistema. Os erros para as eficiências do topo e da base foram calculados a partir da Equação 36.

$$
\operatorname{Erro}(\%)=\left|\frac{\eta_{(\text {topo/base }) 1}-\eta_{(\text {topo/base }) 2}}{\eta_{(\text {topo } / \text { base }) 1}}\right| \cdot 100
$$



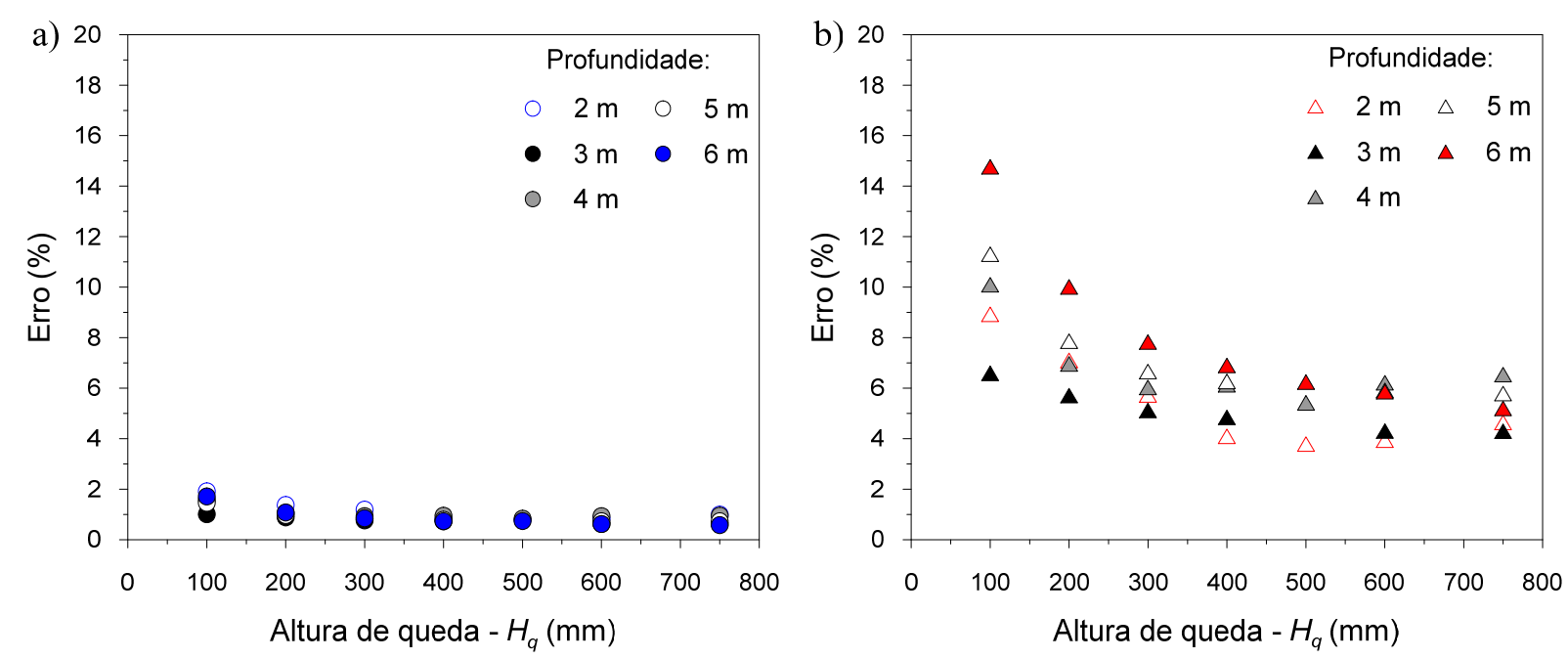

Figura 52 - Erro relativo entre as eficiências considerando o peso do sistema e sem considerar: a) topo; b) base. SP01, todas as profundidades.

A Figura 52 mostra novamente que a consideração do peso do sistema no topo é desnecessária. Entre os ensaios realizados o valor máximo de erro calculado entre as eficiências no topo foi próximo à $2 \%$. Porém, na base, a consideração do peso do sistema aumenta significativamente os valores de eficiência. Para baixas energias ou menores alturas de queda do martelo, o acréscimo do erro é ainda mais acentuado, chegando a erros relativos próximos à $15 \%$.

A influência do peso do sistema na eficiência parece depender do comprimento de hastes. Para a profundidade de $6 \mathrm{~m}$, que corresponde ao maior comprimento de haste utilizado nessa pesquisa, ocorre o maior erro relativo. Para os demais ensaios realizados, verificou-se que os comportamentos são similares (Figuras A94, A95 e A96).

Observa-se que a influência do peso do sistema no cálculo de energia parece ser mais significativa quando se trata de baixas energias. Quanto maior a energia aplicada, menor a influência do peso do sistema (Figura 52). Porém, mesmo para maiores alturas de queda do martelo, o menor erro relativo calculado entre as energias da base foi de aproximadamente $4 \%$. Portanto, nas análises apresentadas a seguir foram utilizadas as energias e as eficiências calculadas considerando o peso do sistema.

\subsubsection{Eficiência versus altura de queda}

De acordo com a Figura 51, os valores de eficiência são praticamente constantes em relação às alturas de queda do martelo. A Figura 53 apresenta a eficiência calculada em relação à energia potencial teórica ou energia nominal $\left(E P_{T}\right)$. Os gráficos para os demais ensaios encontram-se no Anexo (Figuras A97, A98 e A99) 

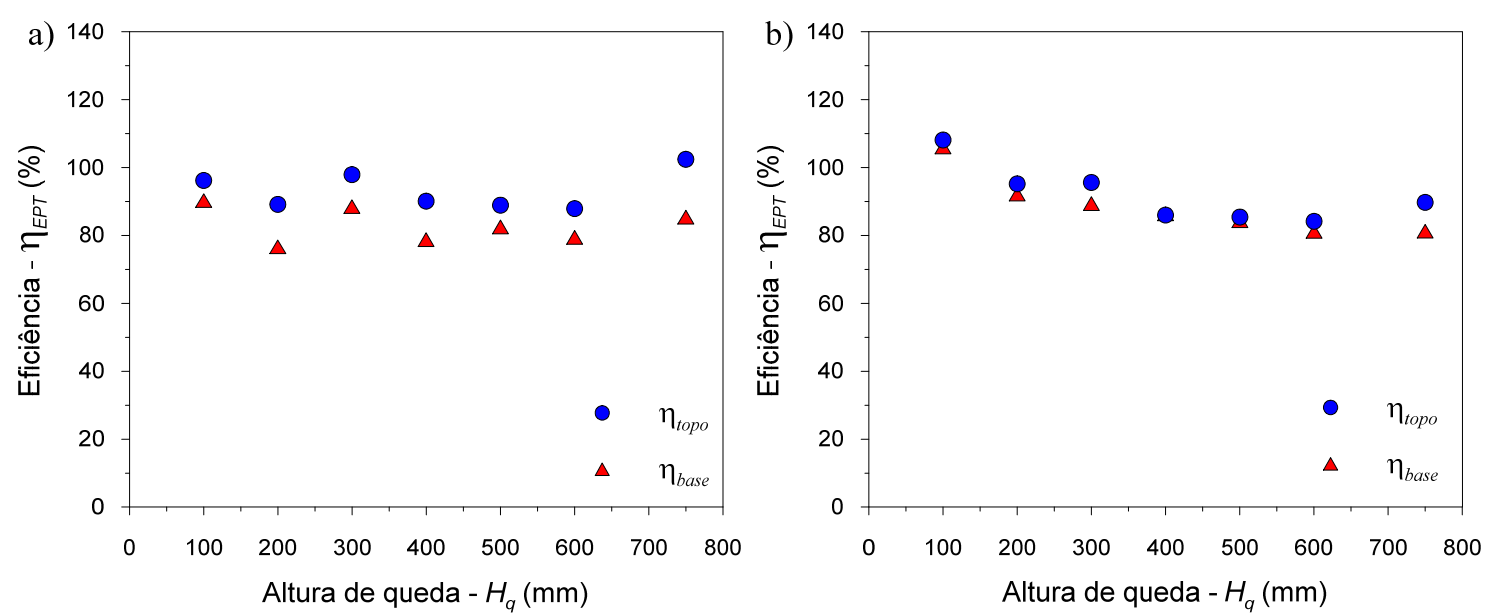

Figura 53 - Eficiência calculada em relação à $E P_{T}$ versus altura de queda para SP01 e profundidades: a) 2 metros; b) 4 metros.

Analisando a Figura 53a os valores de eficiência parecem variar em torno de um valor médio. Já pela Figura 53b, a eficiência parece diminuir com o acréscimo de altura de queda do martelo. Este último comportamento foi o mais verificado entre os ensaios realizados (Anexo). Observa-se que, se calculadas em relação à energia nominal $(E P T)$, as eficiências atingem valores próximos ou maiores do que 100\%. Isso ocorre devido à baixa resistência do solo, que permite grandes deslocamentos. Assim, o acréscimo de energia devido ao deslocamento chega a superar a perda de energia envolvida no evento.

Esses resultados diferem do observado por Youd et al. (2008), onde seus resultados mostraram que quanto maior a altura de queda, maior a eficiência do ensaio. Entretanto, conforme observado por Schnaid et al. (2009b), esses autores não levaram em consideração o acréscimo de energia potencial devido ao deslocamento, ou seja, a eficiência foi calculada em relação à energia nominal $(E P T)$. Porém, independente da altura de queda aplicada, as eficiências analisadas por Youd et al. (2008) foram calculadas como a relação entre a energia que atinge a seção instrumentada e a energia nominal $\left(E P P_{T}\right)$ correspondente à a altura de queda do martelo igual a 30" (762 $\mathrm{mm})$. Os autores variaram a altura de queda do martelo e consequentemente variaram a quantidade de energia aplicada, mas nos cálculos de eficiência, não variaram a energia de referência. Os autores denominaram essa eficiência como $E R 30$.

\subsubsection{Energia versus altura de queda}

A pouca variação nos valores de eficiência em relação às alturas de queda apresentada na Figura 51 também pode ser verificada quando se analisa a relação entre energias e alturas de queda do martelo $\left(H_{q}\right)$. Figura 54 mostra, além das energias na base $\left(E_{\text {base }}\right)$ e no topo $\left(E_{t o p o}\right)$, as 
energias potenciais do sistema $\left(E P_{\text {sistema }}\right)$ e as energias potenciais teóricas $\left(E P_{T}\right)$ em função da altura de queda do martelo.
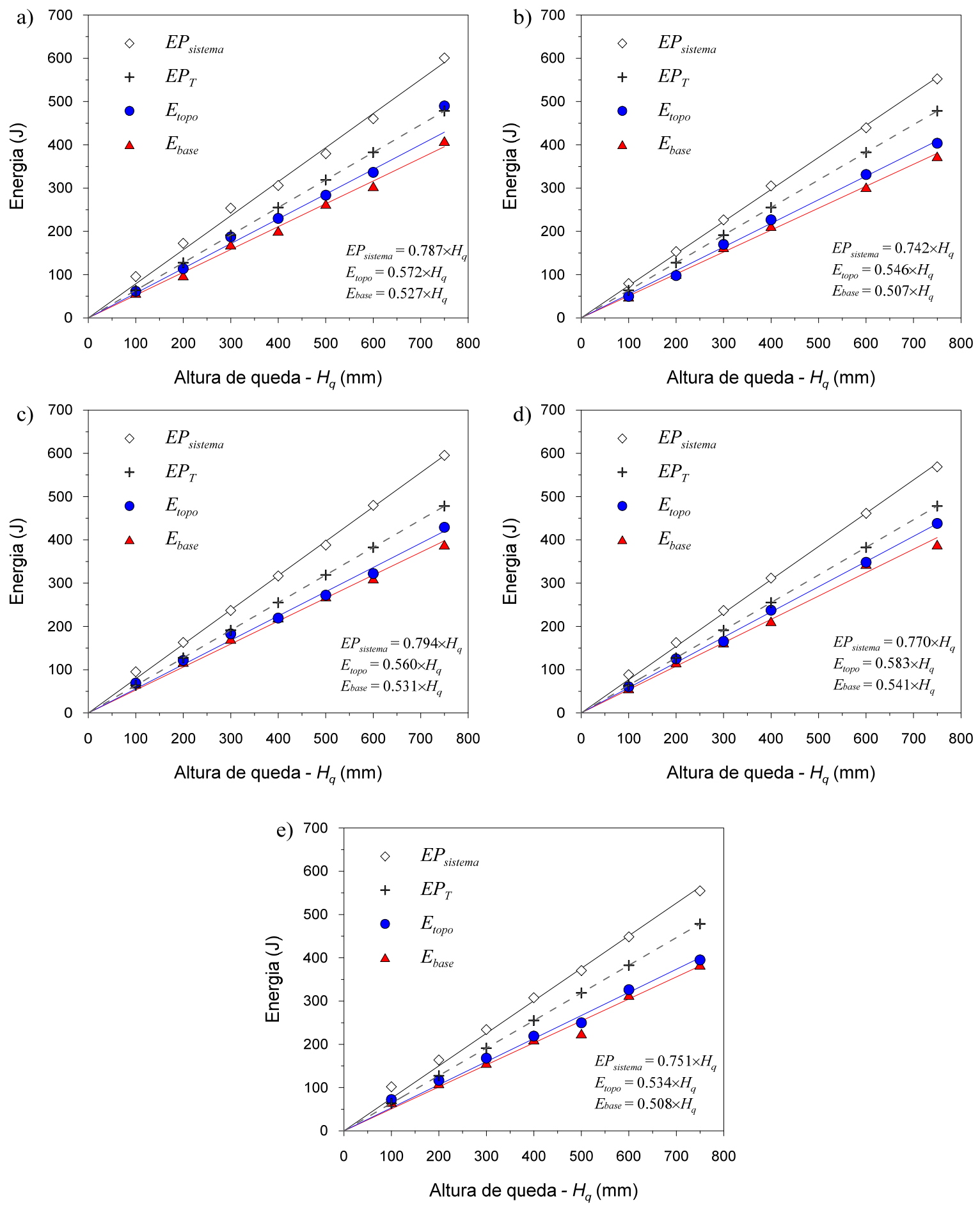

Figura 54 - Relação entre as energias envolvidas no ensaio e as alturas de queda do martelo aplicadas para o furo SP01 e profundidades: a) 2 metros; b) 3 metros; c) 4 metros; d) 5 metros; e) 6 metros.

Observa-se que a altura de queda do martelo e as energias envolvidas no ensaio apresentam uma relação linear, tal que o acréscimo de altura de queda provoca um acréscimo proporcional nos valores da energia. Pelos pontos mostrados na Figura 54 foram ajustadas retas que passam 
pela origem (Equações 37 a 39), pois para uma altura de queda nula, a energia também deverá ser nula.

$$
\begin{aligned}
& E P_{\text {sistema }}=a \times H_{q} \\
& E_{\text {topo }}=b \times H_{q} \\
& E_{\text {base }}=c \times H_{q}
\end{aligned}
$$

onde, $a, b$ e $c$ são os coeficientes angulares das retas de ajuste de $E P_{\text {sistema, }}$ Etopo e Ebase, respectivamente. Esse ajuste se mostrou adequado para a maioria dos ensaios realizados.

Considerando as Equações 37 a 39, as expressões para a eficiência podem ser reescritas:

$$
\begin{aligned}
& \eta_{\text {topo }}=\frac{E_{\text {topo }}}{E_{\text {sistema }}}=\frac{b \times H_{q}}{a \times H_{q}}=\frac{b}{a} \\
& \eta_{\text {base }}=\frac{E_{\text {base }}}{E_{\text {sistema }}}=\frac{c \times H_{q}}{a \times H_{q}}=\frac{c}{a}
\end{aligned}
$$

A Tabela 6 apresenta os valores de eficiência para cada profundidade, calculados de

\begin{tabular}{|c|c|c|c|c|c|c|c|c|c|c|}
\hline \multirow[b]{2}{*}{ ENSAIO } & \multirow{2}{*}{$\begin{array}{c}\text { Prof. } \\
\text { (m) }\end{array}$} & \multirow{2}{*}{$\begin{array}{l}L_{h} \\
(\mathbf{m})\end{array}$} & \multirow{2}{*}{$\begin{array}{c}\delta_{\text {acumulado }} \\
(\mathbf{m m})\end{array}$} & \multicolumn{2}{|c|}{ Média } & \multicolumn{5}{|c|}{ Ajuste } \\
\hline & & & & $\begin{array}{l}\eta_{\text {topo }} \\
(\%)\end{array}$ & $\begin{array}{l}\eta_{\text {base }} \\
(\%)\end{array}$ & $a$ & $b$ & $c$ & $\begin{array}{l}\eta_{\text {topo }} \\
(\%)\end{array}$ & $\begin{array}{l}\eta_{\text {base }} \\
(\%)\end{array}$ \\
\hline \multirow{5}{*}{ SP01 } & 2 & 2.7 & 593 & 73 & 65 & 0.787 & 0.572 & 0.528 & 73 & 67 \\
\hline & 3 & 4.7 & 373 & 71 & 68 & 0.742 & 0.546 & 0.507 & 74 & 68 \\
\hline & 4 & 4.7 & 555 & 72 & 69 & 0.794 & 0.560 & 0.531 & 71 & 67 \\
\hline & 5 & 5.7 & 464 & 74 & 69 & 0.770 & 0.583 & 0.541 & 76 & 70 \\
\hline & 6 & 6.7 & 409 & 71 & 67 & 0.751 & 0.534 & 0.508 & 71 & 68 \\
\hline
\end{tabular}
duas maneiras: a primeira pela média entre as eficiências de cada golpe e a segunda a partir das equações de ajuste (Equações 40 e 41).

Tabela 6 - Eficiência calculada de forma convencional e pelos coeficientes angulares das retas, correspondentes ao furo SP01

Os valores de eficiência calculados pelas duas formas são muito próximos. Além disso, observa-se que os valores dos coeficientes angulares das retas também são muito próximos para as diferentes profundidades. Entretanto, para alguns ensaios, os valores de coeficientes angulares são muito superiores quando comparados aos demais (Tabela 7). Os gráficos e as tabelas referentes aos demais ensaios encontram-se no Anexo (Figuras A101 a A103 e Tabela A7). 
Tabela 7 - Eficiências calculadas de forma convencional e pelos coeficientes angulares das retas para casos específicos

\begin{tabular}{|c|c|c|c|c|c|c|c|c|c|c|}
\hline \multirow[b]{2}{*}{ ENSAIO } & \multirow[b]{2}{*}{$\begin{array}{c}\text { Prof. } \\
\text { (m) }\end{array}$} & \multirow[b]{2}{*}{$L_{h}(\mathbf{m})$} & \multirow{2}{*}{$\begin{array}{c}\delta_{\text {acumulado }} \\
\text { (mm) }\end{array}$} & \multicolumn{2}{|c|}{ Média } & \multicolumn{5}{|c|}{ Ajuste } \\
\hline & & & & $\begin{array}{l}\eta_{\text {topo }} \\
(\%)\end{array}$ & $\begin{array}{l}\eta_{\text {base }} \\
(\%)\end{array}$ & $a$ & $b$ & $c$ & $\begin{array}{l}\boldsymbol{\eta}_{\text {topo }} \\
(\%)\end{array}$ & $\begin{array}{l}\eta_{\text {base }} \\
(\%)\end{array}$ \\
\hline SP02 & 2 & 2.7 & 594 & 73 & 72 & 0.932 & 0.657 & 0.659 & 71 & 71 \\
\hline SP03 & 2 & 2.7 & 608 & 76 & 70 & 0.944 & 0.663 & 0.655 & 70 & 69 \\
\hline
\end{tabular}

Nos casos apresentados na Tabela 7, para a profundidade de $2 \mathrm{~m}$ do furo SP02 não foi aplicado o golpe com $750 \mathrm{~mm}$ de altura de queda e para a profundidade de $2 \mathrm{~m}$ do furo SP03, não foram aplicados os golpes com $600 \mathrm{~mm}$ e $750 \mathrm{~mm}$ de altura de queda. Esses golpes não foram aplicados pelo fato de que as penetrações já haviam atingido valores superiores à $450 \mathrm{~mm}$. Isto significa que se todos os golpes tivessem sido aplicados, os deslocamentos totais acumulados seriam muito superiores aos encontrados nos demais ensaios. Pelo valor do deslocamento, observa-se que nestas profundidades, o solo é menos resistente que nas demais. Assim, fica aparente que os coeficientes angulares das retas têm uma relação com a resistência do solo. Isto também pode ser verificado quando são analisados os ensaios que tiveram os menores valores de deslocamentos, pois estes resultaram nos menores valores de coeficientes angulares. Porém, observa-se que, mesmo com os elevados valores dos coeficientes, os valores de eficiências ficam próximos dos demais.

\subsubsection{Estimativa de erros na altura de queda do martelo}

A elevação incorreta do martelo é algo que afeta diretamente a eficiência nos ensaios SPT convencionais. Mesmo havendo marcações nas hastes, sabe-se que a altura de queda nominal do martelo $\left(H_{q n}\right)$ nem sempre é respeitada. Além disso, se o martelo não for solto livremente, a quantidade de energia fornecida ao ensaio também será diretamente afetada. Alguns estudos mostram que no ensaio convencional a altura aplicada é geralmente maior do que a altura nominal (Cavalcante et al., 2011).

Se for considerado que os ajustes das curvas de $E P_{\text {sistema }}$ representem as energias corretas que deveriam ter sido aplicadas e que qualquer variação nessa energia tenha sido devido à elevação incorreta do martelo, pode-se estimar qual a foi a altura de queda realmente aplicada ao golpe $\left(H_{q e}\right)$ (Tabela 8$)$. Os valores apresentados correspondem a ensaios em duas profundidades do furo SP01. Os valores correspondentes a outros ensaios podem ser vistos no Anexo. 
Tabela 8 - Previsão de alturas de queda efetivamente aplicadas para as profundidades de $2 \mathrm{~m}$ e $3 \mathrm{~m}$ do furo SP01

\begin{tabular}{|c|c|c|c|c|c|}
\hline Ensaio & Prof. (m) & $H_{q n}(\mathrm{~mm})$ & $H_{q e}(\mathbf{m m})$ & $\begin{array}{c}\boldsymbol{H}_{q e}-\boldsymbol{H}_{q p} \\
(\mathbf{m m})\end{array}$ & $\begin{array}{c}\left(\boldsymbol{H}_{q e}-\boldsymbol{H}_{q n}\right) / \boldsymbol{H}_{q e} \\
(\%)\end{array}$ \\
\hline \multirow{13}{*}{ SP01 } & \multirow{7}{*}{2} & 100 & 73 & -27 & -36 \\
\hline & & 200 & 176 & -24 & -13 \\
\hline & & 300 & 272 & -28 & -10 \\
\hline & & 400 & 414 & 14 & 3 \\
\hline & & 500 & 522 & 22 & 4 \\
\hline & & 600 & 619 & 19 & 3 \\
\hline & & 750 & 734 & -16 & -2 \\
\hline & \multirow{6}{*}{3} & 100 & 92 & -8 & -9 \\
\hline & & 200 & 193 & -7 & -4 \\
\hline & & 300 & 294 & -6 & -2 \\
\hline & & 400 & 387 & -13 & -3 \\
\hline & & 600 & 610 & 10 & 2 \\
\hline & & 750 & 757 & 7 & 1 \\
\hline
\end{tabular}

Os valores negativos da diferença entre os deslocamentos significam que as alturas de queda aplicadas foram menores do que as nominais. De maneira geral, as três primeiras alturas de queda aplicadas em cada metro foram menores do que deveriam ter sido. Isto significa que as energias aplicadas foram menores que as previstas. Para a maioria das profundidades ensaiadas, a maior diferença entre as alturas de queda foi para o golpe correspondente a altura de queda igual a $100 \mathrm{~mm}$. Quando avaliada a eficiência para os golpes com essa altura de queda (Figura 51), observa-se que elas ficam menores que a média dos valores. Isto enfatiza que o golpe aplicado resultou em energia menor do que a prevista. As diferenças entre as alturas de queda, em média, foram próximas de $20 \mathrm{~mm}$, para mais ou para menos. Quando avaliados os erros relativos entre as alturas de queda, observa-se que quanto menor a altura de queda, maior o erro relativo. As tabelas com os cálculos para os demais ensaios encontram-se no Anexo (Tabela A8 a A10).

\subsubsection{Eficiência versus comprimento de haste}

Considerando o valor médio das eficiências em cada profundidade, pode-se avaliar a influência do comprimento de hastes nos valores de eficiência. Os valores médios das eficiências em função do comprimento de haste (profundidade), correspondentes ao furo SP01 estão mostrados na Figura 55. 


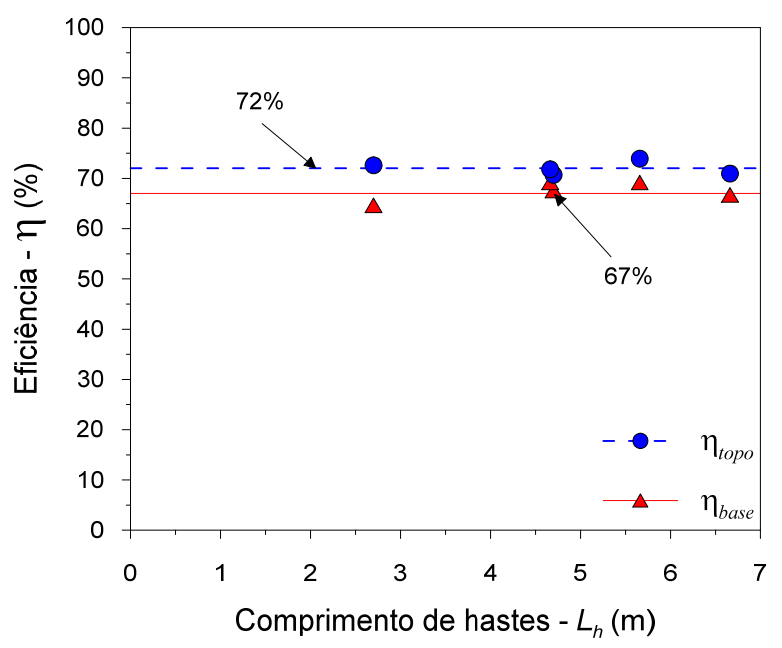

Figura 55 - Eficiência no topo e na base versus comprimento de hastes (Furo SP01)

Mesmo apresentando alguma variação, pelas médias das eficiências observa-se que os valores são muito próximos, não parecendo haver influência do comprimento de hastes na eficiência do ensaio. Esse comportamento foi verificado por outros autores (Cavalcante, 2002; Daniel et al., 2005; Odebrecht et al., 2005; Lukiantchuki et al, 2015). As variações verificadas podem ser referentes à própria execução do ensaio, como a elevação incorreta do martelo ou problemas na aquisição de dados. Isto também foi verificado para os demais ensaios (Figura A100). Para os ensaios correspondentes ao furo SP01, as eficiências médias calculadas em relação à $E P$ sistema no topo e na base foram $72 \%$ e $67 \%$, os desvios padrões de $1.3 \%$ e $1.9 \%$ e os coeficientes de variação iguais a $1.8 \%$ e $2.8 \%$, respectivamente. A Tabela 9 apresenta os valores de eficiência obtidos por alguns autores. A eficiências apresentadas na Tabela 9 foram calculadas em relação à $E P_{\text {sistema }}$.

Tabela 9 - Valores médios de eficiência obtidos em outras pesquisas.

\begin{tabular}{lccc}
\hline \multicolumn{1}{c}{ Autor } & $\boldsymbol{\eta}_{\text {topo }}(\mathbf{\%})$ & $\boldsymbol{\eta}_{\text {base }}(\mathbf{\%})$ & Método de ensaio \\
\hline Lukiantchuki (2012) & 73 & 57 & Manual \\
Morais (2014) & 66 & 62 & Manual \\
Zapata-Galvis (2015) & - & 71 & Manual \\
Eberle (2018) & 79 & 56 & Mecanizado \\
\hline
\end{tabular}

Observa-se que ocorre uma certa variação entre os valores determinados nas pesquisas apresentas e os valores de eficiências obtidos neste trabalho. Entre os ensaios realizados de forma manual, essa variabilidade pode estar associada, por exemplo, à forma de tratamento dos sinais. Atualmente, o tratamento dos dados é feito de forma automática, por meio do programa, enquanto nos trabalhos anteriores o tratamento foi feito por meio de planilhas e rotinas de cálculo. Além disso, as empresas que executaram os ensaios foram diferentes. Em relação ao ensaio mecanizado, já era esperado que os resultados fossem diferentes, devido à diferença do equipamento. 


\subsubsection{Avaliação da resistência}

As resistências mobilizadas em cada golpe foram determinadas de três formas:

a) resistência dinâmica $\left(R_{D}\right)$ determinada a partir dos sinais de força da seção acima do amostrador (Lukiantchuki, 2012);

b) resistência estática $(R S)$ determinada a partir da energia que atinge o amostrador (Aoki et al., 2007);

c) resistência dinâmica $\left(F_{D}\right)$ obtida através de equações teóricas (Schnaid et al., 2009a).

A determinação de resistência dinâmica $R_{D}$ foi mostrada no item 2.4.2.2. O valor de $R_{D}$ apresentado já considera o peso das hastes. A resistência estática $R_{S}$ foi calculada a partir da energia na base, considerando o peso das hastes. Para cálculo da resistência dinâmica $F_{D}$, foram utilizados os coeficientes $\eta_{1}, \eta_{2}$ e $\eta_{3}$ recomendados por Odebrecht (2003), ou seja, $\eta_{1}=0.764$, $\eta_{2}=1$ e $\eta_{3}=1-0.0042 L_{h}$, onde $L_{h}$ representa o comprimento da haste. Os valores das resistências calculadas para o furo SP01 estão apresentados na Tabela 10.

Tabela 10 - Valores de resistências correspondentes ao furo SP01.

\begin{tabular}{|c|c|c|c|c|c|c|c|}
\hline Prof. (m) & $L_{h}(\mathbf{m})$ & $H_{q}(\mathrm{~mm})$ & $\delta_{\text {medido }}(\mathrm{mm})$ & $\delta_{\text {acumulado }}(\mathrm{mm})$ & $R_{D}(\mathrm{kN})$ & $R_{S}(\mathbf{k N})$ & $F_{D}(\mathrm{kN})$ \\
\hline \multirow{7}{*}{2} & \multirow{7}{*}{2.7} & 100 & 42 & 42 & 1.4 & 1.4 & 1.8 \\
\hline & & 200 & 59 & 101 & 1.7 & 1.7 & 2.2 \\
\hline & & 300 & 82 & 183 & 2.2 & 2.1 & 2.4 \\
\hline & & 400 & 67 & 250 & 2.8 & 3.0 & 3.5 \\
\hline & & 500 & 80 & 330 & 3.2 & 3.3 & 3.6 \\
\hline & & 600 & 102 & 432 & 2.9 & 3.0 & 3.4 \\
\hline & & 750 & 161 & 593 & 2.6 & 2.5 & 2.8 \\
\hline \multirow{7}{*}{3} & \multirow{7}{*}{4.7} & 100 & 19 & 19 & 2.6 & 2.6 & 3.2 \\
\hline & & 200 & 31 & 50 & 2.9 & 3.3 & 3.7 \\
\hline & & 300 & 43 & 93 & 3.0 & 3.8 & 4.0 \\
\hline & & 400 & 61 & 154 & 3.6 & 3.5 & 3.8 \\
\hline & & 500 & 60 & 214 & - & - & 4.6 \\
\hline & & 600 & 69 & 283 & 3.8 & 4.4 & 4.8 \\
\hline & & 750 & 90 & 373 & 4.1 & 4.2 & 4.6 \\
\hline \multirow{7}{*}{4} & \multirow{7}{*}{4.7} & 100 & 38 & 38 & 1.8 & 1.8 & 1.9 \\
\hline & & 200 & 43 & 81 & 2.7 & 2.7 & 2.9 \\
\hline & & 300 & 55 & 136 & 3.0 & 3.1 & 3.3 \\
\hline & & 400 & 75 & 211 & 3.2 & 2.9 & 3.2 \\
\hline & & 500 & 84 & 295 & 3.0 & 3.2 & 3.5 \\
\hline & & 600 & 118 & 413 & 3.1 & 2.6 & 3.1 \\
\hline & & 750 & 142 & 555 & 2.6 & 2.7 & 3.2 \\
\hline
\end{tabular}


Continuação da Tabela 10

\begin{tabular}{cccccccc}
\hline Prof. $(\mathbf{m})$ & $\boldsymbol{L}_{\boldsymbol{h}}(\mathbf{m})$ & $\boldsymbol{H}_{\boldsymbol{q}}(\mathbf{m m})$ & $\boldsymbol{\delta}_{\text {medido }}(\mathbf{m m})$ & $\boldsymbol{\delta}_{\text {acumulado }}(\mathbf{m m})$ & $\boldsymbol{R}_{\boldsymbol{D}}(\mathbf{k N})$ & $\boldsymbol{R}_{\boldsymbol{S}}(\mathbf{k N})$ & $\boldsymbol{F}_{\boldsymbol{D}}(\mathbf{k N})$ \\
\hline & & 100 & 29 & 29 & 1.9 & 2.0 & 2.3 \\
& & 200 & 41 & 70 & 2.8 & 2.8 & 3.0 \\
5 & 300 & 53 & 123 & 3.2 & 3.1 & 3.4 \\
& 5.7 & 400 & 66 & 189 & 3.4 & 3.2 & 3.6 \\
& & 500 & 77 & 266 & - & - & 3.8 \\
& & 600 & 92 & 358 & 3.5 & 3.7 & 3.8 \\
& & 750 & 106 & 464 & 3.3 & 3.7 & 4.1 \\
\hline & & 100 & 43 & 43 & 1.8 & 1.5 & 1.8 \\
& & 200 & 41 & 84 & 2.4 & 2.7 & 3.0 \\
6 & 300 & 48 & 132 & 3.2 & 3.3 & 3.7 \\
& & 400 & 59 & 191 & 3.6 & 3.6 & 3.9 \\
& & 500 & 58 & 249 & 3.6 & 3.9 & 4.8 \\
& & 600 & 74 & 323 & 4.1 & 4.2 & 4.6 \\
& & 750 & 86 & 409 & 4.4 & 4.5 & 4.8 \\
\hline
\end{tabular}

Para cálculo de $R_{S}$, considera-se que a energia que chega ao amostrador é igual ao trabalho realizado pelas forças não conservativas na cravação do amostrador. Assim, considerando que $R_{D}$ seja igual à força mobilizada na cravação do amostrador, pode-se fazer o cálculo inverso ao de $R S$, ou seja, calcular o trabalho $(W)$ resultante em cada golpe (Equação 43).

$$
W=R_{D} \cdot \delta_{\text {medido }}
$$

A Figura 56 apresenta a relação entre o trabalho calculado a partir de $R_{D}$ e a energia medida na base da composição de hastes $\left(E_{\text {base }}\right)$.

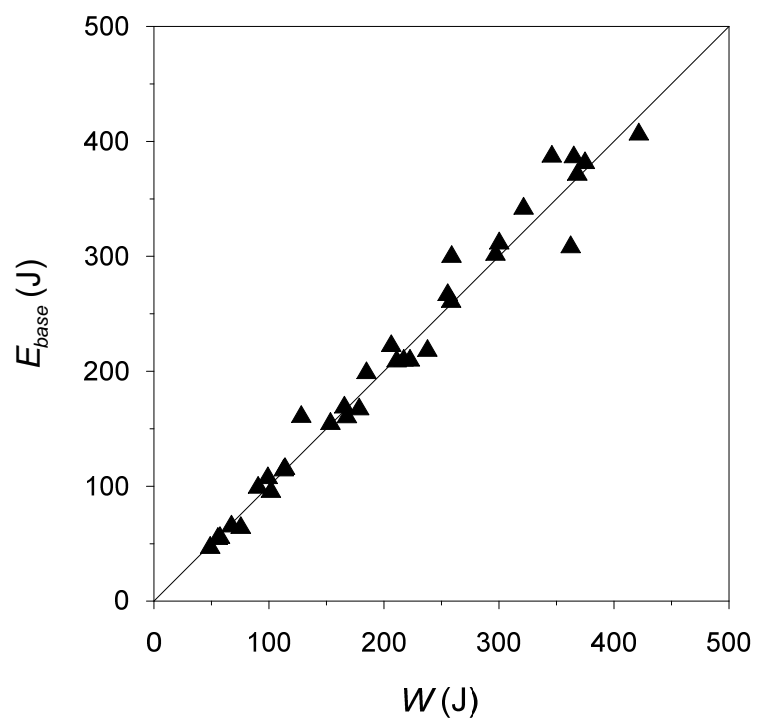

Figura 56 - Relação entre o trabalho $(W)$ calculado a partir de $R_{D}$ com a energia na base ( $\left.E_{\text {base }}\right)$ (Furo SP01)

Observa-se que a para todos os golpes realizados os valores de $W$ e $E_{\text {base }}$ são muito próximos. Este fato também foi observado para os demais furos (Figura A104). Isso significa 
que na maioria dos casos, toda a energia que atinge o amostrador é transformada em trabalho de forças não conservativas, ou seja, não existe recuperação elástica ou esta é desprezível. Isso vai de encontro ao que afirmam Aoki et al. (2004), que com exceção dos solos resilientes, a recuperação elástica do amostrador é desprezível, quando comparada com o deslocamento plástico. Essa análise justifica os valores de $R_{D}$ e $R_{S}$ serem tão próximos e valida o método de determinação de $R_{D}$ proposto por Lukiantchuki (2012). Observa-se, porém, que para maiores energias ocorre maior dispersão dos dados.

A partir dos resultados apresentados pode-se então plotar a resistência mobilizada versus deslocamento acumulado para cada profundidade ensaiada (Figura 57). Alguns golpes apresentaram problemas na instrumentação ou foram excluídos pelos critérios de seleção mencionados anteriormente. Por esse motivo, os gráficos de resistência versus deslocamento para cada profundidade, nem sempre apresentam 7 pontos ( 7 alturas de queda crescentes). Porém, como o método de Schnaid et al. (2009a) é teórico, foi possível calcular $F_{D}$ para todos os golpes realizados. As curvas para os demais furos estão apresentadas no Anexo.

Observa-se que, independentemente do método utilizado para cálculo da resistência, a tendência da resistência mobilizada em função do deslocamento, pode ser conhecida. Aos pontos foi ajustada uma curva de acordo com a equação de Van der Veen, para que se pudesse ter um único parâmetro de resistência $\left(R_{u}\right)$ por profundidade para fazer as análises. Os parâmetros de ajuste estão apresentados na Tabela 11.

Tabela 11 - Parâmetros de ajuste de curva pela Equação de Van der Veen.

\begin{tabular}{cccccccc}
\hline \multirow{2}{*}{ Ensaio } & Prof. (m) & \multicolumn{2}{c}{$\boldsymbol{R}_{\boldsymbol{D}}$} & \multicolumn{2}{c}{$\boldsymbol{R}_{\boldsymbol{S}}$} & \multicolumn{2}{c}{$\boldsymbol{F}_{\boldsymbol{D}}$} \\
\cline { 3 - 8 } & & $\boldsymbol{R} \boldsymbol{u}(\mathbf{k N})$ & Alpha & $\boldsymbol{R} \boldsymbol{u}(\mathbf{k N})$ & Alpha & $\boldsymbol{R} \boldsymbol{u}(\mathbf{k N})$ & Alpha \\
\hline \multirow{5}{*}{ SP01 } & 2.9 & 0.011 & 2.9 & 0.010 & 3.3 & 0.013 \\
& 3 & 3.7 & 0.051 & 4.1 & 0.043 & 4.5 & 0.056 \\
& 4 & 3.0 & 0.025 & 2.9 & 0.028 & 3.3 & 0.025 \\
& 5 & 3.4 & 0.027 & 3.5 & 0.025 & 3.7 & 0.028 \\
& 6 & 4.2 & 0.011 & 4.4 & 0.010 & 4.8 & 0.011 \\
\hline \multirow{3}{*}{ SP02 } & 2 & 2.9 & 0.011 & 2.9 & 0.010 & 3.3 & 0.013 \\
& 3 & 3.7 & 0.051 & 4.1 & 0.043 & 4.5 & 0.056 \\
& 5 & 3.4 & 0.027 & 3.5 & 0.025 & 3.7 & 0.028 \\
& 6 & 4.2 & 0.011 & 4.4 & 0.010 & 4.8 & 0.011 \\
\hline \multirow{3}{*}{ SP03 } & 2 & 2.9 & 0.011 & 2.9 & 0.010 & 3.3 & 0.013 \\
& 3 & 3.7 & 0.051 & 4.1 & 0.043 & 4.5 & 0.056 \\
& 4 & 3.0 & 0.025 & 2.9 & 0.028 & 3.3 & 0.025 \\
& 5 & 3.4 & 0.027 & 3.5 & 0.025 & 3.7 & 0.028 \\
& 6 & 4.2 & 0.011 & 4.4 & 0.010 & 4.8 & 0.011 \\
\hline
\end{tabular}


a)
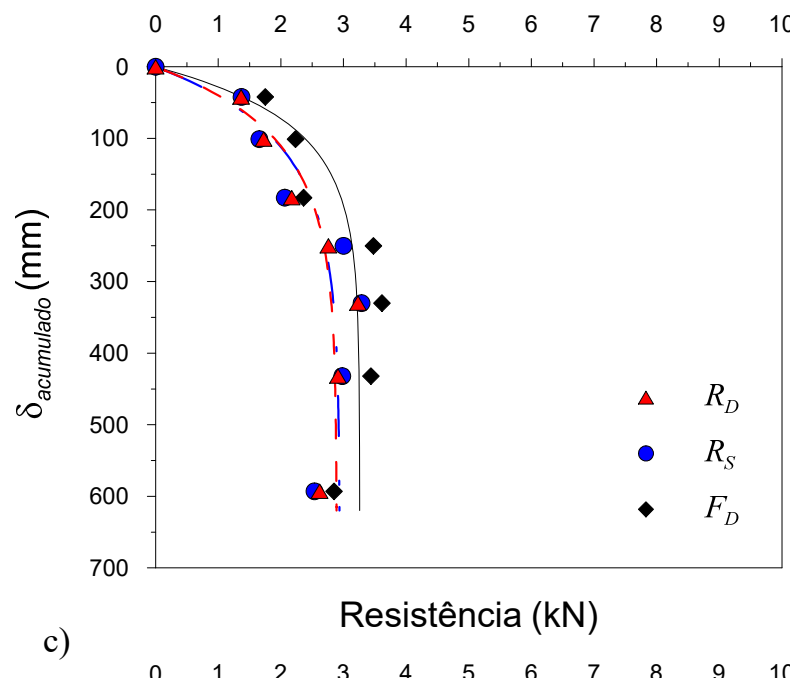

b)

Resistência (kN)

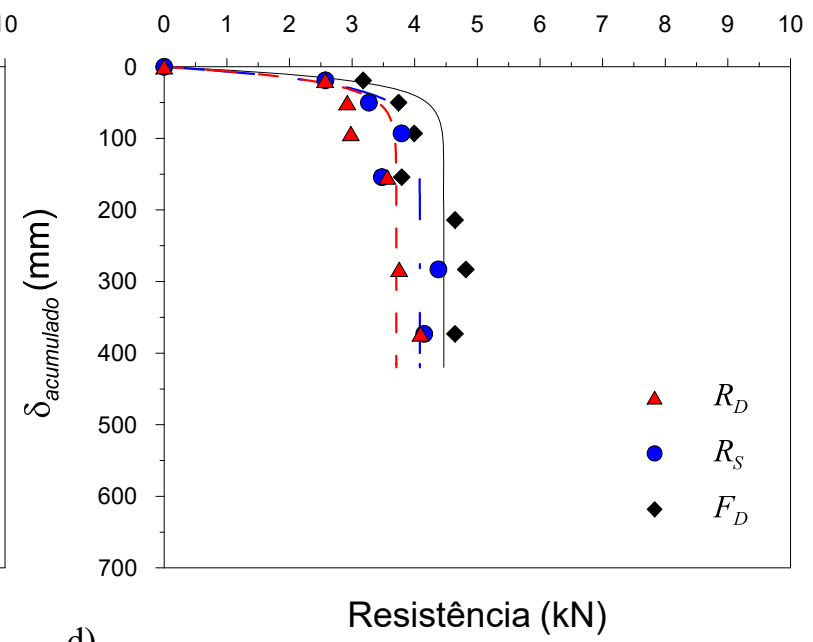

d)

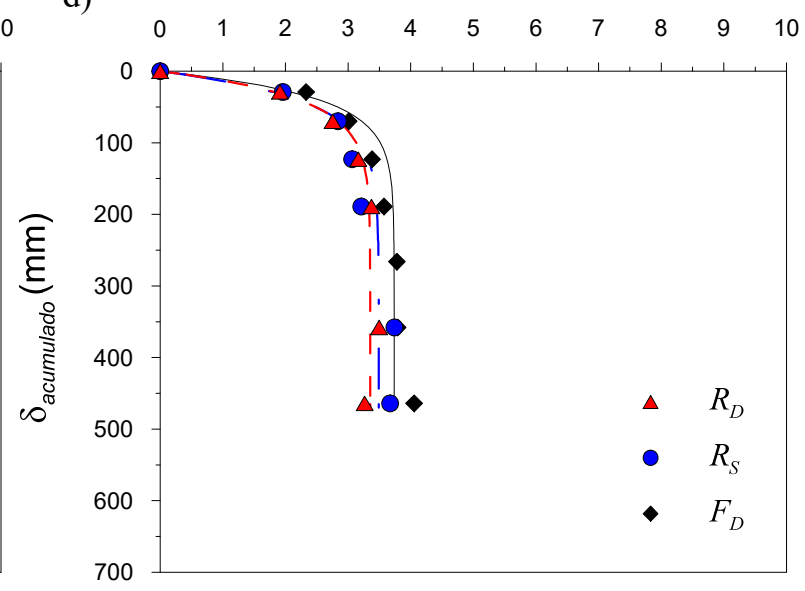

e)

Resistência (kN)

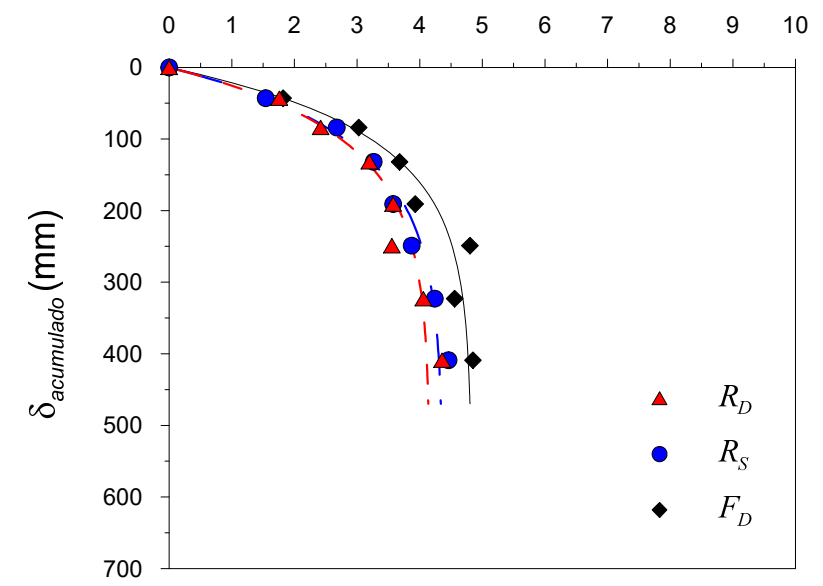

Figura 57 - Curva de resistência mobilizada versus deslocamento acumulado para SP01 e profundidades: a) 2 metros; b) 3 metros; c) 4 metros; d) 5 metros; e) 6 metros.

Pelas curvas apresentadas na Figura 57 é possível verificar que os valores de $F_{D}$ se mostram superiores às demais resistências. Os valores de $R_{S}$ e $R_{D}$ são muito próximos e quando existe uma variação, os valores de $R_{S}$ se mostram superiores aos valores de $R_{D}$. Os valores de $R_{S}$ e $R_{D}$ ficam mais distantes nos pontos onde a resistência se mostra um pouco superior. Porém, as profundidades analisadas neste trabalho apresentam baixas resistências, não podendo se 
assegurar que esta tendência seja mantida. Os resultados de resistência para os demais ensaios encontram-se no Anexo (Tabela A11 a A13 e Figuras A106 e A107).

A Figura 58 apresenta a comparação dos valores de $R_{u}$ determinados a partir de $R_{D}, R_{S}$ e $F_{D}$ para todos os ensaios realizados.

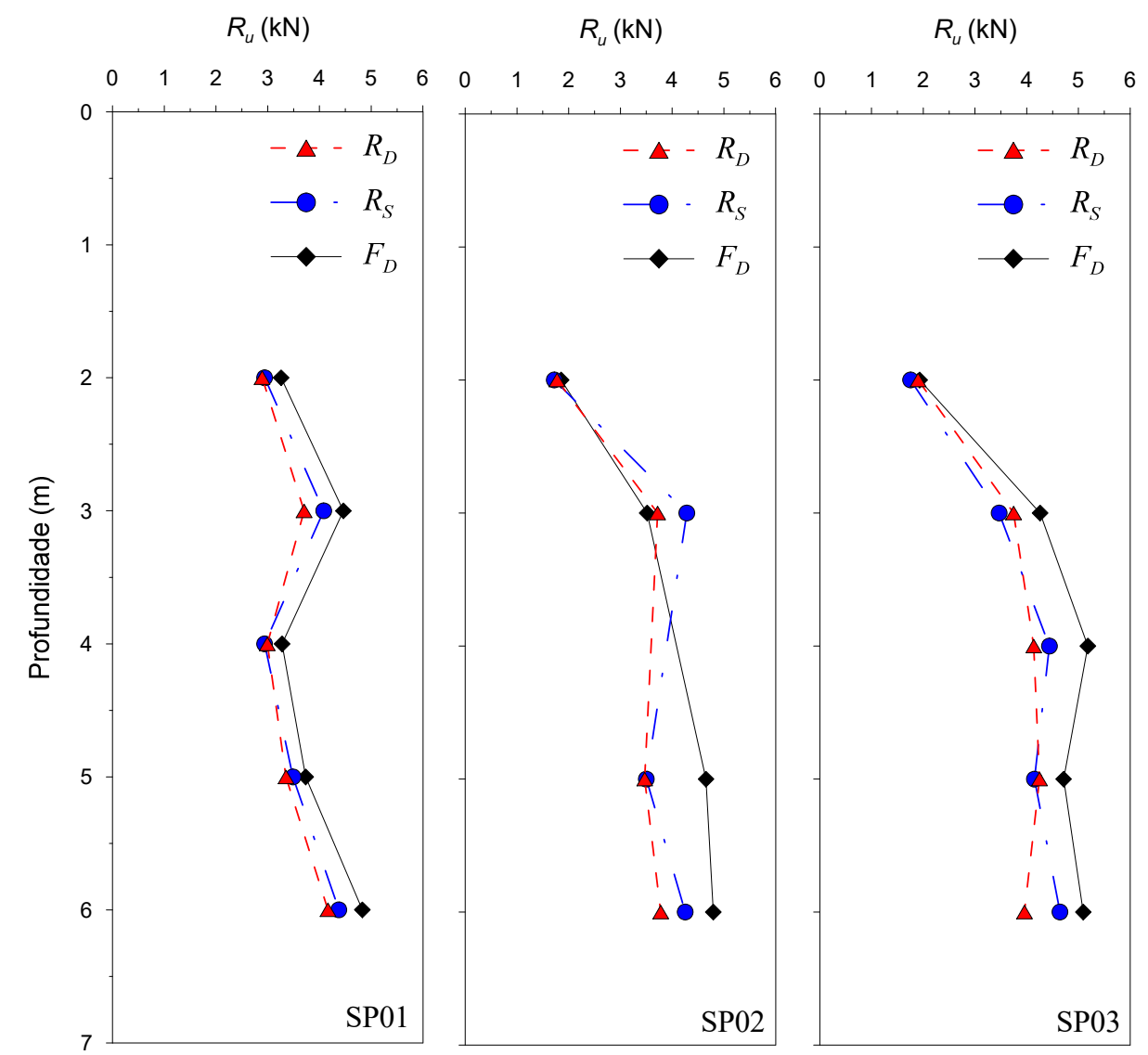

Figura 58 - Comparação entre valores de $R_{u}$, para $R_{D}, R_{S}$ e $F_{D}$ para as profundidades e ensaios analisados.

Observa-se que as resistências determinadas para todos os furos apresentam a mesma ordem de grandeza. Além disso, os valores seguem as mesmas tendências, ou seja, quando $R_{D}$ diminui entre uma profundidade e outra, $R_{S}$ e $F_{D}$ também diminuem e quando $R_{D}$ aumenta, os demais também aumentam, com exceção da profundidade de $5 \mathrm{~m}$ do furo SP02.

A Figura 59 apresenta os valores de $R_{u}$ em função da profundidade. Para efeito de comparação, para as profundidades ensaiadas, também são apresentados valores do índice de penetração NSPT (Giachetti et al., 2004) e valores da resistência de ponta $q_{c}$, obtidos com ensaio CPT (Rocha, 2018). Os valores de $q_{c}$ são referentes à ensaios realizados na mesma época do ano que os ensaios neste trabalho. Já os valores de $N_{S P T}$ não fazem distinção a épocas do ano e foram obtidos por diferentes empresas. 


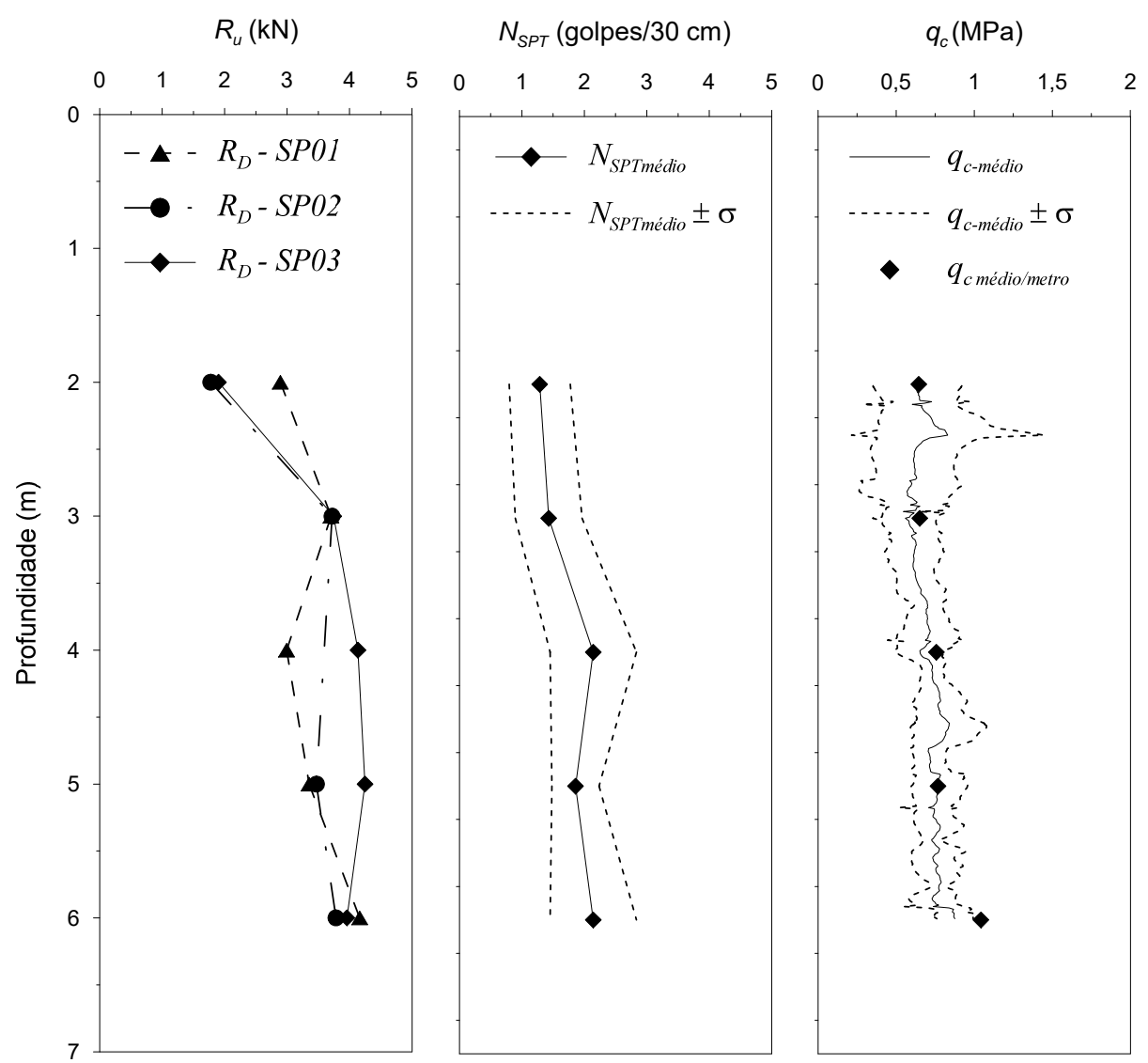

Figura 59 - Comparação entre valores de $R_{u}, N_{S P T}$ e $q_{c}$ para as profundidades e furos analisados.

Comparando os valores de $R_{u}$ para as diferentes profundidades, observa-se que para as profundidades de $3 \mathrm{~m}$ e $6 \mathrm{~m}$, os valores são iguais nos três furos. O SP03 se distancia dos demais entre o $3^{\circ}$ e $6^{\circ}$ metro e o SP01 apresenta resistência maior no $2^{\circ}$ metro.

Observa-se que, de maneira geral, existe uma tendência ao aumento da resistência com a profundidade. Nos 3 gráficos ocorre o aumento da resistência na profundidade de $4 \mathrm{~m}$, seguido de queda na resistência na profundidade de $5 \mathrm{~m}$.

\subsection{ENSAIO DE ATRITO INTERNO}

O ensaio de atrito interno, proposto por Zapata-Galvis (2015), foi realizado em cada profundidade ao término do ensaio de penetração dinâmica com energia crescente. Os gráficos resultantes de cada ensaio estão apresentados no Anexo (Figuras A108 a A119).

Para este ensaio são apresentados os dados dos ensaios correspondentes ao furo SP03. Os resultados correspondentes ao furo SP01 apresentaram alguns problemas, pois o cilindro hidráulico não estava corretamente fixado. Mesmo assim, os valores são apresentados no Anexo. O mesmo problema não ocorreu para o furo SP02 e os resultados também estão no Anexo. 
A resistência interna mobilizada $\left(R_{2}\right)$, determinada no ensaio é referente a todos os golpes, não sendo possível saber ao certo qual a resistência interna mobilizada em cada golpe. Além disso, não se tem a medida do comprimento da amostra a cada golpe $\left(L_{a i}\right)$, mas sim ao final do ensaio em cada profundidade $\left(L_{a}\right)$. Assim considerou-se que a relação entre $L_{a i}$ e $L_{a}$ é igual a relação entre o deslocamento medido a cada golpe $\left(\delta_{\text {medido }}\right)$ e o deslocamento total acumulado em cada profundidade ( $\delta_{\text {acumulado }}$ (Equação 42$)$ :

$$
\frac{L_{a}}{\delta_{\text {acumulado }}}=\frac{L_{a i}}{\delta_{\text {medido }}}
$$

Isso significa que a relação $L_{a i} / \delta_{\text {medido }}$ foi considerada constante para todos os golpes em uma mesma profundidade. A Figura 60 apresenta a relação entre $L_{a} / \delta_{\text {acumulado }}$ obtidas na recuperação das amostras. Observa-se que de modo geral, nos 3 furos ensaiados, praticamente não ocorre embuchamento para profundidades até $4 \mathrm{~m}$, pois as relações $L_{a} / \delta_{\text {acumulado }}$ são muito próximas de 1. O furo SP01, como pode ser visto no Anexo (Figura A105) é uma exceção, pois também não ocorreu embuchamento para a profundidade de $5 \mathrm{~m}$.

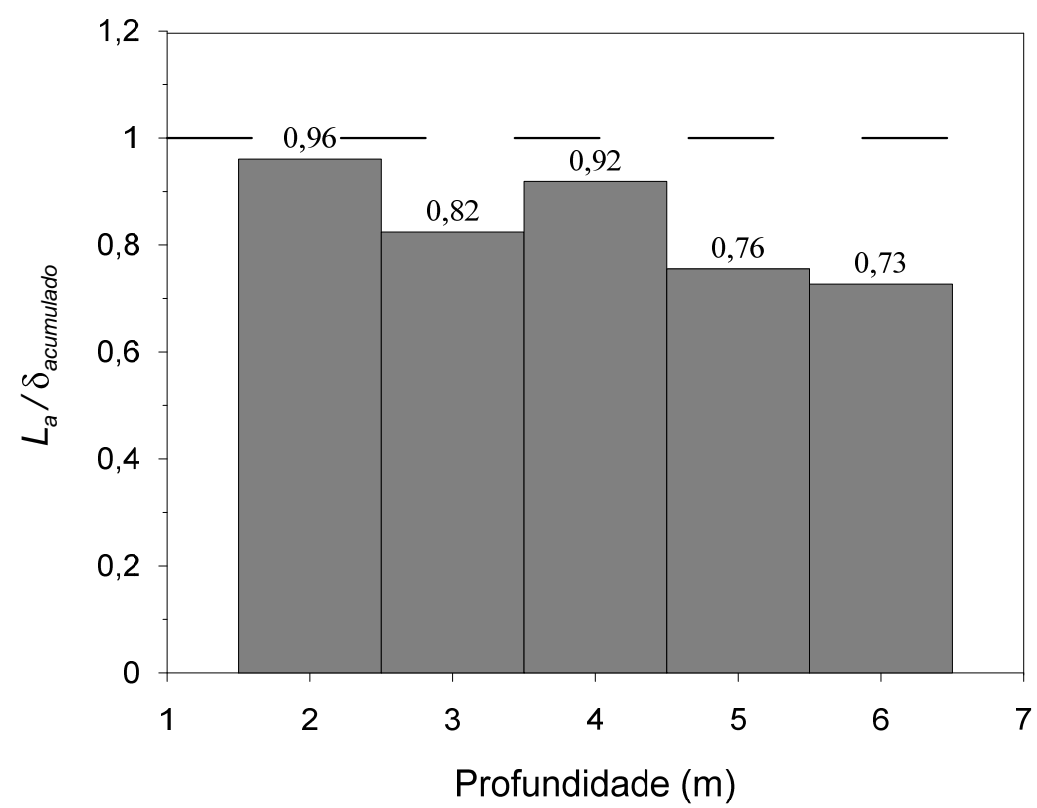

Figura 60 - Relação entre o comprimento da amostra recuperada $\left(L_{a}\right)$ e a penetração acumulada do amostrador ( $\left.\delta_{\text {acumulado }}\right)$ para o furo SP03

Desta forma, para tornar a análise do atrito interno possível, optou-se por considerar a relação entre a resistência interna por golpe $\left(R_{2 i}\right)$ e a resistência medida no ensaio $\left(R_{2}\right)$ igual à relação entre a penetração medida à cada golpe $\left(\delta_{\text {medido }}\right)$ e o deslocamento total acumulado 
( $\delta_{\text {acumulado }}$ (Equação 43). A Tabela 12 apresenta os valores de resistência de atrito interno. Os demais resultados encontram-se em Anexo (Tabela A14 e A15).

$$
\frac{R_{2 i}}{R_{2}}=\frac{\delta_{\text {medido }}}{\delta_{\text {acumulado }}}=\frac{L_{a i}}{L_{a}}
$$

Tabela 12 - Valores de resistência de atrito interno - SP03.

\begin{tabular}{|c|c|c|c|c|c|c|c|}
\hline Prof. (m) & $H_{q}(\mathrm{~mm})$ & $\delta_{\text {medido }}(\mathrm{mm})$ & $\delta_{\text {acumulado }}(\mathrm{mm})$ & $L_{a}(\mathbf{m m})$ & $R_{2}(\mathrm{kN})$ & $\boldsymbol{L}_{a i} / \boldsymbol{L}_{a}$ & $R_{2 i}(\mathbf{k N})$ \\
\hline \multirow{7}{*}{2} & 100 & 75 & \multirow{7}{*}{608} & \multirow{7}{*}{584} & \multirow{7}{*}{0.11} & 0.12 & 0.01 \\
\hline & 200 & 80 & & & & 0.25 & 0.03 \\
\hline & 300 & 114 & & & & 0.44 & 0.05 \\
\hline & 400 & 144 & & & & 0.68 & 0.07 \\
\hline & 500 & 195 & & & & 1.00 & 0.11 \\
\hline & 600 & - & & & & - & - \\
\hline & 750 & - & & & & - & - \\
\hline \multirow{7}{*}{3} & 100 & 55 & \multirow{7}{*}{540} & \multirow{7}{*}{445} & \multirow{7}{*}{0.12} & 0.10 & 0.01 \\
\hline & 200 & 68 & & & & 0.23 & 0.03 \\
\hline & 300 & 71 & & & & 0.36 & 0.04 \\
\hline & 400 & 77 & & & & 0.50 & 0.06 \\
\hline & 500 & 76 & & & & 0.64 & 0.07 \\
\hline & 600 & 89 & & & & 0.81 & 0.09 \\
\hline & 750 & 104 & & & & 1.00 & 0.12 \\
\hline \multirow{7}{*}{4} & 100 & 33 & \multirow{7}{*}{381} & \multirow{7}{*}{350} & \multirow{7}{*}{0.15} & 0.09 & 0.01 \\
\hline & 200 & 45 & & & & 0.20 & 0.03 \\
\hline & 300 & 47 & & & & 0.33 & 0.05 \\
\hline & 400 & 52 & & & & 0.46 & 0.07 \\
\hline & 500 & 62 & & & & 0.63 & 0.09 \\
\hline & 600 & 66 & & & & 0.80 & 0.12 \\
\hline & 750 & 76 & & & & 1.00 & 0.15 \\
\hline \multirow{7}{*}{5} & 100 & 30 & \multirow{7}{*}{417} & \multirow{7}{*}{315} & \multirow{7}{*}{0.18} & 0.07 & 0.01 \\
\hline & 200 & 38 & & & & 0.16 & 0.03 \\
\hline & 300 & 45 & & & & 0.27 & 0.05 \\
\hline & 400 & 54 & & & & 0.40 & 0.07 \\
\hline & 500 & 61 & & & & 0.55 & 0.10 \\
\hline & 600 & 66 & & & & 0.71 & 0.13 \\
\hline & 750 & 123 & & & & 1.00 & 0.18 \\
\hline \multirow{7}{*}{6} & 100 & 32 & \multirow{7}{*}{377} & \multirow{7}{*}{274} & \multirow{7}{*}{0.11} & 0.08 & 0.01 \\
\hline & 200 & 44 & & & & 0.20 & 0.02 \\
\hline & 300 & 33 & & & & 0.29 & 0.03 \\
\hline & 400 & 62 & & & & 0.45 & 0.05 \\
\hline & 500 & 64 & & & & 0.62 & 0.07 \\
\hline & 600 & 68 & & & & 0.80 & 0.09 \\
\hline & 750 & 74 & & & & 1.00 & 0.11 \\
\hline
\end{tabular}

A partir dos valores de $R_{2}$ e $R_{D}$ e das equações apresentadas no item 2.4.4 é possível estimar os valores das demais parcelas de resistências atuantes no amostrador durante sua 
penetração no solo (Figura 61): $R_{1}=$ Força de atrito na parede vertical; $R_{3}=$ Força de reação vertical na seção anelar do amostrador (considerada nula); $R_{4}=$ Componente vertical da força de atrito na parede do bico do amostrador. Observa-se que $R_{1}$ e $R_{2}$ tende a crescer com o deslocamento enquanto $R_{4}$ tende a decrescer. Porém, vale ressaltar que, essa estimativa é dependente da suposição feita para $R_{2}$ a cada golpe, apresentada na Tabela 12.

Força $(\mathrm{kN})$

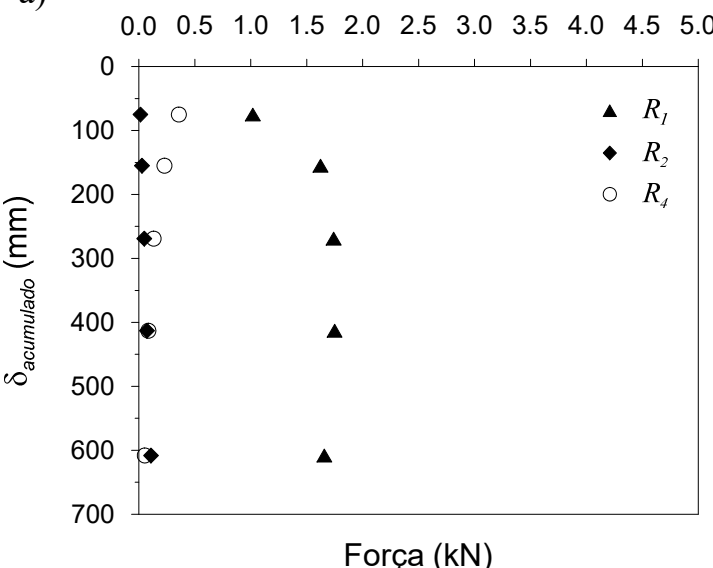

c) $\quad \begin{array}{lllllllllll}0.0 & 0.5 & 1.0 & 1.5 & 2.0 & 2.5 & 3.0 & 3.5 & 4.0 & 4.5 & 5.0\end{array}$

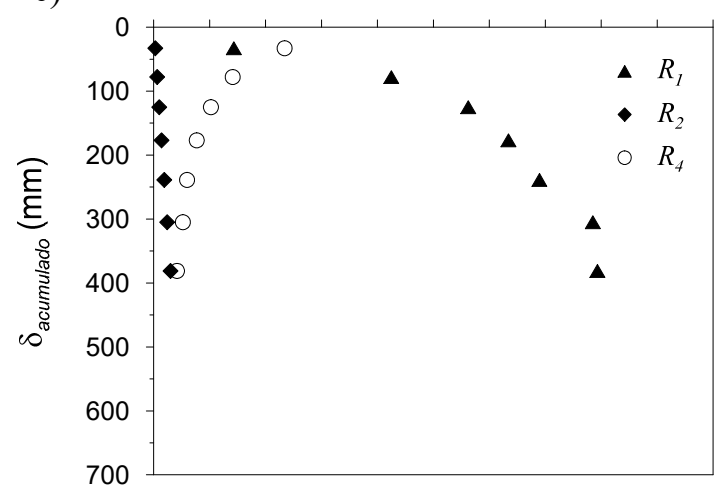

b)

Força $(\mathrm{kN})$

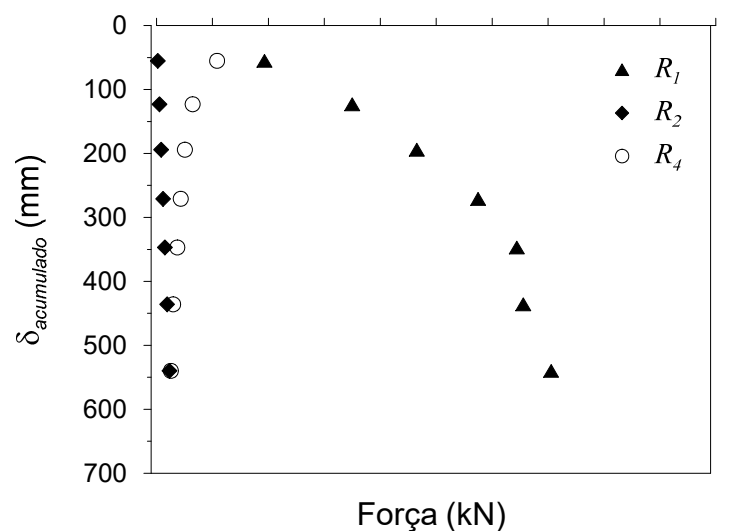

d) $\quad \begin{array}{lllllllllll}0.0 & 0.5 & 1.0 & 1.5 & 2.0 & 2.5 & 3.0 & 3.5 & 4.0 & 4.5 & 5.0\end{array}$

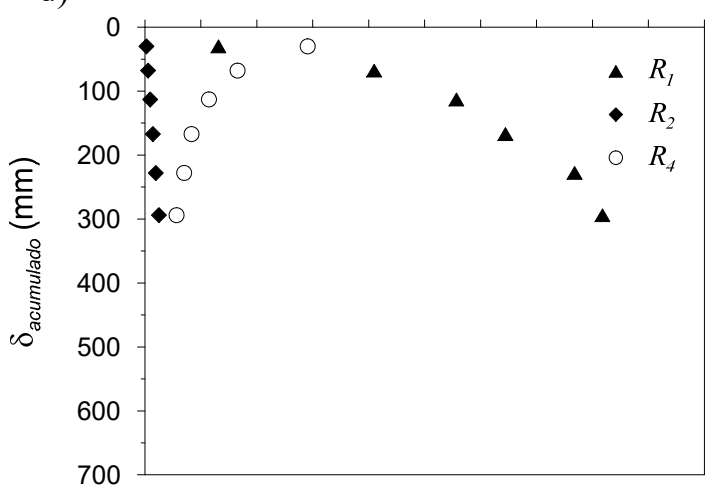

Força $(\mathrm{kN})$

e) $\quad \begin{array}{lllllllllll}0.0 & 0.5 & 1.0 & 1.5 & 2.0 & 2.5 & 3.0 & 3.5 & 4.0 & 4.5 & 5.0\end{array}$

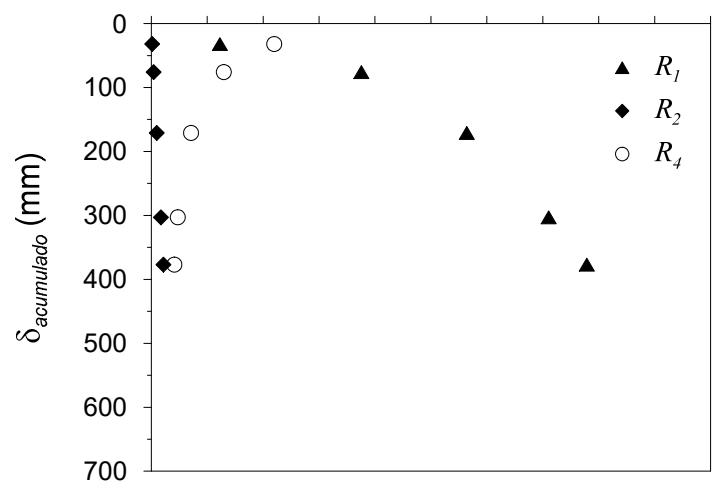

Figura 61 - Resistências desenvolvidas no amostrador no furo SP03, para as profundidades: a) 2 m; b) 3 m; c) 4 m; d) $5 \mathrm{~m}$; e) $6 \mathrm{~m}$ 
Além das forças é possível estimar os atritos atuantes na parede interna $\left(r_{L i}\right)$ e na parede externa $\left(r_{L e}\right)$ e a resistência de ponta $\left(r_{p}\right)$ (Figura 62).

a)

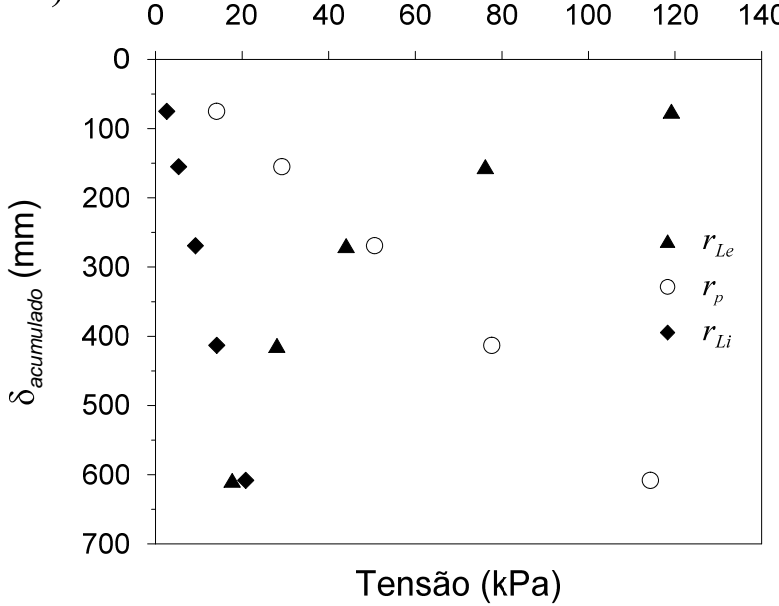

c) $\quad 0 \quad 50100150200250300350400450500$

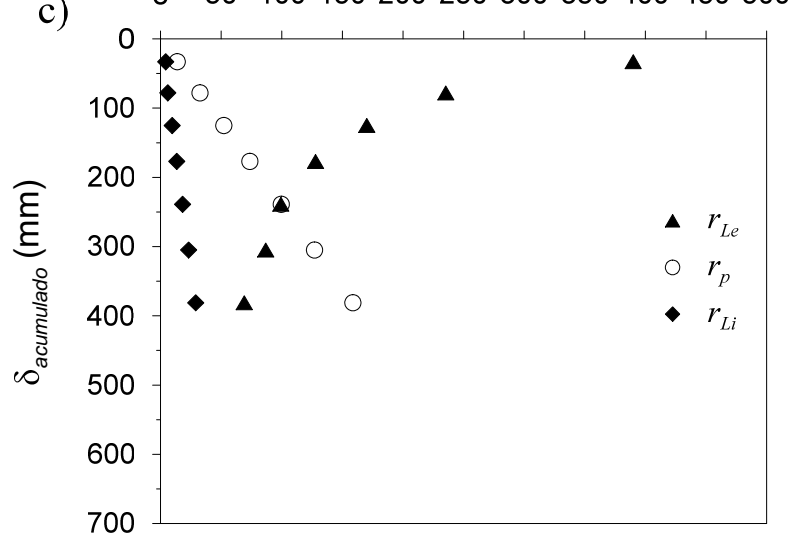

b)

Tensão $(\mathrm{kPa})$

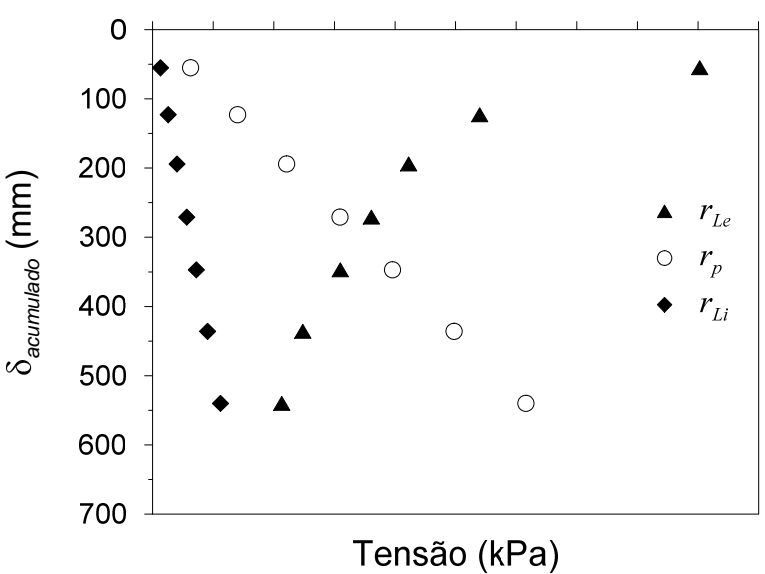

d) $0 \quad 50100150200250300350400450500$

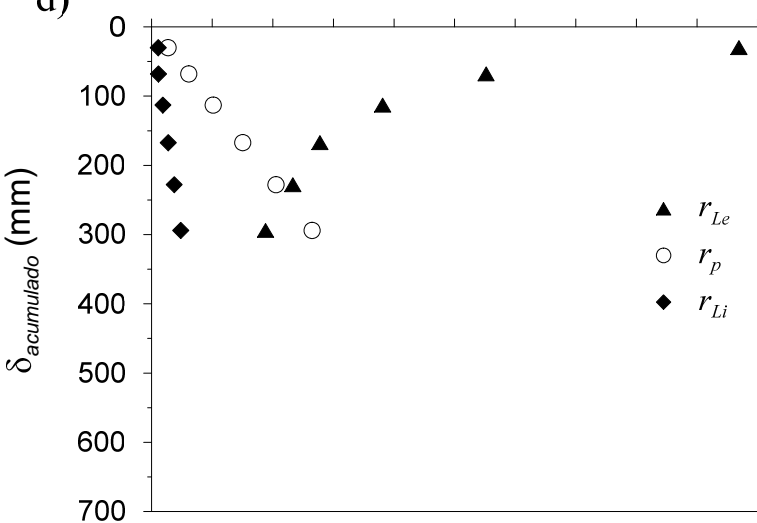

Tensão (kPa)

e) $\quad 0 \quad 50100150200250300350400450500$

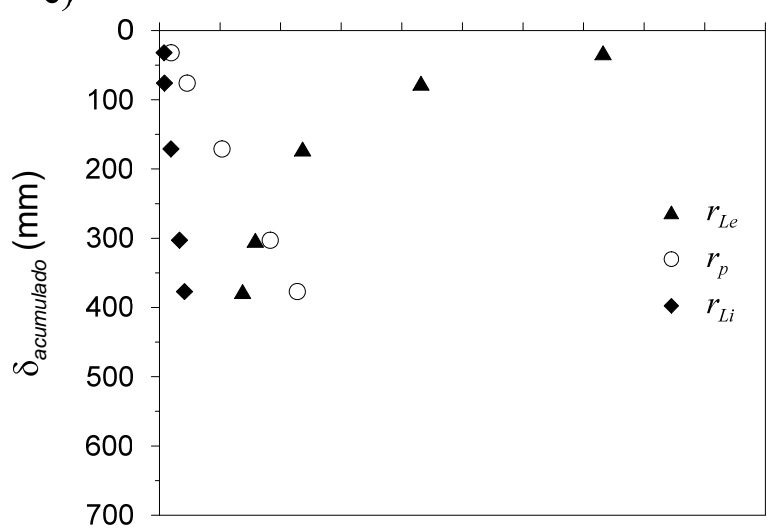

Figura 62 - Tensões desenvolvidas no amostrador para o furo SP03, nas profundidades: a) 2 metros; b) 3 metros; c) 4 metros; d) 5 metros 
Pelas considerações feitas, $r l_{e}$ tende a diminuir com o deslocamento, enquanto $r l_{i}$ e $r_{p}$ tendem a aumentar. A partir da relação entre $r l_{i}$ e $r l_{e}$ é possível determinar o coeficiente $a$ proposto por Aoki (2013) e a partir da relação entre $r l_{e}$ e $r_{p}$ a razão de atrito $\left(R_{f}\right)$ (Tabela 13).

Tabela 13 - Coeficiente $a$ de Aoki e razão de atrito $R_{f}-\mathrm{SP} 03$.

\begin{tabular}{|c|c|c|c|c|c|c|c|}
\hline Prof. (m) & $H_{q}(\mathrm{~mm})$ & $a$ & $\boldsymbol{R}_{f}$ & Prof. (m) & $H_{q}(\mathbf{m m})$ & $a$ & $\boldsymbol{R}_{f}$ \\
\hline \multirow{7}{*}{2} & 100 & 0.02 & 8.45 & \multirow{7}{*}{5} & 100 & 0.01 & 35.89 \\
\hline & 200 & 0.07 & 2.62 & & 200 & 0.02 & 9.02 \\
\hline & 300 & 0.21 & 0.87 & & 300 & 0.05 & 3.75 \\
\hline & 400 & 0.51 & 0.36 & & 400 & 0.10 & 1.85 \\
\hline & 500 & 1.18 & 0.15 & & 500 & 0.16 & 1.14 \\
\hline & 600 & - & - & & 600 & 0.26 & 0.71 \\
\hline & 750 & - & - & & 750 & - & - \\
\hline \multirow{7}{*}{3} & 100 & 0.01 & 14.39 & \multirow{7}{*}{6} & 100 & 0.01 & 37.91 \\
\hline & 200 & 0.05 & 3.85 & & 200 & 0.02 & 9.41 \\
\hline & 300 & 0.10 & 1.91 & & 300 & - & - \\
\hline & 400 & 0.16 & 1.17 & & 400 & 0.08 & 2.29 \\
\hline & 500 & 0.23 & 0.78 & & 500 & - & - \\
\hline & 600 & 0.37 & 0.50 & & 600 & 0.21 & 0.86 \\
\hline & 750 & 0.53 & 0.35 & & 750 & 0.30 & 0.60 \\
\hline \multirow{7}{*}{4} & 100 & 0.01 & 28.36 & & & & \\
\hline & 200 & 0.03 & 7.25 & & & & \\
\hline & 300 & 0.06 & 3.27 & & & & \\
\hline & 400 & 0.11 & 1.73 & & & & \\
\hline & 500 & 0.18 & 1.00 & & & & \\
\hline & 600 & 0.27 & 0.68 & & & & \\
\hline & 750 & 0.42 & 0.44 & & & & \\
\hline
\end{tabular}

Observa-se que o coeficiente $a$ tende a aumentar com a altura de queda. Já a razão de atrito tende a diminuir com a altura de queda. Os valores referentes à $750 \mathrm{~mm}$ de altura de queda se assemelham com os obtidos por Zapata-Galvis (2015). Para as demais alturas de queda não se tem referência.

\subsection{ENSAIO DE PENETRAÇÃO ESTÁTICA}

Entre os ensaios de penetração estática realizados só foi possível fazer análise do ensaio realizado à 5 metros de profundidade. O gráfico de resistência versus deslocamento obtido a partir do ensaio de penetração estática está mostrado na Figura 63. Os deslocamentos plotados referem-se aos deslocamentos acumulados entre as etapas. Aos pontos plotados foi ajustada 
uma curva pela equação de Van der Veen. De acordo com o ajuste, a resistência estática última $(R u)$ resultou em $2.5 \mathrm{kN}$.

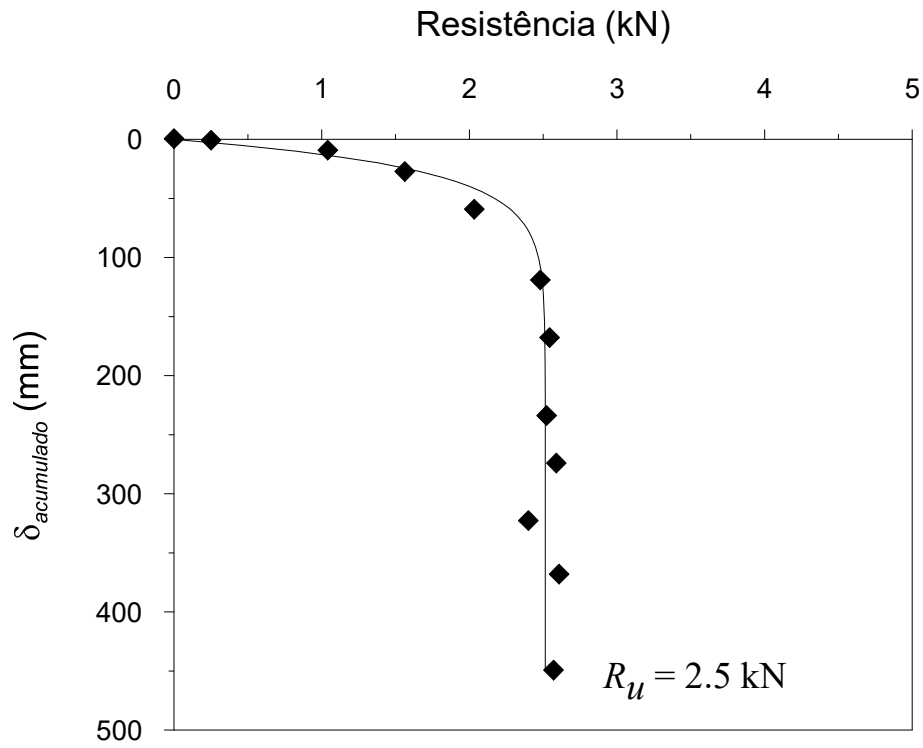

Figura 63 - Curva resistência estática versus deslocamento para ensaio estático $-5 \mathrm{~m}$ de profundidade.

A Figura 64 apresenta a comparação entre a curva de resistência estática obtida pelo ensaio de penetração estática e as curvas de resistência dinâmica $\left(R_{D}\right)$ obtidas para $5 \mathrm{~m}$ de profundidade nos 3 furos ensaiados.

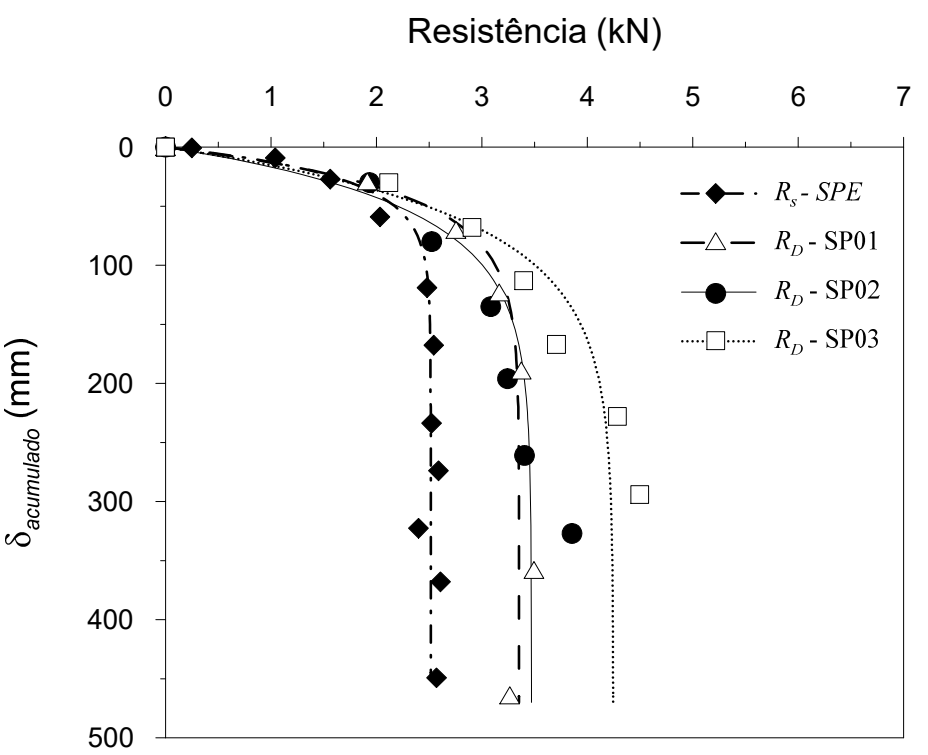

Figura 64 - Curva resistência versus deslocamento - 5m de profundidade.

Primeiramente, avaliando os ensaios dinâmicos entre si, observa-se que para os furos SP01 e SP02, as curvas de resistência dinâmica são praticamente coincidentes. Já a curva de SP03 mostra uma resistência maior. Comparando os ensaios de penetração estática e de penetração dinâmica, observa-se que em todos os casos, a resistência dinâmica ficou superior à resistência estática. 
Quando comparadas na Figura 57, as curvas de resistência dinâmica e resistência estática determinadas a partir do ensaio de penetração dinâmica, foram praticamente coincidentes em todos os casos. Comprovando que a parcela elástica da resistência dinâmica era praticamente nula. Porém observa-se que o ensaio de penetração estática e penetração dinâmica não foram realizados no mesmo furo, podendo, então, haver uma pequena variação espacial. A Figura 65 apresenta os perfis de teores de umidade determinados a partir das amostras extraídas dos ensaios realizados.

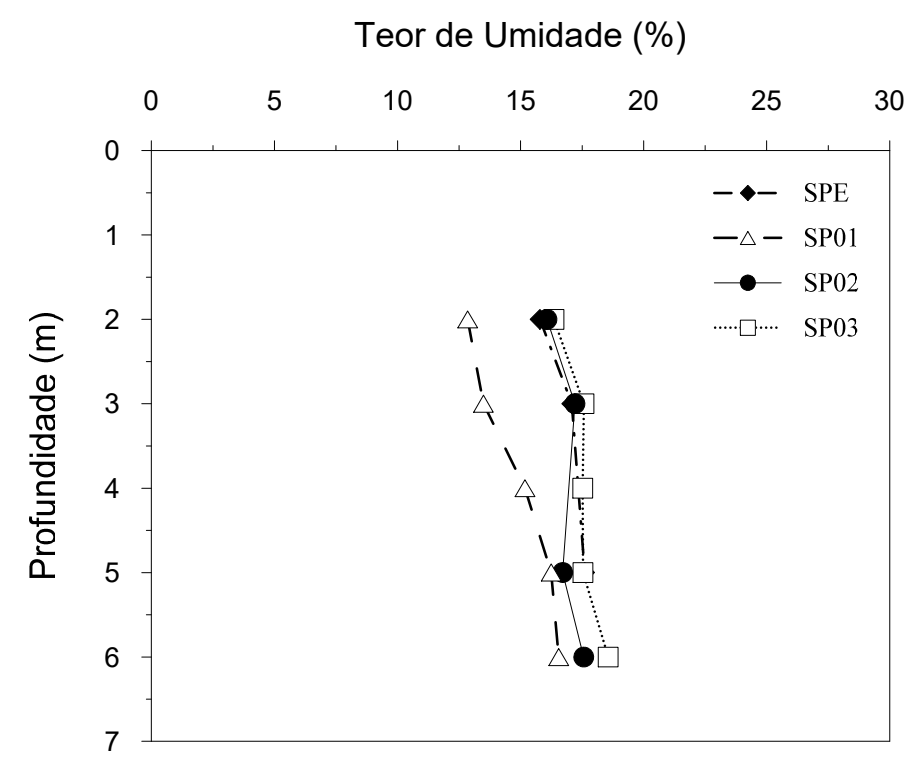

Figura 65 - Perfis de teores de umidade para os ensaios realizados.

Comparando os perfis de teores de umidades, observa-se que principalmente o furo SP01 apresenta teores de umidades menores que os demais, confirmando que ocorre variabilidade espacial no local do ensaio. Porém, no metro analisado na Figura 65, os teores de umidade são muito próximos. Assim, a diferença nos teores de umidade não parece ser a causa para a diferença das curvas apresentadas na Figura 64. 


\section{CONCLUSÕES}

Neste trabalho foram realizados ensaios de penetração dinâmica com energia crescente no amostrador SPT, avaliando-se o comportamento de fatores, tais como as energias envolvidas no ensaio e as resistências atuantes no amostrador. Conclui-se que a consideração do peso do sistema no cálculo da energia que chega à seção instrumentada é importante e necessária principalmente para o cálculo da quantidade de energia que chega na base do conjunto de hastes. $\mathrm{O}$ acréscimo de energia devido ao peso do sistema pode superar a perda de energia devido à propagação da onda de tensão, podendo a energia na base atingir valores iguais aos verificados no topo do conjunto de hastes. Quanto maior o comprimento de hastes e quanto menor a altura de queda maior a necessidade de se considerar o peso do sistema no cálculo da energia que atinge a seção instrumentada.

Se a eficiência for calculada em relação à $E P_{\text {sistema, }}$ ou seja, levando em consideração o acréscimo de energia devido à penetração do amostrador, a altura de queda não afeta a eficiência do ensaio. Se o ensaio SPT for realizado com diferentes alturas de queda do martelo, é válido considerar a média das eficiências entre todos os golpes, mesmo que a altura de queda seja variável ou que ocorra variação do comprimento de hastes. Essas conclusões valem apenas para a eficiência calculada considerando a penetração permanente do amostrador, conforme proposto por Odebrecht (2003). Se a eficiência for calculada em relação à energia potencial teórica $(E P T)$ a eficiência pode atingir valores superiores a $100 \%$, o que é um contrassenso.

A relação entre a quantidade de energia entregue ao sistema e altura de queda do martelo segue uma tendência linear. A partir das equações das retas ajustadas é possível calcular a eficiência e estimar possíveis erros de elevação do martelo que possa ter ocorrido no ensaio. Quanto menor a altura de queda do martelo, maior a sensibilidade na elevação do martelo, ou seja, mais difícil a execução do ensaio.

Levando em consideração a penetração permanente do amostrador, o comprimento de hastes não afeta os valores de eficiência. Essa conclusão também foi observada por Odebrecht et al. (2015), Lukiantchuki et al. (2015), entre outros.

Em relação às resistências obtidas, observa-se que independentemente do método utilizado é possível obter a curva resistência versus deslocamento a partir desse ensaio. Os diferentes métodos aplicados para o cálculo da resistência resultam em curvas de resistência mobilizada versus deslocamento com formatos similares e com a mesma ordem de grandeza. A partir dessas curvas é possível aplicar interpretações e extrapolações para melhor 
compreender o comportamento da resistência do solo. Maiores alturas de queda do martelo mobilizam maiores resistências até o momento que não se tem mais resistência a ser mobilizada. Assim, mesmo com o acréscimo da altura de queda, a resistência mobilizada tende, na maioria das vezes, a um valor constante. Este efeito também foi observado por Aoki (2000). O comportamento do perfil de resistência última $\left(R_{u}\right)$ determinada para cada profundidade é similar ao comportamento do perfil de $N_{S P T}$ e $q_{c}$.

As resistências obtidas a partir dos ensaios dinâmicos mostraram-se mais elevadas do que aquelas obtidas a partir do ensaio de penetração estática. Provavelmente esta diferença ocorreu pelo fato do ensaio estático ter sido iniciado com a ponta do amostrador simplesmente apoiada na superfície do fundo do furo.

O ensaio para determinação da força de atrito interno não parece ser efetivo para o ensaio realizado com energia crescente. Isto porque a força de atrito é medida somente ao final da sequência de golpes, não sendo possível se conhecer o valor da força de atrito correspondente a cada golpe. Para se analisar esses resultados foi necessário se fazer uma série de suposições e considerações. O ideal seria desenvolver um método para estimar a força de atrito interno correspondente à cada golpe, assim como medir o comprimento da amostra também à cada golpe.

\section{RECOMENDAÇÕES DE TRABALHOS FUTUROS}

A fim de dar continuidade nesta pesquisa, recomenda-se:

- Realizar ensaios em maiores profundidades para avaliar a influência da altura de queda em maiores comprimentos de hastes;

- Realizar ensaios em solos com maiores resistências;

- Realizar ensaios de penetração dinâmica com energia crescente no amostrador SPT, fazendo com que seu início seja após a penetração convencional do amostrador para a determinação do índice $N_{S P T}$;

- Desenvolver um programa para a solução da equação da onda aplicado ao ensaio SPT, incluindo a possibilidade de se considerar a variação da altura de queda do martelo;

- Realizar ensaios de penetração estática a cada metro de profundidade, imediatamente após a execução dos golpes para a determinação do índice NSPT; 


\section{REFERÊNCIAS}

ABNT - Associação Brasileira de Normas Técnicas (2001). NBR 6484 - Solo: sondagem de simples reconhecimento com SPT - método de ensaio. 2001. 17 p. Rio de Janeiro.

Abou-Matar, H.; Goble, G. G. SPT Dynamic Analysis and Measurements. Journal of Geotechnical and Geonvironmental Engineering. ASCE, v. 123, n. 10, p. 921-928, 1997.

Aoki, N. Determinação da capacidade de carga última de estaca crava em um ensaio de carregamento dinâmico de energia crescente. 1997. 111p. v.1. Tese (Doutorado em Geotecnia) Escola de Engenharia de São Carlos, Universidade de São Paulo, São Carlos.

Aoki, N. Inovação no SPT. In: Cintra, J.C.A.; Aoki, N; Tsuha, C.H.C.; Giacheti, H.L. Fundações: ensaios estáticos e dinâmicos. São Paulo: Oficina de Textos, 2013. Cap.2, p. 2538, 2013.

Aoki, N. Keynote lecture: Improving the reliability of pile bearing capacity prediction by the dynamic increasing energy test (DIET). In: VI International Conference on The Application of Stress-Wave Theory to Piles, São Paulo, Anais. P. 635-649, 2000.

Aoki, N.; Cintra, J.C.A. The application of energy Conservation Hamilton's Principle to The Determination of Energy Efficiency in SPT Tests. In: International Conference on The Application of Stress Wave Theory to Piles, 6., 2000, São Paulo, vol. 1, p 457-460.

Aoki, N.; Neves, L.F.S.; Esquivel, E.R.; Cintra, J.C.A. Prova de carga estática no amostrador SPT para obtenção da eficiência e da resistência estática em solos arenosos. Solos e Rochas. v.27, p. 147-160, 2004.

Aoki, N; Esquivel, E.R; Neves, L.F.S; Cintra, J.C.A. The impact efficiency obtained from static load test performed on the SPT sampler. Soils and Foundation, v. 47, n. 6, p. 1045-1052, 2007.

Belicanta, A., Ferraz, R. L. Fundamentos e métodos de medidas de energia dinâmica no SPT. Acta Scientiarum, UEM, v. 22, n. 5, p 1473-1482, 2000.

Belincanta, A. Avaliação de fatores intervenientes no índice de resistência à penetração do SPT. 1998. 141p, v.1. Tese (Doutorado em Geotecnia) - Escola de Engenharia de São Carlos, Universidade de São Paulo, São Carlos.

Belincanta, A. Energia dinâmica no SPT - Resultados de uma investigação teórico experimental. 1985. Dissertação (Mestrado em Engenharia) - Escola Politécnica da Universidade de São Paulo, São Paulo.

Bernardes, G. P. Dynamic and Static Testing of Large Model Piles in Sand. 1989. Tese (Doutorado em Engenharia) - Institutt for Geoteknikk, Universitetet I Trondheim.

Bortolucci, A. Caracterização Geológico-Geotécnica da Região Urbana de São Carlos, a partir de Ensaios de Simples Reconhecimento. 1983. Dissertação (Mestrado em Geotecnia) Escola de Engenharia de São Carlos, Universidade de São Paulo, São Carlos.

Cavalcante, E.H. Investigação teórico-experimental sobre SPT. 2002. 410p. v.1. Tese (Doutorado em Ciências em Engenharia Civil) - Universidade Federal do Rio de Janeiro, COPPE/UFRJ, Rio de Janeiro. 
Cavalcante, E.H.; Danziger, B.R.; Danziger, F.A.B. Measurement of Drop Height and Impact Velocity in the Brazilian SPT System. Soil and Rocks. v. 34(3), p. 207-218, 2011.

Cintra, J.C.A.; Aoki, N. Prova de Carga Estática em Estaca. In: Cintra, J.C.A.; Aoki, N; Tsuha, C.H.C.; Giacheti, H.L. Fundações: ensaios estáticos e dinâmicos. São Paulo: Oficina de Textos, 2013. Cap.4, p. 55-96, 2013.

Daniel, C.R.; Howie, J.A.; Jackson, R.S.; Walker, B. Review of Standard Penetration Test Short Rod Corrections. Journal of Geotechnical and Geoenvironmental Engineering - ASCE, v. 131, n. 4, p. 489-497, 2005.

De Mio, G. Condicionantes geológicos na interpretação de ensaios de piezocone para identificação estratigráfica na investigação geotécnica e geoambiental. 2005. 359 f. Tese (Doutorado em Geotecnia) Escola de Engenharia de São Carlos, Universidade de São Paulo, São Carlos, 2005.

Eberle, C. R. Determinação da eficiência de um equipamento automático para a realização de ensaios SPT. 2018. 179p. Dissertação (Mestrado em Geotecnia) - Escola de Engenharia de São Carlos, Universidade de São Paulo, São Carlos.

Fellenius, B.H. Analysis form Routine Static Loading Tests with Emphasis on the Bidirectional Test. In: Anais do XVII Congresso Brasileiro de Mecânica dos Solos e Engenharia Geotécnica, Goiânia, 2014.

Ferreira, M.Q., Tsuha, C.H. C., Schiavon, J.A.; Aoki, N. Determination of SPT End Bearing and Side Friction Resistances Using Static Uplift Tests, Geotechnical Testing Journal, Vol. 39, No. 6, p. 1040-1047, 2016.

Giacheti, H.L.; Peixoto, A.S.P.; Mondelli, G. Comparação entre Resultados de Ensaios de Penetração com os Cones Mecânico e Elétrico em Solos Tropicais. Solos e Rochas, v.27, n. 2, p. 191-200, 2004.

Graff, K. F. Wave Motion in Elastic Solids. Dover Publications, New York, 1991.

Hussein, M. H.; Goble, G. G. A Brief History of the Application of Stress-Wave Theory to Piles. Current Practices and Future Trends in Deep Foudations. Geotechnical Special Publication. American Society of Civil Engineers, Reston, p. 186-201, 2004.

Kovacks, W.D., Salomone, L.A. SPT Hammer energy measurement. Journal. Journal of the Geotechnical Engineering Division - ASCE, v.108, n. GT4, p.599-620, 1982.

Lee, C.; Lee, J.; Na, S.; Lee, W. Effect of Secondary Impacts on SPT Rod Energy and Sampler Penetration, Journal of Geotechnical and Geoenvironmental Engineering - ASCE. v. 136 (3), p. 522-526, 2010.

Lobo, B.O. Mecanismo de Penetração Dinâmica em Solos Granulares. 2009. 231p. Tese (Doutorado em Engenharia Civil) - Universidade Federal do Rio Grande do Sul, Porto Alegre.

Lukiantchuki, J. A. Interpretação de Resultados do Ensaio SPT com Base em Instrumentação Dinâmica. 2012. 358p. Tese (Doutorado em Geotecnia) - Escola de Engenharia de São Carlos, Universidade de São Paulo, São Carlos.

Lukiantchuki, J. A.; Bernardes, G. P.; Esquivel, E. R. Experimental Soil Dynamic Force: an Improvement of Standard Penetration Test (SPT) Interpretation. In: Proc., 4th International 
Conference on Geotechnical and Geophysical Site Characterization, Porto de Galinhas, Brazil, 2013.

Lukiantchuki, J. A.; Bernardes, G. P.; Esquivel, E. R. Interpretation of Force and Acceleration Signals During Hammer Impact in SPT test. In: Proc., 14th Pan-American Conference on Soil Mechanics and Geotechnical Engineering, Toronto, Canadá, 2011.

Lukiantchuki, J. A.; Bernardes, G. P.; Esquivel, E.R. Efficiency in standard penetration test. In: Proceedings of the XVI ECSMGE Geotechnical Engineering for Infrastructure and Development, Edinburgh, 2015.

Lukiantchuki, J.A.; Bernardes, G.P.; Esquivel, E. R. Energy Ratio $\left(E_{R}\right)$ for the Standard Penetration Test Based on Measured Fiel Tests. Soil and Rocks. v. 40(2), p. 77-91, 2017.

Machado, S.L. Aplicação de conceitos de elastoplasticidade a solos não saturados. 1998. 361. Tese (Doutorado em Geotecnia) - Escola de Engenharia de São Carlos, Universidade de São Paulo, 1998.

Morais, T.S.O. Interpretação racional de resultados de ensaios SPT com base em conceitos de energia. 2014, 237p. Dissertação (Mestrado em Geotecnia) - Escola de engenharia de São Carlos, Universidade de São Paulo. São Carlos.

Neves, L. F. S. Metodologia para a determinação das eficiências do ensaio SPT através de prova de carga estática sobre o amostrador padrão. 2004. 90p. Dissertação (Mestrado em Geotecnia) - Escola de Engenharia de São Carlos, Universidade de São Paulo, São Carlos.

Noreña, P.C.T. Estimativa da Eficiência no Ensaio SPT Através da Execução da Prova de Carga Estática Sobre o Amostrador. 2011. 187p. Dissertação (Mestrado em Geotecnia) Escola de Engenharia de São Carlos, Universidade de São Paulo, São Carlos.

Odebrecht, E. Medidas de energia no ensaio do SPT. 2003. 230p. Tese (Doutorado em Engenharia Civil). Universidade Federal do Rio Grande do Sul. Porto Alegre.

Odebrecht, E; Schnaid, F; Rocha, M.M; Bernardes, G. P. Energy Efficiency for Standard Penetration Tests. Journal of Geotechnical and Geonviranmental Engineering. ASCE. p. 1252-1263, 2005.

Odebrecht, E; Schnaid, F; Rocha, M.M; Bernardes, G.P. Transferência de Energia no Ensaio SPT: Efeito do Comprimento de Hastes e da Magnitude dos Deslocamentos. Solos e Rochas. ABMS. v. 27, n.1, p. 69-82, 2004.

Peixoto, A.S.P. Estudo do Ensaio SPT-T em sua Aplicação na Prática de Engenharia de Fundações. 2001. 468p. Tese (Doutorado) - Universidade Estadual de Campinas/ FEAGRI. Campinas, SP.

Quintero-Baños, J.P. Modelagem numérica dos fenômenos que ocorrem durante a penetração do amostrador SPT no solo. 2016. 140 p. Dissertação (Mestrado em Geotecnia) - Escola de Engenharia de São Carlos, Universidade de São Paulo, São Carlos.

Rausche, F., Thendean, G., Abou-Matar, H., Likins, G.E., Goble, G.G. Investigation of Dynamic and Static Pile Behavior From Modified Standard Penetration Tests. Notes from PDA Users Day in Cleveland, OH, Pile Dynamics, Inc., Cleveland, OH, 1995. p.1 - 30. 
Rocha, B.P. Caracterização Geotécnica de Solos Tropicais Não Saturados por meio de Ensaios de Campo. 2018, 240f. Tese (Doutorado em Geotecnia) - Escola de Engenharia de São Carlos, Universidade de São Paulo, São Carlos, 2018.

Santana, C. M. SPT Instrumentado em Câmara de Calibração. 2015. 251p. Tese (Doutorado em Ciências em Engenharia Civil) - COPPE, Universidade Federal do Rio de Janeiro, Rio de Janeiro.

Santana, C.M.; Danziger, F.A.B., Danziger, B.R. The Measurement of Energy Reaching the Sampler in SPT. In: 4th International Conference on Geotechnical and Geophysical Site Characterization, 2013. Porto de Galinhas.

Schmertmann, J.H., Palacios, A. Energy dunamics of SPT. Journal of the Geotechnical Engineering Division - ASCE, v.105, n.GT8, p.909-926, Aug 1979.

Schnaid, F.; Lourenço, D.; Odebrecht, E. Interpretation of Static and Dynamic Penetration Tests in Coarse-Grained Soils. Géotechnique Letters. v.7(2), p. 113-118, 2017.

Schnaid, F.; Odebrecht, E.; Lobo, B.O.; Rocha, M.M. Discussion of "SPT Hammer Energy Ratio versus Drop Height" by T. Leslie Youd, Hannah W. Bartholomew, and Hamison H. Steidl. Journal of Geotechnical and Geoenvironmental Engineering - ASCE. v. 135 (11), p. 1777-1778, 2009b.

Schnaid, F.; Odebrecht, E.; Rocha, M. M; Bernardes, G. P. Prediction of Soil Properties from the Concepts of Energy Transfer in Dynamic Penetration Tests. Journal of Geotechnical and Geoenvironmental Engineering - ASCE, v. 135, n. 8, p. 1092-1100, 2009a.

Seed, R.B.; Tokimatsu, K.; Harder, L.F.; Chung, R.M. Influence os SPT Procedures in Soil Liquefaction Resistance Evaluations. Journal of Geotechnical Engineering Division - ASCE, v.111, n.12, p. 1425-1445, 1985.

Skempton, A.W. Standard penetration test procedures and the effects in sands of overburden pressure, relative density, particle size, ageing and overconsolidation. Géotechnique, v.36, n.3, p.425-447, 1986.

Smith, E. A. L. Pile-Driving Analysis by the Wave Equation. Journal of the Soil Mechanics and Foundation Division - ASCE, v. 86, n. SM4, p. 25-61, 1960.

Sy, A.; Campanella, R.G. Wave equation modeling of SPT. In: ASCE Geotechnical Engineering Congress, 1991, Boulder, Colorado. p. 8-23.

Teixeira, A.H. Sondagens, Prospecção do Subsolo. Recife, Anais. ABMS-NE. p. 39-61, 1977.

Tsuha, C.H.C, Cintra, J.C. A.; Aoki, N. Prova de Carga Estática em Estaca. In: Cintra, J.C.A.; Aoki, N; Tsuha, C.H.C.; Giacheti, H. L. Fundações: ensaios estáticos e dinâmicos. São Paulo: Oficina de Textos, 2013. Cap.5, p. 97-133, 2013.

Velloso, D.A.; Lopes, F.R. Fundações: critérios de projeto, investigação do subsolo, fundações superficiais, fundações profundas. 2. ed. São Paulo: Oficina de Textos, 2010.

Yokel, F. Y. Energy Transfer Mechanism in SPT. Journal of Geotechnical Engineering. ASCE. v. 115 (9), p. 1331-1336, 1989. 
Youd, T. L.; Bartholomew, H. W.; Steidl, J. H. SPT Hammer Energy Ratio versus Drop Height. Journal of Geotechnical and Geoenvironmental Engineering. ASCE, v. 134, n. 3, p. 397 400, 2008.

Zapata, J. G, Estimativa das tensões médias internas e externas no amostrador SPT durante sua cravação. 2015. 178 p. Dissertação (Mestrado) - Escola de Engenharia de São Carlos, Universidade de São Paulo, São Carlos.

Zapata-Galvis, J.; Esquivel, E.R. Evaluation of Internal and External Stresses on th SPT Sampler. DYNA. v. 83 (195), p. 229-236, 2016. 
ANEXO 


\section{Lista de Figuras}

Figura A1 - Sinais típicos de SPT instrumentado para o furo SP01, profundidade de $2 \mathrm{~m}$ e $H_{q}$ de $100 \mathrm{~mm}$.

Figura A2 - Sinais típicos de SPT instrumentado para o furo SP01, profundidade de $2 \mathrm{~m}$ e $H_{q}$ de $200 \mathrm{~mm}$.

Figura A3 - Sinais típicos de SPT instrumentado para o furo SP01, profundidade de $2 \mathrm{~m}$ e $H_{q}$ de $300 \mathrm{~mm}$.

Figura A4 - Sinais típicos de SPT instrumentado para o furo SP01, profundidade de $2 \mathrm{~m}$ e $H_{q}$ de $400 \mathrm{~mm}$. 132

Figura A5 - Sinais típicos de SPT instrumentado para o furo SP01, profundidade de $2 \mathrm{~m}$ e $H_{q}$ de $500 \mathrm{~mm}$.

Figura A6 - Sinais típicos de SPT instrumentado para o furo SP01, profundidade de $2 \mathrm{~m}$ e $H_{q}$ de $600 \mathrm{~mm}$.

Figura A7 - Sinais típicos de SPT instrumentado para o furo SP01, profundidade de $2 \mathrm{~m}$ e $H_{q}$ de $750 \mathrm{~mm}$.

Figura A8 - Sinais típicos de SPT instrumentado para o furo SP01, profundidade de $3 \mathrm{~m}$ e $H_{q}$ de $100 \mathrm{~mm}$.

Figura A9 - Sinais típicos de SPT instrumentado para o furo SP01, profundidade de $3 \mathrm{~m}$ e $H_{q}$ de $200 \mathrm{~mm}$.

Figura A10 - Sinais típicos de SPT instrumentado para o furo SP01, profundidade de $3 \mathrm{~m}$ e $\mathrm{H}_{q}$ de $300 \mathrm{~mm}$.

Figura A11 - Sinais típicos de SPT instrumentado para o furo SP01, profundidade de $3 \mathrm{~m}$ e $H_{q}$ de $400 \mathrm{~mm}$.

Figura A12 - Sinais típicos de SPT instrumentado para o furo SP01, profundidade de $3 \mathrm{~m}$ e $H_{q}$ de $600 \mathrm{~mm}$.

Figura A13 - Sinais típicos de SPT instrumentado para o furo SP01, profundidade de $3 \mathrm{~m}$ e $H_{q}$ de $750 \mathrm{~mm}$.

Figura A14 - Sinais típicos de SPT instrumentado para o furo SP01, profundidade de $4 \mathrm{~m}$ e $H_{q}$ de $100 \mathrm{~mm}$.

Figura A15 - Sinais típicos de SPT instrumentado para o furo SP01, profundidade de $4 \mathrm{~m}$ e $H_{q}$ de $200 \mathrm{~mm}$.

Figura A16 - Sinais típicos de SPT instrumentado para o furo SP01, profundidade de $4 \mathrm{~m}$ e $H_{q}$ de $300 \mathrm{~mm}$.

Figura A17 - Sinais típicos de SPT instrumentado para o furo SP01, profundidade de $4 \mathrm{~m}$ e $H_{q}$ de $400 \mathrm{~mm}$.

Figura A18 - Sinais típicos de SPT instrumentado para o furo SP01, profundidade de $4 \mathrm{~m}$ e $H_{q}$ de $500 \mathrm{~mm}$.

Figura A19 - Sinais típicos de SPT instrumentado para o furo SP01, profundidade de $4 \mathrm{~m}$ e $H_{q}$ de $600 \mathrm{~mm}$. 
Figura A20 - Sinais típicos de SPT instrumentado para o furo SP01, profundidade de $4 \mathrm{~m}$ e $\mathrm{H}_{q}$ de $750 \mathrm{~mm}$.

Figura A21 - Sinais típicos de SPT instrumentado para o furo SP01, profundidade de $5 \mathrm{~m}$ e $H_{q}$ de $100 \mathrm{~mm}$.

Figura A22 - Sinais típicos de SPT instrumentado para o furo SP01, profundidade de $5 \mathrm{~m}$ e $\mathrm{H}_{q}$ de $200 \mathrm{~mm}$.

Figura A23 - Sinais típicos de SPT instrumentado para o furo SP01, profundidade de $5 \mathrm{~m}$ e $\mathrm{H}_{q}$ de $300 \mathrm{~mm}$.

Figura A24 - Sinais típicos de SPT instrumentado para o furo SP01, profundidade de $5 \mathrm{~m}$ e $H_{q}$ de $400 \mathrm{~mm}$.

Figura A25 - Sinais típicos de SPT instrumentado para o furo SP01, profundidade de $5 \mathrm{~m}$ e $H_{q}$ de $500 \mathrm{~mm}$ - Erro na instrumentação inferior.

Figura A26 - Sinais típicos de SPT instrumentado para o furo SP01, profundidade de $5 \mathrm{~m}$ e $\mathrm{H}_{q}$ de $600 \mathrm{~mm}$.

Figura A27 - Sinais típicos de SPT instrumentado para o furo SP01, profundidade de $5 \mathrm{~m}$ e $H_{q}$ de $750 \mathrm{~mm}$.

Figura A28 - Sinais típicos de SPT instrumentado para o furo SP01, profundidade de $6 \mathrm{~m}$ e $H_{q}$ de $100 \mathrm{~mm}$

Figura A29 - Sinais típicos de SPT instrumentado para o furo SP01, profundidade de $6 \mathrm{~m}$ e $\mathrm{H}_{q}$ de $200 \mathrm{~mm}$

Figura A30 - Sinais típicos de SPT instrumentado. profundidade de: $6 \mathrm{~m}$; Lh: $6.77 \mathrm{~m} ; \mathrm{H}_{q}: 300$ $\mathrm{mm}$.

Figura A31 - Sinais típicos de SPT instrumentado para o furo SP01, profundidade de $6 \mathrm{~m}$ e $H_{q}$ de $400 \mathrm{~mm}$

Figura A32 - Sinais típicos de SPT instrumentado para o furo SP01, profundidade de $6 \mathrm{~m}$ e $H_{q}$ de $500 \mathrm{~mm}$.

Figura A33 - Sinais típicos de SPT instrumentado para o furo SP01, profundidade de $6 \mathrm{~m}$ e $H_{q}$ de $600 \mathrm{~mm}$.

Figura A34 - Sinais típicos de SPT instrumentado para o furo SP01, profundidade de $6 \mathrm{~m}$ e $\mathrm{H}_{q}$ de $750 \mathrm{~mm}$.

Figura A35 - Sinais típicos de SPT instrumentado para o furo SP02, profundidade de $2 \mathrm{~m}$ e $\mathrm{H}_{q}$ de $100 \mathrm{~mm}$. 163

Figura A36 - Sinais típicos de SPT instrumentado para o furo SP02, profundidade de $2 \mathrm{~m}$ e $H_{q}$ de $200 \mathrm{~mm}$. 164

Figura A37 - Sinais típicos de SPT instrumentado para o furo SP02, profundidade de $2 \mathrm{~m}$ e $H_{q}$ de $300 \mathrm{~mm}$. 165

Figura A38 - Sinais típicos de SPT instrumentado para o furo SP02, profundidade de $2 \mathrm{~m}$ e $\mathrm{H}_{q}$ de $400 \mathrm{~mm}$ 166

Figura A39 - Sinais típicos de SPT instrumentado para o furo SP02, profundidade de $2 \mathrm{~m}$ e $\mathrm{H}_{q}$ de $500 \mathrm{~mm}$.

Figura A40 - Sinais típicos de SPT instrumentado para o furo SP02, profundidade de $2 \mathrm{~m}$ e $H_{q}$ de $600 \mathrm{~mm}$ 
Figura A41- Sinais típicos de SPT instrumentado para o furo SP02, profundidade de $3 \mathrm{~m}$ e $\mathrm{H}_{q}$ de $200 \mathrm{~mm}$ - Falha no sinal de força da haste inferior.

Figura A42 - Sinais típicos de SPT instrumentado para o furo SP02, profundidade de $3 \mathrm{~m}$ e $\mathrm{H}_{q}$ de $300 \mathrm{~mm}$.

Figura A43 - Sinais típicos de SPT instrumentado para o furo SP02, profundidade de $3 \mathrm{~m}$ e $H_{q}$ de $400 \mathrm{~mm}$.

Figura A44 - Sinais típicos de SPT instrumentado para o furo SP02, profundidade de $3 \mathrm{~m}$ e $\mathrm{H}_{q}$ de $500 \mathrm{~mm}$.

Figura A45 - Sinais típicos de SPT instrumentado para o furo SP02, profundidade de $3 \mathrm{~m}$ e $\mathrm{H}_{q}$ de $600 \mathrm{~mm}$.

Figura A46 - Sinais típicos de SPT instrumentado para o furo SP02, profundidade de $3 \mathrm{~m}$ e $H_{q}$ de $750 \mathrm{~mm}$.

Figura A47 - Sinais típicos de SPT instrumentado para o furo SP02, profundidade de $5 \mathrm{~m}$ e $\mathrm{H}_{q}$ de $100 \mathrm{~mm}$.

Figura A48 - Sinais típicos de SPT instrumentado para o furo SP02, profundidade de $5 \mathrm{~m}$ e $H_{q}$ de $200 \mathrm{~mm}$.

Figura A49 - Sinais típicos de SPT instrumentado para o furo SP02, profundidade de $5 \mathrm{~m}$ e $H_{q}$ de $300 \mathrm{~mm}$.

Figura A50 - Sinais típicos de SPT instrumentado para o furo SP02, profundidade de $5 \mathrm{~m}$ e $\mathrm{H}_{q}$ de $400 \mathrm{~mm}$.

Figura A51 - Sinais típicos de SPT instrumentado para o furo SP02, profundidade de $5 \mathrm{~m}$ e $\mathrm{H}_{q}$ de $500 \mathrm{~mm}$.

Figura A52 - Sinais típicos de SPT instrumentado para o furo SP02, profundidade de $5 \mathrm{~m}$ e $H_{q}$ de $600 \mathrm{~mm}$.

Figura A53 - Sinais típicos de SPT instrumentado para o furo SP02, profundidade de $5 \mathrm{~m}$ e $\mathrm{H}_{q}$ de $750 \mathrm{~mm}$.

Figura A54 - Sinais típicos de SPT instrumentado para o furo SP02, profundidade de $6 \mathrm{~m}$ e $H_{q}$ de $100 \mathrm{~mm}$.

Figura A55 - Sinais típicos de SPT instrumentado para o furo SP02, profundidade de $6 \mathrm{~m}$ e $\mathrm{H}_{q}$ de $300 \mathrm{~mm}$.

Figura A56 - Sinais típicos de SPT instrumentado para o furo SP02, profundidade de $6 \mathrm{~m}$ e $\mathrm{H}_{q}$ de $400 \mathrm{~mm}$

Figura A57 - Sinais típicos de SPT instrumentado para o furo SP02, profundidade de $6 \mathrm{~m}$ e $\mathrm{H}_{q}$ de $600 \mathrm{~mm}$

Figura A58 - Sinais típicos de SPT instrumentado para o furo SP02, profundidade de $6 \mathrm{~m}$ e $H_{q}$ de $750 \mathrm{~mm}$.

Figura A59 - Sinais típicos de SPT instrumentado para o furo SP03, profundidade de $2 \mathrm{~m}$ e $\mathrm{H}_{q}$ de $100 \mathrm{~mm}$.

Figura A60 - Sinais típicos de SPT instrumentado para o furo SP03, profundidade de $2 \mathrm{~m}$ e $H_{q}$ de $200 \mathrm{~mm}$.

Figura A61 - Sinais típicos de SPT instrumentado para o furo SP03, profundidade de $2 \mathrm{~m}$ e $H_{q}$ de $300 \mathrm{~mm}$. 
Figura A62 - Sinais típicos de SPT instrumentado para o furo SP03, profundidade de $2 \mathrm{~m}$ e $\mathrm{H}_{q}$ de $400 \mathrm{~mm}$.

Figura A63 - Sinais típicos de SPT instrumentado para o furo SP03, profundidade de $2 \mathrm{~m}$ e $H_{q}$ de $500 \mathrm{~mm}$.

Figura A64 - Sinais típicos de SPT instrumentado para o furo SP03, profundidade de $3 \mathrm{~m}$ e $\mathrm{H}_{q}$ de $100 \mathrm{~mm}$.

Figura A65 - Sinais típicos de SPT instrumentado para o furo SP03, profundidade de $3 \mathrm{~m}$ e $\mathrm{H}_{q}$ de $200 \mathrm{~mm}$.

Figura A66 - Sinais típicos de SPT instrumentado para o furo SP03, profundidade de $3 \mathrm{~m}$ e $H_{q}$ de $300 \mathrm{~mm}$. 194

Figura A67 - Sinais típicos de SPT instrumentado para o furo SP03, profundidade de $3 \mathrm{~m}$ e $H_{q}$ de $400 \mathrm{~mm}$. 195

Figura A68 - Sinais típicos de SPT instrumentado para o furo SP03, profundidade de $3 \mathrm{~m}$ e $\mathrm{H}_{q}$ de $500 \mathrm{~mm}$. 196

Figura A69 - Sinais típicos de SPT instrumentado para o furo SP03, profundidade de $3 \mathrm{~m}$ e $H_{q}$ de $600 \mathrm{~mm}$. 197

Figura A70 - Sinais típicos de SPT instrumentado para o furo SP03, profundidade de $3 \mathrm{~m}$ e $H_{q}$ de $750 \mathrm{~mm}$ 198

Figura A71 - Sinais típicos de SPT instrumentado para o furo SP03, profundidade de $4 \mathrm{~m}$ e $H_{q}$ de $100 \mathrm{~mm}$.

Figura A72 - Sinais típicos de SPT instrumentado para o furo SP03, profundidade de $4 \mathrm{~m}$ e $\mathrm{H}_{q}$ de $200 \mathrm{~mm}$. 200

Figura A73 - Sinais típicos de SPT instrumentado para o furo SP03, profundidade de $4 \mathrm{~m}$ e $H_{q}$ de $300 \mathrm{~mm}$. 201

Figura A74 - Sinais típicos de SPT instrumentado para o furo SP03, profundidade de $4 \mathrm{~m}$ e $\mathrm{H}_{q}$ de $400 \mathrm{~mm}$. 202

Figura A75 - Sinais típicos de SPT instrumentado para o furo SP03, profundidade de $4 \mathrm{~m}$ e $H_{q}$ de $500 \mathrm{~mm}$. 203

Figura A76 - Sinais típicos de SPT instrumentado para o furo SP03, profundidade de $4 \mathrm{~m}$ e $H_{q}$ de $600 \mathrm{~mm}$. 204

Figura A77 - Sinais típicos de SPT instrumentado para o furo SP03, profundidade de $4 \mathrm{~m}$ e $\mathrm{H}_{q}$ de $750 \mathrm{~mm}$ 205

Figura A78 - Sinais típicos de SPT instrumentado para o furo SP03, profundidade de $5 \mathrm{~m}$ e $H_{q}$ de $100 \mathrm{~mm}$. 206

Figura A79 - Sinais típicos de SPT instrumentado para o furo SP03, profundidade de $5 \mathrm{~m}$ e $H_{q}$ de $200 \mathrm{~mm}$. 207

Figura A80 - Sinais típicos de SPT instrumentado para o furo SP03, profundidade de $5 \mathrm{~m}$ e $\mathrm{H}_{q}$ de $300 \mathrm{~mm}$ 208

Figura A81 - Sinais típicos de SPT instrumentado para o furo SP03, profundidade de $5 \mathrm{~m}$ e $H_{q}$ de $400 \mathrm{~mm}$ 209

Figura A82 - Sinais típicos de SPT instrumentado para o furo SP03, profundidade de $5 \mathrm{~m}$ e $H_{q}$ de $500 \mathrm{~mm}$ 
Figura A83 - Sinais típicos de SPT instrumentado para o furo SP03, profundidade de $5 \mathrm{~m}$ e $H_{q}$ de $600 \mathrm{~mm}$.

Figura A84 - Sinais típicos de SPT instrumentado para o furo SP03, profundidade de $5 \mathrm{~m}$ e $\mathrm{H}_{q}$ de $750 \mathrm{~mm}$.

Figura A85 - Sinais típicos de SPT instrumentado para o furo SP03, profundidade de $6 \mathrm{~m}$ e $H_{q}$ de $100 \mathrm{~mm}$.

Figura A86 Sinais típicos de SPT instrumentado para o furo SP03, profundidade de $6 \mathrm{~m}$ e $H_{q}$ de $200 \mathrm{~mm}$.

Figura A87 - Sinais típicos de SPT instrumentado para o furo SP03, profundidade de $6 \mathrm{~m}$ e $H_{q}$ de $300 \mathrm{~mm}$.

Figura A88 - Sinais típicos de SPT instrumentado para o furo SP03, profundidade de $6 \mathrm{~m}$ e $H_{q}$ de $400 \mathrm{~mm}$.

Figura A89 - Sinais típicos de SPT instrumentado para o furo SP03, profundidade de $6 \mathrm{~m}$ e $H_{q}$ de $600 \mathrm{~mm}$.

Figura A90 - Sinais típicos de SPT instrumentado para o furo SP03, profundidade de $6 \mathrm{~m}$ e $H_{q}$ de $750 \mathrm{~mm}$.

Figura A92 Avaliação da influência do peso do sistema nos valores de eficiência no topo e na base para os ensaios do furo SP01 e profundidades: a) 2 metros; b) 3 metros; c) 4 metros; d) 5 metros; e) 6 metros .

Figura A93 - Avaliação da influência do peso do sistema nos valores de eficiência no topo e na base para os ensaios do furo SP02 e profundidades: a) 2 metros; b) 3 metros; c) 5 metros; d) 6 metros.

Figura A94 - Avaliação da influência do peso do sistema nos valores de eficiência no topo e na base para os ensaios do furo SP03 e profundidades: a) 2 metros; b) 3 metros; c) 4 metros; d) 5 metros; e) 6 metros.

Figura A95 - Erro relativo entre as eficiências considerando o peso do sistema e sem considerar - furo SP01: a) topo; b) base.

Figura A96 - Erro relativo entre as eficiências considerando o peso do sistema e sem considerar - furo SP02: a) topo; b) base.

Figura A97 - Erro relativo entre as eficiências considerando o peso do sistema e sem considerar - furo SP03: a) topo; b) base. 233

Figura A98 - Eficiência calculada em relação à EPT no topo e na base para os ensaios do furo SP01 e profundidades: a) 2 metros; b) 3 metros; c) 4 metros; d) 5 metros; e) 6 metros. .......234

Figura A99 - Eficiência calculada em relação à EPT no topo e na base para os ensaios do furo SP02 e profundidades: a) 2 metros; b) 3 metros; c) 4 metros; d) 5 metros; e) 6 metros. .......235

Figura A100 - Eficiência calculada em relação à EPT no topo e na base para os ensaios do furo SP03 e profundidades: a) 2 metros; b) 3 metros; c) 4 metros; d) 5 metros; e) 6 metros. 236

Figura A101 - Eficiência em relação ao comprimento de hastes: a) furo SP01; b) furo SP02; c) furo SP03.

Figura A102 - Relação entre as energias envolvidas no ensaio e as alturas de queda do martelo aplicadas - furo SP01 profundidades: a) 2 metros; b) 3 metros; c) 4 metros; d) 5 metros; e) 6 metros. 
Figura A103 - Relação entre as energias envolvidas no ensaio e as alturas de queda do martelo aplicadas - furo SP02 profundidades: a) 2 metros; b) 3 metros; c) 4 metros; d) 5 metros; e) 6 metros.

Figura A104 - Relação entre as energias envolvidas no ensaio e as alturas de queda do martelo aplicadas - furo SP03 profundidades: a) 2 metros; b) 3 metros; c) 4 metros; d) 5 metros; e) 6 metros.

Figura A105 - Relação entre o trabalho $(W)$ calculado a partir de $R_{D}$ com a energia na base (Ebase): a) furo SP02; b) furo SP03. 248

Figura A105 - Relação entre o comprimento da amostra recuperada $(L a)$ e a penetração acumulada do amostrador $\left(\delta_{\text {acumulado }}\right)$ : a) furo SP01; furo SP02. 249

Figura A106 - Curva de resistência mobilizada versus deslocamento acumulado para o Furo furo SP02 e profundidades: a) 2 metros; b) 3 metros; c) 5 metros; d) 6 metros. 249

Figura A107 - Curva de resistência mobilizada versus deslocamento acumulado para o Furo furo SP03 e profundidades: a) 2 metros; b) 3 metros; c) 4 metros; d) 5 metros, e) 6 metros. 250 Figura A109 - Resultado do ensaio de atrito para furo SP01, profundidade de $3 \mathrm{~m}$............ 253

Figura A110 - Resultado do ensaio de atrito para furo SP01, profundidade de $4 \mathrm{~m}$............ 253

Figura A111 - Resultado do ensaio de atrito para furo SP01, profundidade de $5 \mathrm{~m}$............ 253

Figura A112 - Resultado do ensaio de atrito para furo SP01, profundidade de $6 \mathrm{~m}$. ........... 254

Figura A113 - Resultado do ensaio de atrito para furo SP02, profundidade de $3 \mathrm{~m}$........... 254

Figura A114 - Resultado do ensaio de atrito para furo SP02, profundidade de $5 \mathrm{~m}$........... 254

Figura A115 - Resultado do ensaio de atrito para furo SP02, profundidade de $6 \mathrm{~m}$........... 255

Figura A116 - Resultado do ensaio de atrito para furo SP02, profundidade de $2 \mathrm{~m}$........... 255

Figura A117 - Resultado do ensaio de atrito para furo SP03, profundidade de $3 \mathrm{~m}$............ 255

Figura A118 - Resultado do ensaio de atrito para furo SP03, profundidade de $4 \mathrm{~m}$. ........... 256

Figura A119 - Resultado do ensaio de atrito para furo SP03, profundidade de $5 \mathrm{~m}$. ........... 256

Figura A120 - Resultado do ensaio de atrito para furo SP03, profundidade de $6 \mathrm{~m}$............ 256 


\section{Lista de Tabelas}

Tabela A1 - Dados de deslocamento - furo SP01 ..........................................................221

Tabela A 2- Dados de deslocamento - furo SP02 ................................................................ 222

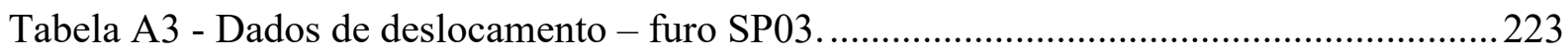

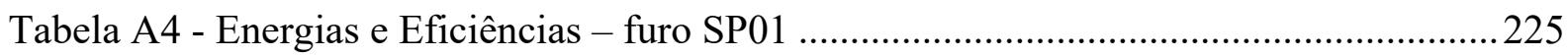

Tabela A5- Energias e Eficiências - furo SP02 …............................................................. 228

Tabela A6 - Energias e Eficiências - furo SP03 …..........................................................229

Tabela A7 - Eficiência calculada de forma convencional e pelos coeficientes angulares das

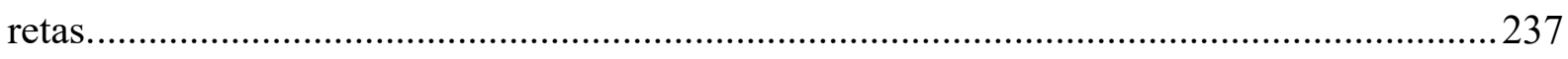

Tabela A8 - Previsão de alturas de queda efetivamente aplicadas - furo SP01 ....................241

Tabela A9 - Previsão de alturas de queda efetivamente aplicadas - furo SP02 ...................242

Tabela A10 - Previsão de alturas de queda efetivamente aplicadas - furo SP03..................243

Tabela A11 - Valores de resistências - furo SP01 ................................................................ 246

Tabela A12 - Valores de resistências - furo SP02 ...........................................................247

Tabela A13 - Valores de resistências - furo SP03 .............................................................. 248

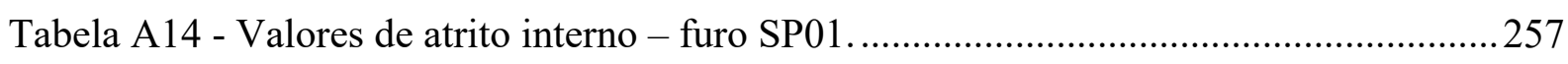

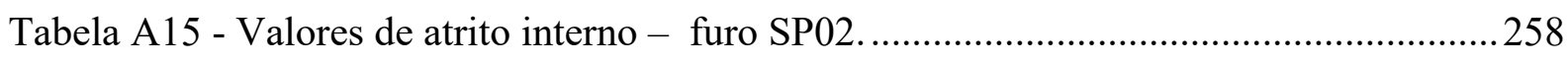


Resultados típicos dos ensaios SPT instrumentados 
Superior

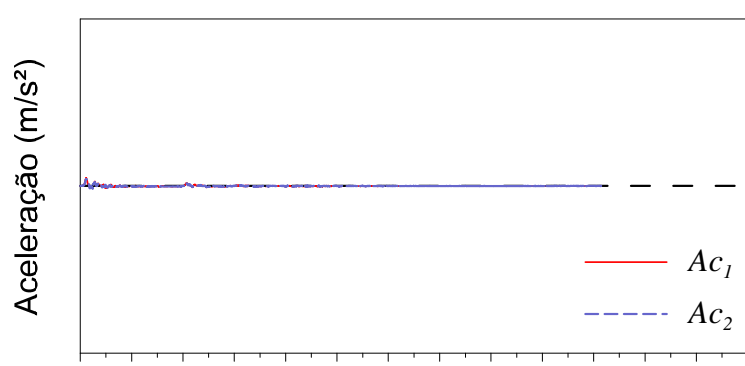

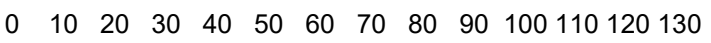
Tempo (ms)

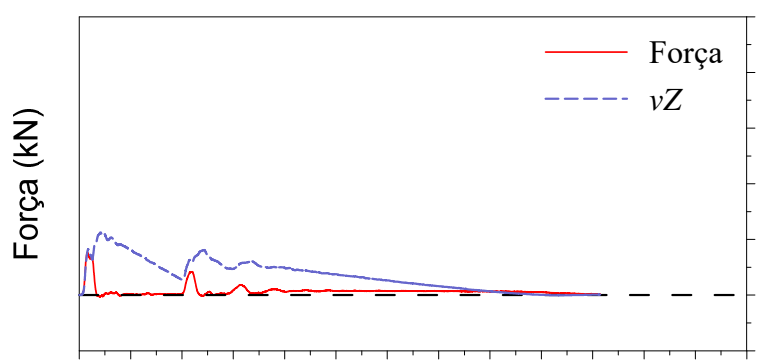

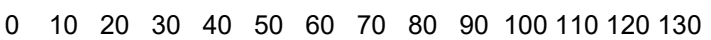
Tempo (ms)

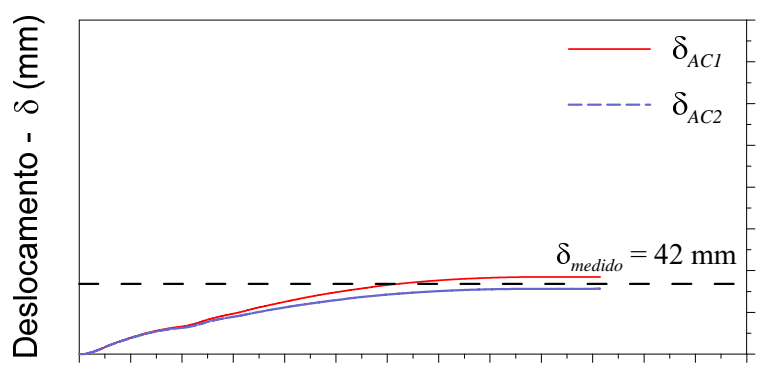

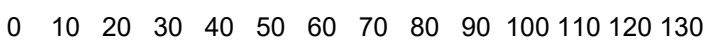
Tempo (ms)

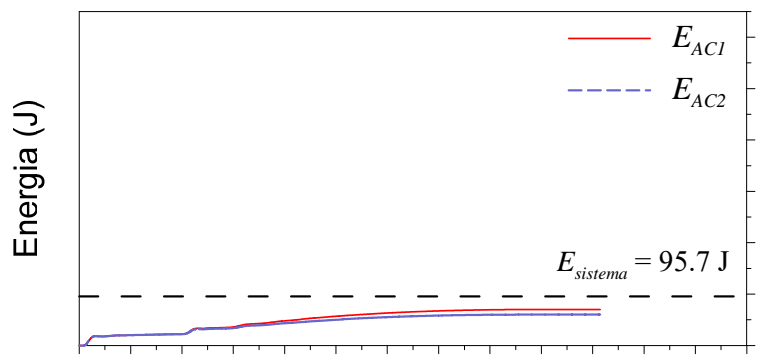

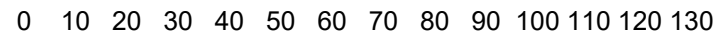
Tempo (ms)
Inferior

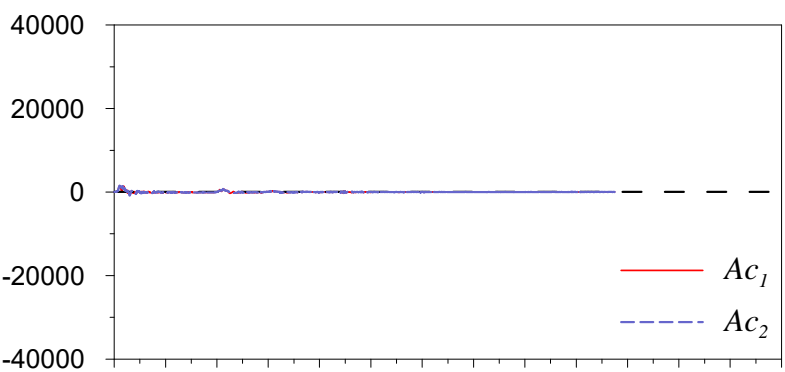

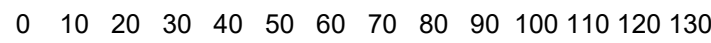

Tempo (ms)

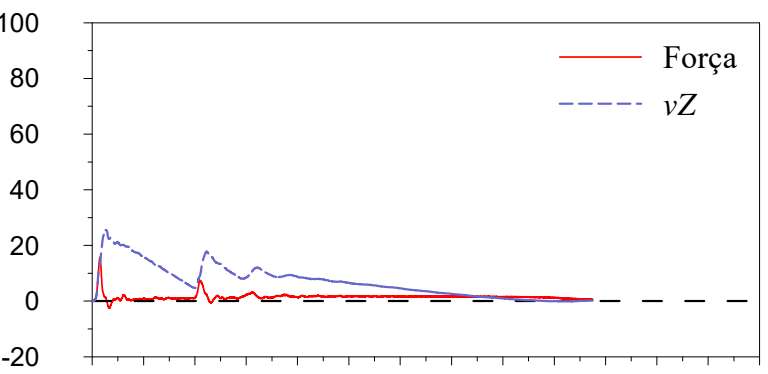

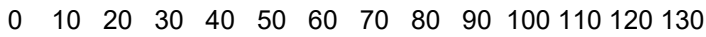
Tempo (ms)

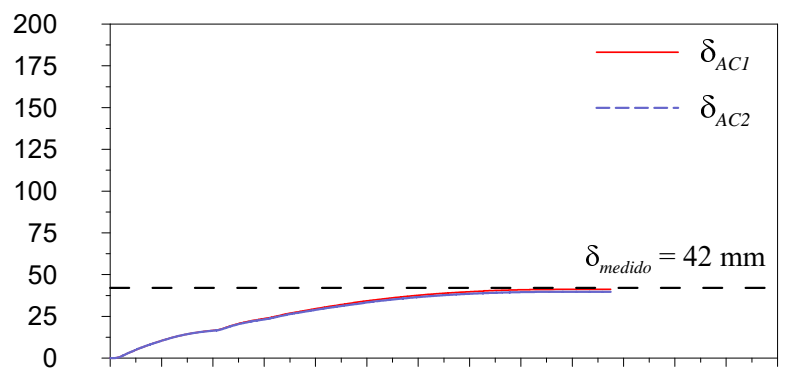

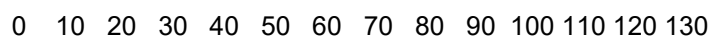
Tempo (ms)

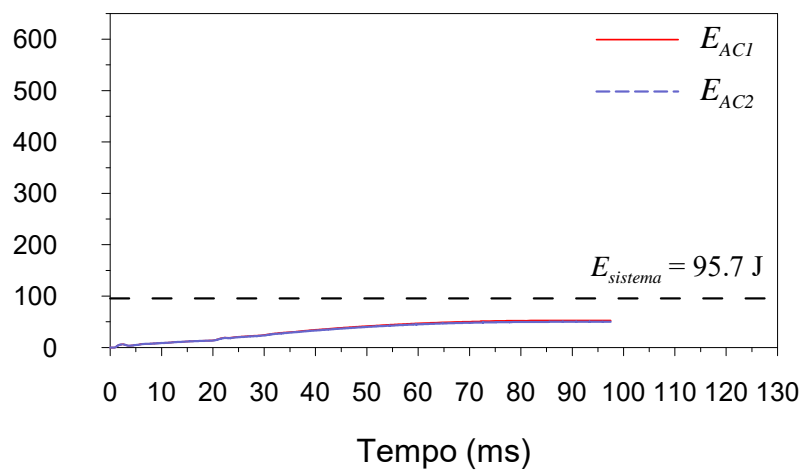

Figura A1 - Sinais típicos de SPT instrumentado para o furo SP01, profundidade de $2 \mathrm{~m}$ e $H_{q}$ de $100 \mathrm{~mm}$. 
Superior

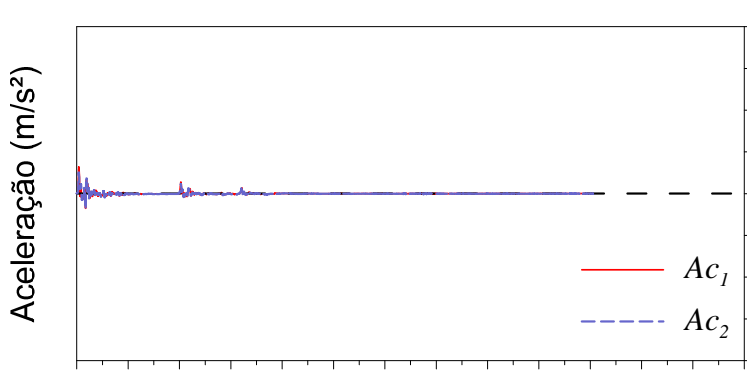

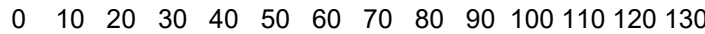

Tempo (ms)

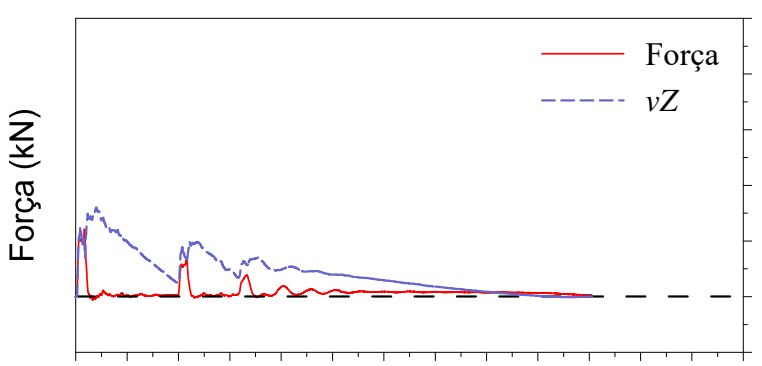

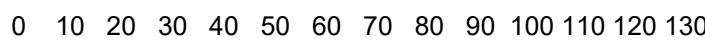

Tempo (ms)

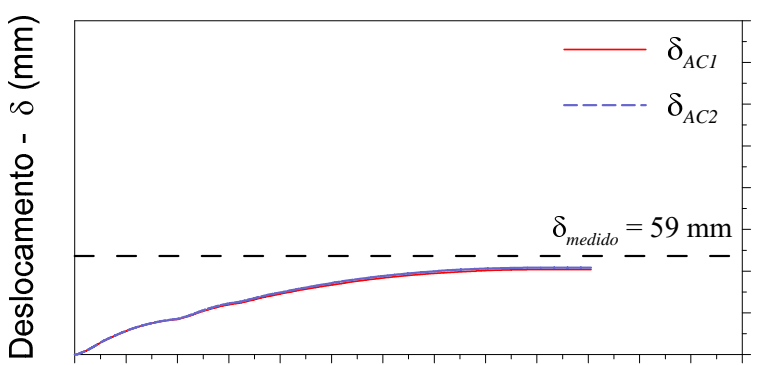

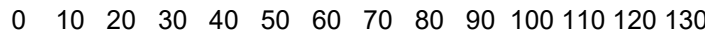

Tempo (ms)

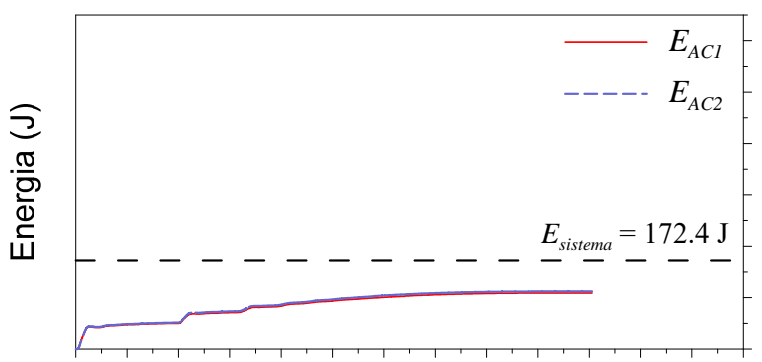

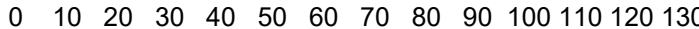

Tempo (ms)
Inferior

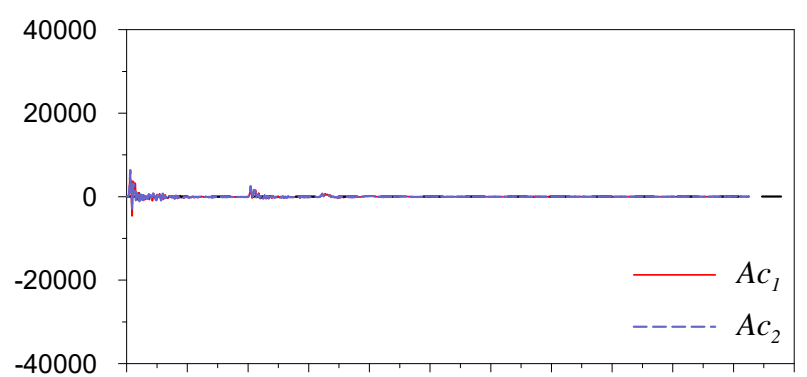

$\begin{array}{llllllllllll}0 & 10 & 20 & 30 & 40 & 50 & 60 & 70 & 80 & 90 & 100 & 110\end{array}$

Tempo (ms)

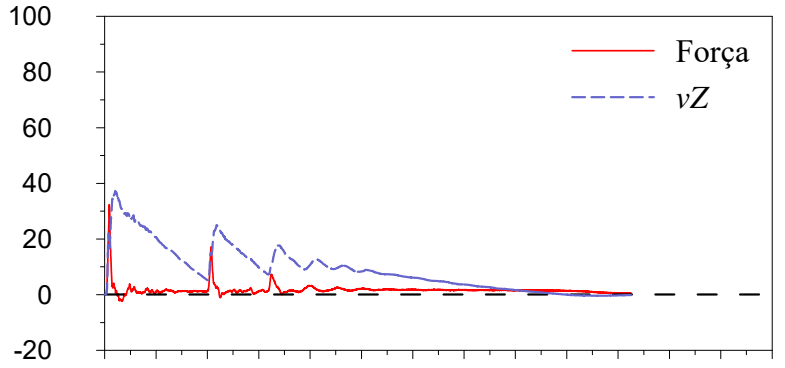

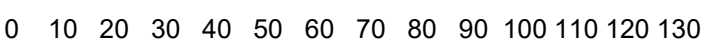
Tempo (ms)

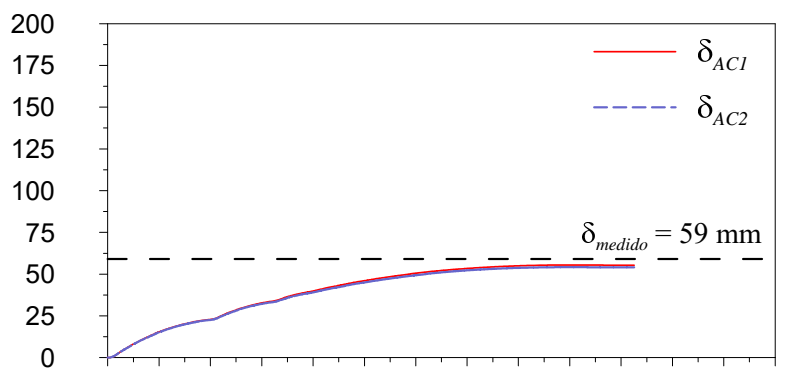

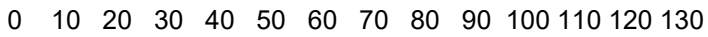

Tempo (ms)

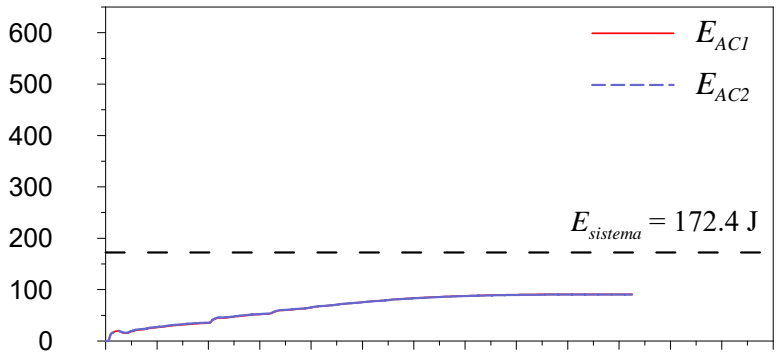

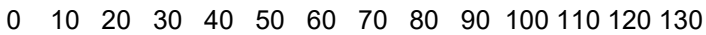
Tempo (ms)

Figura A2 - Sinais típicos de SPT instrumentado para o furo SP01, profundidade de $2 \mathrm{~m}$ e $H_{q}$ de $200 \mathrm{~mm}$. 

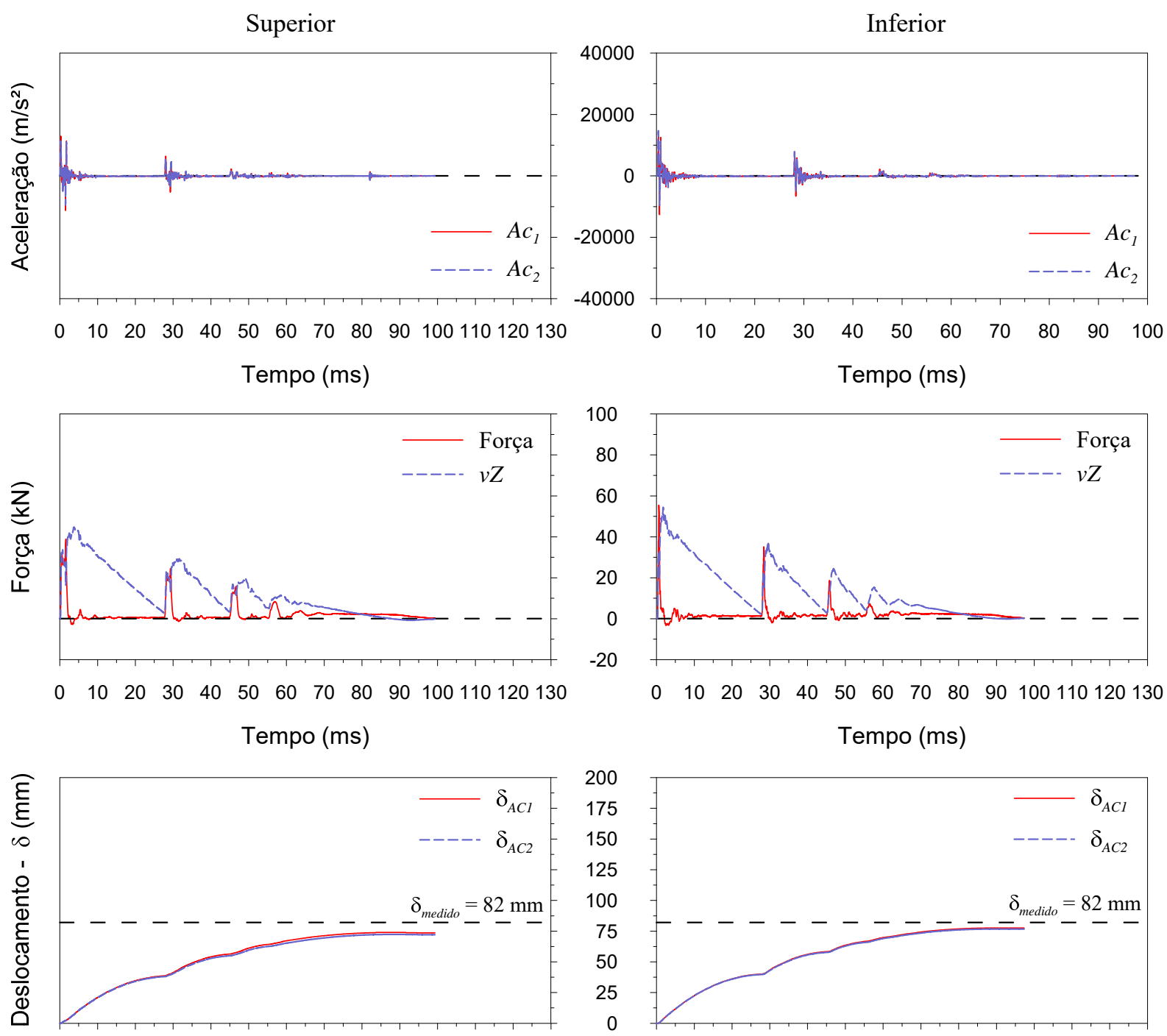

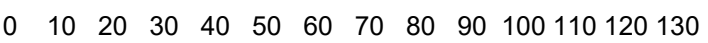
Tempo (ms)

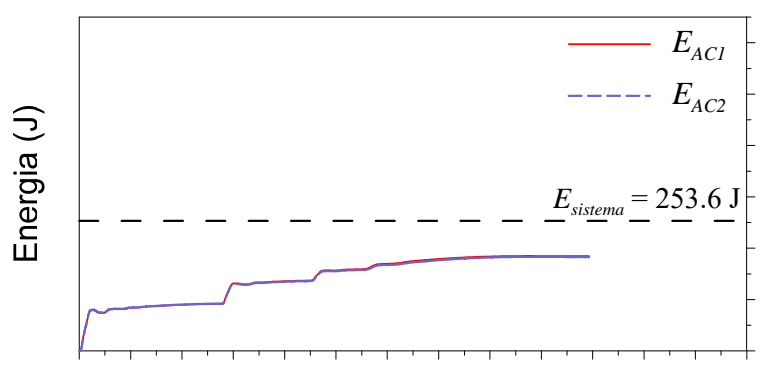

Tempo (ms)

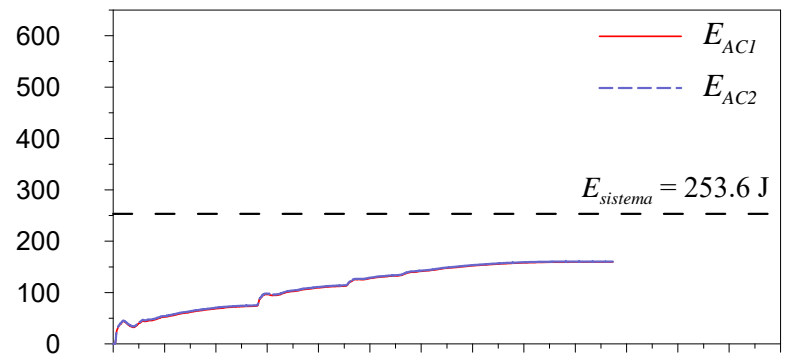

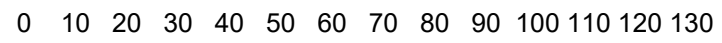

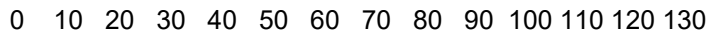
Tempo (ms)

Tempo (ms)

Figura A3 - Sinais típicos de SPT instrumentado para o furo SP01, profundidade de $2 \mathrm{~m}$ e $H_{q}$ de $300 \mathrm{~mm}$. 


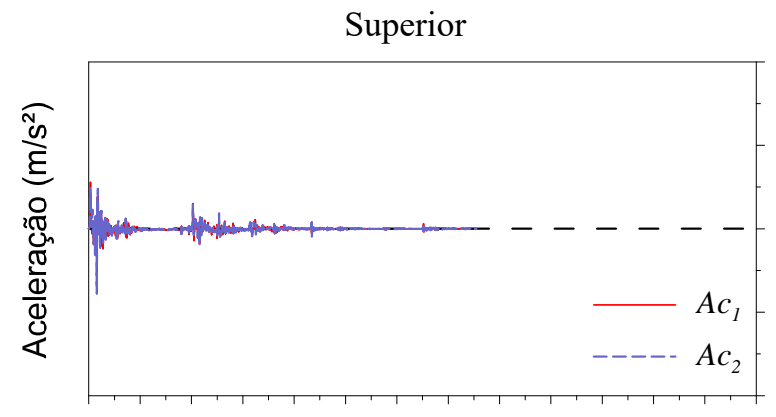

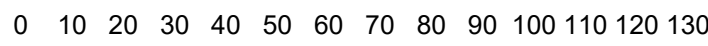
Tempo (ms)

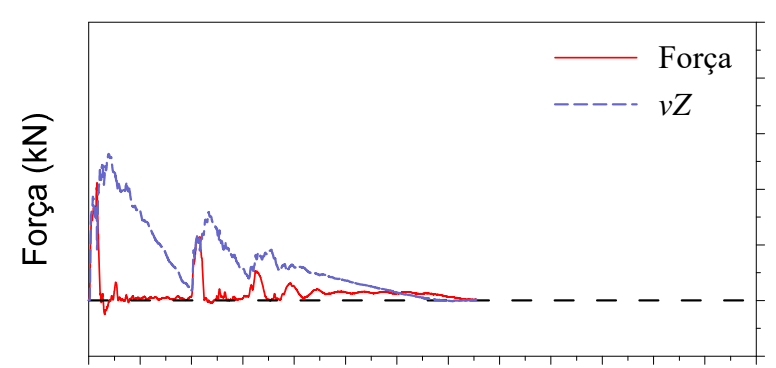

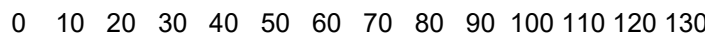
Tempo (ms)

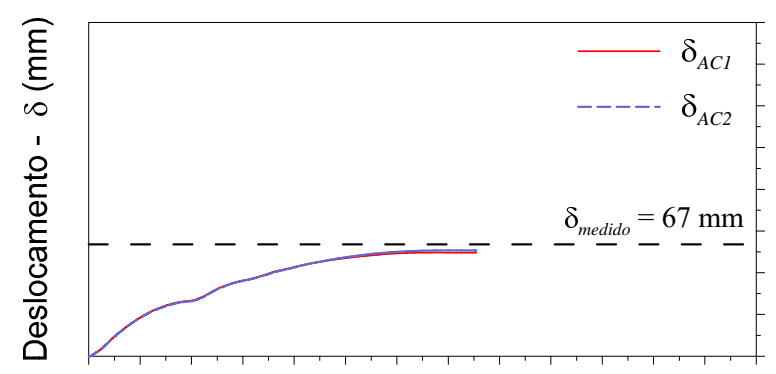

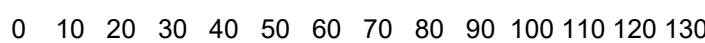

Tempo (ms)

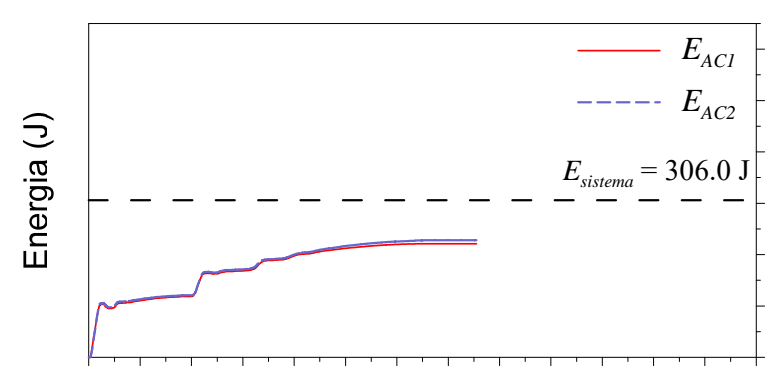

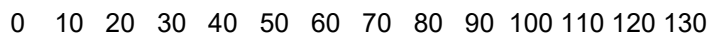

Tempo (ms)

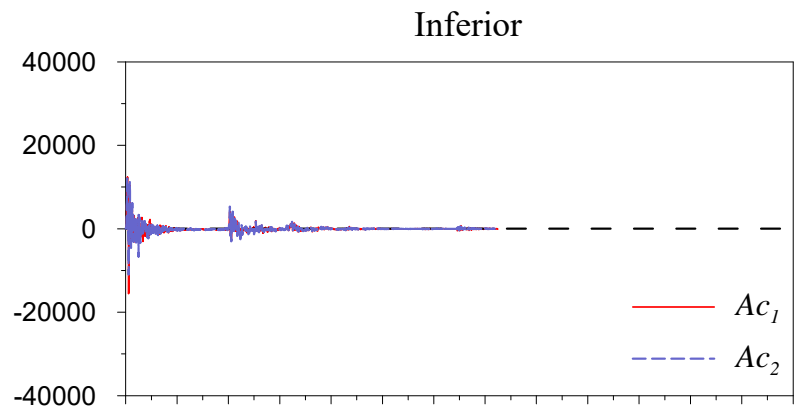

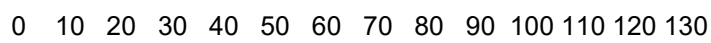
Tempo (ms)

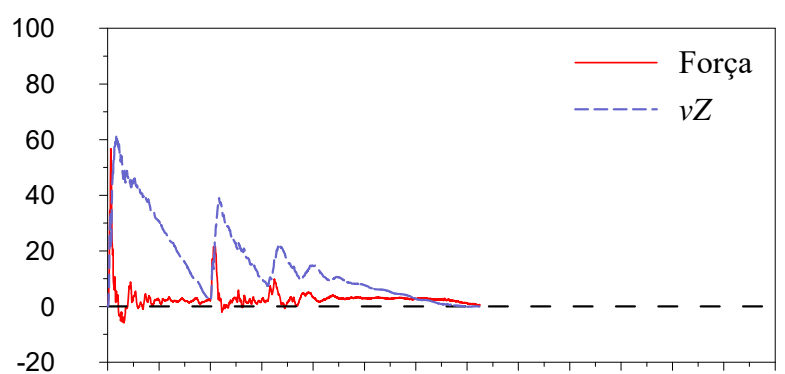

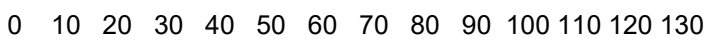
Tempo (ms)

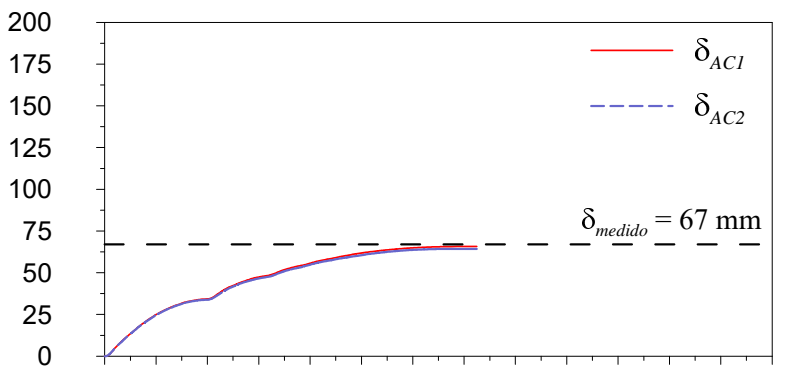

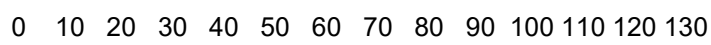

Tempo (ms)

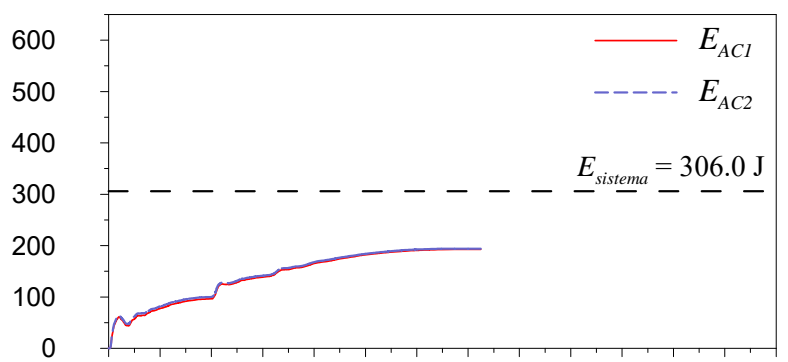

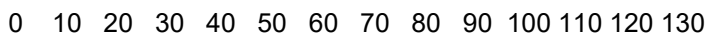

Tempo (ms)

Figura A4 - Sinais típicos de SPT instrumentado para o furo SP01, profundidade de $2 \mathrm{~m}$ e $H_{q}$ de $400 \mathrm{~mm}$. 

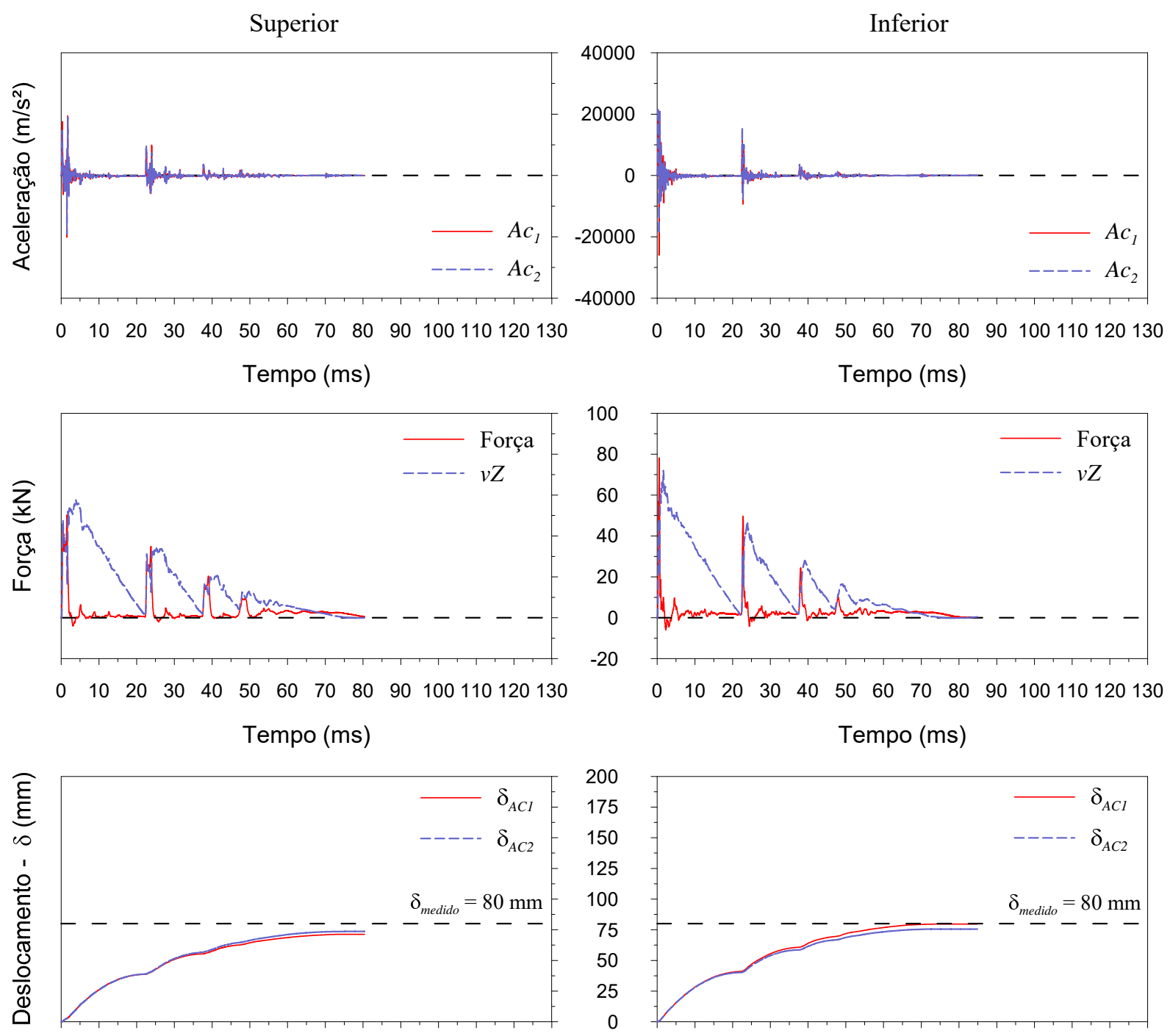

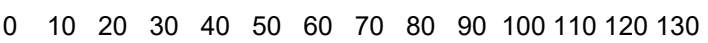
Tempo (ms)
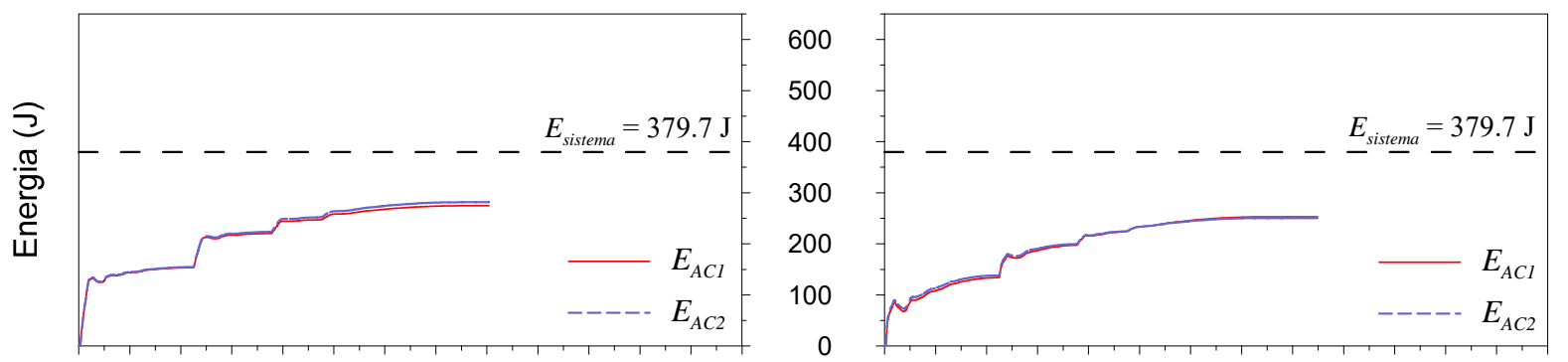

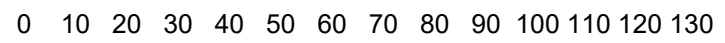

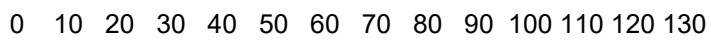
Tempo (ms)

\section{Tempo (ms)}

Figura A5 - Sinais típicos de SPT instrumentado para o furo SP01, profundidade de $2 \mathrm{~m}$ e $H_{q}$ de $500 \mathrm{~mm}$. 


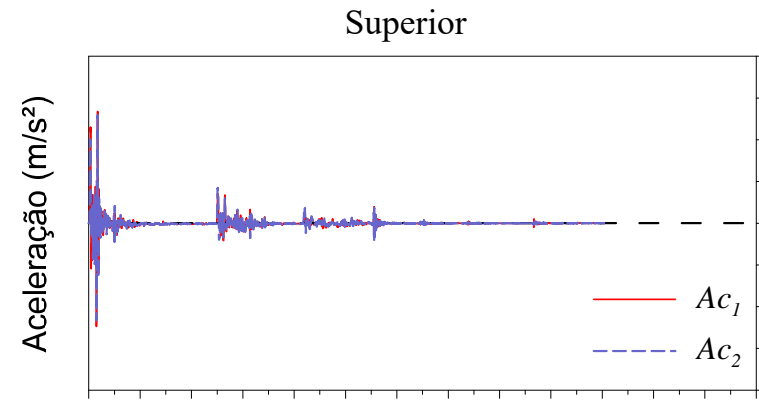

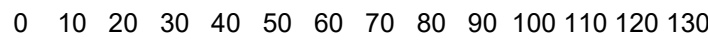

Tempo (ms)

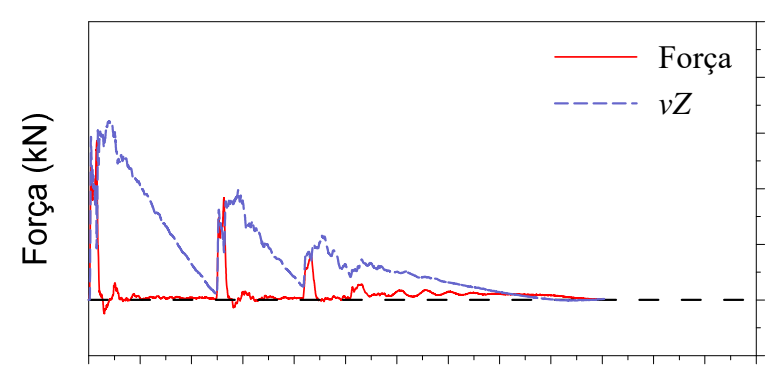

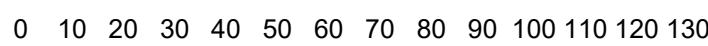

Tempo (ms)

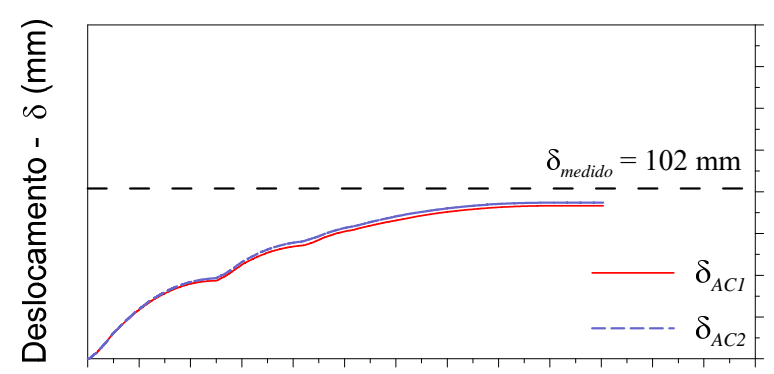

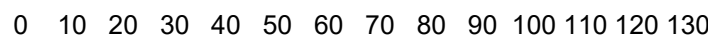

Tempo (ms)

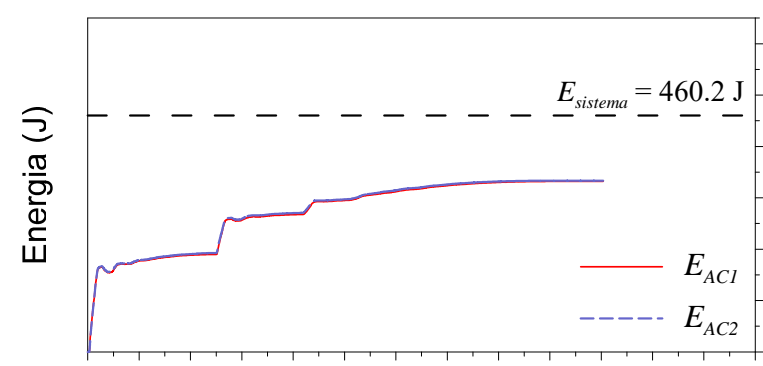

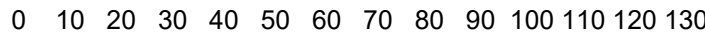

Tempo (ms)

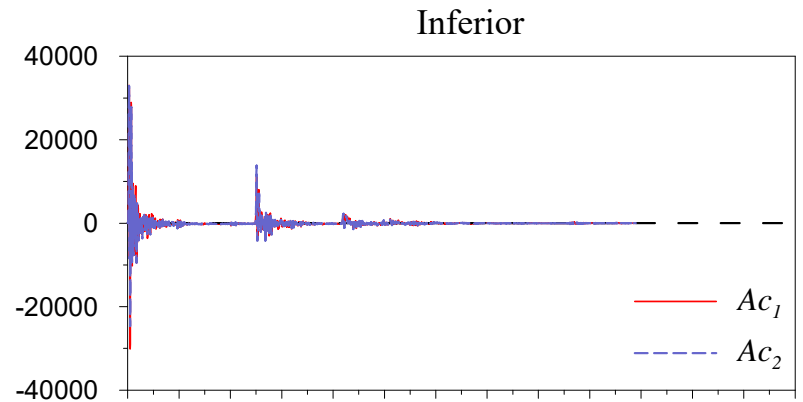

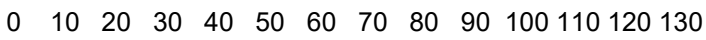

Tempo (ms)

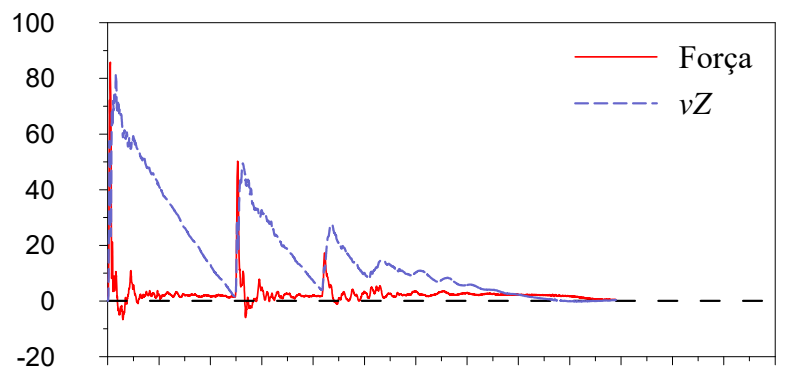

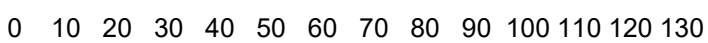
Tempo (ms)

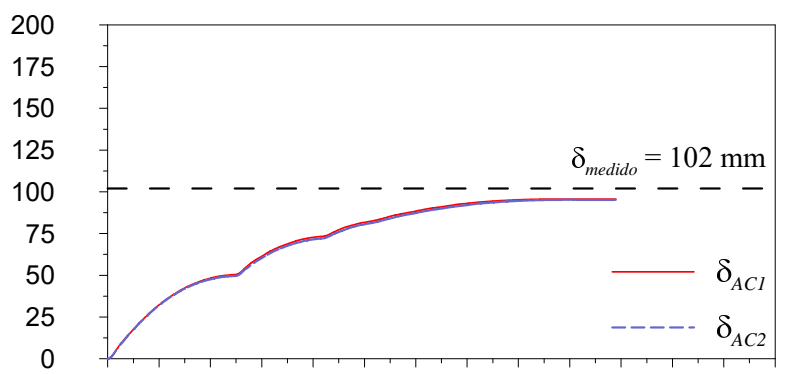

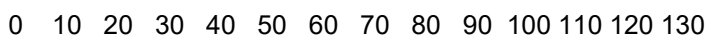
Tempo (ms)

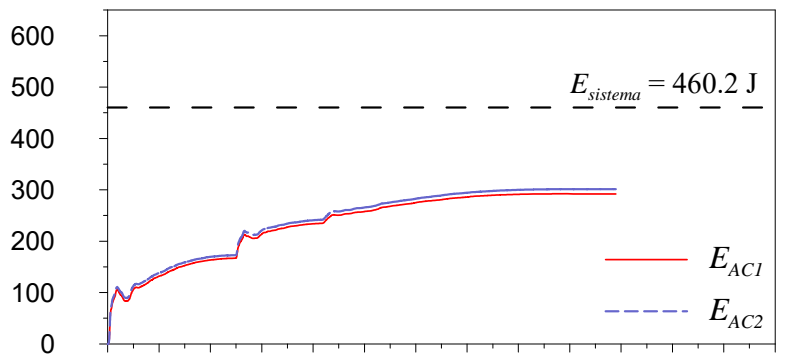

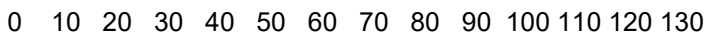
Tempo (ms)

Figura A6 - Sinais típicos de SPT instrumentado para o furo SP01, profundidade de $2 \mathrm{~m}$ e $H_{q}$ de $600 \mathrm{~mm}$. 

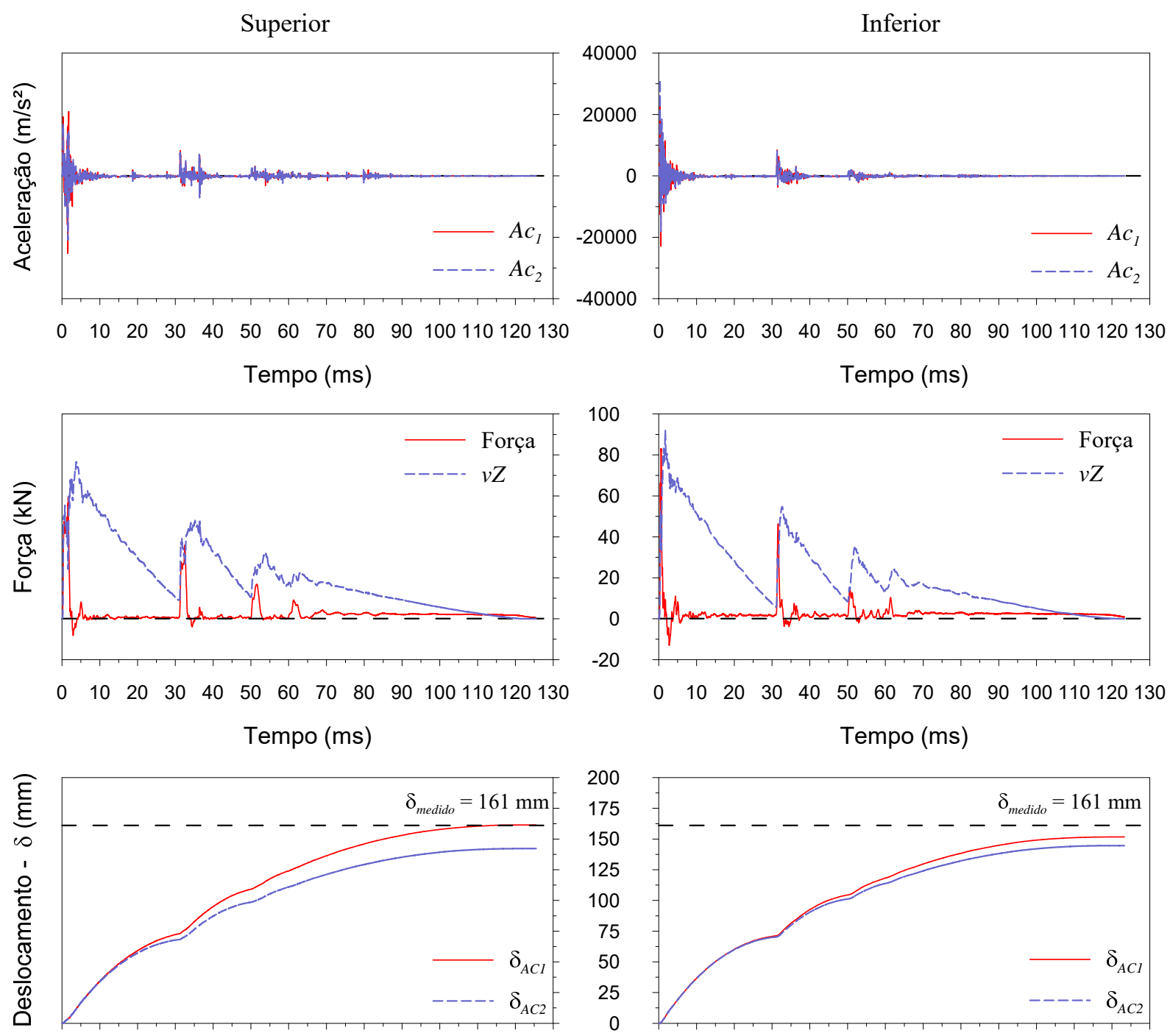

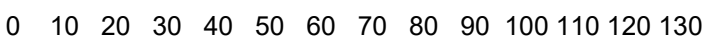
Tempo (ms)

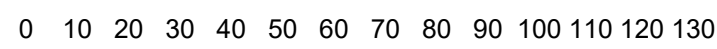
Tempo (ms)
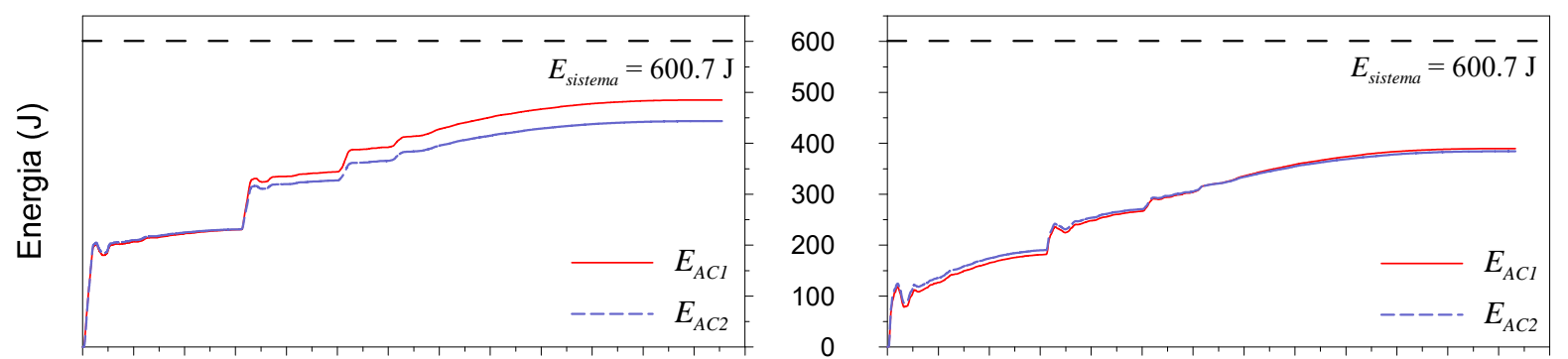

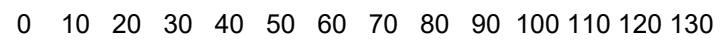

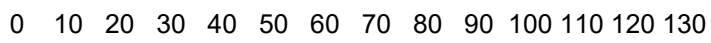
Tempo (ms)

\section{Tempo (ms)}

Figura A7 - Sinais típicos de SPT instrumentado para o furo SP01, profundidade de $2 \mathrm{~m}$ e $H_{q}$ de $750 \mathrm{~mm}$. 

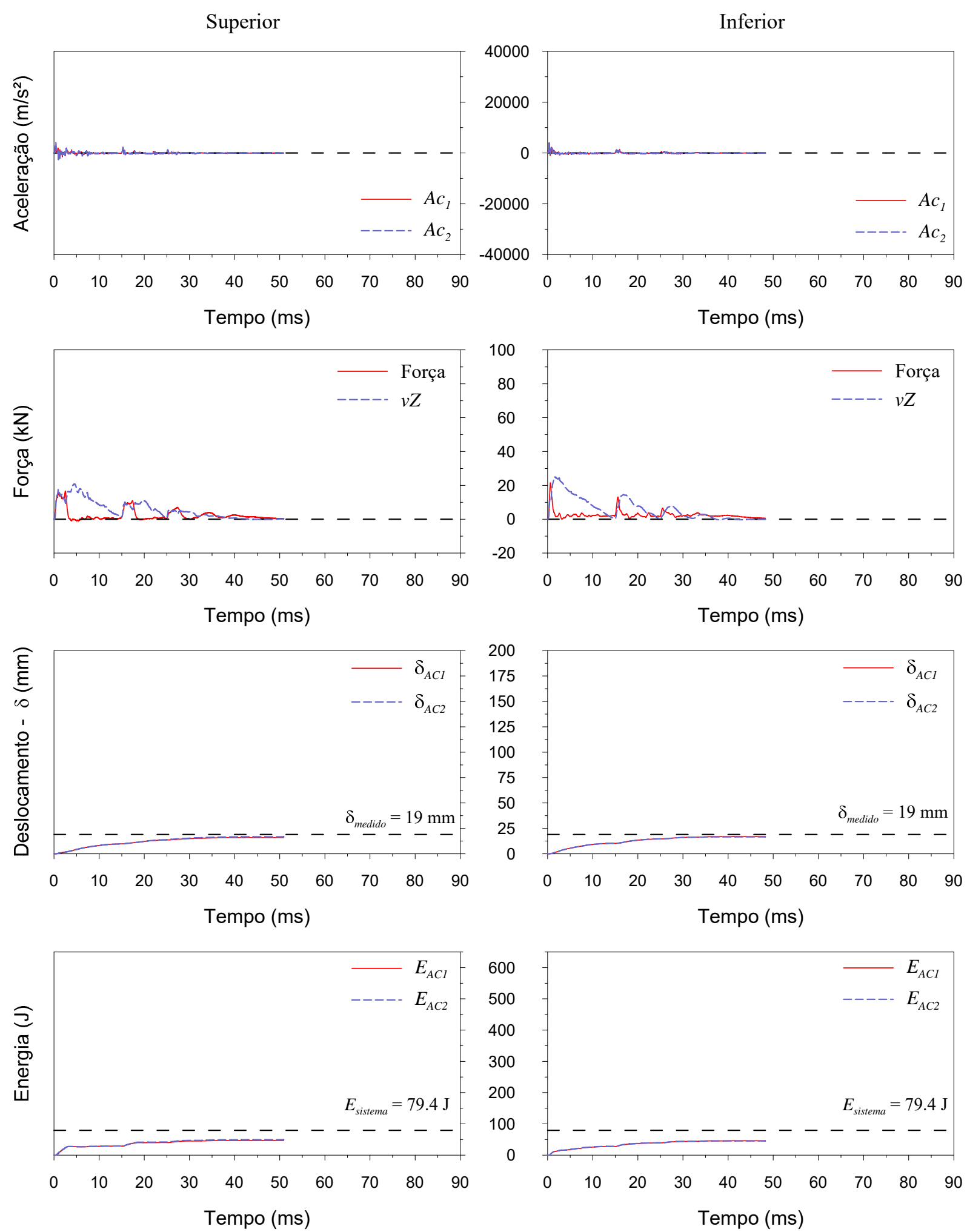

Figura A8 - Sinais típicos de SPT instrumentado para o furo SP01, profundidade de $3 \mathrm{~m}$ e $H_{q}$ de $100 \mathrm{~mm}$. 
Superior
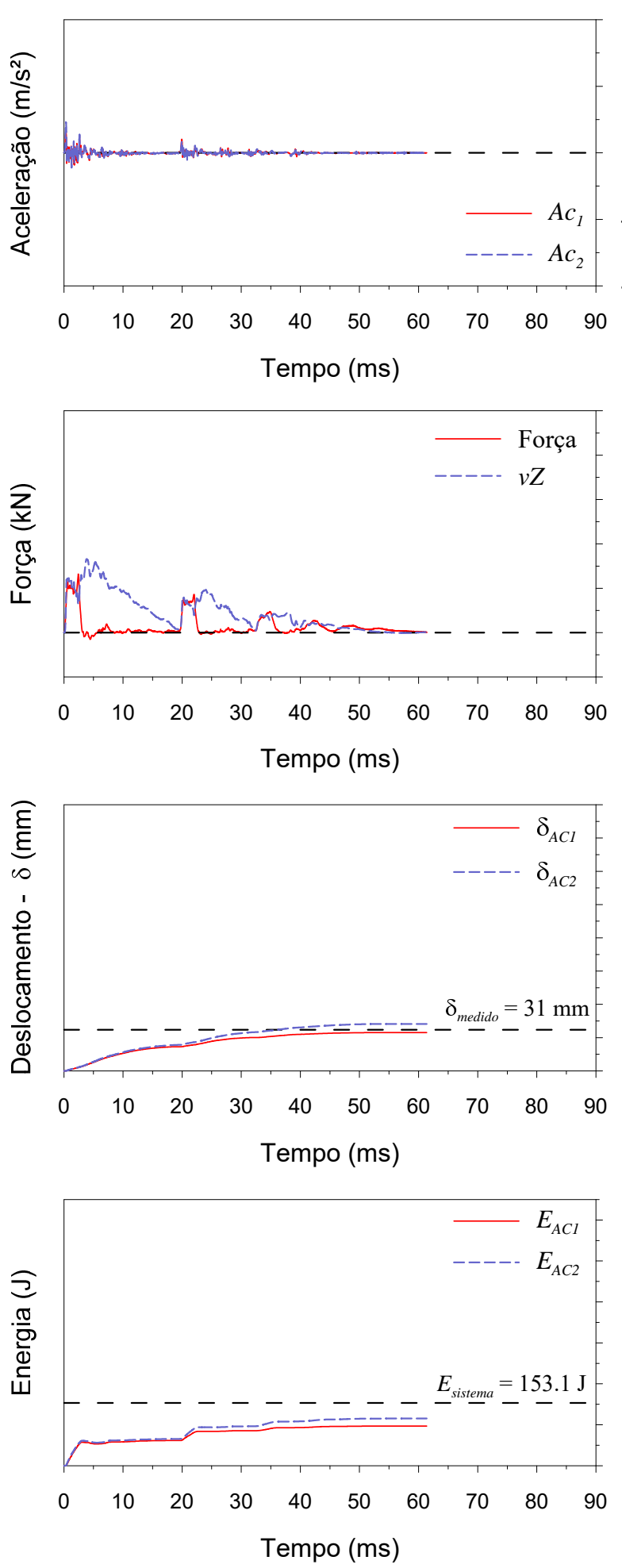

Inferior
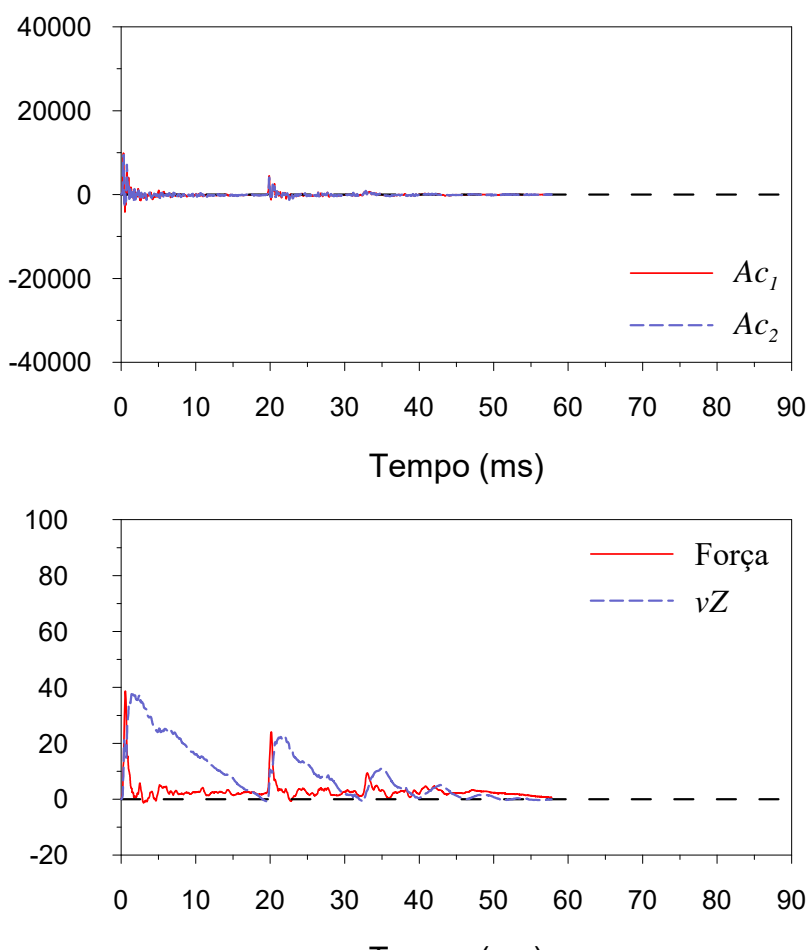

Tempo (ms)
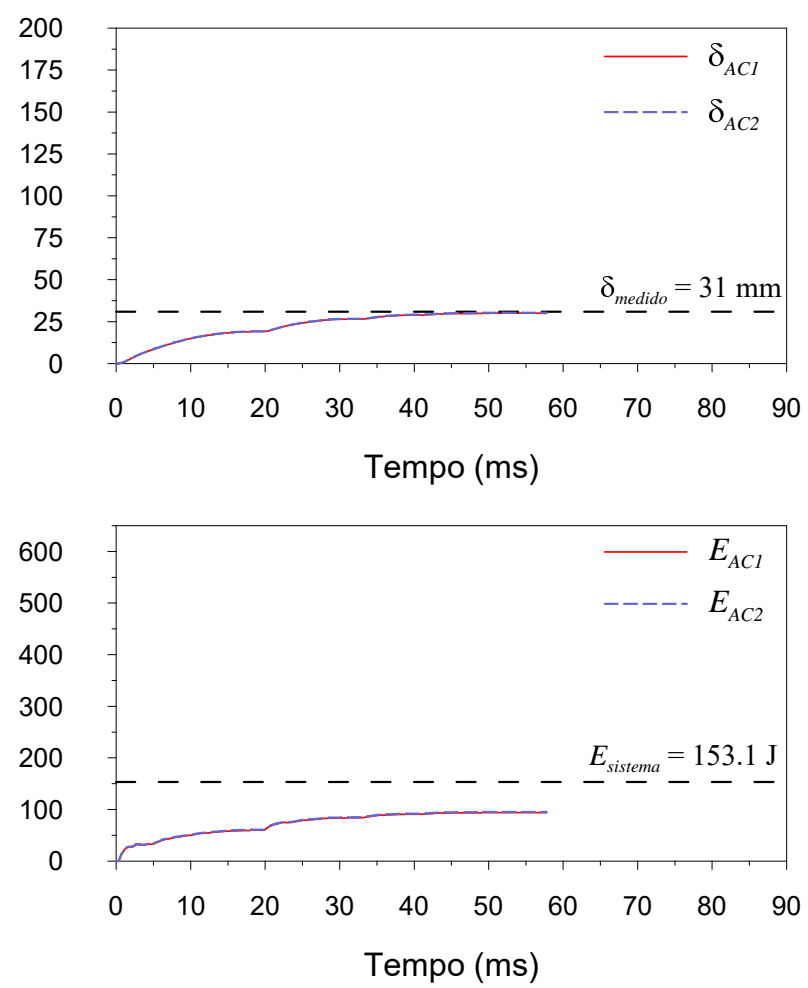

Figura A9 - Sinais típicos de SPT instrumentado para o furo SP01, profundidade de $3 \mathrm{~m}$ e $H_{q}$ de $200 \mathrm{~mm}$. 

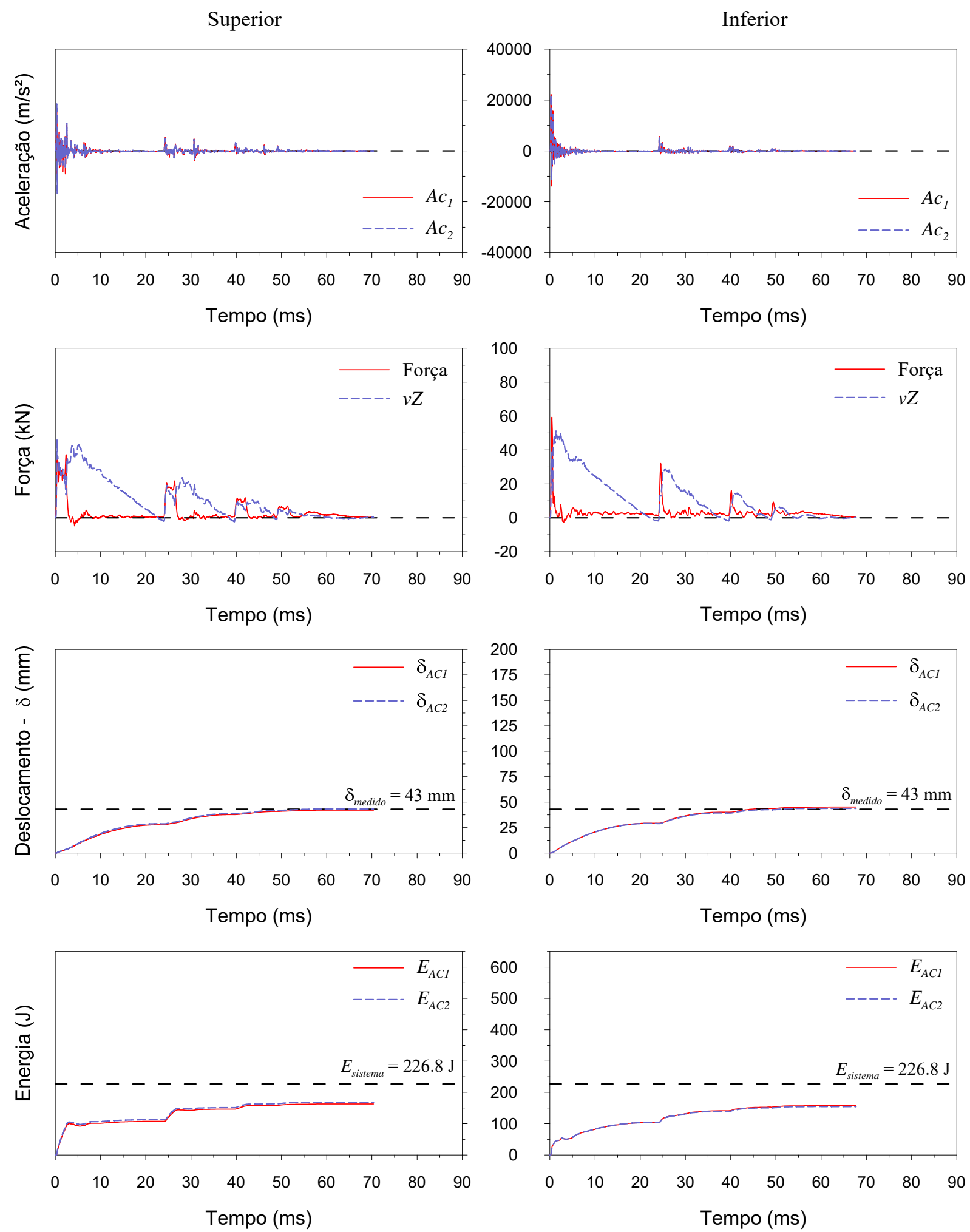

Figura A10 - Sinais típicos de SPT instrumentado para o furo SP01, profundidade de $3 \mathrm{~m}$ e $H_{q}$ de $300 \mathrm{~mm}$. 
Superior
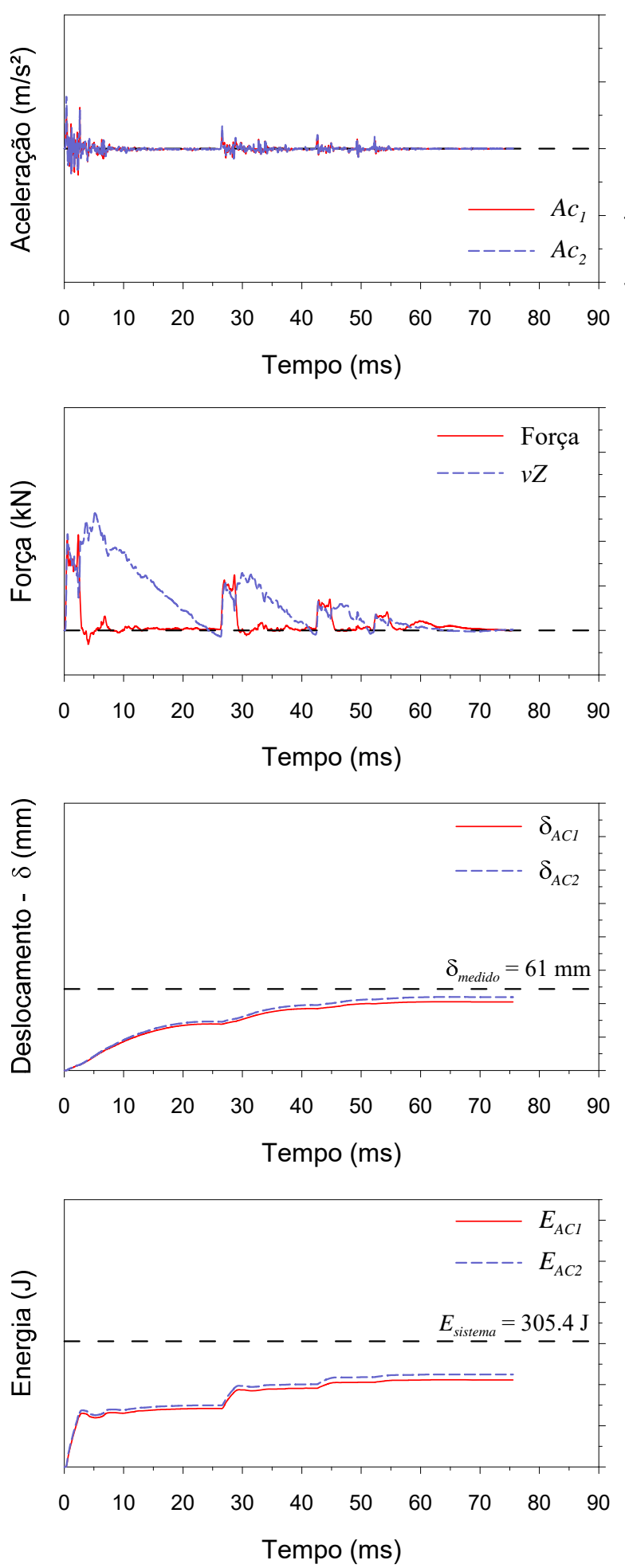

Inferior
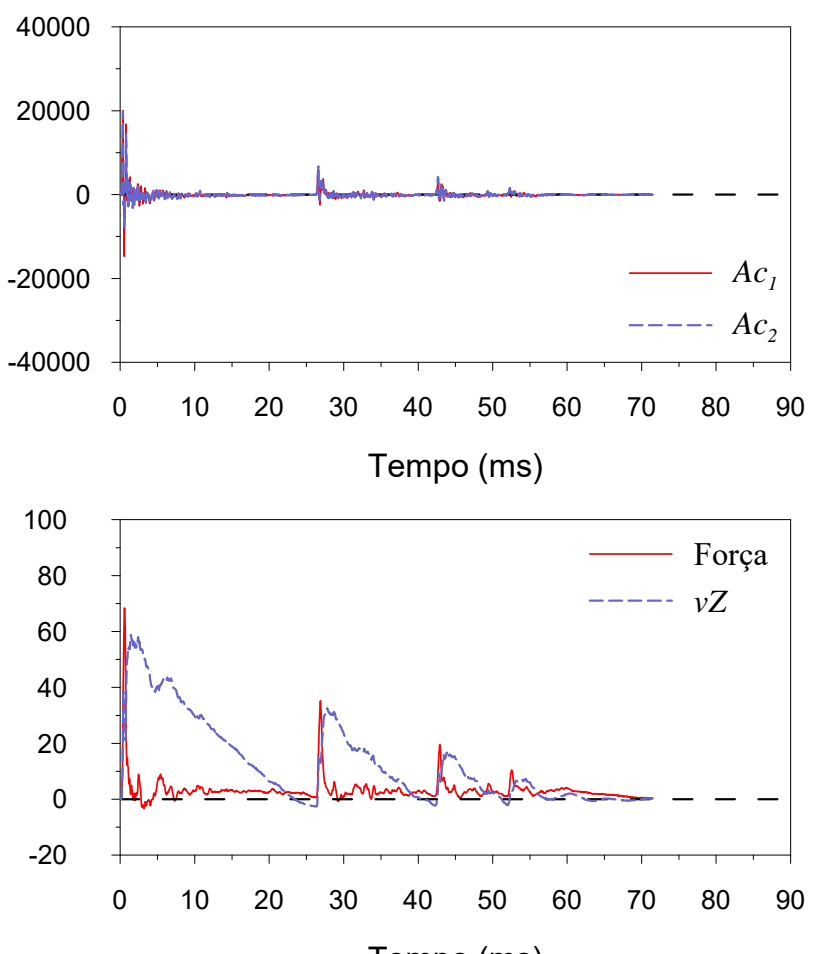

Tempo (ms)
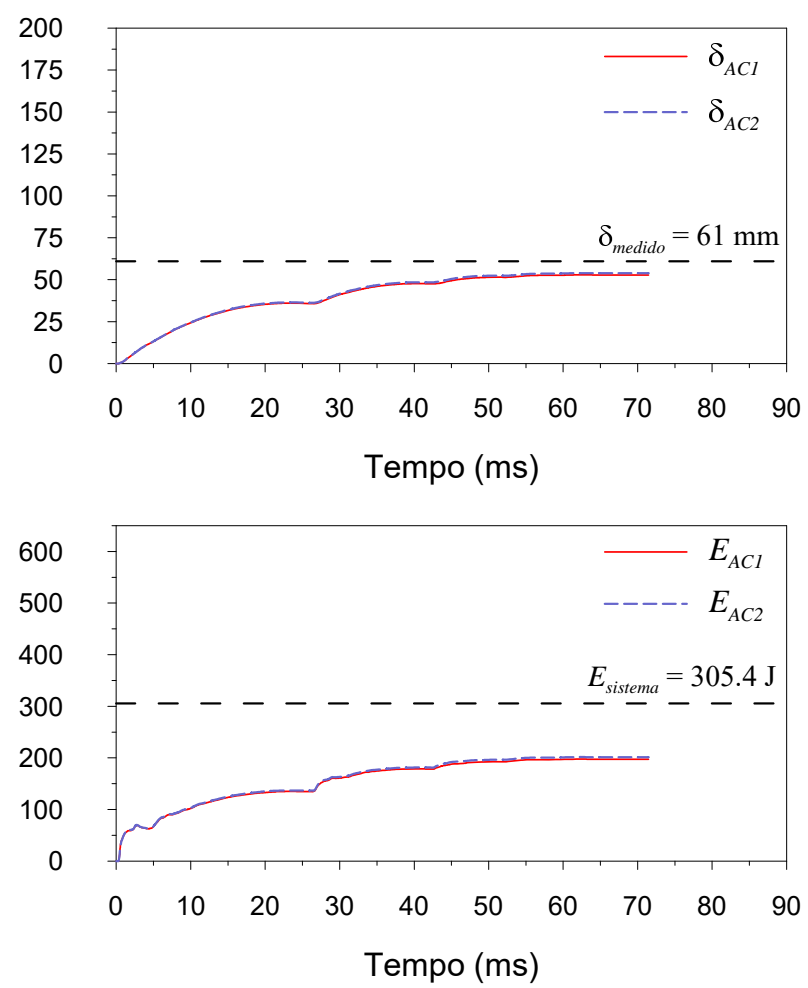

Figura A11 - Sinais típicos de SPT instrumentado para o furo SP01, profundidade de $3 \mathrm{~m}$ e $H_{q}$ de $400 \mathrm{~mm}$. 

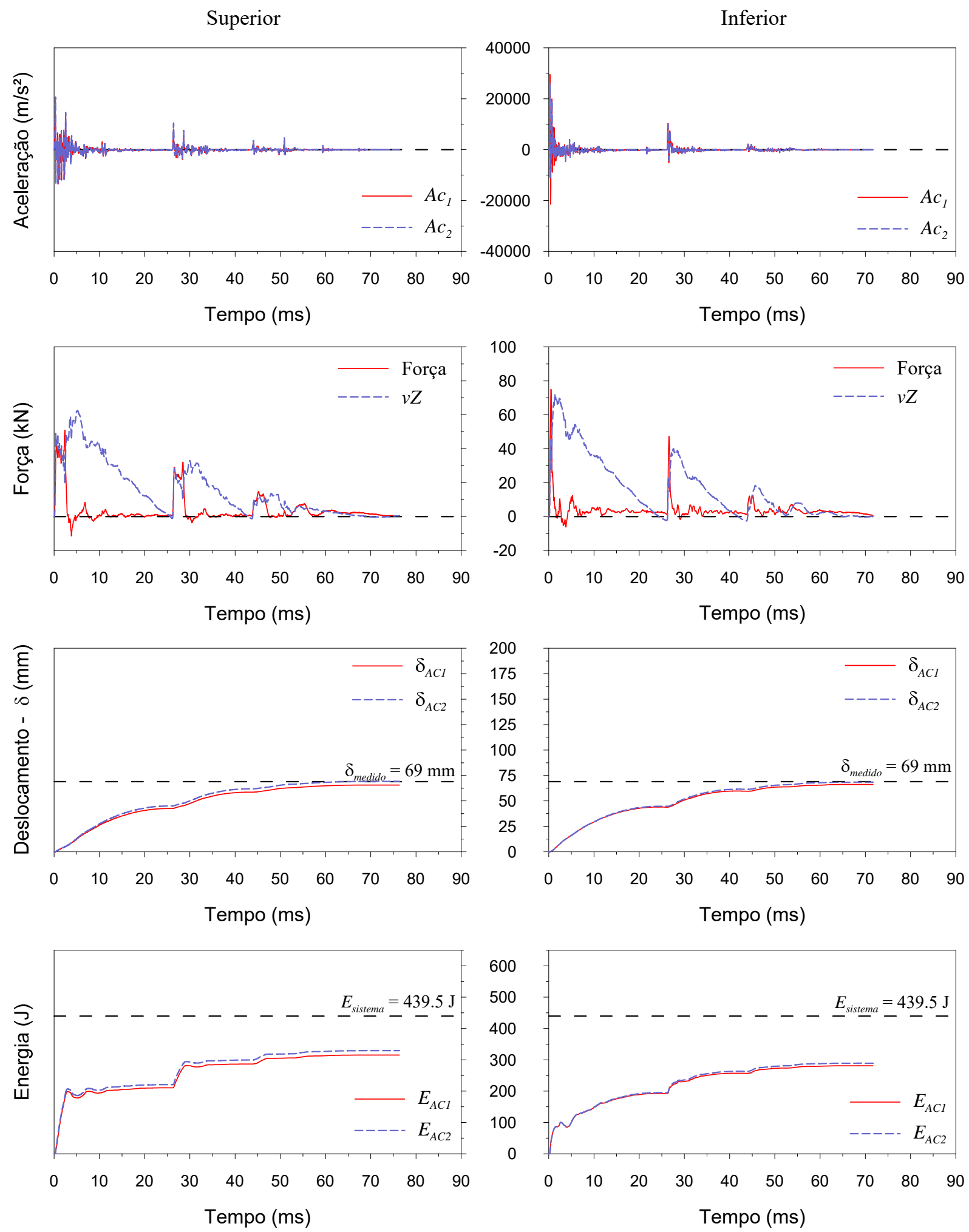

Figura A12 - Sinais típicos de SPT instrumentado para o furo SP01, profundidade de $3 \mathrm{~m}$ e $H_{q}$ de $600 \mathrm{~mm}$. 
Superior
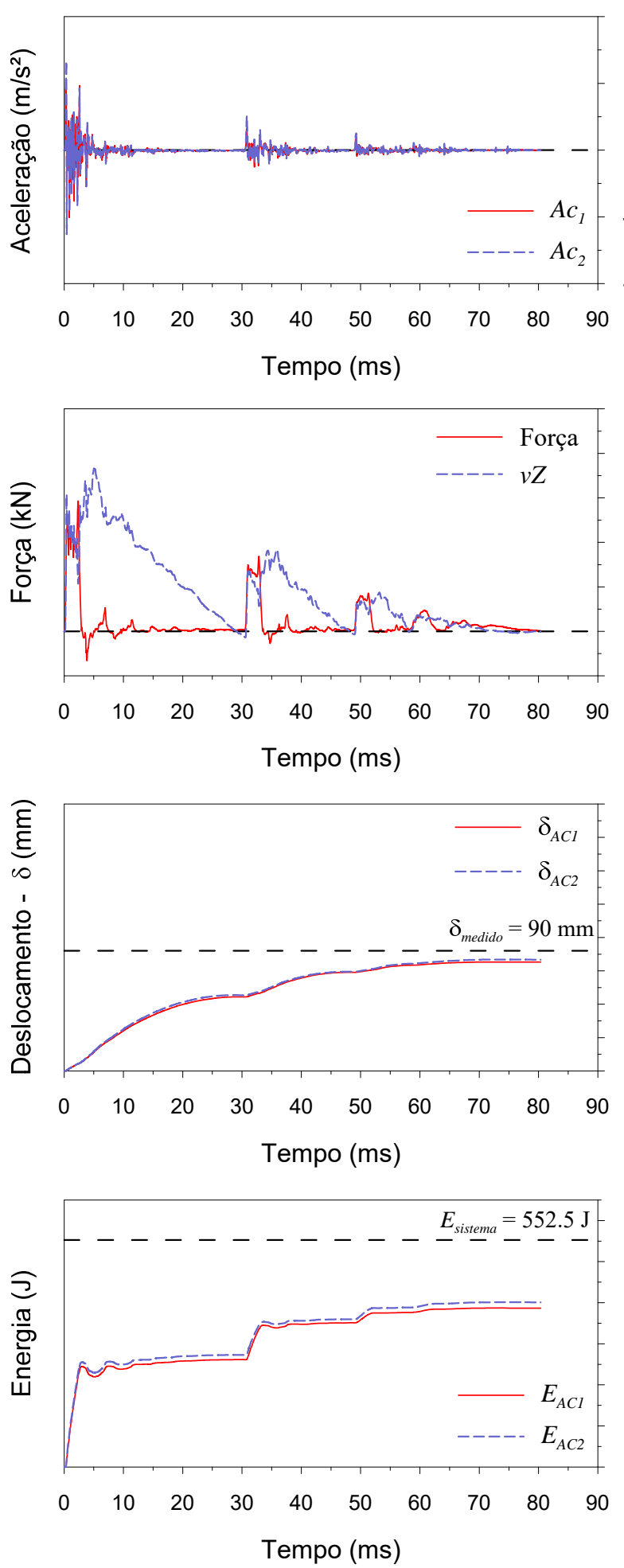

Inferior
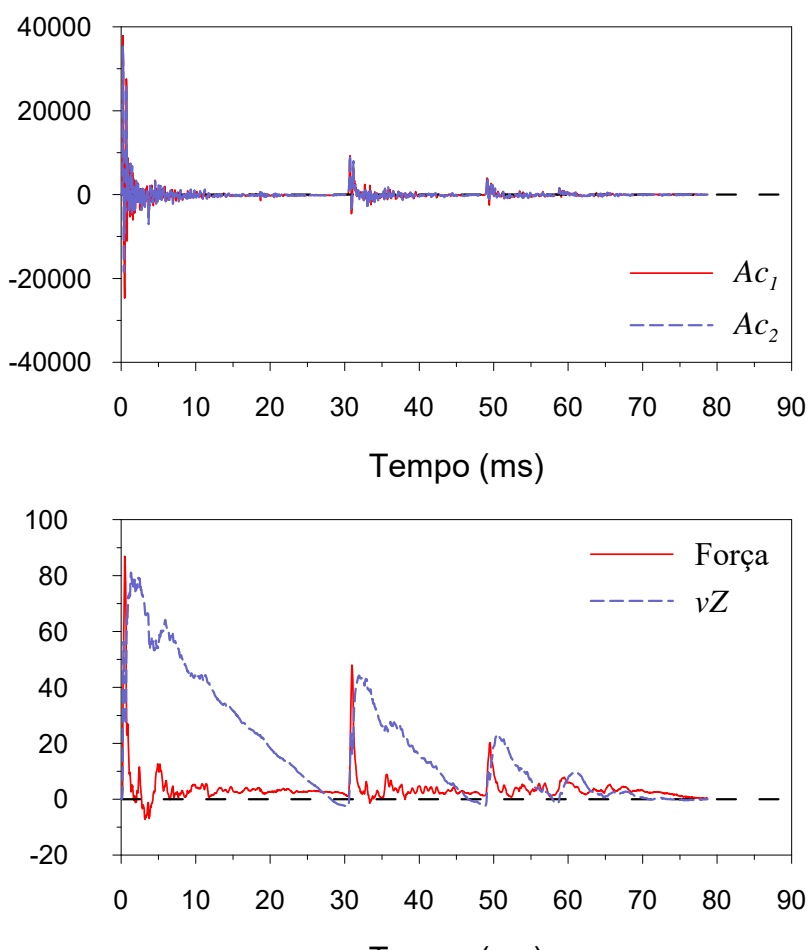

Tempo (ms)
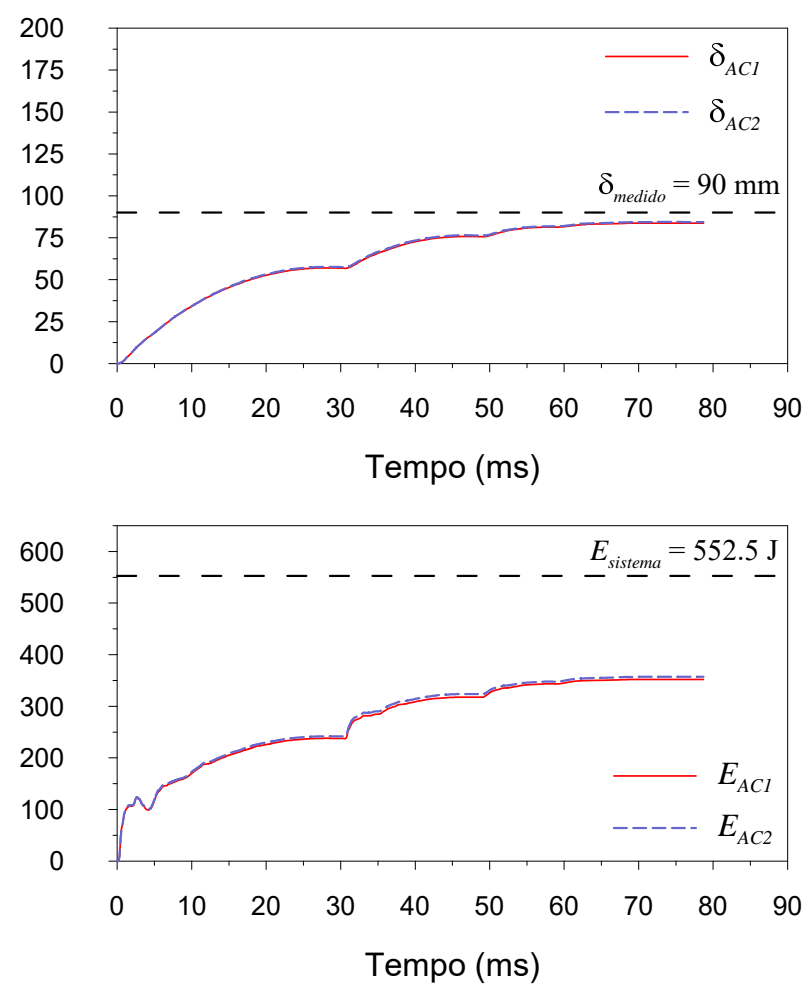

Figura A13 - Sinais típicos de SPT instrumentado para o furo SP01, profundidade de $3 \mathrm{~m}$ e $H_{q}$ de $750 \mathrm{~mm}$. 


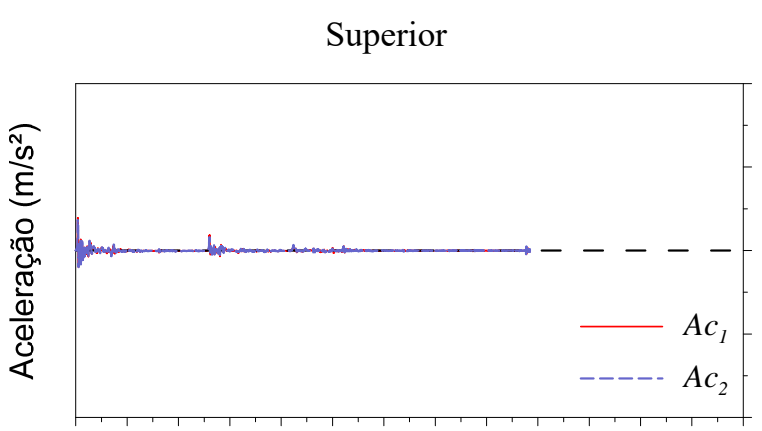

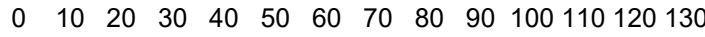

Tempo (ms)

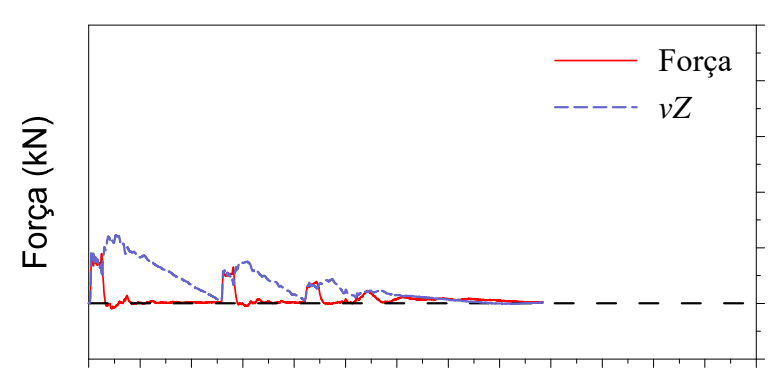

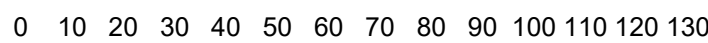

Tempo (ms)

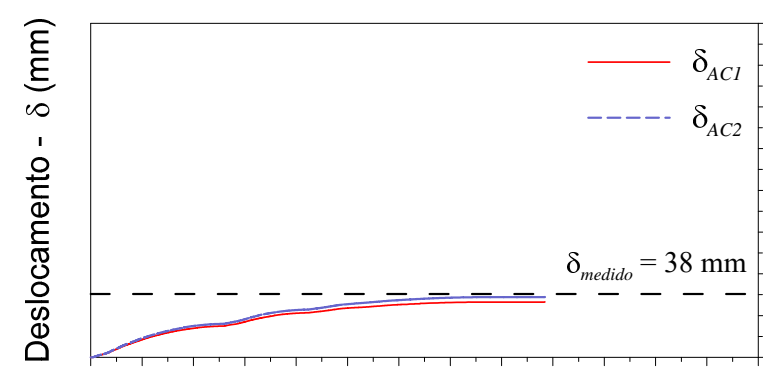

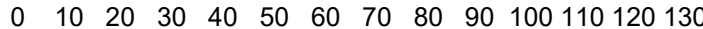

Tempo (ms)

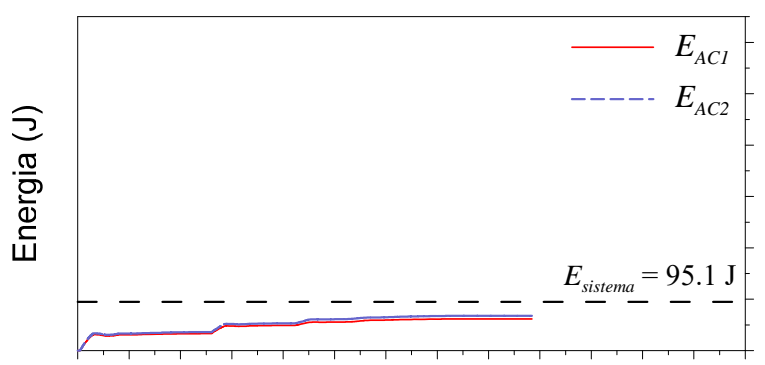

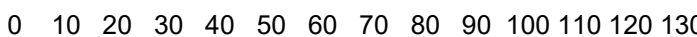

Inferior

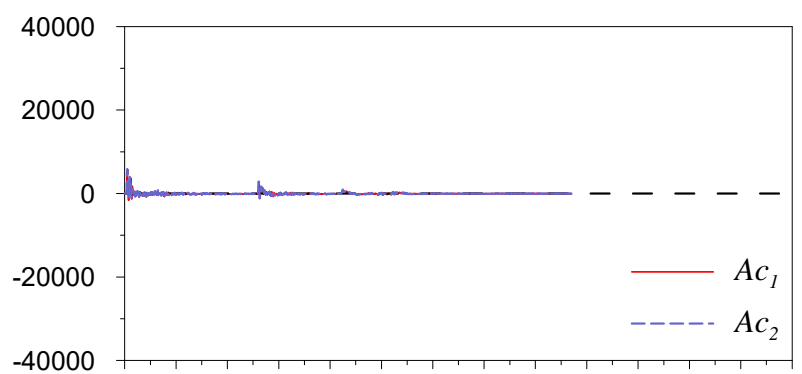

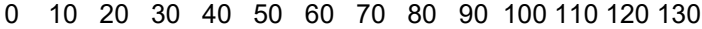
Tempo (ms)

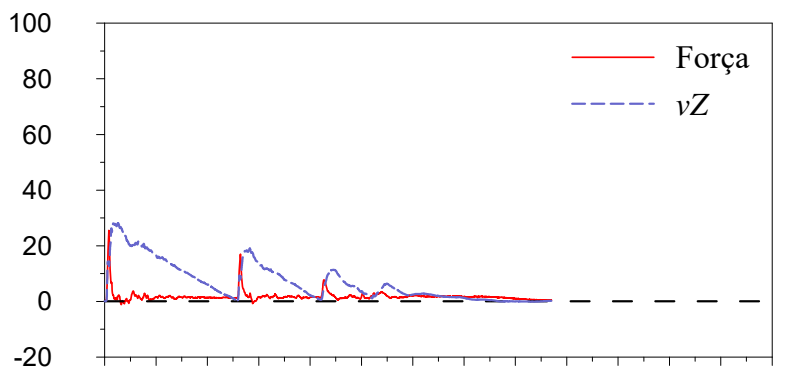

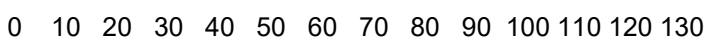

Tempo (ms)

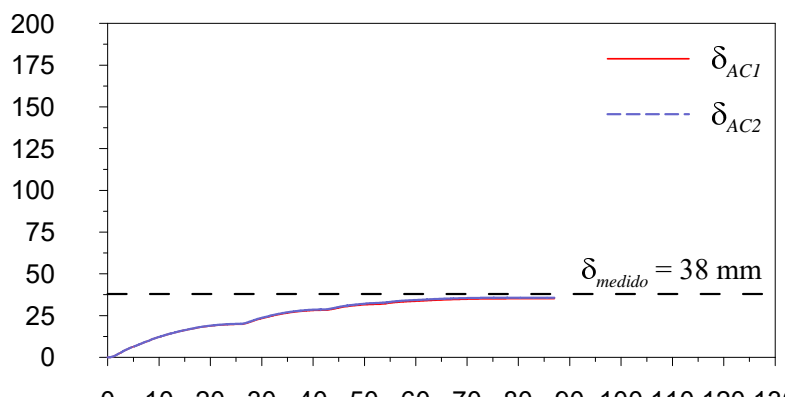

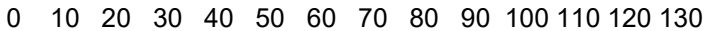

Tempo (ms)

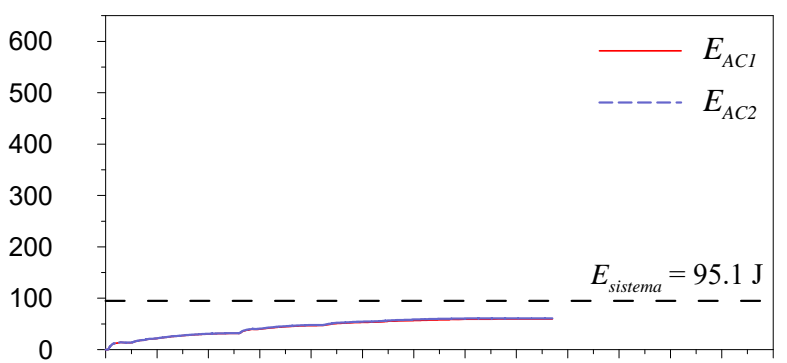

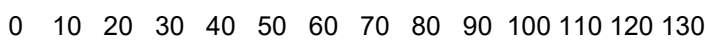
Tempo (ms)

Figura A14 - Sinais típicos de SPT instrumentado para o furo SP01, profundidade de $4 \mathrm{~m}$ e $H_{q}$ de $100 \mathrm{~mm}$. 

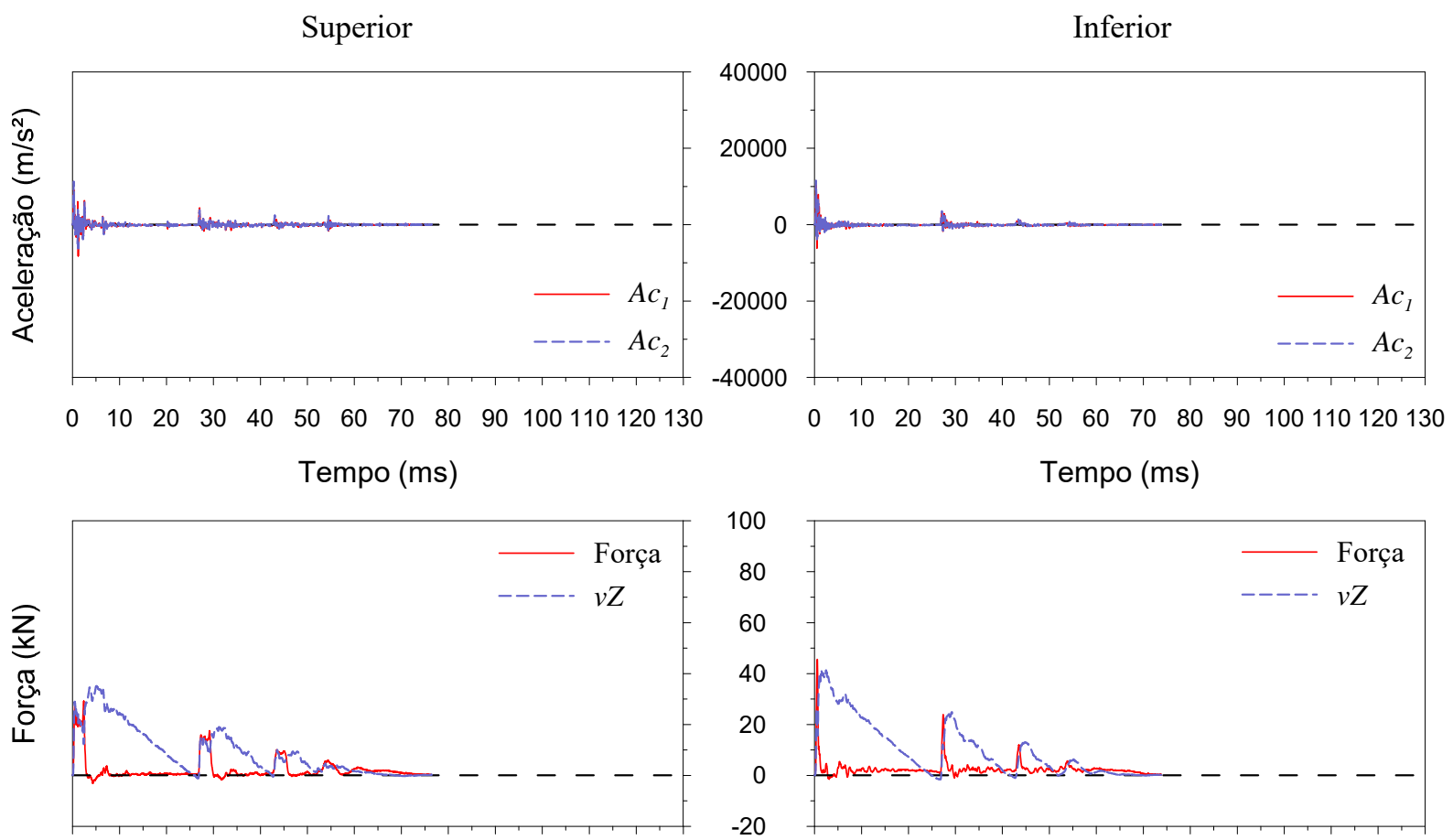

$0 \quad 10 \quad 20 \quad 30 \quad 40 \quad 50 \quad 60 \quad 70 \quad 80 \quad 90 \quad 100110120130$

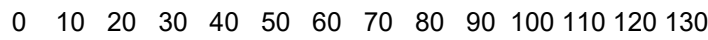

Tempo (ms)
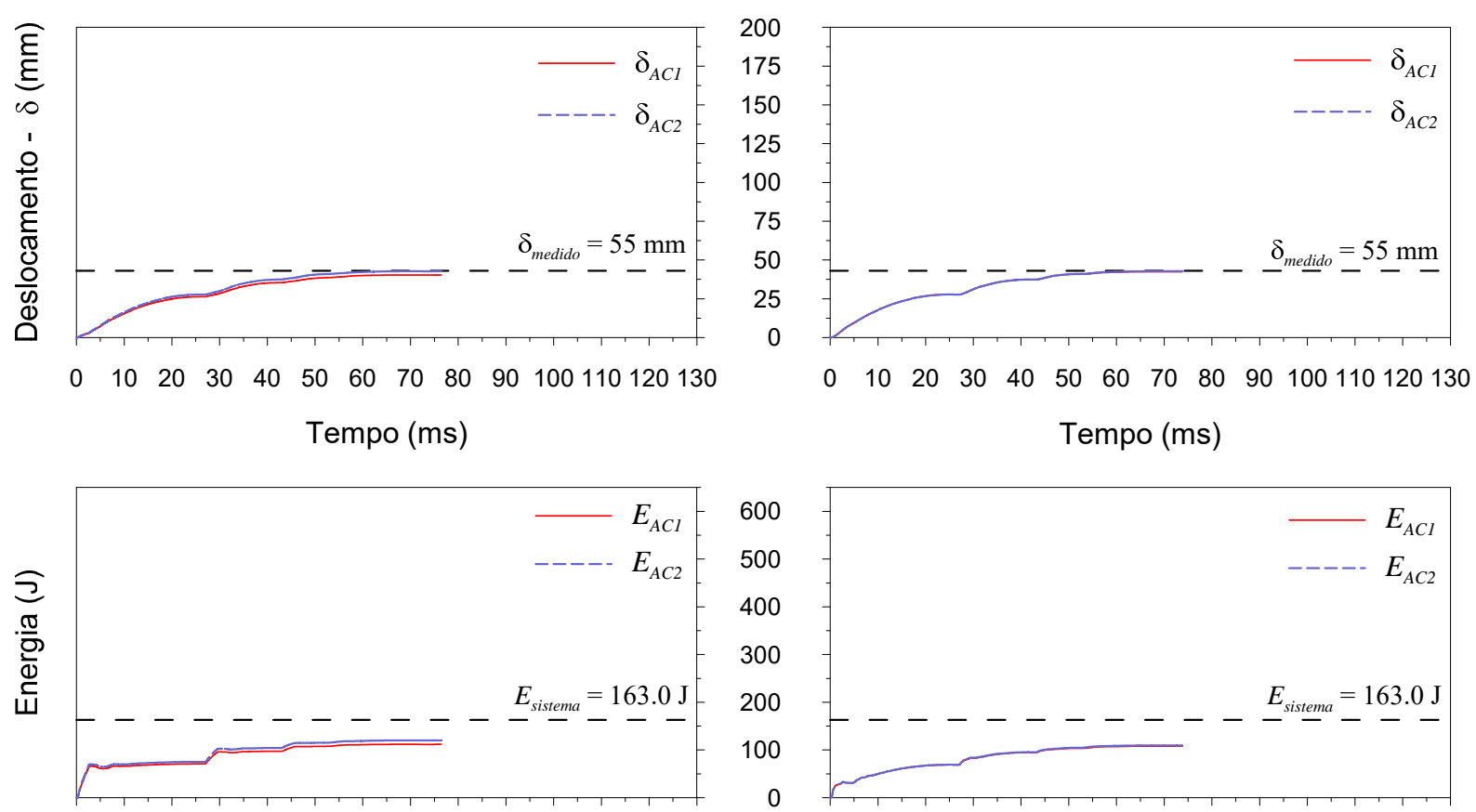

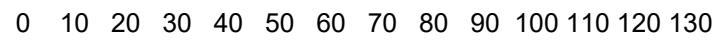
Tempo (ms)

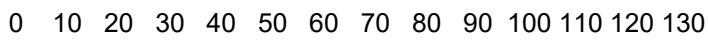
Tempo (ms)

Figura A15 - Sinais típicos de SPT instrumentado para o furo SP01, profundidade de $4 \mathrm{~m}$ e $H_{q}$ de $200 \mathrm{~mm}$. 


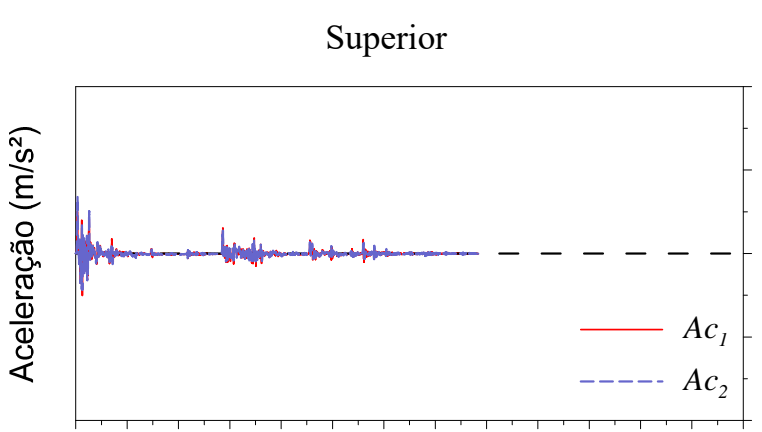

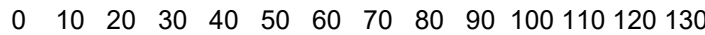

Tempo (ms)

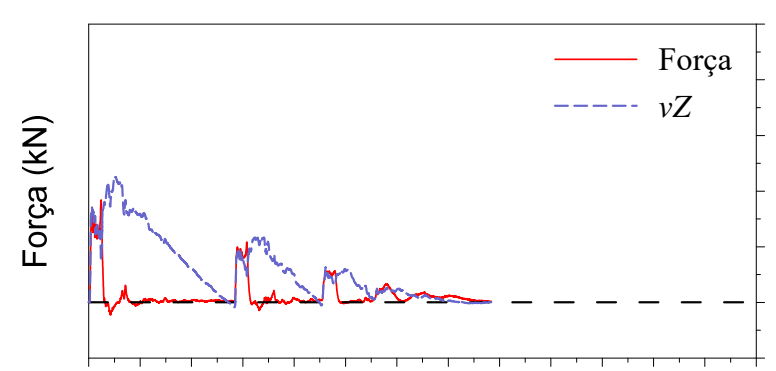

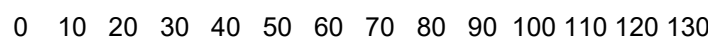

Tempo (ms)

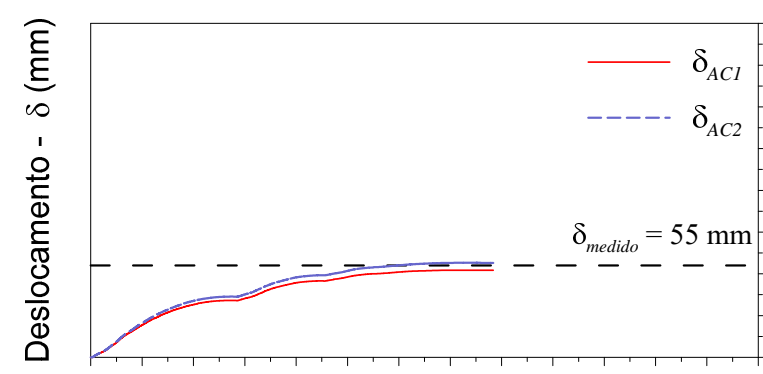

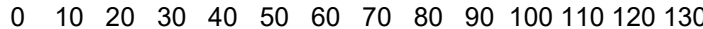

Tempo (ms)

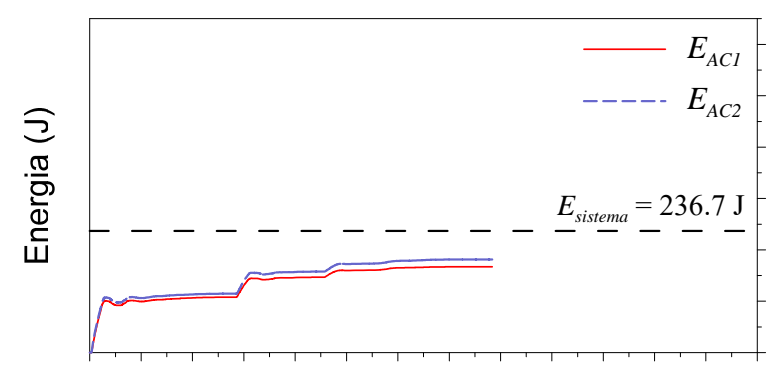

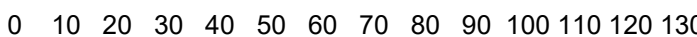

Inferior

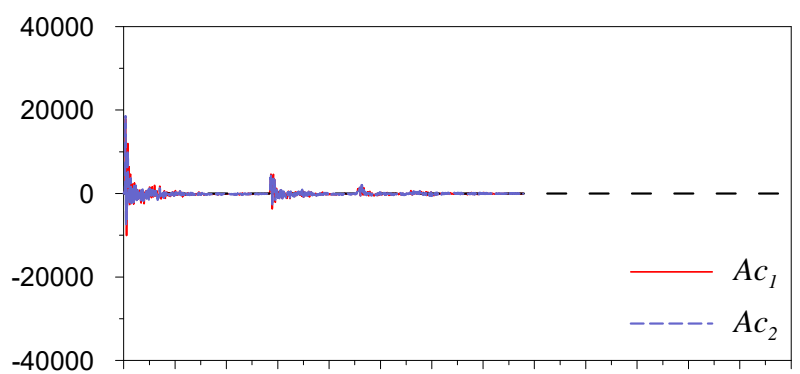

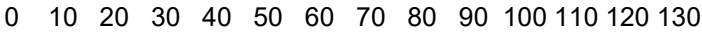
Tempo (ms)

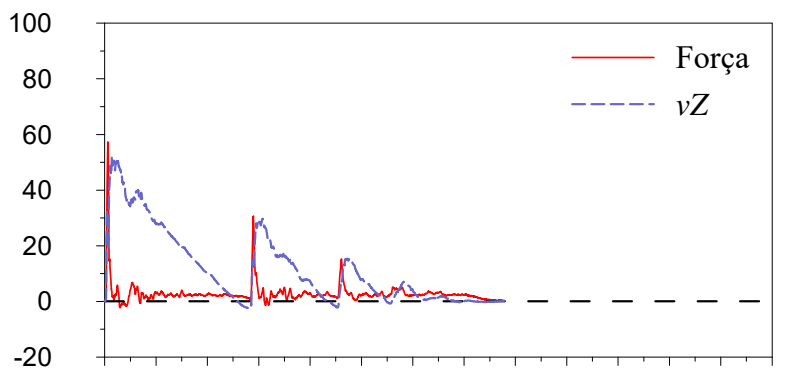

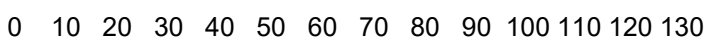

Tempo (ms)

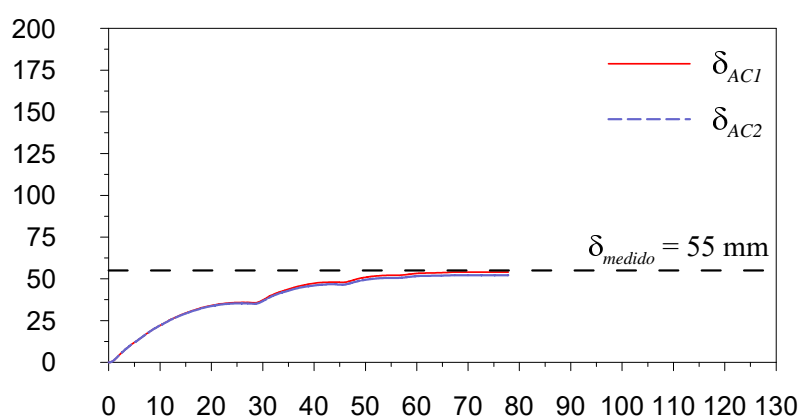

Tempo (ms)

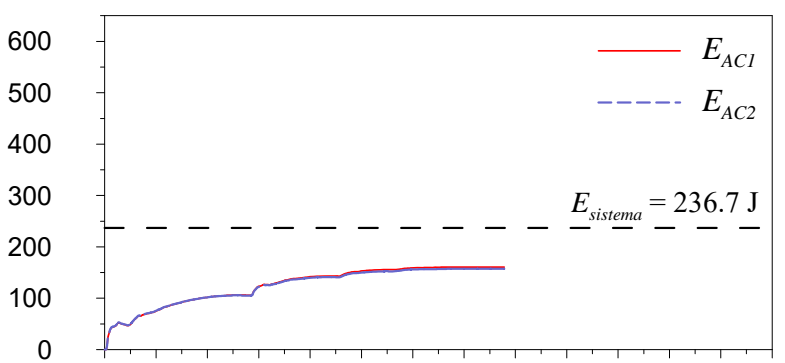

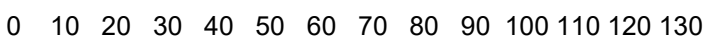
Tempo (ms)

Figura A16 - Sinais típicos de SPT instrumentado para o furo SP01, profundidade de $4 \mathrm{~m}$ e $H_{q}$ de $300 \mathrm{~mm}$. 

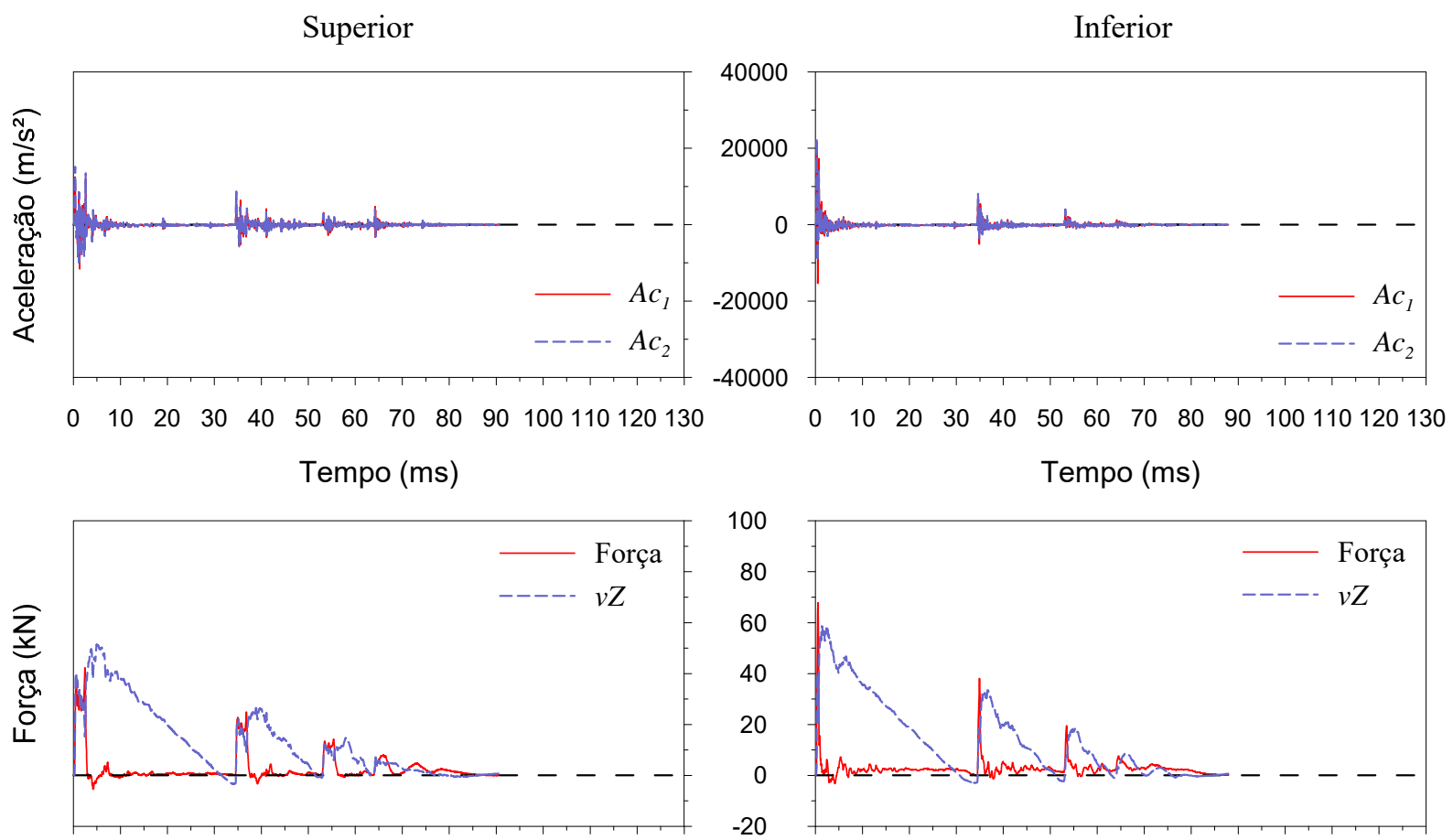

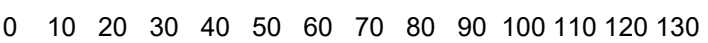

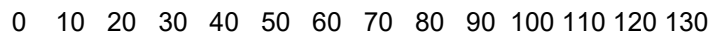

Tempo (ms)

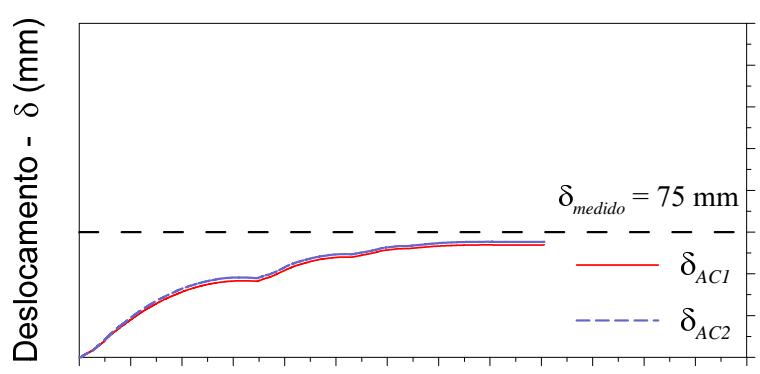

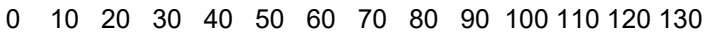

Tempo (ms)
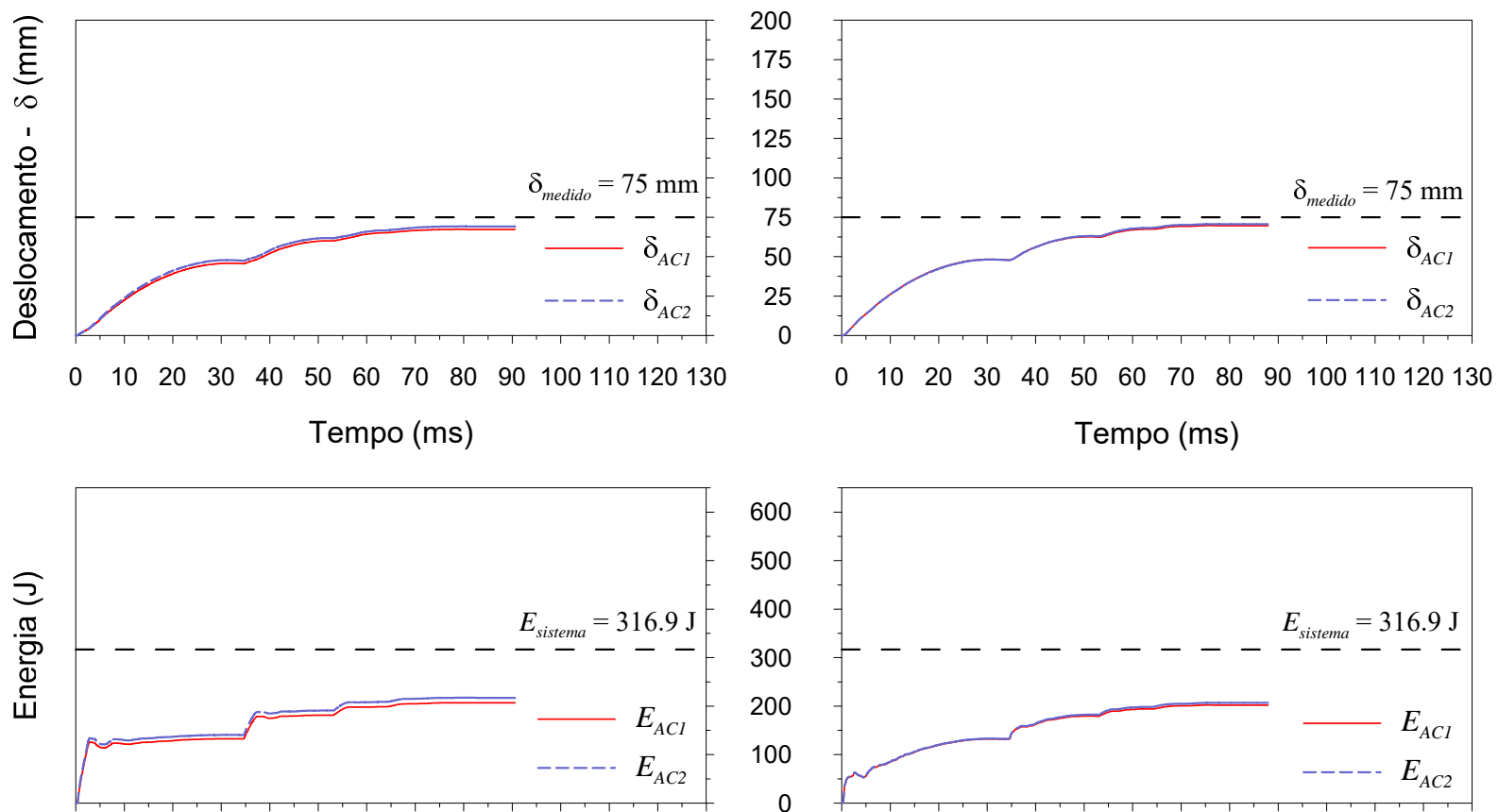

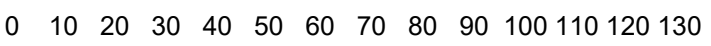
Tempo (ms)

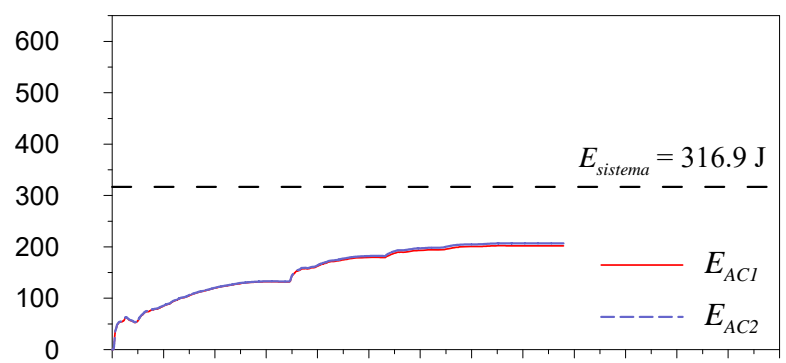

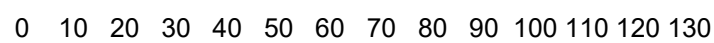
Tempo (ms)

Figura A17 - Sinais típicos de SPT instrumentado para o furo SP01, profundidade de $4 \mathrm{~m}$ e $H_{q}$ de $400 \mathrm{~mm}$. 


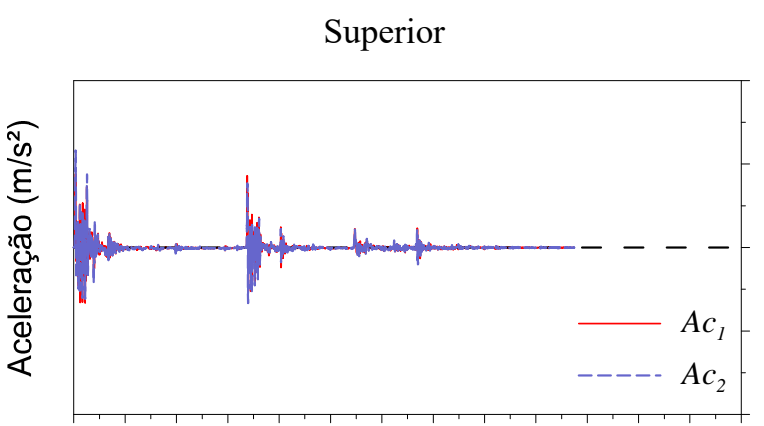

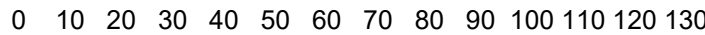

Tempo (ms)

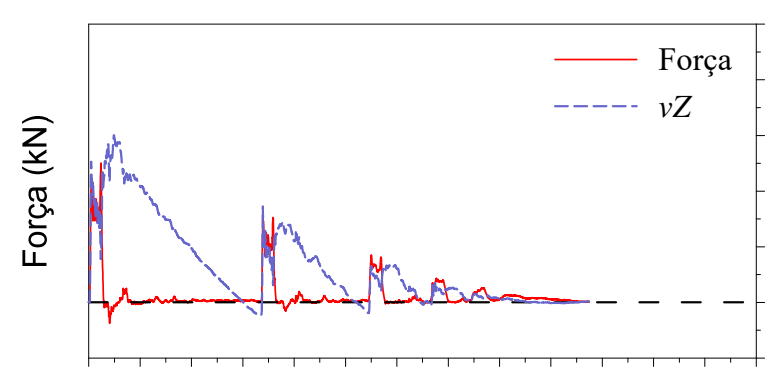

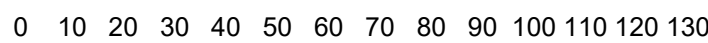

Tempo (ms)

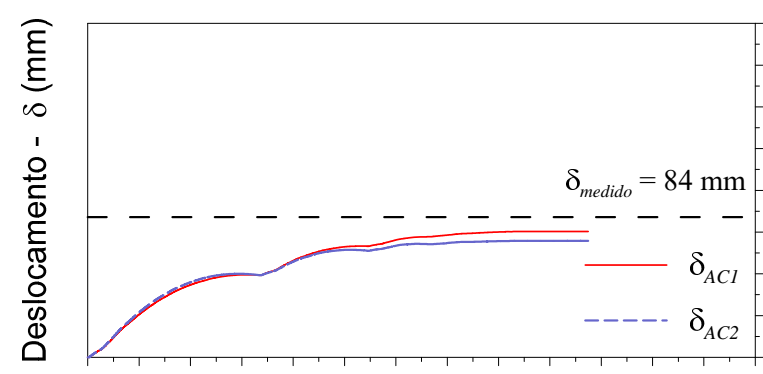

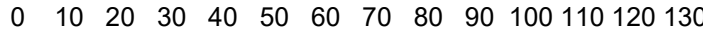

Tempo (ms)

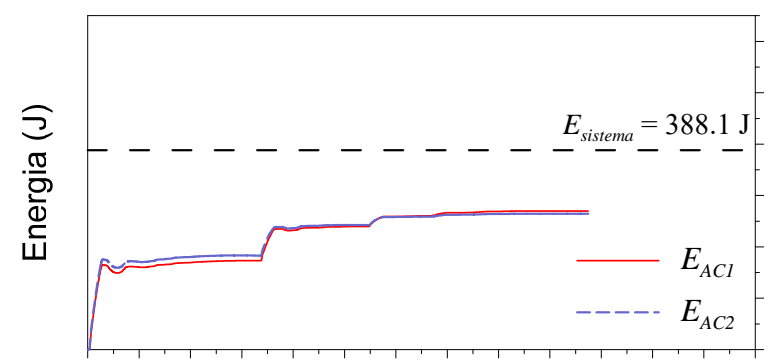

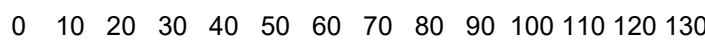
Tempo (ms)
Inferior

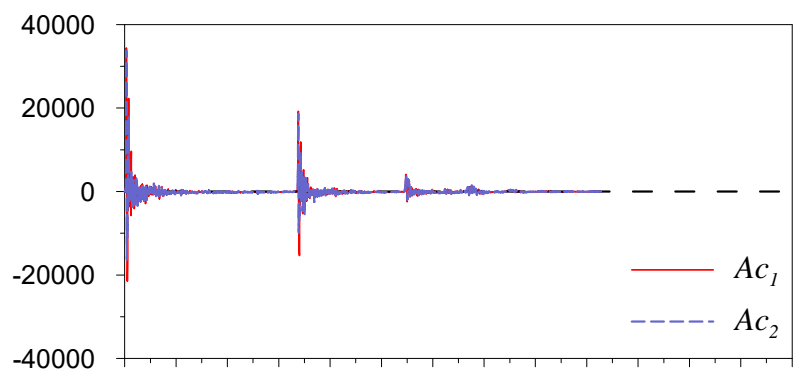

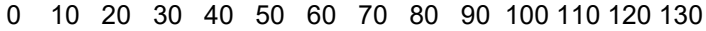
Tempo (ms)

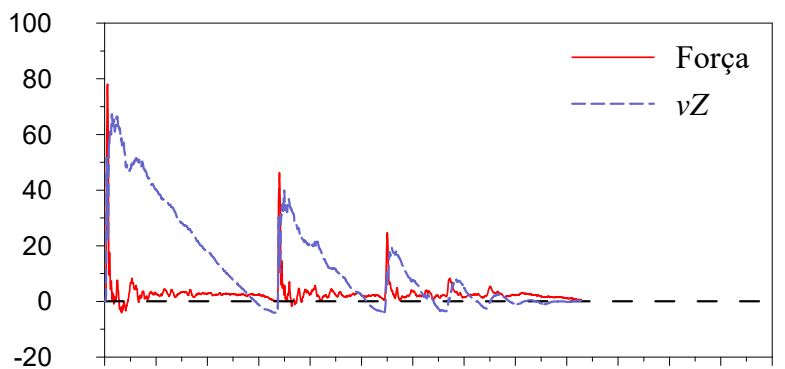

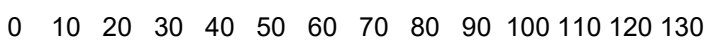
Tempo (ms)

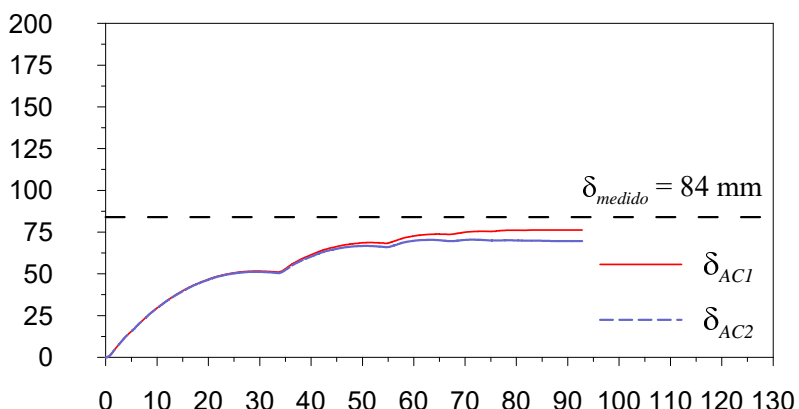

Tempo (ms)

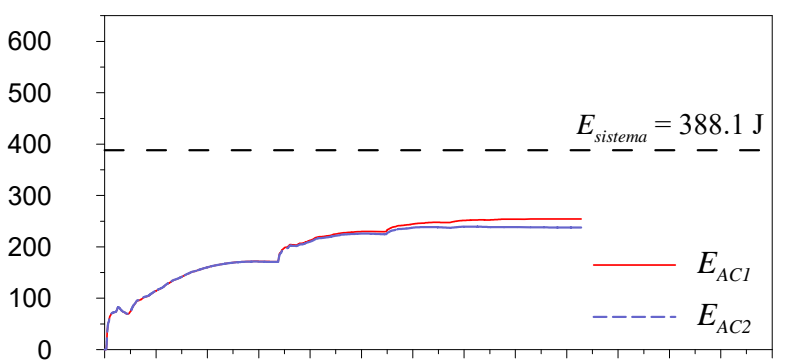

$0 \quad 10 \quad 20 \quad 30 \quad 40 \quad 50 \quad 60 \quad 70 \quad 80 \quad 90 \quad 100110120130$ Tempo (ms)

Figura A18 - Sinais típicos de SPT instrumentado para o furo SP01, profundidade de $4 \mathrm{~m}$ e $H_{q}$ de $500 \mathrm{~mm}$. 

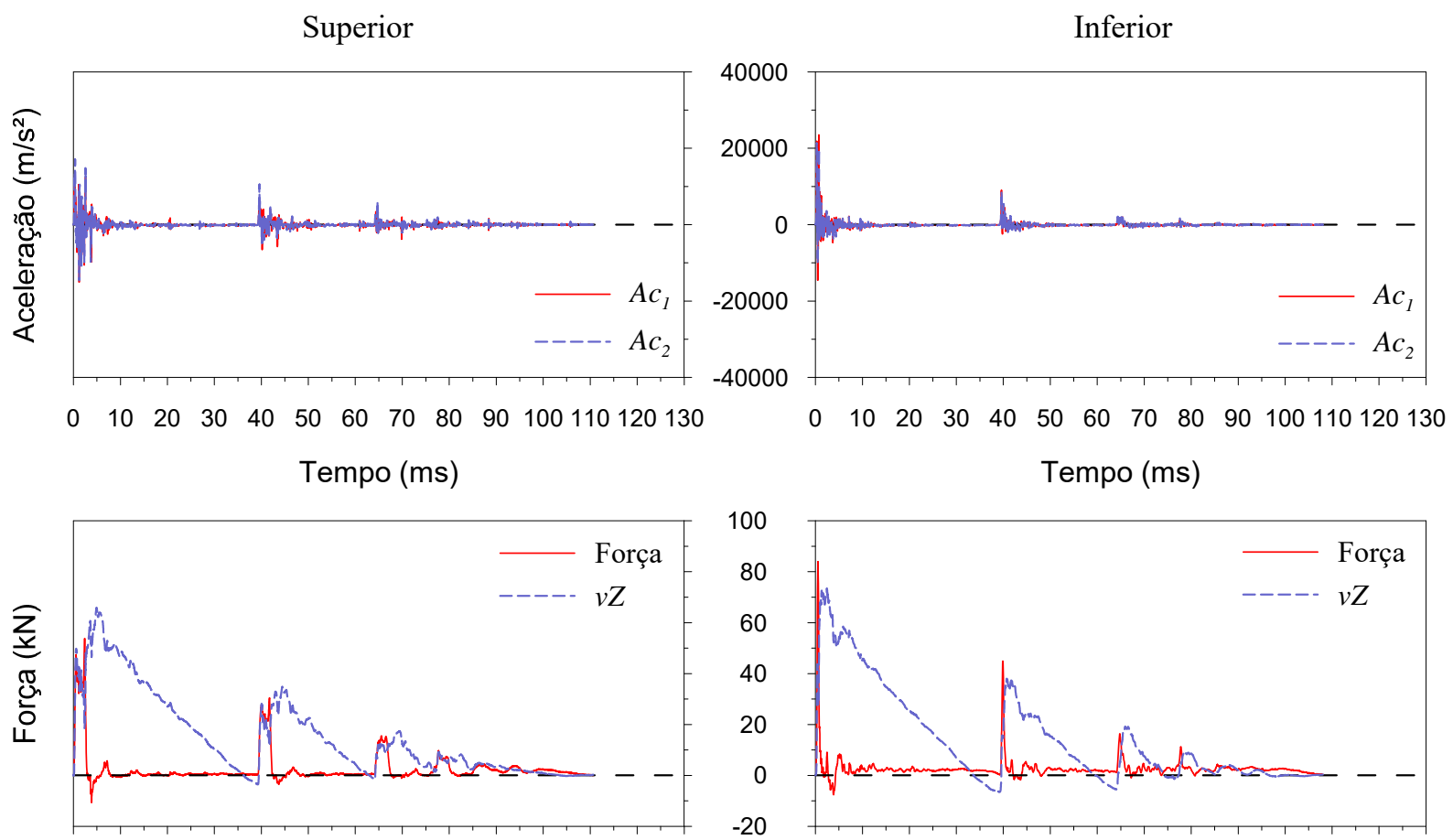

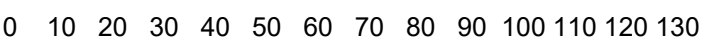

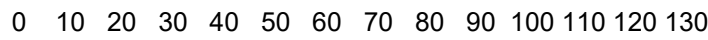

Tempo (ms)

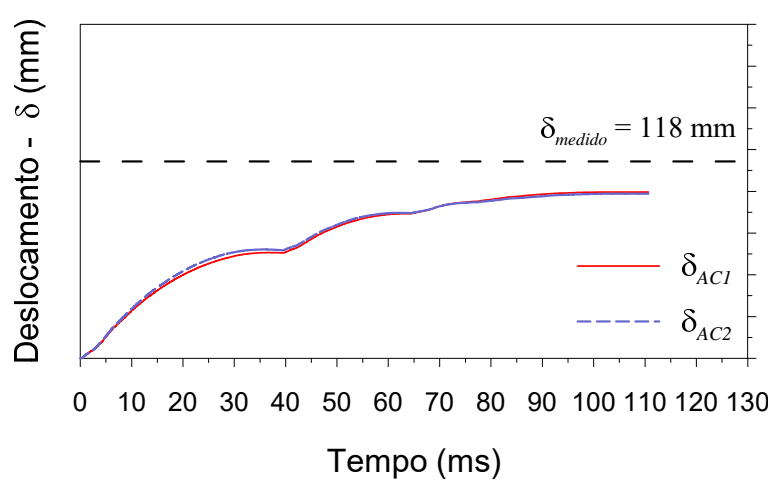

Tempo (ms)
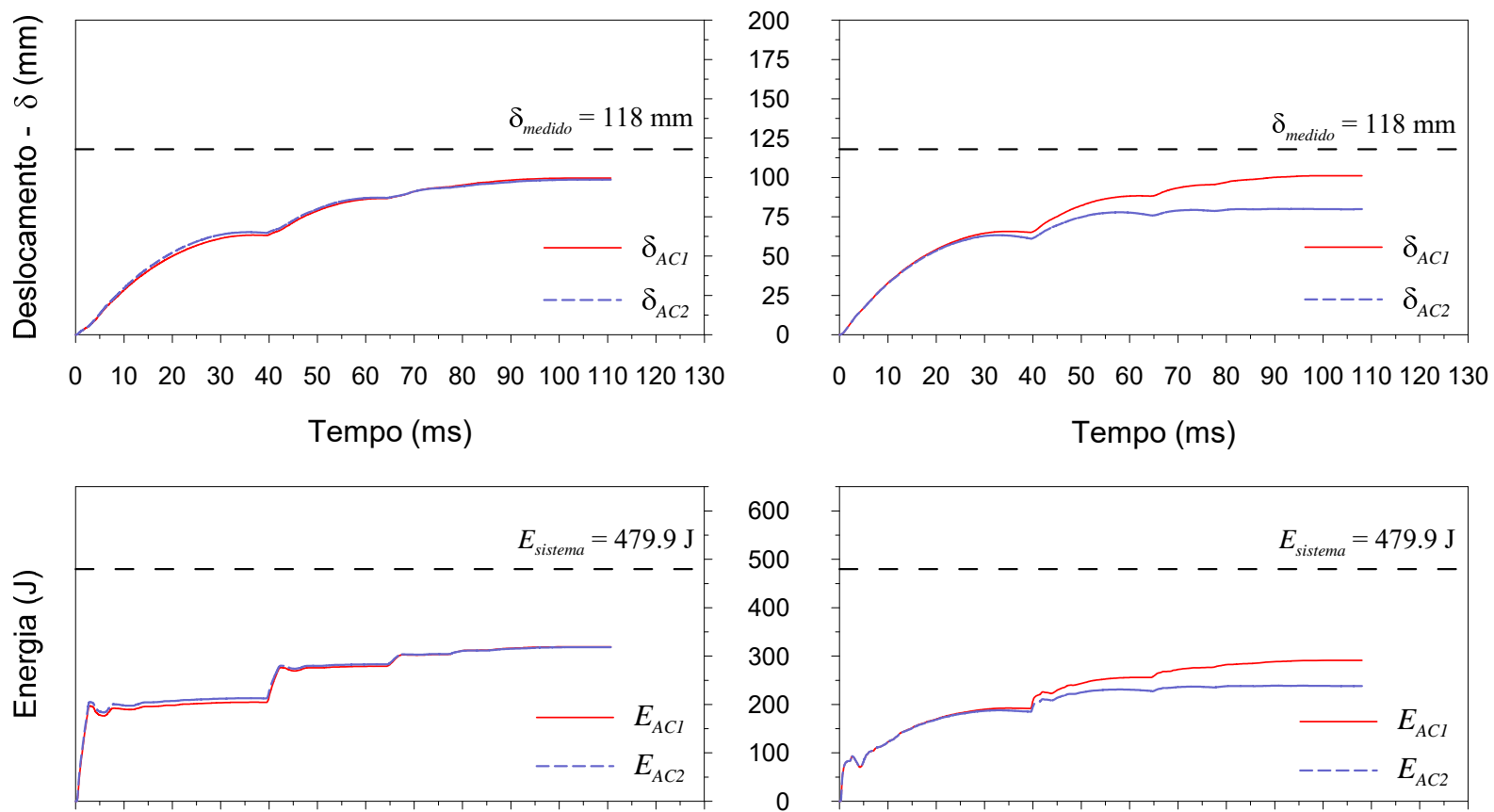

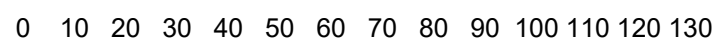
Tempo (ms)

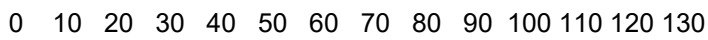
Tempo (ms)

Figura A19 - Sinais típicos de SPT instrumentado para o furo SP01, profundidade de $4 \mathrm{~m}$ e $H_{q}$ de $600 \mathrm{~mm}$. 


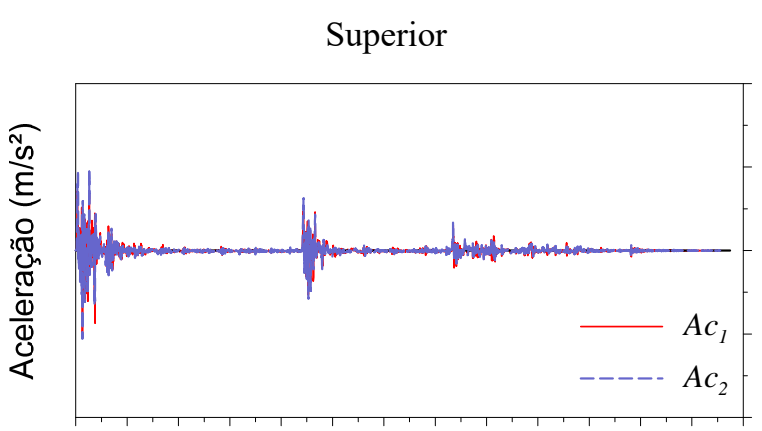

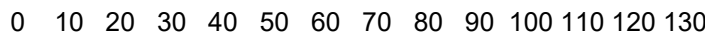

Tempo (ms)

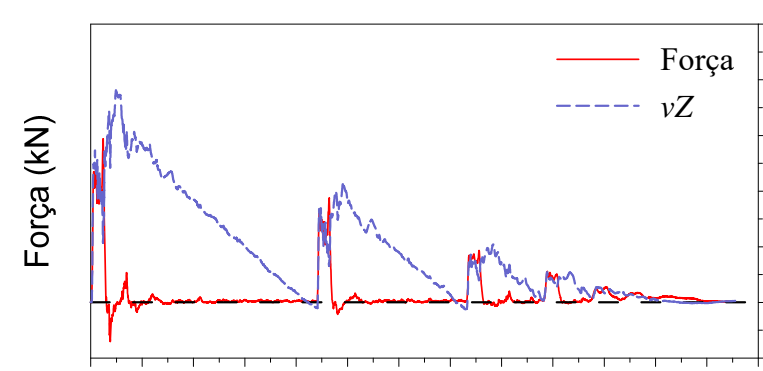

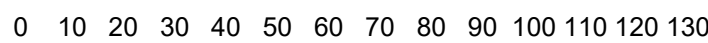

Tempo (ms)

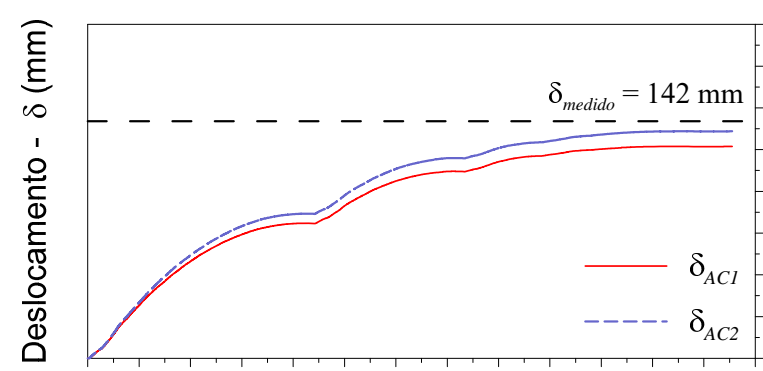

$\begin{array}{lllllllllllll}0 & 10 & 20 & 30 & 40 & 50 & 60 & 70 & 80 & 90 & 100110 & 120 & 130\end{array}$

Tempo (ms)

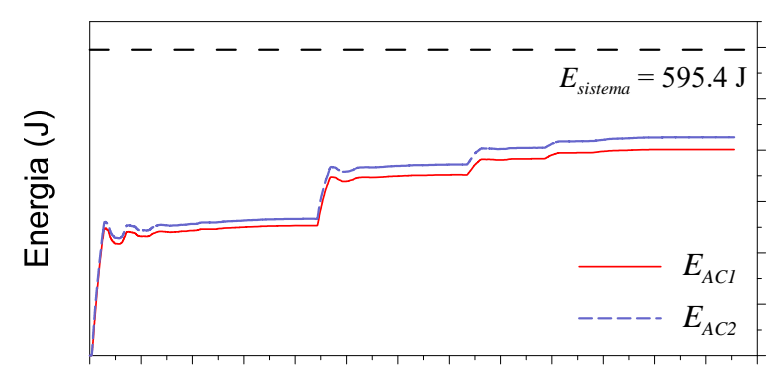

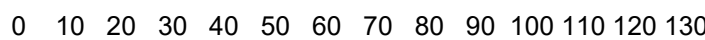

Tempo (ms)
Inferior

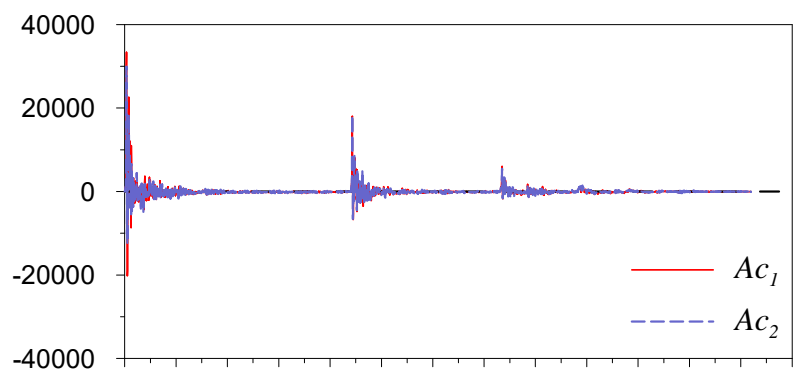

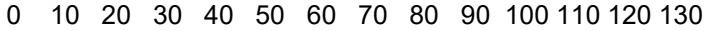
Tempo (ms)

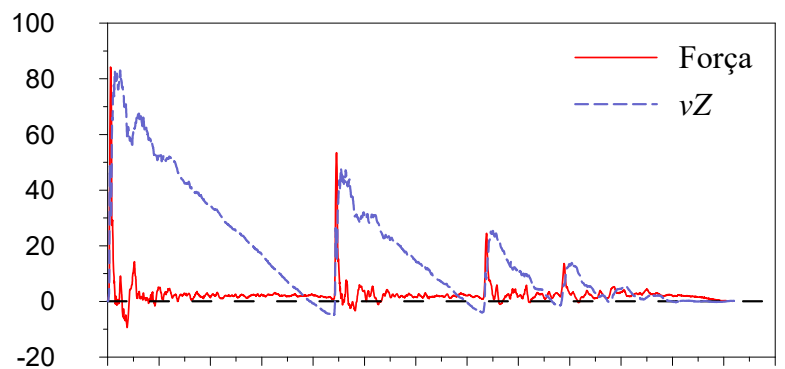

$0 \quad 10 \quad 20 \quad 30 \quad 40 \quad 50 \quad 60 \quad 70 \quad 80 \quad 90 \quad 100110120130$ Tempo (ms)

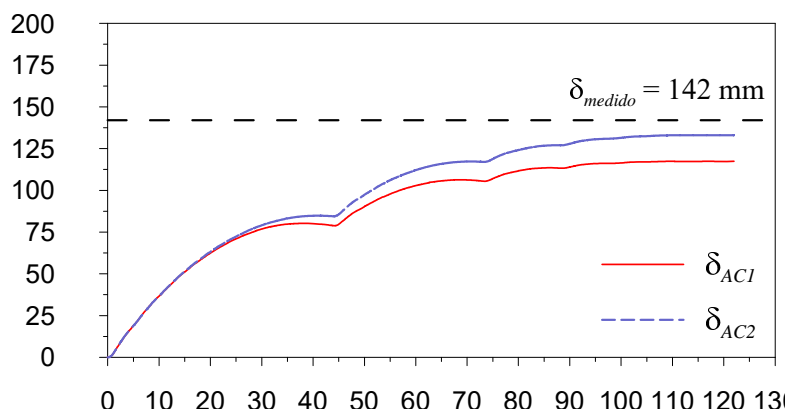

Tempo (ms)

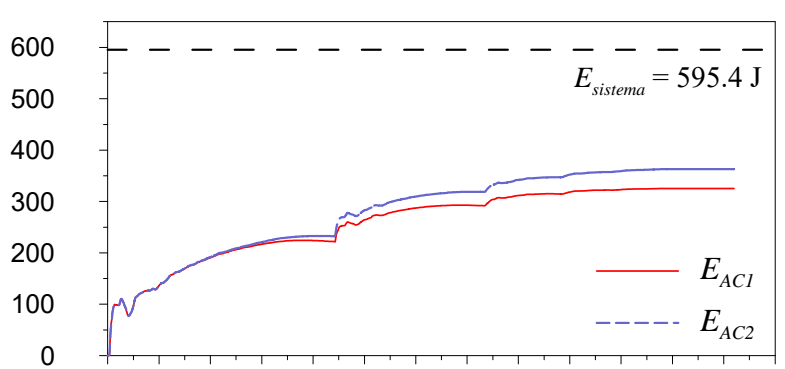

$0 \quad 10 \quad 20 \quad 30 \quad 40 \quad 50 \quad 60 \quad 70 \quad 80 \quad 90 \quad 100110120130$ Tempo (ms)

Figura A20 - Sinais típicos de SPT instrumentado para o furo SP01, profundidade de $4 \mathrm{~m}$ e $H_{q}$ de $750 \mathrm{~mm}$. 

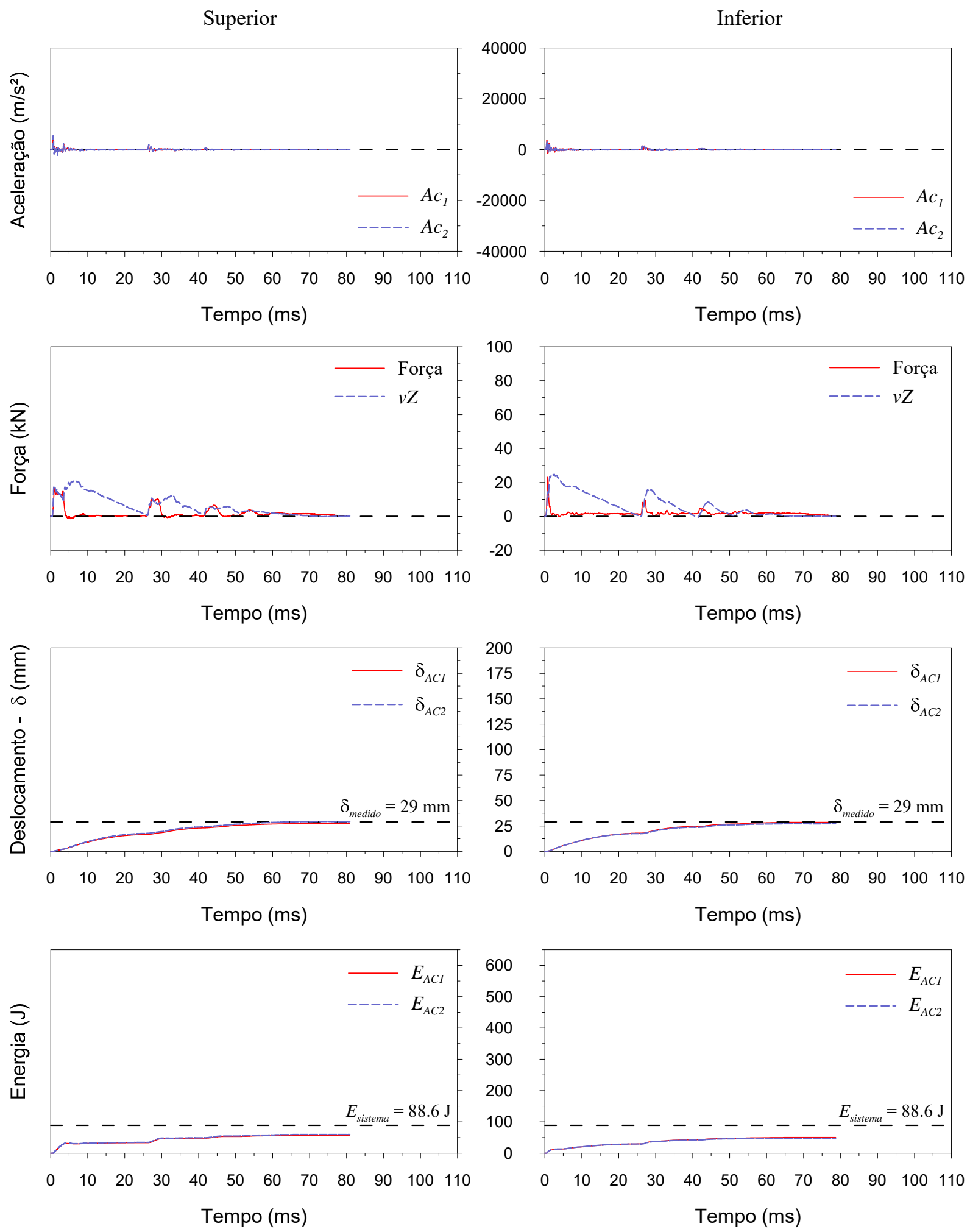

Figura A21 - Sinais típicos de SPT instrumentado para o furo SP01, profundidade de $5 \mathrm{~m}$ e $H_{q}$ de $100 \mathrm{~mm}$. 


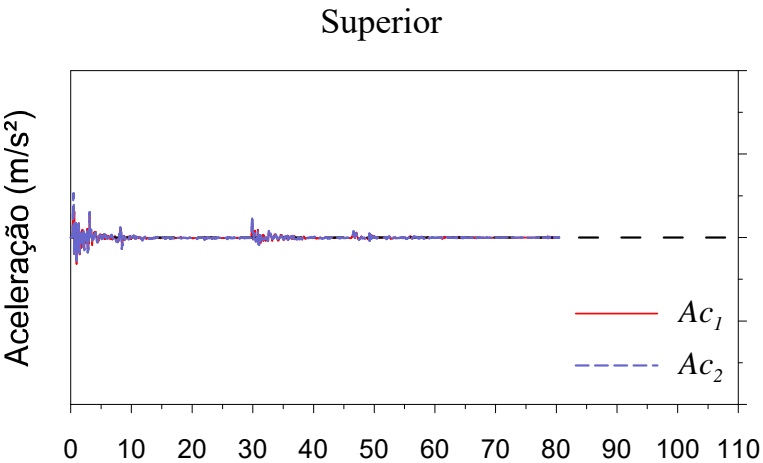

Tempo (ms)
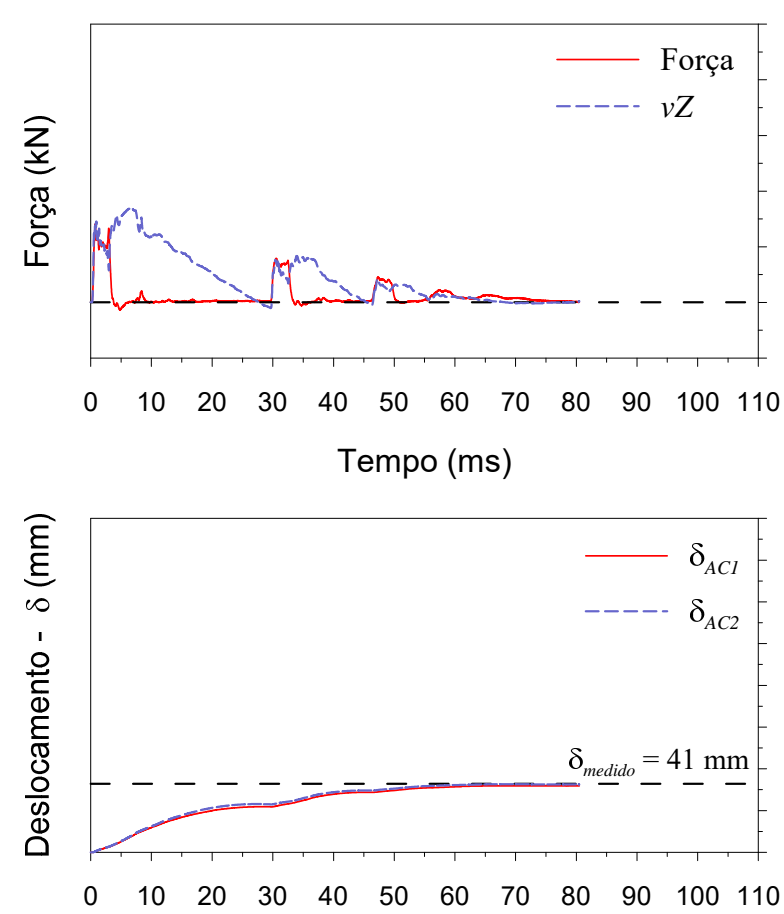

Tempo (ms)

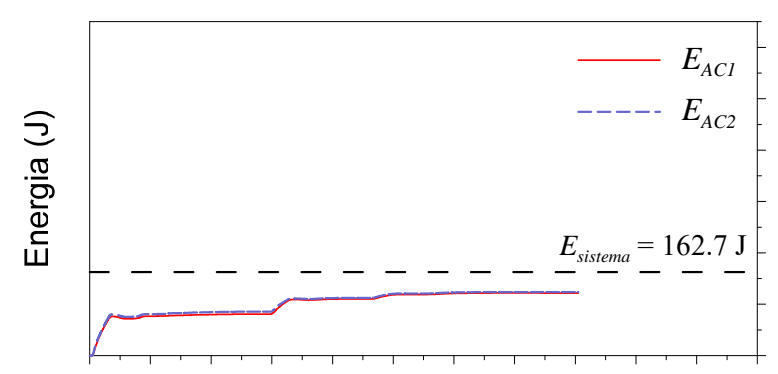

$\begin{array}{llllllllllll}0 & 10 & 20 & 30 & 40 & 50 & 60 & 70 & 80 & 90 & 100 & 110\end{array}$

Tempo (ms)
Inferior
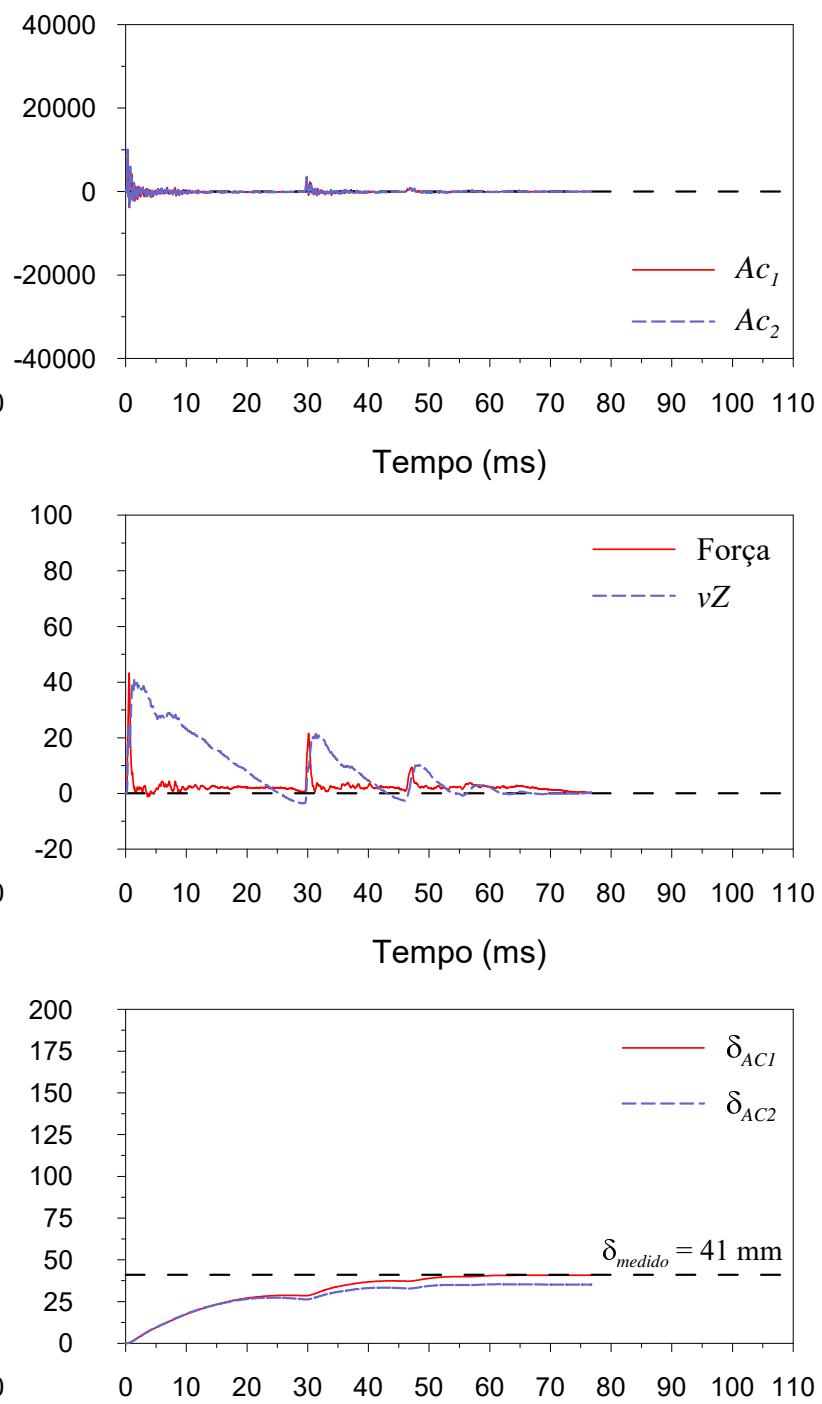

Tempo (ms)

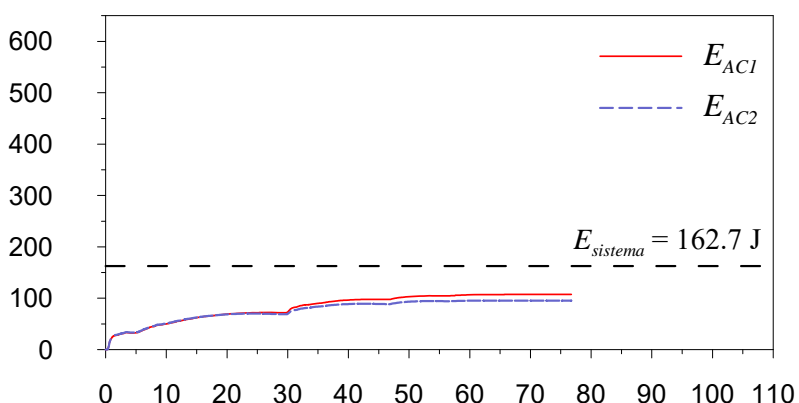

Tempo (ms)

Figura A22 - Sinais típicos de SPT instrumentado para o furo SP01, profundidade de $5 \mathrm{~m}$ e $H_{q}$ de $200 \mathrm{~mm}$. 

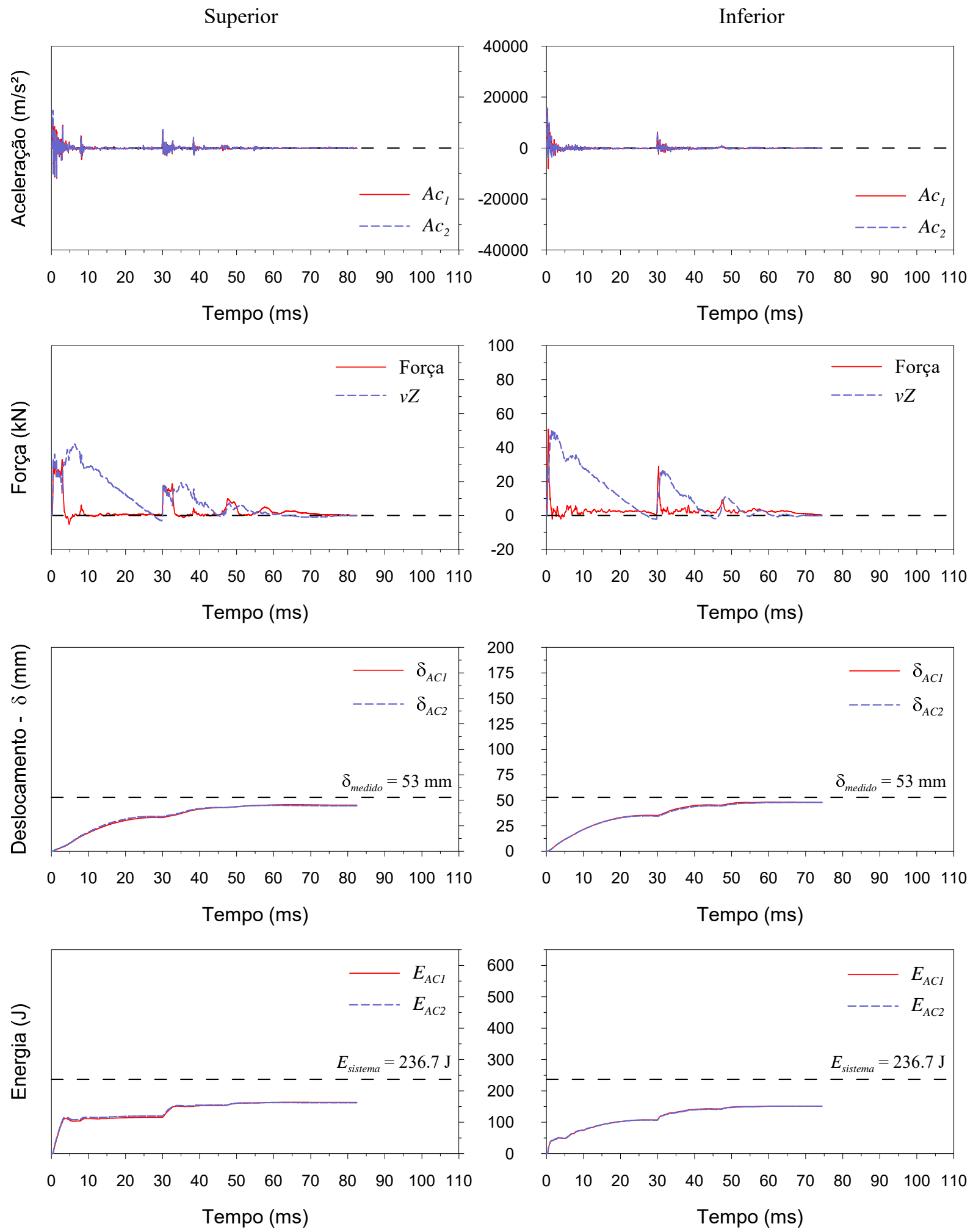

Figura A23 - Sinais típicos de SPT instrumentado para o furo SP01, profundidade de $5 \mathrm{~m}$ e $H_{q}$ de $300 \mathrm{~mm}$. 


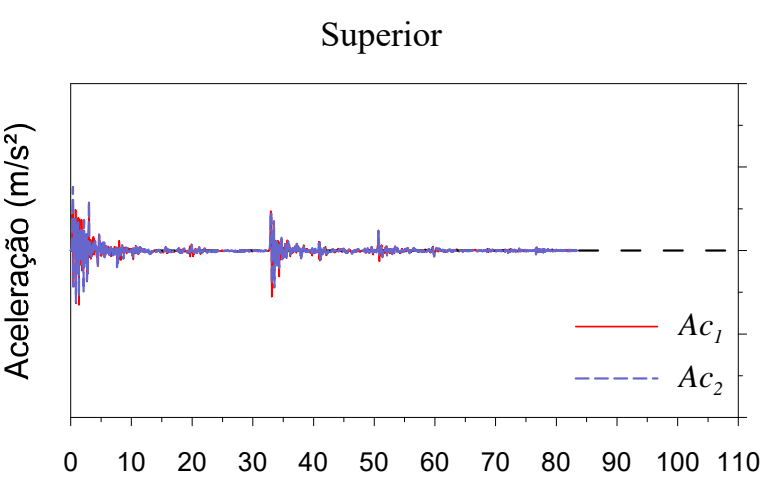

Tempo (ms)
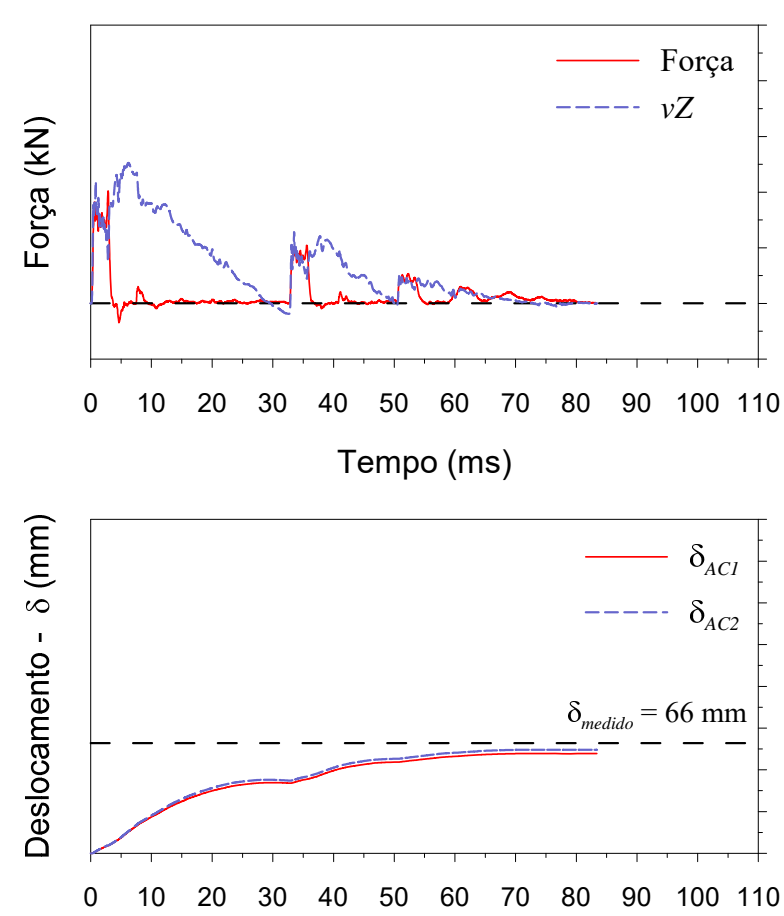

Tempo (ms)

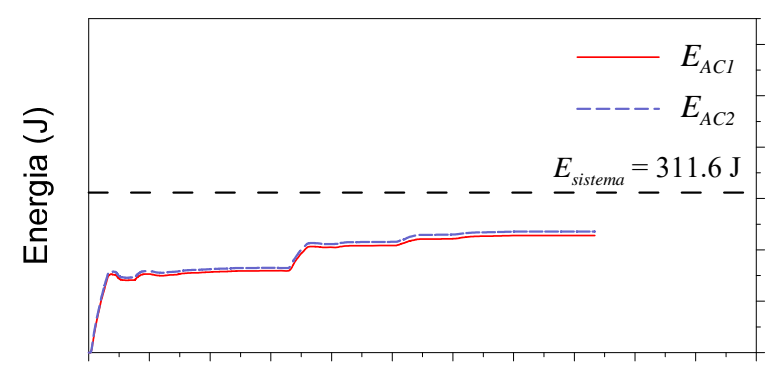

$\begin{array}{llllllllllll}0 & 10 & 20 & 30 & 40 & 50 & 60 & 70 & 80 & 90 & 100 & 110\end{array}$

Tempo (ms)
Inferior
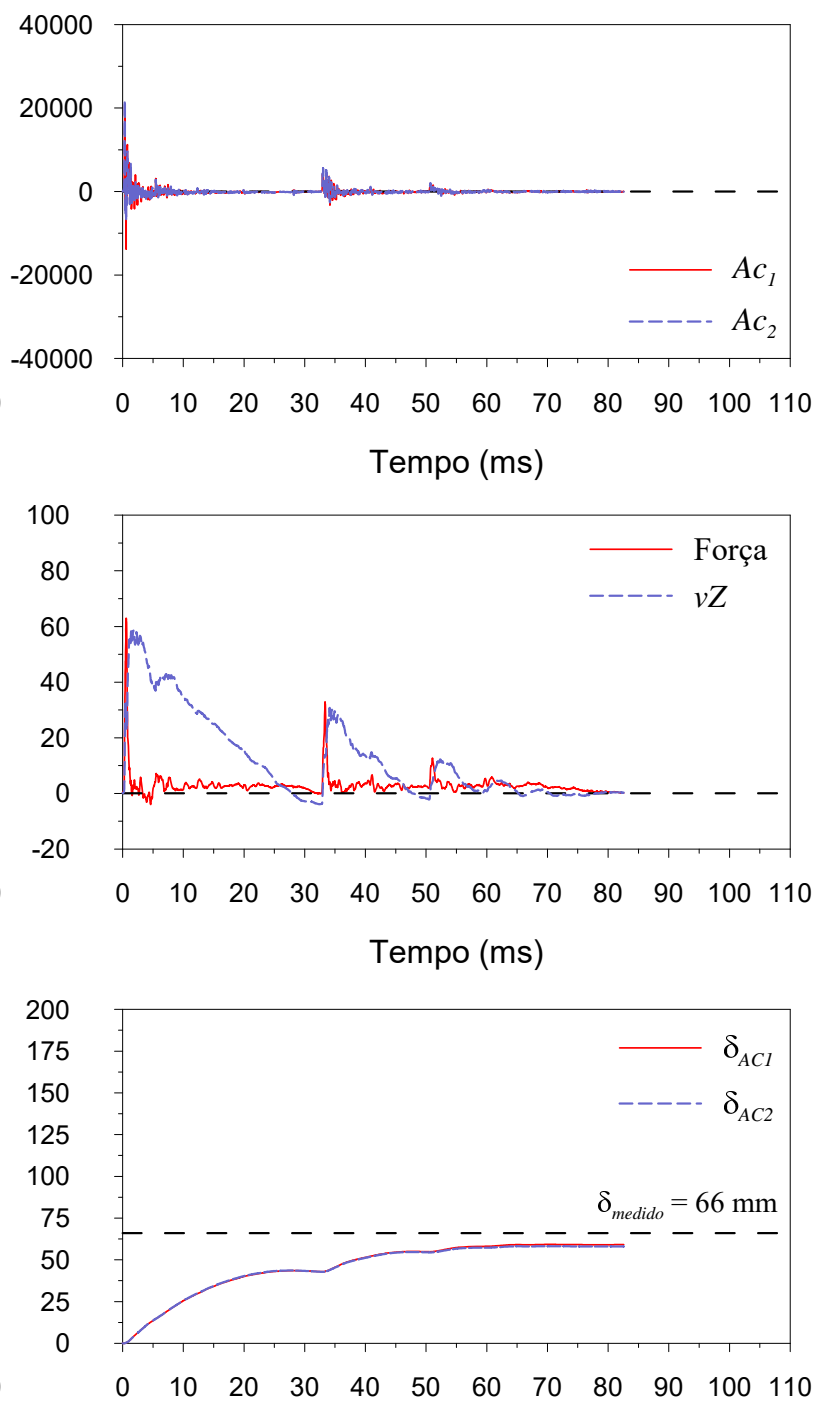

Tempo (ms)

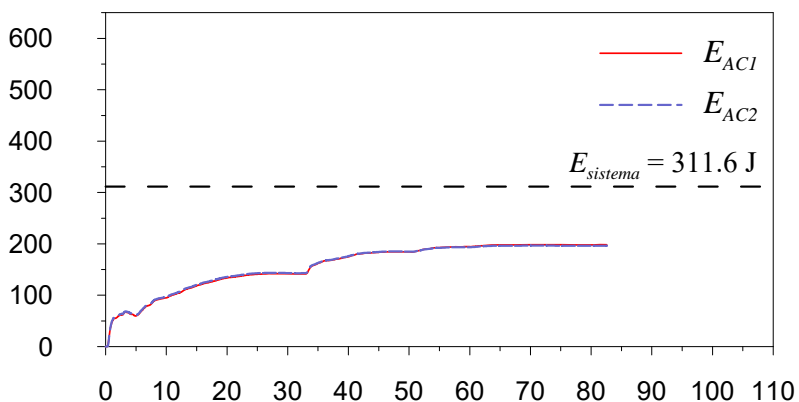

Tempo (ms)

Figura A24 - Sinais típicos de SPT instrumentado para o furo SP01, profundidade de $5 \mathrm{~m}$ e $H_{q}$ de $400 \mathrm{~mm}$. 

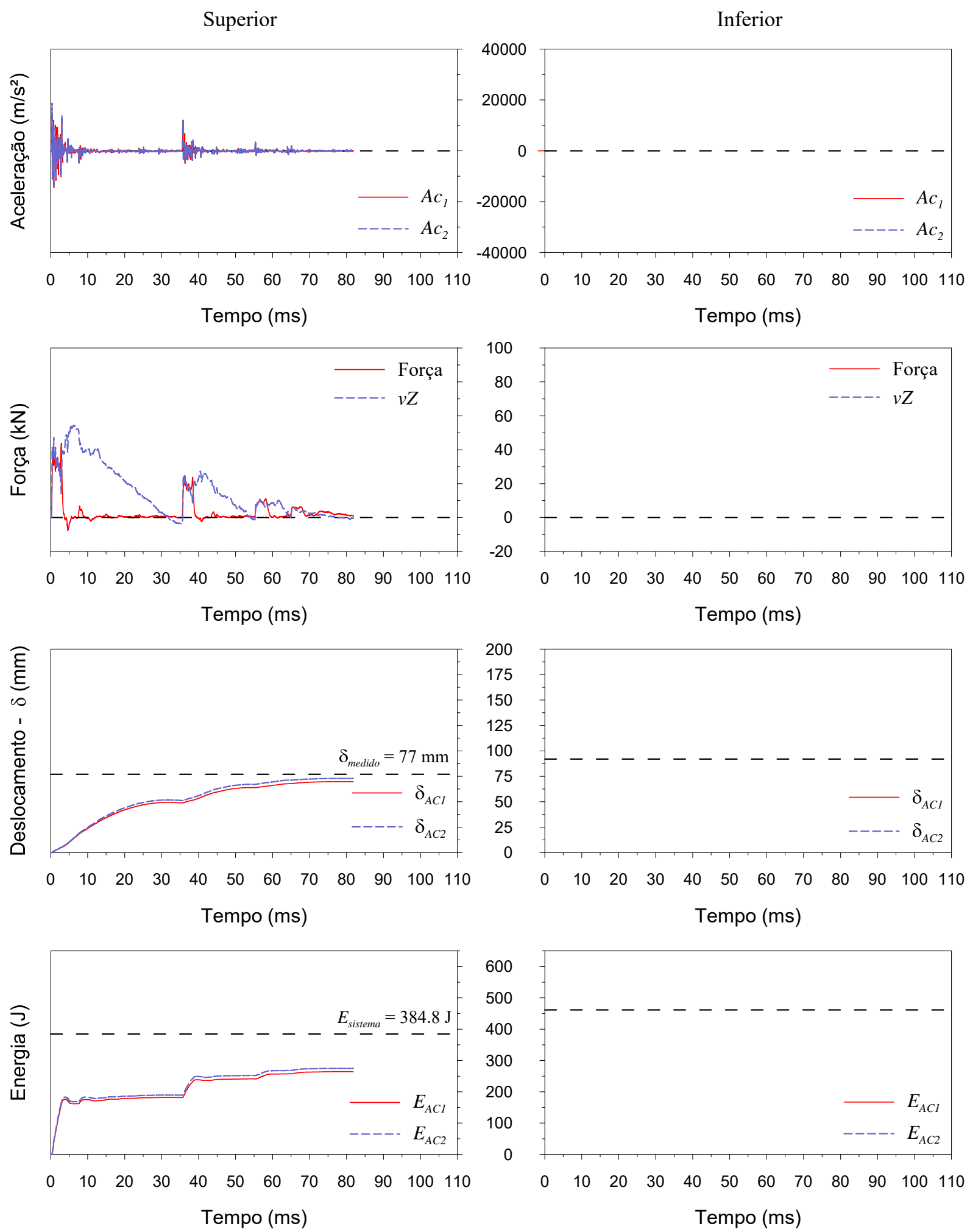

Figura A25 - Sinais típicos de SPT instrumentado para o furo SP01, profundidade de $5 \mathrm{~m}$ e $H_{q}$ de $500 \mathrm{~mm}$ - Erro na instrumentação inferior. 


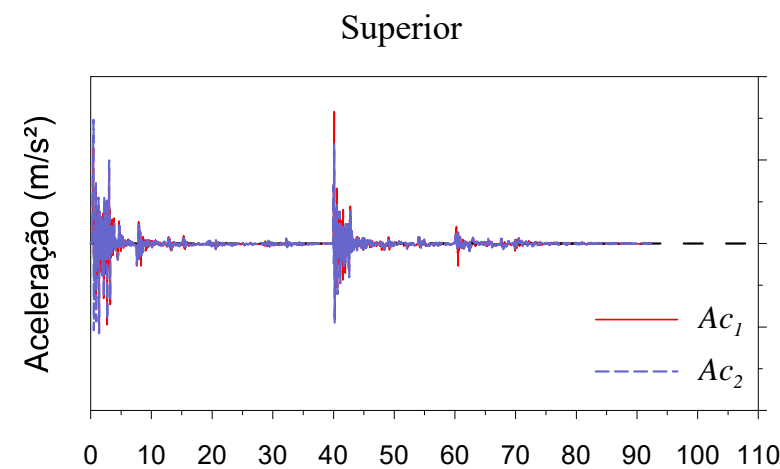

Tempo (ms)
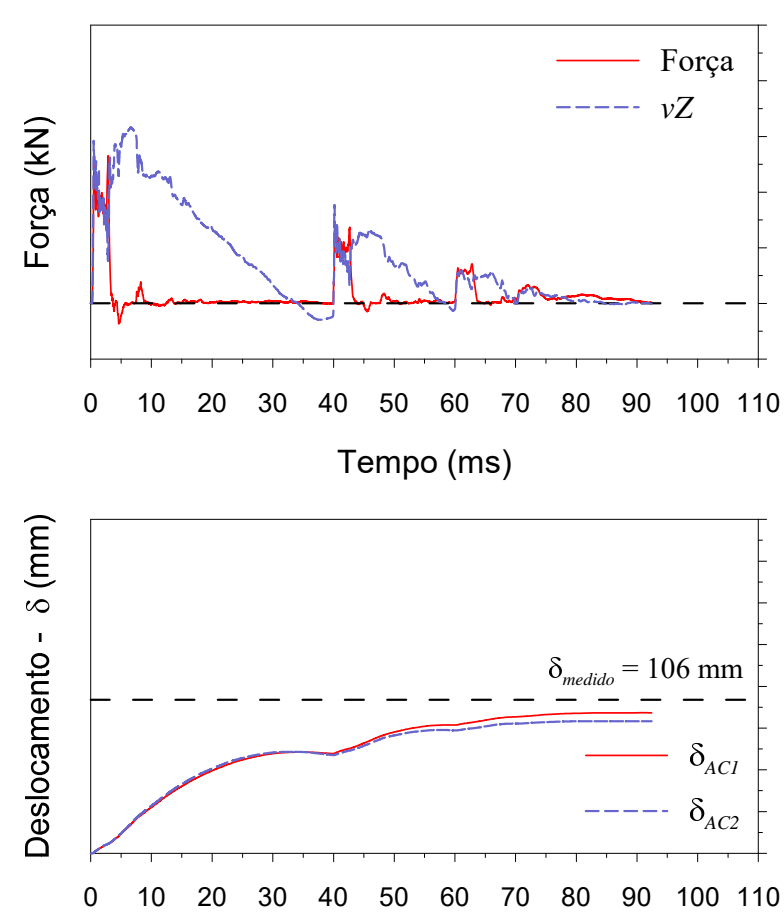

Tempo (ms)

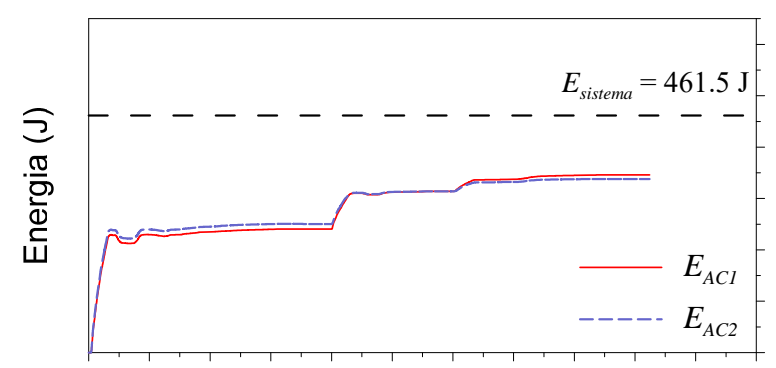

$\begin{array}{llllllllllll}0 & 10 & 20 & 30 & 40 & 50 & 60 & 70 & 80 & 90 & 100 & 110\end{array}$

Tempo (ms)
Inferior

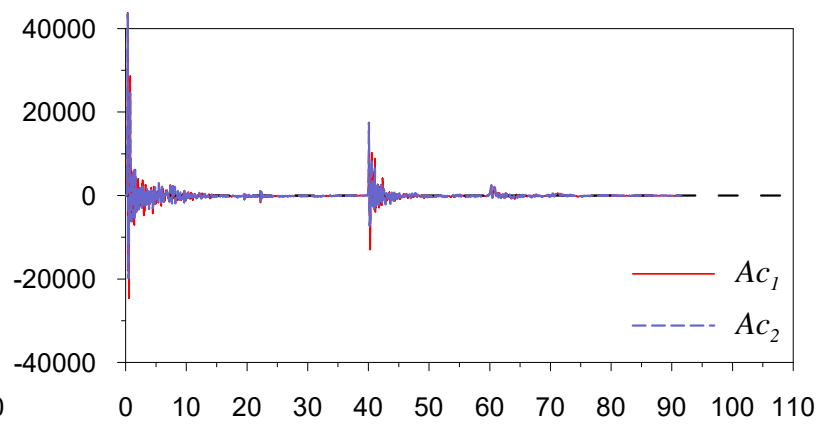

Tempo (ms)

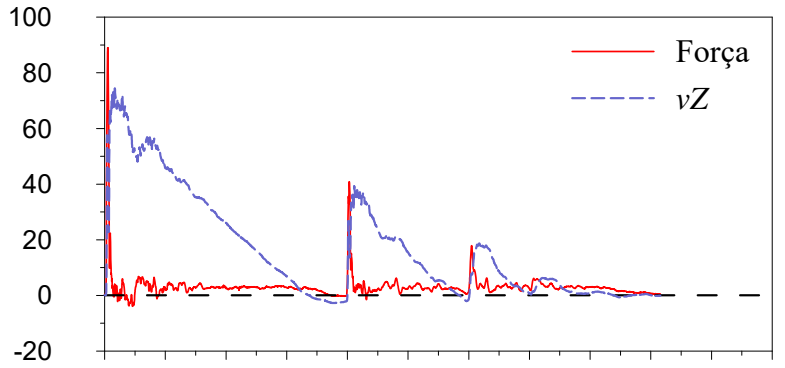

$\begin{array}{llllllllllll}0 & 10 & 20 & 30 & 40 & 50 & 60 & 70 & 80 & 90 & 100 & 110\end{array}$

Tempo (ms)

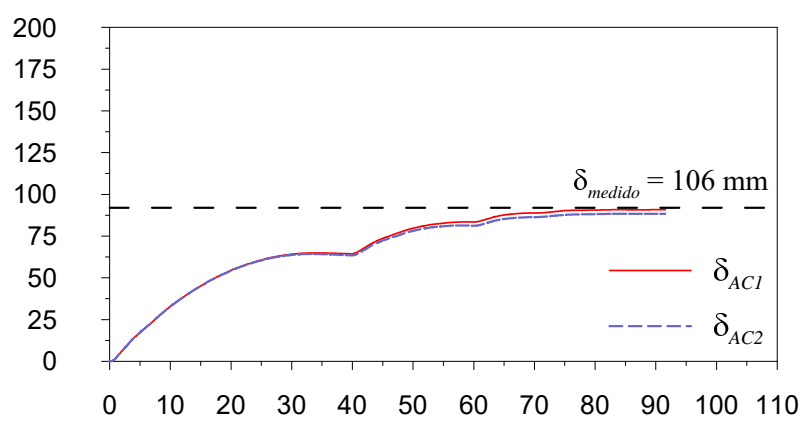

Tempo (ms)

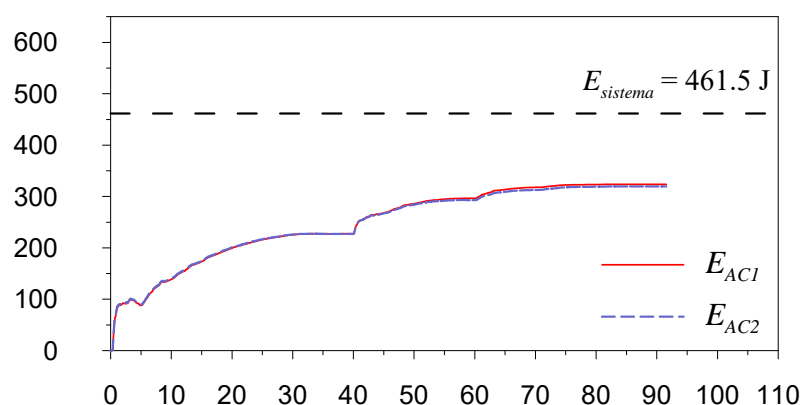

Tempo (ms)

Figura A26 - Sinais típicos de SPT instrumentado para o furo SP01, profundidade de $5 \mathrm{~m}$ e $H_{q}$ de $600 \mathrm{~mm}$. 

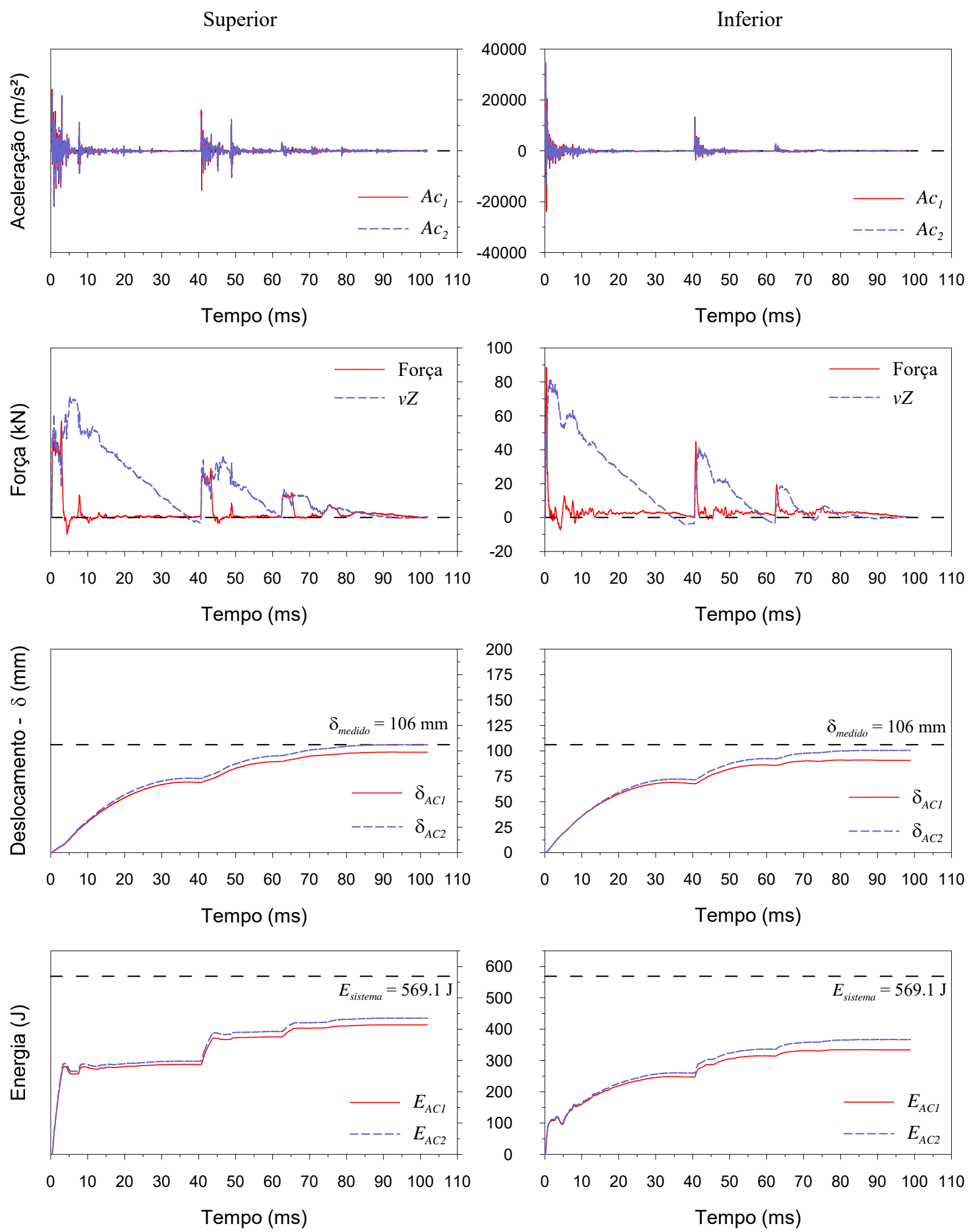

Figura A27 - Sinais típicos de SPT instrumentado para o furo SP01, profundidade de $5 \mathrm{~m}$ e $H_{q}$ de $750 \mathrm{~mm}$. 


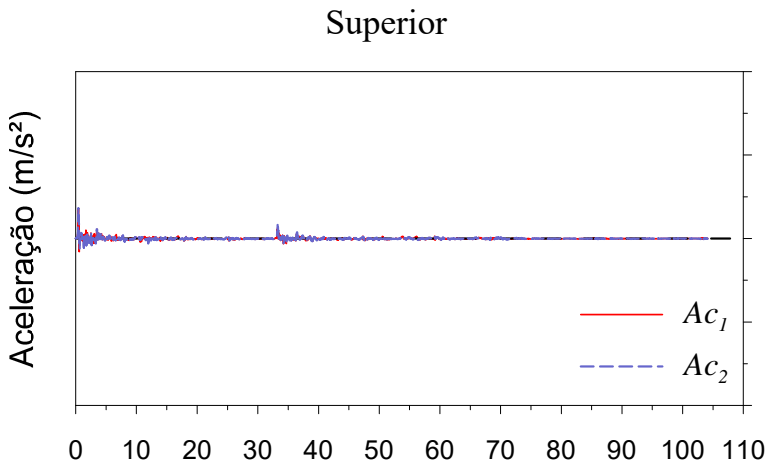

Tempo (ms)
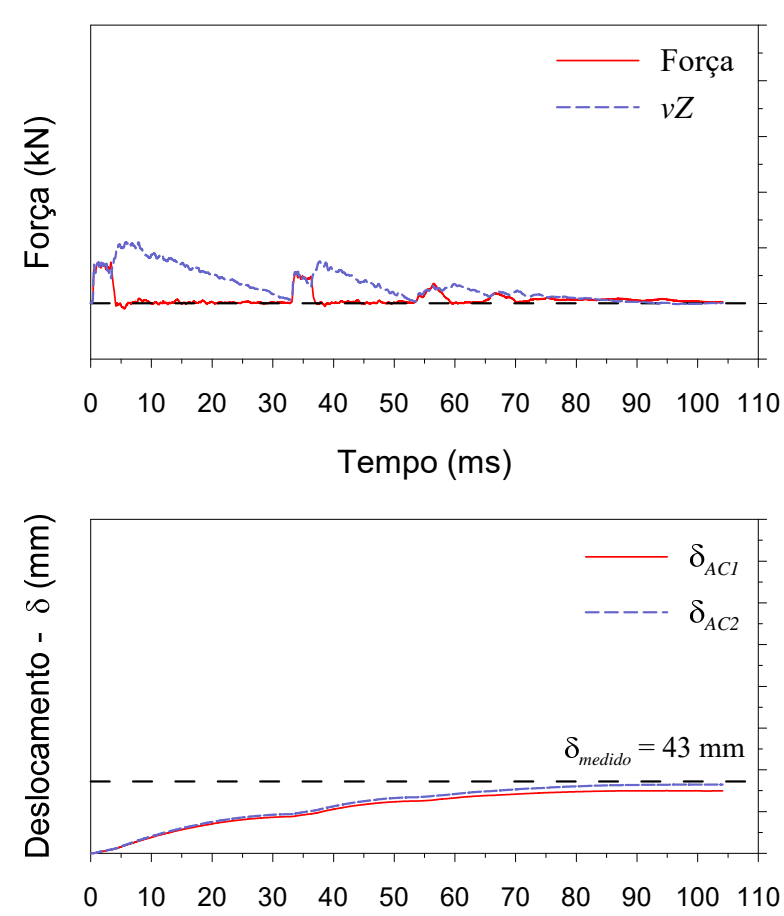

Tempo (ms)

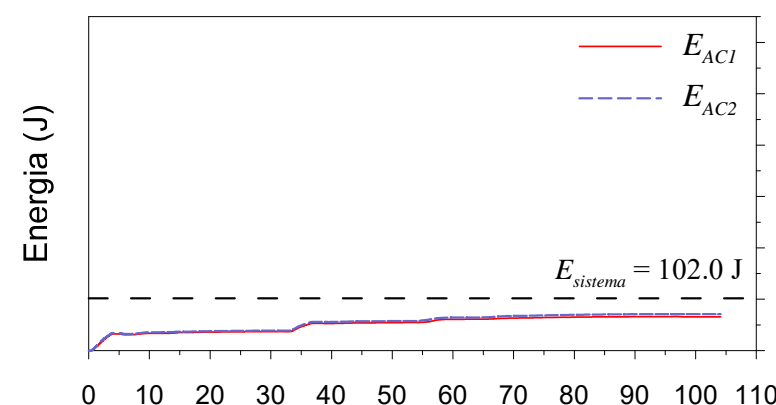

Tempo (ms)
Inferior
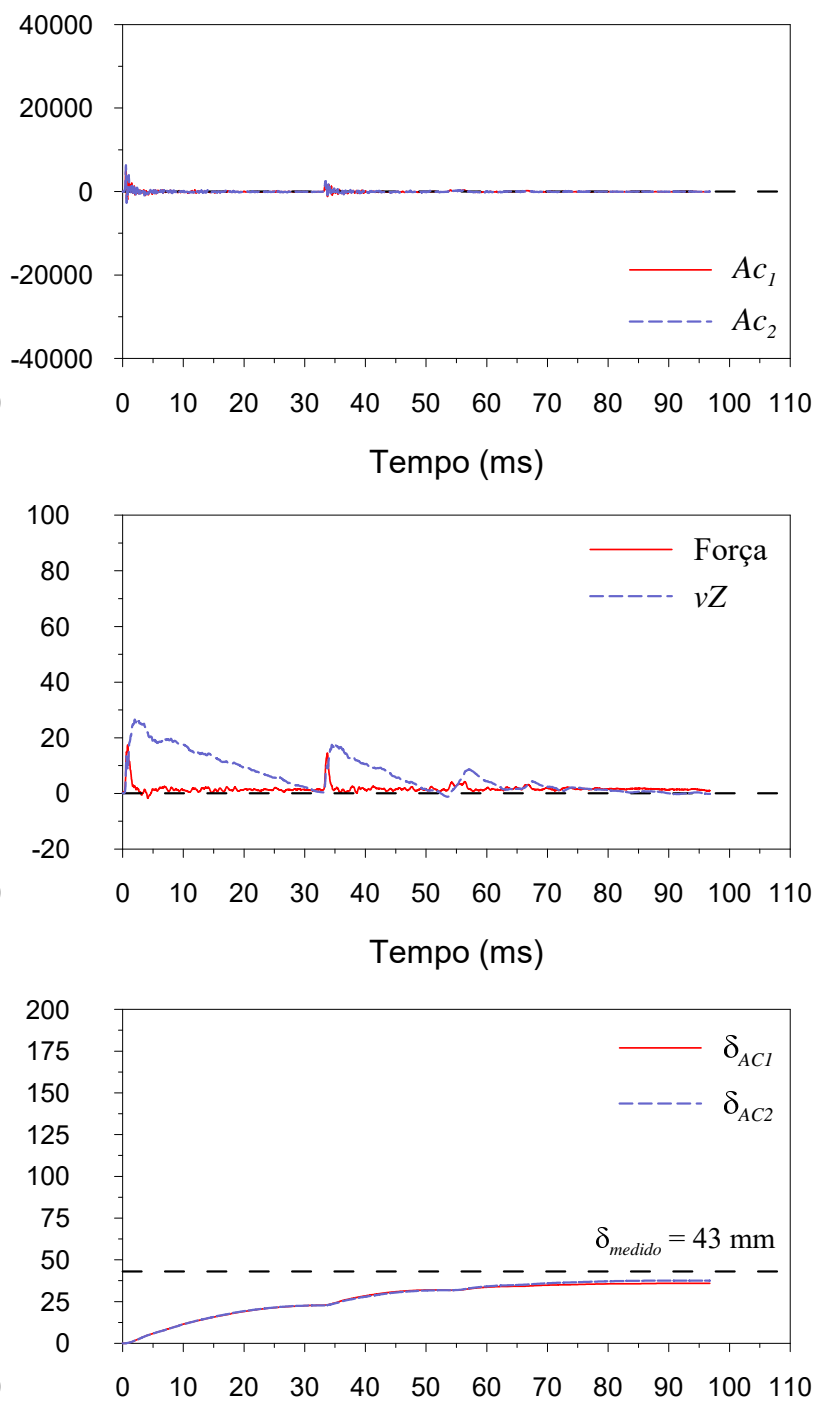

Tempo (ms)

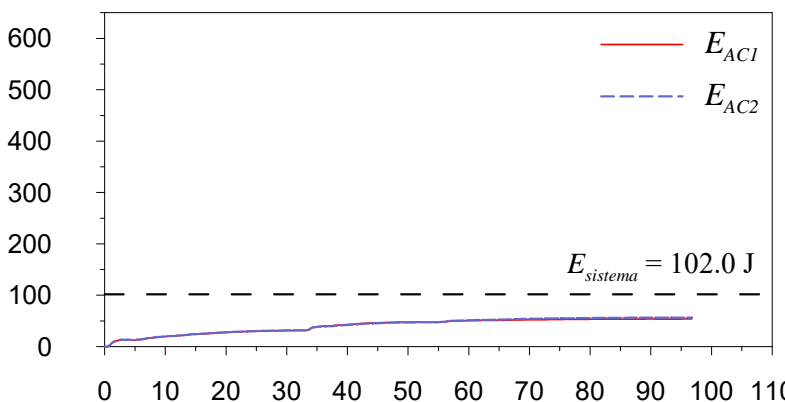

Tempo (ms)

Figura A28 - Sinais típicos de SPT instrumentado para o furo SP01, profundidade de $6 \mathrm{~m}$ e $H_{q}$ de $100 \mathrm{~mm}$. 

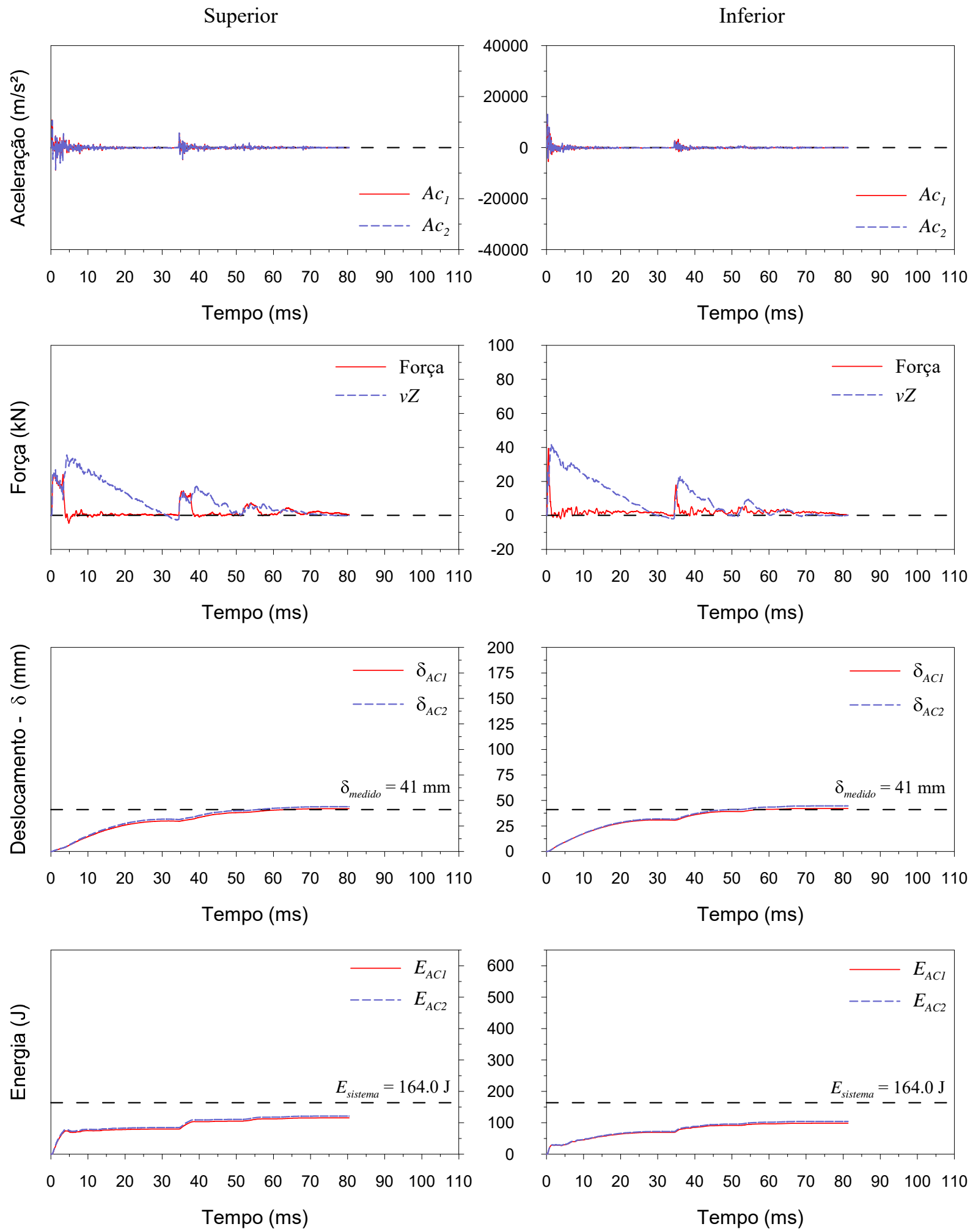

Figura A29 - Sinais típicos de SPT instrumentado para o furo SP01, profundidade de $6 \mathrm{~m}$ e $H_{q}$ de $200 \mathrm{~mm}$. 


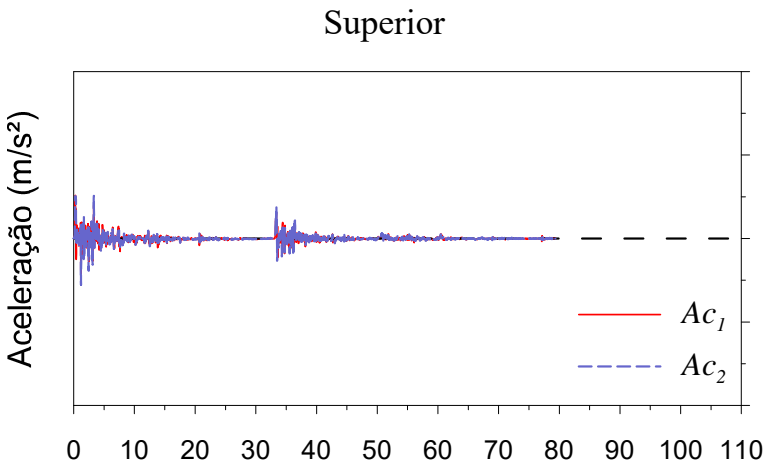

Tempo (ms)
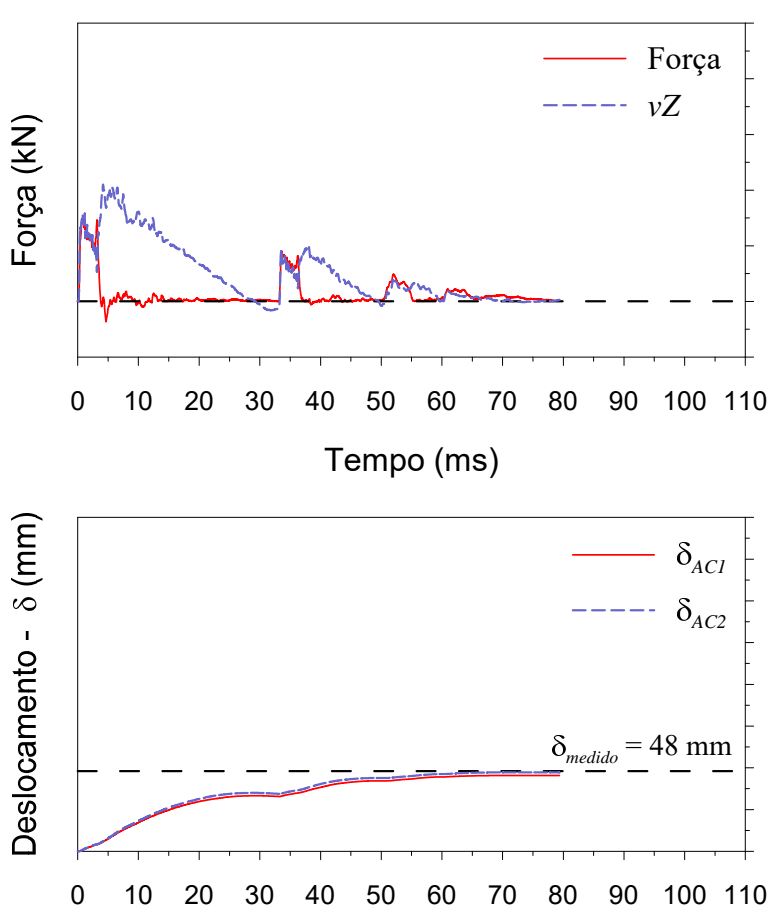

Tempo (ms)

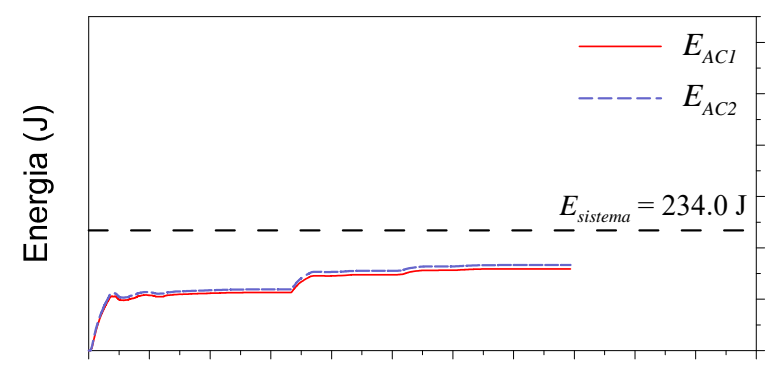

$\begin{array}{llllllllllll}0 & 10 & 20 & 30 & 40 & 50 & 60 & 70 & 80 & 90 & 100 & 110\end{array}$

Tempo (ms)
Inferior
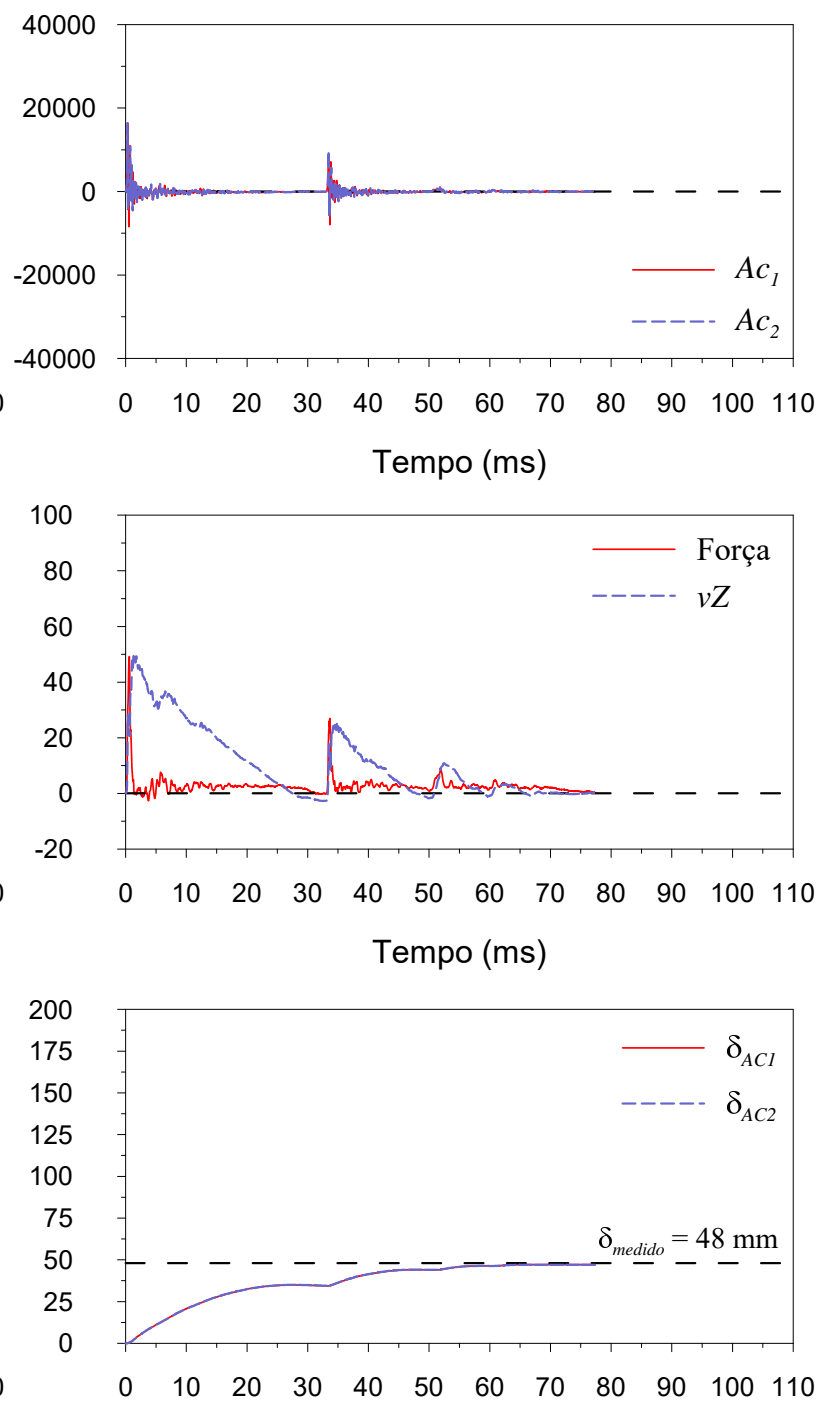

Tempo (ms)

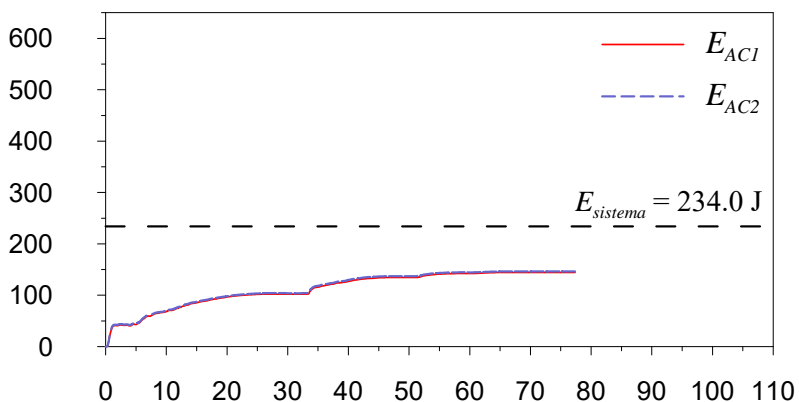

Tempo (ms)

Figura A30 - Sinais típicos de SPT instrumentado. profundidade de: $6 \mathrm{~m}$; Lh: $6.77 \mathrm{~m} ; H_{q}: 300 \mathrm{~mm}$. 

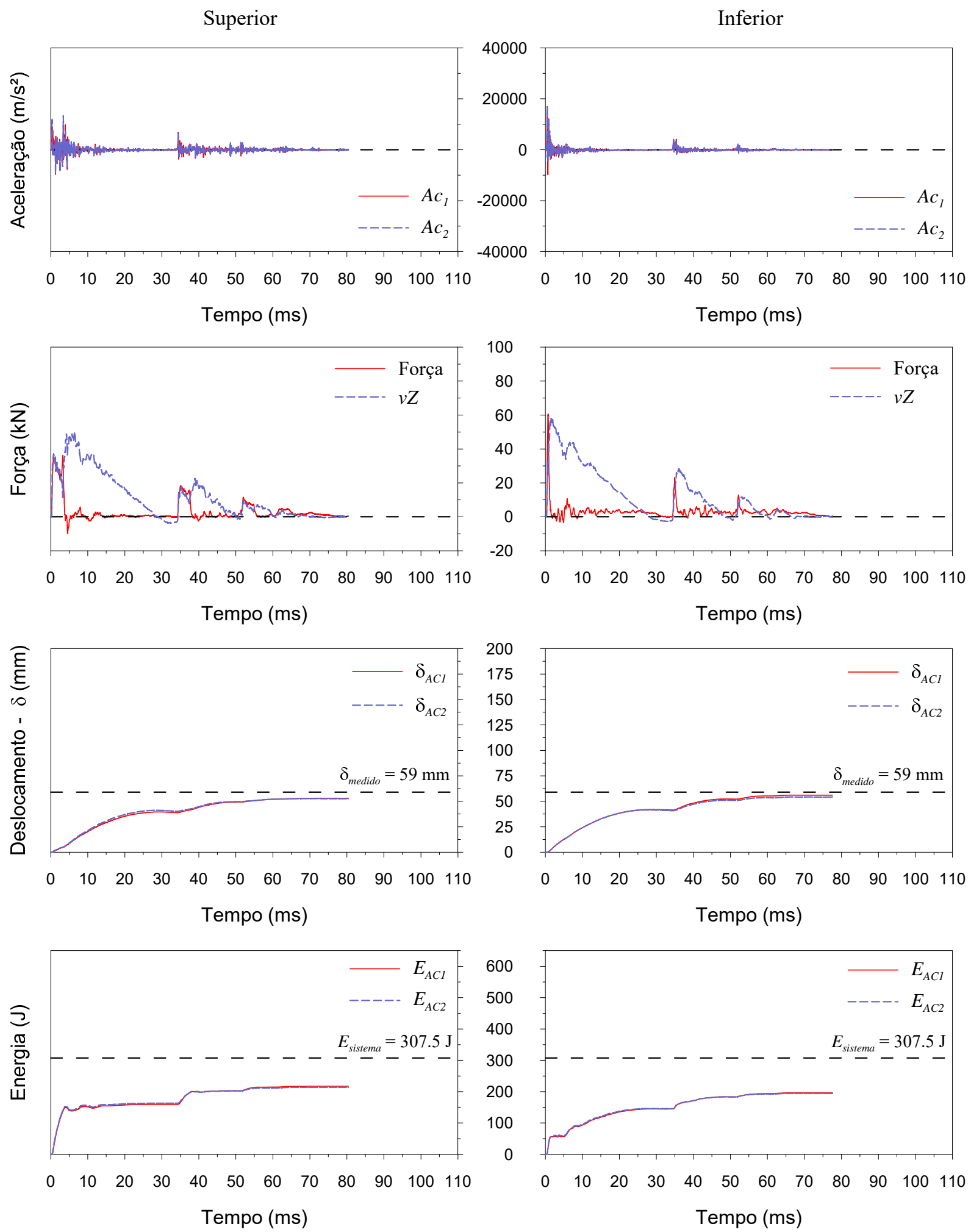

Figura A31 - Sinais típicos de SPT instrumentado para o furo SP01, profundidade de $6 \mathrm{~m}$ e $H_{q}$ de $400 \mathrm{~mm}$. 


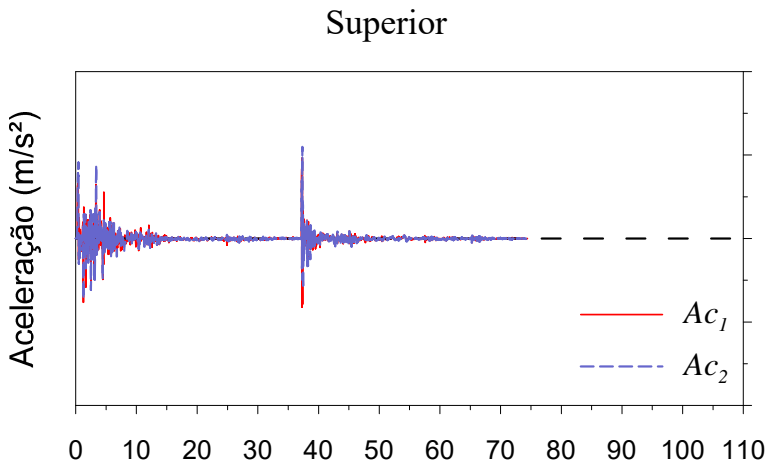

Tempo (ms)
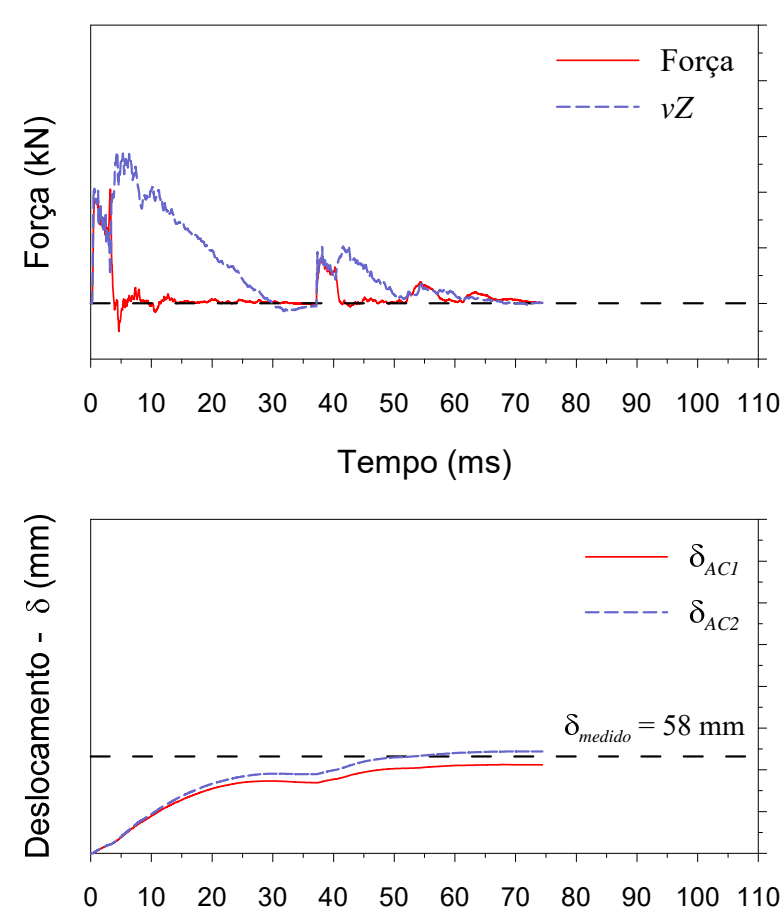

Tempo (ms)

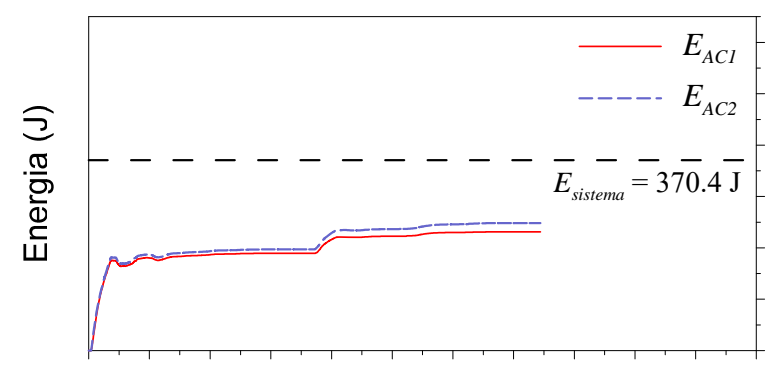

$\begin{array}{llllllllllll}0 & 10 & 20 & 30 & 40 & 50 & 60 & 70 & 80 & 90 & 100 & 110\end{array}$

Tempo (ms)
Inferior
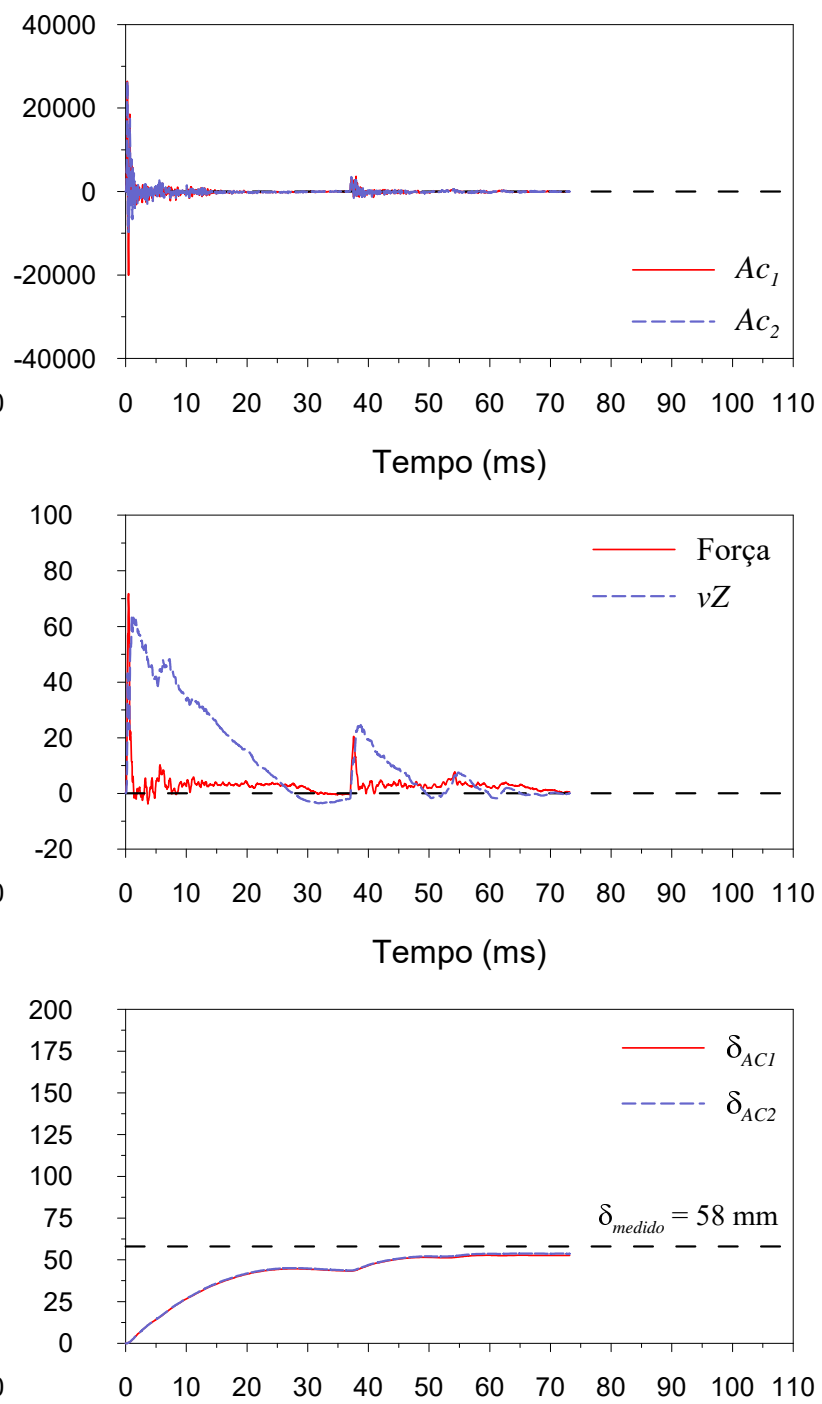

Tempo (ms)

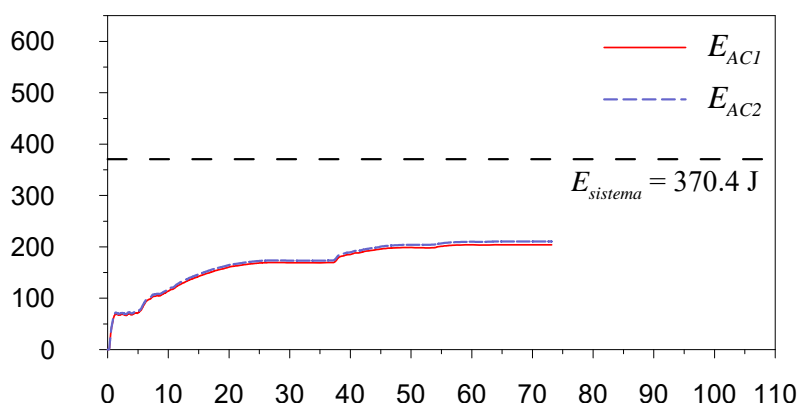

Tempo (ms)

Figura A32 - Sinais típicos de SPT instrumentado para o furo SP01, profundidade de $6 \mathrm{~m}$ e $H_{q}$ de $500 \mathrm{~mm}$. 

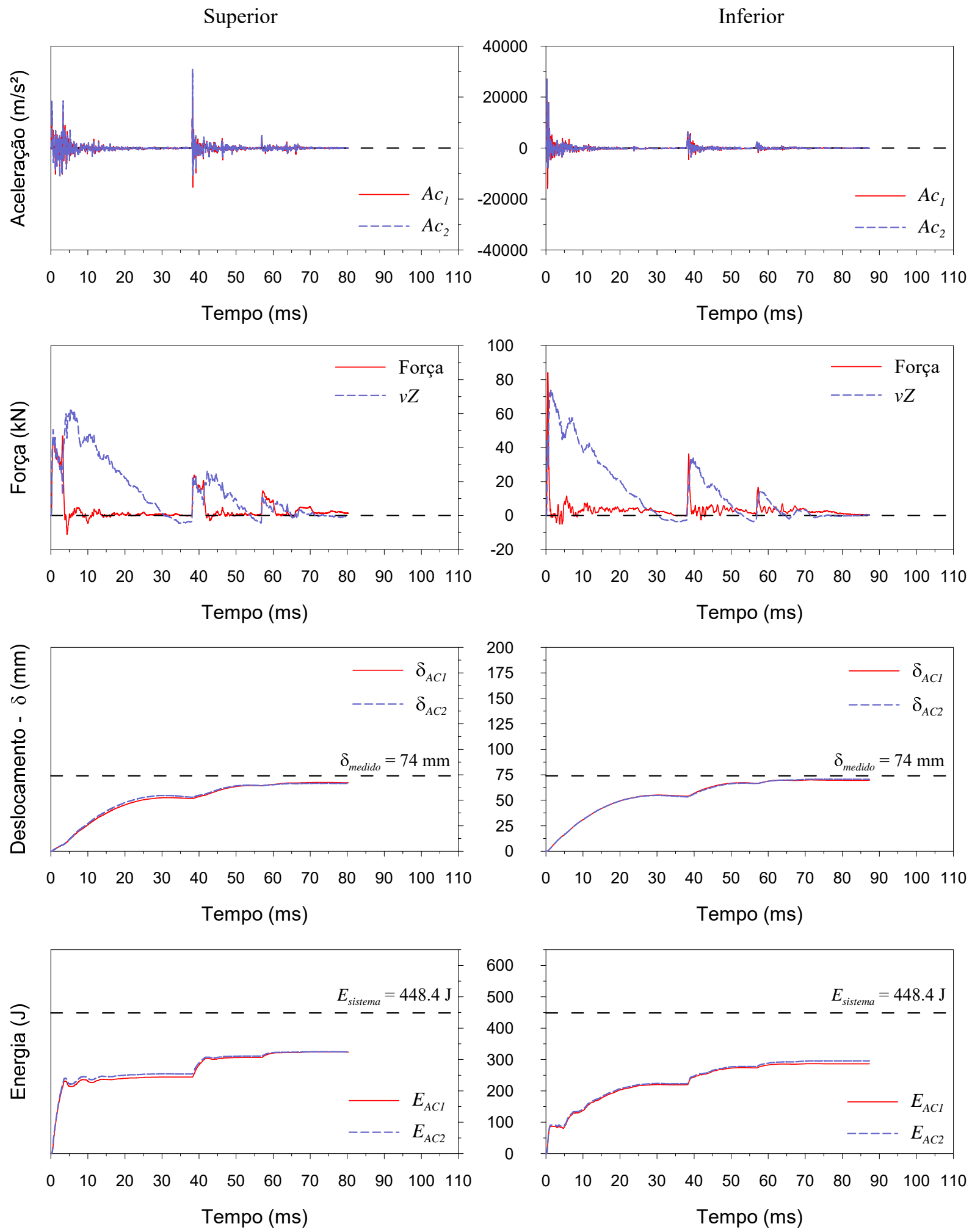

Figura A33 - Sinais típicos de SPT instrumentado para o furo SP01, profundidade de $6 \mathrm{~m}$ e $H_{q}$ de $600 \mathrm{~mm}$. 


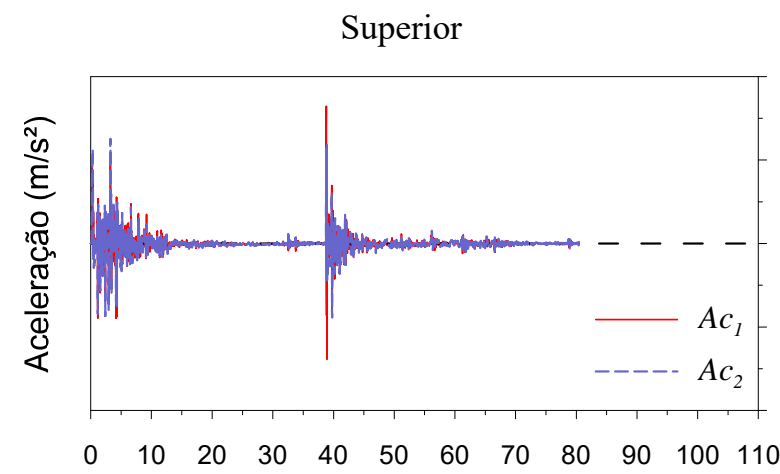

Tempo (ms)
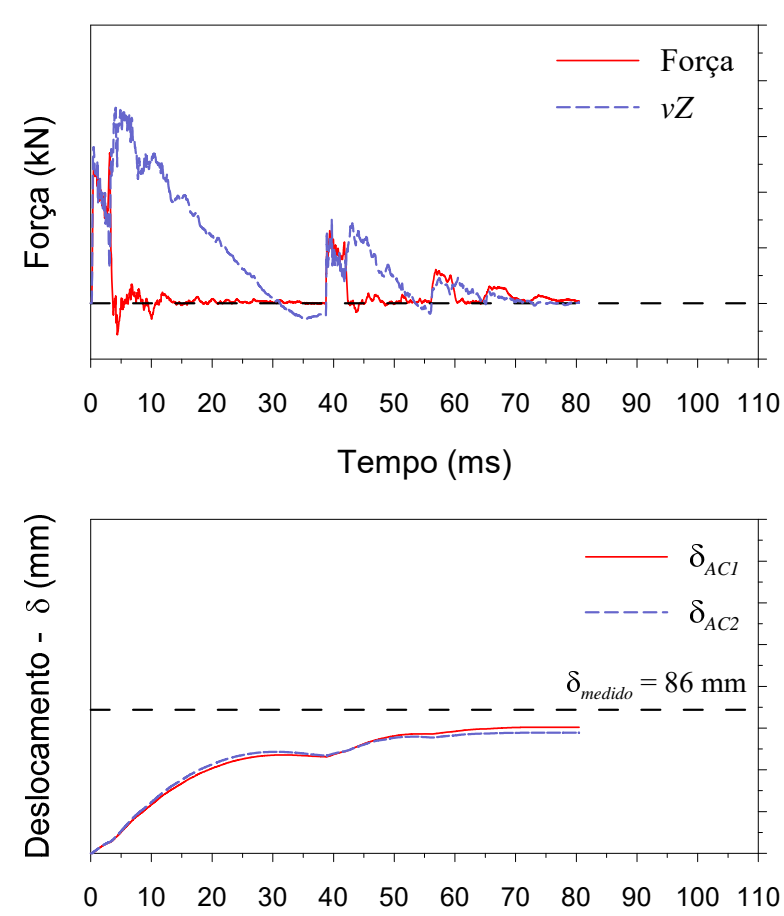

Tempo (ms)

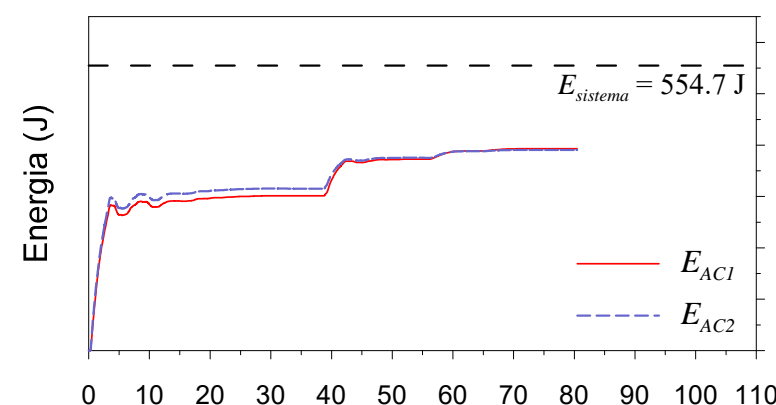

Tempo (ms)
Inferior

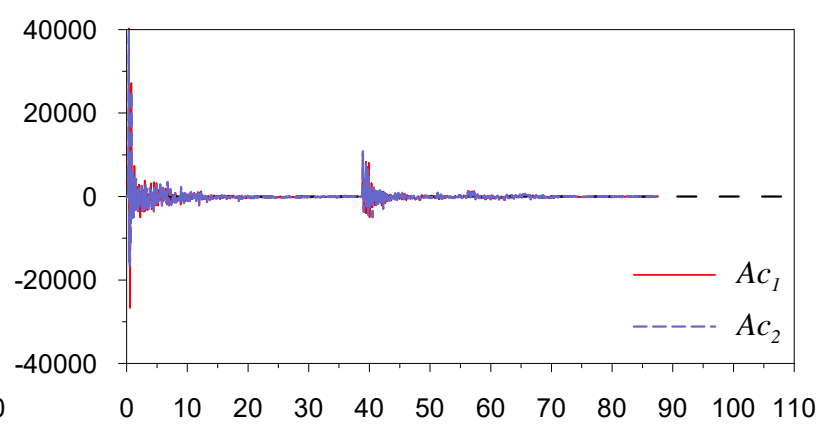

Tempo (ms)

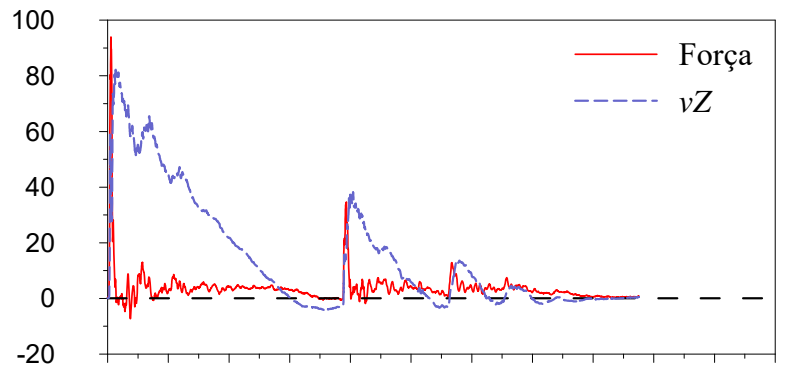

$\begin{array}{llllllllllll}0 & 10 & 20 & 30 & 40 & 50 & 60 & 70 & 80 & 90 & 100 & 110\end{array}$

Tempo (ms)

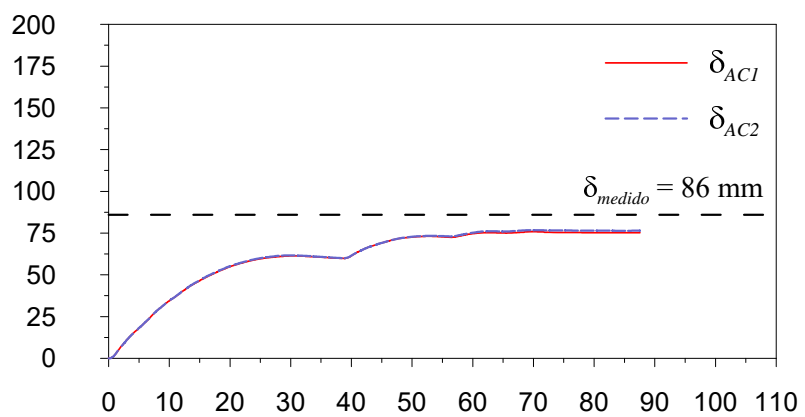

Tempo (ms)

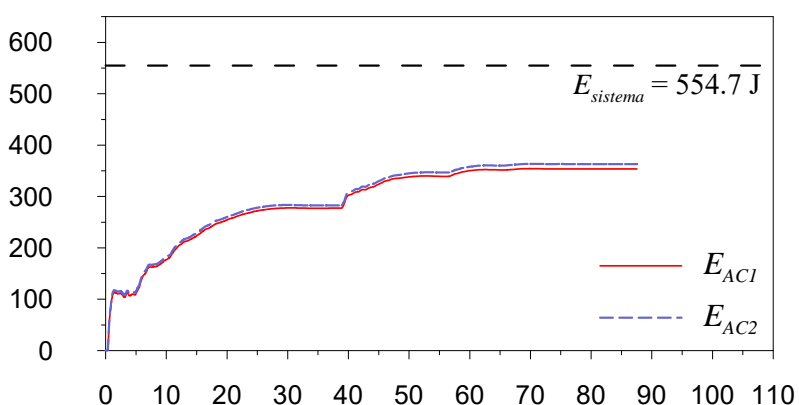

Tempo (ms)

Figura A34 - Sinais típicos de SPT instrumentado para o furo SP01, profundidade de $6 \mathrm{~m}$ e $H_{q}$ de $750 \mathrm{~mm}$. 

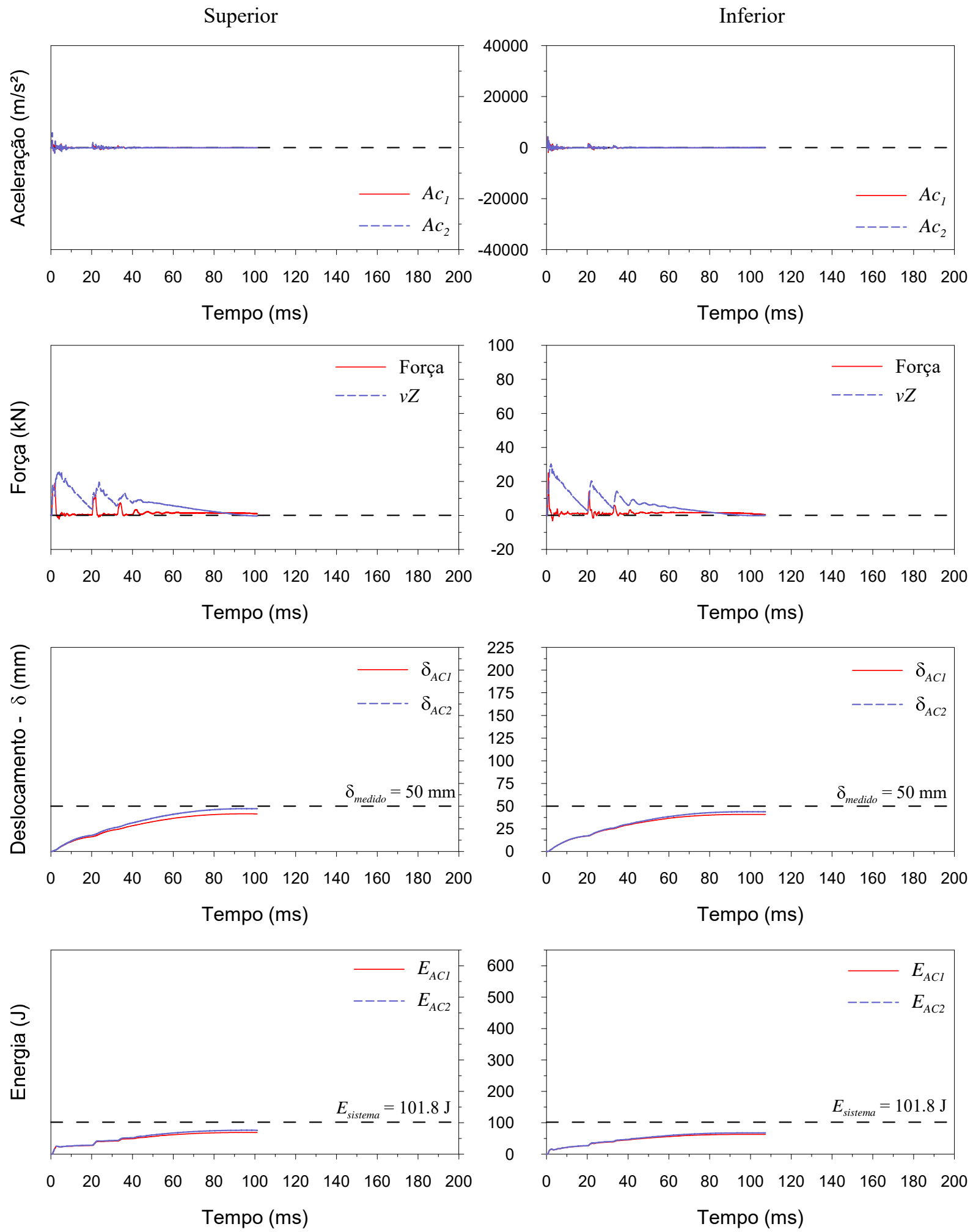

Figura A35 - Sinais típicos de SPT instrumentado para o furo SP02, profundidade de $2 \mathrm{~m}$ e $H_{q}$ de $100 \mathrm{~mm}$. 

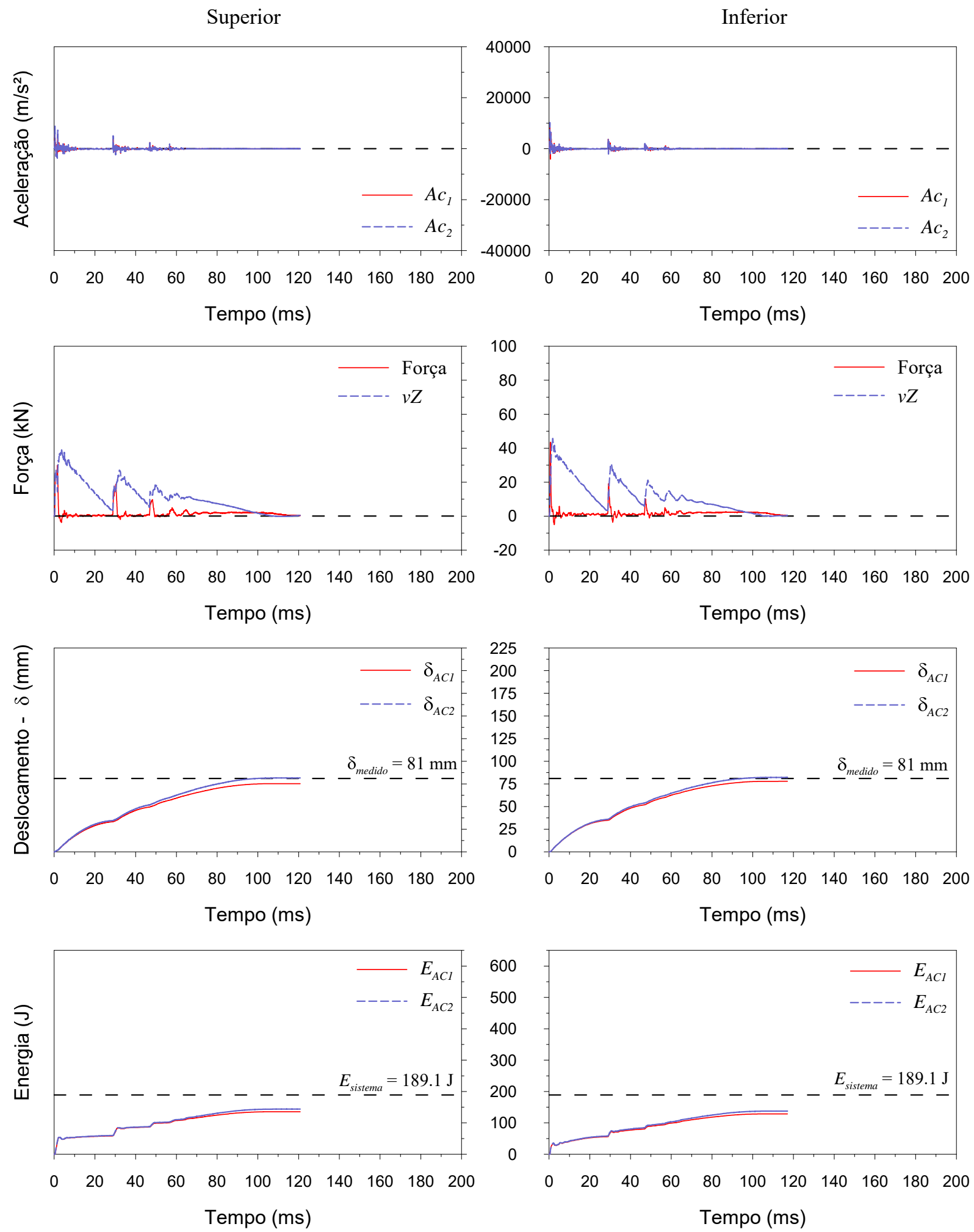

Figura A36 - Sinais típicos de SPT instrumentado para o furo SP02, profundidade de $2 \mathrm{~m}$ e $H_{q}$ de $200 \mathrm{~mm}$. 

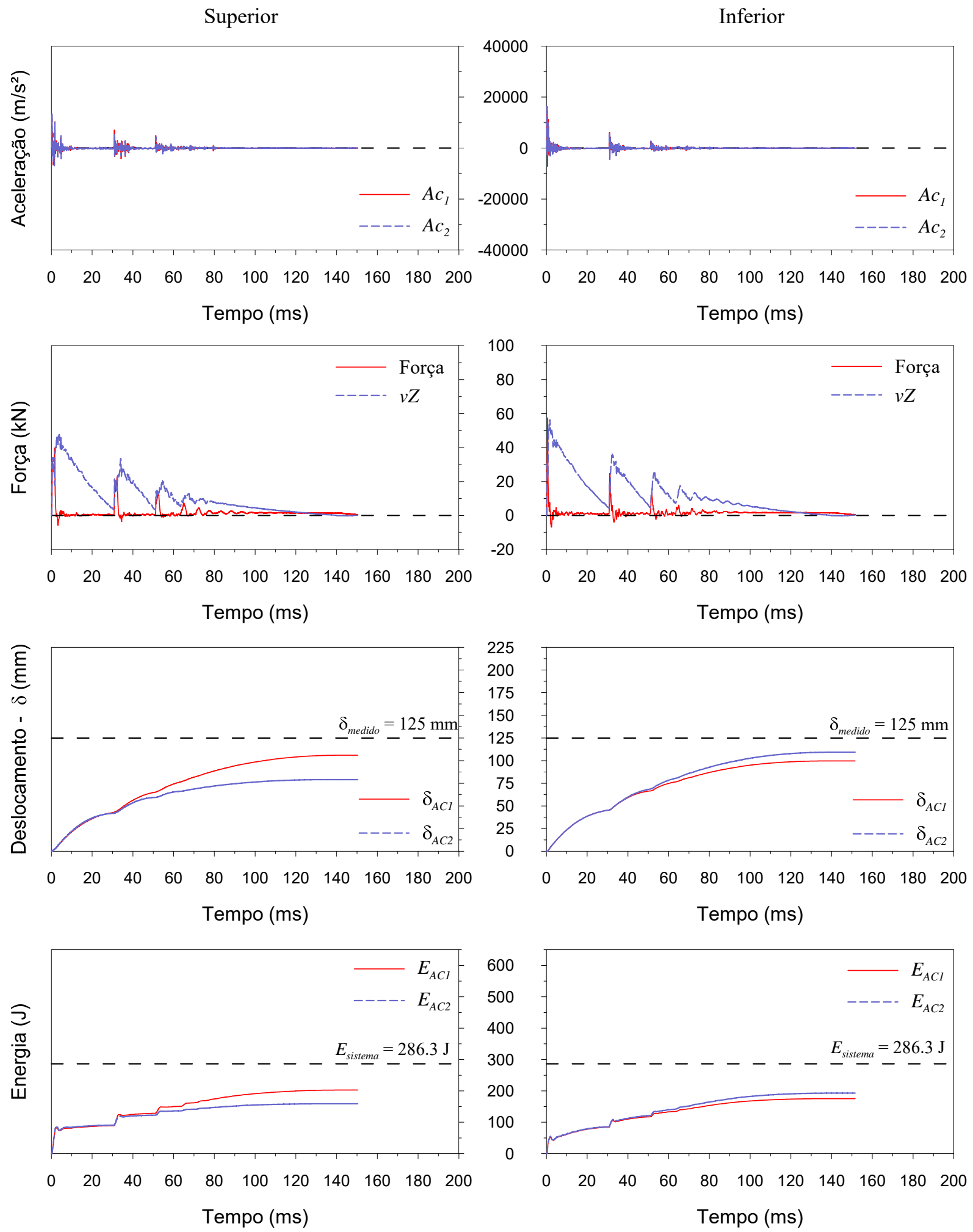

Figura A37 - Sinais típicos de SPT instrumentado para o furo SP02, profundidade de $2 \mathrm{~m}$ e $H_{q}$ de $300 \mathrm{~mm}$. 

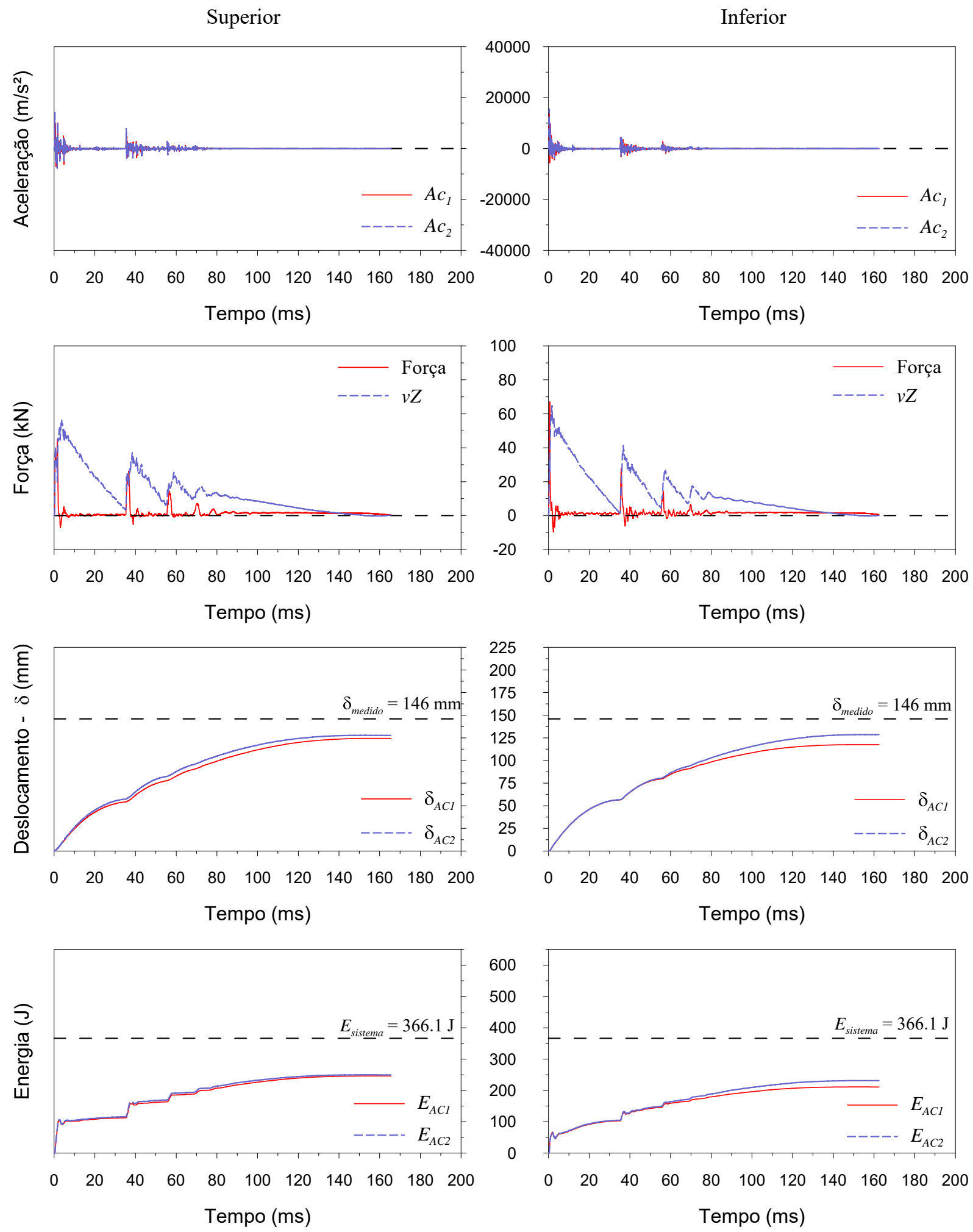

Figura A38 - Sinais típicos de SPT instrumentado para o furo SP02, profundidade de $2 \mathrm{~m}$ e $H_{q}$ de $400 \mathrm{~mm}$. 

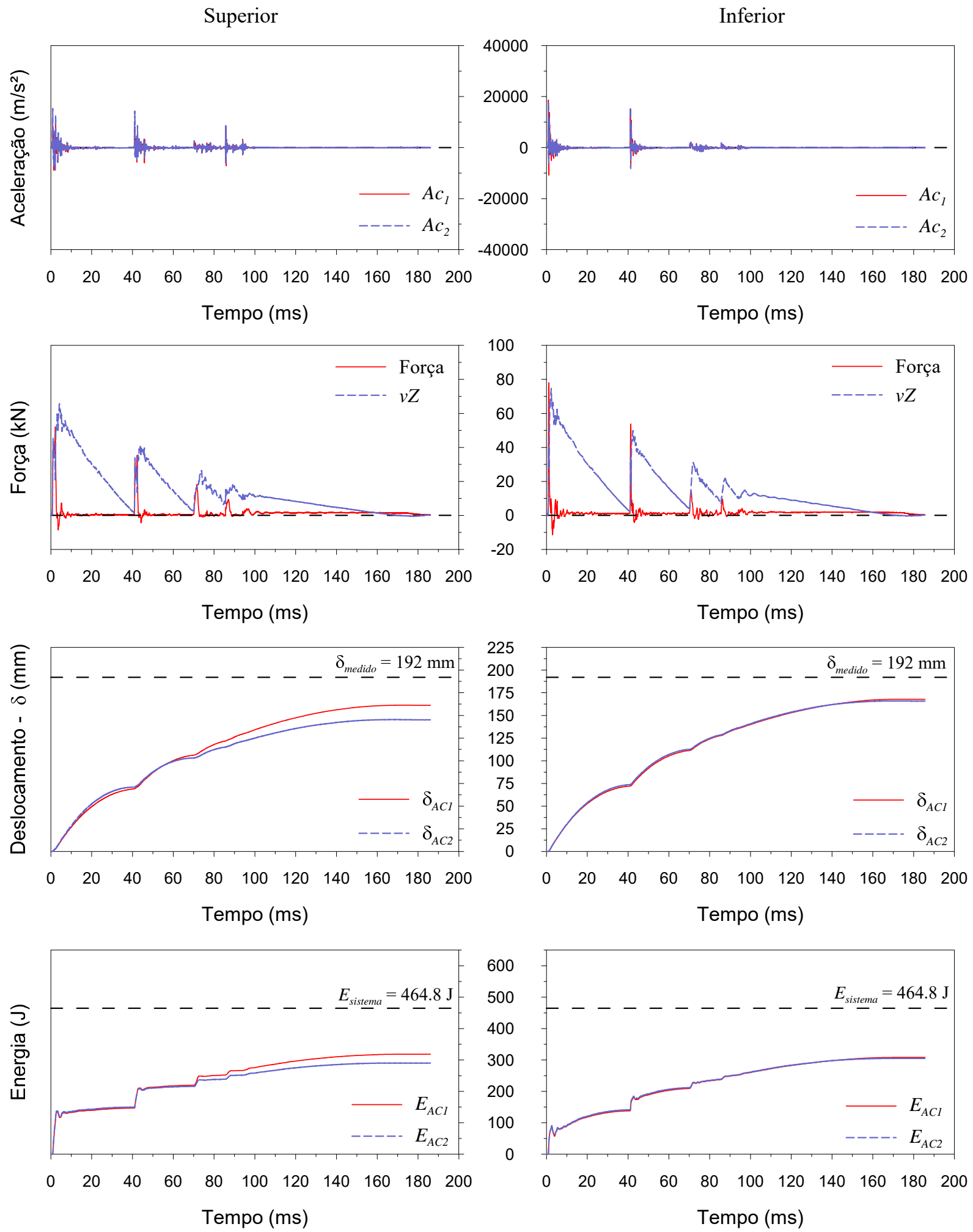

Figura A39 - Sinais típicos de SPT instrumentado para o furo SP02, profundidade de $2 \mathrm{~m}$ e $H_{q}$ de $500 \mathrm{~mm}$. 

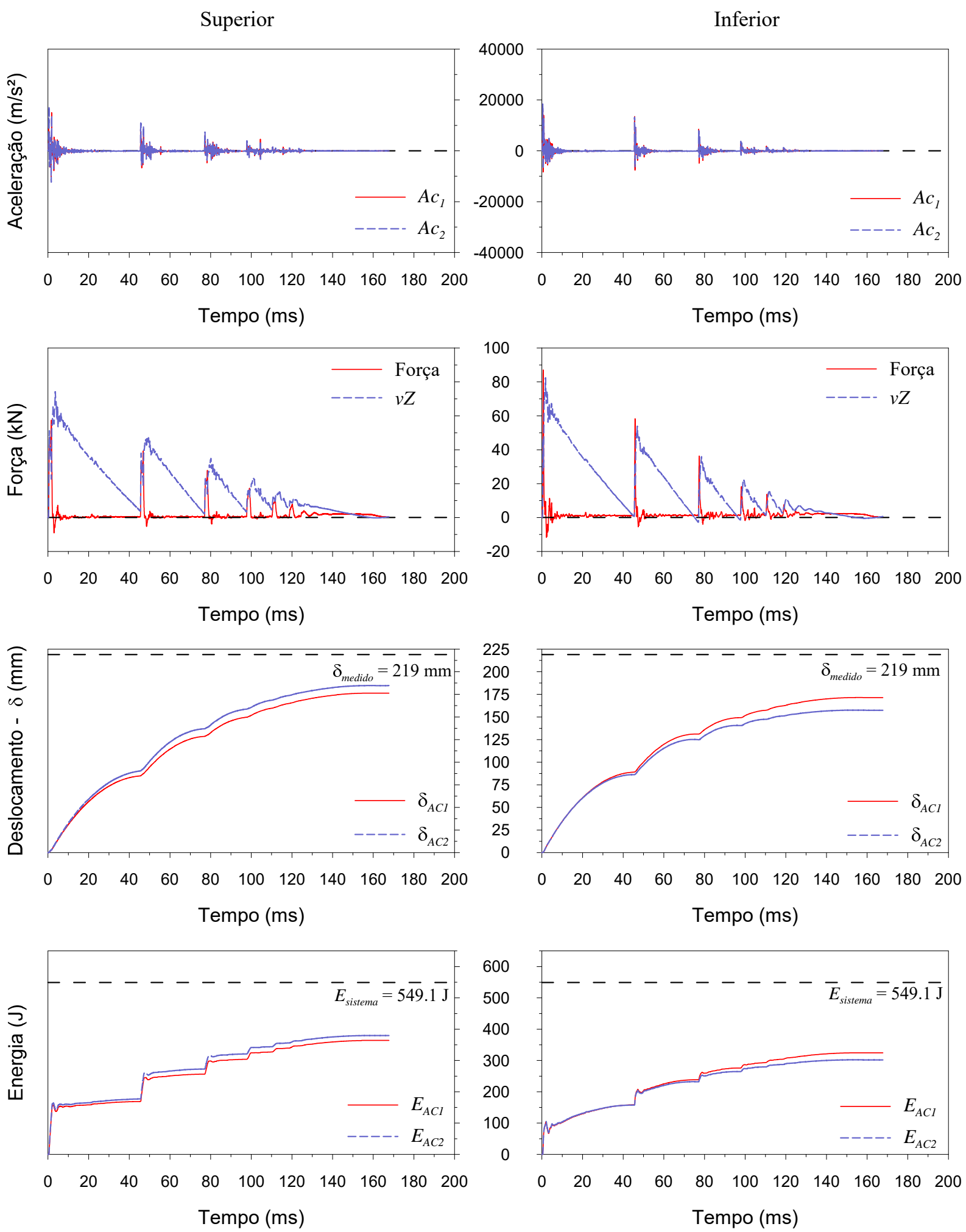

Figura A40 - Sinais típicos de SPT instrumentado para o furo SP02, profundidade de $2 \mathrm{~m}$ e $H_{q}$ de $600 \mathrm{~mm}$. 

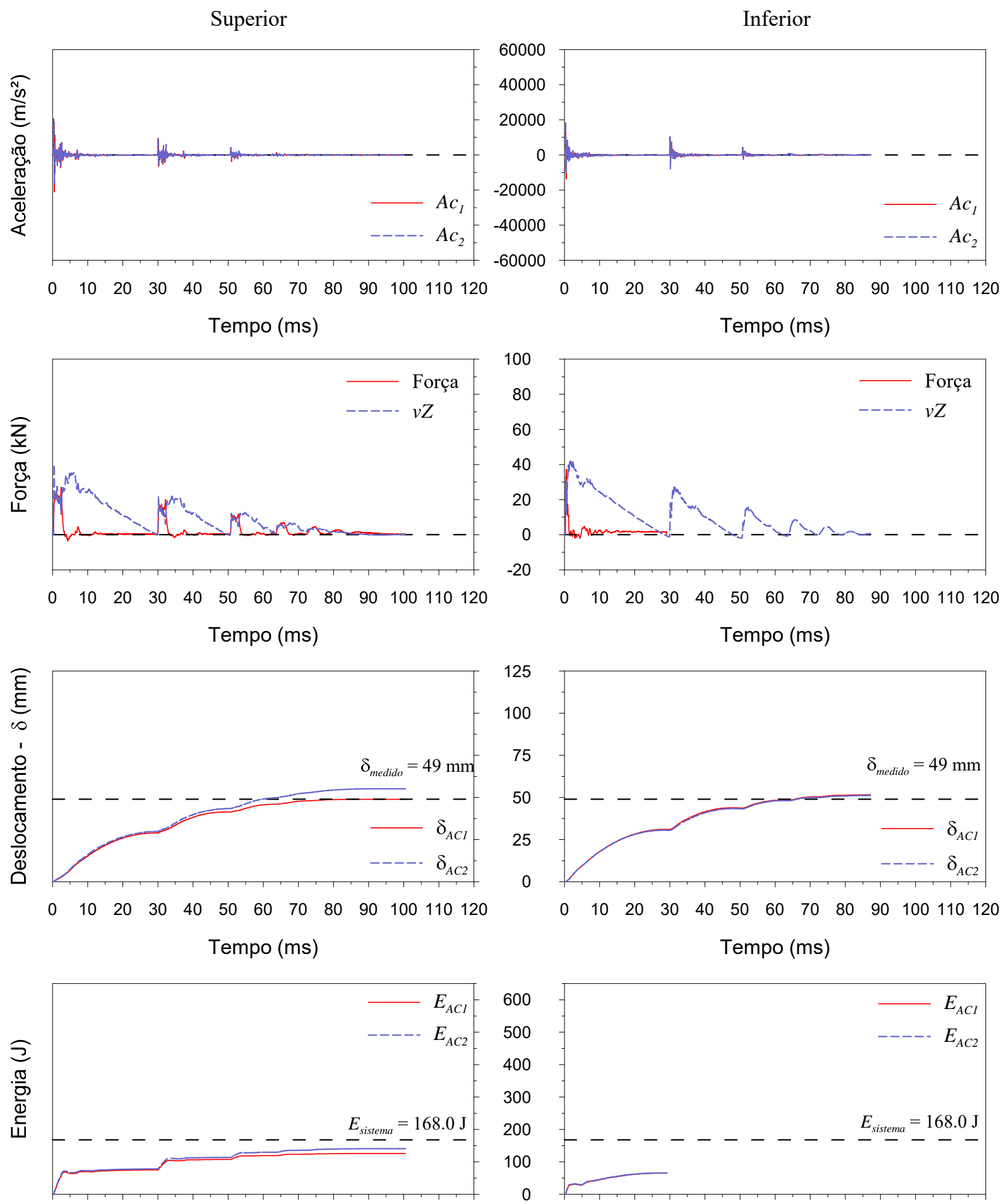

$\begin{array}{lllllllllllll}0 & 10 & 20 & 30 & 40 & 50 & 60 & 70 & 80 & 90 & 100 & 110 & 120\end{array}$ Tempo (ms)

$\begin{array}{lllllllllllll}0 & 10 & 20 & 30 & 40 & 50 & 60 & 70 & 80 & 90 & 100 & 110 & 120\end{array}$ Tempo (ms)

Figura A41- Sinais típicos de SPT instrumentado para o furo SP02, profundidade de $3 \mathrm{~m}$ e $H_{q}$ de $200 \mathrm{~mm}-$ Falha no sinal de força da haste inferior. 


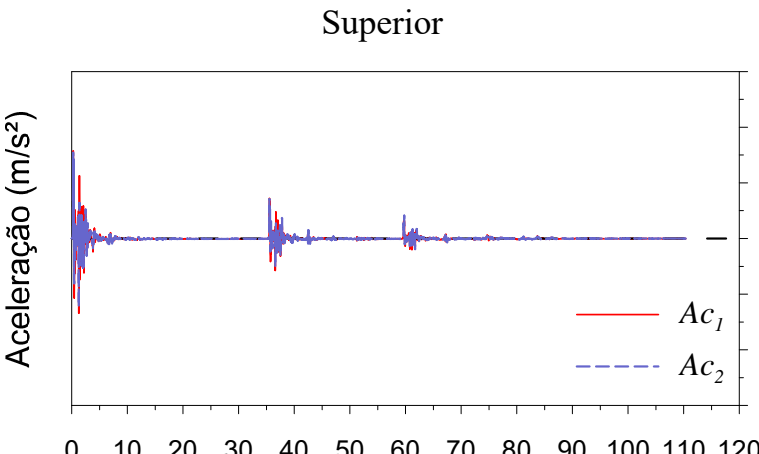

Tempo (ms)
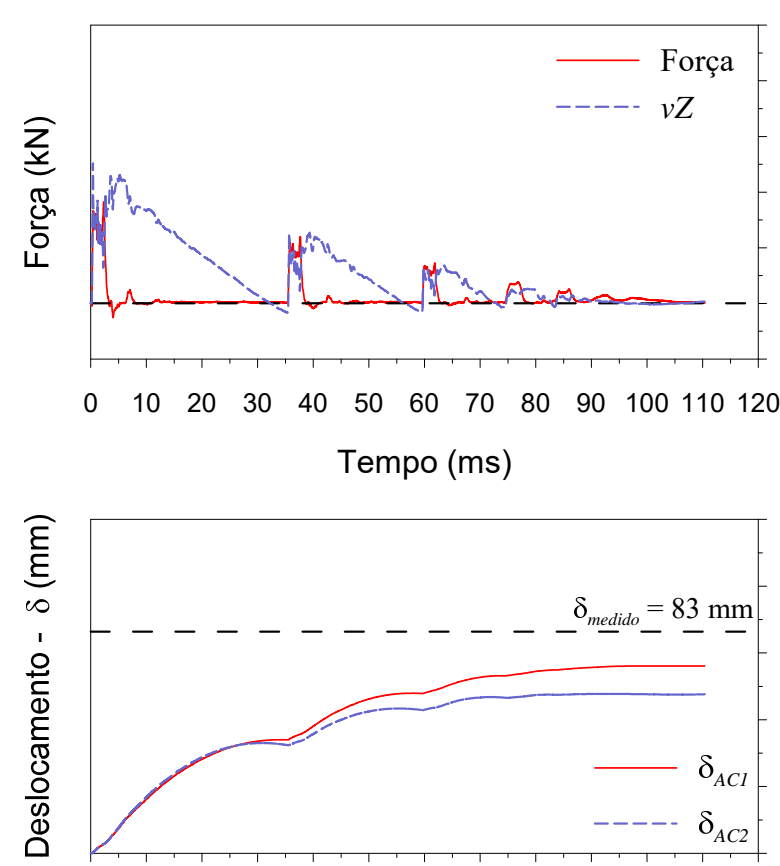

$\begin{array}{lllllllllllll}0 & 10 & 20 & 30 & 40 & 50 & 60 & 70 & 80 & 90 & 100 & 110 & 120\end{array}$

Tempo (ms)

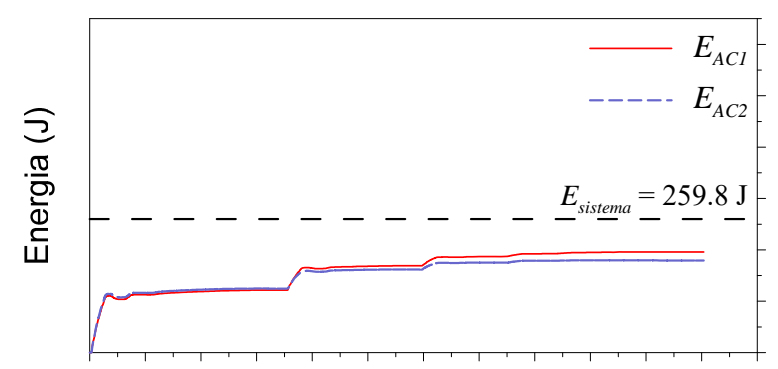

$\begin{array}{lllllllllllll}0 & 10 & 20 & 30 & 40 & 50 & 60 & 70 & 80 & 90 & 100 & 110 & 120\end{array}$

Tempo (ms)
Inferior

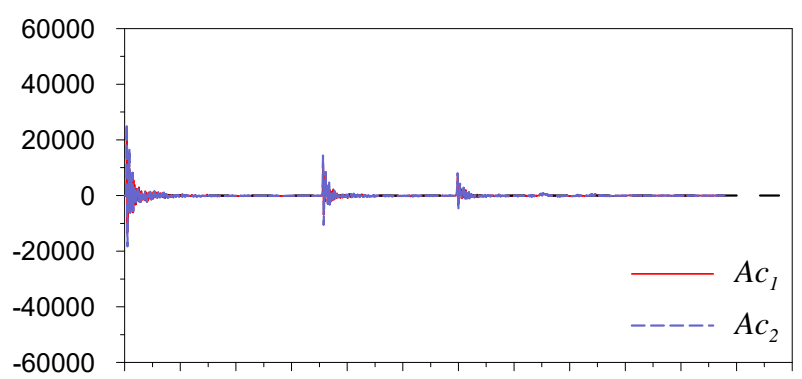

$\begin{array}{lllllllllllll}0 & 10 & 20 & 30 & 40 & 50 & 60 & 70 & 80 & 90 & 100 & 110 & 120\end{array}$

Tempo (ms)

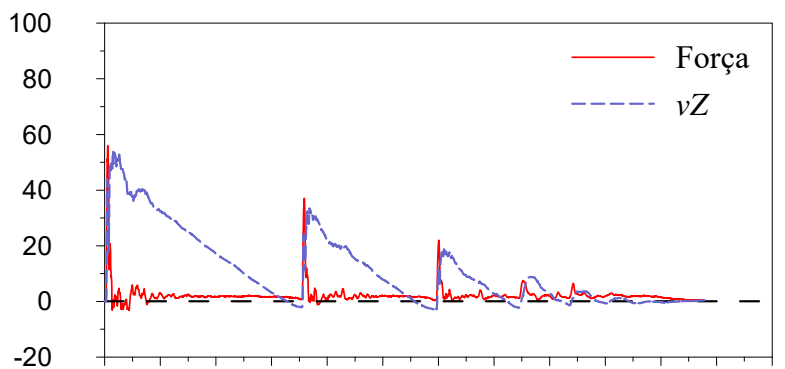

$\begin{array}{lllllllllllll}0 & 10 & 20 & 30 & 40 & 50 & 60 & 70 & 80 & 90 & 100 & 110 & 120\end{array}$

Tempo (ms)

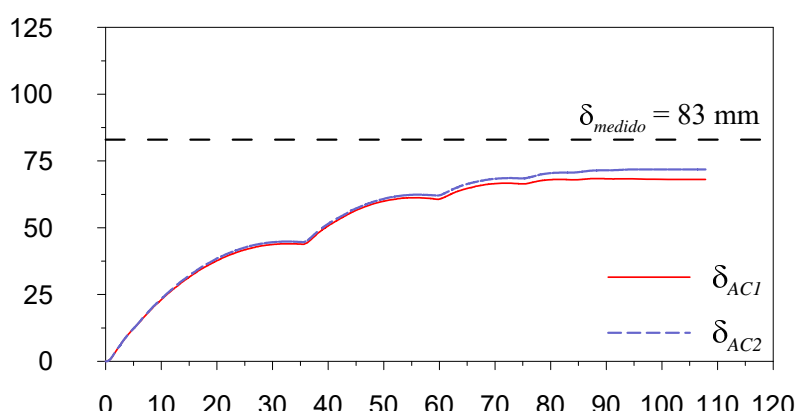

Tempo (ms)

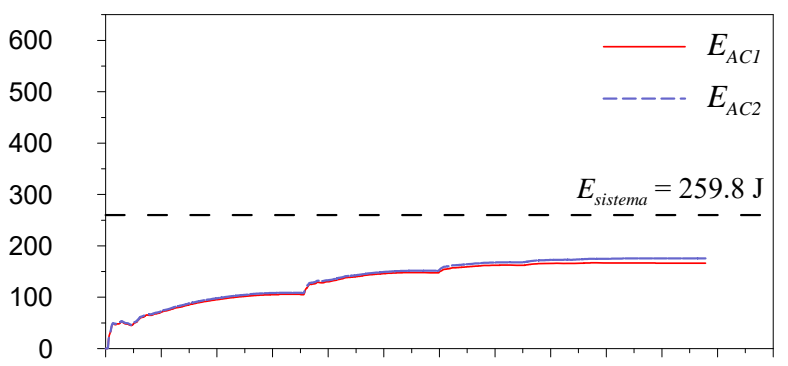

$\begin{array}{lllllllllllll}0 & 10 & 20 & 30 & 40 & 50 & 60 & 70 & 80 & 90 & 100 & 110 & 120\end{array}$ Tempo (ms)

Figura A42 - Sinais típicos de SPT instrumentado para o furo SP02, profundidade de $3 \mathrm{~m}$ e $H_{q}$ de $300 \mathrm{~mm}$. 
Superior
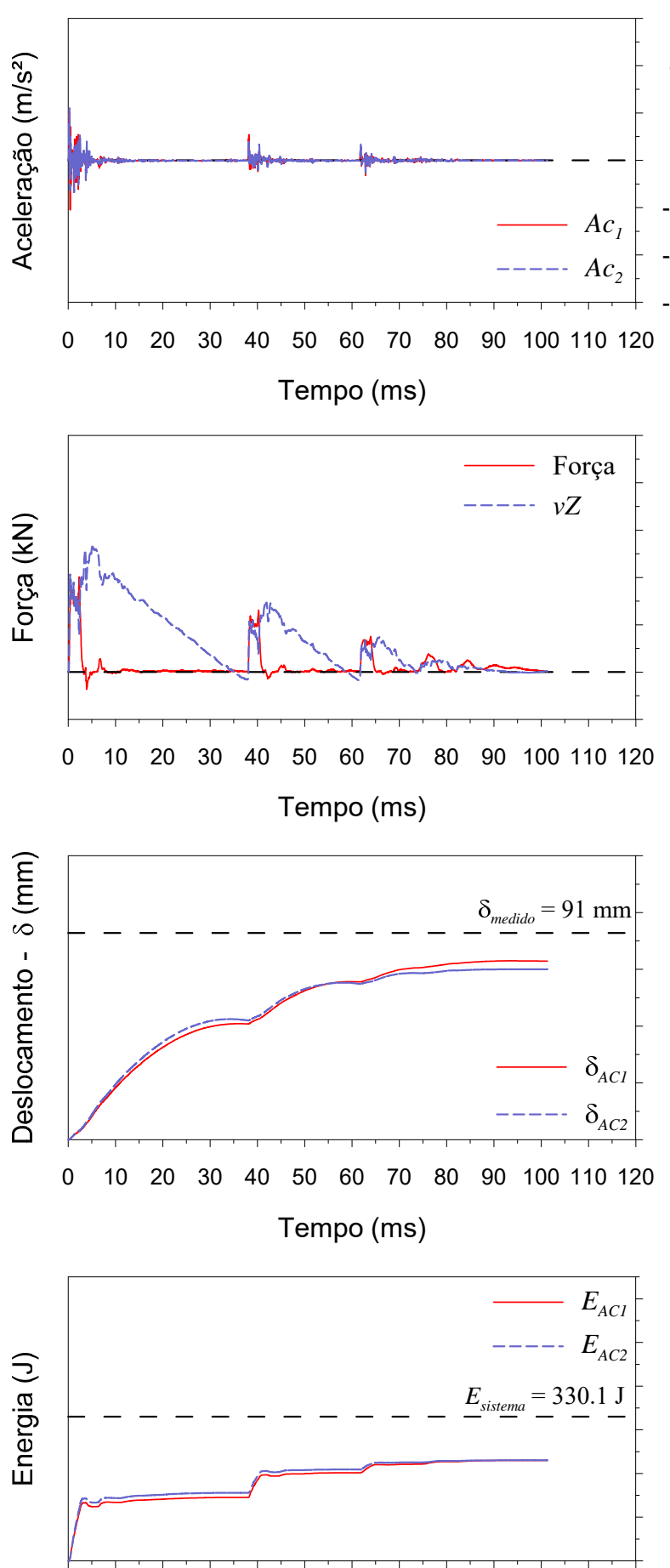

$\begin{array}{lllllllllllll}0 & 10 & 20 & 30 & 40 & 50 & 60 & 70 & 80 & 90 & 100 & 110 & 120\end{array}$ Tempo (ms)
Inferior
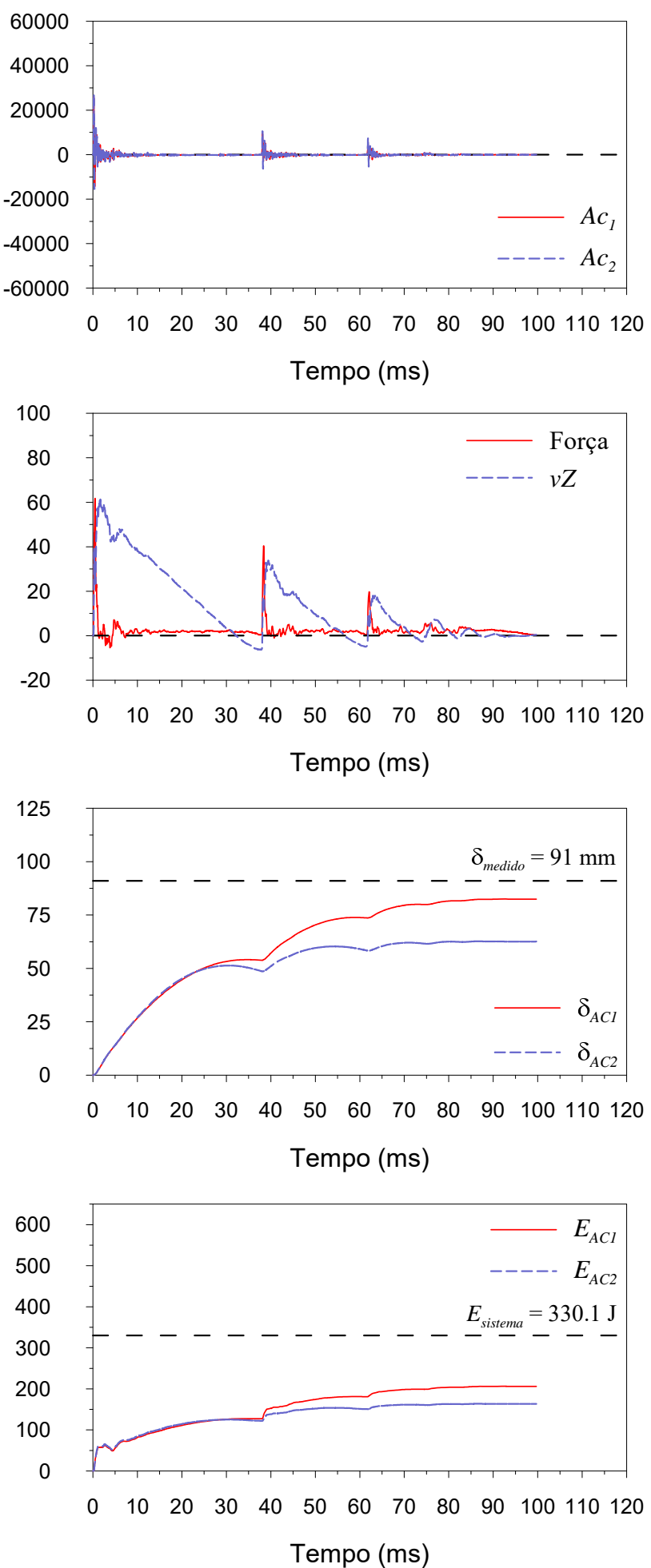

Figura A43 - Sinais típicos de SPT instrumentado para o furo SP02, profundidade de $3 \mathrm{~m}$ e $H_{q}$ de $400 \mathrm{~mm}$. 


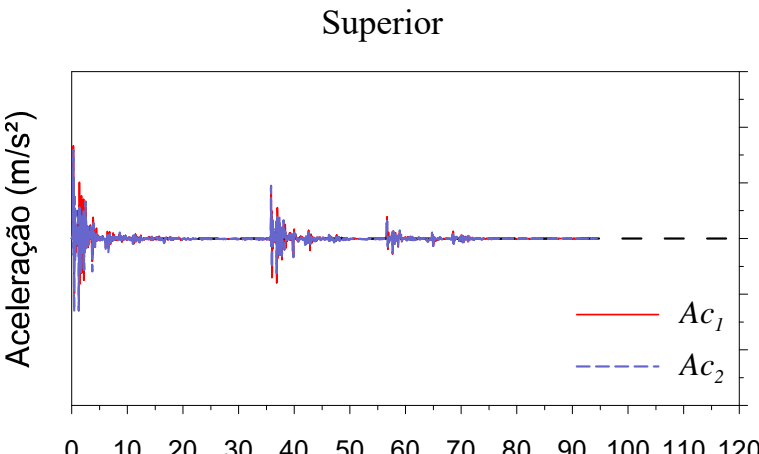

Tempo (ms)

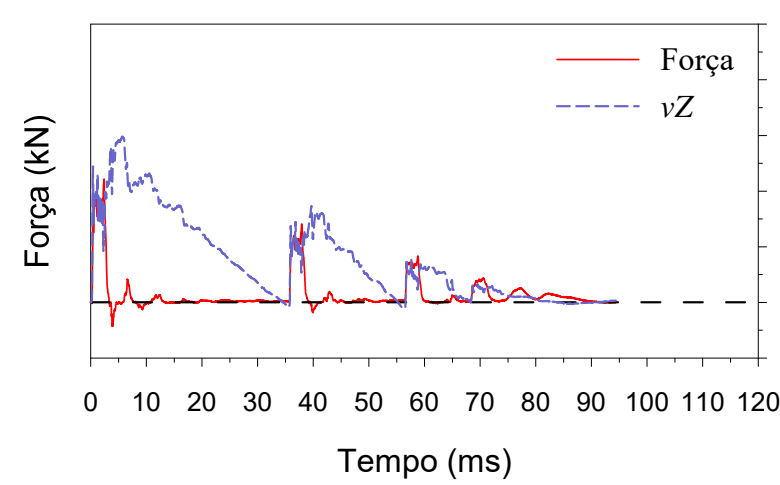

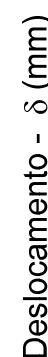

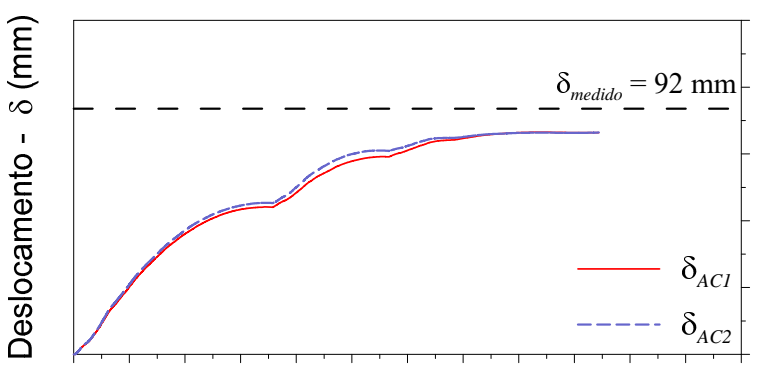

$\begin{array}{lllllllllllll}0 & 10 & 20 & 30 & 40 & 50 & 60 & 70 & 80 & 90 & 100 & 110 & 120\end{array}$

Tempo (ms)

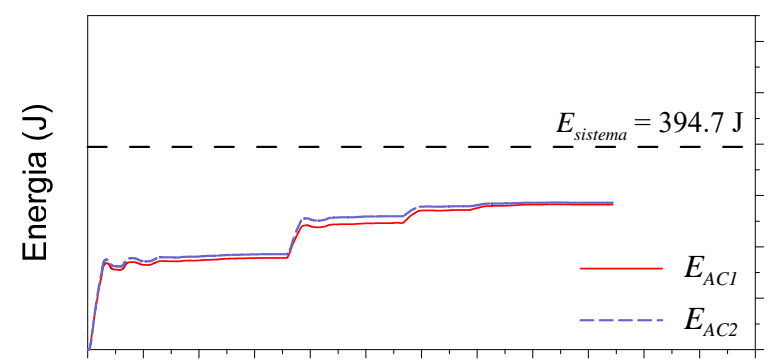

$\begin{array}{lllllllllllll}0 & 10 & 20 & 30 & 40 & 50 & 60 & 70 & 80 & 90 & 100 & 110 & 120\end{array}$

Tempo (ms)
Inferior

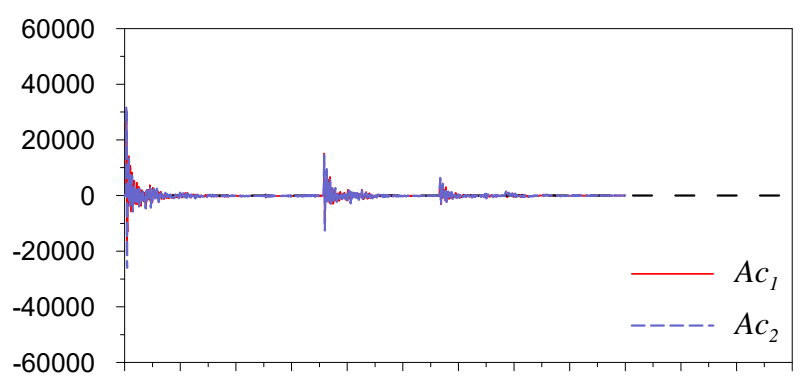

$\begin{array}{lllllllllllll}0 & 10 & 20 & 30 & 40 & 50 & 60 & 70 & 80 & 90 & 100 & 110 & 120\end{array}$

Tempo (ms)

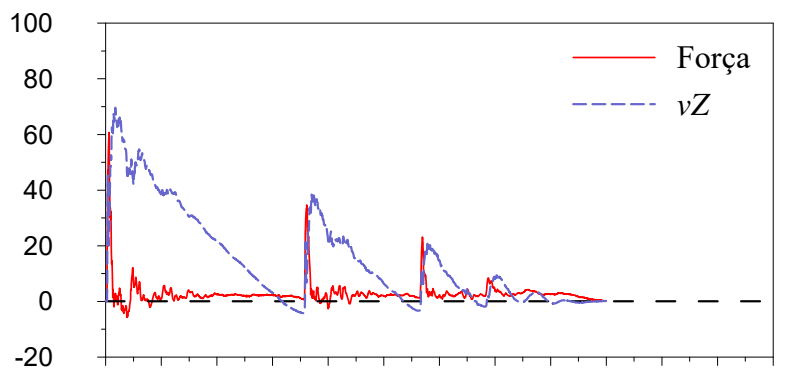

$\begin{array}{lllllllllllll}0 & 10 & 20 & 30 & 40 & 50 & 60 & 70 & 80 & 90 & 100 & 110 & 120\end{array}$

Tempo (ms)

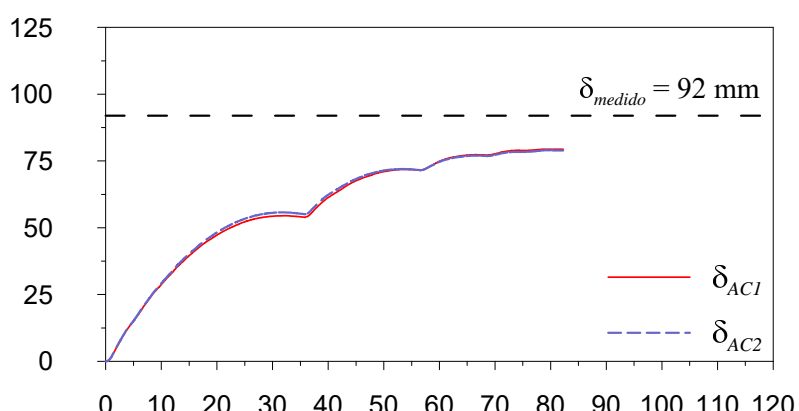

Tempo (ms)

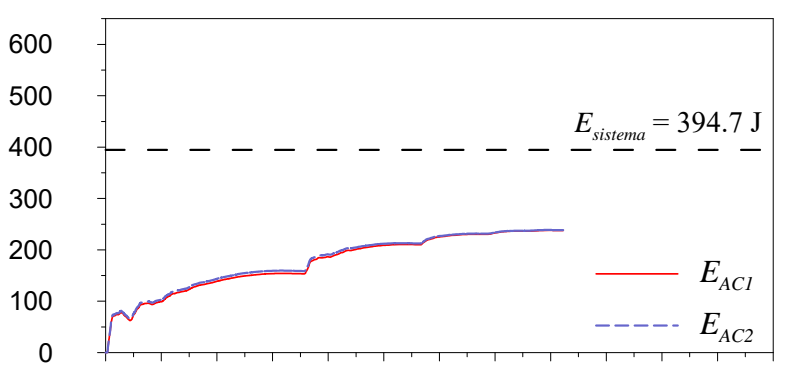

$\begin{array}{lllllllllllll}0 & 10 & 20 & 30 & 40 & 50 & 60 & 70 & 80 & 90 & 100 & 110 & 120\end{array}$ Tempo (ms)

Figura A44 - Sinais típicos de SPT instrumentado para o furo SP02, profundidade de $3 \mathrm{~m}$ e $H_{q}$ de $500 \mathrm{~mm}$. 

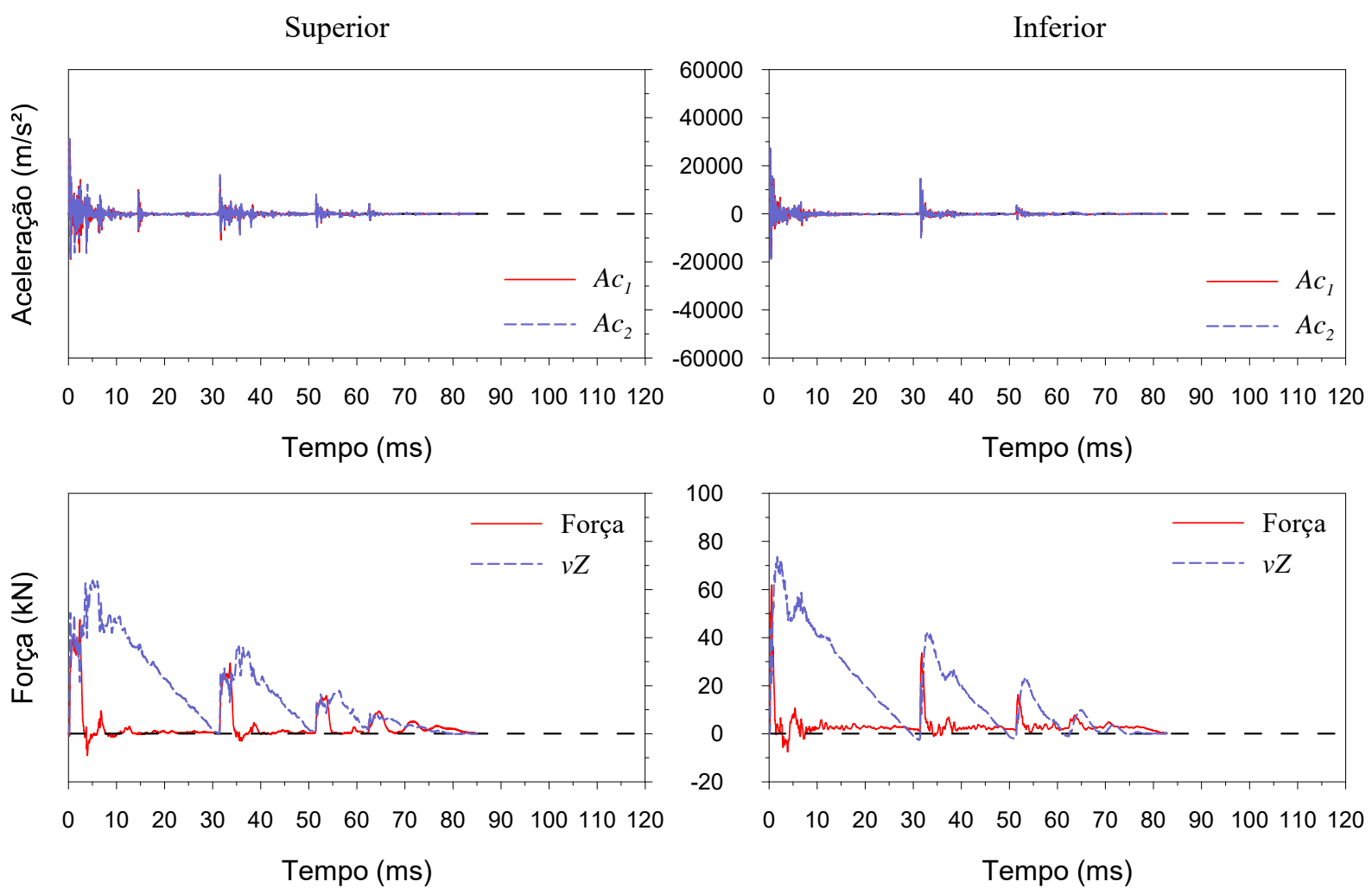

$\begin{array}{lllllllllllll}0 & 10 & 20 & 30 & 40 & 50 & 60 & 70 & 80 & 90 & 100 & 110 & 120\end{array}$

Tempo (ms)

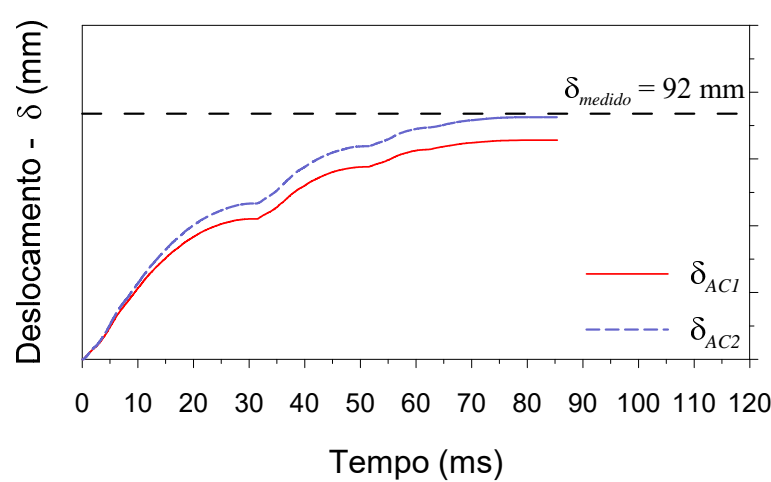

Tempo (ms)
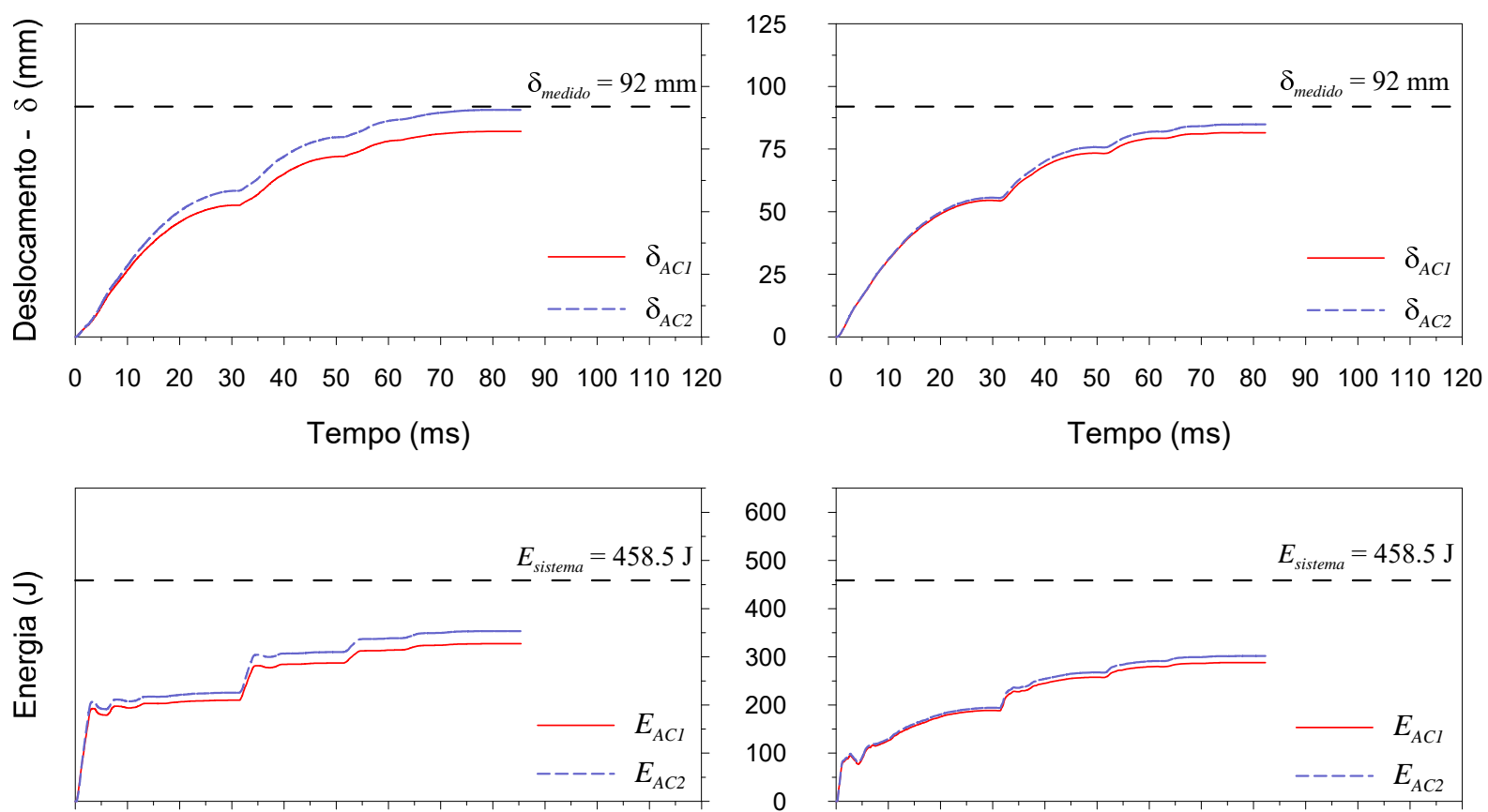

$\begin{array}{lllllllllllll}0 & 10 & 20 & 30 & 40 & 50 & 60 & 70 & 80 & 90 & 100 & 110 & 120\end{array}$ Tempo (ms)

$\begin{array}{lllllllllllll}0 & 10 & 20 & 30 & 40 & 50 & 60 & 70 & 80 & 90 & 100 & 110 & 120\end{array}$ Tempo (ms)

Figura A45 - Sinais típicos de SPT instrumentado para o furo SP02, profundidade de $3 \mathrm{~m}$ e $H_{q}$ de $600 \mathrm{~mm}$. 


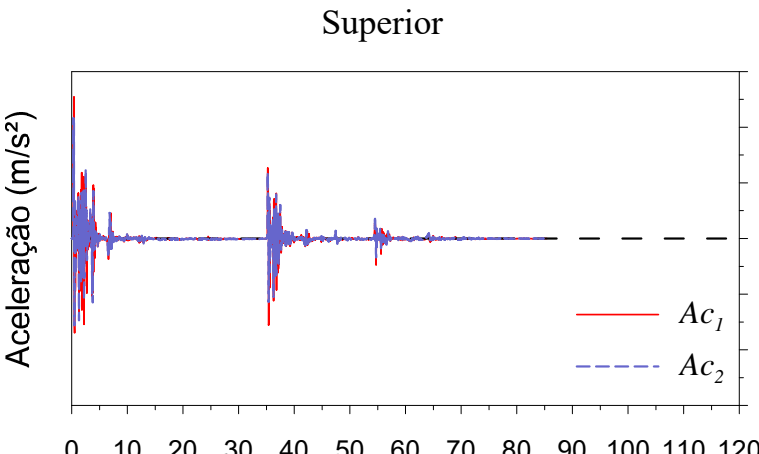

Tempo (ms)

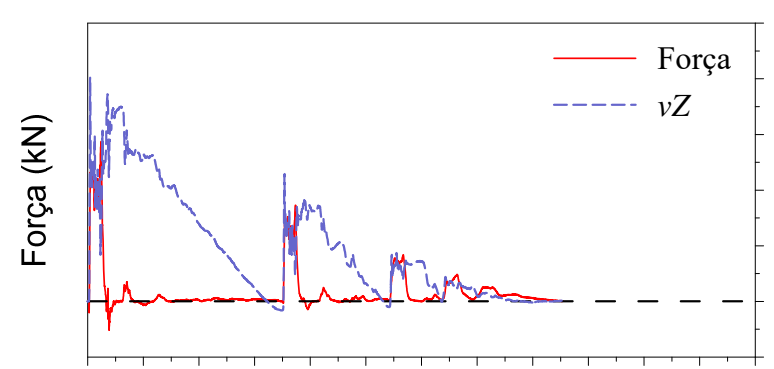

$\begin{array}{lllllllllllll}0 & 10 & 20 & 30 & 40 & 50 & 60 & 70 & 80 & 90 & 100 & 110 & 120\end{array}$

Tempo (ms)

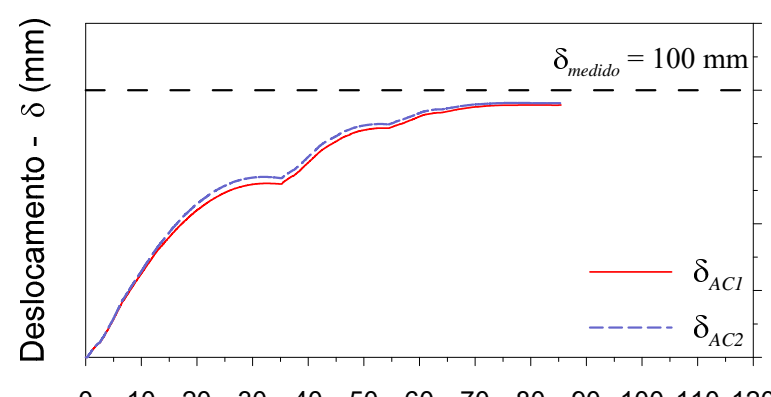

Tempo (ms)

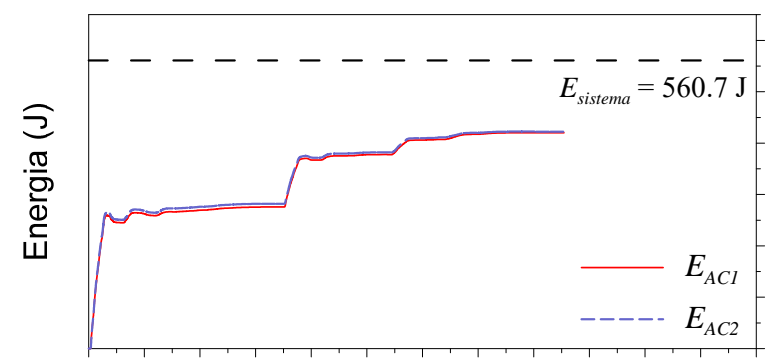

$\begin{array}{lllllllllllll}0 & 10 & 20 & 30 & 40 & 50 & 60 & 70 & 80 & 90 & 100 & 110 & 120\end{array}$

Tempo (ms)
Inferior

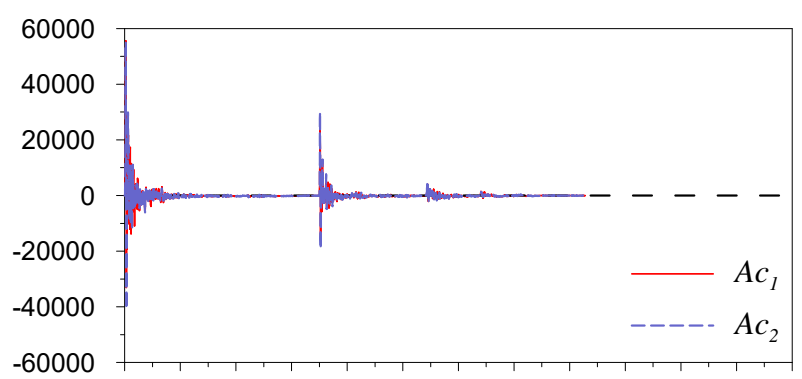

$\begin{array}{lllllllllllll}0 & 10 & 20 & 30 & 40 & 50 & 60 & 70 & 80 & 90 & 100 & 110 & 120\end{array}$ Tempo (ms)

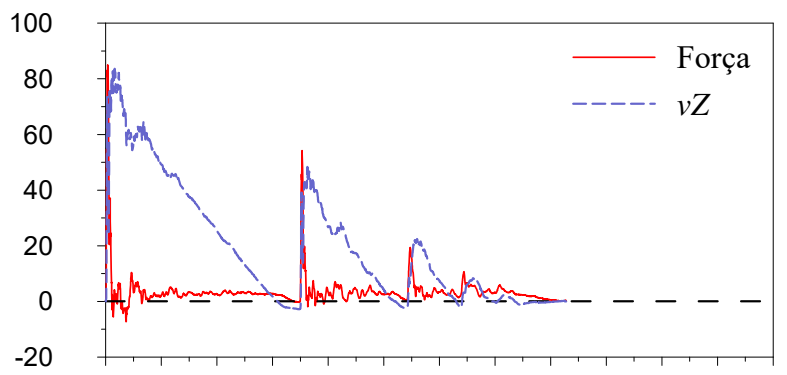

$\begin{array}{lllllllllllll}0 & 10 & 20 & 30 & 40 & 50 & 60 & 70 & 80 & 90 & 100 & 110 & 120\end{array}$ Tempo (ms)

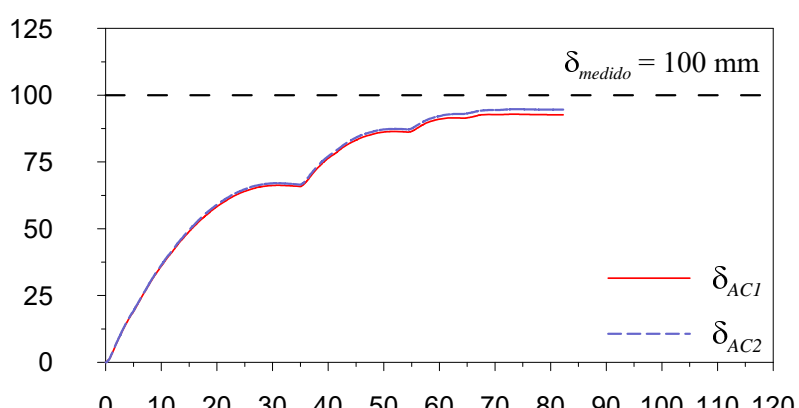

Tempo (ms)

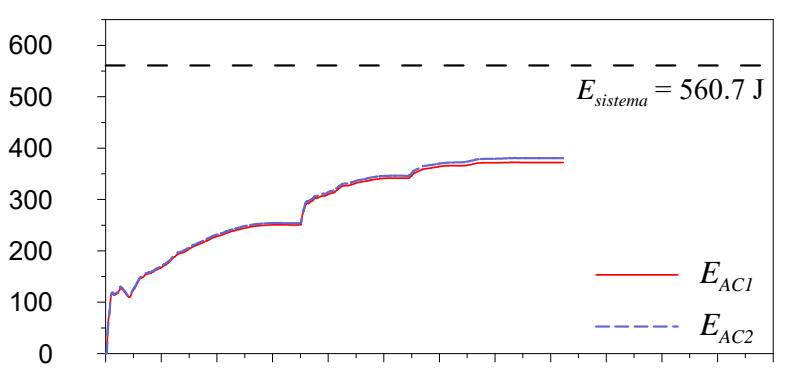

$\begin{array}{lllllllllllll}0 & 10 & 20 & 30 & 40 & 50 & 60 & 70 & 80 & 90 & 100 & 110 & 120\end{array}$ Tempo (ms)

Figura A46 - Sinais típicos de SPT instrumentado para o furo SP02, profundidade de $3 \mathrm{~m}$ e $H_{q}$ de $750 \mathrm{~mm}$. 

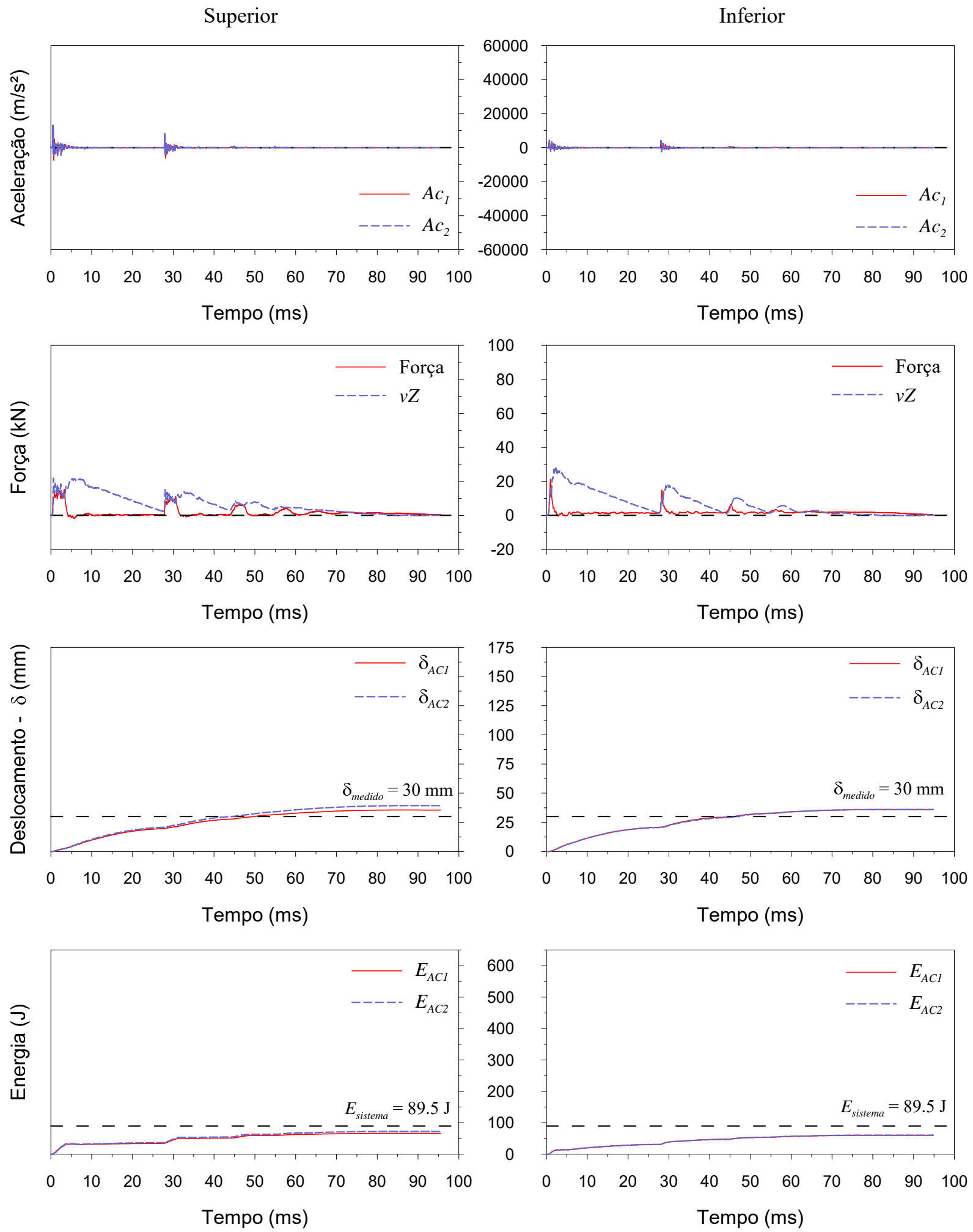

Figura A47 - Sinais típicos de SPT instrumentado para o furo SP02, profundidade de $5 \mathrm{~m}$ e $H_{q}$ de $100 \mathrm{~mm}$. 

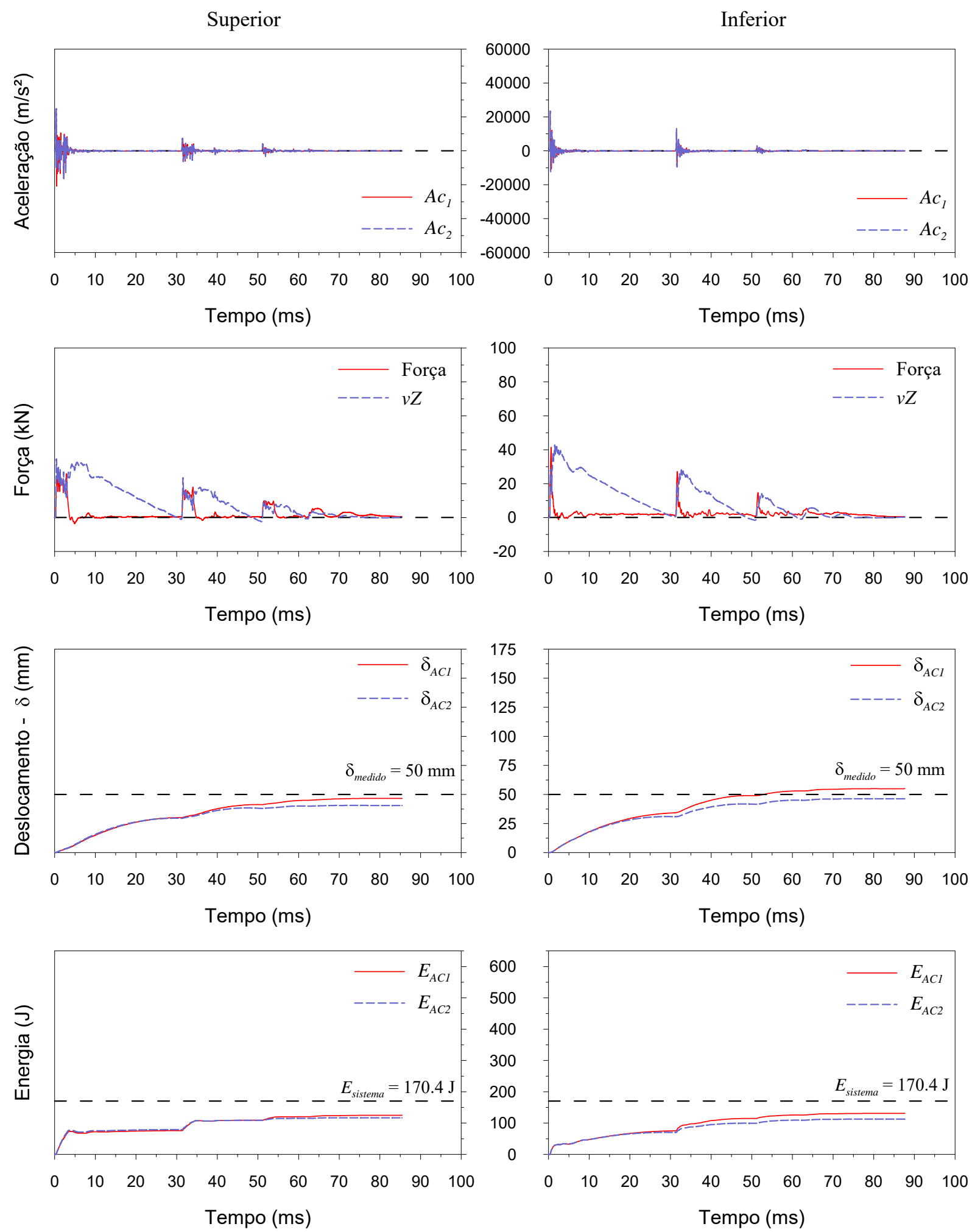

Figura A48 - Sinais típicos de SPT instrumentado para o furo SP02, profundidade de $5 \mathrm{~m}$ e $H_{q}$ de $200 \mathrm{~mm}$. 

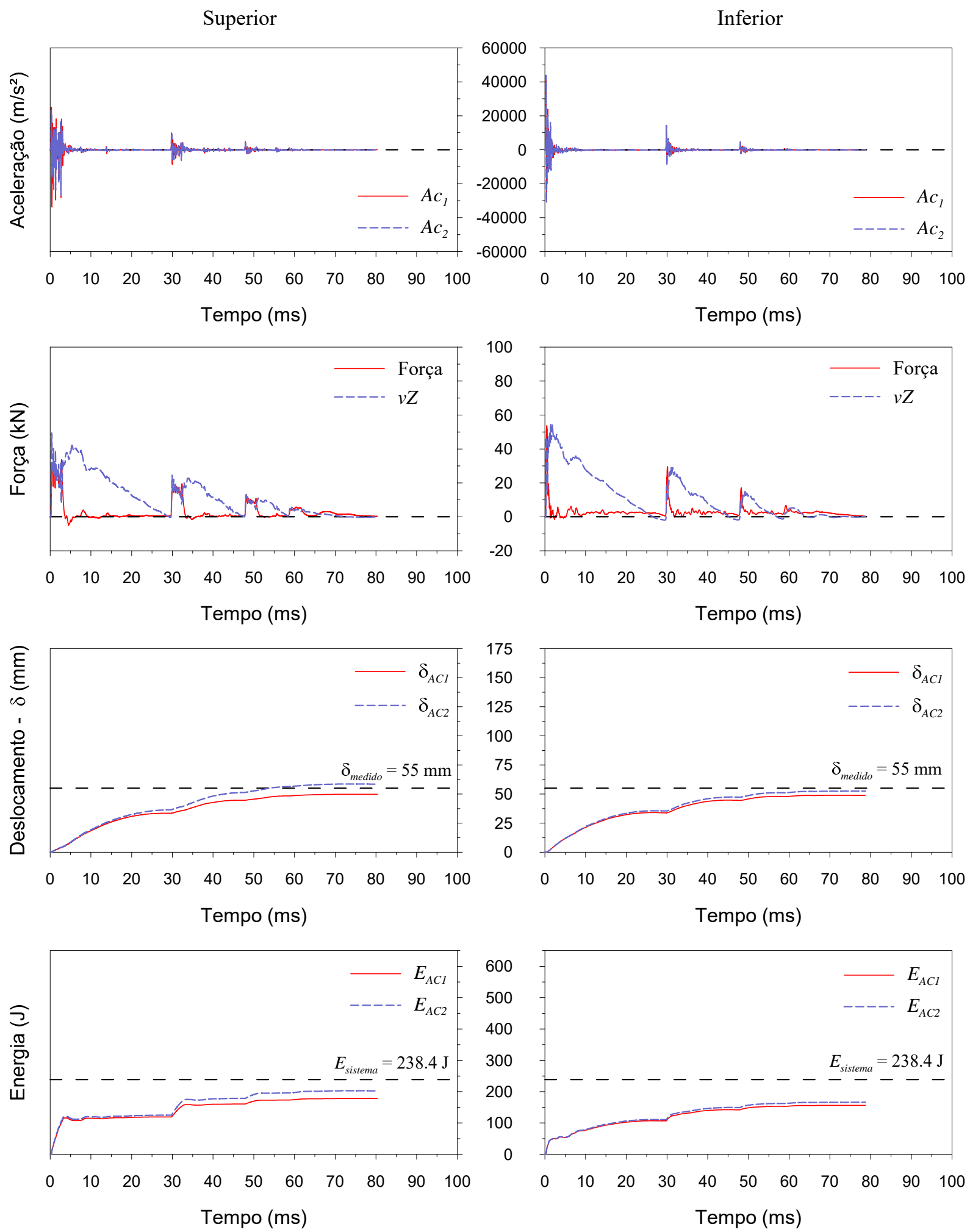

Figura A49 - Sinais típicos de SPT instrumentado para o furo SP02, profundidade de $5 \mathrm{~m}$ e $H_{q}$ de $300 \mathrm{~mm}$. 

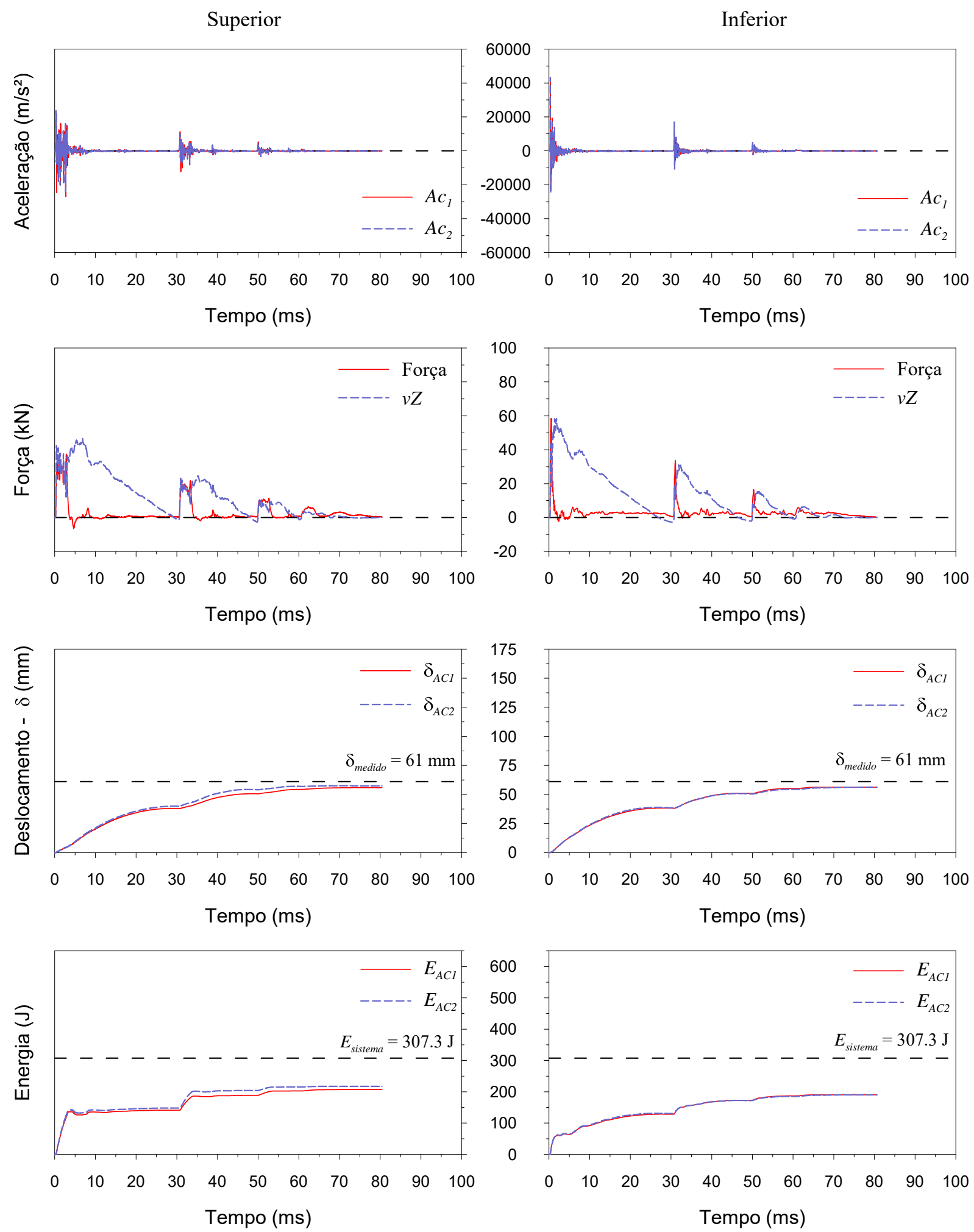

Figura A50 - Sinais típicos de SPT instrumentado para o furo SP02, profundidade de $5 \mathrm{~m}$ e $H_{q}$ de $400 \mathrm{~mm}$. 

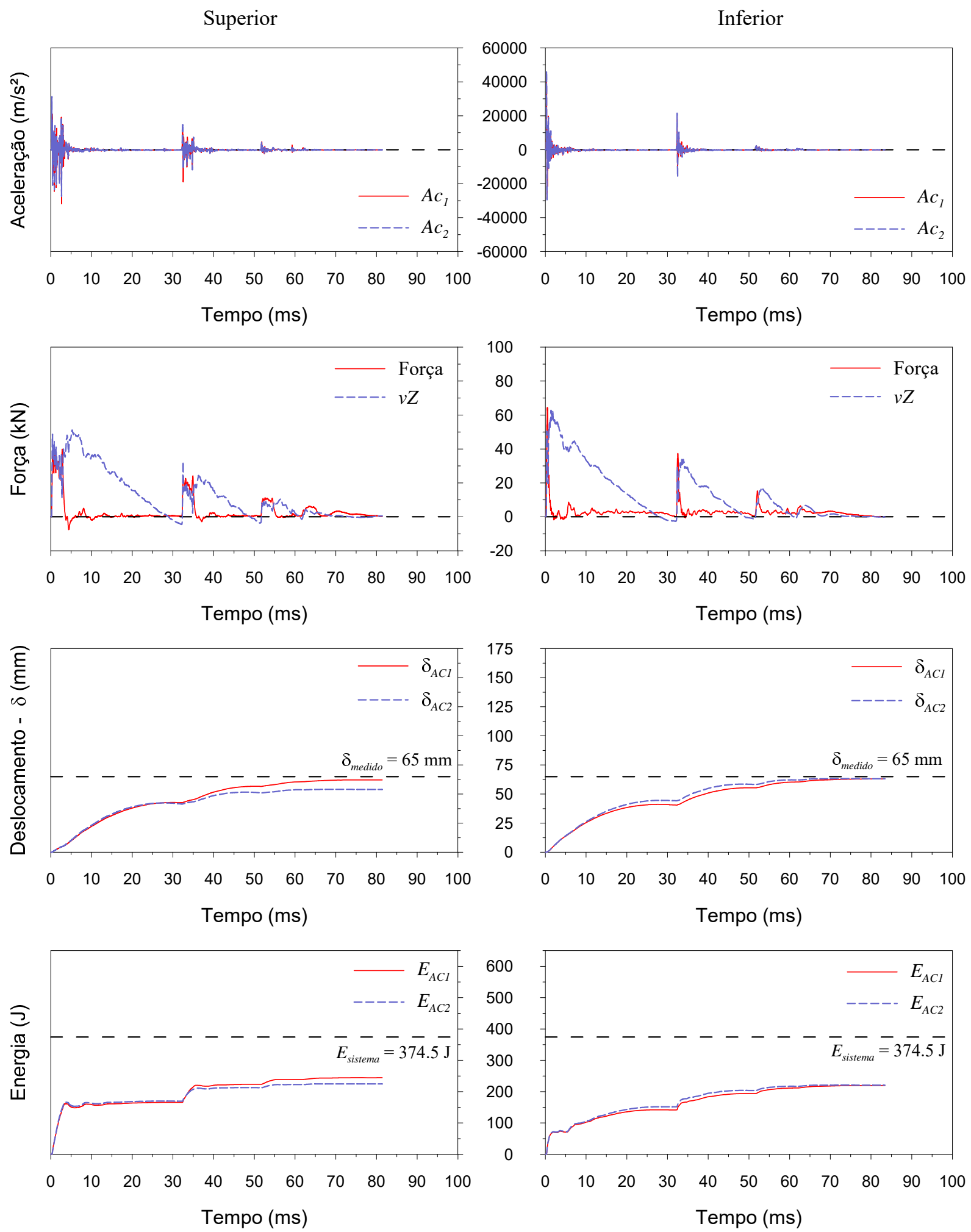

Figura A51 - Sinais típicos de SPT instrumentado para o furo SP02, profundidade de $5 \mathrm{~m}$ e $H_{q}$ de $500 \mathrm{~mm}$. 

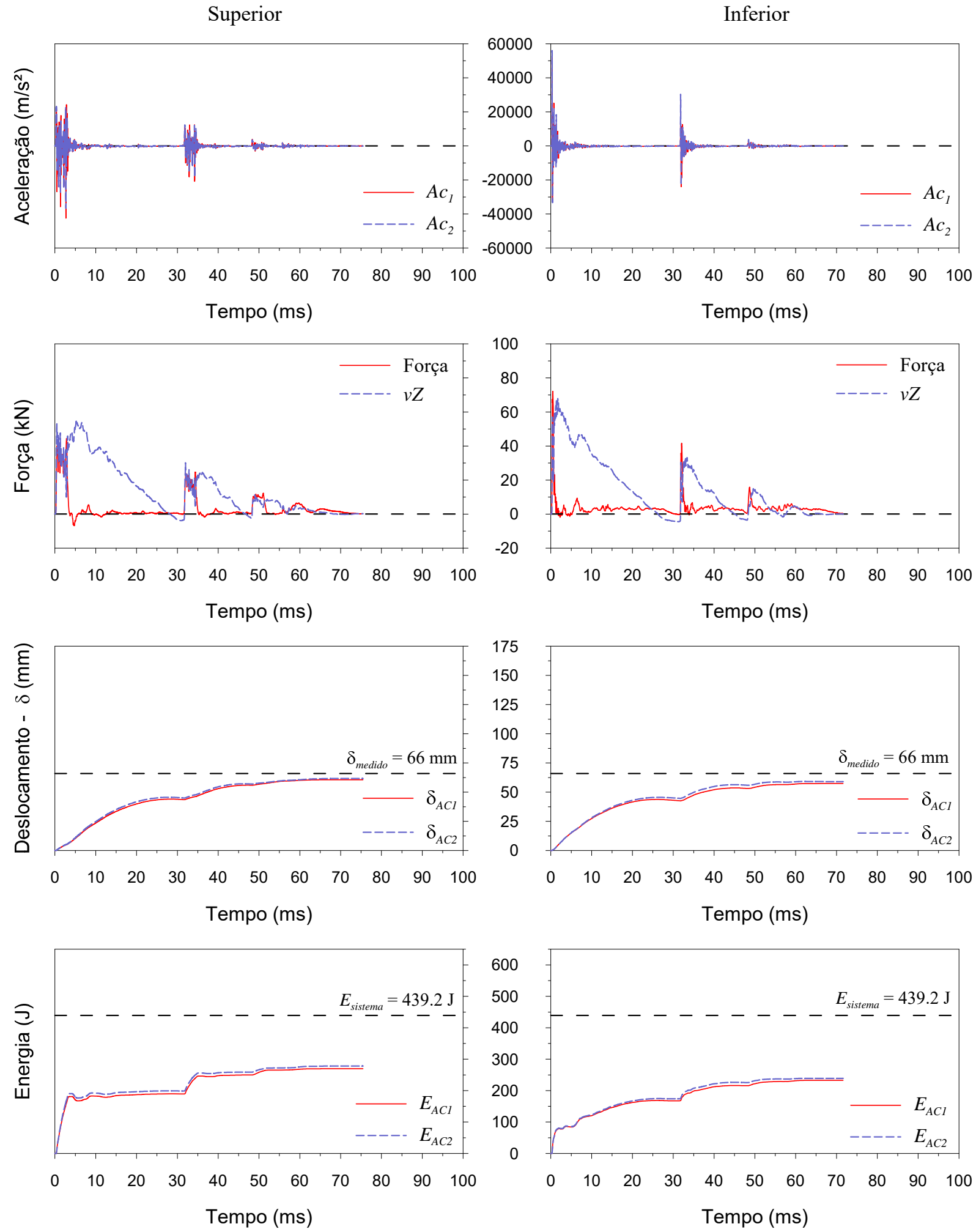

Figura A52 - Sinais típicos de SPT instrumentado para o furo SP02, profundidade de $5 \mathrm{~m}$ e $H_{q}$ de $600 \mathrm{~mm}$. 

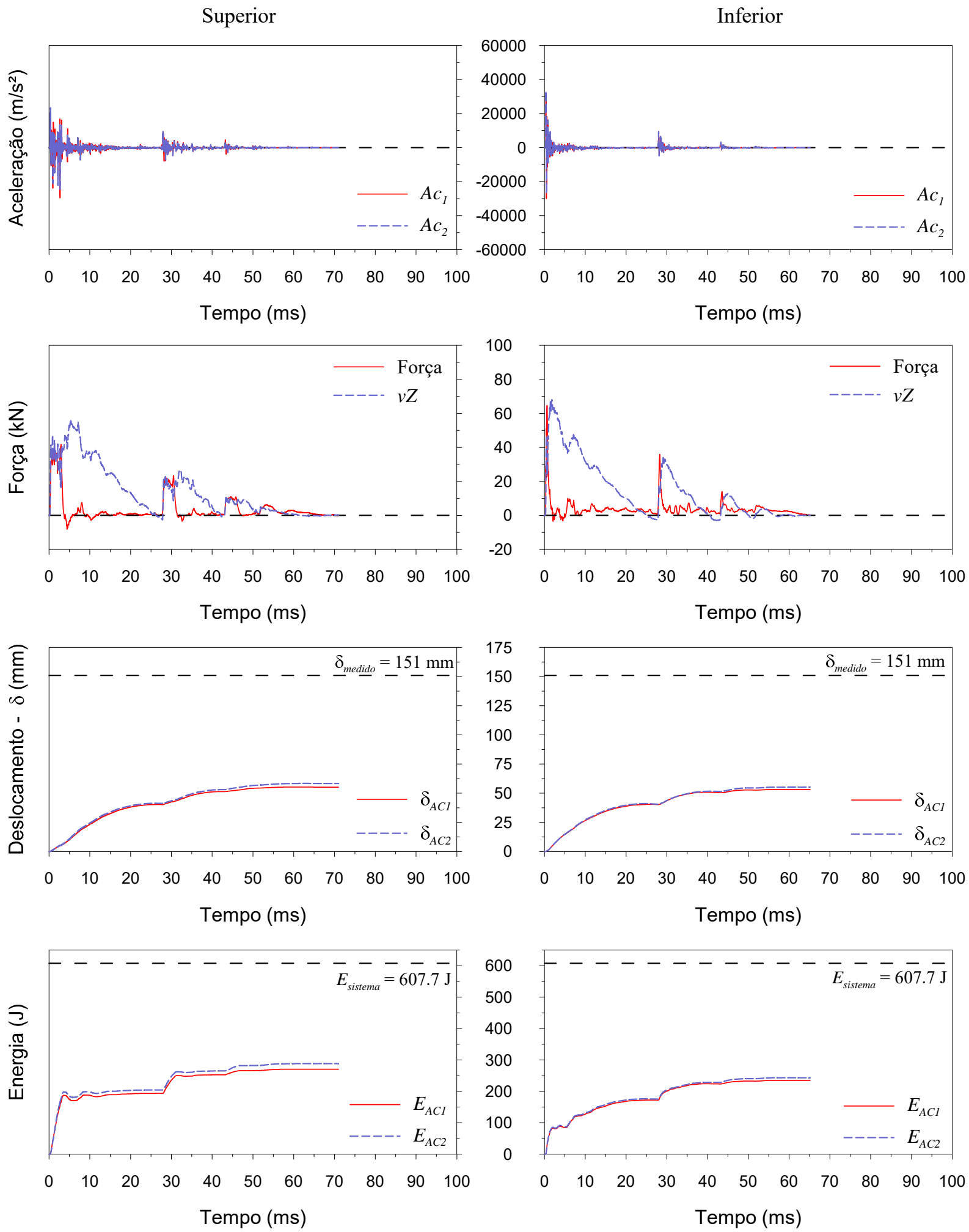

Figura A53 - Sinais típicos de SPT instrumentado para o furo SP02, profundidade de $5 \mathrm{~m}$ e $H_{q}$ de $750 \mathrm{~mm}$. 

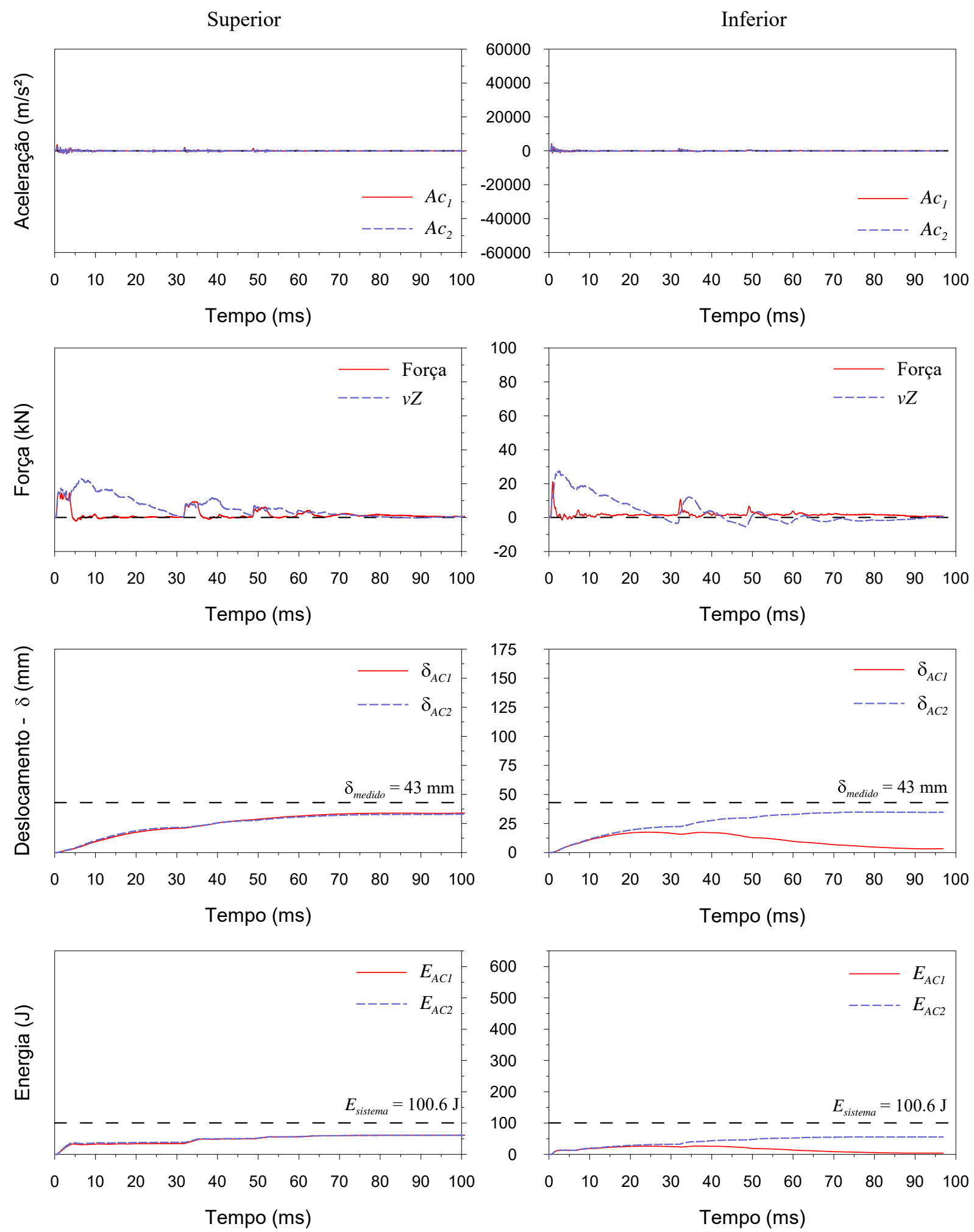

Figura A54 - Sinais típicos de SPT instrumentado para o furo SP02, profundidade de $6 \mathrm{~m}$ e $H_{q}$ de $100 \mathrm{~mm}$. 

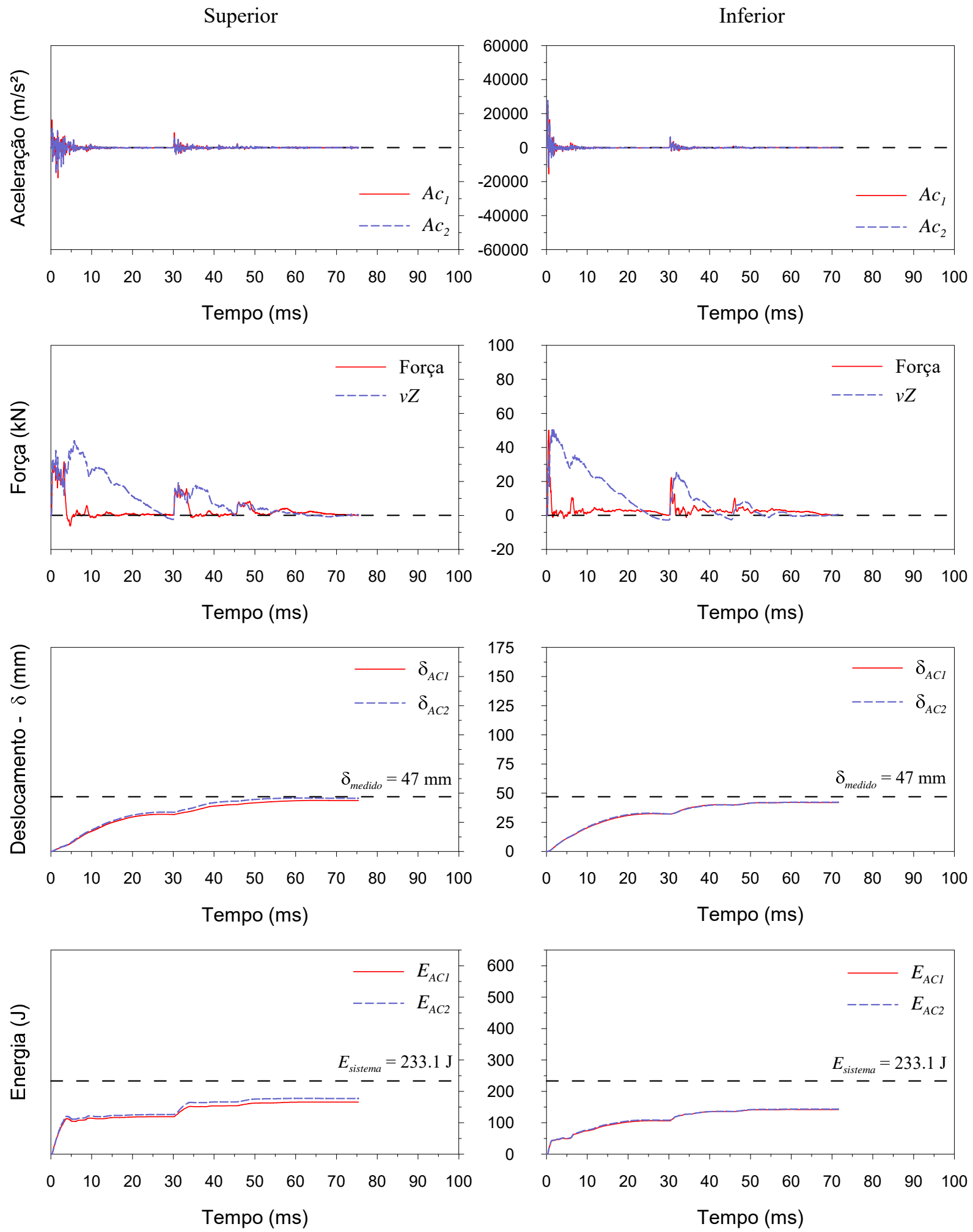

Figura A55 - Sinais típicos de SPT instrumentado para o furo SP02, profundidade de $6 \mathrm{~m}$ e $H_{q}$ de $300 \mathrm{~mm}$. 

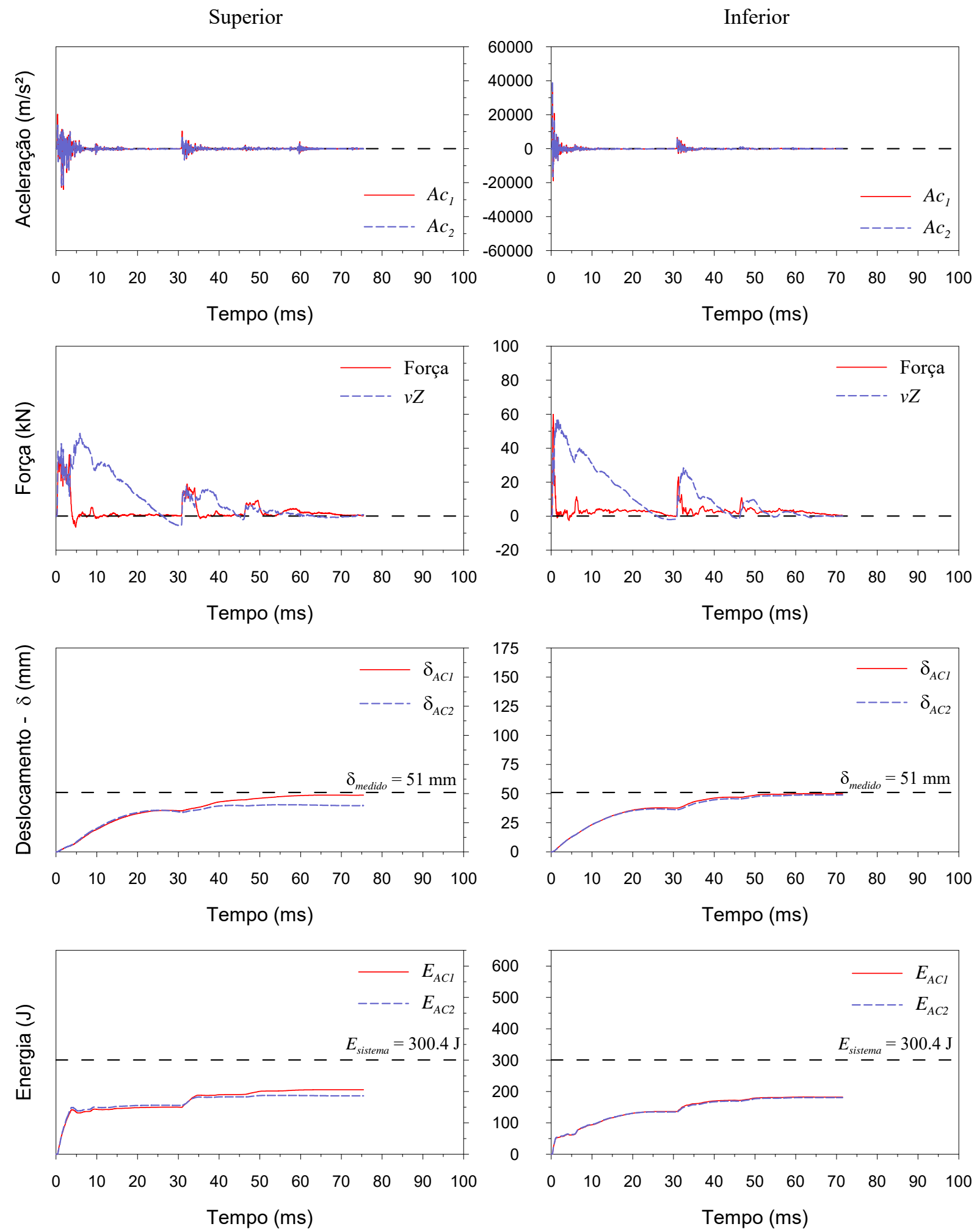

Figura A56 - Sinais típicos de SPT instrumentado para o furo SP02, profundidade de $6 \mathrm{~m}$ e $H_{q}$ de $400 \mathrm{~mm}$. 

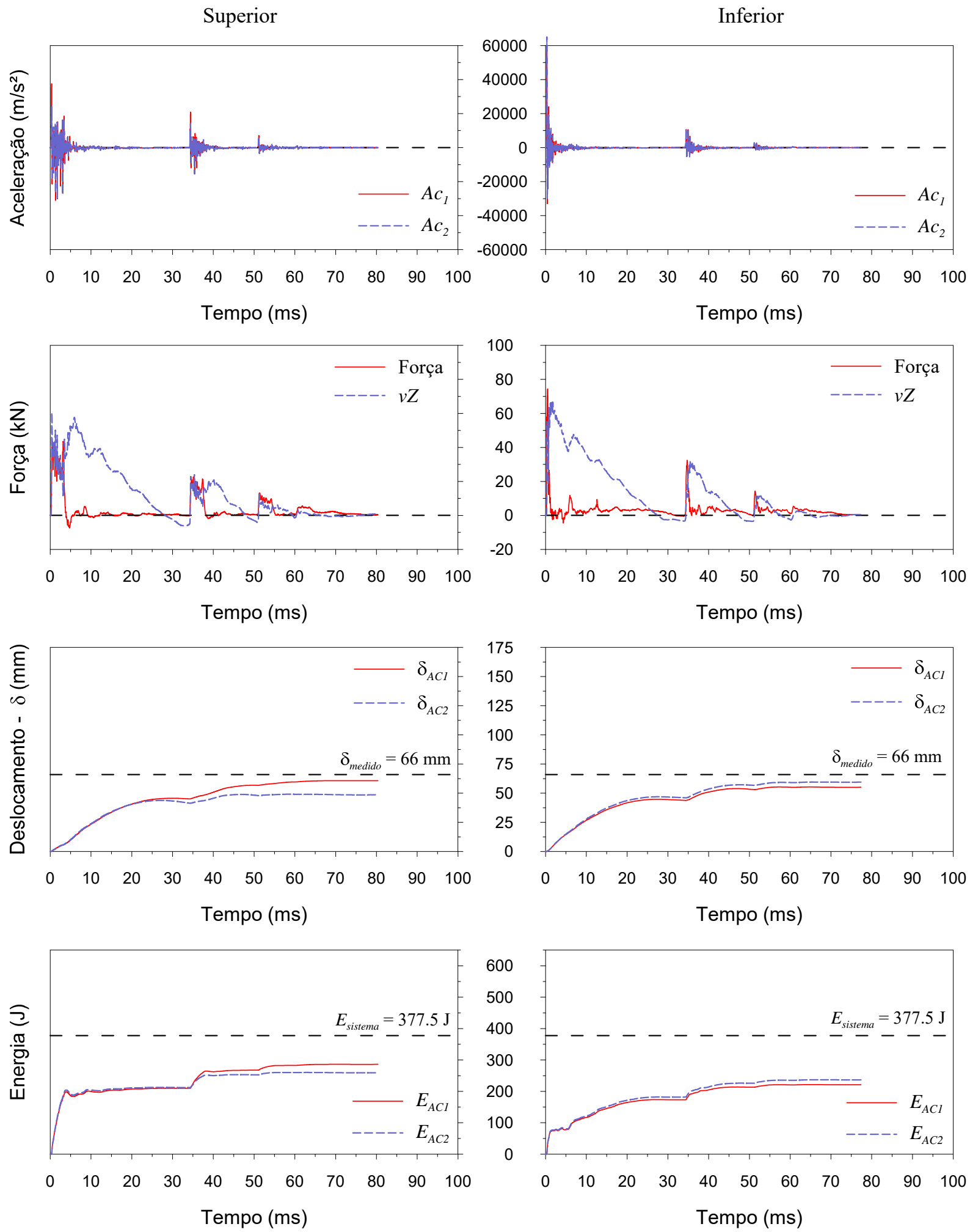

Figura A57 - Sinais típicos de SPT instrumentado para o furo SP02, profundidade de $6 \mathrm{~m}$ e $H_{q}$ de $600 \mathrm{~mm}$. 

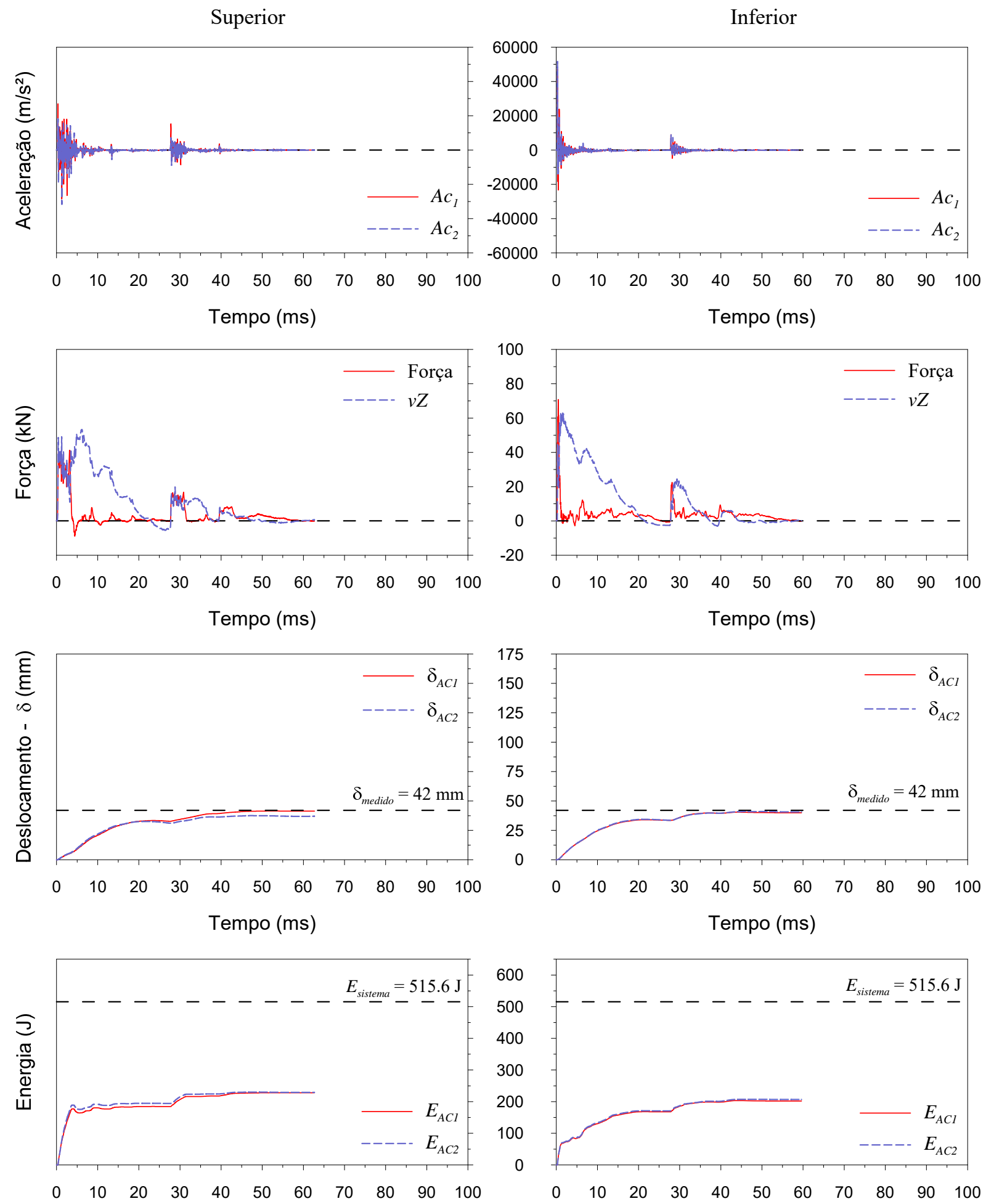

Tempo (ms)

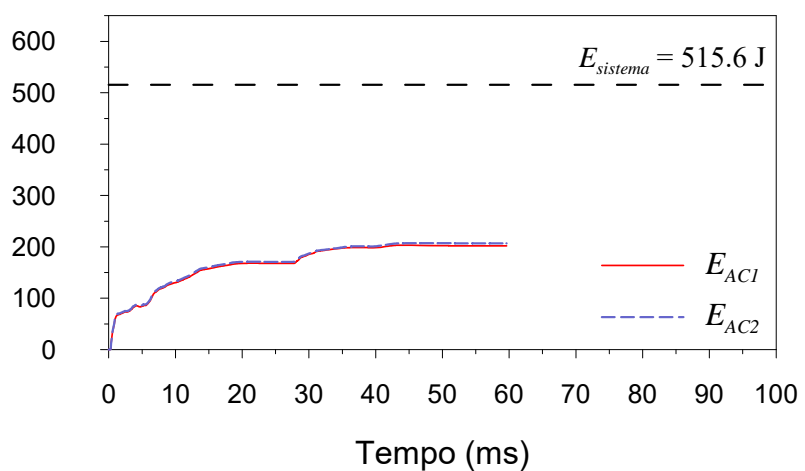

Figura A58 - Sinais típicos de SPT instrumentado para o furo SP02, profundidade de $6 \mathrm{~m}$ e $H_{q}$ de $750 \mathrm{~mm}$. 

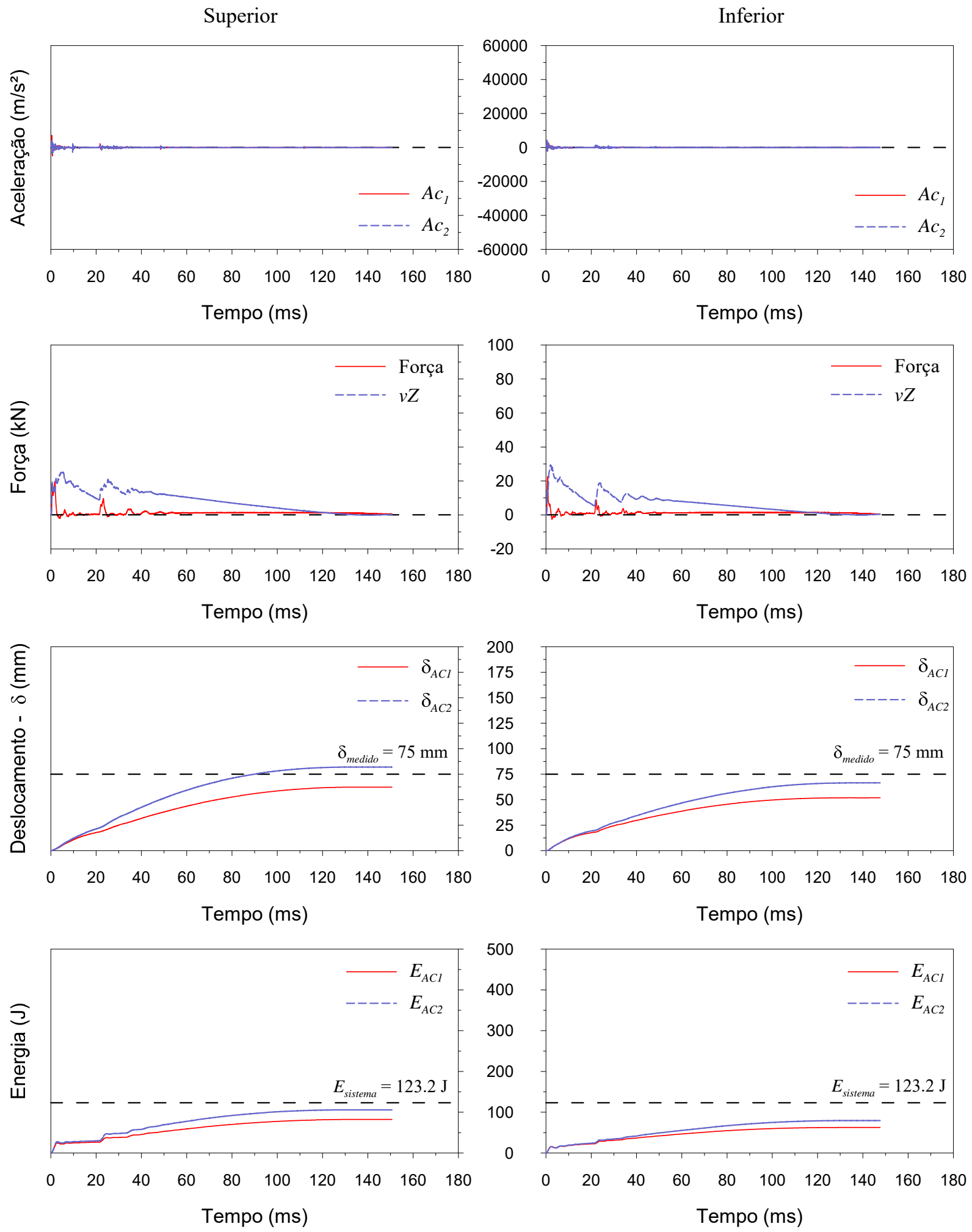

Figura A59 - Sinais típicos de SPT instrumentado para o furo SP03, profundidade de $2 \mathrm{~m}$ e $H_{q}$ de $100 \mathrm{~mm}$. 

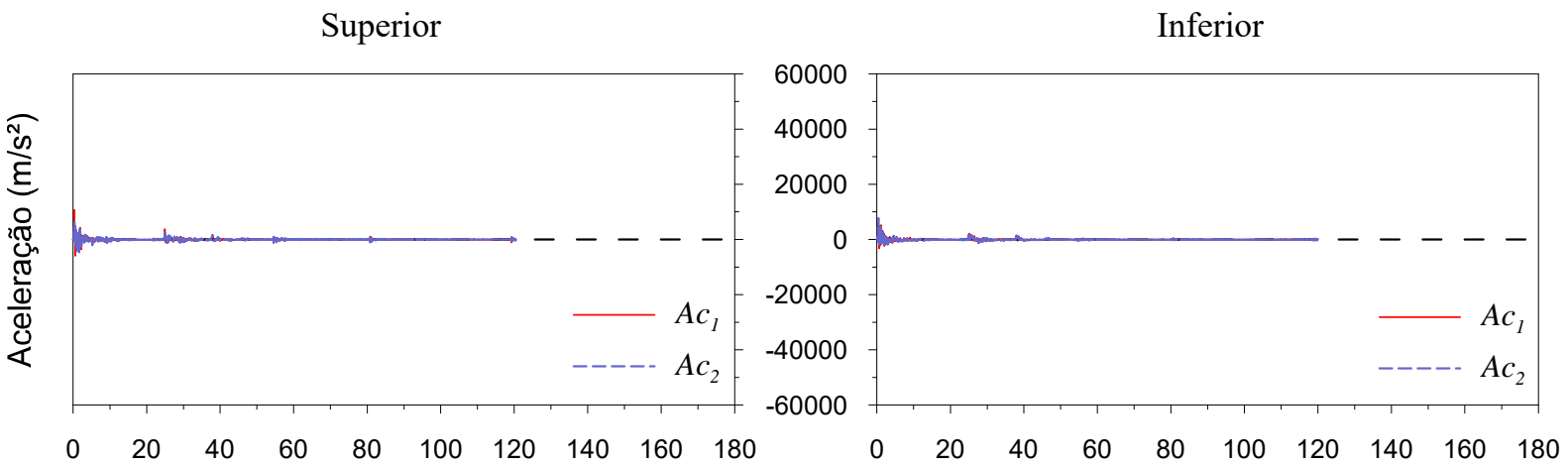

Tempo (ms)

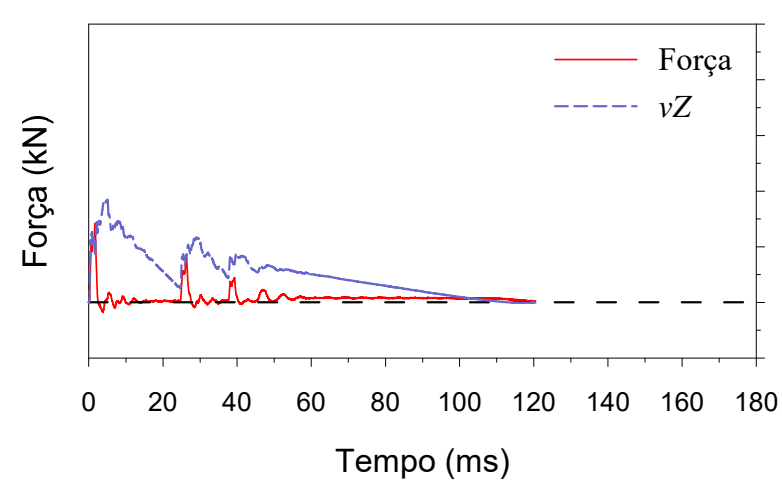

Tempo (ms)
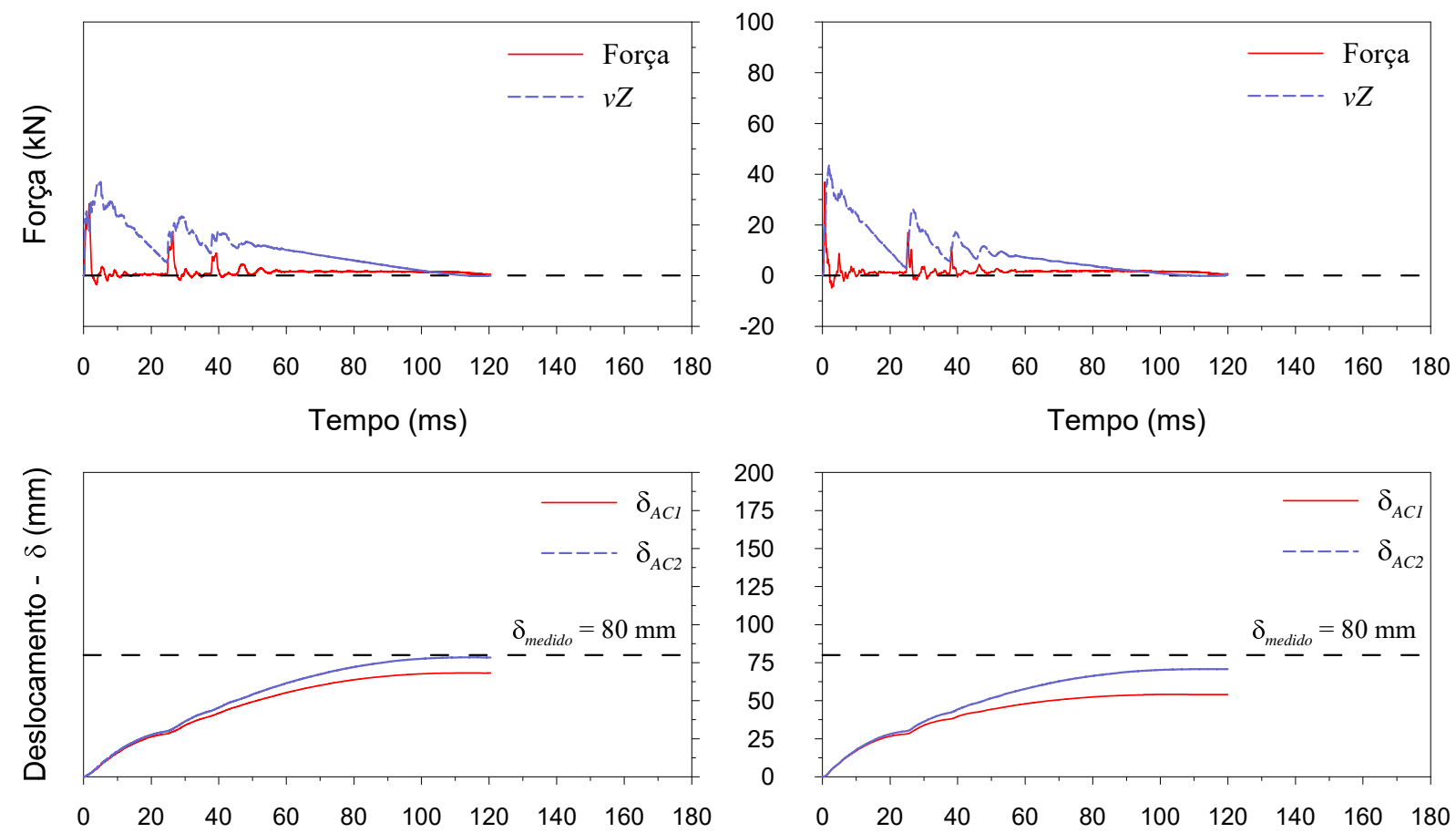

Tempo (ms)
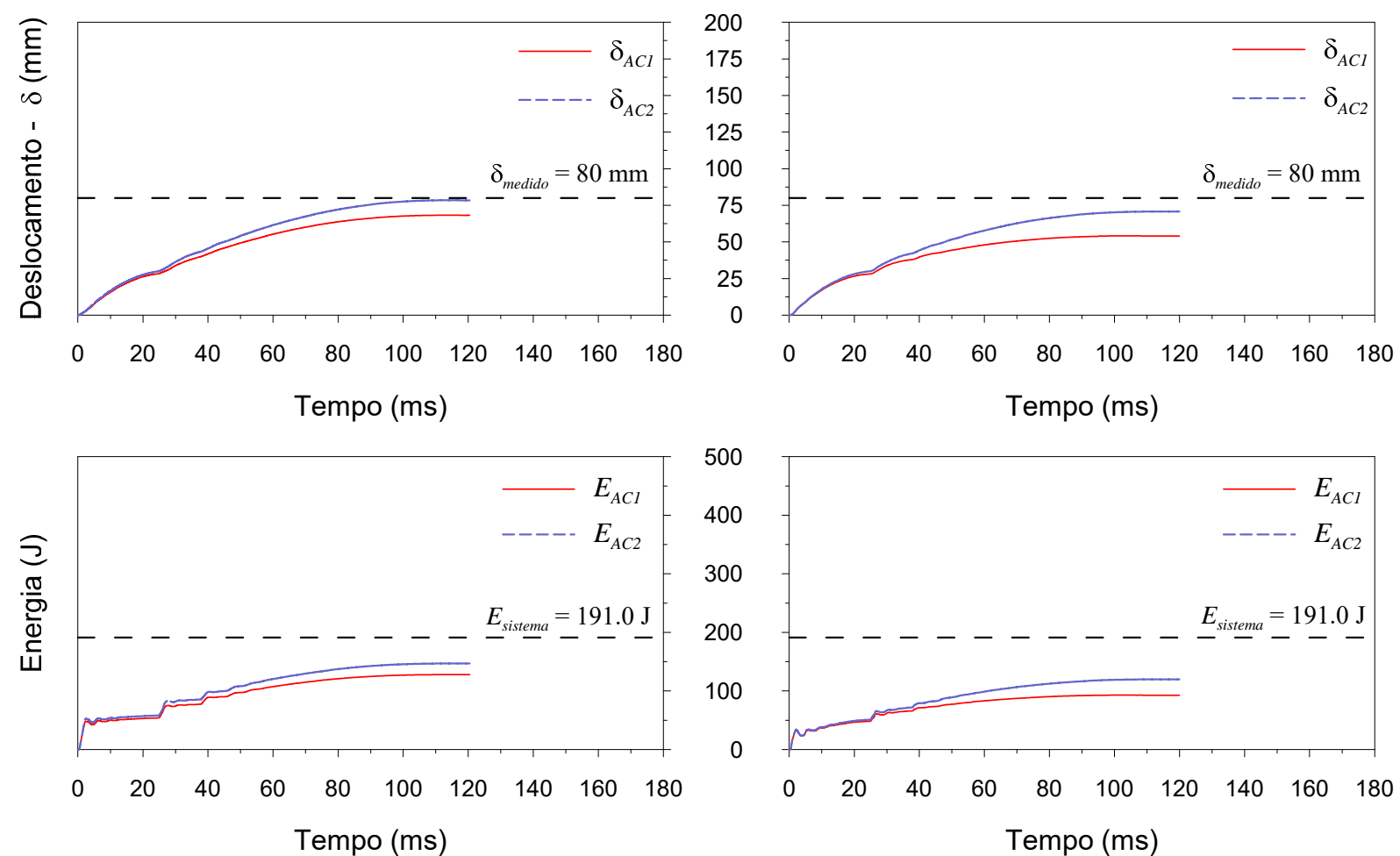

Figura A60 - Sinais típicos de SPT instrumentado para o furo SP03, profundidade de $2 \mathrm{~m}$ e $H_{q}$ de $200 \mathrm{~mm}$. 

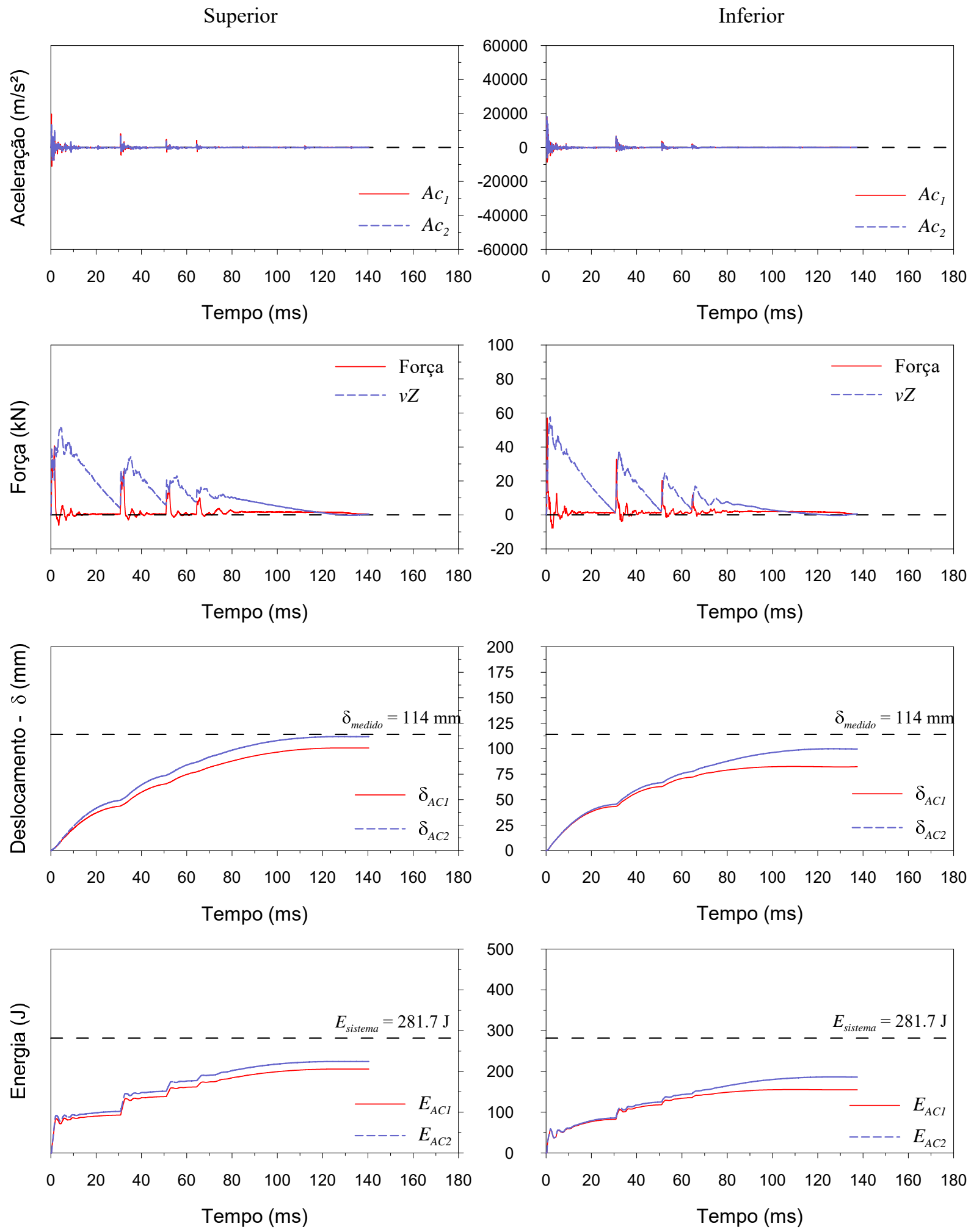

Figura A61 - Sinais típicos de SPT instrumentado para o furo SP03, profundidade de $2 \mathrm{~m}$ e $H_{q}$ de $300 \mathrm{~mm}$. 

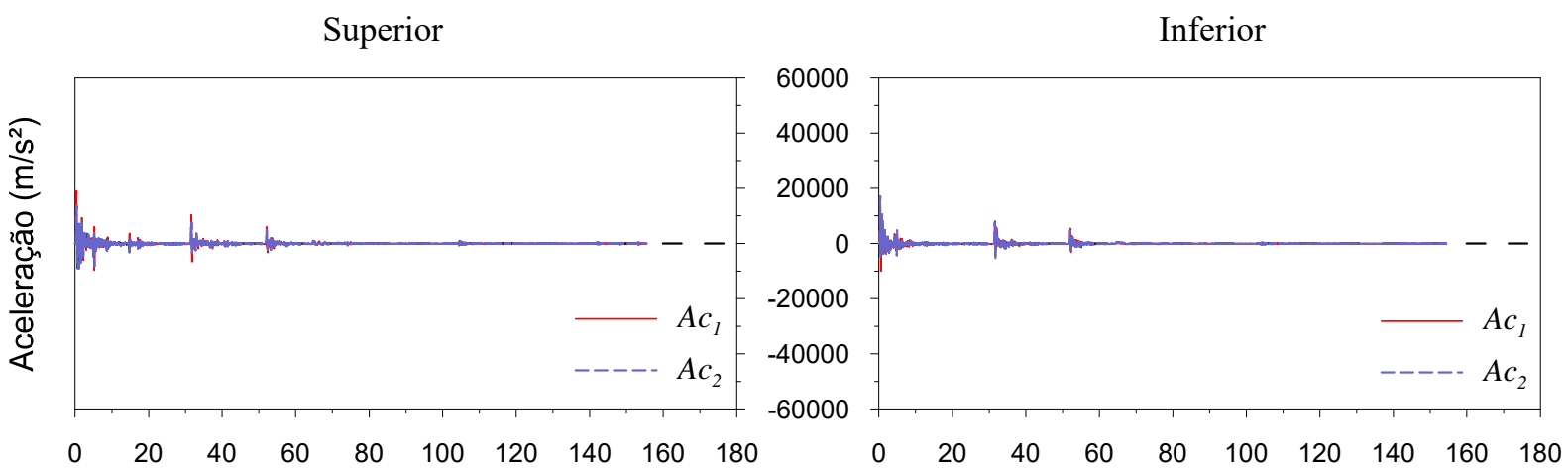

Tempo (ms)

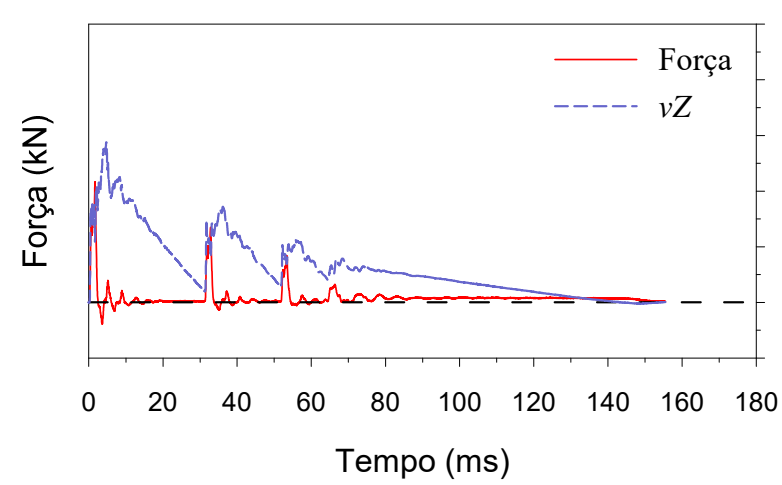

Tempo (ms)
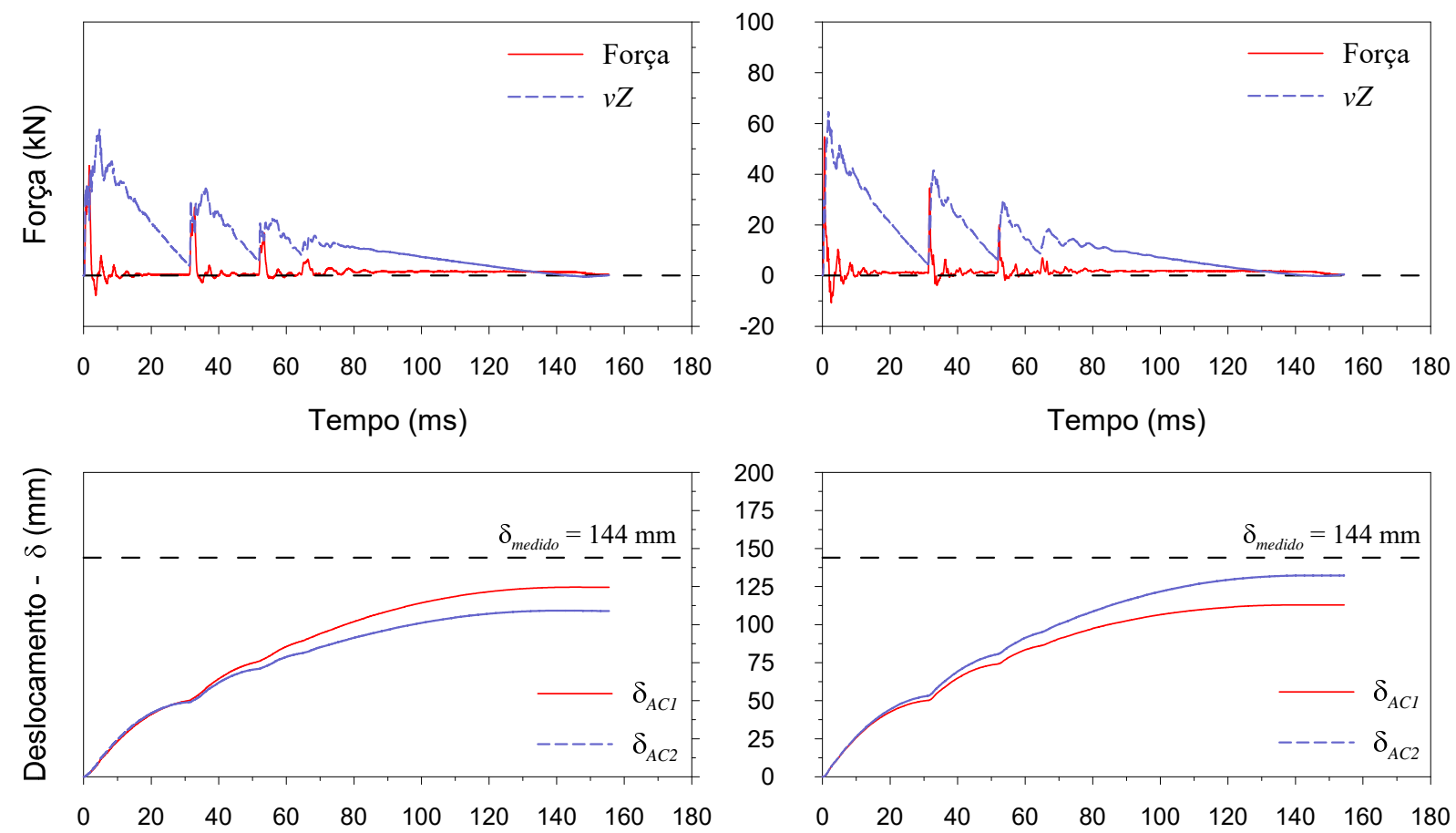

Tempo (ms)
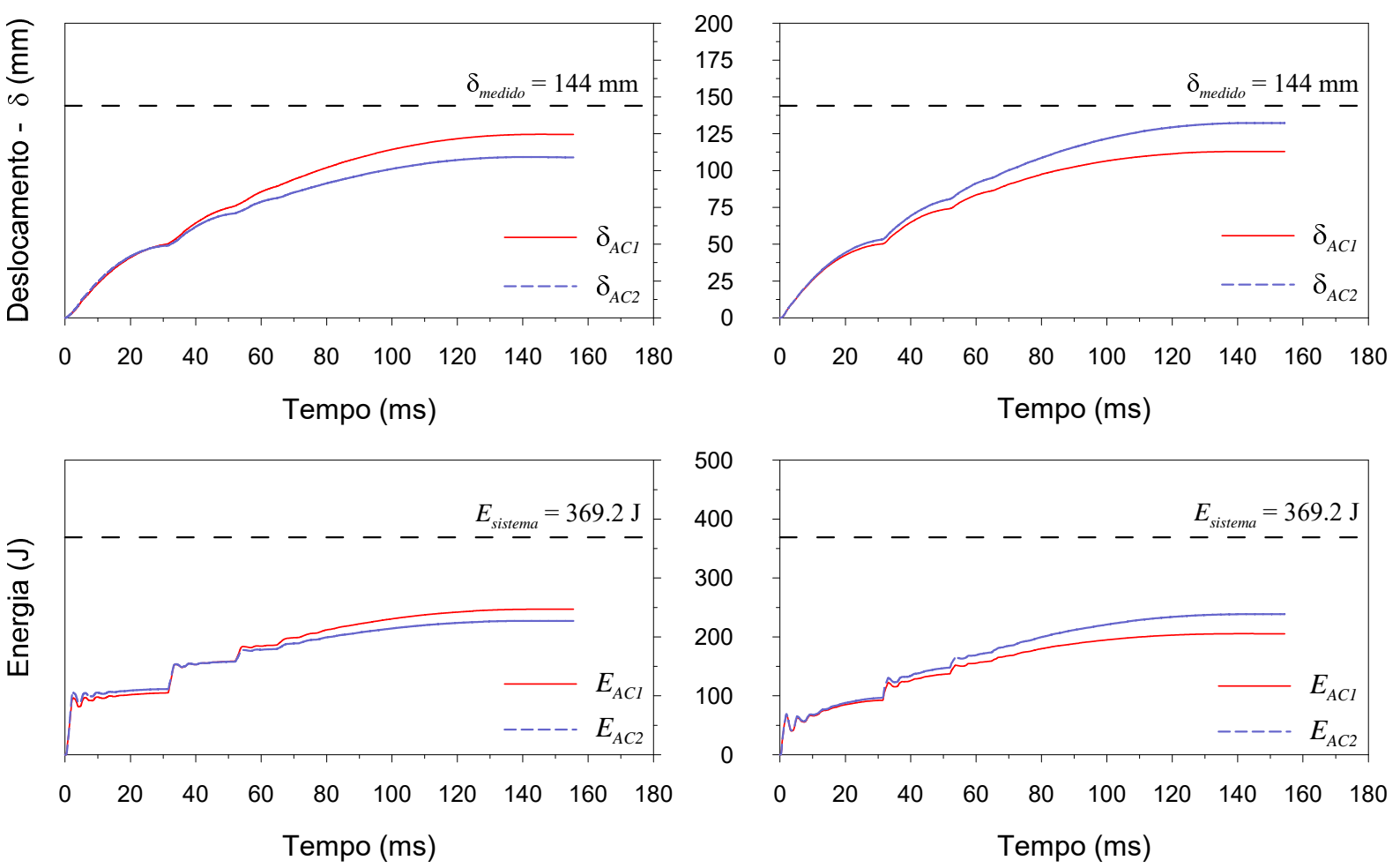

Figura A62 - Sinais típicos de SPT instrumentado para o furo SP03, profundidade de $2 \mathrm{~m}$ e $H_{q}$ de $400 \mathrm{~mm}$. 
Superior
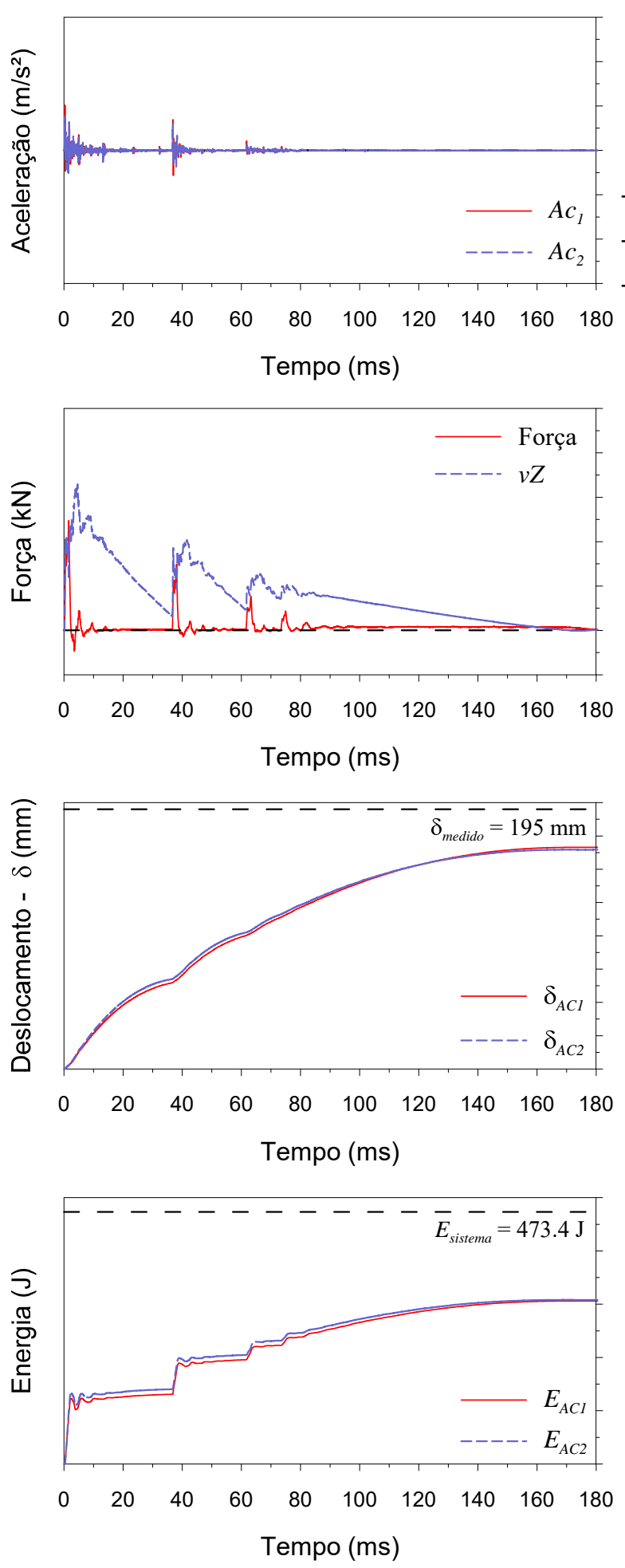

Inferior
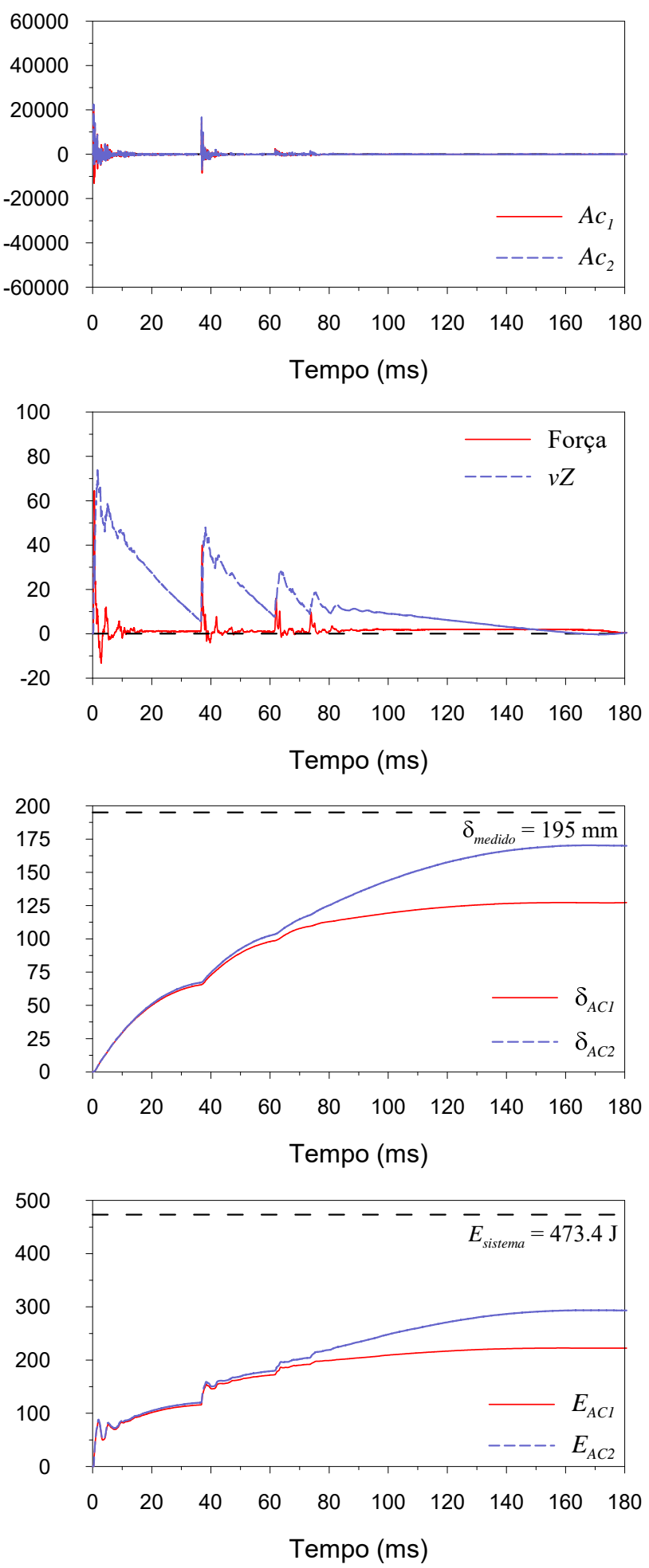

Figura A63 - Sinais típicos de SPT instrumentado para o furo SP03, profundidade de $2 \mathrm{~m}$ e $H_{q}$ de $500 \mathrm{~mm}$. 

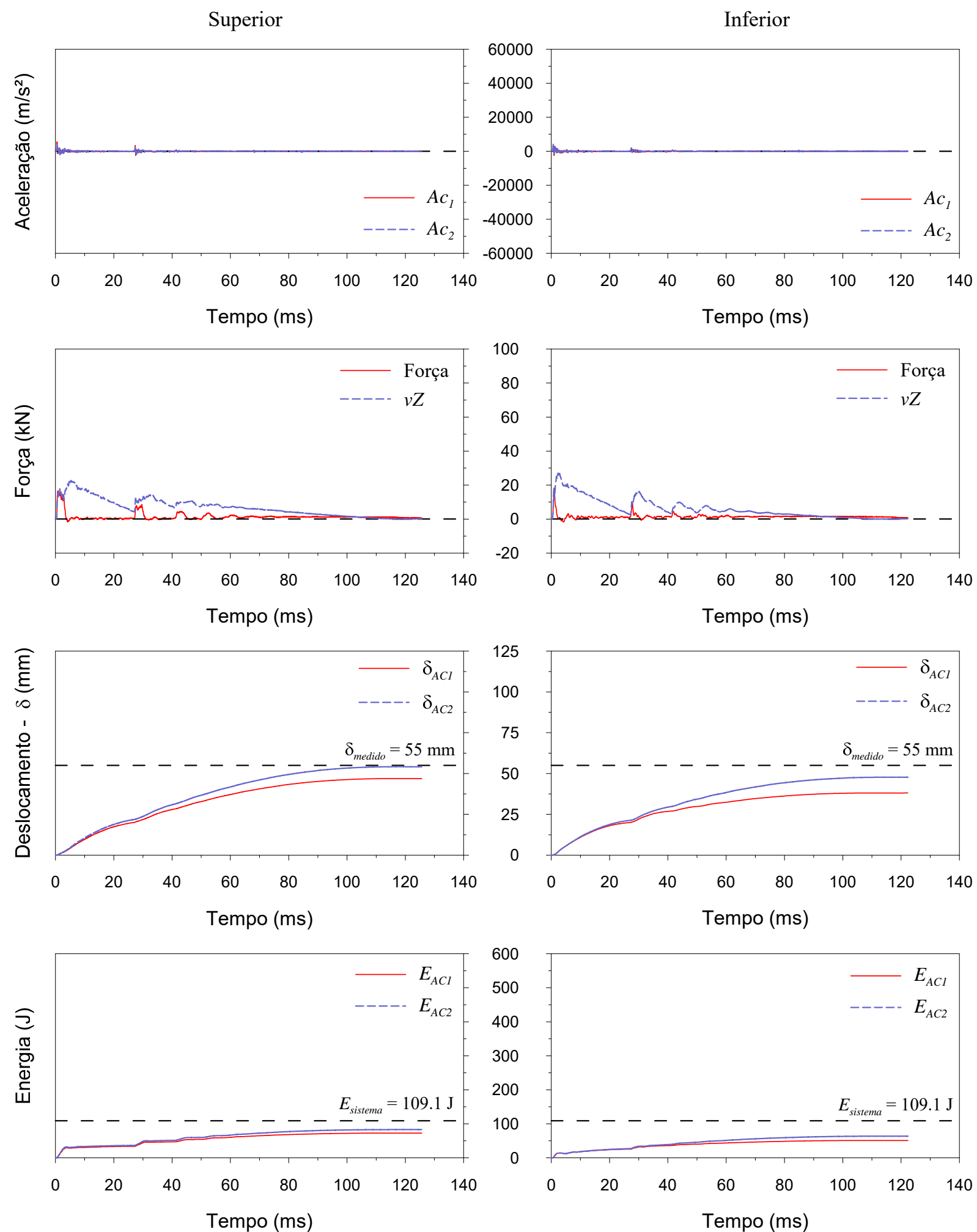

Figura A64 - Sinais típicos de SPT instrumentado para o furo SP03, profundidade de $3 \mathrm{~m}$ e $H_{q}$ de $100 \mathrm{~mm}$. 

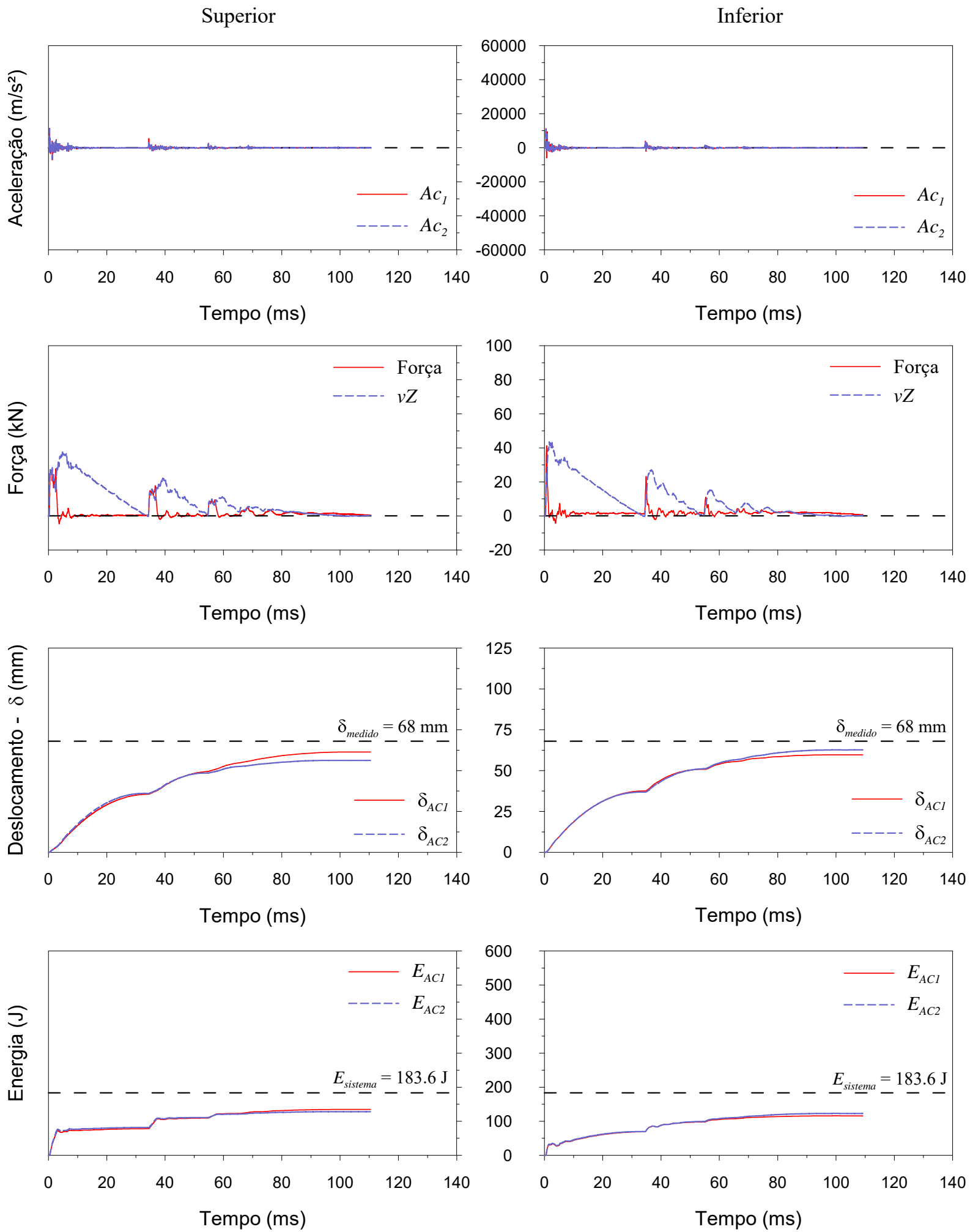

Figura A65 - Sinais típicos de SPT instrumentado para o furo SP03, profundidade de $3 \mathrm{~m}$ e $H_{q}$ de $200 \mathrm{~mm}$. 

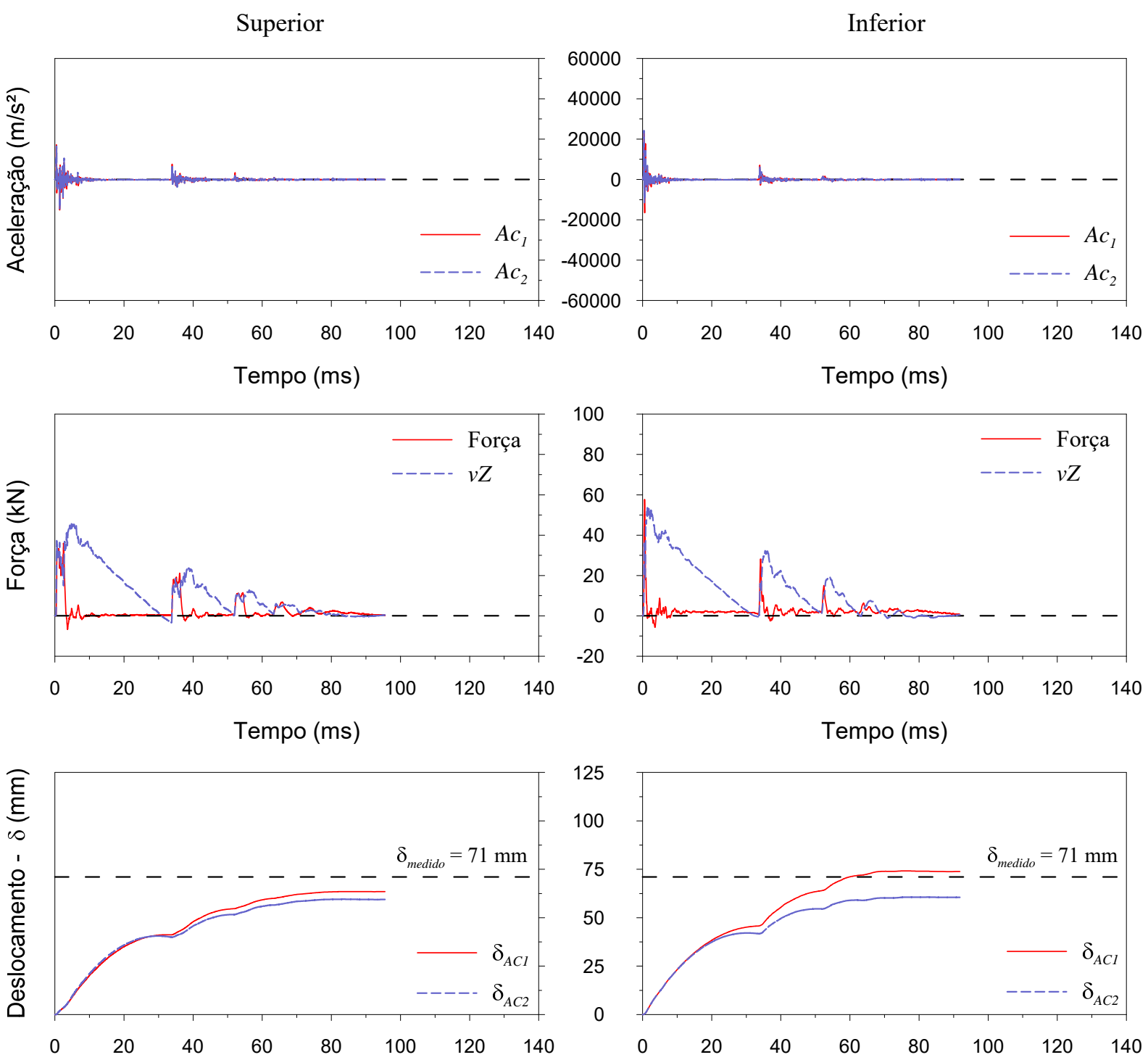

Tempo (ms)

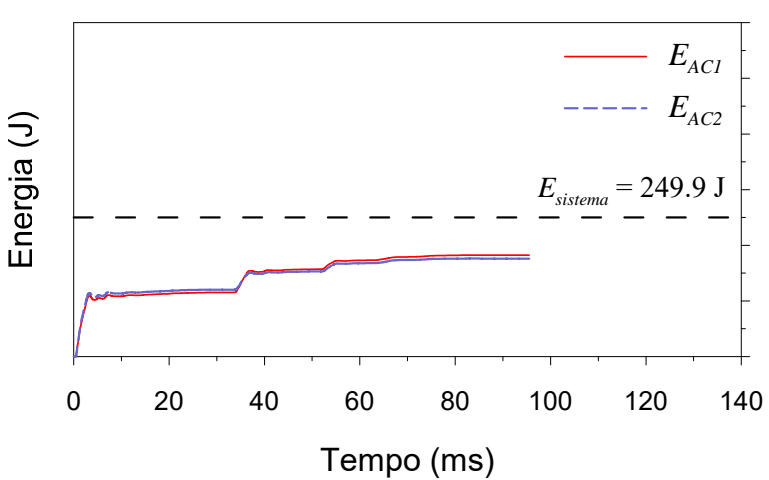

Tempo (ms)

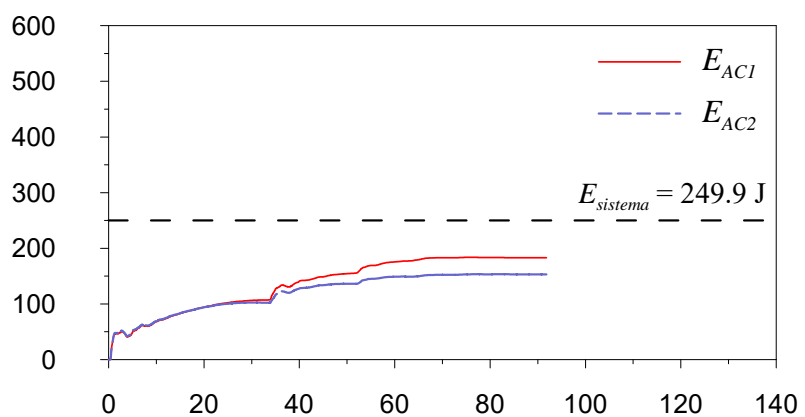

Tempo (ms)

Figura A66 - Sinais típicos de SPT instrumentado para o furo SP03, profundidade de $3 \mathrm{~m}$ e $H_{q}$ de $300 \mathrm{~mm}$. 

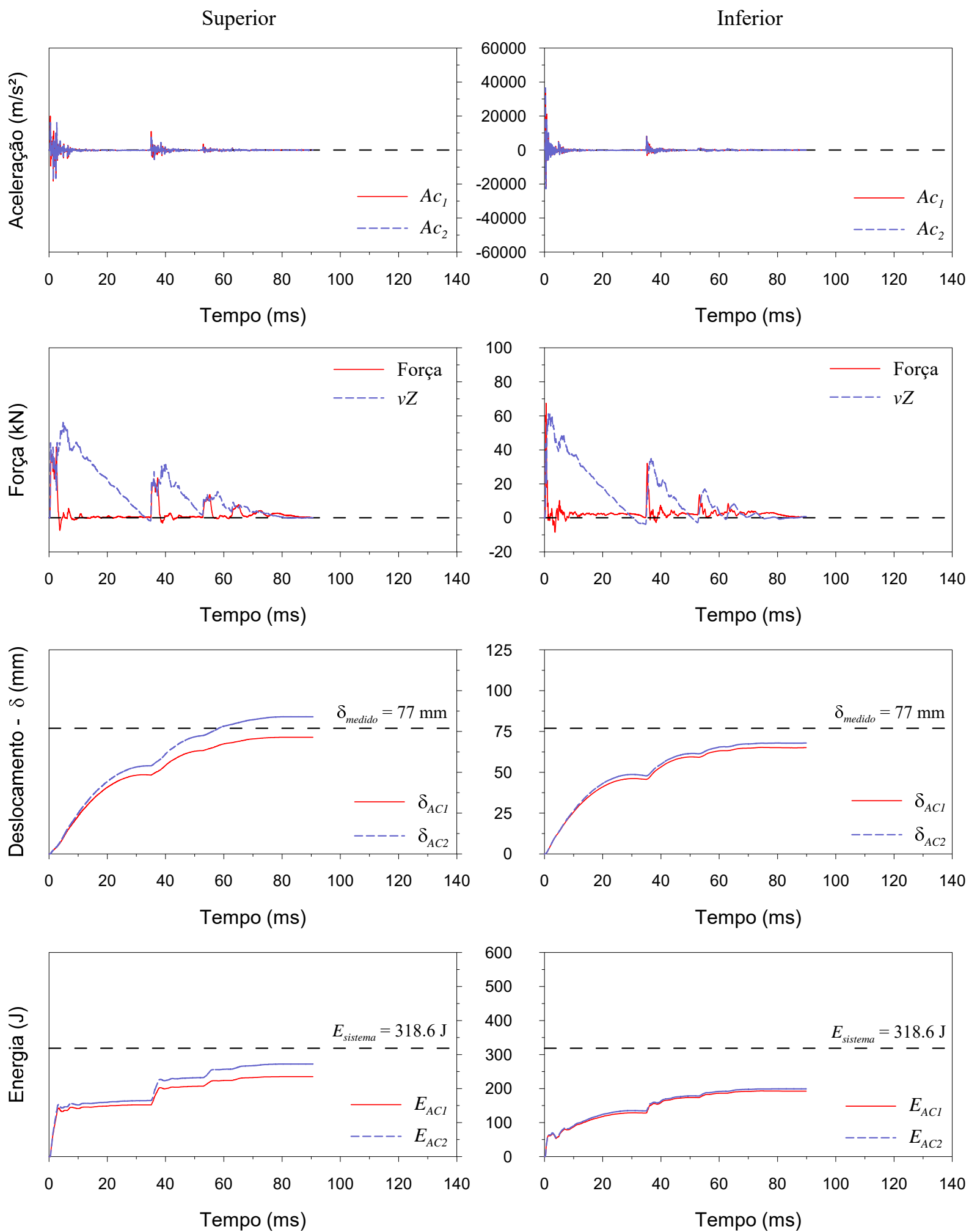

Figura A67 - Sinais típicos de SPT instrumentado para o furo SP03, profundidade de $3 \mathrm{~m}$ e $H_{q}$ de $400 \mathrm{~mm}$. 

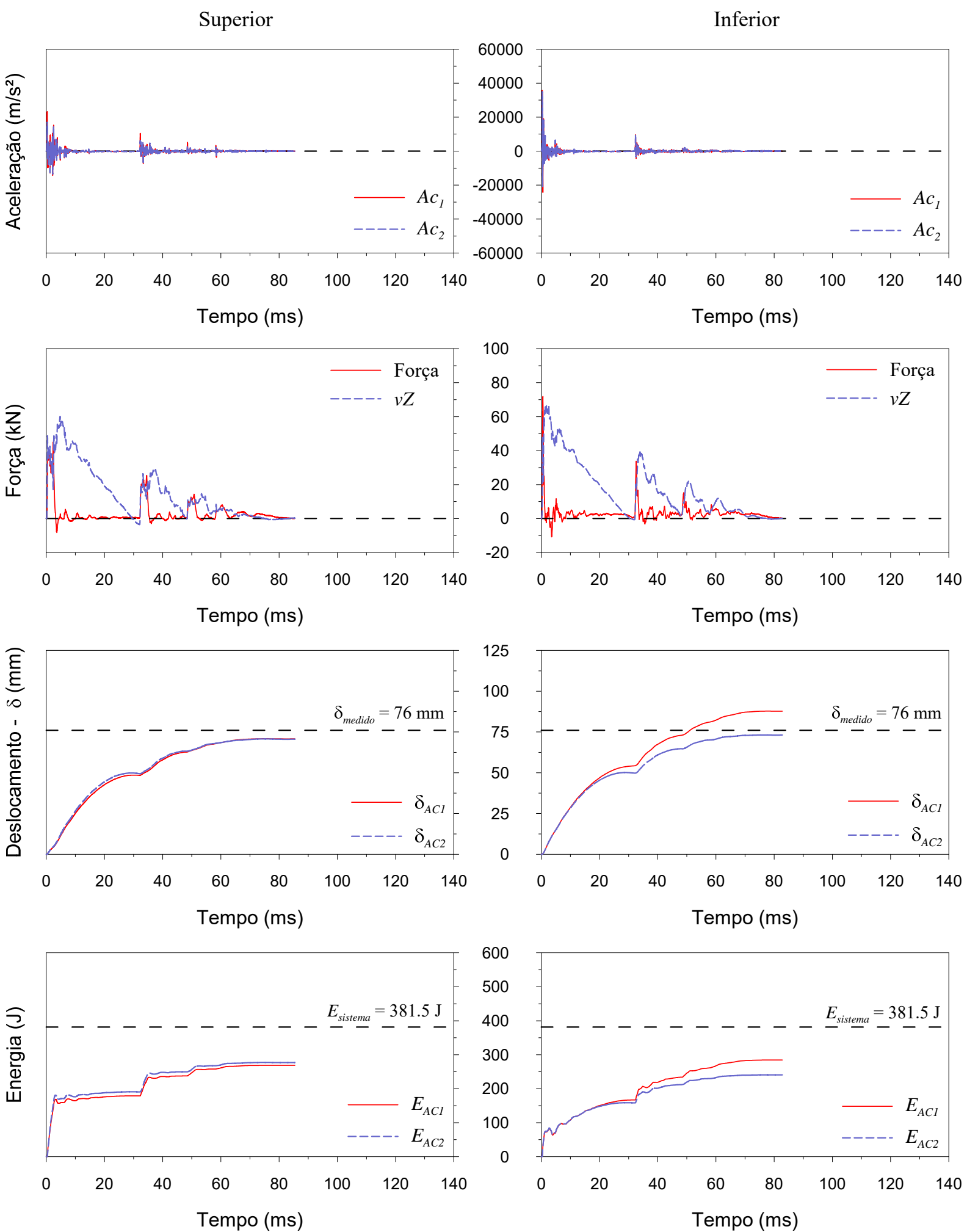

Figura A68 - Sinais típicos de SPT instrumentado para o furo SP03, profundidade de $3 \mathrm{~m}$ e $H_{q}$ de $500 \mathrm{~mm}$. 

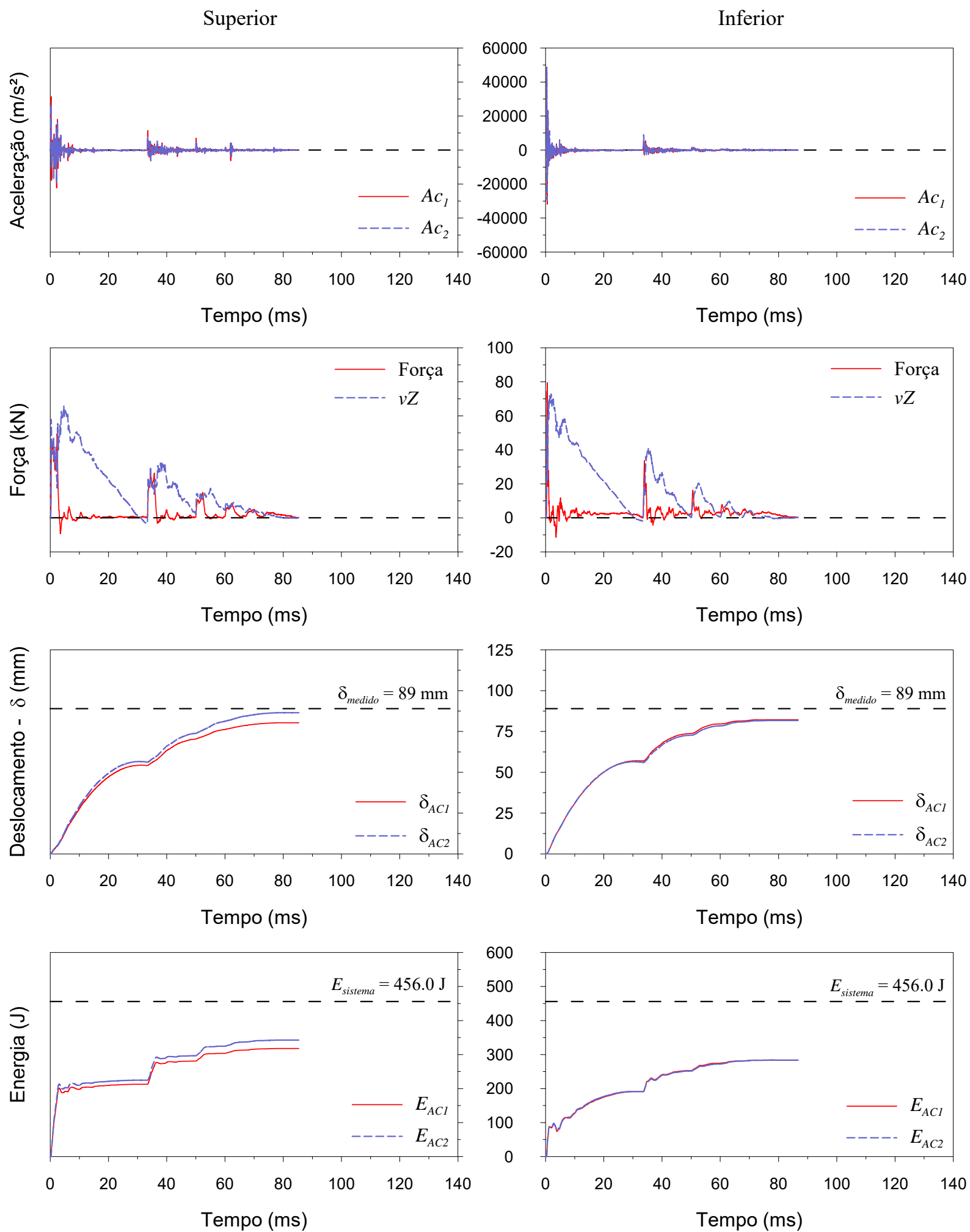

Figura A69 - Sinais típicos de SPT instrumentado para o furo SP03, profundidade de $3 \mathrm{~m}$ e $H_{q}$ de $600 \mathrm{~mm}$. 

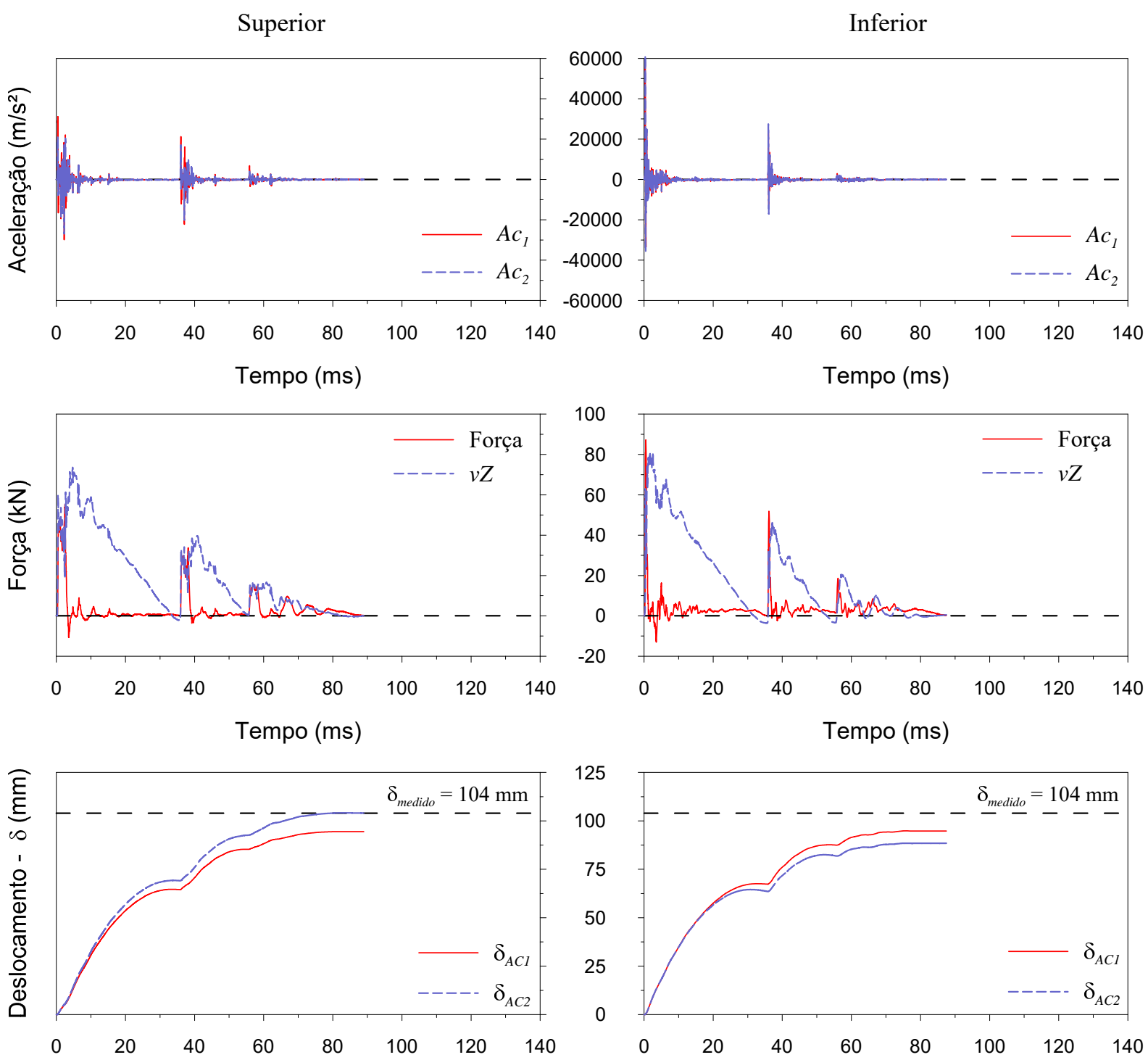

Tempo (ms)

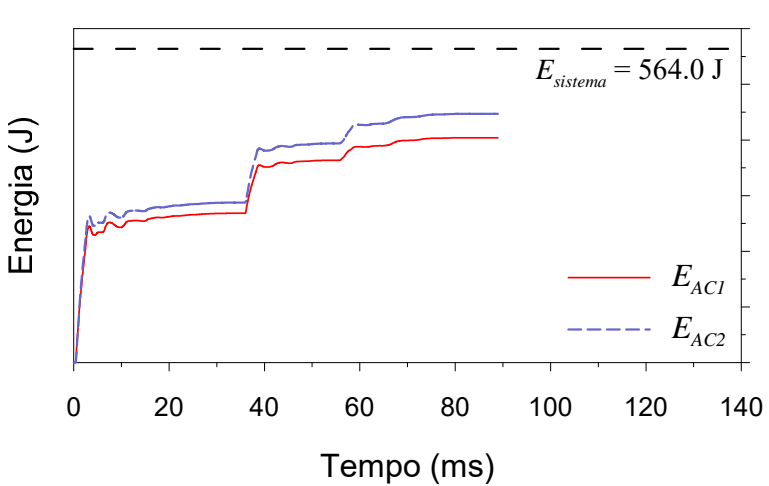

Tempo (ms)

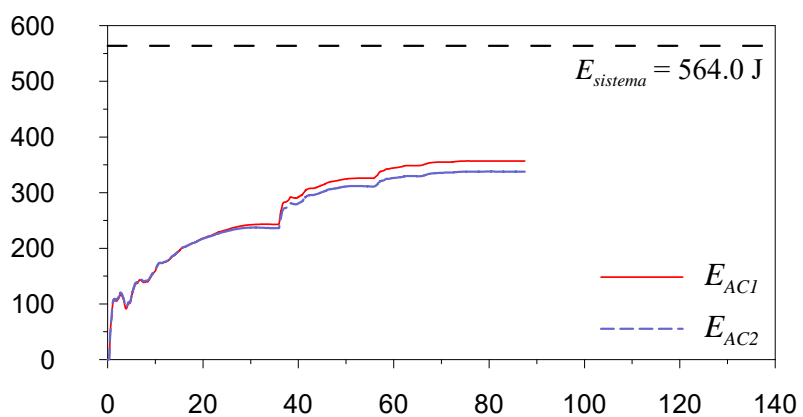

Figura A70 - Sinais típicos de SPT instrumentado para o furo SP03, profundidade de $3 \mathrm{~m}$ e $H_{q}$ de $750 \mathrm{~mm}$. 

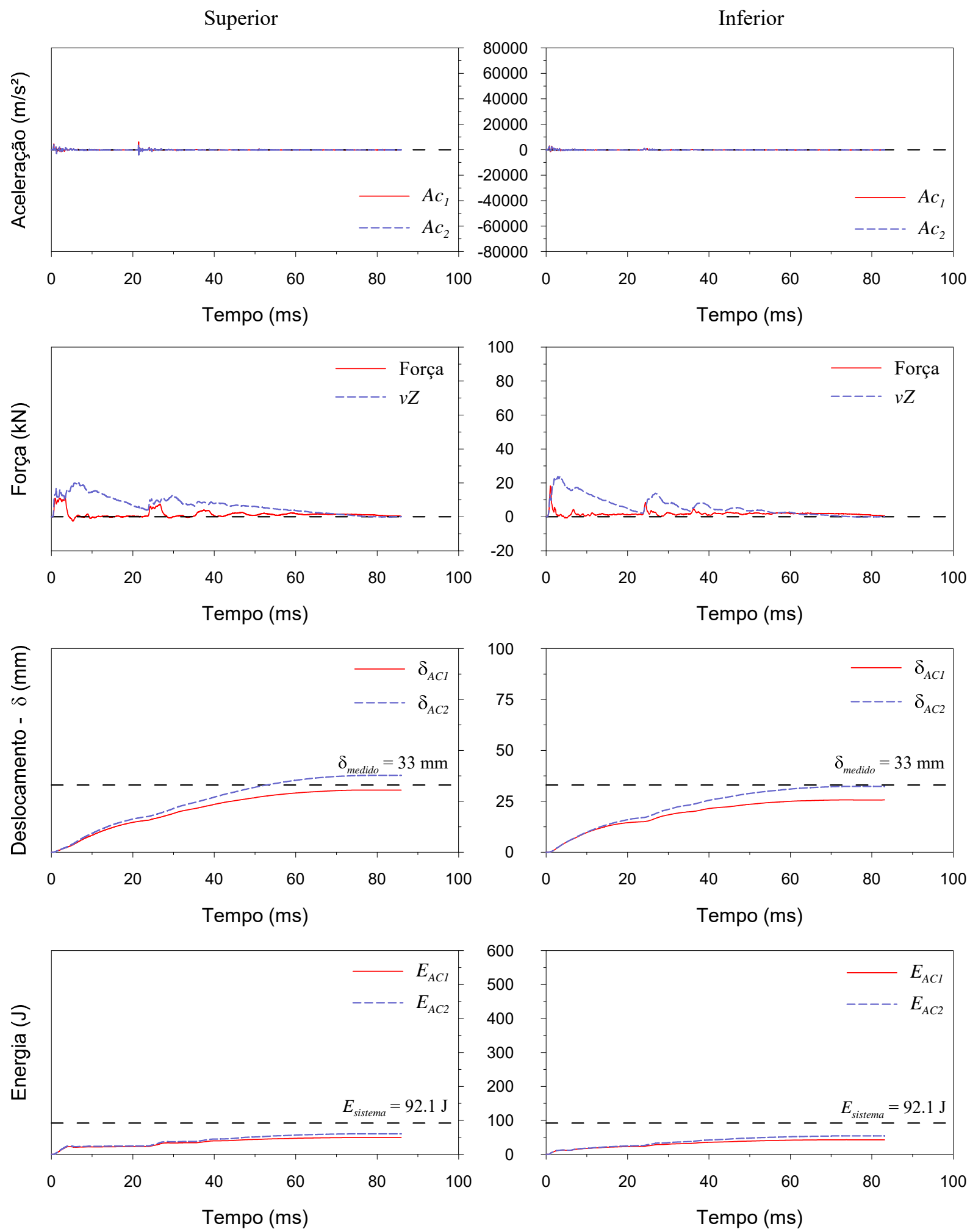

Figura A71 - Sinais típicos de SPT instrumentado para o furo SP03, profundidade de $4 \mathrm{~m}$ e $H_{q}$ de $100 \mathrm{~mm}$. 

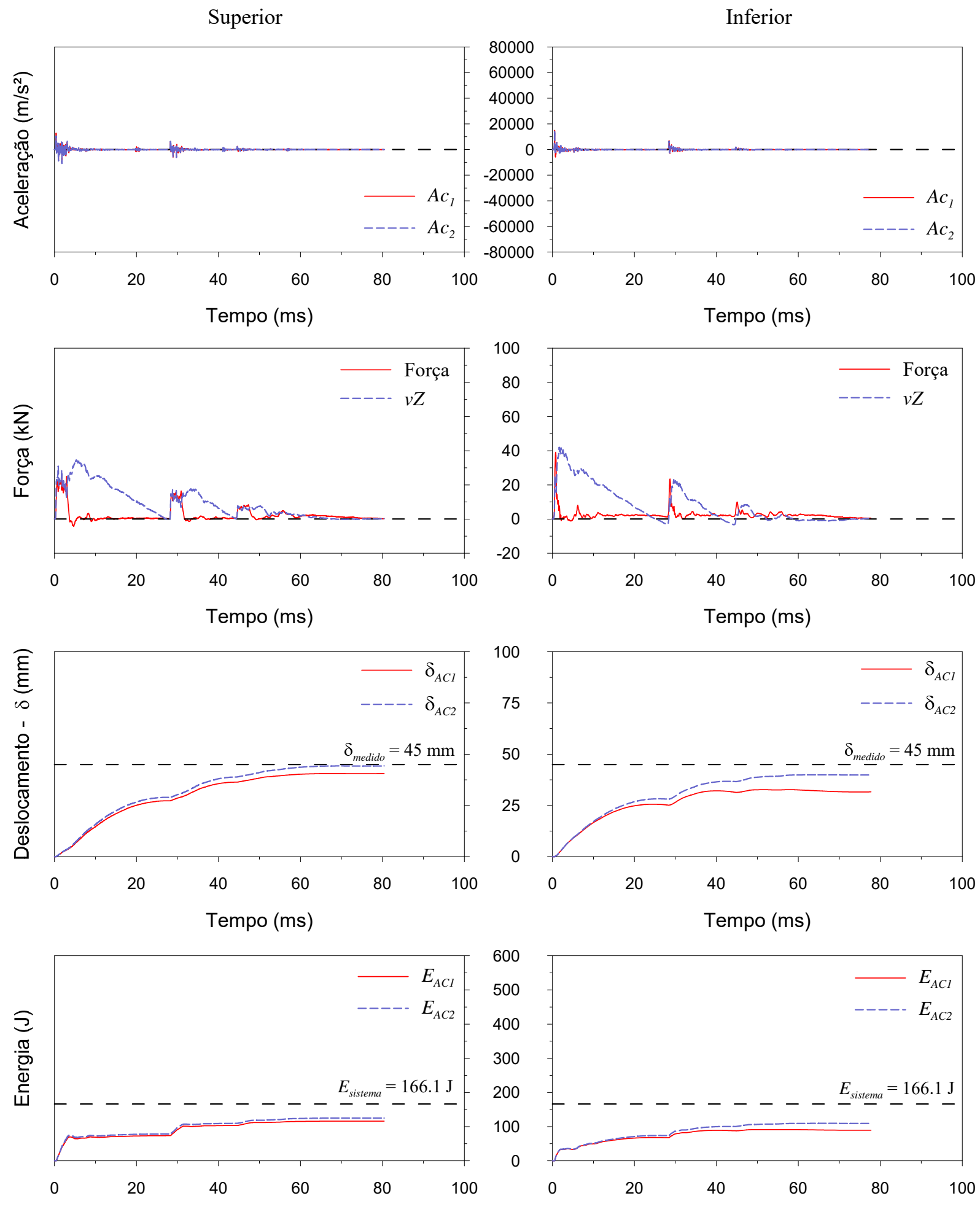

Tempo (ms)

Tempo (ms)

Figura A72 - Sinais típicos de SPT instrumentado para o furo SP03, profundidade de $4 \mathrm{~m}$ e $H_{q}$ de $200 \mathrm{~mm}$. 

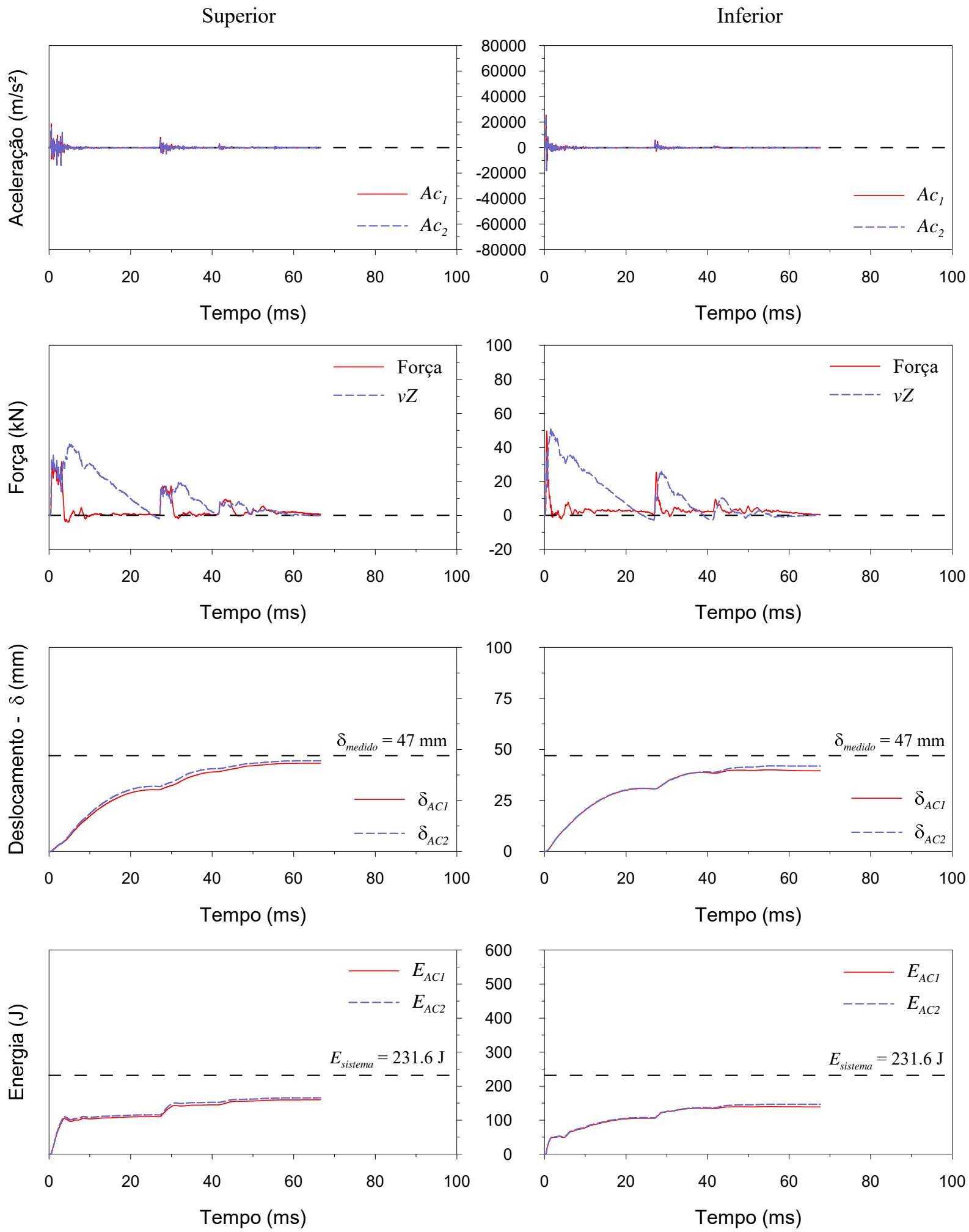

Figura A73 - Sinais típicos de SPT instrumentado para o furo SP03, profundidade de $4 \mathrm{~m}$ e $H_{q}$ de $300 \mathrm{~mm}$. 

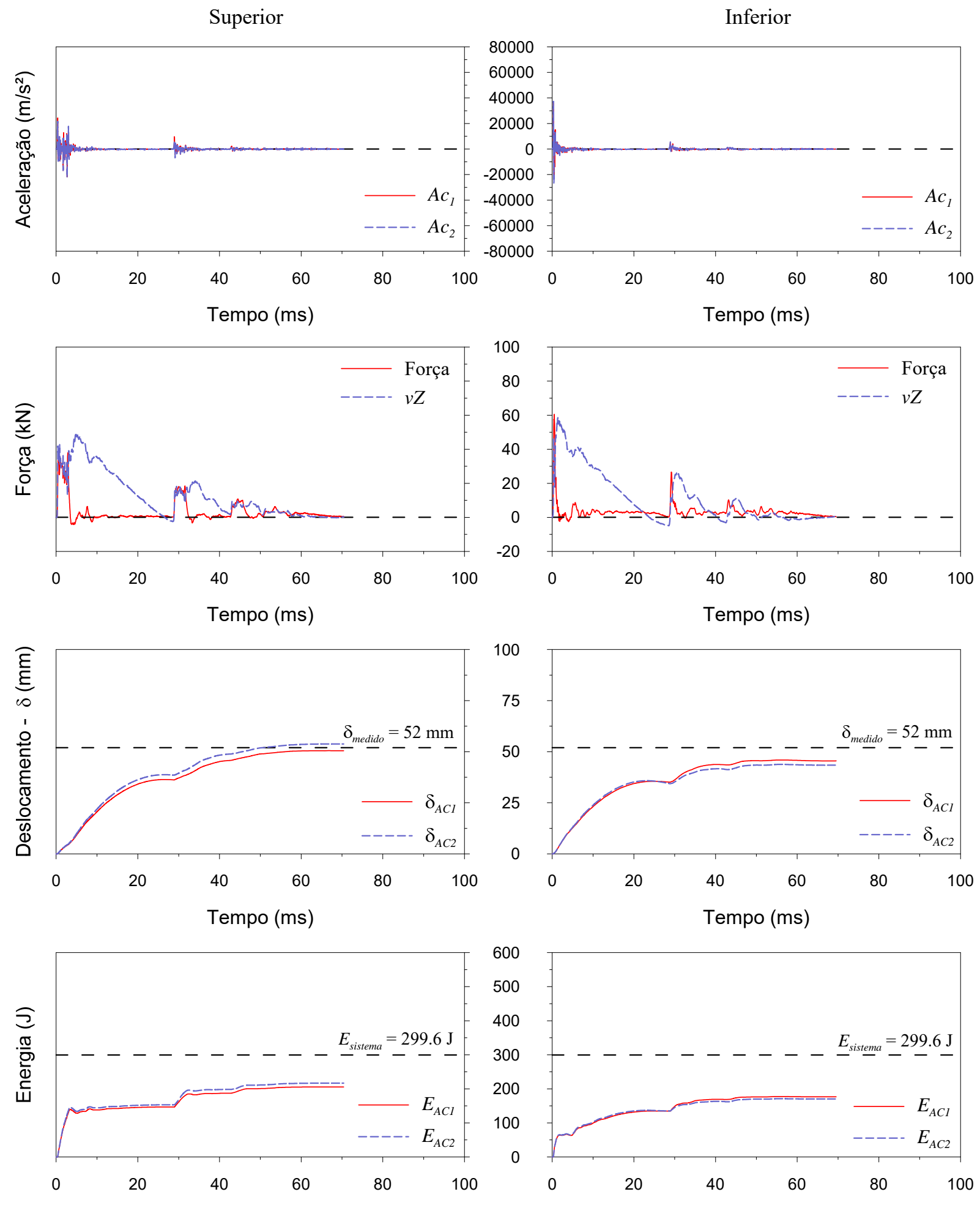

Tempo (ms)

Tempo (ms)

Figura A74 - Sinais típicos de SPT instrumentado para o furo SP03, profundidade de $4 \mathrm{~m}$ e $H_{q}$ de $400 \mathrm{~mm}$. 

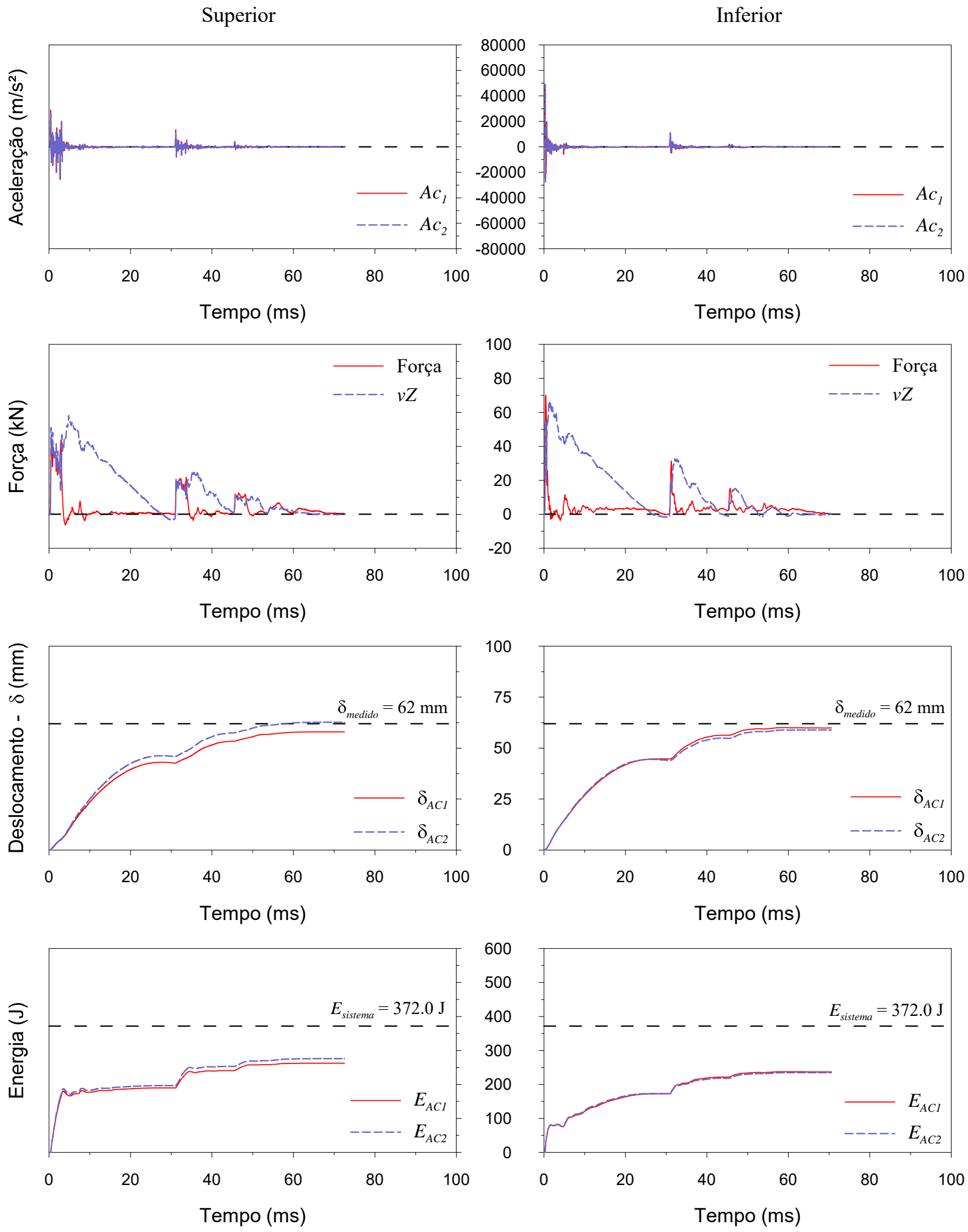

Figura A75 - Sinais típicos de SPT instrumentado para o furo SP03, profundidade de $4 \mathrm{~m}$ e $H_{q}$ de $500 \mathrm{~mm}$. 

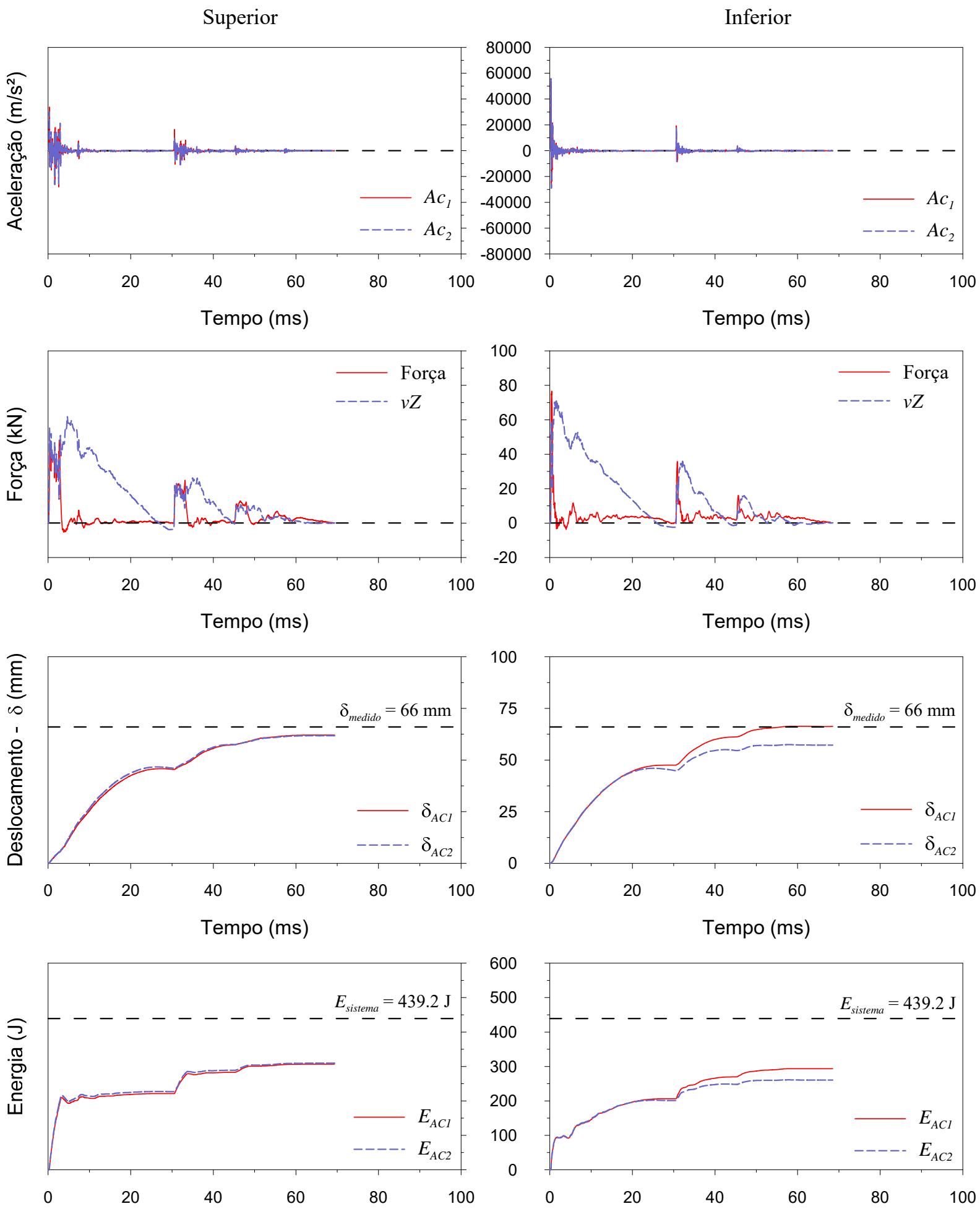

Tempo (ms)

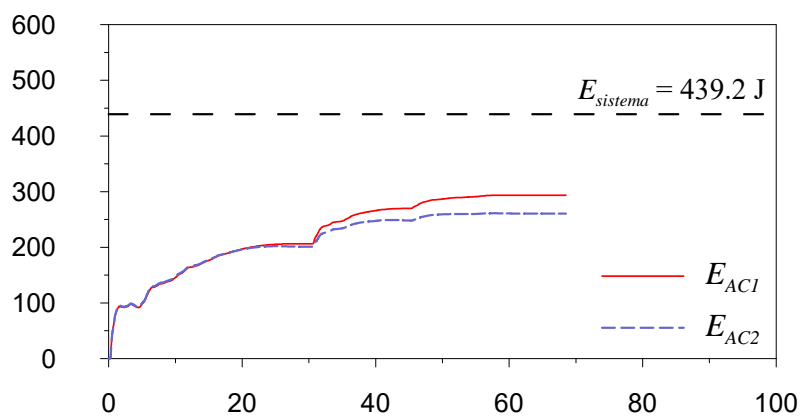

Tempo (ms)

Figura A76 - Sinais típicos de SPT instrumentado para o furo SP03, profundidade de $4 \mathrm{~m}$ e $H_{q}$ de $600 \mathrm{~mm}$. 

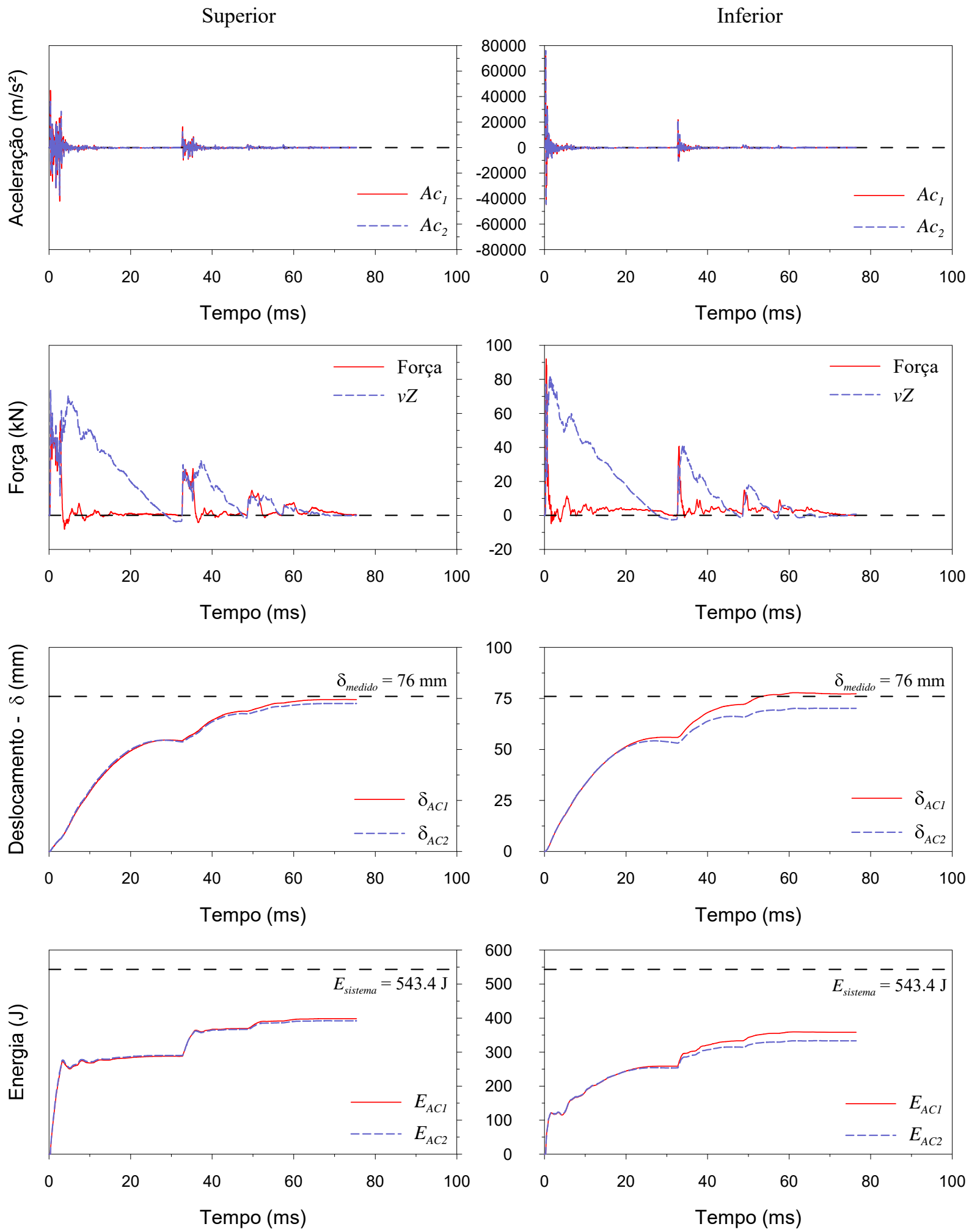

Figura A77 - Sinais típicos de SPT instrumentado para o furo SP03, profundidade de $4 \mathrm{~m}$ e $H_{q}$ de $750 \mathrm{~mm}$. 

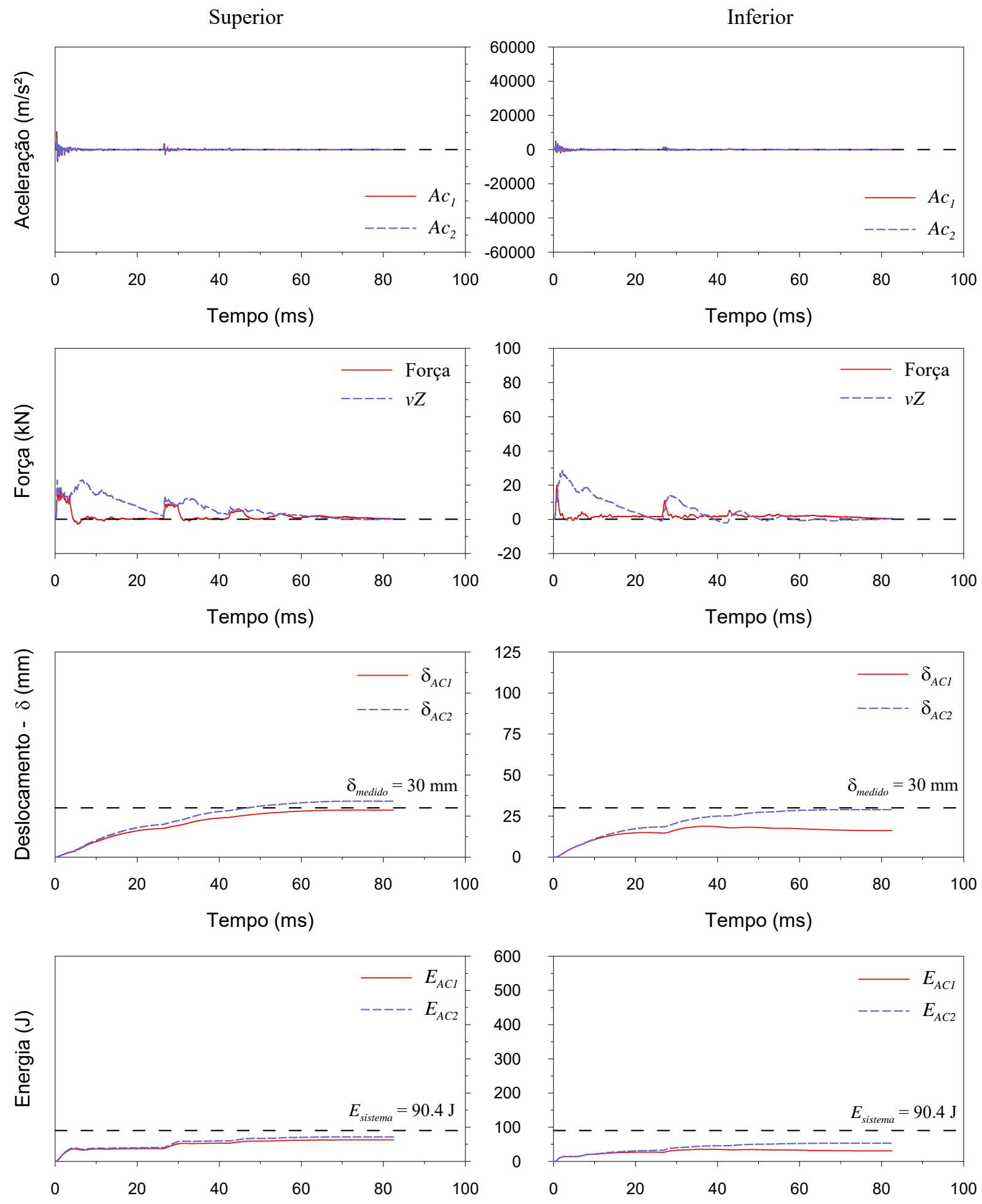

Tempo (ms)

Tempo (ms)

Figura A78 - Sinais típicos de SPT instrumentado para o furo SP03, profundidade de $5 \mathrm{~m}$ e $H_{q}$ de $100 \mathrm{~mm}$. 

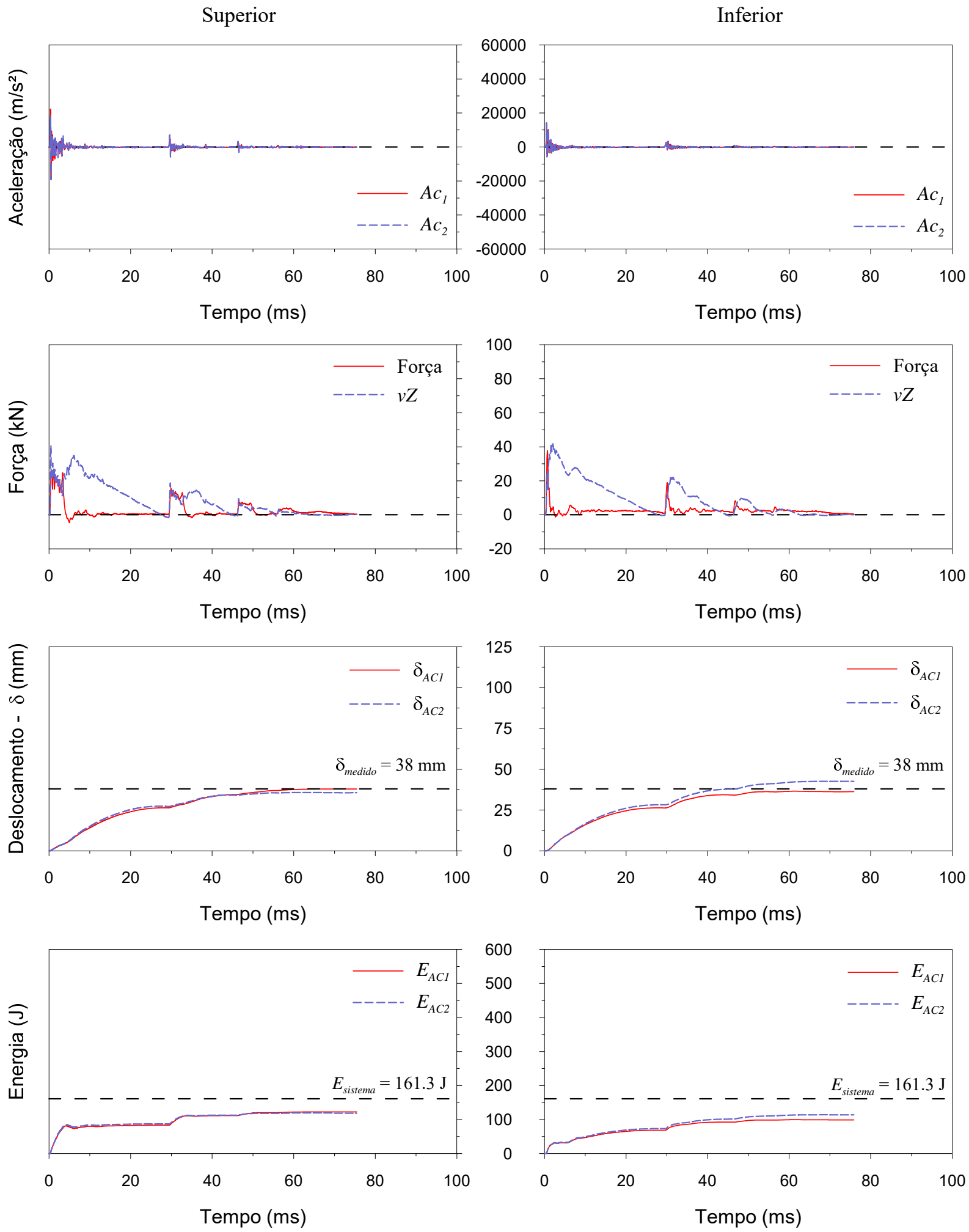

Figura A79 - Sinais típicos de SPT instrumentado para o furo SP03, profundidade de $5 \mathrm{~m}$ e $H_{q}$ de $200 \mathrm{~mm}$. 

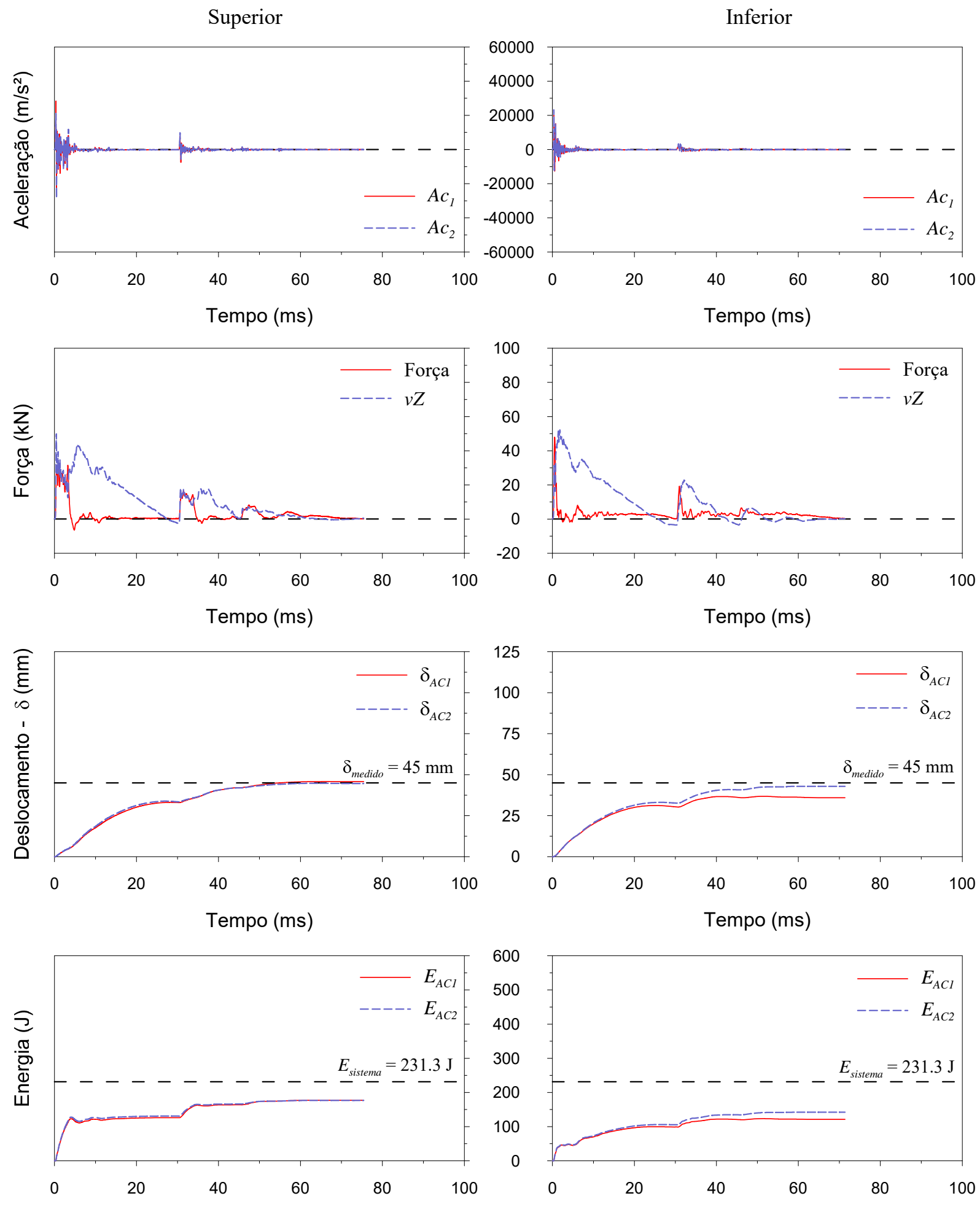

Tempo (ms)

Tempo (ms)

Figura A80 - Sinais típicos de SPT instrumentado para o furo SP03, profundidade de $5 \mathrm{~m}$ e $H_{q}$ de $300 \mathrm{~mm}$. 

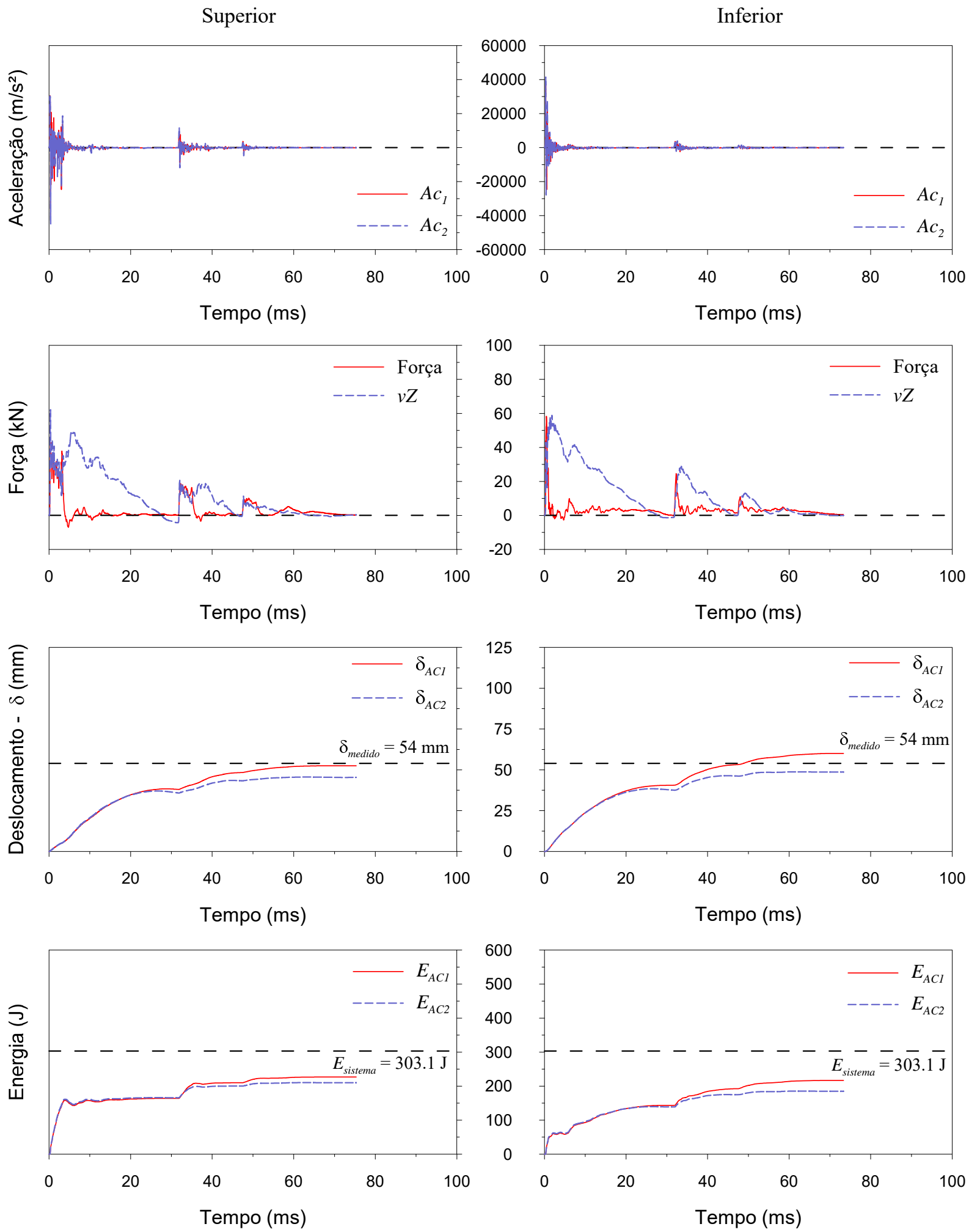

Figura A81 - Sinais típicos de SPT instrumentado para o furo SP03, profundidade de $5 \mathrm{~m}$ e $H_{q}$ de $400 \mathrm{~mm}$. 

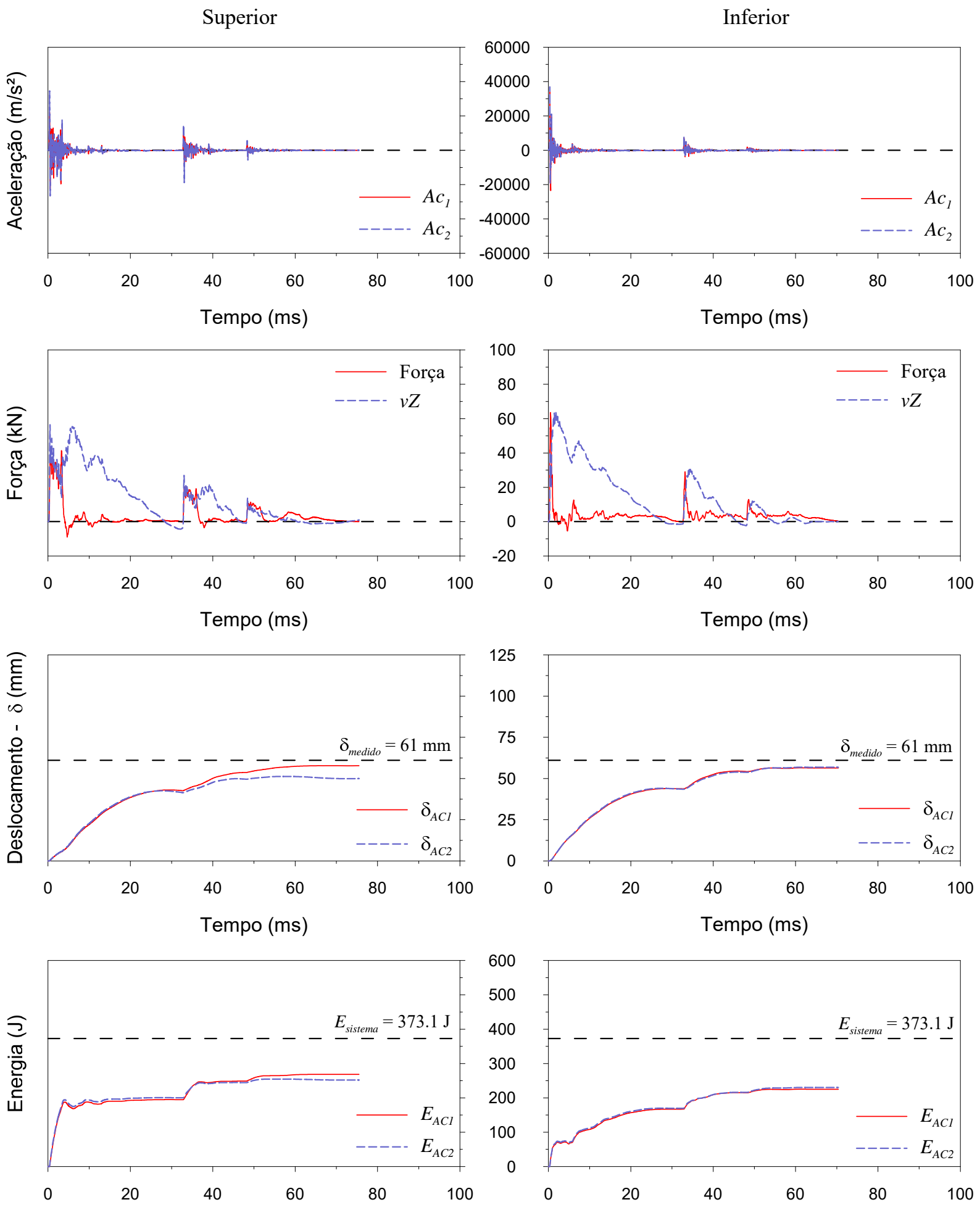

Tempo (ms)

Tempo (ms)

Figura A82 - Sinais típicos de SPT instrumentado para o furo SP03, profundidade de $5 \mathrm{~m}$ e $H_{q}$ de $500 \mathrm{~mm}$. 

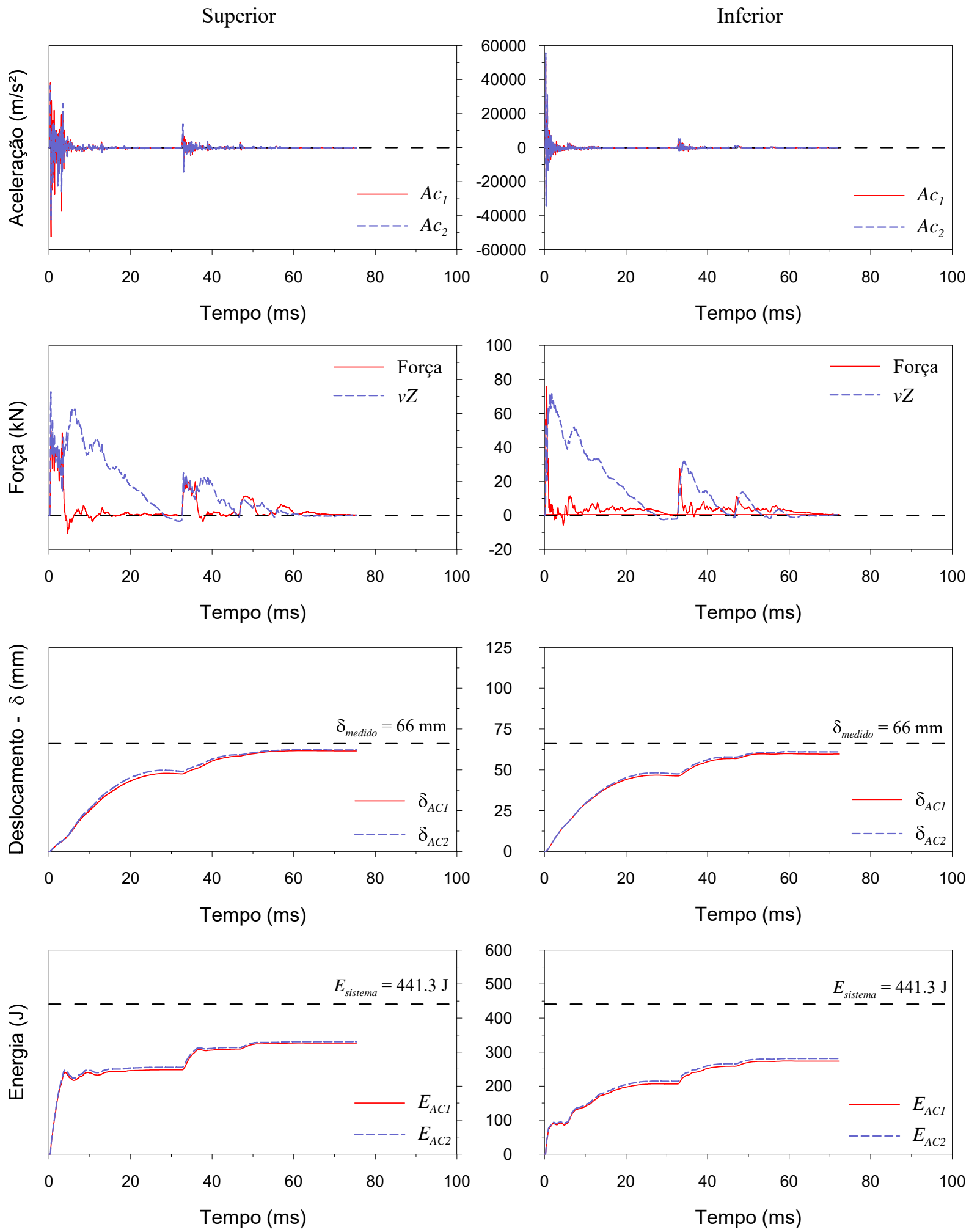

Figura A83 - Sinais típicos de SPT instrumentado para o furo SP03, profundidade de $5 \mathrm{~m}$ e $H_{q}$ de $600 \mathrm{~mm}$. 

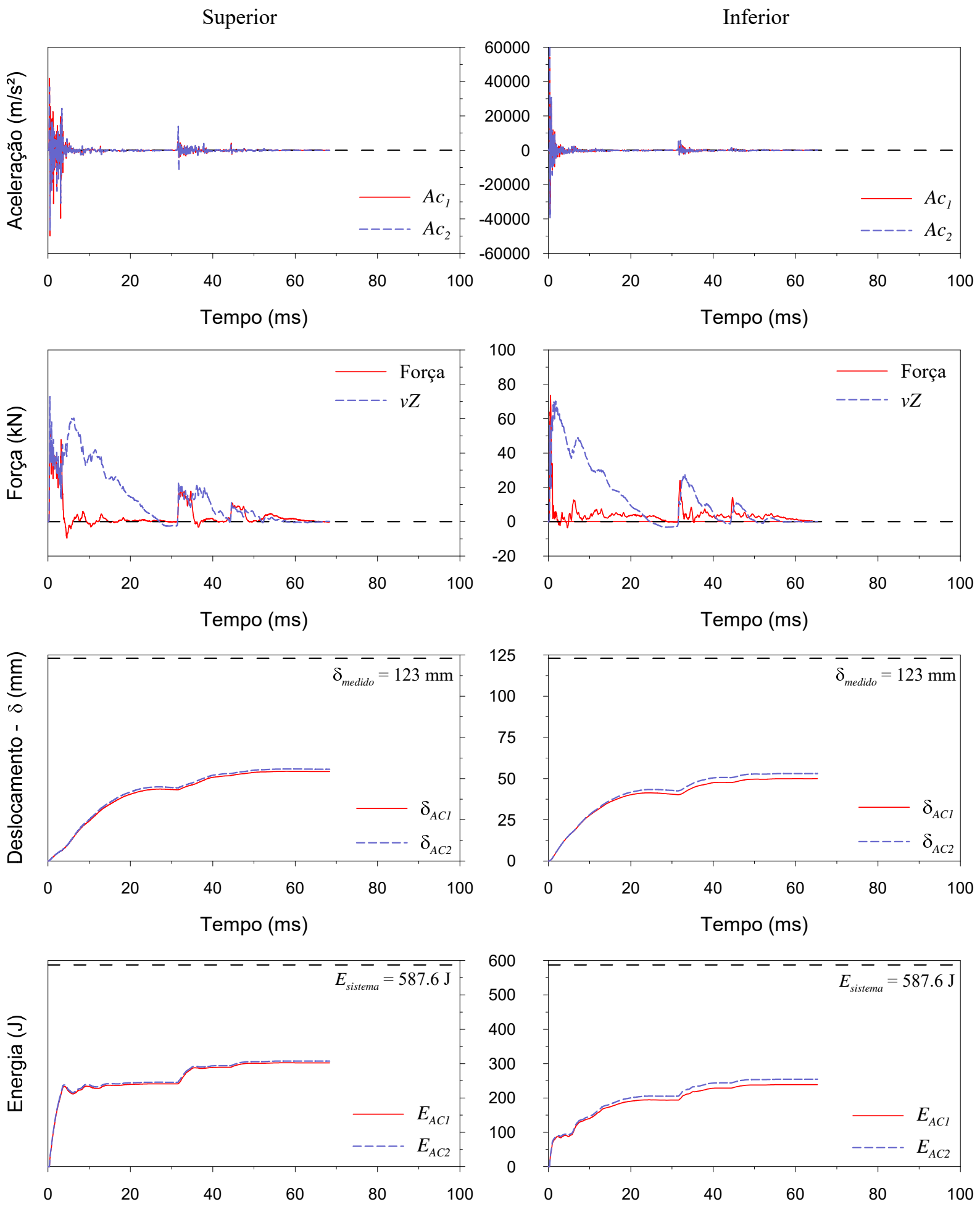

Tempo (ms)

Tempo (ms)

Figura A84 - Sinais típicos de SPT instrumentado para o furo SP03, profundidade de $5 \mathrm{~m}$ e $H_{q}$ de $750 \mathrm{~mm}$. 

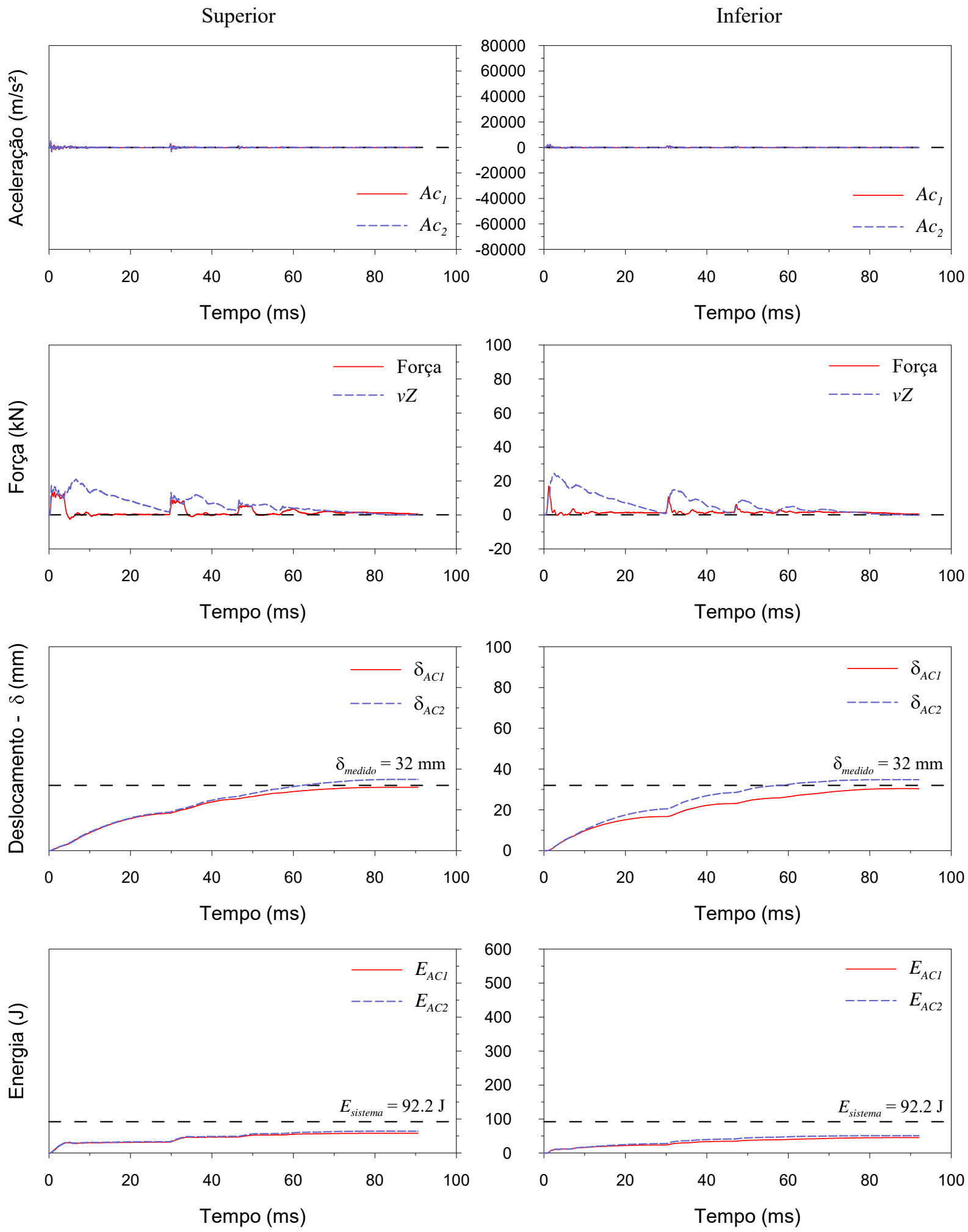

Figura A85 - Sinais típicos de SPT instrumentado para o furo SP03, profundidade de $6 \mathrm{~m}$ e $H_{q}$ de $100 \mathrm{~mm}$. 

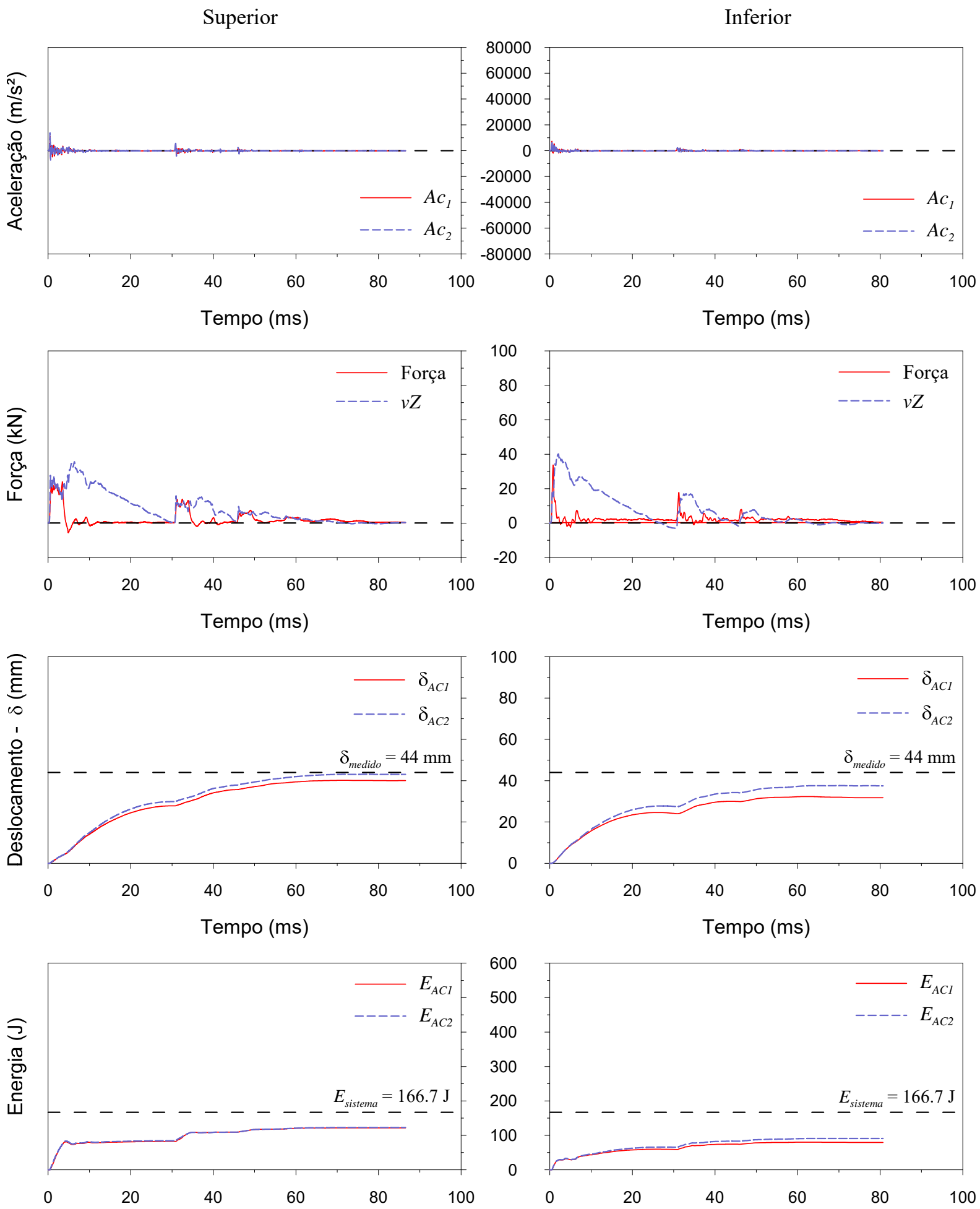

Tempo (ms)

Tempo (ms)

Figura A86 Sinais típicos de SPT instrumentado para o furo SP03, profundidade de $6 \mathrm{~m}$ e $H_{q}$ de $200 \mathrm{~mm}$. 

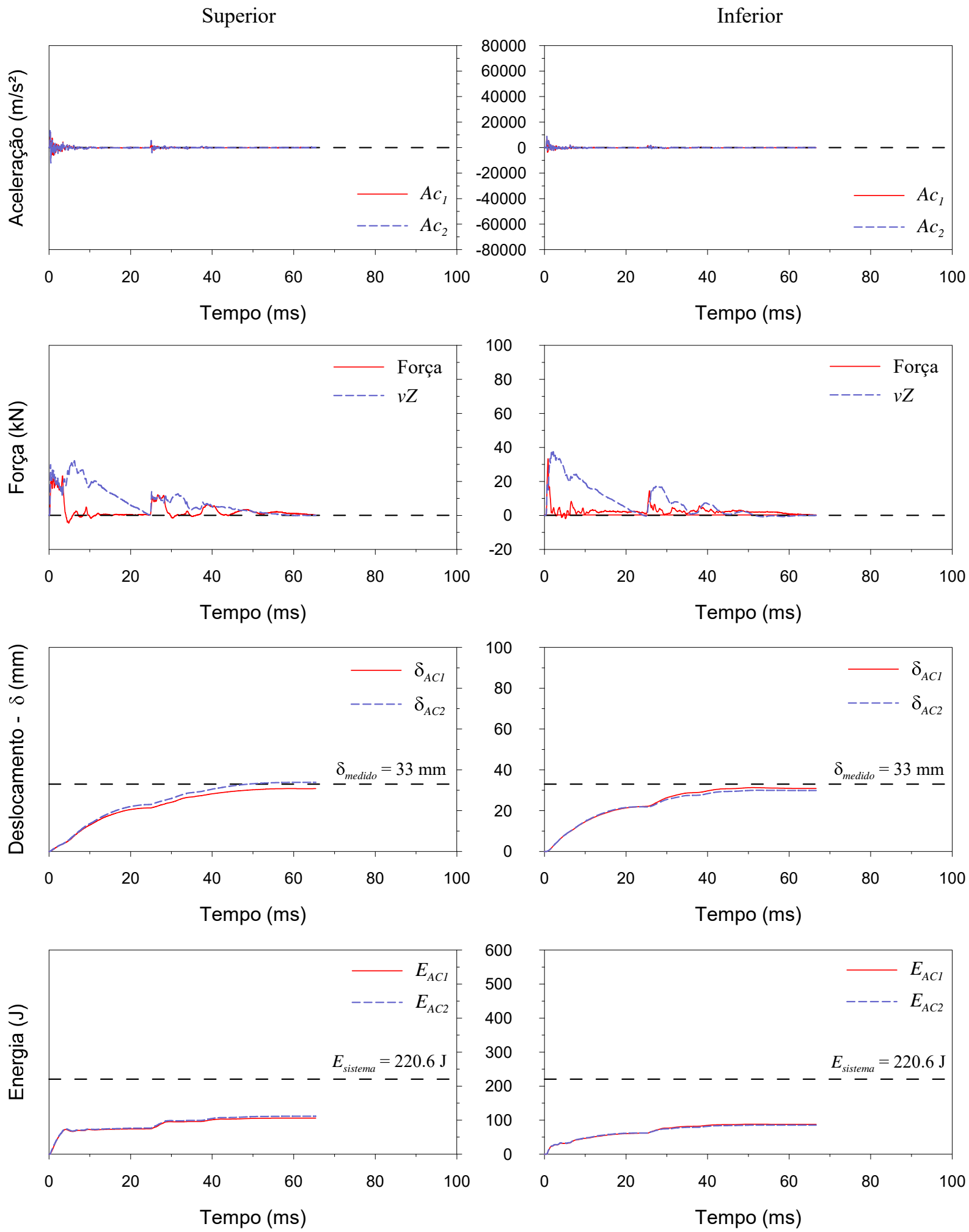

Figura A87 - Sinais típicos de SPT instrumentado para o furo SP03, profundidade de $6 \mathrm{~m}$ e $H_{q}$ de $300 \mathrm{~mm}$. 

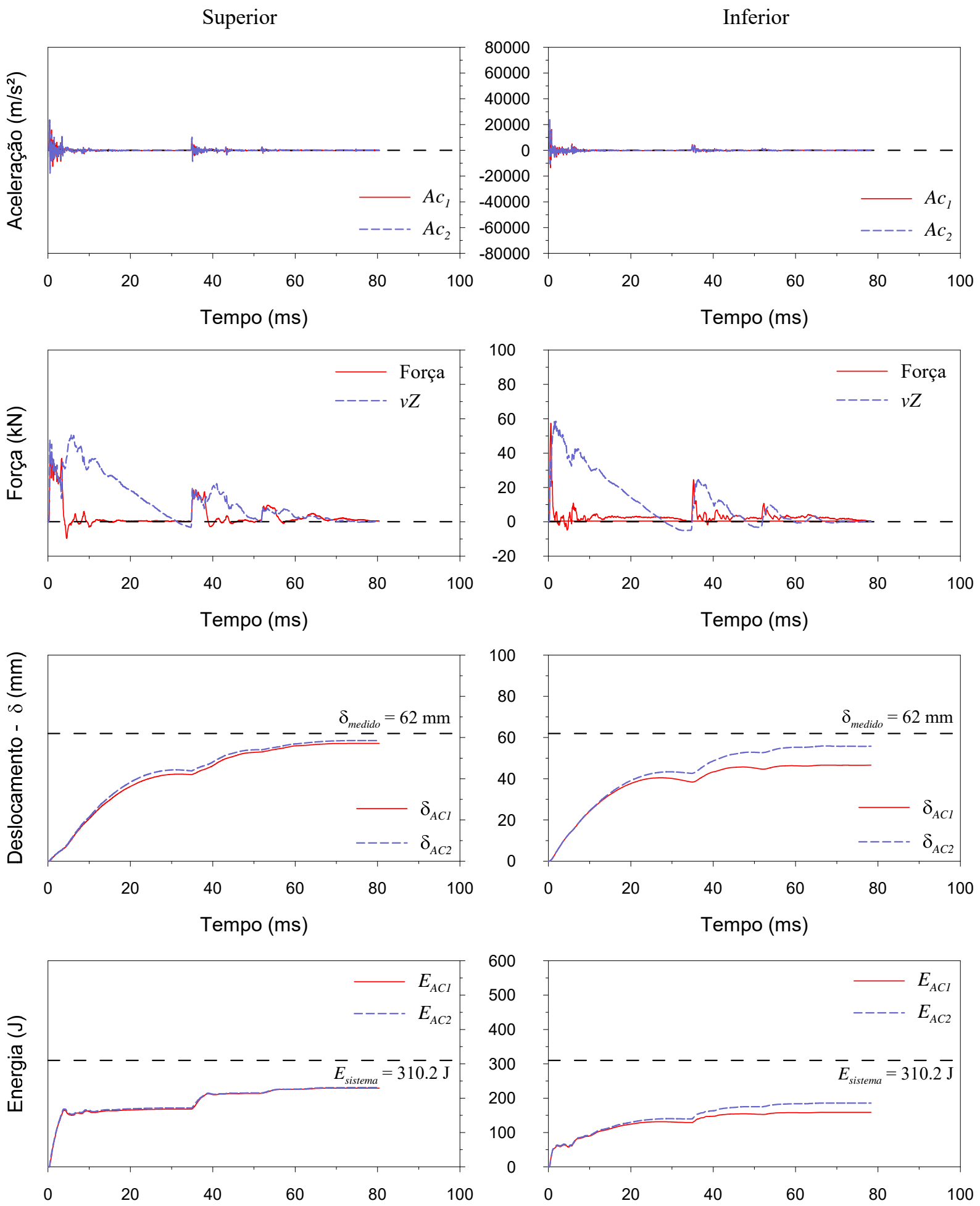

Tempo (ms)

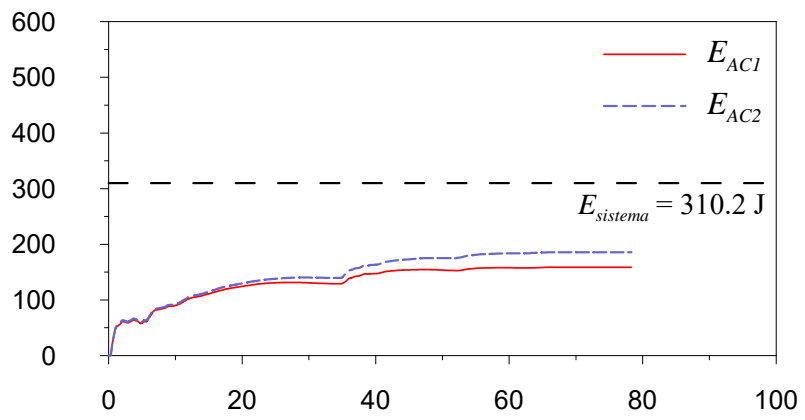

Tempo (ms)

Figura A88 - Sinais típicos de SPT instrumentado para o furo SP03, profundidade de $6 \mathrm{~m}$ e $H_{q}$ de $400 \mathrm{~mm}$. 

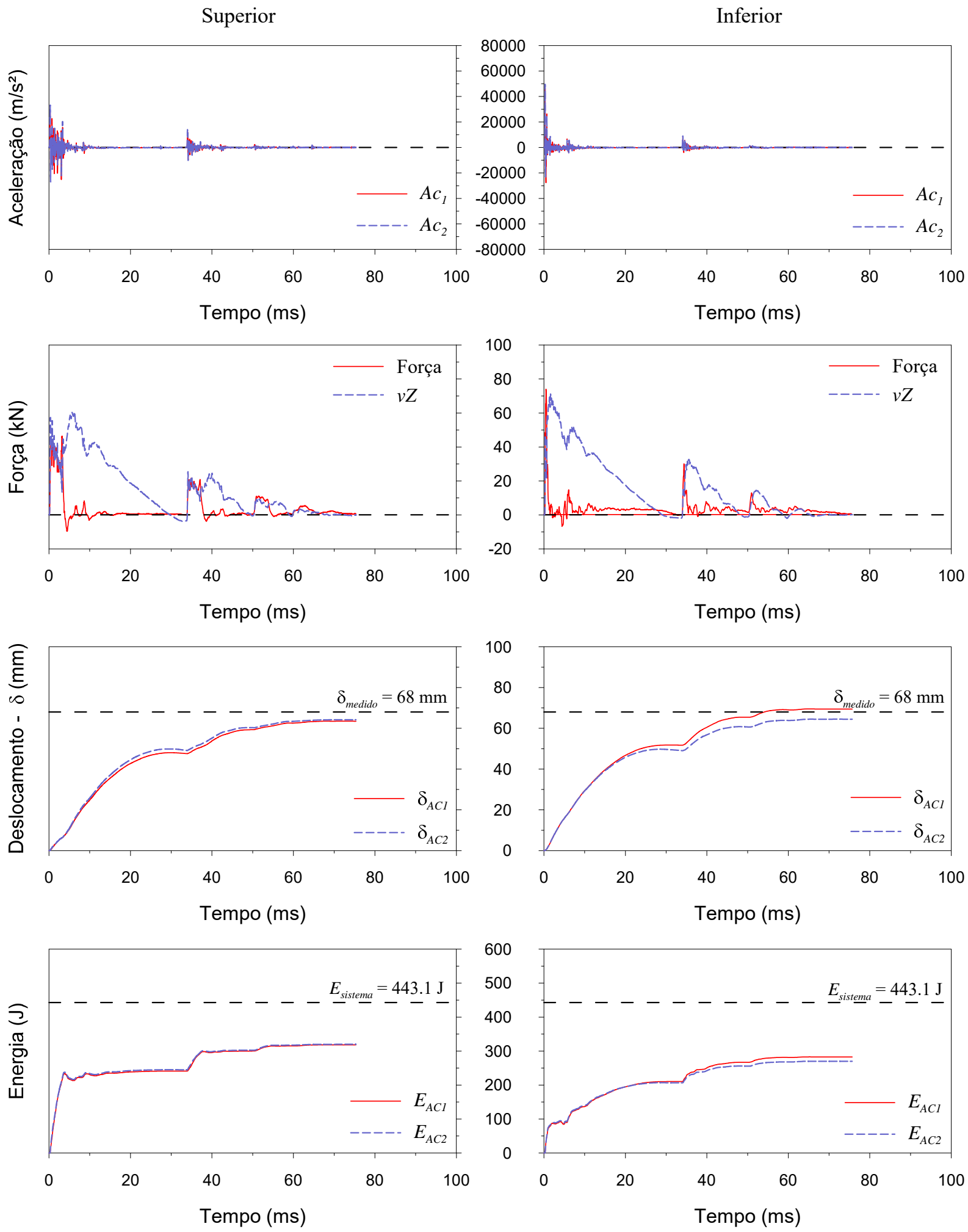

Figura A89 - Sinais típicos de SPT instrumentado para o furo SP03, profundidade de $6 \mathrm{~m}$ e $H_{q}$ de $600 \mathrm{~mm}$. 

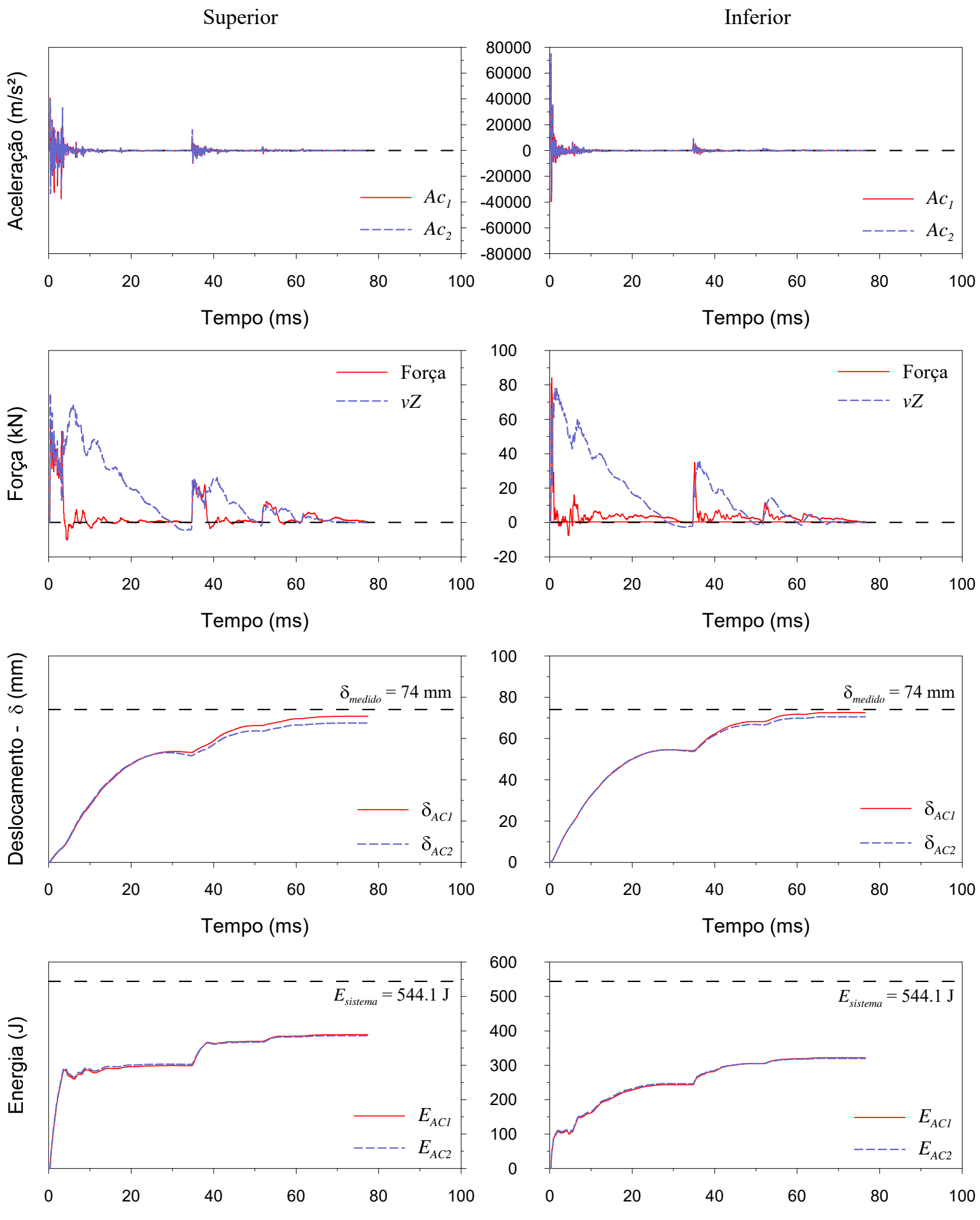

Tempo (ms)

Tempo (ms)

Figura A90 - Sinais típicos de SPT instrumentado para o furo SP03, profundidade de $6 \mathrm{~m}$ e $H_{q}$ de $750 \mathrm{~mm}$. 


\section{Dados de Deslocamentos}


Tabela A1 - Dados de deslocamento - furo SP01

\begin{tabular}{|c|c|c|c|c|c|c|c|c|c|c|}
\hline $\begin{array}{l}\text { profundidade de } \\
(\mathrm{m})\end{array}$ & $\begin{array}{c}\boldsymbol{H}_{q} \\
(\mathbf{m m})\end{array}$ & $\begin{array}{l}\begin{array}{l}\delta_{\text {medido }} \\
(\mathrm{mm})\end{array} \\
\end{array}$ & $\begin{array}{c}\delta_{A C l t o p o} \\
(\mathrm{~mm})\end{array}$ & $\begin{array}{c}\text { Erro- } A C 1 \\
(\%)\end{array}$ & $\begin{array}{c}\delta_{A C 2 t o p o} \\
(\mathrm{~mm})\end{array}$ & $\begin{array}{c}\text { Erro- } A C 2 \\
(\%)\end{array}$ & $\begin{array}{c}\delta_{A C 2 b a s e} \\
(\mathrm{~mm})\end{array}$ & $\begin{array}{c}\text { Erro- } A C 1 \\
(\%) \\
\end{array}$ & $\begin{array}{c}\delta_{A C 2 b a s e} \\
(\mathrm{~mm})\end{array}$ & $\begin{array}{c}\text { Erro- } A C 2 \\
(\%) \\
\end{array}$ \\
\hline \multirow{7}{*}{$(2)$} & 100 & 42 & 46.3 & 10.2 & 39.2 & 6.7 & 41.1 & 2.1 & 39.8 & 5.2 \\
\hline & 200 & 59 & 50.9 & 13.7 & 52.1 & 11.7 & 55.5 & 5.9 & 54.2 & 8.2 \\
\hline & 300 & 82 & 73.9 & 9.8 & 72.4 & 11.7 & 77.6 & 5.4 & 76.7 & 6.5 \\
\hline & 400 & 67 & 62.0 & 7.4 & 63.4 & 5.4 & 65.7 & 1.9 & 64.3 & 4.0 \\
\hline & 500 & 80 & 71.3 & 10.9 & 73.6 & 8.0 & 79.6 & 0.5 & 75.6 & 5.5 \\
\hline & 600 & 102 & 91.7 & 10.1 & 93.4 & 8.4 & 95.7 & 6.2 & 95.2 & 6.7 \\
\hline & 750 & 161 & 161.4 & 0.2 & 142.2 & 11.7 & 151.7 & 5.8 & 144.6 & 10.2 \\
\hline \multirow{7}{*}{$3-4$} & 100 & 19 & 15.9 & 16.1 & 16.7 & 11.9 & 17.0 & 10.7 & 16.7 & 12.3 \\
\hline & 200 & 31 & 28.8 & 7.1 & 35.4 & 14.1 & 30.1 & 3.0 & 30.4 & 1.9 \\
\hline & 300 & 43 & 42.2 & 1.9 & 43.2 & 0.6 & 45.2 & 5.1 & 43.9 & 2.0 \\
\hline & 400 & 61 & 51.4 & 15.7 & 55.0 & 9.9 & 52.9 & 13.2 & 54.0 & 11.5 \\
\hline & 500 & 60 & - & - & - & - & - & - & - & - \\
\hline & 600 & 69 & 65.7 & 4.8 & 69.2 & 0.2 & 66.1 & 4.2 & 68.4 & 0.9 \\
\hline & 750 & 90 & 81.7 & 9.2 & 83.5 & 7.2 & 83.7 & 7.0 & 84.4 & 6.2 \\
\hline \multirow{7}{*}{$4-5$} & 100 & 38 & 33.1 & 12.9 & 36.1 & 4.9 & 35.2 & 7.5 & 35.7 & 6.0 \\
\hline & 200 & 43 & 40.3 & 6.4 & 42.7 & 0.6 & 42.5 & 1.2 & 42.8 & 0.4 \\
\hline & 300 & 55 & 52.2 & 5.0 & 56.6 & 2.9 & 54.0 & 1.8 & 52.2 & 5.1 \\
\hline & 400 & 75 & 67.4 & 10.2 & 69.1 & 7.8 & 69.7 & 7.1 & 70.6 & 5.8 \\
\hline & 500 & 84 & 75.5 & 10.1 & 69.8 & 16.9 & 76.2 & 9.2 & 70.4 & 16.2 \\
\hline & 600 & 118 & 99.6 & 15.6 & 98.5 & 16.5 & 101.1 & 14.3 & 80.1 & 32.1 \\
\hline & 750 & 142 & 126.9 & 10.7 & 135.9 & 4.3 & 117.4 & 17.3 & 133.1 & 6.3 \\
\hline \multirow{7}{*}{$5-6$} & 100 & 29 & 27.4 & 5.5 & 29.3 & 1.0 & 28.6 & 1.3 & 27.1 & 6.5 \\
\hline & 200 & 41 & 39.8 & 2.9 & 40.8 & 0.6 & 40.8 & 0.4 & 35.4 & 13.7 \\
\hline & 300 & 53 & 45.8 & 13.5 & 45.1 & 15.0 & 48.3 & 8.9 & 47.9 & 9.6 \\
\hline & 400 & 66 & 59.8 & 9.4 & 62.0 & 6.0 & 59.3 & 10.2 & 58.2 & 11.8 \\
\hline & 500 & 77 & - & - & - & - & - & - & - & - \\
\hline & 600 & 92 & 84.1 & 8.5 & 79.2 & 13.9 & 90.8 & 1.3 & 88.4 & 3.9 \\
\hline & 750 & 106 & 98.7 & 6.8 & 106.0 & 0.0 & 90.9 & 14.2 & 100.5 & 5.2 \\
\hline \multirow{7}{*}{$6-7$} & 100 & 43 & 37.5 & 12.7 & 41.1 & 4.4 & 35.9 & 16.5 & 37.6 & 12.4 \\
\hline & 200 & 41 & 41.9 & 2.3 & 43.9 & 7.1 & 42.2 & 3.0 & 44.7 & 9.0 \\
\hline & 300 & 48 & 45.5 & 5.2 & 47.3 & 1.5 & 47.2 & 1.7 & 47.0 & 2.0 \\
\hline & 400 & 59 & 53.1 & 10.1 & 52.7 & 10.7 & 56.0 & 5.0 & 54.2 & 8.2 \\
\hline & 500 & 58 & 53.2 & 8.3 & 61.1 & 5.3 & 52.8 & 9.0 & 53.9 & 7.1 \\
\hline & 600 & 74 & 67.6 & 8.7 & 66.6 & 10.0 & 69.9 & 5.5 & 70.7 & 4.5 \\
\hline & 750 & 86 & 75.6 & 12.1 & 72.3 & 16.0 & 75.8 & 11.9 & 76.8 & 10.7 \\
\hline
\end{tabular}


Tabela A 2- Dados de deslocamento - furo SP02

\begin{tabular}{|c|c|c|c|c|c|c|c|c|c|c|}
\hline $\begin{array}{c}\text { profundidade de } \\
(\mathrm{m})\end{array}$ & $\begin{array}{c}H_{q} \\
(\mathbf{m m}) \\
\end{array}$ & $\begin{array}{l}\delta_{\text {medido }} \\
(\mathrm{mm})\end{array}$ & $\begin{array}{c}\delta_{A C l t o p o} \\
(\mathrm{~mm})\end{array}$ & $\begin{array}{c}\text { Erro- } A C 1 \\
(\%) \\
\end{array}$ & $\begin{array}{c}\delta_{A C 2 t o p o} \\
(\mathrm{~mm})\end{array}$ & $\begin{array}{c}\text { Erro- } A C 2 \\
(\%) \\
\end{array}$ & $\begin{array}{c}\delta_{A C 2 b a s e} \\
(\mathrm{~mm})\end{array}$ & $\begin{array}{c}\text { Erro- } A C 1 \\
(\%) \\
\end{array}$ & $\begin{array}{c}\delta_{A C 2 b a s e} \\
(\mathrm{~mm})\end{array}$ & $\begin{array}{c}\text { Erro- } A C 2 \\
(\%) \\
\end{array}$ \\
\hline \multirow{7}{*}{$2-3$} & 100 & 50 & 41.6 & 16.9 & 47.2 & 5.7 & 40.9 & 18.3 & 43.9 & 12.3 \\
\hline & 200 & 81 & 75.4 & 7.0 & 81.5 & 0.7 & 77.8 & 3.9 & 82.2 & 1.5 \\
\hline & 300 & 125 & 106.0 & 15.2 & 79.1 & 36.7 & 99.7 & 20.2 & 109.4 & 12.5 \\
\hline & 400 & 146 & 124.5 & 14.7 & 127.8 & 12.5 & 117.6 & 19.5 & 128.6 & 11.9 \\
\hline & 500 & 192 & 161.3 & 16.0 & 145.4 & 24.3 & 167.8 & 12.6 & 166.1 & 13.5 \\
\hline & 600 & 219 & 176.3 & 19.5 & 184.7 & 15.7 & 171.5 & 21.7 & 157.6 & 28.0 \\
\hline & 750 & - & - & - & - & - & - & - & - & - \\
\hline \multirow{7}{*}{$3-4$} & 100 & - & - & - & - & - & - & - & - & - \\
\hline & 200 & 49 & 48.9 & 0.2 & 55.2 & 12.6 & 51.7 & 5.4 & 51.2 & 4.6 \\
\hline & 300 & 83 & 70.1 & 15.5 & 59.7 & 28.1 & 68.4 & 17.5 & 71.8 & 13.5 \\
\hline & 400 & 91 & 78.8 & 13.4 & 75.0 & 17.5 & 82.5 & 9.3 & 62.7 & 31.1 \\
\hline & 500 & 92 & 83.2 & 9.6 & 83.1 & 9.7 & 79.4 & 13.7 & 79.0 & 14.2 \\
\hline & 600 & 92 & 82.1 & 10.8 & 90.7 & 1.5 & 81.5 & 11.4 & 84.8 & 7.8 \\
\hline & 750 & 100 & 94.4 & 5.6 & 95.2 & 4.8 & 92.8 & 7.2 & 94.8 & 5.2 \\
\hline \multirow{7}{*}{$5-6$} & 100 & 30 & 35.5 & 18.4 & 39.4 & 31.2 & 35.8 & 19.5 & 36.0 & 20.1 \\
\hline & 200 & 50 & 46.7 & 6.6 & 40.6 & 18.7 & 54.9 & 9.9 & 46.4 & 7.2 \\
\hline & 300 & 55 & 49.8 & 9.5 & 58.7 & 6.7 & 48.9 & 11.1 & 52.5 & 4.5 \\
\hline & 400 & 61 & 55.8 & 8.5 & 57.5 & 5.7 & 56.4 & 7.6 & 56.3 & 7.7 \\
\hline & 500 & 65 & 62.2 & 4.4 & 54.0 & 16.9 & 63.0 & 3.1 & 63.2 & 2.7 \\
\hline & 600 & 66 & 60.6 & 8.2 & 61.7 & 6.5 & 57.4 & 13.0 & 59.2 & 10.3 \\
\hline & 750 & 151 & 55.3 & 63.4 & 58.4 & 61.3 & 53.3 & 64.7 & 55.2 & 63.4 \\
\hline \multirow{7}{*}{$6-7$} & 100 & 43 & 34.0 & 20.9 & 33.2 & 22.9 & 17.5 & 59.2 & 34.8 & 19.1 \\
\hline & 200 & - & - & - & - & - & - & - & - & - \\
\hline & 300 & 47 & 43.8 & 6.9 & 45.9 & 2.4 & 42.0 & 10.5 & 42.2 & 10.2 \\
\hline & 400 & 51 & 48.7 & 4.5 & 40.5 & 20.6 & 50.0 & 2.0 & 48.8 & 4.3 \\
\hline & 500 & 66 & 60.7 & 8.0 & 49.1 & 25.6 & 55.3 & 16.2 & 59.6 & 9.7 \\
\hline & 600 & - & - & - & - & - & - & - & - & - \\
\hline & 750 & 42 & 41.4 & 1.4 & 37.5 & 10.7 & 40.5 & 3.5 & 41.0 & 2.5 \\
\hline
\end{tabular}


Tabela A3 - Dados de deslocamento - furo SP03

\begin{tabular}{|c|c|c|c|c|c|c|c|c|c|c|}
\hline $\begin{array}{l}\text { profundidade de } \\
(\mathbf{m})\end{array}$ & $\begin{array}{c}H_{q} \\
(\mathbf{m m})\end{array}$ & $\begin{array}{l}\delta_{\text {medido }} \\
(\mathrm{mm})\end{array}$ & $\begin{array}{c}\delta_{A C 1 t o p o} \\
(\mathrm{~mm})\end{array}$ & $\begin{array}{c}\text { Erro- } A C 1 \\
(\%)\end{array}$ & $\begin{array}{c}\delta_{A C 2 t o p o} \\
(\mathrm{~mm})\end{array}$ & $\begin{array}{c}\text { Erro- } A C 2 \\
(\%)\end{array}$ & $\begin{array}{c}\delta_{A C 2 b a s e} \\
(\mathrm{~mm})\end{array}$ & $\begin{array}{c}\text { Erro- } A C 1 \\
(\%)\end{array}$ & $\begin{array}{c}\delta_{A C 2 b a s e} \\
(\mathrm{~mm})\end{array}$ & $\begin{array}{c}\text { Erro- } A C 2 \\
(\%)\end{array}$ \\
\hline \multirow{7}{*}{$2-3$} & 100 & 75 & 62.3 & 17.0 & 82.1 & 9.4 & 52.0 & 30.7 & 66.6 & 11.2 \\
\hline & 200 & 80 & 68.3 & 14.7 & 78.4 & 1.9 & 54.1 & 32.4 & 70.7 & 11.6 \\
\hline & 300 & 114 & 100.8 & 11.6 & 111.8 & 1.9 & 82.6 & 27.5 & 99.9 & 12.3 \\
\hline & 400 & 144 & 124.6 & 13.4 & 109.3 & 24.1 & 112.9 & 21.6 & 132.4 & 8.1 \\
\hline & 500 & 195 & 166.4 & 14.6 & 164.7 & 15.6 & 127.2 & 34.8 & 170.2 & 12.7 \\
\hline & 600 & - & - & - & - & - & - & - & - & - \\
\hline & 750 & - & - & - & - & - & - & - & - & - \\
\hline \multirow{7}{*}{$3-4$} & 100 & 55 & 46.9 & 14.7 & 54.2 & 1.5 & 38.1 & 30.6 & 47.7 & 13.3 \\
\hline & 200 & 68 & 61.3 & 9.8 & 56.3 & 17.2 & 59.7 & 12.2 & 62.7 & 7.8 \\
\hline & 300 & 71 & 63.5 & 10.5 & 59.6 & 16.1 & 74.2 & 4.6 & 60.7 & 14.5 \\
\hline & 400 & 77 & 71.4 & 7.2 & 84.0 & 9.1 & 65.3 & 15.2 & 67.9 & 11.8 \\
\hline & 500 & 76 & 70.9 & 6.8 & 70.7 & 6.9 & 87.8 & 15.6 & 73.2 & 3.7 \\
\hline & 600 & 89 & 80.3 & 9.7 & 86.5 & 2.8 & 82.3 & 7.6 & 81.8 & 8.1 \\
\hline & 750 & 104 & 94.5 & 9.2 & 104.1 & 0.1 & 94.8 & 8.8 & 88.4 & 15.0 \\
\hline \multirow{7}{*}{$4-5$} & 100 & 33 & 30.6 & 7.4 & 37.8 & 14.5 & 25.7 & 22.1 & 32.3 & 2.0 \\
\hline & 200 & 45 & 40.6 & 9.8 & 44.3 & 1.6 & 32.7 & 27.3 & 40.0 & 11.2 \\
\hline & 300 & 47 & 43.2 & 8.0 & 44.5 & 5.4 & 40.0 & 14.9 & 41.9 & 10.8 \\
\hline & 400 & 52 & 50.5 & 2.9 & 53.8 & 3.5 & 45.9 & 11.7 & 43.8 & 15.8 \\
\hline & 500 & 62 & 58.0 & 6.5 & 62.7 & 1.1 & 60.0 & 3.2 & 58.9 & 5.0 \\
\hline & 600 & 66 & 62.1 & 5.9 & 61.8 & 6.4 & 66.3 & 0.5 & 57.5 & 12.9 \\
\hline & 750 & 76 & 74.4 & 2.0 & 72.5 & 4.6 & 77.8 & 2.4 & 70.2 & 7.6 \\
\hline \multirow{7}{*}{$5-6$} & 100 & 30 & 28.7 & 4.3 & 34.1 & 13.5 & 18.8 & 37.4 & 29.0 & 3.4 \\
\hline & 200 & 38 & 37.9 & 0.1 & 35.7 & 5.9 & 36.6 & 3.8 & 42.6 & 12.2 \\
\hline & 300 & 45 & 45.8 & 1.9 & 44.8 & 0.5 & 36.9 & 18.1 & 42.9 & 4.7 \\
\hline & 400 & 54 & 52.4 & 2.9 & 45.6 & 15.5 & 60.1 & 11.3 & 48.8 & 9.7 \\
\hline & 500 & 61 & 57.8 & 5.3 & 51.3 & 15.9 & 56.5 & 7.4 & 56.8 & 6.8 \\
\hline & 600 & 66 & 61.7 & 6.5 & 62.3 & 5.6 & 60.0 & 9.2 & 61.1 & 7.5 \\
\hline & 750 & 123 & 54.4 & 55.8 & 55.9 & 54.6 & 50.0 & 59.4 & 53.0 & 56.9 \\
\hline \multirow{7}{*}{$6-7$} & 100 & 32 & 31.0 & 3.0 & 34.9 & 9.2 & 30.5 & 4.8 & 34.8 & 8.7 \\
\hline & 200 & 44 & 40.2 & 8.7 & 43.1 & 2.1 & 32.3 & 26.5 & 37.6 & 14.4 \\
\hline & 300 & 33 & 30.8 & 6.7 & 33.9 & 2.7 & 31.3 & 5.2 & 30.0 & 9.0 \\
\hline & 400 & 62 & 57.2 & 7.8 & 58.5 & 5.6 & 46.6 & 24.8 & 55.9 & 9.9 \\
\hline & 500 & - & - & - & - & - & - & - & - & - \\
\hline & 600 & 68 & 63.5 & 6.6 & 64.2 & 5.6 & 69.5 & 2.3 & 64.5 & 5.2 \\
\hline & 750 & 74 & 70.8 & 4.4 & 67.5 & 8.8 & 72.6 & 1.9 & 70.5 & 4.7 \\
\hline
\end{tabular}


Dados de Energia e Eficiência 
Tabela A4 - Energias e Eficiências - furo SP01

\begin{tabular}{|c|c|c|c|c|c|c|c|c|c|c|c|c|c|c|c|}
\hline $\begin{array}{l}\text { profundidade de } \\
(\mathrm{m})\end{array}$ & $\begin{array}{l}L_{h} \\
(\mathbf{m})\end{array}$ & $\begin{array}{c}H_{q} \\
(\mathbf{m m})\end{array}$ & $\begin{array}{l}\delta_{\text {medido }} \\
(\mathrm{mm})\end{array}$ & $\begin{array}{c}E P_{T} \\
(J)\end{array}$ & $\begin{array}{c}E P_{\text {sistema }} \\
(\mathbf{J})\end{array}$ & $\begin{array}{c}E_{\text {topol }} \\
(\mathrm{J})\end{array}$ & $\begin{array}{c}E_{\text {topo2 }} \\
(\mathrm{J})\end{array}$ & $\begin{array}{c}E_{\text {basel }} \\
(\mathbf{J})\end{array}$ & $\begin{array}{c}E_{\text {base } 2} \\
(\mathbf{J})\end{array}$ & $\begin{array}{c}\eta_{\text {topol }} \\
(\%)\end{array}$ & $\begin{array}{c}\eta_{\text {topo } 2} \\
(\%)\end{array}$ & $\begin{array}{c}\eta_{\text {base } 1} \\
(\%)\end{array}$ & $\begin{array}{c}\eta_{\text {base } 2} \\
(\%)\end{array}$ & $\begin{array}{c}\text { Erro } \\
(\%) \eta_{\text {topo }}\end{array}$ & $\begin{array}{c}\text { Erro } \\
(\%) \eta_{\text {base }}\end{array}$ \\
\hline \multirow{7}{*}{$2-3$} & \multirow{7}{*}{2.7} & 100 & 42 & 63.8 & 95.7 & 60.1 & 61.3 & 52.4 & 57.6 & 62.8 & 64.1 & 54.8 & 60.1 & 8.9 & 1.9 \\
\hline & & 200 & 59 & 127.5 & 172.4 & 112.1 & 113.7 & 90.8 & 97.8 & 65.0 & 65.9 & 52.7 & 56.7 & 7.1 & 1.4 \\
\hline & & 300 & 82 & 191.3 & 253.6 & 185.1 & 187.3 & 159.5 & 169.2 & 73.0 & 73.9 & 62.9 & 66.7 & 5.7 & 1.2 \\
\hline & & 400 & 67 & 255.1 & 306.0 & 228.0 & 229.9 & 192.7 & 200.9 & 74.5 & 75.1 & 63.0 & 65.7 & 4.1 & 0.8 \\
\hline & & 500 & 80 & 318.8 & 379.7 & 281.3 & 283.5 & 253.1 & 263.0 & 74.1 & 74.7 & 66.7 & 69.3 & 3.8 & 0.8 \\
\hline & & 600 & 102 & 382.6 & 460.2 & 333.5 & 336.3 & 292.0 & 304.0 & 72.5 & 73.1 & 63.5 & 66.1 & 3.9 & 0.8 \\
\hline & & 750 & 161 & 478.2 & 600.7 & 484.9 & 489.8 & 389.6 & 408.5 & 80.7 & 81.5 & 64.9 & 68.0 & 4.6 & 1.0 \\
\hline \multirow{7}{*}{$3-4$} & \multirow{7}{*}{4.7} & 100 & 19 & 63.8 & 79.4 & 49.4 & 49.9 & 45.7 & 48.9 & 62.2 & 62.8 & 57.5 & 61.6 & 6.6 & 1.0 \\
\hline & & 200 & 31 & 127.5 & 153.1 & 96.9 & 97.7 & 95.5 & 101.3 & 63.3 & 63.8 & 62.4 & 66.2 & 5.7 & 0.9 \\
\hline & & 300 & 43 & 191.3 & 226.8 & 168.5 & 169.8 & 154.6 & 162.9 & 74.3 & 74.9 & 68.2 & 71.8 & 5.1 & 0.8 \\
\hline & & 400 & 61 & 255.1 & 305.4 & 225.1 & 226.7 & 201.6 & 211.9 & 73.7 & 74.2 & 66.0 & 69.4 & 4.8 & 0.7 \\
\hline & & 500 & 60 & 318.8 & - & - & - & - & - & - & - & - & - & - & - \\
\hline & & 600 & 69 & 382.6 & 439.5 & 329.3 & 331.3 & 289.1 & 302.1 & 74.9 & 75.4 & 65.8 & 68.7 & 4.3 & 0.6 \\
\hline & & 750 & 90 & 478.2 & 552.5 & 401.0 & 403.5 & 357.5 & 373.5 & 72.6 & 73.0 & 64.7 & 67.6 & 4.3 & 0.6 \\
\hline \multirow{7}{*}{$4-5$} & \multirow{7}{*}{4.7} & 100 & 38 & 63.8 & 95.1 & 67.8 & 68.9 & 60.8 & 67.6 & 71.3 & 72.5 & 63.9 & 71.1 & 10.1 & 1.6 \\
\hline & & 200 & 43 & 127.5 & 163.0 & 120.1 & 121.4 & 109.4 & 117.5 & 73.7 & 74.5 & 67.1 & 72.1 & 7.0 & 1.1 \\
\hline & & 300 & 55 & 191.3 & 236.7 & 181.2 & 182.9 & 160.7 & 171.0 & 76.6 & 77.3 & 67.9 & 72.3 & 6.0 & 0.9 \\
\hline & & 400 & 75 & 255.1 & 316.9 & 217.3 & 219.4 & 206.7 & 220.2 & 68.6 & 69.2 & 65.2 & 69.5 & 6.1 & 0.9 \\
\hline & & 500 & 84 & 318.8 & 388.1 & 270.0 & 272.2 & 254.3 & 268.8 & 69.6 & 70.1 & 65.5 & 69.3 & 5.4 & 0.8 \\
\hline & & 600 & 118 & 382.6 & 479.9 & 319.1 & 322.1 & 291.3 & 310.6 & 66.5 & 67.1 & 60.7 & 64.7 & 6.2 & 0.9 \\
\hline & & 750 & 142 & 478.2 & 595.4 & 425.0 & 429.1 & 363.3 & 388.7 & 71.4 & 72.1 & 61.0 & 65.3 & 6.5 & 1.0 \\
\hline \multirow{7}{*}{$5-6$} & \multirow{7}{*}{5.7} & 100 & 29 & 63.8 & 88.6 & 59.6 & 60.4 & 50.3 & 56.8 & 67.2 & 68.2 & 56.8 & 64.0 & 11.3 & 1.5 \\
\hline & & 200 & 41 & 127.5 & 162.7 & 124.0 & 125.2 & 107.2 & 116.3 & 76.2 & 77.0 & 65.9 & 71.5 & 7.9 & 1.0 \\
\hline & & 300 & 53 & 191.3 & 236.7 & 163.9 & 165.3 & 151.7 & 162.5 & 69.2 & 69.8 & 64.1 & 68.6 & 6.7 & 0.8 \\
\hline & & 400 & 66 & 255.1 & 311.6 & 235.7 & 237.5 & 198.6 & 211.9 & 75.6 & 76.2 & 63.7 & 68.0 & 6.3 & 0.8 \\
\hline & & 500 & 77 & 318.8 & - & - & - & - & - & - & - & - & - & - & - \\
\hline & & 600 & 92 & 382.6 & 461.5 & 345.7 & 348.2 & 323.7 & 344.1 & 74.9 & 75.5 & 70.2 & 74.6 & 5.9 & 0.7 \\
\hline & & 750 & 106 & 478.2 & 569.1 & 434.9 & 438.1 & 366.7 & 389.2 & 76.4 & 77.0 & 64.4 & 68.4 & 5.8 & 0.7 \\
\hline \multirow{7}{*}{$6-7$} & \multirow{7}{*}{6.7} & 100 & 43 & 63.8 & 102.0 & 71.0 & 72.2 & 56.5 & 66.3 & 69.6 & 70.8 & 55.4 & 65.0 & 14.8 & 1.7 \\
\hline & & 200 & 41 & 127.5 & 164.0 & 115.5 & 116.8 & 98.7 & 109.6 & 70.4 & 71.2 & 60.2 & 66.8 & 10.0 & 1.1 \\
\hline & & 300 & 48 & 191.3 & 234.0 & 166.8 & 168.2 & 144.5 & 156.8 & 71.3 & 71.9 & 61.8 & 67.0 & 7.8 & 0.8 \\
\hline & & 400 & 59 & 255.1 & 307.5 & 217.4 & 219.0 & 196.5 & 211.1 & 70.7 & 71.2 & 63.9 & 68.6 & 6.9 & 0.7 \\
\hline & & 500 & 58 & 318.8 & 370.4 & 248.1 & 250.0 & 210.5 & 224.5 & 67.0 & 67.5 & 56.8 & 60.6 & 6.2 & 0.7 \\
\hline & & 600 & 74 & 382.6 & 448.4 & 324.2 & 326.2 & 295.4 & 313.8 & 72.3 & 72.7 & 65.9 & 70.0 & 5.9 & 0.6 \\
\hline & & 750 & 86 & 478.2 & 554.7 & 392.8 & 395.1 & 363.7 & 383.7 & 70.8 & 71.2 & 65.6 & 69.2 & 5.2 & 0.6 \\
\hline
\end{tabular}


Tabela A5- Energias e Eficiências - furo SP02

\begin{tabular}{|c|c|c|c|c|c|c|c|c|c|c|c|c|c|c|c|}
\hline $\begin{array}{l}\text { profundidade de } \\
\text { (m) }\end{array}$ & $\begin{array}{l}L_{h} \\
(\mathbf{m})\end{array}$ & $\begin{array}{c}\boldsymbol{H}_{q} \\
(\mathbf{m m})\end{array}$ & $\begin{array}{l}\delta_{\text {medido }} \\
(\mathbf{m m})\end{array}$ & $\begin{array}{l}E P_{T} \\
(J)\end{array}$ & $\begin{array}{c}E P_{\text {sistema }} \\
\text { (J) }\end{array}$ & $\begin{array}{c}E_{\text {topol }} \\
(\mathbf{J})\end{array}$ & $\begin{array}{c}E_{\text {topo2 }} \\
(\mathbf{J})\end{array}$ & $\begin{array}{c}E_{\text {base1 }} \\
(\mathbf{J})\end{array}$ & $\begin{array}{c}E_{\text {base } 2} \\
(\mathbf{J})\end{array}$ & $\begin{array}{c}\eta_{\text {topol }} \\
(\%)\end{array}$ & $\begin{array}{c}\eta_{\text {topo } 2} \\
(\%)\end{array}$ & $\begin{array}{c}\eta_{\text {base } 1} \\
(\%)\end{array}$ & $\begin{array}{c}\eta_{\text {base } 2} \\
(\%)\end{array}$ & $\begin{array}{c}\text { Erro } \\
(\%) \eta_{\text {topo }}\end{array}$ & $\begin{array}{c}\text { Erro } \\
(\%) \eta_{\text {base }}\end{array}$ \\
\hline \multirow{7}{*}{$2-3$} & \multirow{7}{*}{2.7} & 100 & 50 & 63.8 & 101.8 & 76.2 & 77.6 & 67.6 & 73.0 & 74.9 & 76.2 & 66.4 & 71.8 & 7.5 & 1.8 \\
\hline & & 200 & 81 & 127.5 & 189.1 & 143.9 & 146.3 & 137.4 & 147.7 & 76.1 & 77.4 & 72.6 & 78.1 & 7.0 & 1.7 \\
\hline & & 300 & 125 & 191.3 & 286.3 & 202.5 & 205.7 & 193.1 & 206.7 & 70.7 & 71.8 & 67.4 & 72.2 & 6.6 & 1.5 \\
\hline & & 400 & 146 & 255.1 & 366.1 & 249.5 & 253.4 & 231.2 & 247.3 & 68.2 & 69.2 & 63.2 & 67.6 & 6.5 & 1.5 \\
\hline & & 500 & 192 & 318.8 & 464.8 & 318.1 & 323.0 & 308.2 & 329.2 & 68.4 & 69.5 & 66.3 & 70.8 & 6.4 & 1.5 \\
\hline & & 600 & 219 & 382.6 & 594.1 & 379.6 & 385.2 & 324.4 & 345.9 & 69.1 & 70.1 & 59.1 & 63.0 & 6.2 & 1.4 \\
\hline & & 750 & - & 478.2 & - & - & - & - & - & - & - & - & - & - & - \\
\hline \multirow{7}{*}{$3-4$} & \multirow{7}{*}{4.7} & 100 & - & 63.8 & - & - & - & - & - & - & - & - & - & - & - \\
\hline & & 200 & 49 & 127.5 & 168.0 & 125.8 & 127.2 & 65.8 & 71.6 & 74.9 & 75.8 & 39.2 & 42.7 & 8.1 & 1.2 \\
\hline & & 300 & 83 & 191.3 & 259.8 & 196.0 & 198.1 & 175.8 & 189.5 & 75.4 & 76.3 & 67.7 & 72.9 & 7.2 & 1.1 \\
\hline & & 400 & 91 & 255.1 & 330.1 & 230.0 & 232.4 & 206.2 & 221.8 & 69.7 & 70.4 & 62.4 & 67.2 & 7.1 & 1.0 \\
\hline & & 500 & 92 & 318.8 & 394.7 & 282.6 & 285.1 & 238.0 & 253.1 & 71.6 & 72.2 & 60.3 & 64.1 & 6.0 & 0.9 \\
\hline & & 600 & 92 & 382.6 & 458.5 & 353.5 & 356.2 & 301.7 & 317.8 & 77.1 & 77.7 & 65.8 & 69.3 & 5.1 & 0.8 \\
\hline & & 750 & 100 & 478.2 & 560.7 & 422.5 & 425.3 & 380.7 & 398.7 & 75.3 & 75.9 & 67.9 & 71.1 & 4.5 & 0.7 \\
\hline \multirow{7}{*}{$5-6$} & \multirow{7}{*}{5.7} & 100 & 30 & 63.8 & 89.5 & 66.1 & 67.2 & 59.8 & 67.9 & 73.9 & 75.1 & 66.9 & 75.8 & 11.8 & 1.6 \\
\hline & & 200 & 50 & 127.5 & 170.4 & 124.9 & 126.3 & 112.6 & 123.0 & 73.3 & 74.2 & 66.1 & 72.2 & 8.4 & 1.1 \\
\hline & & 300 & 55 & 191.3 & 238.4 & 202.5 & 204.2 & 166.1 & 177.9 & 84.9 & 85.7 & 69.7 & 74.6 & 6.6 & 0.9 \\
\hline & & 400 & 61 & 255.1 & 307.3 & 217.5 & 219.3 & 190.7 & 203.3 & 70.8 & 71.3 & 62.0 & 66.2 & 6.2 & 0.8 \\
\hline & & 500 & 65 & 318.8 & 374.5 & 244.6 & 246.4 & 221.1 & 235.3 & 65.3 & 65.8 & 59.0 & 62.8 & 6.0 & 0.8 \\
\hline & & 600 & 66 & 382.6 & 439.2 & 278.3 & 280.2 & 239.1 & 252.4 & 63.4 & 63.8 & 54.5 & 57.5 & 5.3 & 0.7 \\
\hline & & 750 & 151 & 478.2 & 607.7 & 288.4 & 290.1 & 243.5 & 255.9 & 47.5 & 47.7 & 40.1 & 42.1 & 4.8 & 0.6 \\
\hline \multirow{7}{*}{$6-7$} & \multirow{7}{*}{6.7} & 100 & 43 & 63.8 & 102.0 & 60.8 & 61.8 & 55.7 & 64.6 & 59.6 & 60.6 & 54.6 & 63.3 & 13.8 & 1.7 \\
\hline & & 200 & - & 127.5 & - & - & - & - & - & - & - & - & - & - & - \\
\hline & & 300 & 47 & 191.3 & 233.1 & 177.4 & 178.8 & 143.7 & 154.5 & 76.1 & 76.7 & 61.6 & 66.3 & 7.0 & 0.8 \\
\hline & & 400 & 51 & 255.1 & 300.4 & 205.5 & 206.9 & 182.3 & 195.2 & 68.4 & 68.9 & 60.7 & 65.0 & 6.6 & 0.7 \\
\hline & & 500 & 66 & 318.8 & 377.5 & 286.3 & 288.1 & 236.9 & 252.4 & 75.8 & 76.3 & 62.7 & 66.8 & 6.1 & 0.6 \\
\hline & & 600 & - & 382.6 & - & - & - & - & - & - & - & - & - & - & - \\
\hline & & 750 & 42 & 478.2 & 515.6 & 227.7 & 229.0 & 207.1 & 217.8 & 44.2 & 44.4 & 40.2 & 42.2 & 4.9 & 0.5 \\
\hline
\end{tabular}


Tabela A6 - Energias e Eficiências - furo SP03

\begin{tabular}{|c|c|c|c|c|c|c|c|c|c|c|c|c|c|c|c|}
\hline $\begin{array}{l}\text { profundidade de } \\
\text { (m) }\end{array}$ & $\begin{array}{l}L_{h} \\
(\mathbf{m})\end{array}$ & $\begin{array}{c}H_{q} \\
(\mathbf{m m})\end{array}$ & $\begin{array}{l}\delta_{\text {medido }} \\
(\mathrm{mm})\end{array}$ & $\begin{array}{c}E P_{T} \\
(J)\end{array}$ & $\begin{array}{c}E P_{\text {sistema }} \\
\text { (J) }\end{array}$ & $\begin{array}{c}E_{\text {topol }} \\
\text { (J) }\end{array}$ & $\begin{array}{c}E_{\text {topo2 }} \\
\text { (J) }\end{array}$ & $\begin{array}{c}E_{\text {basel }} \\
(\mathbf{J})\end{array}$ & $\begin{array}{c}E_{\text {base2 }} \\
\text { (J) }\end{array}$ & $\begin{array}{c}\eta_{\text {topol }} \\
(\%)\end{array}$ & $\begin{array}{c}\eta_{\text {topo } 2} \\
(\%)\end{array}$ & $\begin{array}{c}\eta_{\text {basel }} \\
(\%)\end{array}$ & $\begin{array}{c}\eta_{\text {base } 2} \\
(\%)\end{array}$ & $\begin{array}{c}\text { Erro } \\
(\%) \eta_{\text {topo }}\end{array}$ & $\begin{array}{c}\text { Erro } \\
(\%) \eta_{\text {base }}\end{array}$ \\
\hline \multirow{7}{*}{$2-3$} & \multirow{7}{*}{3.7} & 100 & 75 & 63.8 & 123.2 & 105.9 & 108.3 & 79.8 & 90.4 & 85.9 & 87.9 & 64.8 & 73.4 & 11.8 & 2.3 \\
\hline & & 200 & 80 & 127.5 & 191.0 & 146.9 & 149.3 & 119.6 & 130.9 & 76.9 & 78.2 & 62.6 & 68.6 & 8.6 & 1.6 \\
\hline & & 300 & 114 & 191.3 & 281.7 & 224.6 & 227.9 & 186.6 & 202.6 & 79.7 & 80.9 & 66.3 & 71.9 & 7.9 & 1.5 \\
\hline & & 400 & 144 & 255.1 & 369.2 & 246.9 & 250.7 & 238.7 & 259.9 & 66.9 & 67.9 & 64.7 & 70.4 & 8.1 & 1.5 \\
\hline & & 500 & 195 & 318.8 & 473.4 & 306.0 & 311.0 & 293.7 & 321.0 & 64.6 & 65.7 & 62.0 & 67.8 & 8.5 & 1.6 \\
\hline & & 600 & - & 382.6 & - & - & - & - & - & - & - & - & - & - & - \\
\hline & & 750 & - & 478.2 & - & - & - & - & - & - & - & - & - & - & - \\
\hline \multirow{7}{*}{$3-4$} & \multirow{7}{*}{4.7} & 100 & 55 & 63.8 & 109.1 & 82.9 & 84.5 & 63.7 & 72.7 & 75.9 & 77.4 & 58.3 & 66.6 & 12.5 & 1.9 \\
\hline & & 200 & 68 & 127.5 & 183.6 & 134.8 & 136.7 & 122.9 & 134.8 & 73.4 & 74.4 & 66.9 & 73.4 & 8.8 & 1.3 \\
\hline & & 300 & 71 & 191.3 & 249.9 & 182.5 & 184.4 & 183.9 & 198.1 & 73.0 & 73.8 & 73.6 & 79.3 & 7.1 & 1.0 \\
\hline & & 400 & 77 & 255.1 & 318.6 & 235.0 & 237.1 & 199.2 & 212.1 & 73.8 & 74.4 & 62.5 & 66.6 & 6.1 & 0.9 \\
\hline & & 500 & 76 & 318.8 & 381.5 & 268.9 & 271.0 & 240.6 & 254.5 & 70.5 & 71.0 & 63.1 & 66.7 & 5.5 & 0.8 \\
\hline & & 600 & 89 & 382.6 & 456.0 & 342.5 & 345.1 & 284.0 & 299.6 & 75.1 & 75.7 & 62.3 & 65.7 & 5.2 & 0.8 \\
\hline & & 750 & 104 & 478.2 & 564.0 & 447.0 & 450.1 & 357.1 & 375.2 & 79.2 & 79.8 & 63.3 & 66.5 & 4.8 & 0.7 \\
\hline \multirow{7}{*}{$4-5$} & \multirow{7}{*}{5.7} & 100 & 33 & 63.8 & 92.1 & 49.6 & 50.5 & 54.2 & 61.5 & 53.9 & 54.9 & 58.9 & 66.8 & 11.8 & 1.8 \\
\hline & & 200 & 45 & 127.5 & 166.1 & 125.0 & 126.3 & 109.6 & 118.5 & 75.2 & 76.0 & 66.0 & 71.4 & 7.6 & 1.1 \\
\hline & & 300 & 47 & 191.3 & 231.6 & 165.5 & 166.9 & 146.8 & 156.2 & 71.5 & 72.1 & 63.4 & 67.4 & 6.0 & 0.8 \\
\hline & & 400 & 52 & 255.1 & 299.6 & 205.7 & 207.3 & 177.5 & 187.8 & 68.7 & 69.2 & 59.2 & 62.7 & 5.5 & 0.7 \\
\hline & & 500 & 62 & 318.8 & 372.0 & 275.7 & 277.6 & 237.4 & 250.8 & 74.1 & 74.6 & 63.8 & 67.4 & 5.4 & 0.7 \\
\hline & & 600 & 66 & 382.6 & 439.2 & 306.6 & 308.5 & 293.5 & 308.3 & 69.8 & 70.2 & 66.8 & 70.2 & 4.8 & 0.6 \\
\hline & & 750 & 76 & 478.2 & 543.4 & 398.5 & 400.8 & 359.4 & 376.8 & 73.3 & 73.8 & 66.1 & 69.4 & 4.6 & 0.6 \\
\hline \multirow{7}{*}{$5-6$} & \multirow{7}{*}{6.7} & 100 & 30 & 63.8 & 90.4 & 62.8 & 63.6 & 53.4 & 60.9 & 69.4 & 70.3 & 59.0 & 67.3 & 12.4 & 1.4 \\
\hline & & 200 & 38 & 127.5 & 161.3 & 122.4 & 123.5 & 99.3 & 108.8 & 75.9 & 76.6 & 61.6 & 67.5 & 8.7 & 0.9 \\
\hline & & 300 & 45 & 191.3 & 231.3 & 176.8 & 178.1 & 142.0 & 153.2 & 76.4 & 77.0 & 61.4 & 66.2 & 7.3 & 0.8 \\
\hline & & 400 & 54 & 255.1 & 303.1 & 227.0 & 228.5 & 185.1 & 197.8 & 74.9 & 75.4 & 61.1 & 65.3 & 6.4 & 0.7 \\
\hline & & 500 & 61 & 318.8 & 373.1 & 268.7 & 270.4 & 230.1 & 244.9 & 72.0 & 72.5 & 61.7 & 65.6 & 6.0 & 0.6 \\
\hline & & 600 & 66 & 382.6 & 441.3 & 330.7 & 332.5 & 281.2 & 297.1 & 74.9 & 75.4 & 63.7 & 67.3 & 5.3 & 0.6 \\
\hline & & 750 & 123 & 478.2 & 587.6 & 307.6 & 309.2 & 254.4 & 268.2 & 52.3 & 52.6 & 43.3 & 45.6 & 5.1 & 0.5 \\
\hline \multirow{7}{*}{$6-7$} & \multirow{7}{*}{6.7} & 100 & 32 & 63.8 & 92.2 & 58.0 & 58.9 & 45.2 & 53.1 & 62.9 & 63.9 & 49.0 & 57.6 & 14.9 & 1.6 \\
\hline & & 200 & 44 & 127.5 & 166.7 & 122.8 & 124.1 & 91.1 & 100.9 & 73.7 & 74.4 & 54.7 & 60.5 & 9.7 & 1.0 \\
\hline & & 300 & 33 & 191.3 & 220.6 & 111.5 & 112.5 & 88.1 & 96.2 & 50.5 & 51.0 & 39.9 & 43.6 & 8.4 & 0.9 \\
\hline & & 400 & 62 & 255.1 & 310.2 & 230.7 & 232.5 & 185.5 & 200.0 & 74.4 & 74.9 & 59.8 & 64.5 & 7.3 & 0.8 \\
\hline & & 500 & - & 318.8 & - & - & - & - & - & - & - & - & - & - & - \\
\hline & & 600 & 68 & 382.6 & 443.1 & 319.8 & 321.8 & 282.9 & 300.9 & 72.2 & 72.6 & 63.8 & 67.9 & 6.0 & 0.6 \\
\hline & & 750 & 74 & 478.2 & 544.1 & 388.8 & 390.9 & 322.1 & 341.0 & 71.5 & 71.9 & 59.2 & 62.7 & 5.5 & 0.5 \\
\hline
\end{tabular}



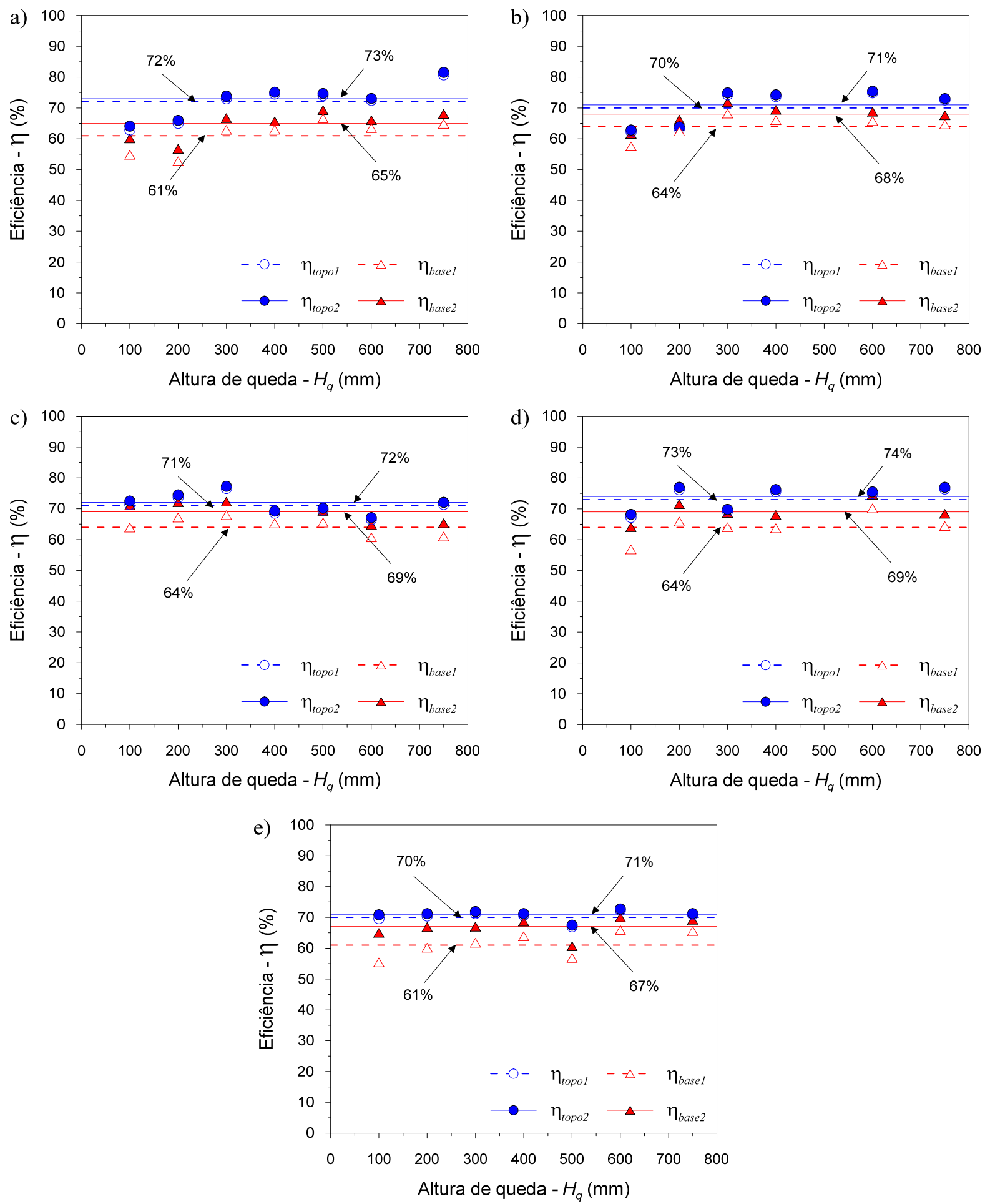

Figura A91 Avaliação da influência do peso do sistema nos valores de eficiência no topo e na base para os ensaios do furo SP01 e profundidades: a) 2 metros; b) 3 metros; c) 4 metros; d) 5 metros; e) 6 metros 

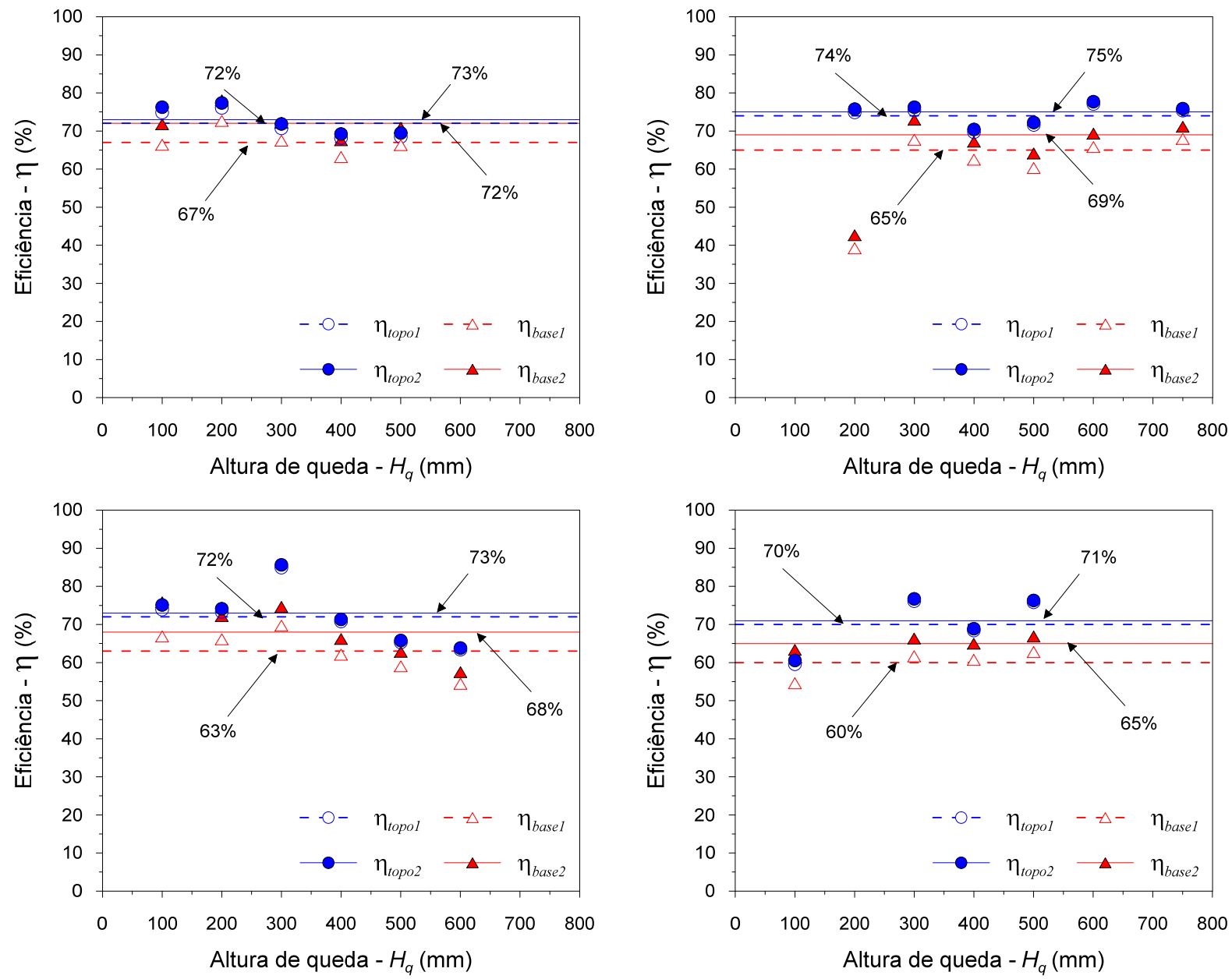

Figura A92 - Avaliação da influência do peso do sistema nos valores de eficiência no topo e na base para os ensaios do furo SP02 e profundidades: a) 2 metros; b) 3 metros; c) 5 metros; d) 6 metros. 

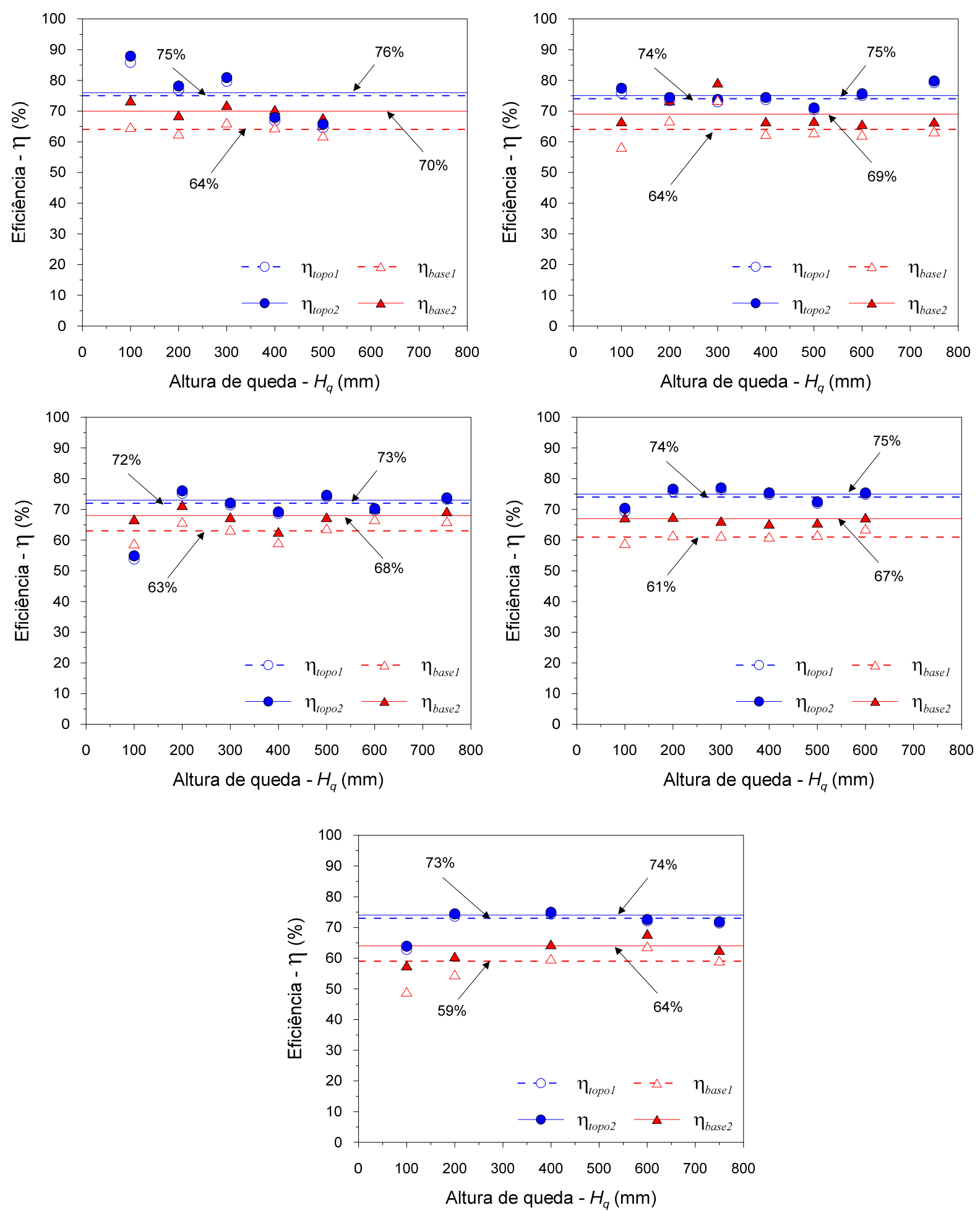

Figura A93 - Avaliação da influência do peso do sistema nos valores de eficiência no topo e na base para os ensaios do furo SP03 e profundidades: a) 2 metros; b) 3 metros; c) 4 metros; d) 5 metros; e) 6 metros. 

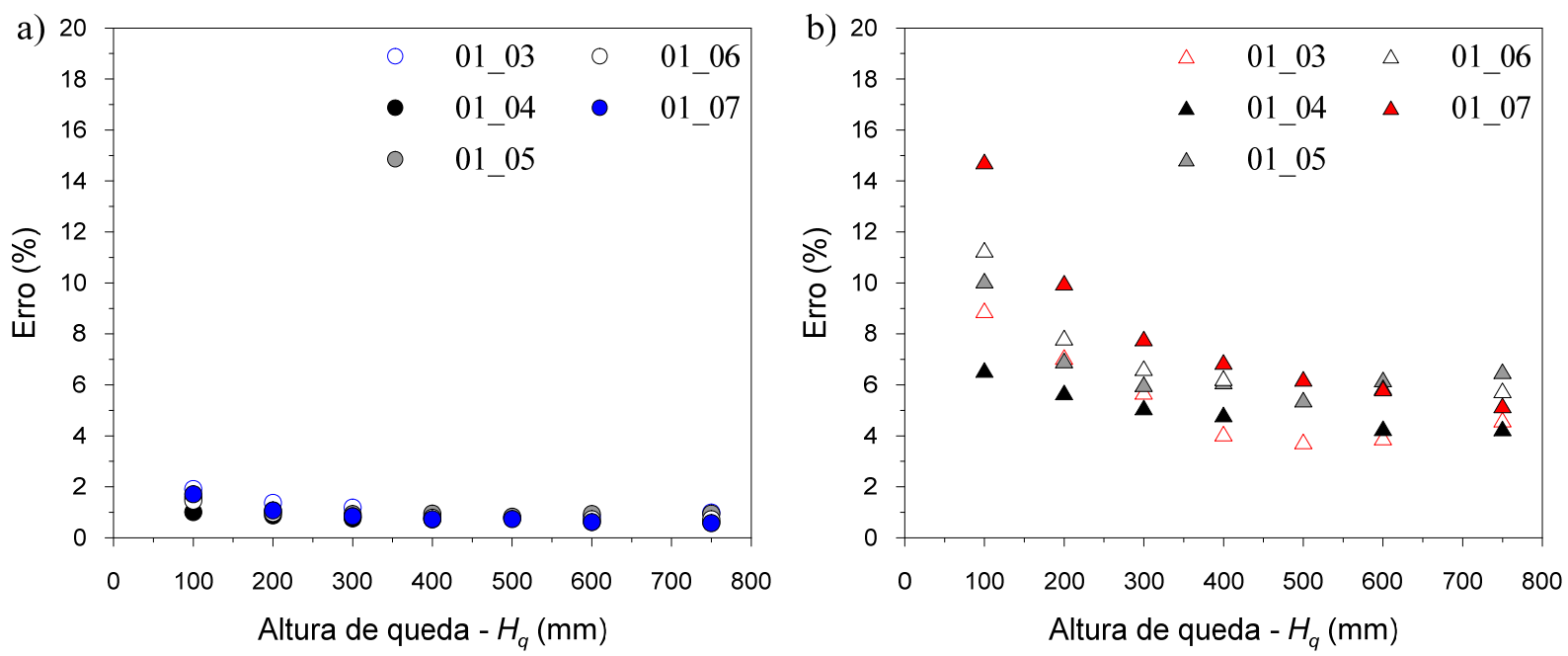

Figura A94 - Erro relativo entre as eficiências considerando o peso do sistema e sem considerar - furo SP01: a) topo; b) base.
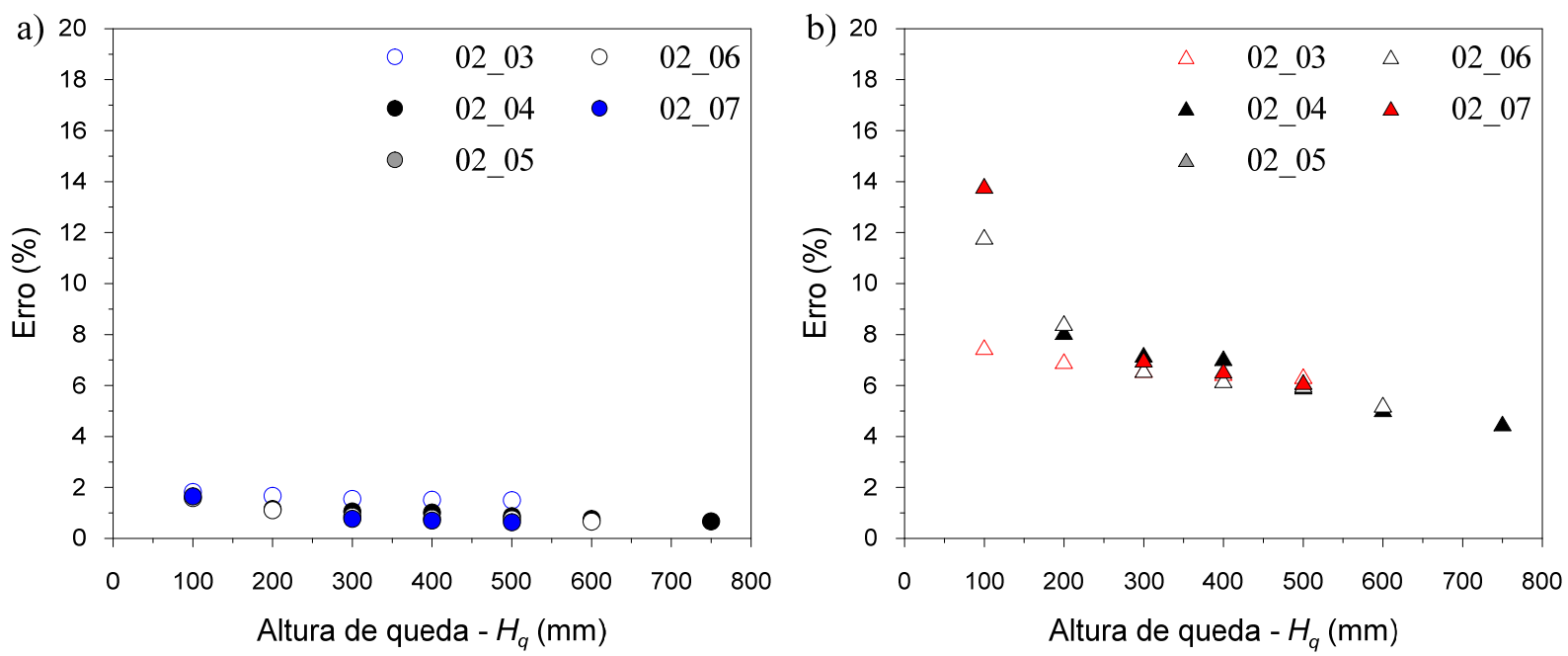

Figura A95 - Erro relativo entre as eficiências considerando o peso do sistema e sem considerar - furo SP02: a) topo; b) base.
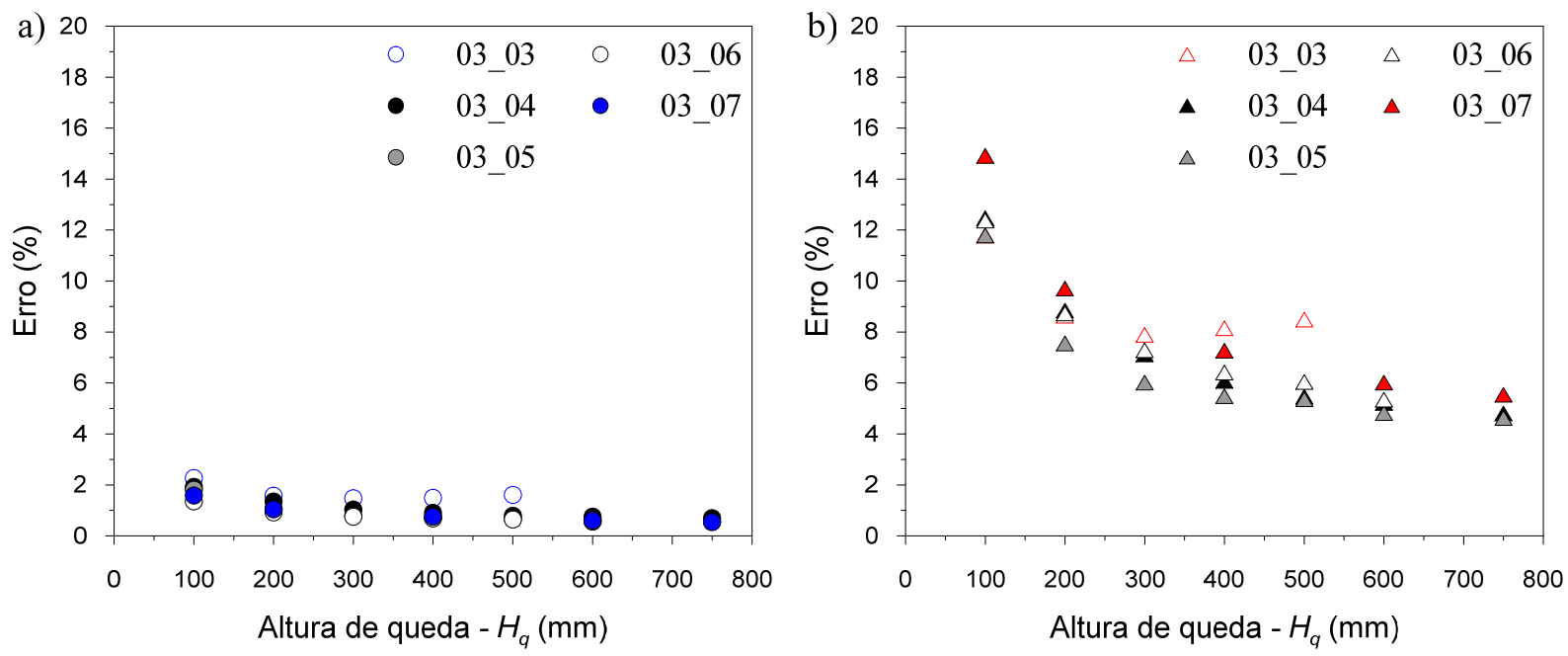

Figura A96 - Erro relativo entre as eficiências considerando o peso do sistema e sem considerar - furo SP03: a) topo; b) base. 

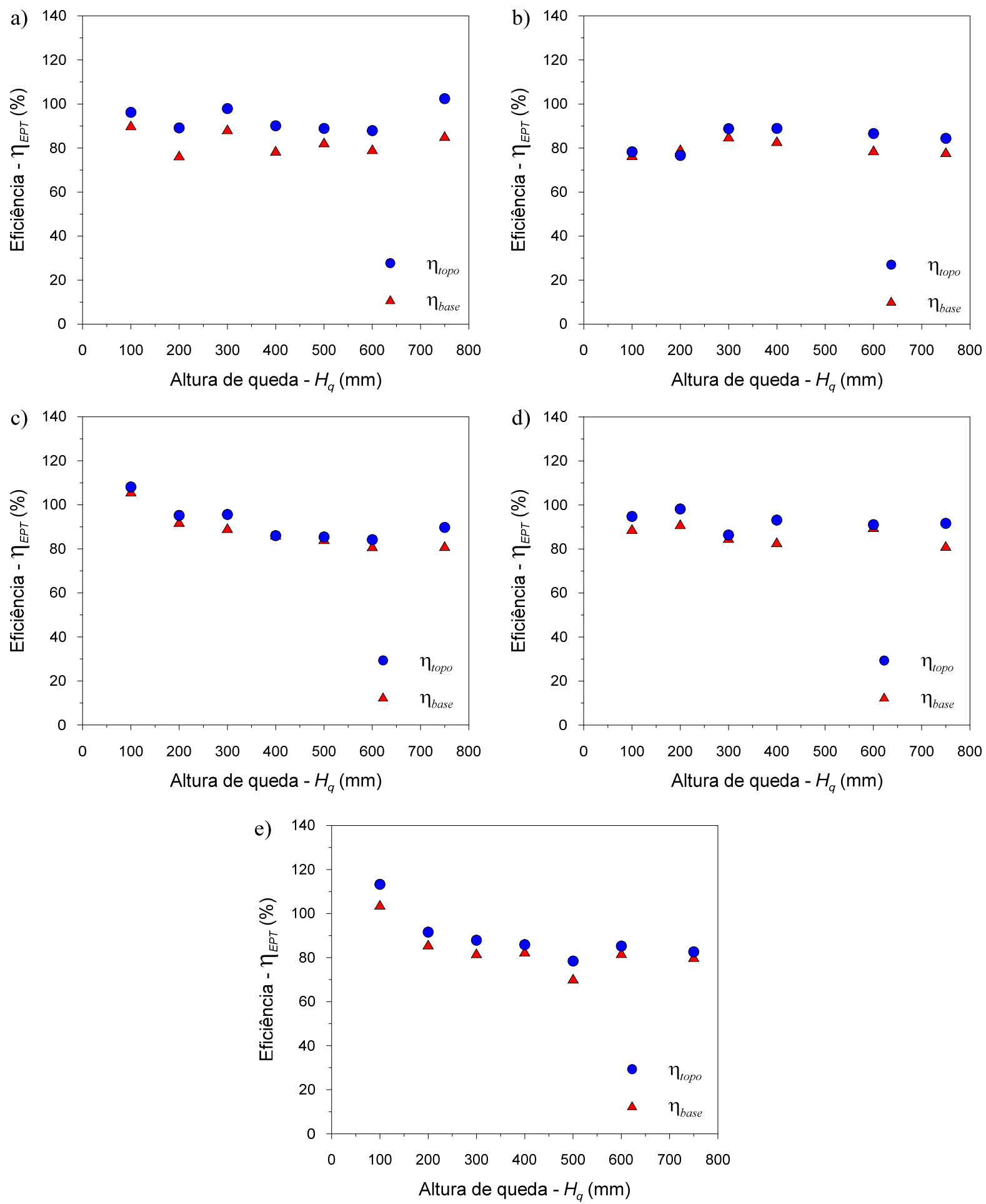

Figura A97 - Eficiência calculada em relação à EPT no topo e na base para os ensaios do furo SP01 e profundidades: a) 2 metros; b) 3 metros; c) 4 metros; d) 5 metros; e) 6 metros. 

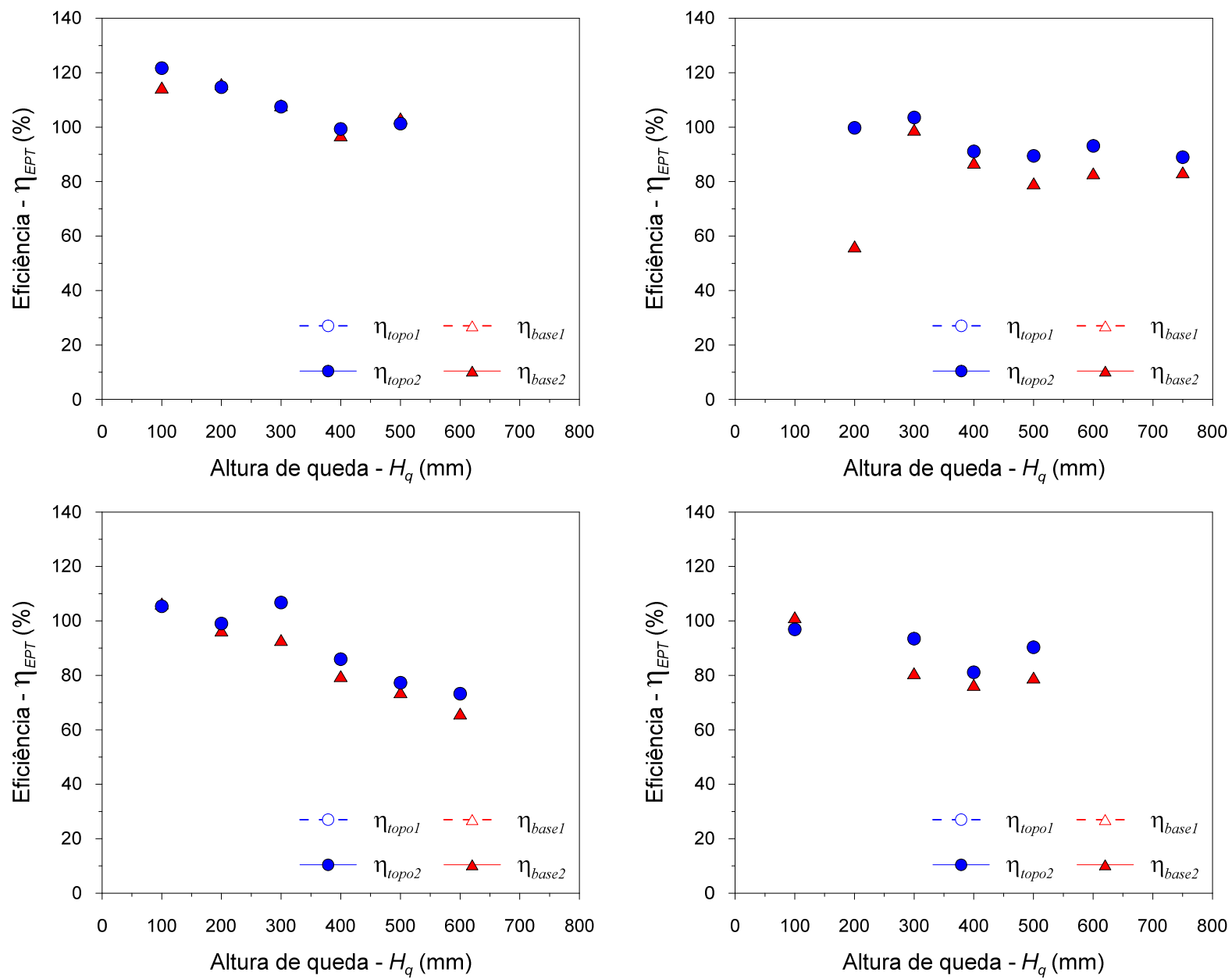

Figura A98 - Eficiência calculada em relação à EPT no topo e na base para os ensaios do furo SP02 e profundidades: a) 2 metros; b) 3 metros; c) 4 metros; d) 5 metros; e) 6 metros. 

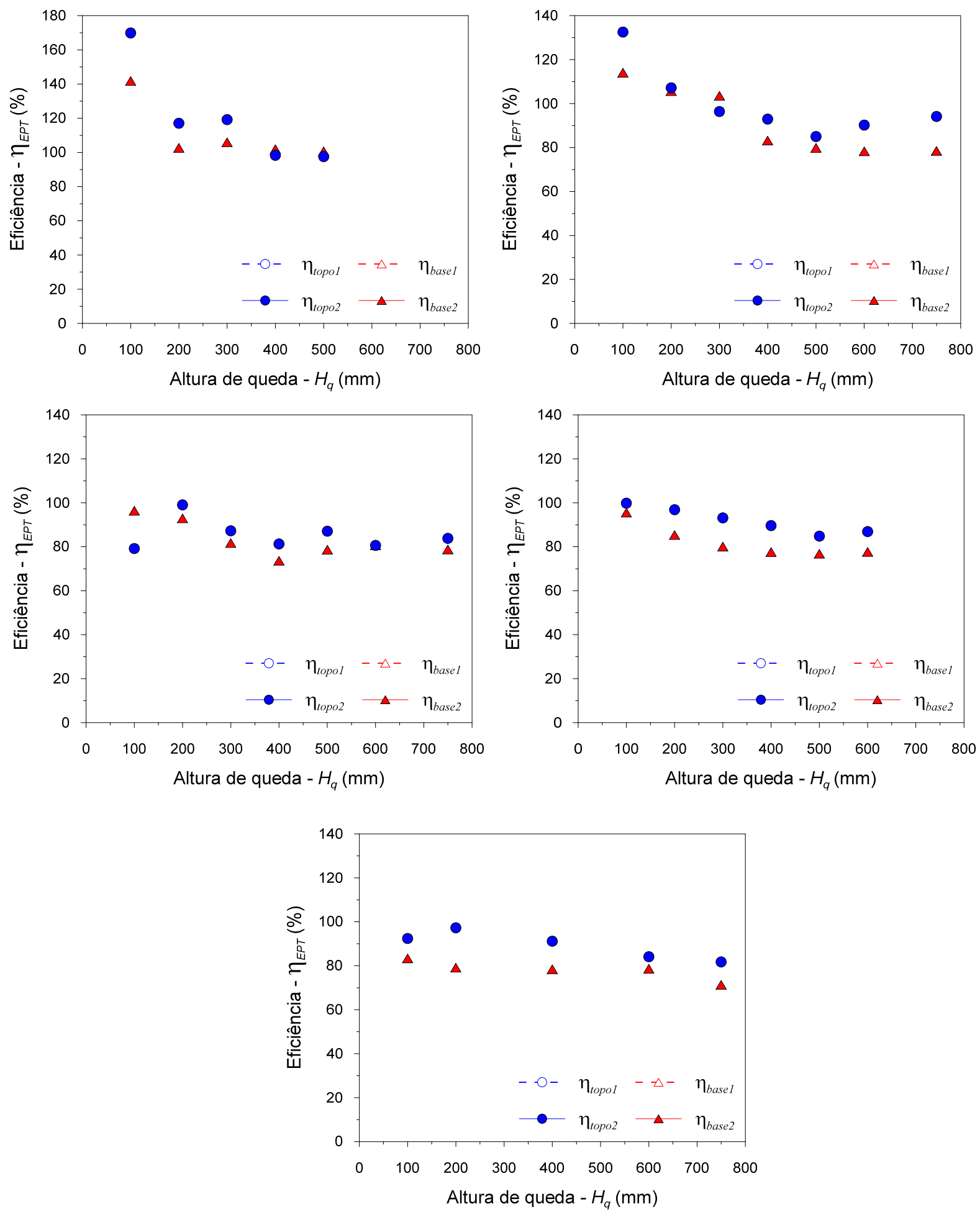

Figura A99 - Eficiência calculada em relação à EPT no topo e na base para os ensaios do furo SP03 e profundidades: a) 2 metros; b) 3 metros; c) 4 metros; d) 5 metros; e) 6 metros. 

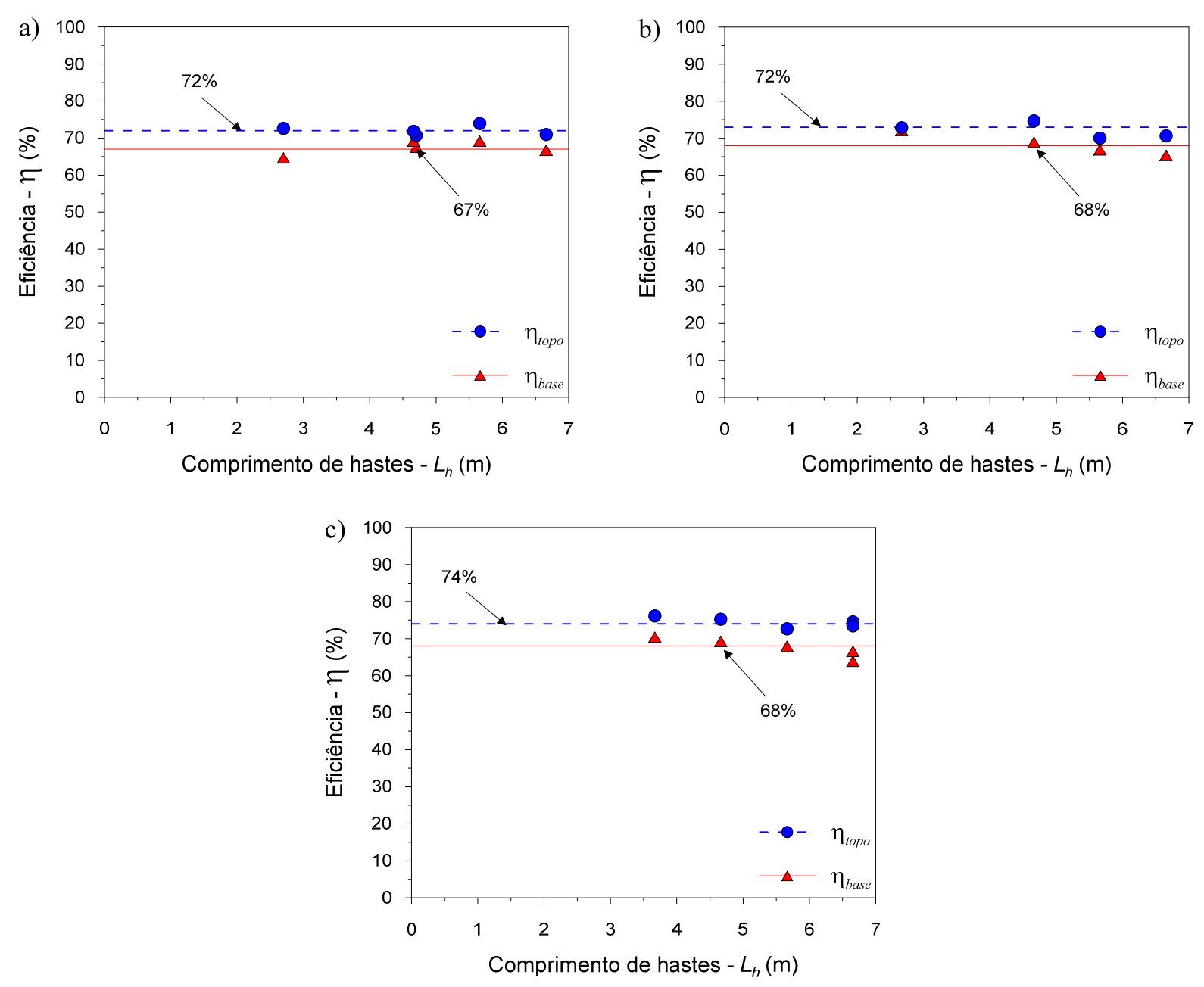

Figura A100 - Eficiência em relação ao comprimento de hastes: a) furo SP01; b) furo SP02; c) furo SP03.

Tabela A7 - Eficiência calculada de forma convencional e pelos coeficientes angulares das retas.

\begin{tabular}{|c|c|c|c|c|c|c|c|c|c|c|}
\hline \multirow[b]{2}{*}{ Ensaio } & \multirow{2}{*}{$\begin{array}{l}\text { profundidade } \\
\text { de(m) }\end{array}$} & \multirow{2}{*}{$\begin{array}{l}L_{h} \\
(\mathbf{m})\end{array}$} & \multirow{2}{*}{$\begin{array}{c}\delta_{\text {acumulado }} \\
(\mathbf{m m})\end{array}$} & \multicolumn{2}{|c|}{ Média } & \multicolumn{5}{|c|}{ Ajuste } \\
\hline & & & & $\begin{array}{l}\eta_{\text {topo }} \\
(\%)\end{array}$ & $\begin{array}{l}\eta_{\text {base }} \\
(\mathbf{\%})\end{array}$ & $a$ & $b$ & $c$ & $\begin{array}{l}\eta_{\text {topo }} \\
(\%)\end{array}$ & $\begin{array}{l}\eta_{\text {base }} \\
(\mathbf{\%})\end{array}$ \\
\hline \multirow{5}{*}{$\begin{array}{r}\text { furo } \\
\text { SP01 }\end{array}$} & $2-3$ & 2.7 & 593 & 73 & 65 & 0.787 & 0.572 & 0.528 & 73 & 67 \\
\hline & $3-4$ & 4.7 & 373 & 71 & 68 & 0.742 & 0.546 & 0.507 & 74 & 68 \\
\hline & $4-5$ & 4.7 & 555 & 72 & 69 & 0.794 & 0.560 & 0.531 & 71 & 67 \\
\hline & $5-6$ & 5.7 & 464 & 74 & 69 & 0.770 & 0.583 & 0.541 & 76 & 70 \\
\hline & $6-7$ & 6.7 & 409 & 71 & 67 & 0.751 & 0.534 & 0.508 & 71 & 68 \\
\hline \multirow{4}{*}{$\begin{array}{r}\text { furo } \\
\text { SP02 }\end{array}$} & $2-3$ & 2.7 & 813 & 73 & 72 & 0.932 & 0.657 & 0.659 & 71 & 71 \\
\hline & $3-4$ & 4.7 & 547 & 75 & 69 & 0.777 & 0.583 & 0.536 & 75 & 69 \\
\hline & $5-6$ & 5.7 & 478 & 70 & 67 & 0.756 & 0.519 & 0.478 & 69 & 63 \\
\hline & $6-7$ & 6.7 & 346 & 71 & 65 & 0.763 & 0.562 & 0.504 & 74 & 66 \\
\hline \multirow{5}{*}{$\begin{array}{l}\text { furo } \\
\text { SP03 }\end{array}$} & $2-3$ & 3.7 & 608 & 76 & 70 & 0.944 & 0.663 & 0.655 & 70 & 69 \\
\hline & $3-4$ & 4.7 & 540 & 75 & 69 & 0.772 & 0.588 & 0.521 & 76 & 67 \\
\hline & $4-5$ & 5.7 & 381 & 73 & 68 & 0.739 & 0.535 & 0.506 & 72 & 68 \\
\hline & $5-6$ & 6.7 & 417 & 75 & 67 & 0.751 & 0.561 & 0.498 & 75 & 66 \\
\hline & $6-7$ & 6.7 & 377 & 73 & 64 & 0.742 & 0.539 & 0.478 & 73 & 64 \\
\hline
\end{tabular}



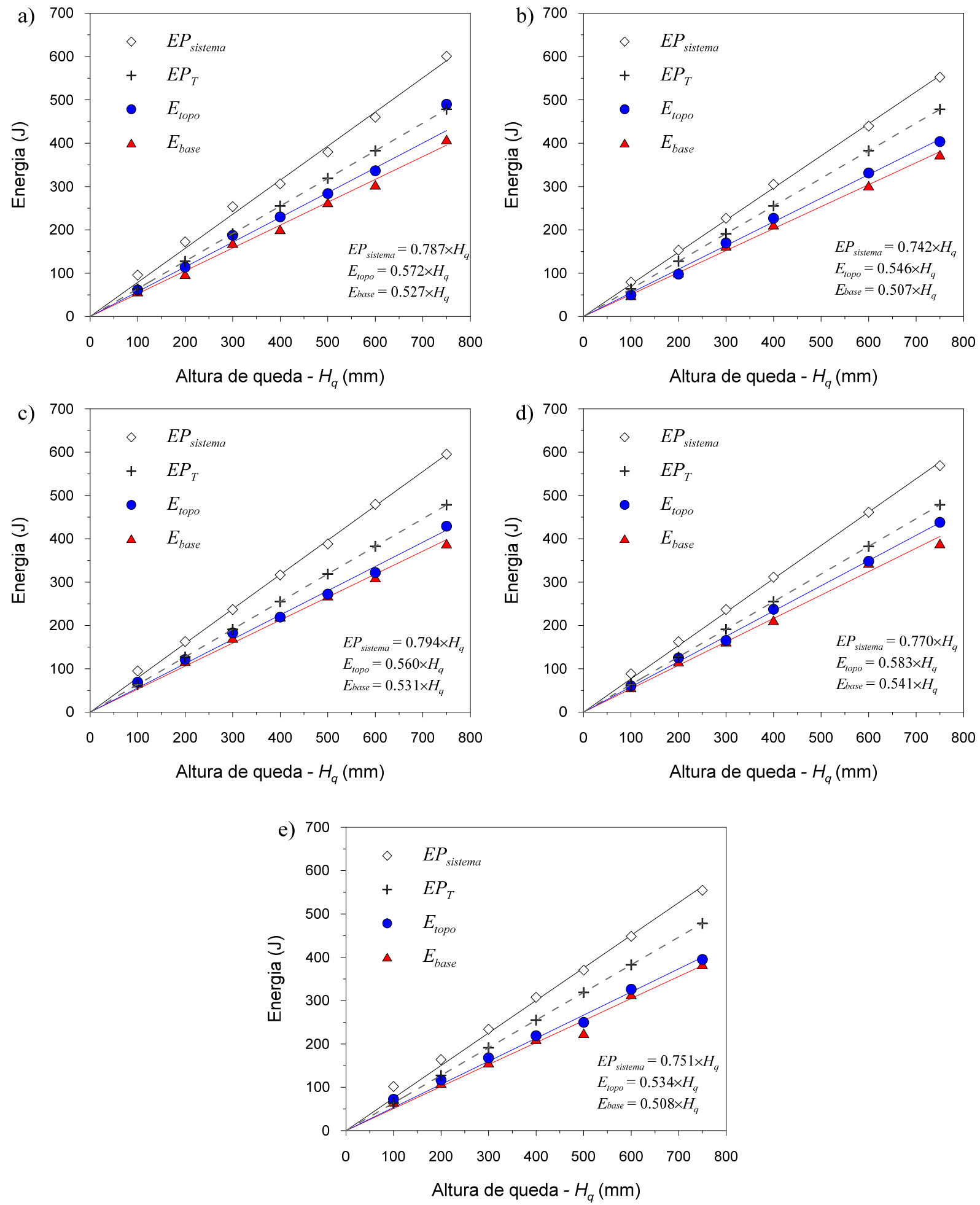

Figura A101 - Relação entre as energias envolvidas no ensaio e as alturas de queda do martelo aplicadas - furo SP01 profundidades: a) 2 metros; b) 3 metros; c) 4 metros; d) 5 metros; e) 6 metros. 

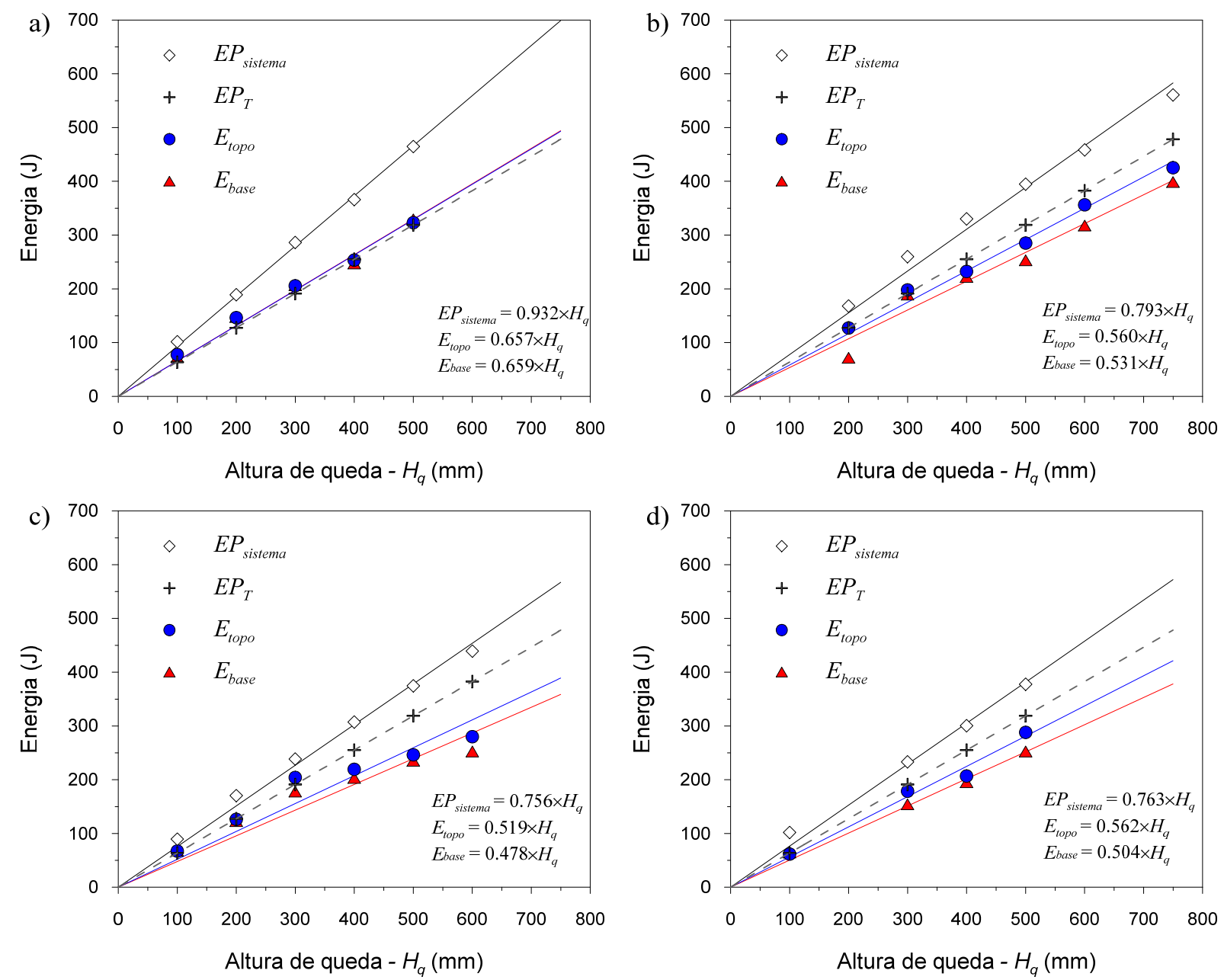

Figura A102 - Relação entre as energias envolvidas no ensaio e as alturas de queda do martelo aplicadas - furo SP02 profundidades: a) 2 metros; b) 3 metros; c) 4 metros; d) 5 metros; e) 6 metros. 

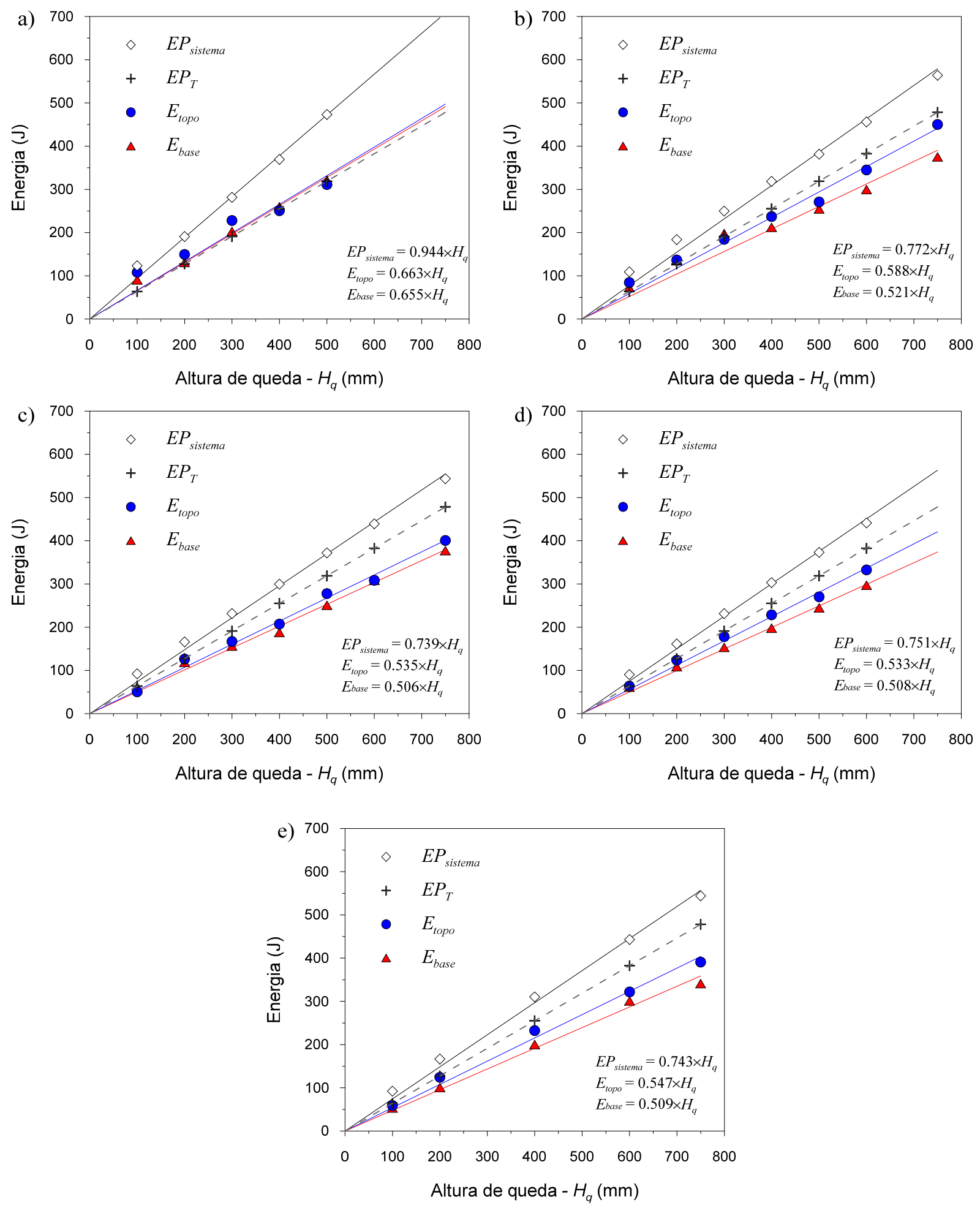

Figura A103 - Relação entre as energias envolvidas no ensaio e as alturas de queda do martelo aplicadas - furo SP03 profundidades: a) 2 metros; b) 3 metros; c) 4 metros; d) 5 metros; e) 6 metros. 
Tabela A8 - Previsão de alturas de queda efetivamente aplicadas - furo SP01.

\begin{tabular}{|c|c|c|c|c|c|}
\hline $\begin{array}{l}\text { profundidade de } \\
\text { (m) }\end{array}$ & $\begin{array}{l}L_{h} \\
\text { (m) }\end{array}$ & $\underset{(\mathbf{m m})}{H_{q} \text { previsto }} H_{q p}$ & $\underset{(\mathbf{m m})}{H_{q} \text { estimada }} \boldsymbol{H}_{q e}$ & $\begin{array}{c}\boldsymbol{H}_{q e}-\boldsymbol{H}_{q p} \\
(\mathbf{m m})\end{array}$ & $\begin{array}{c}\left(\boldsymbol{H}_{q e}-\boldsymbol{H}_{q p}\right) / \boldsymbol{H}_{q e} \\
(\mathbf{\%})\end{array}$ \\
\hline \multirow{7}{*}{$2-3$} & \multirow{7}{*}{3.7} & 100 & 73 & -27 & -36 \\
\hline & & 200 & 176 & -24 & -13 \\
\hline & & 300 & 272 & -28 & -10 \\
\hline & & 400 & 414 & 14 & 3 \\
\hline & & 500 & 522 & 22 & 4 \\
\hline & & 600 & 619 & 19 & 3 \\
\hline & & 750 & 734 & -16 & -2 \\
\hline \multirow{7}{*}{$3-4$} & \multirow{7}{*}{4.7} & 100 & 92 & -8 & -9 \\
\hline & & 200 & 193 & -7 & -4 \\
\hline & & 300 & 294 & -6 & -2 \\
\hline & & 400 & 387 & -13 & -3 \\
\hline & & 500 & - & - & - \\
\hline & & 600 & 610 & 10 & 2 \\
\hline & & 750 & 757 & 7 & 1 \\
\hline \multirow{7}{*}{$4-5$} & \multirow{7}{*}{5.7} & 100 & 75 & -25 & -33 \\
\hline & & 200 & 193 & -7 & -4 \\
\hline & & 300 & 302 & 2 & 1 \\
\hline & & 400 & 400 & 0 & 0 \\
\hline & & 500 & 513 & 13 & 3 \\
\hline & & 600 & 594 & -6 & -1 \\
\hline & & 750 & 749 & -1 & 0 \\
\hline \multirow{7}{*}{$5-6$} & \multirow{7}{*}{6.7} & 100 & 82 & -18 & -23 \\
\hline & & 200 & 186 & -14 & -7 \\
\hline & & 300 & 291 & -9 & -3 \\
\hline & & 400 & 394 & -6 & -2 \\
\hline & & 500 & - & - & - \\
\hline & & 600 & 600 & 0 & 0 \\
\hline & & 750 & 762 & 12 & 2 \\
\hline \multirow{7}{*}{$6-7$} & \multirow{7}{*}{6.7} & 100 & 58 & -42 & -73 \\
\hline & & 200 & 178 & -22 & -12 \\
\hline & & 300 & 286 & -14 & -5 \\
\hline & & 400 & 389 & -11 & -3 \\
\hline & & 500 & 508 & 8 & 2 \\
\hline & & 600 & 603 & 3 & 1 \\
\hline & & 750 & 763 & 13 & 2 \\
\hline
\end{tabular}


Tabela A9 - Previsão de alturas de queda efetivamente aplicadas - furo SP02

\begin{tabular}{|c|c|c|c|c|c|}
\hline $\begin{array}{l}\text { profundidade de } \\
\text { (m) }\end{array}$ & $\begin{array}{c}L_{h} \\
(\mathbf{m})\end{array}$ & $\begin{array}{c}H_{q} \text { previsto } H_{q p} \\
(\mathrm{~mm})\end{array}$ & $\begin{array}{c}H_{q} \text { estimada } H_{q e} \\
(\mathrm{~mm})\end{array}$ & $\begin{array}{l}H_{q e}-H_{q p} \\
\quad(\mathbf{m m})\end{array}$ & $\begin{array}{c}\left(\boldsymbol{H}_{q e}-\boldsymbol{H}_{q p}\right) / \boldsymbol{H}_{q e} \\
(\%)\end{array}$ \\
\hline \multirow{7}{*}{$2-3$} & \multirow{7}{*}{2.7} & 100 & 87 & -13 & -16 \\
\hline & & 200 & 196 & -4 & -2 \\
\hline & & 300 & 289 & -11 & -4 \\
\hline & & 400 & 411 & 11 & 3 \\
\hline & & 500 & 502 & 2 & 0 \\
\hline & & 600 & - & - & - \\
\hline & & 750 & - & - & - \\
\hline \multirow{7}{*}{$3-4$} & \multirow{7}{*}{4.7} & 100 & - & - & - \\
\hline & & 200 & 180 & -20 & -11 \\
\hline & & 300 & 258 & -42 & -16 \\
\hline & & 400 & 370 & -30 & -8 \\
\hline & & 500 & 490 & -10 & -2 \\
\hline & & 600 & 612 & 12 & 2 \\
\hline & & 750 & 785 & 35 & 4 \\
\hline \multirow{7}{*}{$5-6$} & \multirow{7}{*}{5.7} & 100 & 78 & -22 & -28 \\
\hline & & 200 & 170 & -30 & -18 \\
\hline & & 300 & 282 & -18 & -6 \\
\hline & & 400 & 392 & -8 & -2 \\
\hline & & 500 & 505 & 5 & 1 \\
\hline & & 600 & 623 & 23 & 4 \\
\hline & & 750 & - & - & - \\
\hline \multirow{7}{*}{$6-7$} & \multirow{7}{*}{6.7} & 100 & 60 & -40 & -68 \\
\hline & & 200 & - & - & - \\
\hline & & 300 & 293 & -7 & -2 \\
\hline & & 400 & 407 & 7 & 2 \\
\hline & & 500 & 506 & 6 & 1 \\
\hline & & 600 & - & - & - \\
\hline & & 750 & - & - & - \\
\hline
\end{tabular}


Tabela A10 - Previsão de alturas de queda efetivamente aplicadas - furo SP03

\begin{tabular}{|c|c|c|c|c|c|}
\hline $\begin{array}{l}\text { profundidade } \\
\text { de (m) }\end{array}$ & $L_{h}(\mathbf{m})$ & $\begin{array}{c}H_{q} \text { previsto } H_{q p} \\
(\mathrm{~mm})\end{array}$ & $\begin{array}{c}H_{q} \text { estimada } \\
H_{q e}(\mathbf{m m})\end{array}$ & $\boldsymbol{H}_{q e}-\boldsymbol{H}_{q p}(\mathbf{m m})$ & $\begin{array}{c}\left(\boldsymbol{H}_{q e}-\boldsymbol{H}_{q p}\right) / \boldsymbol{H}_{q e} \\
(\boldsymbol{\%})\end{array}$ \\
\hline \multirow{7}{*}{$2-3$} & \multirow{7}{*}{3.7} & 100 & 55 & -45 & -82 \\
\hline & & 200 & 197 & -3 & -2 \\
\hline & & 300 & 303 & 3 & 1 \\
\hline & & 400 & 413 & 13 & 3 \\
\hline & & 500 & 498 & -2 & 0 \\
\hline & & 600 & - & - & - \\
\hline & & 750 & - & - & - \\
\hline \multirow{7}{*}{$3-4$} & \multirow{7}{*}{4.7} & 100 & 57 & -43 & -74 \\
\hline & & 200 & 169 & -31 & -18 \\
\hline & & 300 & 294 & -6 & -2 \\
\hline & & 400 & 415 & 15 & 4 \\
\hline & & 500 & 545 & 45 & 8 \\
\hline & & 600 & 656 & 56 & 9 \\
\hline & & 750 & 830 & 80 & 10 \\
\hline \multirow{7}{*}{$4-5$} & \multirow{7}{*}{5.7} & 100 & 73 & -27 & -37 \\
\hline & & 200 & 175 & -25 & -14 \\
\hline & & 300 & 290 & -10 & -4 \\
\hline & & 400 & 401 & 1 & 0 \\
\hline & & 500 & 505 & 5 & 1 \\
\hline & & 600 & 617 & 17 & 3 \\
\hline & & 750 & 780 & 30 & 4 \\
\hline \multirow{7}{*}{$5-6$} & \multirow{7}{*}{6.7} & 100 & 75 & -25 & -34 \\
\hline & & 200 & 180 & -20 & -11 \\
\hline & & 300 & 287 & -13 & -5 \\
\hline & & 400 & 390 & -10 & -2 \\
\hline & & 500 & 497 & -3 & -1 \\
\hline & & 600 & 607 & 7 & 1 \\
\hline & & 750 & 74 & -26 & -36 \\
\hline \multirow{7}{*}{$6-7$} & \multirow{7}{*}{6.7} & 100 & - & - & - \\
\hline & & 200 & 175 & -25 & -14 \\
\hline & & 300 & - & - & - \\
\hline & & 400 & 386 & -14 & -4 \\
\hline & & 500 & - & - & - \\
\hline & & 600 & 615 & 15 & 2 \\
\hline & & 750 & 784 & 34 & 4 \\
\hline
\end{tabular}


Resultados de Resistência 
Tabela A11 - Valores de resistências - furo SP01.

\begin{tabular}{|c|c|c|c|c|c|c|c|}
\hline profundidade de (m) & $L_{h}(\mathrm{~m})$ & $H_{q}(\mathbf{m m})$ & $\delta_{\text {medido }}(\mathrm{mm})$ & $\delta_{\text {acumulado }}(\mathrm{mm})$ & $R_{D}(\mathbf{k N})$ & $R_{S}(\mathbf{k N})$ & $F_{D}(\mathrm{kN})$ \\
\hline \multirow{7}{*}{$2-3$} & \multirow{7}{*}{2.7} & 100 & 42 & 42 & 1.4 & 1.4 & 1.8 \\
\hline & & 200 & 59 & 101 & 1.7 & 1.7 & 2.2 \\
\hline & & 300 & 82 & 183 & 2.2 & 2.1 & 2.4 \\
\hline & & 400 & 67 & 250 & 2.8 & 3.0 & 3.5 \\
\hline & & 500 & 80 & 330 & 3.2 & 3.3 & 3.6 \\
\hline & & 600 & 102 & 432 & 2.9 & 3.0 & 3.4 \\
\hline & & 750 & 161 & 593 & 2.6 & 2.5 & 2.8 \\
\hline \multirow{7}{*}{$3-4$} & \multirow{7}{*}{4.7} & 100 & 19 & 19 & 2.6 & 2.6 & 3.2 \\
\hline & & 200 & 31 & 50 & 2.9 & 3.3 & 3.7 \\
\hline & & 300 & 43 & 93 & 3.0 & 3.8 & 4.0 \\
\hline & & 400 & 61 & 154 & 3.6 & 3.5 & 3.8 \\
\hline & & 500 & 60 & 214 & - & - & 4.6 \\
\hline & & 600 & 69 & 283 & 3.8 & 4.4 & 4.8 \\
\hline & & 750 & 90 & 373 & 4.1 & 4.2 & 4.6 \\
\hline \multirow{7}{*}{$4-5$} & \multirow{7}{*}{4.7} & 100 & 38 & 38 & 1.8 & 1.8 & 1.9 \\
\hline & & 200 & 43 & 81 & 2.7 & 2.7 & 2.9 \\
\hline & & 300 & 55 & 136 & 3.0 & 3.1 & 3.3 \\
\hline & & 400 & 75 & 211 & 3.2 & 2.9 & 3.2 \\
\hline & & 500 & 84 & 295 & 3.0 & 3.2 & 3.5 \\
\hline & & 600 & 118 & 413 & 3.1 & 2.6 & 3.1 \\
\hline & & 750 & 142 & 555 & 2.6 & 2.7 & 3.2 \\
\hline \multirow{7}{*}{$5-6$} & \multirow{7}{*}{5.7} & 100 & 29 & 29 & 1.9 & 2.0 & 2.3 \\
\hline & & 200 & 41 & 70 & 2.8 & 2.8 & 3.0 \\
\hline & & 300 & 53 & 123 & 3.2 & 3.1 & 3.4 \\
\hline & & 400 & 66 & 189 & 3.4 & 3.2 & 3.6 \\
\hline & & 500 & 77 & 266 & - & - & 3.8 \\
\hline & & 600 & 92 & 358 & 3.5 & 3.7 & 3.8 \\
\hline & & 750 & 106 & 464 & 3.3 & 3.7 & 4.1 \\
\hline \multirow{7}{*}{$6-7$} & \multirow{7}{*}{6.7} & 100 & 43 & 43 & 1.8 & 1.5 & 1.8 \\
\hline & & 200 & 41 & 84 & 2.4 & 2.7 & 3.0 \\
\hline & & 300 & 48 & 132 & 3.2 & 3.3 & 3.7 \\
\hline & & 400 & 59 & 191 & 3.6 & 3.6 & 3.9 \\
\hline & & 500 & 58 & 249 & 3.6 & 3.9 & 4.8 \\
\hline & & 600 & 74 & 323 & 4.1 & 4.2 & 4.6 \\
\hline & & 750 & 86 & 409 & 4.4 & 4.5 & 4.8 \\
\hline
\end{tabular}


Tabela A12 - Valores de resistências - furo SP02.

\begin{tabular}{|c|c|c|c|c|c|c|c|}
\hline $\begin{array}{l}\text { profundidade } \\
\text { de (m) }\end{array}$ & $L_{h}(\mathrm{~m})$ & $H_{q}(\mathrm{~mm})$ & $\delta_{\text {medido }}(\mathrm{mm})$ & $\begin{array}{c}\delta_{\text {acumulado }} \\
(\mathrm{mm})\end{array}$ & $R_{D}(\mathbf{k N})$ & $R_{S}(\mathbf{k N})$ & $F_{D}(\mathrm{kN})$ \\
\hline \multirow{7}{*}{$2-3$} & \multirow{7}{*}{2.7} & 100 & 50 & 50 & 1.6 & 1.5 & 1.6 \\
\hline & & 200 & 81 & 131 & 1.7 & 1.8 & 1.8 \\
\hline & & 300 & 125 & 256 & 1.8 & 1.7 & 1.8 \\
\hline & & 400 & 146 & 402 & 1.8 & 1.7 & 1.9 \\
\hline & & 500 & 192 & 594 & 1.9 & 1.7 & 1.9 \\
\hline & & 600 & - & - & - & - & 1.9 \\
\hline & & 750 & - & - & - & - & - \\
\hline \multirow{7}{*}{$3-4$} & \multirow{7}{*}{4.7} & 100 & - & - & - & - & 1.9 \\
\hline & & 200 & 49 & 89 & 2.2 & 1.5 & 2.6 \\
\hline & & 300 & 83 & 172 & 2.3 & 2.3 & 2.4 \\
\hline & & 400 & 91 & 263 & 2.5 & 2.4 & 2.8 \\
\hline & & 500 & 92 & 355 & 3.2 & 2.8 & 3.3 \\
\hline & & 600 & 92 & 447 & 3.4 & 3.5 & 3.8 \\
\hline & & 750 & 100 & 547 & 4.0 & 4.0 & 4.2 \\
\hline \multirow{7}{*}{$5-6$} & \multirow{7}{*}{5.7} & 100 & 30 & 30 & 1.9 & 2.3 & 2.3 \\
\hline & & 200 & 50 & 80 & 2.5 & 2.5 & 2.6 \\
\hline & & 300 & 55 & 135 & 3.1 & 3.2 & 3.3 \\
\hline & & 400 & 61 & 196 & 3.2 & 3.3 & 3.8 \\
\hline & & 500 & 65 & 261 & 3.4 & 3.6 & 4.3 \\
\hline & & 600 & 66 & 327 & 3.9 & 3.8 & 5.0 \\
\hline & & 750 & - & - & - & - & - \\
\hline \multirow{7}{*}{$6-7$} & \multirow{7}{*}{6.7} & 100 & 43 & 43 & 1.9 & 1.5 & 1.8 \\
\hline & & 200 & - & - & - & - & 3.8 \\
\hline & & 300 & 47 & 121 & 3.3 & 3.3 & 3.7 \\
\hline & & 400 & 51 & 172 & 3.6 & 3.8 & 4.4 \\
\hline & & 500 & 66 & 238 & 3.7 & 3.8 & 4.3 \\
\hline & & 600 & - & - & - & - & 5.0 \\
\hline & & 750 & - & - & - & - & - \\
\hline
\end{tabular}


Tabela A13 - Valores de resistências - furo SP03.

\begin{tabular}{|c|c|c|c|c|c|c|c|}
\hline $\begin{array}{c}\text { profundidade } \\
\text { de (m) }\end{array}$ & $L_{h}(\mathrm{~m})$ & $H_{q}(\mathbf{m m})$ & $\delta_{\text {medido }}(\mathrm{mm})$ & $\begin{array}{c}\delta_{\text {acumulado }} \\
(\mathbf{m m})\end{array}$ & $R_{D}(\mathbf{k N})$ & $R_{S}(\mathbf{k N})$ & $F_{D}(\mathbf{k N})$ \\
\hline \multirow{7}{*}{$2-3$} & \multirow{7}{*}{2.7} & 100 & 75 & 75 & 1.4 & 1.2 & 1.3 \\
\hline & & 200 & 80 & 155 & 1.9 & 1.6 & 1.8 \\
\hline & & 300 & 114 & 269 & 1.9 & 1.8 & 1.9 \\
\hline & & 400 & 144 & 413 & 1.9 & 1.8 & 2.0 \\
\hline & & 500 & 195 & 608 & 1.8 & 1.6 & 1.9 \\
\hline & & 600 & - & - & - & - & - \\
\hline & & 750 & - & - & - & - & - \\
\hline \multirow{7}{*}{$3-4$} & \multirow{7}{*}{4.7} & 100 & 55 & 55 & 1.5 & 1.3 & 1.5 \\
\hline & & 200 & 68 & 123 & 2.1 & 2.0 & 2.1 \\
\hline & & 300 & 71 & 194 & 2.6 & 2.8 & 2.7 \\
\hline & & 400 & 77 & 271 & 3.2 & 2.8 & 3.1 \\
\hline & & 500 & 76 & 347 & 3.5 & 3.3 & 3.8 \\
\hline & & 600 & 89 & 436 & 3.5 & 3.4 & 3.9 \\
\hline & & 750 & 104 & 540 & 3.8 & 3.6 & 4.1 \\
\hline \multirow{7}{*}{$4-5$} & \multirow{7}{*}{4.7} & 100 & 33 & 33 & 1.9 & 1.9 & 2.1 \\
\hline & & 200 & 45 & 78 & 2.9 & 2.6 & 2.8 \\
\hline & & 300 & 47 & 125 & 3.4 & 3.3 & 3.7 \\
\hline & & 400 & 52 & 177 & 3.6 & 3.6 & 4.3 \\
\hline & & 500 & 62 & 239 & 3.8 & 4.0 & 4.5 \\
\hline & & 600 & 66 & 305 & 4.3 & 4.7 & 5.0 \\
\hline & & 750 & 76 & 381 & 4.3 & 5.0 & 5.4 \\
\hline \multirow{7}{*}{$5-6$} & \multirow{7}{*}{5.7} & 100 & 30 & 30 & 2.1 & 2.0 & 2.3 \\
\hline & & 200 & 38 & 68 & 2.9 & 2.9 & 3.2 \\
\hline & & 300 & 45 & 113 & 3.4 & 3.4 & 3.9 \\
\hline & & 400 & 54 & 167 & 3.7 & 3.7 & 4.2 \\
\hline & & 500 & 61 & 228 & 4.3 & 4.0 & 4.6 \\
\hline & & 600 & 66 & 294 & 4.5 & 4.5 & 5.0 \\
\hline & & 750 & - & - & - & - & - \\
\hline \multirow{7}{*}{$6-7$} & \multirow{7}{*}{6.7} & 100 & 32 & 32 & 1.7 & 1.7 & 2.2 \\
\hline & & 200 & 44 & 76 & 2.5 & 2.3 & 2.9 \\
\hline & & 300 & - & - & - & - & - \\
\hline & & 400 & 62 & 171 & 3.2 & 3.2 & 3.8 \\
\hline & & 500 & - & - & - & - & 4.4 \\
\hline & & 600 & 68 & 303 & 3.9 & 4.4 & 4.9 \\
\hline & & 750 & 74 & 377 & 4.2 & 4.6 & 5.5 \\
\hline
\end{tabular}
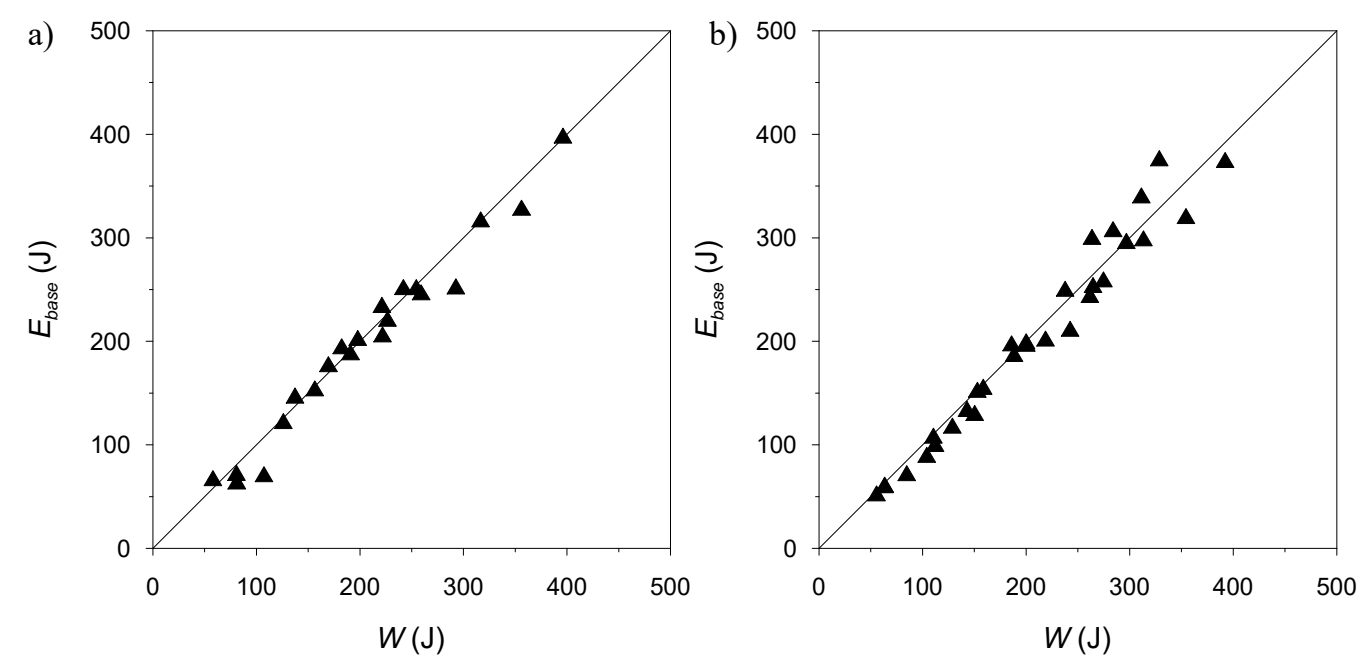

Figura A104 - Relação entre o trabalho $(W)$ calculado a partir de $R_{D}$ com a energia na base $\left(E_{b a s e}\right)$ : a) furo SP02; b) furo SP03. 

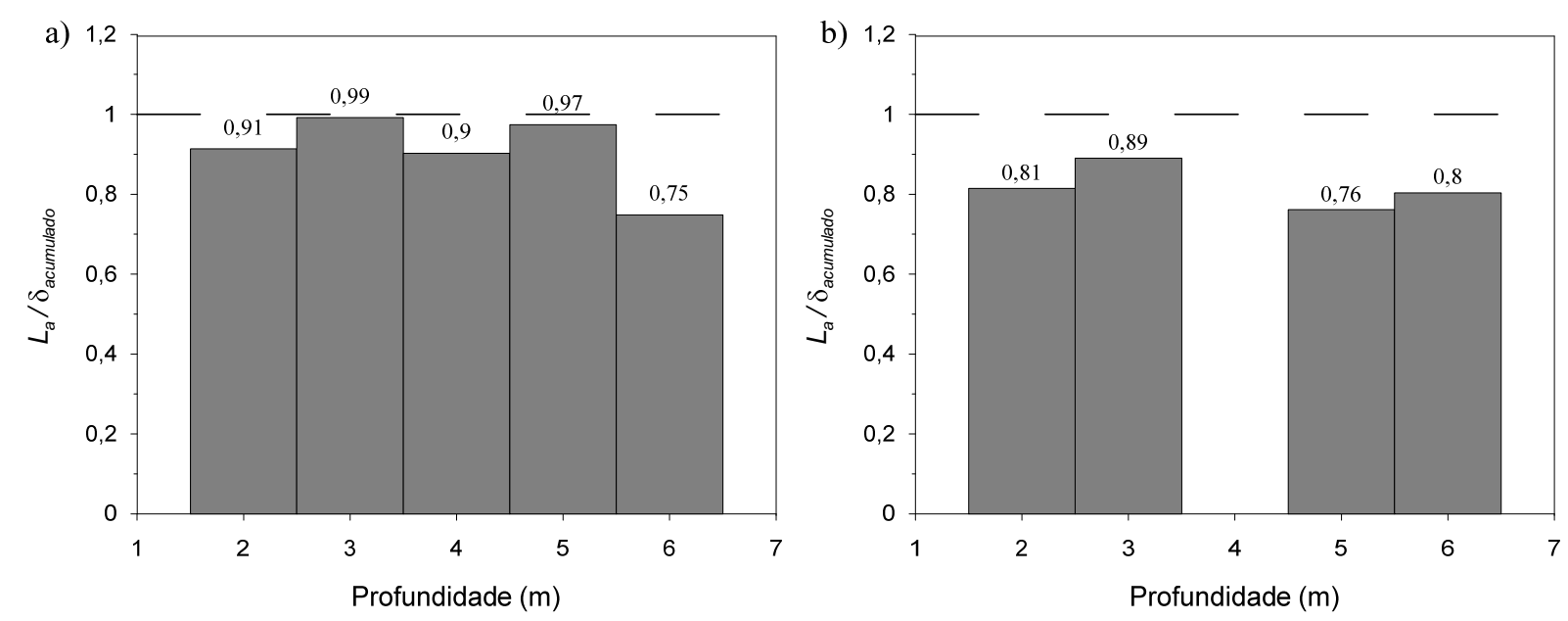

Figura A105 - Relação entre o comprimento da amostra recuperada $\left(L_{a}\right)$ e a penetração acumulada do amostrador ( $\left.\delta_{\text {acumulado }}\right)$ : a) furo SP01; furo SP02.

a)

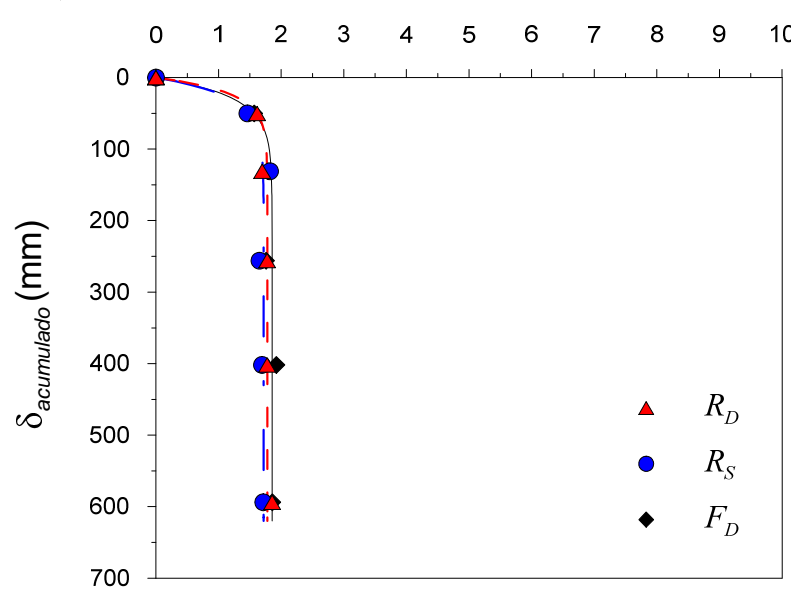

c)

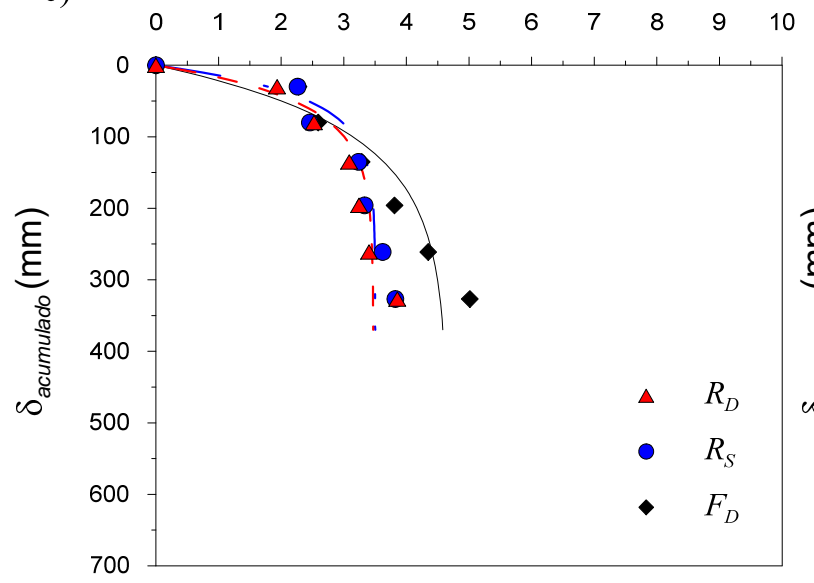

b)

\section{Resistência $(\mathrm{kN})$}

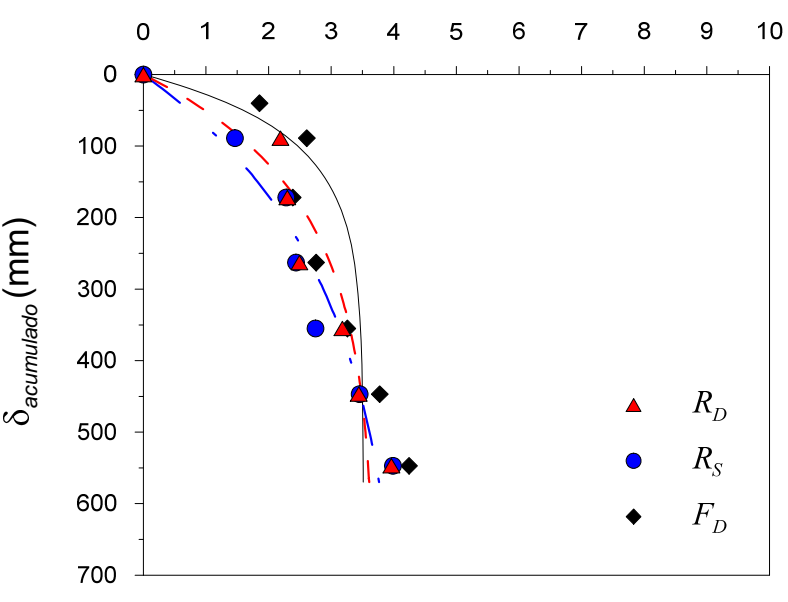

d)

Resistência (kN)

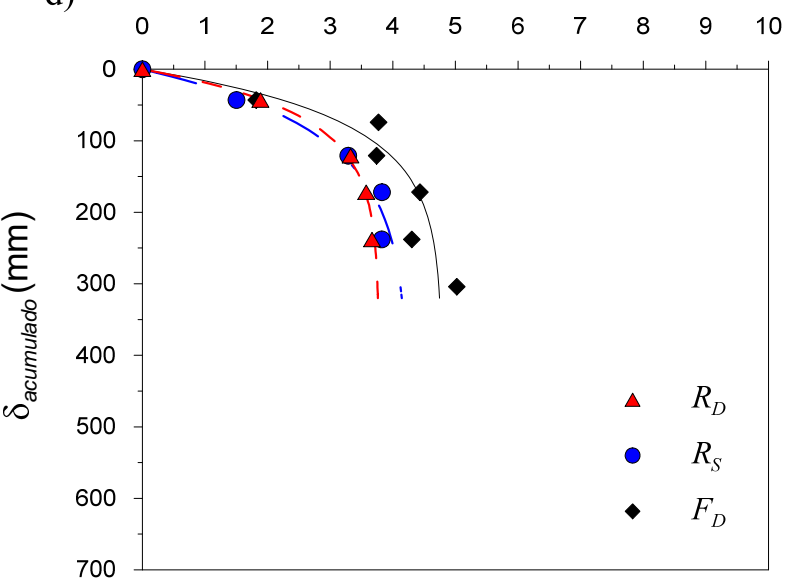

Figura A106 - Curva de resistência mobilizada versus deslocamento acumulado para o Furo furo SP02 e profundidades: a) 2 metros; b) 3 metros; c) 5 metros; d) 6 metros. 
a)

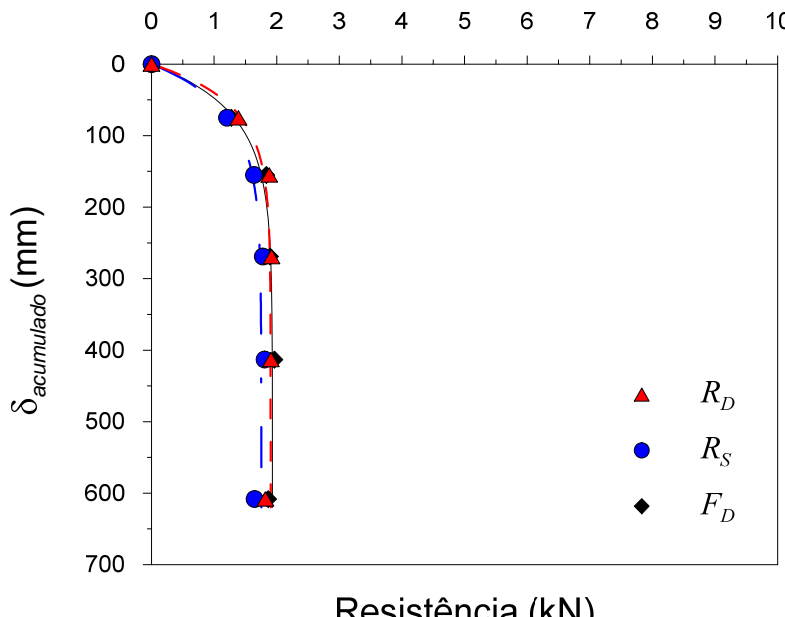

c)

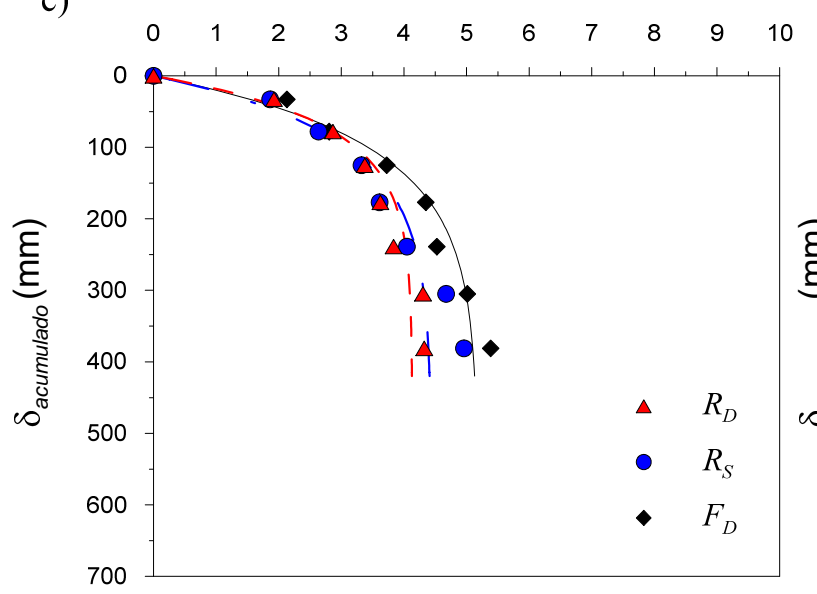

b) Resistência (kN)

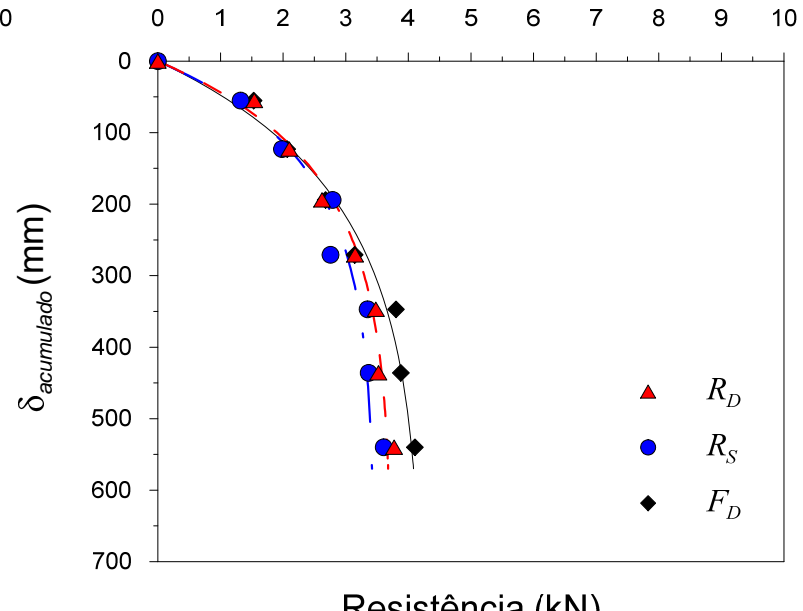

d)

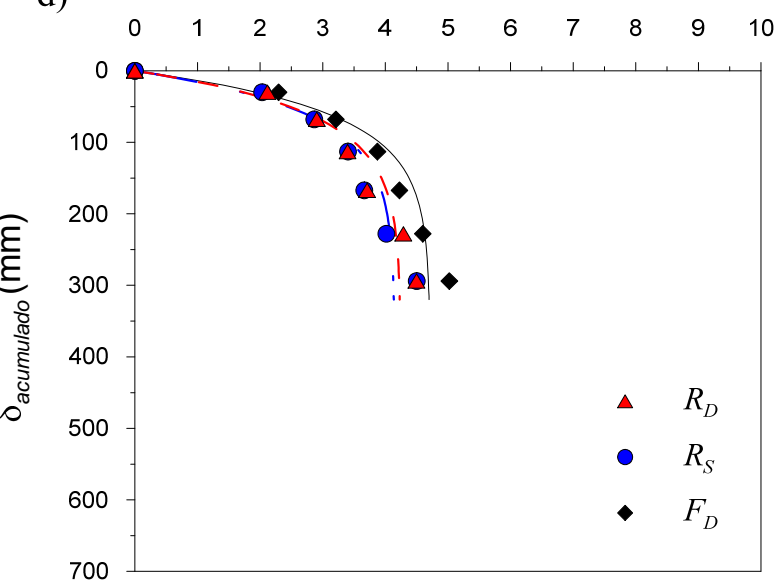

e)

Resistência (kN)

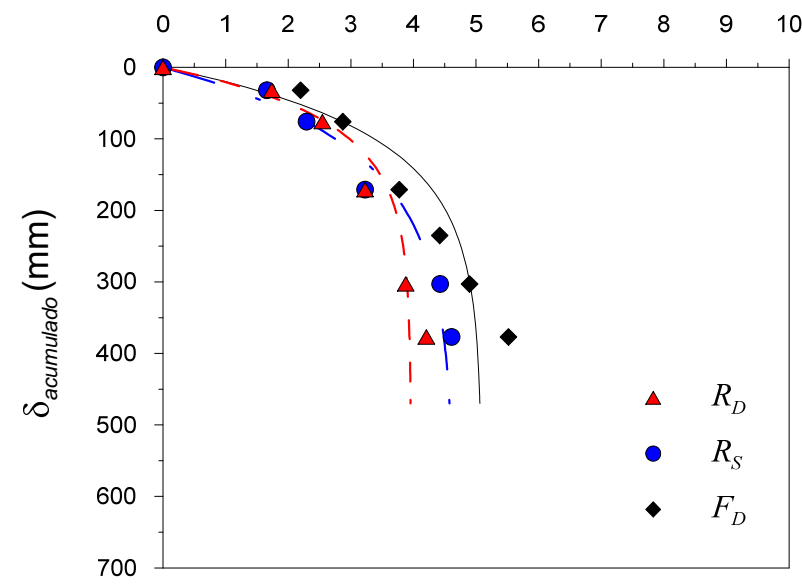

Figura A107 - Curva de resistência mobilizada versus deslocamento acumulado para o Furo furo SP03 e profundidades: a) 2 metros; b) 3 metros; c) 4 metros; d) 5 metros, e) 6 metros. 
Resultados do ensaio de determinação do atrito interno 


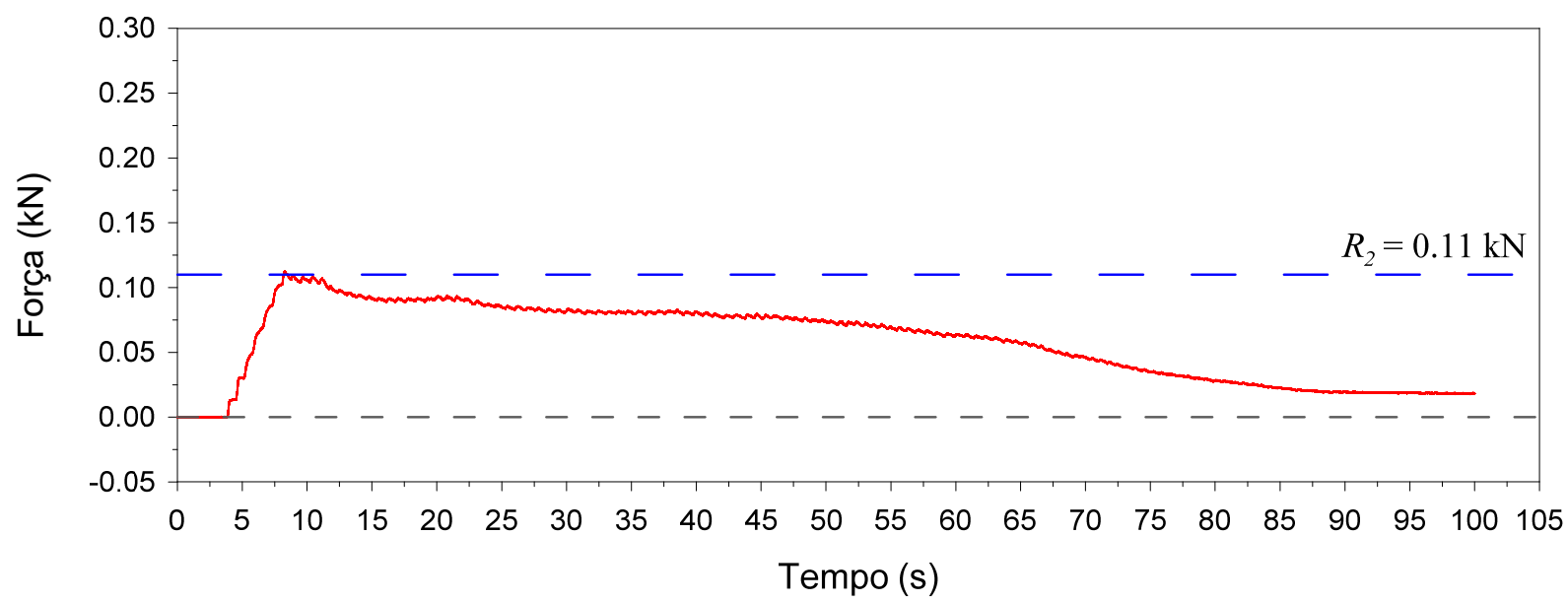

Figura A108 - Resultado do ensaio de atrito para furo SP01, profundidade de $3 \mathrm{~m}$.

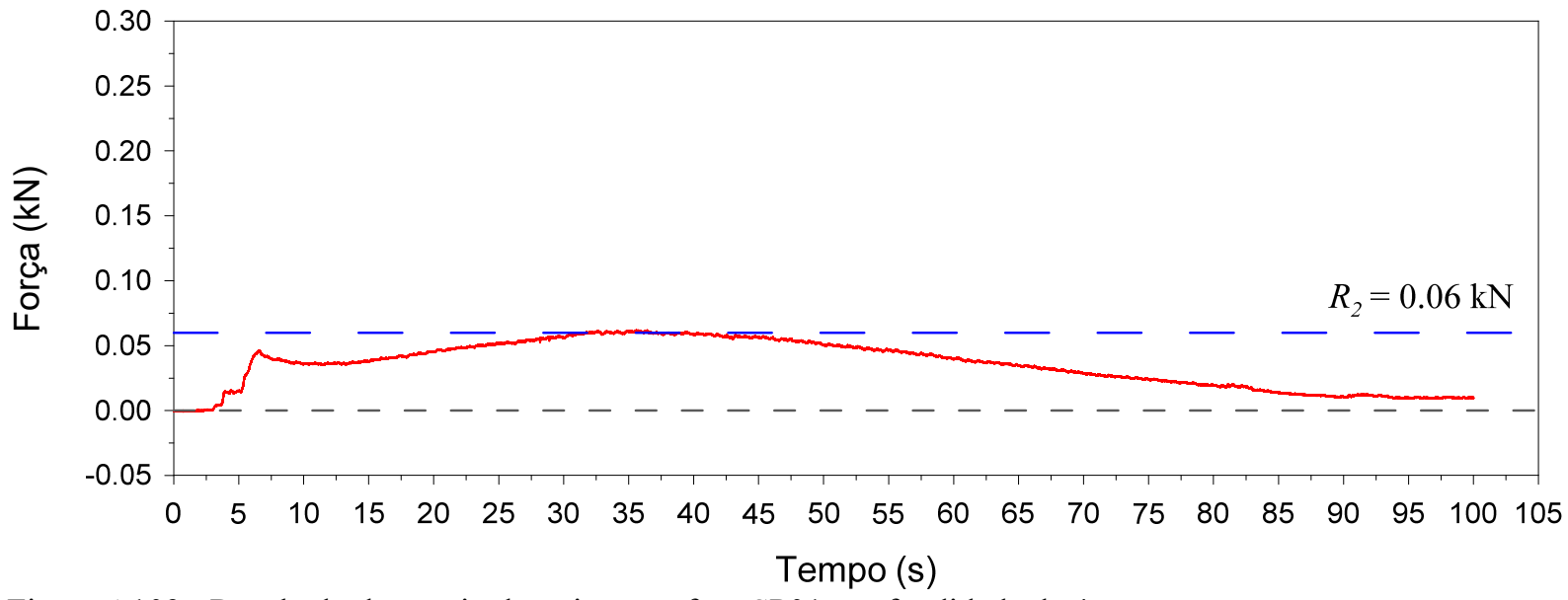

Figura A109 - Resultado do ensaio de atrito para furo SP01, profundidade de $4 \mathrm{~m}$.

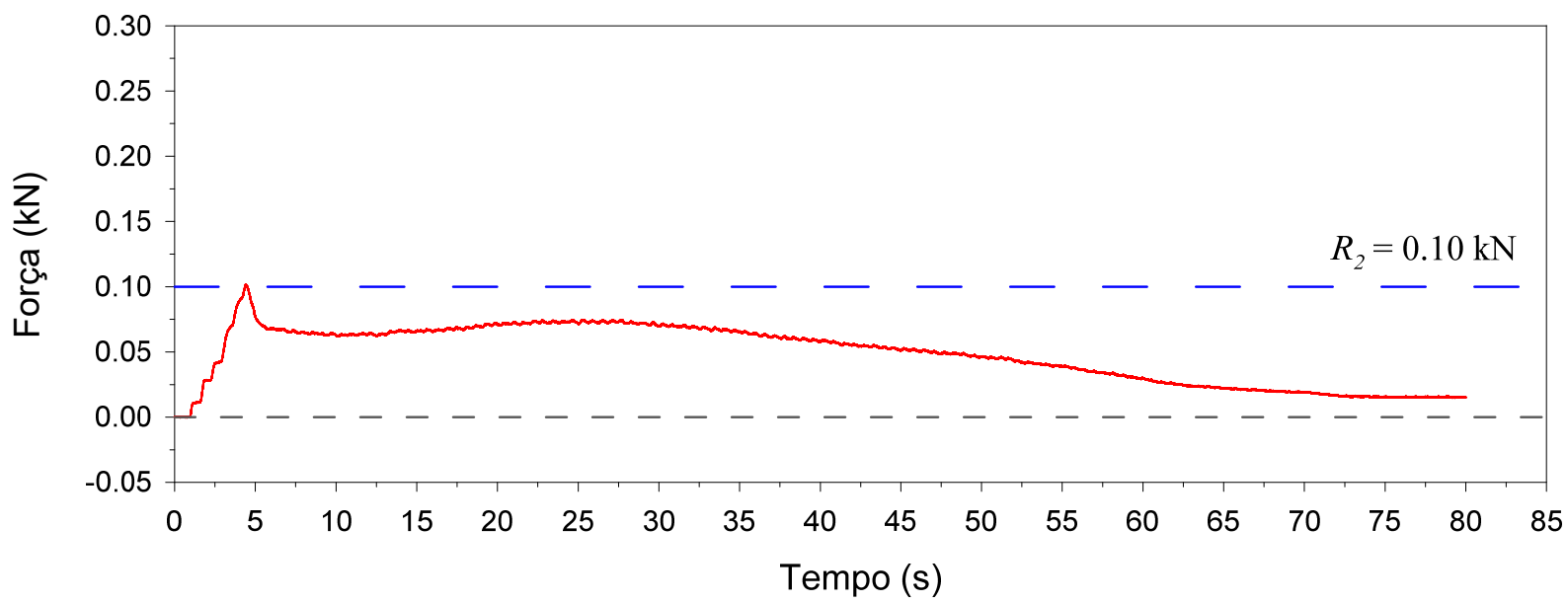

Figura A110 - Resultado do ensaio de atrito para furo SP01, profundidade de $5 \mathrm{~m}$. 


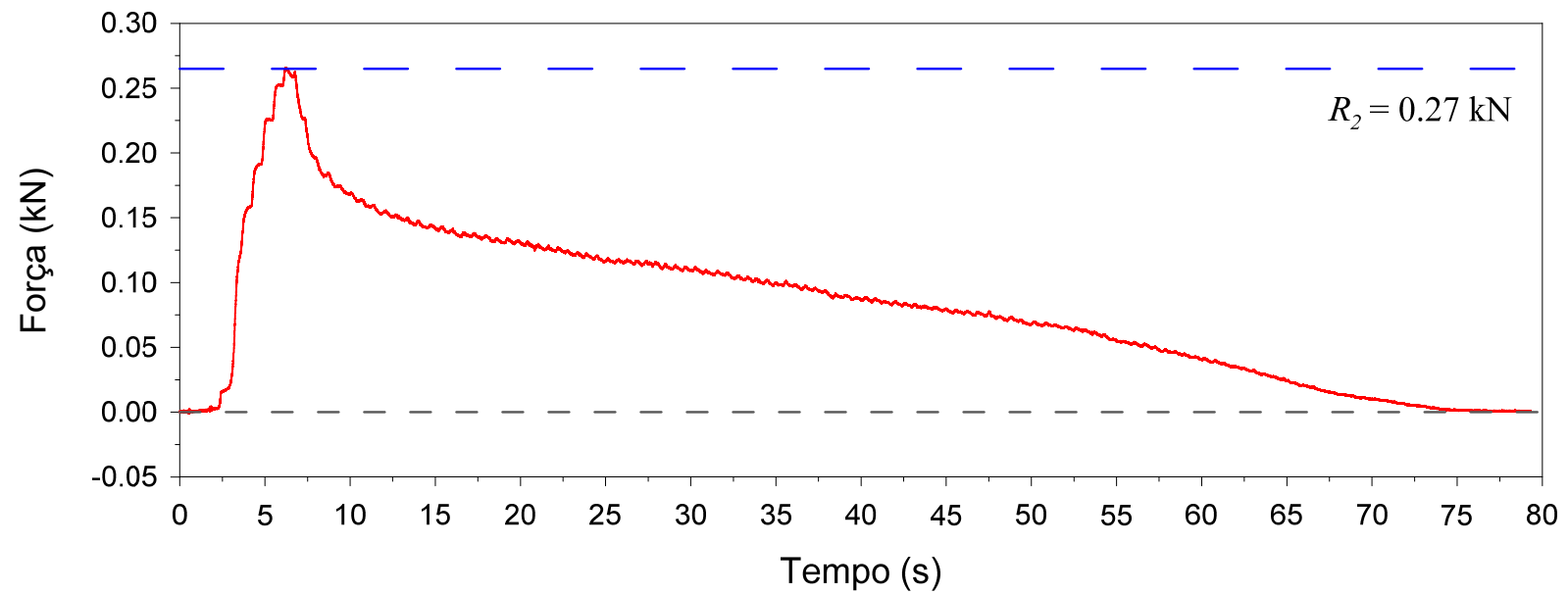

Figura A111 - Resultado do ensaio de atrito para furo SP01, profundidade de $6 \mathrm{~m}$.

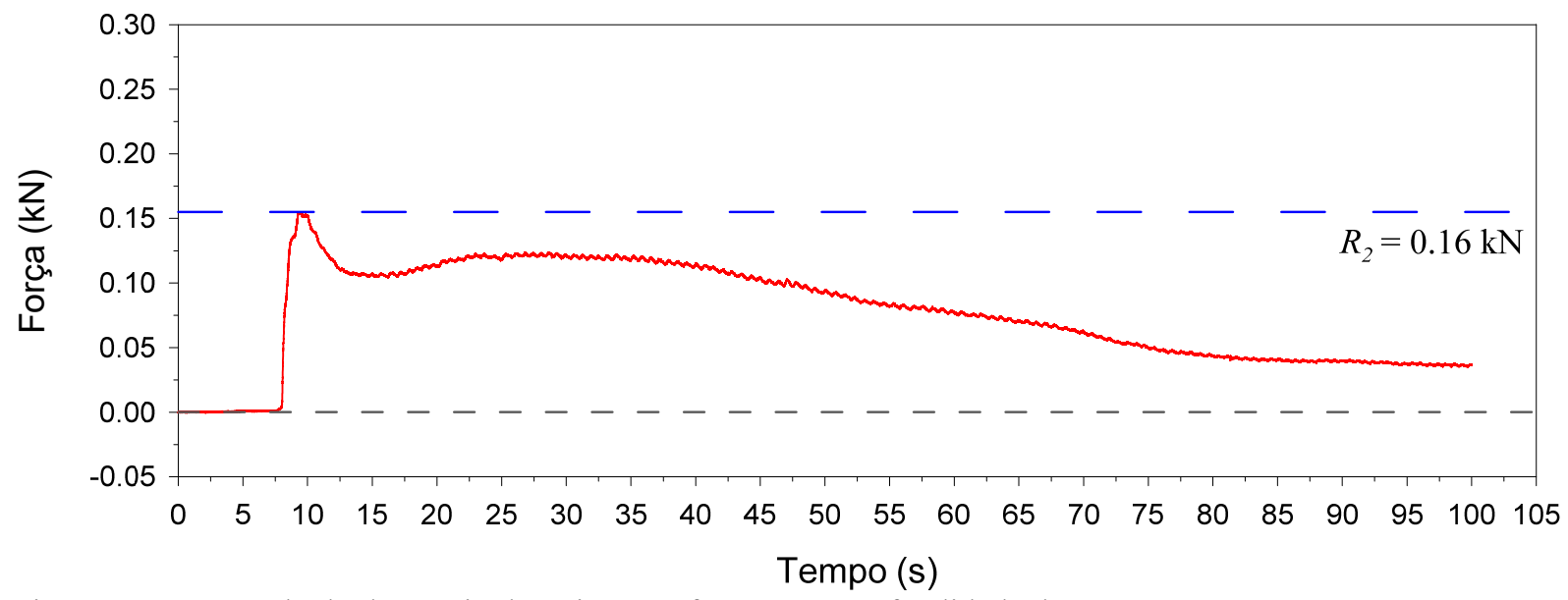

Figura A112 - Resultado do ensaio de atrito para furo SP02, profundidade de $3 \mathrm{~m}$.

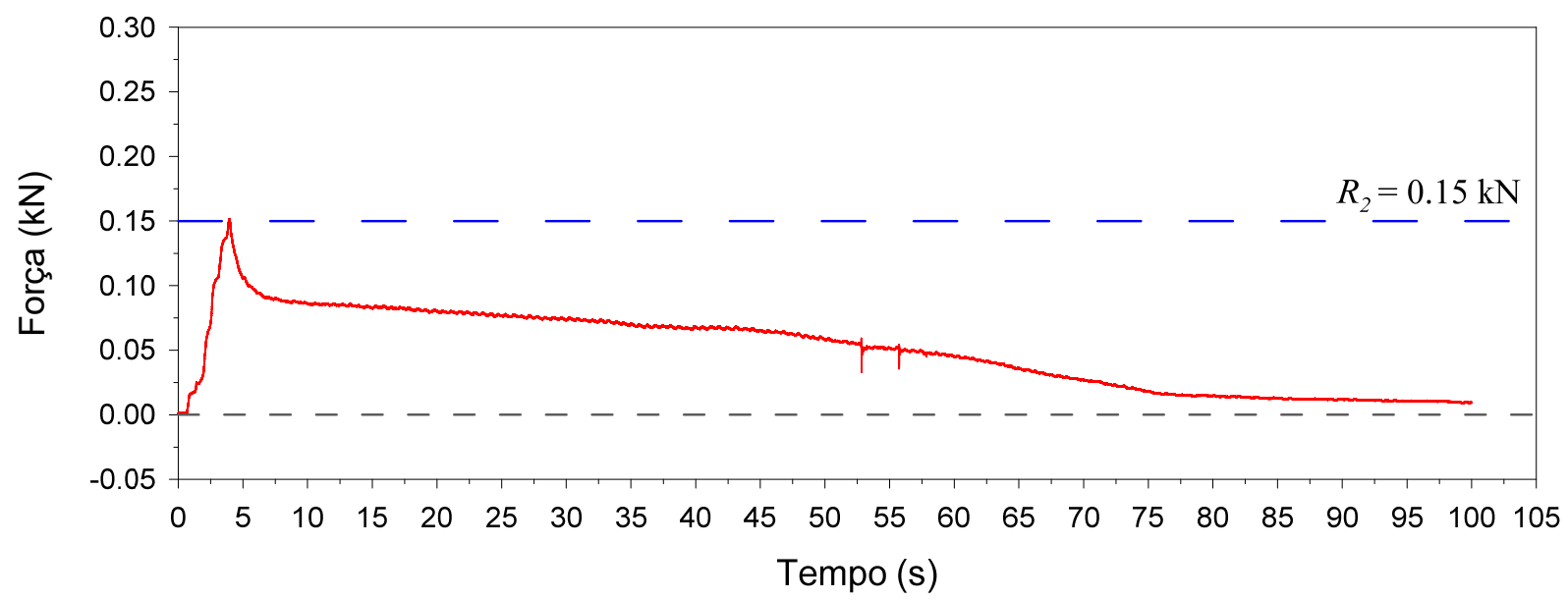

Figura A113 - Resultado do ensaio de atrito para furo SP02, profundidade de $5 \mathrm{~m}$. 


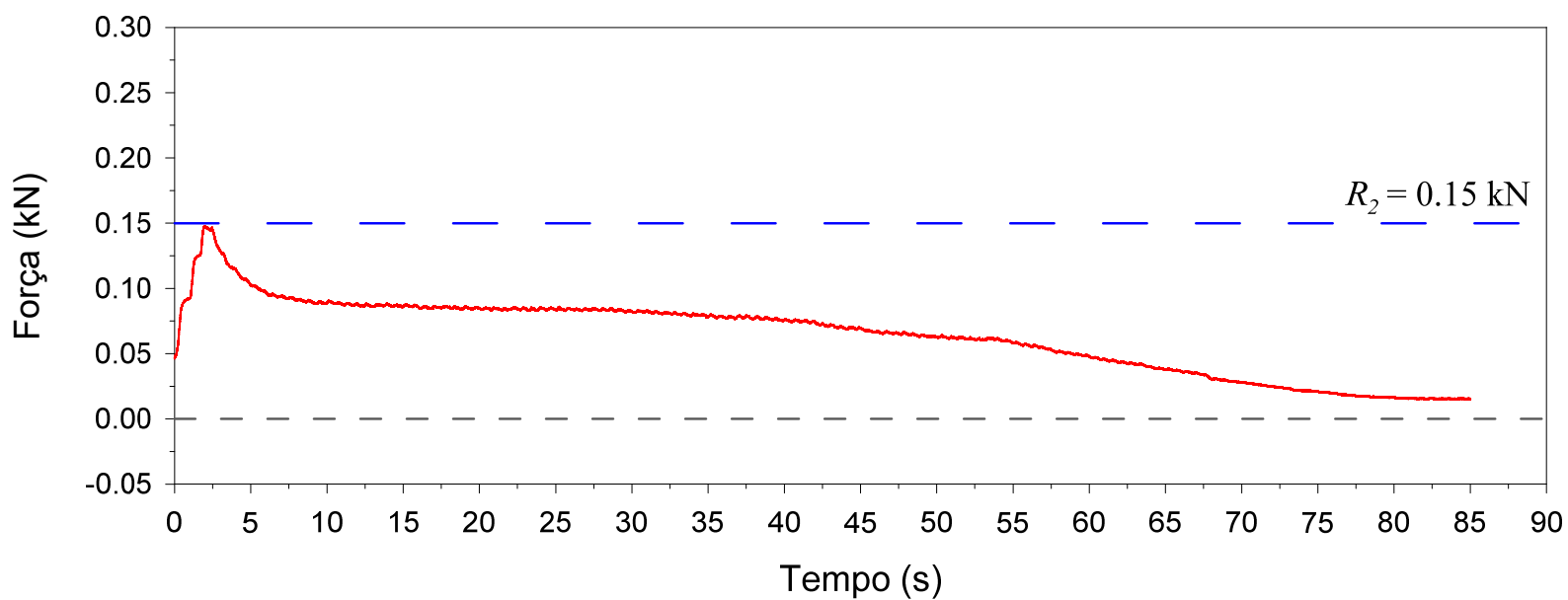

Figura A114 - Resultado do ensaio de atrito para furo SP02, profundidade de $6 \mathrm{~m}$.

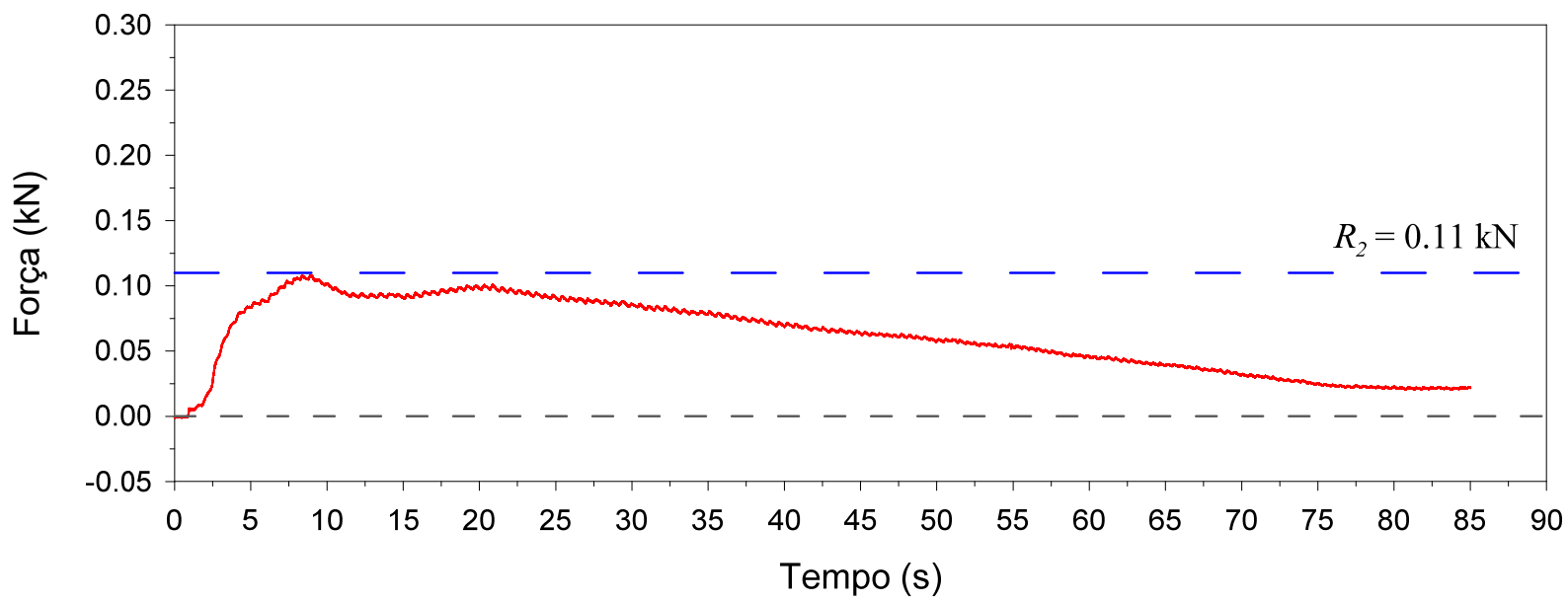

Figura A115 - Resultado do ensaio de atrito para furo SP02, profundidade de $2 \mathrm{~m}$.

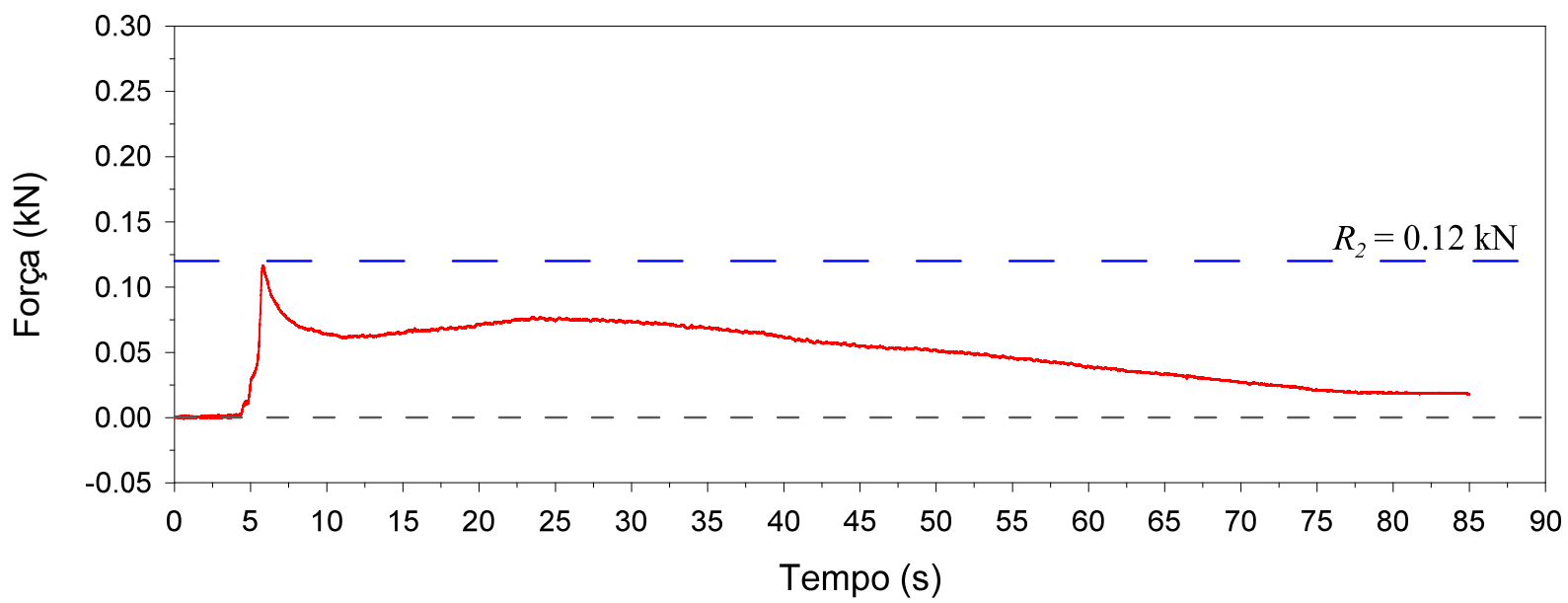

Figura A116 - Resultado do ensaio de atrito para furo SP03, profundidade de $3 \mathrm{~m}$. 


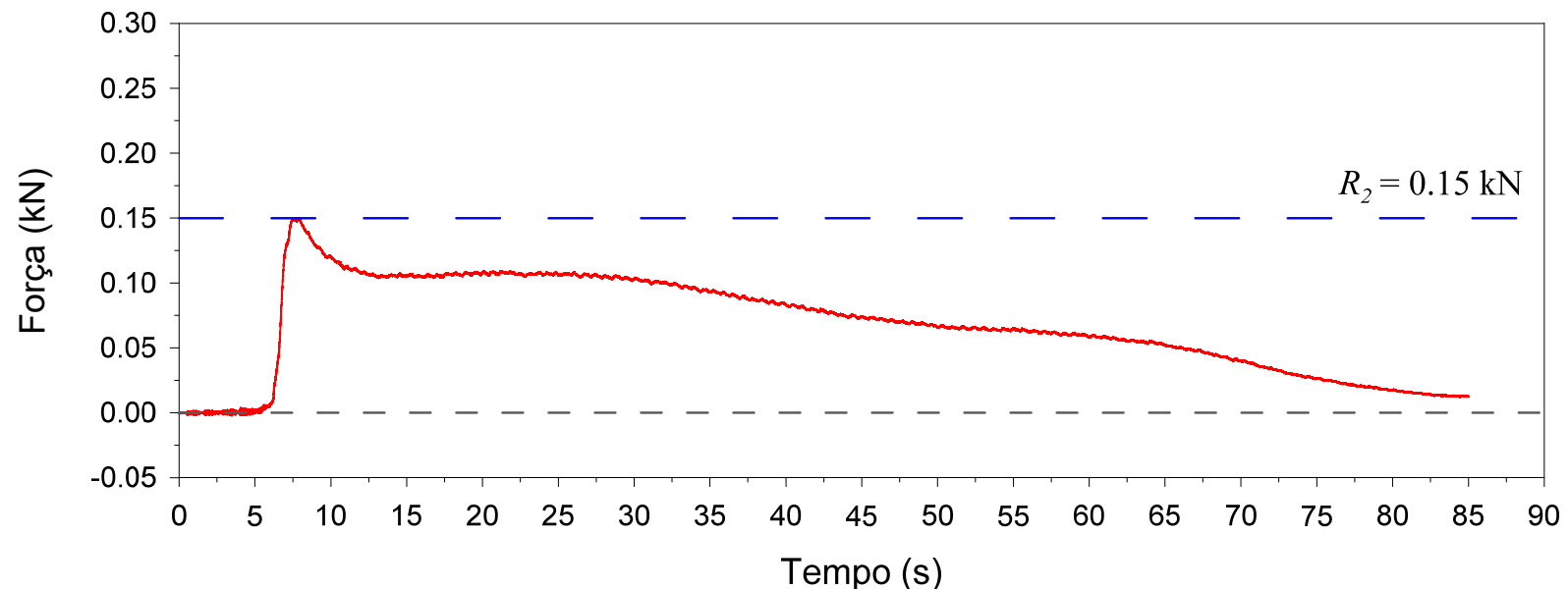

Figura A117 - Resultado do ensaio de atrito para furo SP03, profundidade de $4 \mathrm{~m}$.

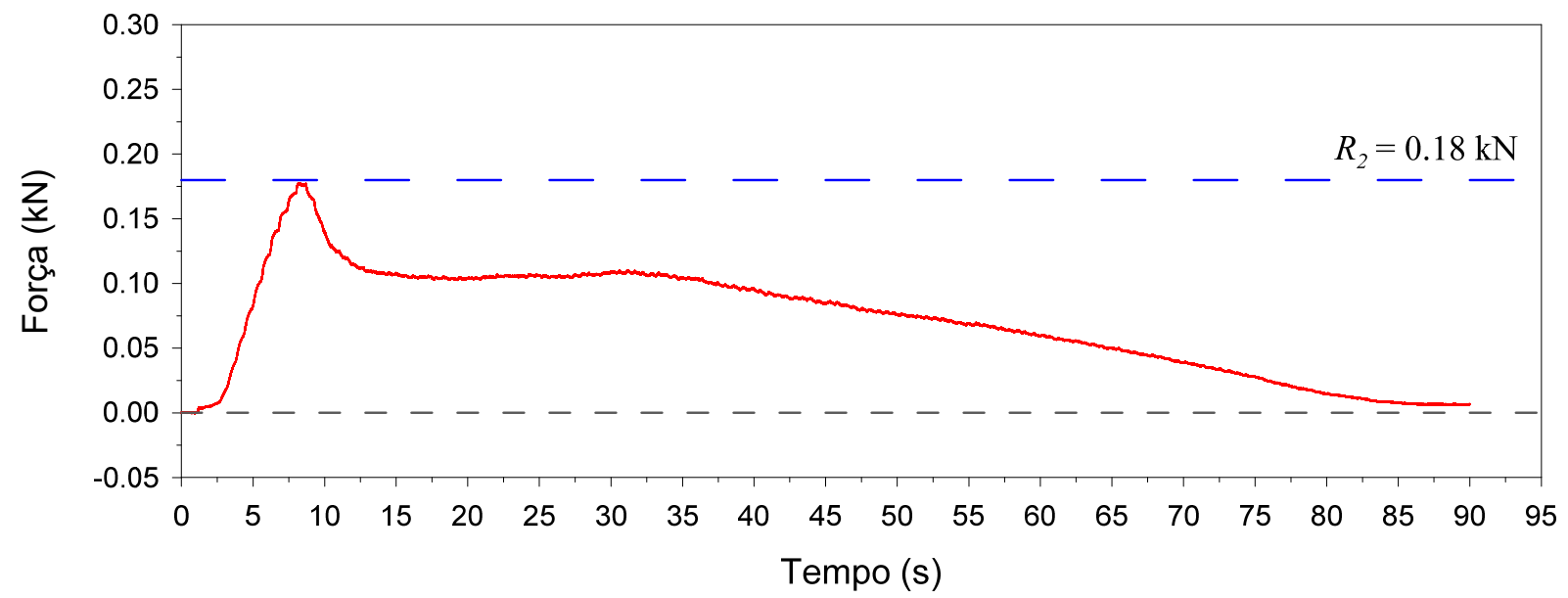

Figura A118 - Resultado do ensaio de atrito para furo SP03, profundidade de $5 \mathrm{~m}$.

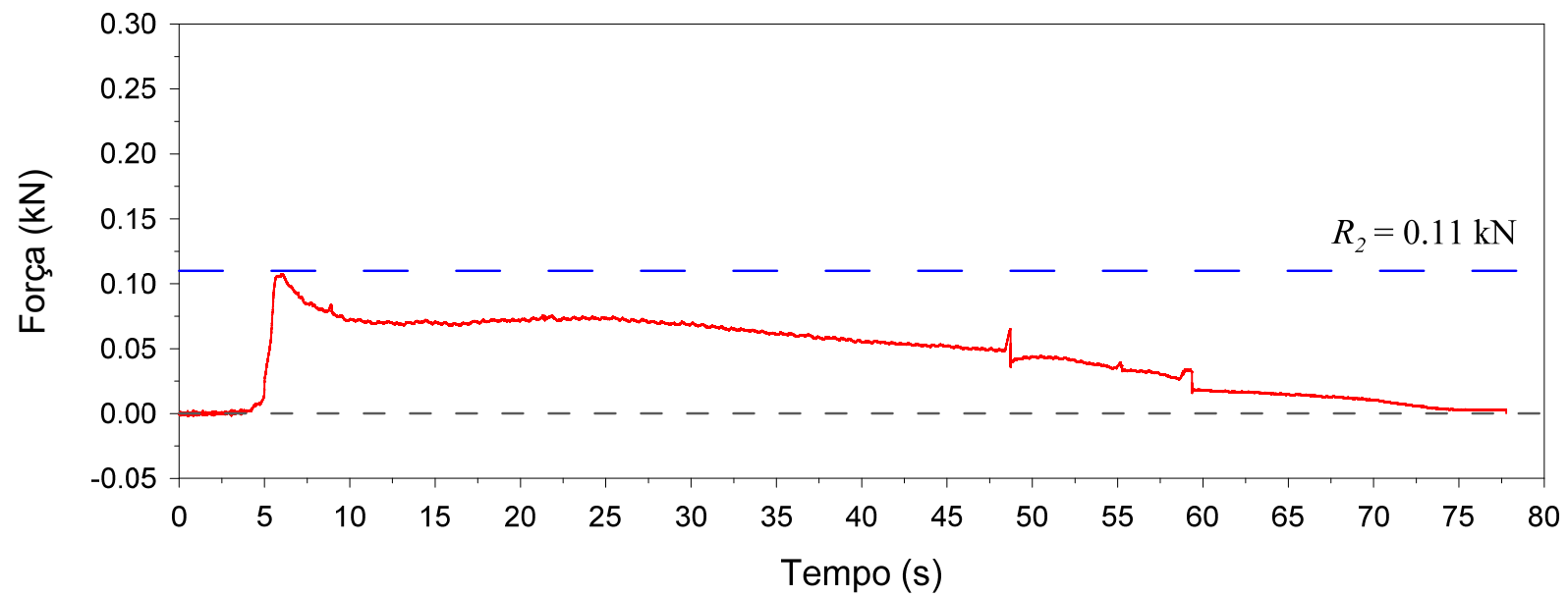

Figura A119 - Resultado do ensaio de atrito para furo SP03, profundidade de $6 \mathrm{~m}$. 
Tabela A14 - Valores de atrito interno - furo SP01.

\begin{tabular}{|c|c|c|c|c|c|c|c|}
\hline $\begin{array}{l}\text { profundidade } \\
\text { de (m) }\end{array}$ & $\begin{array}{c}H_{q} \\
(\mathbf{m m})\end{array}$ & $\begin{array}{l}\delta_{\text {medido }} \\
(\mathbf{m m})\end{array}$ & $\delta_{\text {total }}(\mathrm{mm})$ & $L_{a}(\mathbf{m m})$ & $\begin{array}{c}\boldsymbol{R}_{2} \\
(\mathbf{k N}) *\end{array}$ & $\delta_{\text {medido }} / \delta_{\text {total }}$ & $\begin{array}{c}\boldsymbol{R}_{2 i} \\
(\mathbf{k N})\end{array}$ \\
\hline \multirow{7}{*}{$2-3$} & 100 & 42 & \multirow{7}{*}{593} & \multirow{7}{*}{542} & \multirow{7}{*}{-} & - & - \\
\hline & 200 & 59 & & & & - & - \\
\hline & 300 & 82 & & & & - & - \\
\hline & 400 & 67 & & & & - & - \\
\hline & 500 & 80 & & & & - & - \\
\hline & 600 & 102 & & & & - & - \\
\hline & 750 & 161 & & & & - & - \\
\hline \multirow{7}{*}{$3-4$} & 100 & 19 & \multirow{7}{*}{373} & \multirow{7}{*}{370} & \multirow{7}{*}{0.11} & 0.05 & 0.01 \\
\hline & 200 & 31 & & & & 0.13 & 0.02 \\
\hline & 300 & 43 & & & & 0.25 & 0.03 \\
\hline & 400 & 61 & & & & 0.41 & 0.05 \\
\hline & 500 & 60 & & & & 0.57 & 0.06 \\
\hline & 600 & 69 & & & & 0.76 & 0.09 \\
\hline & 750 & 90 & & & & 1.00 & 0.11 \\
\hline \multirow{7}{*}{$4-5$} & 100 & 38 & \multirow{7}{*}{555} & \multirow{7}{*}{501} & \multirow{7}{*}{0.06} & 0.07 & 0.00 \\
\hline & 200 & 43 & & & & 0.15 & 0.01 \\
\hline & 300 & 55 & & & & 0.25 & 0.02 \\
\hline & 400 & 75 & & & & 0.38 & 0.02 \\
\hline & 500 & 84 & & & & 0.53 & 0.03 \\
\hline & 600 & 118 & & & & 0.74 & 0.05 \\
\hline & 750 & 142 & & & & 1.00 & 0.06 \\
\hline \multirow{7}{*}{$5-6$} & 100 & 29 & \multirow{7}{*}{464} & \multirow{7}{*}{452} & \multirow{7}{*}{0.10} & 0.06 & 0.01 \\
\hline & 200 & 41 & & & & 0.15 & 0.02 \\
\hline & 300 & 53 & & & & 0.27 & 0.03 \\
\hline & 400 & 66 & & & & 0.41 & 0.04 \\
\hline & 500 & 77 & & & & 0.57 & 0.06 \\
\hline & 600 & 92 & & & & 0.77 & 0.08 \\
\hline & 750 & 106 & & & & 1.00 & 0.10 \\
\hline \multirow{7}{*}{$6-7$} & 100 & 43 & \multirow{7}{*}{409} & \multirow{7}{*}{306} & \multirow{7}{*}{0.27} & 0.11 & 0.03 \\
\hline & 200 & 41 & & & & 0.21 & 0.05 \\
\hline & 300 & 48 & & & & 0.32 & 0.09 \\
\hline & 400 & 59 & & & & 0.47 & 0.12 \\
\hline & 500 & 58 & & & & 0.61 & 0.16 \\
\hline & 600 & 74 & & & & 0.79 & 0.21 \\
\hline & 750 & 86 & & & & 1.00 & 0.27 \\
\hline
\end{tabular}

*Valores obtidos a partir do ensaio de atrito interno 
Tabela A15 - Valores de atrito interno - furo SP02.

\begin{tabular}{|c|c|c|c|c|c|c|c|}
\hline $\begin{array}{c}\text { profundidade } \\
\text { de (m) }\end{array}$ & $\begin{array}{c}H_{q} \\
(\mathbf{m m})\end{array}$ & $\begin{array}{l}\delta_{\text {medido }} \\
(\mathrm{mm})\end{array}$ & $\delta_{\text {total }}(\mathrm{mm})$ & $L_{a}(\mathrm{~mm})$ & $\begin{array}{c}\boldsymbol{R}_{2} \\
(\mathbf{k N})^{*}\end{array}$ & $\delta_{\text {medido }} / \delta_{\text {total }}$ & $\begin{array}{c}\boldsymbol{R}_{2 i} \\
(\mathbf{k N}) \\
\end{array}$ \\
\hline \multirow{7}{*}{$2-3$} & 100 & 50 & \multirow{7}{*}{813} & \multirow{7}{*}{662} & \multirow{7}{*}{-} & 0.06 & - \\
\hline & 200 & 81 & & & & 0.16 & - \\
\hline & 300 & 125 & & & & 0.31 & - \\
\hline & 400 & 146 & & & & 0.49 & - \\
\hline & 500 & 192 & & & & 0.73 & - \\
\hline & 600 & 219 & & & & 1.00 & - \\
\hline & 750 & - & & & & - & - \\
\hline \multirow{7}{*}{$3-4$} & 100 & 40 & \multirow{7}{*}{547} & \multirow{7}{*}{487} & \multirow{7}{*}{0.16} & 0.07 & 0.01 \\
\hline & 200 & 49 & & & & 0.16 & 0.03 \\
\hline & 300 & 83 & & & & 0.31 & 0.05 \\
\hline & 400 & 91 & & & & 0.48 & 0.07 \\
\hline & 500 & 92 & & & & 0.65 & 0.10 \\
\hline & 600 & 92 & & & & 0.82 & 0.13 \\
\hline & 750 & 100 & & & & 1.00 & 0.16 \\
\hline \multirow{7}{*}{$5-6$} & 100 & 30 & \multirow{7}{*}{478} & \multirow{7}{*}{364} & \multirow{7}{*}{0.15} & 0.06 & 0.01 \\
\hline & 200 & 50 & & & & 0.17 & 0.03 \\
\hline & 300 & 55 & & & & 0.28 & 0.04 \\
\hline & 400 & 61 & & & & 0.41 & 0.06 \\
\hline & 500 & 65 & & & & 0.55 & 0.08 \\
\hline & 600 & 66 & & & & 0.68 & 0.10 \\
\hline & 750 & 151 & & & & 1.00 & 0.15 \\
\hline \multirow{7}{*}{$6-7$} & 100 & 43 & \multirow{7}{*}{346} & \multirow{7}{*}{278} & \multirow{7}{*}{0.15} & 0.12 & 0.02 \\
\hline & 200 & 31 & & & & 0.21 & 0.03 \\
\hline & 300 & 47 & & & & 0.35 & 0.05 \\
\hline & 400 & 51 & & & & 0.50 & 0.07 \\
\hline & 500 & 66 & & & & 0.69 & 0.10 \\
\hline & 600 & 66 & & & & 0.88 & 0.13 \\
\hline & 750 & 42 & & & & 1.00 & 0.15 \\
\hline
\end{tabular}

*Valores obtidos a partir do ensaio de atrito interno 
